\title{
GÜNTER GRASS UND DIE BILDENDE KUNST
}

Eine interdisziplinäre Untersuchung der Schaffensjahre 1947 bis 1977

Dissertation zur Erlangung des philosophischen Doktorgrades an der Philosophischen Fakultät der Georg-August-Universität Göttingen

vorgelegt von Viktoria Krason

aus Laurahütte/Siemianowice Śląskie, Polen

Göttingen 2019 
1. Gutachter: Prof. Dr. Dr. h. c. Heinrich Detering

2. Gutachter: Prof. Dr. Horst Bredekamp

Tag der mündlichen Prüfung: 22. Juni 2017 
Ich setze ein Zeichen und lösche es mit dem nächsten.

Die Hühner, die Nonnen, die Vögel, die Scheuchen...

Und als ich heimkam, zerredet ganz und hartgesotten,

ging ich zu, kamen mir Pilze entgegen,

Schirmlinge und Boviste, entwurzelte Pimmel,

die himmelwärts zeugen.

Günter Grass, aus dem Gedicht „Mariazuehren“, 1973 


\section{INHALT}

I. Einleitung

II. Lehrjahre (1947-1956): Auf dem Weg zu einer Bildsprache .............................................. 17

1. Düsseldorf: Das Menschenbild fragmentieren............................................................ 17

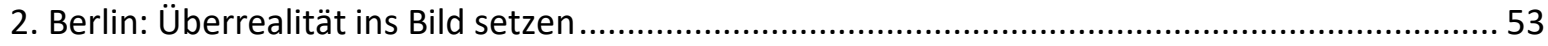

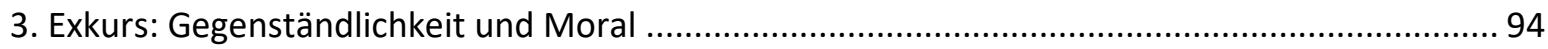

III. Motivwanderungen im Umkreis der ,Danziger Trilogie' (1959, 1961, 1963):

Zwischen Artistik und Gesellschaftskritik.................................................................... 106

1. Vögel: Geflügelte Zeichen einer neuen Ästhetik......................................................... 106

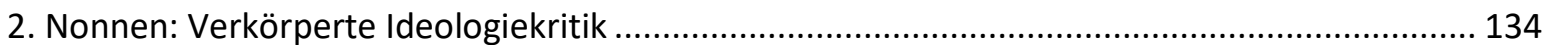

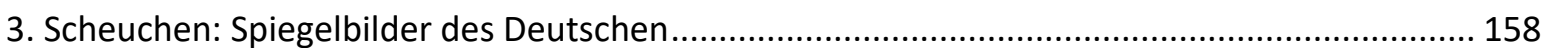

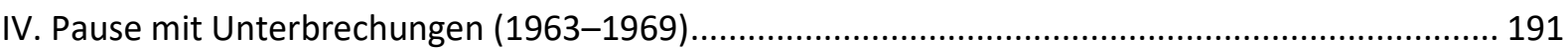

V. Motivwanderungen im Umkreis des Tagebuchs einer Schnecke (1972) und des Butt (1977):

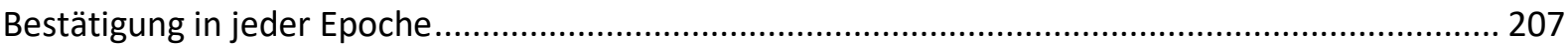

1. Schnecken: Aufklärung der Vernunft mit den Mitteln der Aufklärung ................................ 207

2. Pilze: Ausloten des Irrationalen ......................................................................... 240

3. Fische: Schreiben und Zeichnen jederzeit ............................................................... 270

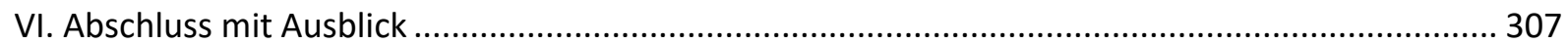

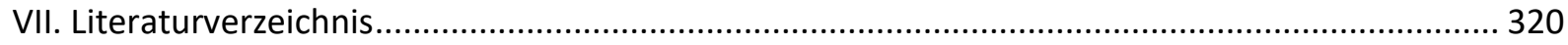

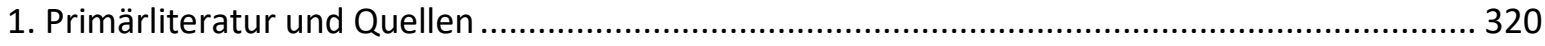

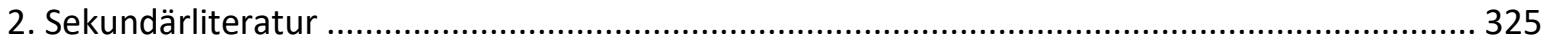

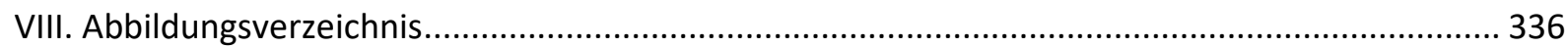

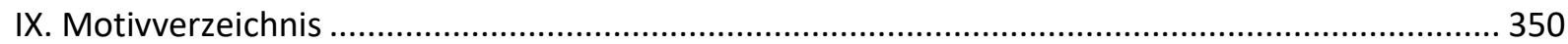




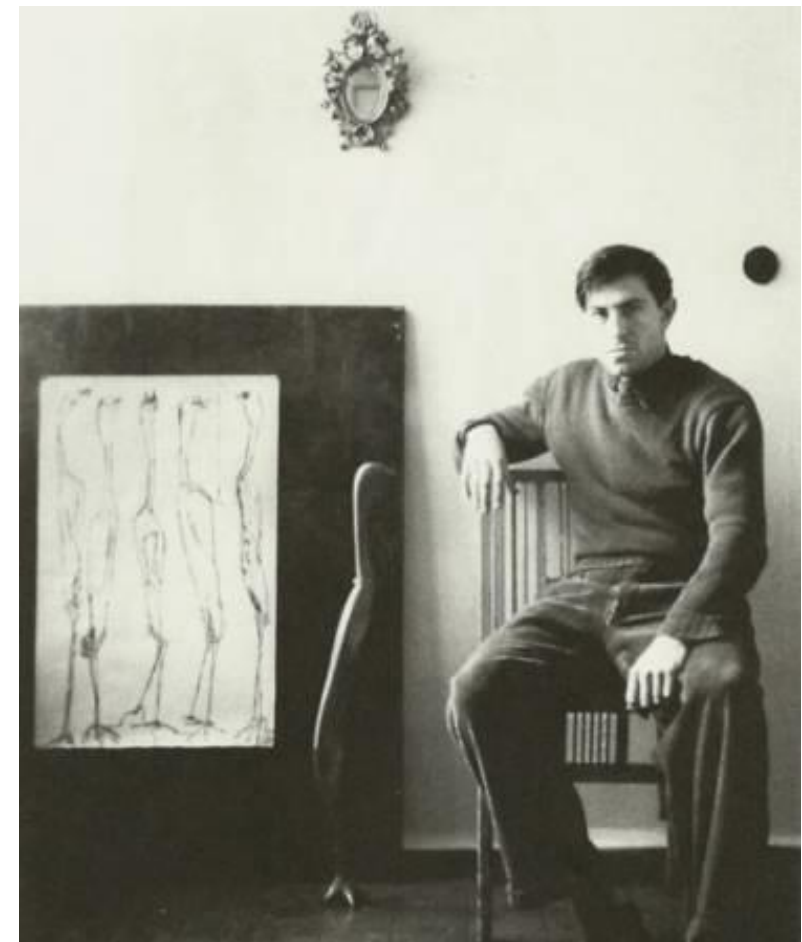

Abb. 1, Hans Rama, Günter Grass in Berlin, 1955, Fotografie, Akademie der Künste, Berlin, Sammlung Maria Rama, Nr. 42 


\section{EINLEITUNG}

Die Fotografie von Hans Rama zeigt Günter Grass im Jahr 1955 und damit gegen Ende seiner Ausbildung als Bildhauer und Grafiker (Abb. 1). Obwohl er bereits als Heranwachsender Gedichte und Prosa geschrieben hatte und diese Tätigkeit nicht einzustellen plante, wollte er zunächst und in erster Linie bildender Künstler werden (X 313-498). ${ }^{1}$ Im Wintersemester 1948 nahm er ein Studium der Bildhauerei an der Kunstakademie Düsseldorf auf, lernte dort bei Josef Mages und Otto Pankok und wechselte fünf Jahre später an die Berliner Hochschule für Bildende Künste in die Klasse von Karl Hartung. In der Aufnahme von Hans Rama ist Grass im Jahr seiner ersten Einzelausstellung neben zwei eigenen Arbeiten zu sehen. ${ }^{2}$ Mit seiner rechten Körperhälfte ist er einer Bronzeplastik zugewandt, die einen schmalbrüstigen Vogel darstellt. Der aus verkanteten Flächen zusammengesetzte Torso der Figur entfaltet in die Tiefe des Raums hinein kaum Volumen. Mit ihrem Schnabel deutet sie auf die rechte Hand des Künstlers, der in der rechten Hälfte des Fotos zu sehen ist. Die linke Hälfte nimmt eine an einem Holzbrett angebrachte Kohlezeichnung ein. Schlanke Vögel finden sich hier in einer zweidimensionalen Darstellung wieder. Genau fünf von innen sind in einer Reihe nebeneinander angeordnet. Die unnatürlich aufrechte Körperhaltung verleiht ihnen nahezu menschliche Proportionen. Sie changieren damit zwischen Repräsentationen des Vogels, einem Symbol des Geistes, ${ }^{3}$ und Repräsentationen des Menschen. Mit ihm steht die Zeichnung nicht nur durch die Gestalt der Tiere, sondern auch durch ihre Anzahl, die mit der Zahl der Finger der menschlichen Hand identisch ist, in Verbindung. Die Wesen haben einerseits das Potenzial, sich in die Luft zu erheben und scheinen andererseits aufgrund ihrer anthropomorphisierten Körper und enganliegenden Flügel an die Erde gebunden zu sein. Eine Interpretation der Zeichnung als Sinnbild für den geistig und handwerklich tätigen Künstler wird durch ihre Ablichtung im Rahmen der fotografischen Künstlerinszenierung befördert und durch einen im selben Jahr verfassten Text gestützt und erweitert.

Im Entstehungsjahr des Fotos arbeitete Grass an seinem ersten Gedicht- und Prosaband Die Vorzüge der Windhühner (1956), den er mit Reproduktionen seiner eigenen Federzeichnungen ausstatten ließ. Der einzige Prosatext der Veröffentlichung trägt den Titel „Fünf Vögel“ und steht mit den von Rama fotografierten Arbeiten in engem Zusammenhang. Die Geschichte dieser literarischen Vögel, deren „Herkunft“, „Viele Berufe“ und „Ziel“ die so überschriebenen drei Kapitel des Textes bestimmen, ist eine Allegorie der zweckfreien Dichtung. Die Vögel, deren Bildungsweg darin vorgestellt wird, können gleichermaßen als Verkörperung von Kunst und Künstlern gedeutet werden. ${ }^{4}$ Die Vogelgestalt bildet das Element des Textes, das dessen einzelne Handlungsetappen miteinander verknüpft. Die Leserinnen und Leser müssen sich diese Tiere notwendig schlank und

\footnotetext{
${ }^{1}$ Grass' Werke werden, soweit in den gesammelten Werken erfasst, im Folgenden im Fließtext nach der Göttinger Ausgabe, Göttingen 2007, unter Angabe des Bandes (römische Zahl) und der Seiten (arabische Zahl) zitiert. Die Aufschlüsselung der Bandangaben befindet sich im Literaturverzeichnis.

2 Vgl. Böttiger (2012): Grass' erste Einzelausstellung fand in der Stuttgarter Galerie Lutz \& Meyer vom 19. Oktober bis zum 8. November 1955 statt. Sie wurde in der Frankfurter Allgemeinen Zeitung vom 21. November 1955 positiv besprochen. Den Artikel „Das Knochengerüst der Dinge. Günter-Grass-Ausstellung in Stuttgart" verfasste Walter Höllerer unter dem Autorenkürzel „-ck“.

${ }^{3}$ Vgl. Lurker (1988), S. $773 \mathrm{f}$.

${ }^{4}$ Eine Interpretation des Textes als „verspielte Apologie der subversiven Möglichkeiten dichterischer Einbildungskraft“ ist zu finden bei: Stolz (1994), S. 26-28.
} 
von geradem Wuchs vorstellen, denn sie erfüllen in der Erzählung kurzzeitig und erfolglos verschiedene Funktionen, indem sie Objekte ersetzen, die eine ebensolche Grundform aufweisen, darunter Kamine, Telegrafenmaste und bezeichnenderweise Finger. Es entsteht eine surreale Assoziationsfolge, deren Zusammenhang als Kette verwandter Vorstellungsbilder einleuchtet.

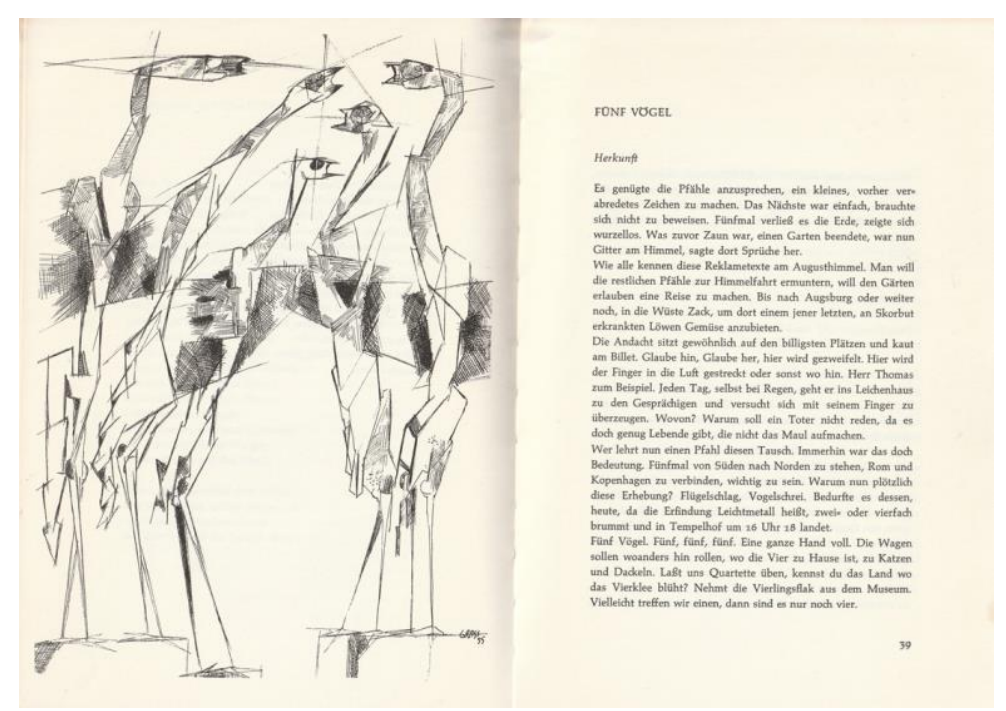

Abb. 2, Die Vorzüge der Windhühner, Berlin-Frohnau/Neuwied am Rhein 1956, 2. Auflage, 1963, S. 38 f.

In der zweiten Auflage des Gedichtbandes von 1963 wurde der Kurzprosa eine Federzeichnung des Dichters aus dem Jahr 1955 vorangestellt, die der Kohlezeichnung ähnelt und die die Gestalt der Vögel, auf der die Handlungsverknüpfungen beruhen, für die Lesenden tatsächlich sichtbar macht (Abb. 2). ${ }^{5}$ Diese Arbeit zeigt ebenfalls fünf schlanke Vögel nebeneinander. Die Tiere stehen hier auf Sockeln, sind durch ihre leicht gehobenen und schematisch gestalteten Flügel miteinander verbunden und einander zugewandt. Ihre Körper sind ebenso in die Vertikale gestreckt wie die der Vögel in der Kohlezeichnung. Auch wenn nicht rekonstruiert werden kann, ob Grass zuerst den Text schrieb oder die Zeichnung schuf, wird den Betrachterinnen und Betrachtern mit der Medienkomposition aus Wort und Bild umso deutlicher vor Augen geführt, dass es die sinnlich wahrnehmbare Vogelform ist, die die Narration grundlegend strukturiert. Den in der Prosa aufgezeigten Formanalogien liegt die Beobachtungsgabe des Dichters zugrunde, die im Zuge seiner Ausbildung zum Grafiker und Bildhauer besonders geschult wurde. ${ }^{6}$

Die Vorzüge der Windhühner waren der Auftakt für ein intensives Zusammenwirken von bildender Kunst und Literatur im Schaffen von Günter Grass und damit für eine Artikulation des „bildnerischen Denkens ${ }^{\prime 7}$ in Texten, zu welchen wiederum Zeichnungen entstanden sind. In seiner

\footnotetext{
${ }^{5}$ Vgl. Grass (1963a), S. 38.

${ }^{6}$ Vgl. weitere Ausführungen zu den hier kurz vorgestellten Kunstwerken in Kap. III.1. der vorliegenden Untersuchung.

7 Der Begriff „bildnerisches Denken“ geht auf Paul Klee zurück und wurde von der Kolleg-Forschergruppe „Bildakt und Verkörperung“ für die Auseinandersetzung mit Zeichnungen und Aufzeichnungen von Charles Sanders Peirce verwendet. Die visuelle Imaginationskraft wurde zuvor von Gottfried Boehm als „,bildhaftes“, von Rudolf Arnheim als „anschauliches Denken“ bezeichnet. Das „bildnerische Denken“ transportiert nicht
} 
bildenden Kunst behandelte Grass von da an fast ausschließlich dieselben Motive wie in seiner Literatur. In seinen Romanen zitierte und beschrieb er eigene Kunstwerke und suggerierte auf diese Weise, dass sie für die Entstehung des entsprechenden Textes von Bedeutung waren. Mit Hilfe von Bezugnahmen auf Werke anderer Künstler verhandelte er Wechselwirkungen zwischen bildender Kunst, Ökonomie und Politik. Er setzte Künstlerfiguren als Erzähler ein und evozierte mitunter über deren auf Bilder konzentrierte Weltsicht ein von der Sprache verschiedenes semiotisches System. ${ }^{8}$ Es ist Grass' Beschäftigung mit der bildenden Kunst in ihrer ganzen Vielfalt, die in der vorliegenden Veröffentlichung zum ersten Mal systematisch untersucht wird.

Indes ist die wichtige Rolle der anderen Ausdrucksform im Schaffen des Schriftstellers nie ein Geheimnis gewesen. Augenfällig wurde sie in seinen Gedichtbänden, die er stets mit eigenen Zeichnungen, Druckgrafiken oder Aquarellen versah, und darin, dass er die Umschläge für jedes seiner Bücher unter Verwendung eigener Grafiken gestalten ließ. Seine medienübergreifende Arbeitsweise wird auch aus dem 1991 veröffentlichten Werkstattbericht. Vier Jahrzehnte ersichtlich, der in Abständen von zehn und dreizehn Jahren in jeweils überarbeiteter Form zwei Mal neu aufgelegt wurde. ${ }^{9}$ Das zahlreiche Ablichtungen von Plastiken und Bildern sowie von Arbeitsplänen und Manuskripten enthaltende Buch ist eine Werkautobiografie, in der der Schriftsteller und Künstler mit Nachdruck auf die Intermedialität seines Schaffens hinweist. Auf den ersten Blick fällt auch darin auf, dass der Berührungspunkt zwischen bildkünstlerischen und literarischen Ausdrucksformen bei einzelnen Motiven liegt, die Grass in verschiedenen Medien realisierte.

Der Begriff des Motivs wird in der vorliegenden Untersuchung verwendet, um diese strukturellen und inhaltlichen Elemente eines Stoffes, Grundbausteine von Texten und Bildwerken, unabhängig von dem Medium, der literarischen Gattung und den Stilfiguren, in welchen sie präsentiert werden, in den Blick nehmen zu können. ${ }^{10}$ Im Motivbegriff kommt die handlungstreibende Kraft zum Ausdruck, die in den Dramen und Erzählwerken des Schriftstellers von ihnen ausgeht. Zudem wird darin ihre wiederholte Realisierung im Gesamtwerk angedeutet, die durch relative Gehaltkonstanz ein Gefüge aus autoreferenziellen Bezügen und erweiterten Bedeutungszusammenhängen schafft. ${ }^{11}$ Geht es um das verwirklichte Motiv, wird von Zeichen die Rede sein, ohne dass damit die materielle Qualität der visuellen Artefakte unter den Motivdarstellungen missachtet würde. Grass selbst hat diesen Begriff in einem programmatischen Resümee von 1973, dem Gedicht „Mariazuehren“ verwendet. ${ }^{12}$ Hervorgehoben wird darin sowohl das Ähnlichkeitsverhältnis der Motivdarstellungen zu ihren Gegenständen als auch ihre Bezugnahme auf kognitive Objekte und darüber hinaus die Möglichkeit ihrer Realisierung in Wort und Bild zugleich. In einer Aufzählung

nur den visuellen Charakter des Denkens, sondern auch den Aspekt des bildkünstlerischen Schaffens und wird deshalb in dieser Arbeit genutzt. Vgl. Klee (1971), Boehm (2001) und Engel (2012).

${ }^{8}$ Vgl. zum Thema „Kunst und Künstlerexistenz im Frühwerk von Günter Grass“: Stallbaum (1989).

${ }^{9}$ Grass (1991, 2001a, 2014).

${ }^{10}$ Vgl. Frenzel (2008), S. V-XVI, Daemmrich (1987), S. IX-XII und Wilpert (2001), S. 533 f.

11 Zum bildhaften und zugleich handlungsbestimmenden Charakter des literarischen Motivs vgl. Frenzel (2008), S. VIII; zur Entwicklung des literarischen Werkes von Günter Grass „Vom privaten Motivkomplex zum poetischen Weltentwurf" vgl. Stolz (1994); in Bezug auf Grass' bildende Kunst vgl. Mayer (1982), S. 123 f.; zur Bedeutungskonstanz der Motive in Grass' Werk insbesondere: Tank (1965), S. 13, S. 17, S. 21, Spycher (1976), S. 40, S. 20, Rothenberg (1976), S. 162 und Hartung (1984), S. 151.

12 Grass (1973). Ausführlicher zu „Mariazuehren“: vgl. S. 279-289 dieser Forschungsarbeit. 
ließ Grass sein bis dato veröffentlichtes Werk Revue passieren: „Die Vögel, die Nonnen, die Scheuchen: Ich setze ein Zeichen und lösche es mit dem nächsten."

Die große Bedeutung der keineswegs traditionellen, häufig der Natur oder dem modernen Alltag entnommenen Motive für die Konstitution des Grass'schen Gesamtwerks, für die mit ihrer Hilfe geschaffene Kunstwelt ${ }^{13}$ und dafür, dass seine Literatur als besonders „bildhaft“ und „gegenständlich" wahrgenommen wird, ${ }^{14}$ sind der Forschung nicht entgangen. Grass' literarische Darstellungen von Tieren, Objekten und Figurentypen forderten dabei an sich sowie hinsichtlich der Art ihrer Einbettung in den jeweiligen Text immer wieder eine Suche nach weiteren geschärften philologischen Begriffen heraus.

Die in Texten oder in bildkünstlerischen Arbeiten realisierten Motive vermitteln Bedeutung über die äußere Erscheinung der dargestellten Objekte, über deren Ähnlichkeit mit oder Analogien zu anderen Gegenständen sowie über die ungewöhnliche Konfrontation oder metamorphe Kombination verschiedener Objekte miteinander. Die Zeichen stehen für abstrakte Begriffe, für Ideen, für emotionale oder gesellschaftliche Zustände ein. Gerade die bildnerischen lösen die Komplexität der thematisierten Inhalte nicht auf, bleiben dicht und sperrig und lassen durch die vielen von ihnen ausgelösten Assoziationen Wege für verschiedene Interpretationen offen.

Im literarischen Bereich entfalten Grass' Zeichen ihre Aussagekraft durch ihre Integration in Stilfiguren oder narrative Strukturen, sodass sowohl die von T. S. Eliot geprägte Bezeichnung des „objektiven Korrelats ${ }^{\prime 15}$ als auch die des Emblems ${ }^{16}$ auf die Passagen angewandt werden konnten. Seltener wurden sie als Metaphern oder als Bestandteile von Vergleichen und Allegorien benannt, obwohl diese Figuren besonders häufig im Gesamtwerk zu finden sind. ${ }^{17}$ Der fehlende Konsens in dieser Frage hängt nicht nur mit Grass' freiem Spiel mit Stilfiguren zusammen, sondern auch mit der Fülle verschiedenartiger bildgebender Passagen in seinen Werken. Über die Bezeichnung der Art, wie die Grass'schen Motive jeweils in seine Texte integriert werden, entscheidet in dieser Arbeit deshalb der Einzelfall. Auf eine Bezeichnung als „Bild“ wird in jedem Fall verzichtet, da die-

\footnotetext{
${ }^{13}$ Vgl. Stolz (1994), Engels (2005), vorab: Wieser (1968), S. 13 ff., Jurgensen (1974), S. 7 und Rothenberg (1974).

${ }^{14}$ Vgl. Wagenbach (1963), Jurgensen (1974), Hille-Sandvoss (1987) und Standfuss (2008).

${ }^{15} \mathrm{Vgl}$. Just (1972), S. 110 f. Just belegte Grass' bildgebende Verfahren in der Literatur mit dem Begriff des objektiven Korrelats, den er aus seiner Auseinandersetzung mit T. S. Eliot herleitete. Eliot sah die einzige Möglichkeit der Kunst, Emotionen darzustellen, darin, dass sie Entsprechungen zu ihnen finden müsse, und zwar in „einer Reihe von Gegenständen, einer Situation, einer Kette von Ereignissen, welche die Formel dieses besonderen Erlebnisses sein sollen, so daß, wenn die äußeren Tatsachen, die sinnlich wahrnehmbar sein müssen, gegeben sind, das Erlebnis unmittelbar hervorgerufen wird." (zitiert nach Just (1972), S. 111).

${ }^{16}$ Vgl. Weber (1995): In der Untersuchung werden schlüssig Parallelen zwischen Grass' Zeichen und frühneuzeitlichen Emblemen nachgewiesen. Bereits in Grass' Frühwerk lassen sich solche Verwandtschaften aufzeigen. Erst im Tagebuch einer Schnecke, im Butt und im Treffen in Telgte treten sie jedoch deutlich zu Tage und werden durch die Handlungszeit der Prosapassagen, in welchen sie auftreten, zusätzlich akzentuiert. Grass wies in Bezug auf das Treffen in Telgte darauf hin, dass er sich in diesem Werk und der dazugehörenden Titelgrafik an der Tradition der Emblematik orientierte. (XI 1047), vgl. auch Neuhaus (1985), S. 28, Neuhaus (2012), S. $276 \mathrm{f}$.

17 Vgl. Hille-Sandvoss (1987), S. 16-21. Der Begriff der Metapher wird in der ersten Dissertation zu Grass' bildkünstlerischem Werk bewusst ausgeschlossen. Die Motivdarstellungen haben Hille-Sandvoss zufolge über den Bezug zum bezeichneten Gegenstand hinaus keine Verweiskraft. Die Allegorie wird, wohl ebenfalls in Folge dieser Auffassung, gar nicht erst als Bezeichnung in Erwägung gezogen.
} 
ser gleichwohl umfassende Terminus präzise Benennungen der einzelnen Phänomene verhindert, wo sie durchaus möglich sind und gerade in einer Untersuchung der Zusammenhänge von bildender Kunst und Literatur, wie sie hier vorliegt, wenig Licht ins Dunkle bringt. Dass er bereits in einer Studie mit vergleichbarem Anliegen gewählt wurde, verweist allerdings auf das verwandtschaftliche Verhältnis, das früh zwischen den Zeichen des Schriftstellers und bildenden Künstlers ausgemacht werden konnte. ${ }^{18}$

Klaus Wagenbach stellte 1963 als Erster fest, dass der Autor der Blechtrommel „bildlich und präzis" schreibe, was sich in einer Vorliebe für Gegenstände äußere, die er im Sinne eines Fetischs mit Bedeutung und durch Anthropomorphismen mit einem Eigenleben ausstatte. Ein naiver Erzählerblick reduziere Grass' literarische Welt zudem auf das sinnlich Erfahrbare und sei Ausdruck der ausgeprägten Ideologiefeindlichkeit des Schriftstellers. Als rhetorische Mittel, auf welchen diese Art des Erzählens gründe, hob Wagenbach in seiner wegweisenden Analyse ein Verlangsamen der Narration durch Wortwiederholungen, das Anhäufen von Details und die Konzentration auf Objekte hervor. ${ }^{19}$

Eine Brücke von der Arbeitsweise des bildenden Künstlers zur Rhetorik des Schriftstellers schlug erstmals Manfred Jurgensen 1974: Weil in beiden Ausdrucksformen Bedeutung durch Objektdarstellungen vermittelt werde, sei Grass' bildkünstlerisches Schaffen die Wurzel seiner dingverhafteten literarischen Stilfiguren:

Erst wenn erkannt worden ist, daß die Erfahrung des Bildhauers Grass, eine gegenständliche Selbstverwirklichung des Stoffes zu erzwingen, auch zur Grundlage seines literarischen Ausdrucks wird, lässt sich die Bildhaftigkeit seiner Sprache näher kennzeichnen. Grass gestaltet das sprachliche Bild als formalen Ausdruck, der sich selbst beinhaltet. ${ }^{20}$

Warum aber Grass' bildende Kunst zwangsläufig Ursache für eine Form des Erzählens sein sollte, die in einer literarischen Tradition des, Objektzwangs' von Melville über Döblin und lonesco bis hin zum Nouveau Roman steht, ${ }^{21}$ und nicht etwa umgekehrt, begründete Jurgensen nicht. Auch Volker Neuhaus zog 1979 aus den Parallelen zwischen Grass' literarischer und bildkünstlerischer Gegenstandsfixierung, aus dem Ineinander von Schreiben und Zeichnen in Grass' Arbeitsprozess und - hier genauer als Jurgensen - der zeitlichen Abfolge von Kunststudium und Beginn der literarischen Karriere den Schluss, dass „das künstlerische Bild dem lyrischen Bild etwas von seinen Eigenschaften“ mitgeteilt habe. ${ }^{22}$ Da spätestens seit der Veröffentlichung der Grass'schen Autobiografie bekannt ist, dass von einem „Primat" der bildenden Kunst in seinem Leben nicht die Rede sein kann, sondern beide Ausdrucksformen durchgehend gleichzeitig von ihm genutzt wurden, kann die angenommene Reihenfolge als Argument für ein Einflussverhältnis der Künste nicht

\footnotetext{
${ }^{18} \mathrm{Vgl}$. ebd., S. 20 f. Forschungsüberblicke zum Thema der literarischen Bildlichkeit und ihres angenommenen Zusammenhangs mit Grass' bildender Kunst bieten die Dissertationen von Hille-Sandvoss (1987),

S. 2-12 und Engels (2005), S. 27-36.

${ }^{19} \mathrm{Vgl}$. Wagenbach (1963), S. 135. Vgl. ferner zu Grass' Fixierung auf Objekte in der Literatur: Wieser (1963),

S. 23 f, Just (1972), S. 111, Zissel-May (1974), S. 27, S. 47.

${ }^{20} \mathrm{Vgl}$. Jurgensen (1974), S. 199.

${ }^{21}$ Vgl. Tank (1965), S. 47 und Neuhaus (1979), S. 12.

${ }^{22}$ Vgl. Neuhaus (1979), S. 18 f. und Neuhaus (2010), S. 3 und S. 36.
} 
taugen. Selbst wenn sie belegbar wäre, könnte sie allein die Beziehung zwischen dem Schreiben und der bildkünstlerischen Tätigkeit nicht näher charakterisieren. Vielmehr gilt es, an Grass' Grafiken, Plastiken und Texten herauszuarbeiten, welche genuinen Eigenschaften einer Kulturtechnik für die andere fruchtbar geworden sein könnten.

Neuhaus charakterisierte Grass' lyrische Zeichen 1979 erstmals vor dem Hintergrund der grafischen. Dabei verkürzte er beide künstlerischen Ausdrucksformen auf mimetische Repräsentationen ohne doppelten Boden. Der Literaturwissenschaftler ging (und geht weiterhin) davon aus, dass Grass' Motive in der Lyrik nicht über sich selbst hinausweisen, sondern wie „der Gegenstand oder die Gegenstände einer Zeichnung, einer Grafik“ "nur sich selbst“ bedeuten. ${ }^{23}$ Diese Erläuterung wird jedoch weder Grass' lyrischen noch seinen grafischen Motivdarstellungen gerecht, in welchen, wie die vorliegende Arbeit zeigen wird, die Darstellung des Objekts, die von ihm ausgehenden Assoziationen, sein kultureller Kontext und ggf. die Zusammenstellung von Wort und Bild im intermedialen Kunstwerk gleichermaßen und unmittelbar Bedeutungen generieren. Grass' besondere Betonung der Gegenstände in seinen Texten und ihre isolierte Präsentation im grafischen Bild, die meist ohne Andeutung eines umgebenden Raumes auskommt, die häufig groteske Zusammenstellung der Gegenstände und ihre oftmals surreale Deformation setzen in beiden Medien Signale dafür, dass es sich bei seinen Zeichen - wie etwa den oben vorgestellten anthropomorphen fünf Vögeln - nicht (allein) um Repräsentationen realer Objekte handelt. ${ }^{24}$

Neuhaus' Annäherung an Grass' bildende Kunst ist aus einer Auseinandersetzung hervorgegangen, die vorrangig die schwere Zugänglichkeit der frühen Grass'schen Lyrik zum Thema hatte. Weil sich die Gedichte und Zeichnungen auf dieselben Motive konzentrieren, wurde dabei auch die Frage nach der Zugänglichkeit der bildkünstlerischen Darstellungen berührt. ${ }^{25}$ Wie einige Rezipienten vor inm geht Neuhaus davon aus, dass die Sprache des Lyrikers „privat“ und selbstbezüglich sei, sogar überhaupt nicht verstanden werden wolle. ${ }^{26}$ Grass' Motive würden für die Lesenden vielfach erst aus dem Vergleich mit ihrer Verwirklichung in der Dramatik und Prosa eine über den Gegenstand hinausweisende Bedeutung entfalten, weil erst darin die Bezüge der fragmenthaften lyrischen Zeichen ausformuliert würden. ${ }^{27}$ Gleichwohl in der Forschung Einigkeit darüber besteht, dass die Kenntnis des Gesamtwerks das Verständnis des Werkstücks wesentlich erweitert, ist die Zuspitzung dieser Annahme sowohl für den Umgang mit Grass' Lyrik als auch für den mit seiner Grafik problematisch: In ihrer ganzen Radikalität verstanden, degradiert sie das Einzelwerk - sie spricht ihm seine Eigenständigkeit ab und stellt damit, im Gegensatz zum Urteil vieler Rezensenten der ersten Veröffentlichungen, ${ }^{28}$ und scheinbar ohne sich dessen bewusst zu sein, seine Qualität in Frage. Die werkimmanente Analyse einzelner Gedichte wird vorab zum aussichtslosen Unterfangen erklärt und das Übersehen von Abweichungen und Nuancen, die bei aller Bedeutungskonstanz zwischen den einzelnen Zeichen erkennbar sind, befördert. ${ }^{29}$ Zahlreiche Interpretatio-

\footnotetext{
${ }^{23}$ Vgl. Neuhaus (1979), S. 19 und Neuhaus (2010), S. 36.

${ }^{24} \mathrm{Vgl}$. zu dieser Position: Tank (1965), S. 14-26 und Spycher (1976), S. 38 f.

${ }^{25} \mathrm{Vgl}$. Neuhaus (1979), S. 18.

${ }^{26}$ Vgl. Piontek (1970), S. 179 und Neuhaus (1993), S. 208.

${ }^{27} \mathrm{Vgl}$. Neuhaus (1979), S. 52, Neuhaus (1985), S. 20-23 und Neuhaus (2010), S. 6 f.

${ }^{28} \mathrm{Vgl}$. Arnold (1997), S. 75-78.

${ }^{29}$ Kritische Auseinandersetzungen mit dieser Position sind zu finden bei: Zissel-May (1974), S. 171, Geißler (1976), S. 173, und Hartung (1984), S. 151 f., Stolz (1994), S. 19 f. und Engels (2005), S. 27-36.
} 
nen der Grass'schen Lyrik, die die Gedichte im Kontext des Gesamtwerks betrachten und zugleich aussagekräftige werkimmanente Analysen bieten, widersprechen dieser Auffassung. ${ }^{30}$ In Bezug auf Günter Grass' Bildwerke kann das noch nicht behauptet werden.

Forschungsliteratur, die sich mit Grass' bildender Kunst oder dem Umgang des Schriftstellers mit bildender Kunst in seinen Texten beschäftigt, ist bisher nur in geringem Maße vorhanden. Von zwei Ausnahmen abgesehen, handelt es sich um Aufsätze und um Beiträge zu Ausstellungskatalogen, denen zwar kundige Blicke auf einen Teil des veröffentlichten Werkes zugrunde liegen, jedoch weder eingehende kunstwissenschaftliche Auseinandersetzungen mit einzelnen Arbeiten, noch eine systematische Untersuchung der Bezüge zwischen Wort und Bild. ${ }^{31}$ Die häufig mit dem Ziel des Gesamtüberblicks ansetzenden Darstellungen beschäftigen sich zudem mit einem Gegenstand, der in Abbildungen erst seit 1982 nach und nach zugänglich wurde. Grass' originale Zeichnungen und Grafiken konnten in einem für das Gesamtwerk repräsentativen Umfang sogar erst seit 2002 öffentlich im Archiv des Günter Grass-Hauses betrachtet werden. ${ }^{32}$

Dennoch befinden sich unter den Beiträgen wichtige Ansätze, auf die die vorliegende Untersuchung dankbar zurückgreift: Ansätze zur generellen kunsthistorischen Einordnung der Plastiken und Bilder von Günter Grass, zur produktionsästhetischen Analyse der Beziehung zwischen Schreiben und Zeichnen sowie zur rezeptionsästhetischen Untersuchung des Verhältnisses von Literatur und bildender Kunst in seinem Werk.

Eine Gliederung der bis 1982 entstandenen und einsehbaren Grass'schen Bildkunst in stilistische Etappen leistete Sigrid Mayer. ${ }^{33}$ In ihrem Nachwort zur ersten Veröffentlichung einer Auswahl von Zeichnungen des Schriftstellers unterteilte die Kunsthistorikerin seine Arbeiten in drei Zeiträume ihrer Entstehung: 1954 bis 1959, 1959 bis 1963 und 1972 bis 1977. Obwohl vorhandene Ausnahmen und Abstufungen darin nicht berücksichtigt werden, ist die Beobachtung zutreffend, dass die in diesen Arbeitsphasen entstandenen Werke stilistische Gemeinsamkeiten aufwei-

\footnotetext{
${ }^{30} \mathrm{Vgl}$. Zissel-May (1974), Stolz (1994), Frizen $(1992,2010)$ und Neuhaus (1985). Auch in Neuhaus' eigenen Analysen liefern Verweise auf Parallelstellen zwar weitere Anregungen zum Verständnis der Gedichte, seine Interpretationen sind jedoch dank seiner verständigen werkimmanenten Annäherungen nicht unbedingt notwendig, um einen Zugang zu Grass' Texten zu bieten.

${ }^{31}$ Vgl. zu Günter Grass' bildkünstlerischem Schaffen im Allgemeinen: Arnold (1978), Mayer (1982, 1984, 1995), Jensen (1987), Thompson (1990), Neuhaus (1994), Joch (1997, 2000) und Artinger (2002). Monografische Forschungsbeiträge liegen mit den Dissertationen von Hille-Sandvoss (1987) und Standfuss (2008) vor. Zur Rezeption der bildenden Kunst von Günter Grass in Zeitungen, Zeitschriften und Magazinen anlässlich der Veröffentlichungen Mariazuehren, Zeichnen und Schreiben I und II, In Kupfer, auf Stein, Vier Jahrzehnte: Arnold (1997), S. 239-258.

${ }^{32}$ Erst 1982/1984 wurde eine größere Auswahl der Zeichnungen und Radierungen veröffentlicht, 1986 ein Werkverzeichnis der Druckgrafiken, 2001 eine Auswahl der Aquarelle und 2002 eine der Plastiken. Ein zweibändiger Catalogue Raisonné der Radierungen und Lithografien erschien 2007. Die Originale sind in Auswahl 1991 zusammen mit dem literarischen Nachlass des Schriftstellers in die Bestände der Akademie der Künste Berlin eingegangen. In repräsentativer Zusammenstellung ist das zeichnerische und druckgrafische Werk seit 2002 im Lübecker Günter Grass-Haus zugänglich. Weitere bildkünstlerische Arbeiten befinden sich in der Kunsthalle Bremen, im Ludwig Forum für internationale Kunst in Aachen, in der Sammlung Würth, in den Städtischen Galerien bzw. der Günter-Grass-Galerie in Gdańsk und im Günter Grass Archiv des Steidl Verlags. Vgl. weiterführend: Neumann (2016), Wróblewska (2016) und das Motivverzeichnis in der vorliegenden Veröffentlichung.
}

${ }^{33}$ Vgl. Mayer (1982), S. 122. 
sen und die in bzw. kurz vor diesen Etappen in Gedichtbänden veröffentlichten Zeichnungen repräsentativ für sie sind: Während in der ersten Phase feine Feder-, Kohle- und Bleistiftzeichnungen dominieren, die surrealistische und kubistische Darstellungselemente aufweisen (Die Vorzüge der Windhühner, 1956), herrschen in der zweiten Phase expressive Fettkreide- und Pinselzeichnungen vor (Gleisdreieck, 1963). In der dritten Phase entstehen vor allem kontrastarme, die einzelnen Bildelemente naturnah darstellende Bleistiftzeichnungen (Ausgefragt, 1967) sowie detailreiche und stärker den Eindruck von Plastizität erzeugende Radierungen und Lithografien (Ach Butt, Dein Märchen geht böse aus, 1983). ${ }^{34}$ Jens Jensen konnte dem 1987 hinzufügen, dass sich Grass' Zeichnungen Mitte der Sechzigerjahre von Prägungen des zeitgenössischen Kunstbetriebs lösten und Fragen der Form und der Komposition zusehends einer naturalistischen Darstellung des einzelnen Gegenstandes wichen. ${ }^{35}$

Jensen unternahm in seinem Essay zu Zeichnungen des Schriftstellers zudem ihre Verortung in der Kunstgeschichte. Er verwies auf den figurativen, aber vom Gegenstand abstrahierenden Mischstil der Kunst der Fünfzigerjahre, der an die bildende Kunst der Klassischen Moderne anknüpfte, und betonte insbesondere die Nähe vieler Zeichnungen von Günter Grass zu solchen Pablo Picassos. ${ }^{36}$ Diese Beobachtungen werden jedoch nicht von vergleichenden Bildanalysen gestützt. Die Frage, auf welche Art Grass mit seinen mutmaßlichen Vorbildern umging, bleibt in diesem Beitrag folglich unbeantwortet. ${ }^{37}$

Das Verhältnis von Schreiben und Zeichnen in Grass' Arbeitsprozess wurde in den vergangenen Jahren sporadisch behandelt. Festgestellt wurde mehrfach, insbesondere im Rahmen der Untersuchungen von Dieter Stolz und Benedikt Engels, die sich mit dem Transfer der Grass'schen Motive und Themen durch verschiedene literarische Gattungen befassten, dass der Schriftsteller seine Ideen häufig zunächst in der Lyrik und Grafik, dann in Theaterspielen und schließlich in der Prosa realisiert hat, worin die früheren Arbeiten wiederum als lyrische und dramatische Passagen integriert wurden. ${ }^{38}$ Volker Neuhaus verdeutlichte ferner, dass Grass' bildkünstlerische Produktion zyklisch, in der ersten Vorbereitungsphase epischer Großwerke zu- und dann wieder abnahm. ${ }^{39}$ Darüber hinaus stützte sich die Forschung auf dem Gebiet der Produktionsästhetik jedoch bisher weitgehend auf die Äußerungen des Künstlers. ${ }^{40}$

In seinem Essay „Bin ich Schreiber oder Zeichner?“ für das Kunstmagazin art vom November 1979 gab Grass in konzentrierter Form Auskunft über die Rolle, die das Zeichnen in seinem Schaffen spielt: Als er darin auf eine wechselseitige Anregung der beiden Kulturtechniken hinwies, legte er selbst keine Abfolge zwischen dem Schreiben und Zeichnen fest. Er betonte vielmehr den

\footnotetext{
${ }^{34}$ Vgl. ebd.

${ }^{35} \mathrm{Vgl}$. Jensen (1987), S. 19, S. 21.

${ }^{36}$ Vgl. ebd., S. 17.

${ }^{37}$ Vgl. Zur Problematik der bisherigen kunsthistorischen Rezeption: Arnold (1997), S. 250: „Aufzählungen dieser Art [Vergleiche mit Werken anderer Künstler, V. K.] wirken grotesk, wenn sie den zuvor notwendigen Schritt stilistischer Beschreibung überspringen. Dabei läge es auf der Hand, Grass' künstlerische Ausbildung, seine Lehrer und damit die Tradition, aus der heraus er zu schaffen beginnt, genauer zu beleuchten. Seine eigene Technik und sein Stil könnten verglichen werden mit denen der zeitgenössischen Künstler, wobei zumindest Unterschiede in der Darstellungsweise zutage treten würden."

${ }^{38} \mathrm{Vgl}$. Stolz (1994), insbes. S. 18 und Engels (2005).

${ }^{39} \mathrm{Vgl}$. Neuhaus (2007), S. 224.

${ }^{40} \mathrm{VgI}$. Jensen (1987), S. 15-17 und Neuhaus (2010), S. 3-5.
} 
„zeichnerischen Einfall“, der beiden Erzeugnissen vorausgehe: „[A]us Gründen der Bildhaftigkeit stehen Zeichnen und Schreiben zueinander in Wechselbeziehung" (XI 1047). Jens Jensen folgerte daraus in seinem Essay, dass das Zeichnen Ausdruck des „bildhaften Denkens“ von Günter Grass sei und ein wichtiges Verfahren für den Künstler und Schriftsteller darstelle, um die Gestalt der fokussierten Gegenstände besser nachzuvollziehen. ${ }^{41}$

Wie die Forschung betonte auch Grass ferner den engen Zusammenhang zwischen seiner Lyrik und seinen Zeichnungen. In beiden Ausdrucksformen würden Widersprüche der Wirklichkeit durch ungewöhnliche Objektkonfrontationen vermittelt. ${ }^{42}$ Seiner Grafik schrieb Grass insbesondere die Aufgabe der Überprüfung von Metaphern zu. Grafische Bilder hatten für ihn eine stärkere Evidenz als die Sprache:

Sie [die Grafik, V. K.] ist genauer. Sie läßt sich nicht durch Wortklang verführen. Mehr als die eindeutige Linie ist der Vers durch das Geschwätz beliebiger Deutungen gefährdet. Erst ins grafische Bild übersetzt beweist die Wortmetapher, ob sie Bestand hat. Seht, sagt die Zeichnung, wie wenige Wörter ich brauche; hört, sagt das Gedicht, was zwischen den Linien ist. (XI 1048)

Die Auseinandersetzung der Forschung mit dem Verhältnis von Text und Bild in Grass' Werk aus rezeptionsästhetischer Perspektive baut auf dem Befund der Motiväquivalenz in beiden Medien auf: 1987 leistete Angelika Hille-Sandvoss in ihrer Dissertation eine Zusammenstellung derselben Motive aus Grass' Grafik und Literatur. ${ }^{43}$ Die Untersuchung verdeutlicht, dass sein Motivnetz über die Mediengrenzen hinweg gesponnen wurde. Wie Bedeutung jeweils in Wort und Bild hergestellt wird und wie verschiedenartige Darstellungen desselben Motivs als Medienkompositionen in den Gedichtbänden nebeneinander wirken, wurde dabei allerdings nicht erörtert. Hille-Sandvoss folgte zudem Neuhaus' oben skizzierter Annahme einer Selbstgenügsamkeit der Grass'schen Zeichen und rechtfertigte damit die in der Studie häufig fehlende nähere Auseinandersetzung mit Bedeutungen, die ein dargestelltes Objekt transportiert. ${ }^{44}$

Eine Gegenposition vertrat Peter Joch 1997 in einem als Überblick über Grass' Schaffen konzipierten Essay ${ }^{45}$ und leistete dabei die bisher präziseste Charakterisierung der bildkünstlerischen Arbeiten des Schriftstellers:

Genauso wie Grass in seinen ausnahmslos folgerichtig ablaufenden Epen die literarischen ,Standbilder' in den grundlegenden Bogen der Erzählung zurückbindet, sind auch die grafischen Darstellungen mit ihrem minimalen Bildpersonal keine selbstgenügsamen Studien. Die Figuren sind oft Repräsen-

\footnotetext{
${ }^{41}$ Vgl. Jensen (1987), S. 17.

42 Vgl. Grass in dem kurzen Aufsatz „Bin ich nun Schreiber oder Zeichner“, XI 1048: „Wie der lyrische Vers Distanzen kürzt und dehnt, oder der kurzen Erhellung Dauer sichert, so hält die Zeichnung kaum merkliche Überschneidungen fest: Mit gleichmütiger Linie hebt sie Fremdheiten auf, sie bettet Gegensätzliches unter einer Schraffur, sie widerlegt - wie das Gedicht - die Gewohnheit, sie macht das Niegehörte sichtbar. Die Konfrontation des Gegenständlichen ist mein Thema."

${ }^{43} \mathrm{Vgl}$. Hille-Sandvoss (1987).

${ }^{44}$ Vgl. ebd. (1987), S. 13: „In diesem Kontext muss berücksichtigt werden, daß einige Grafiken, die in diesem Bezugssystem stehen, ,blind' bleiben, auf keine weiterführenden, andere Sinnzusammenhänge stiftenden Bedeutungen verweisen; was auch mit der von Neuhaus konstatierten Selbstgenügsamkeit der grafischen Bilder zusammenhängt, die ihren ,Sinn' oder ihre ,Bedeutung' allein in der Abbildung oder Wiedergabe eines Gegenstandes konstituieren und auch ohne zusätzliche ,Bedeutung' auskommen."

${ }^{45} \mathrm{Vgl}$. Joch (1997), insbesondere: S. 18, Joch (2000) und Kniesche (2002).
} 
tanten, Archetypen, die auf ,übergeordnete' Bedeutungszusammenhänge - vom Abbild der Natur bis zum vielschichtigen Spiel mit Zeichensystemen - angelegt sind. ${ }^{46}$

Dabei würden die Darstellungen den Rezeptionsvorgang augenblicklich auslösen, nicht erst in einem zweiten Schritt, und häufig mit literarischen Stilfiguren oder Sprichwörtern in engem Zusammenhang stehen. ${ }^{47}$

Die erste Untersuchung von Bezügen der Grass'schen Prosa zu Werken anderer bildender Künstler bot Ingeborg Hoesterey 1988 mit einer intertextuellen Analyse, in welcher sie im Text zitierte Bilder als Referenztexte auffasste. Im Rahmen ihrer Monografie zu intertextuellen Verfahren der Moderne und Postmoderne behandelte sie die Blechtrommel (1959) und den Butt (1977). Dabei warf sie allerdings weniger die Frage auf, inwieweit intermediale Bezüge die Struktur und die Rezeption der Erzählwerke bestimmen, als vielmehr diejenige, in welchem Verhältnis diese zur Biografie des realen Autors stehen. ${ }^{48}$

Die vorliegende Untersuchung greift die angeführten Ansätze in modifizierter Form auf, vertieft sie am heute in großem Umfang zur Verfügung stehenden Archivmaterial und bedient sich insbesondere der Methoden der Bildwissenschaft und der Intermedialitätsforschung. Die kunsthistorische Einordnung und stilkritische Untersuchung der Bildwerke von Günter Grass, das Beleuchten seines gattungsübergreifenden Arbeitsprozesses und der intermedialen Bezüge zwischen Bildern und Texten bauen aufeinander auf, da Grass seine bildende Kunst und seine Gattungsgrenzen überschreitende Arbeitsweise in seiner Literatur thematisierte. Angestrebt ist eine in der Forschung zu Grass' bildender Kunst fehlende, von dem einzelnen Werkstück ausgehende Analyse.

Dieser Blick fürs Detail macht eine Eingrenzung des zu betrachtenden Zeitraums notwendig. Die Untersuchung fokussiert die ersten dreißig Schaffensjahre des bildenden Künstlers und Schriftstellers, die sich in drei Phasen gliedern lassen: 1. Grass' Ausbildungsjahre zum bildenden Künstler in Berlin und Düsseldorf (1947-1956), in welchen seine Ästhetik und seine Poetologie nachhaltig geprägt wurden, 2. die Jahre der Arbeit an der sogenannten ,Danziger Trilogie' (bestehend aus der Blechtrommel (1959), Katz und Maus (1961) und den Hundejahren (1963)) samt der bereits ab 1954 auf sie zusteuernden Gedichte und Theaterspiele und damit die Etappe, in der verschiedene Künste in seinem Werk zum ersten Mal intensiv zusammenwirkten, sowie 3. die nach der Bundestagswahl von 1969 begonnene Arbeit am Tagebuch einer Schnecke (1972), worin die bildende Kunst nach einigen Jahren der weitgehenden Absenz erneut in enger Verbindung mit der Literatur auf den Plan trat und zum Großprojekt des Butt (1977) führte. Die ,Pause' zwischen der zweiten und dritten Phase, die vor allem durch Grass' politisches Engagement geprägt war und deshalb in Forschungsbeiträgen zu seiner bildenden Kunst weitgehend ausgeklammert wird, ${ }^{49}$ behandelt die vorliegende Untersuchung zum ersten Mal. Grass führte in dieser Zeit Zeichnungen zu der in erweiterter Form veröffentlichten Büchner-Preis-Rede von Ingeborg Bachmann, Ein Ort

\footnotetext{
${ }^{46} \mathrm{Vgl}$. Joch (1997), S. 16.

${ }^{47}$ Vgl. ebd., S. 18.

${ }^{48} \mathrm{Vgl}$. Hoesterey (1988), S. 71-100.

${ }^{49}$ Vgl. z. B. die oben erwähnte Unterteilung der bildkünstlerischen Werketappen bei Mayer (1982), S. 122, in der die Jahre 1959-1972 eine Leerstelle bilden.
} 
für Zufälle (1965), aus, die als seine ersten Bildwerke zu einem fremden Prosatext ein besonderes Licht auf seine eigene Ästhetik werfen. Zudem bietet der Blick auf seine in diesen Jahren entstandenen Texte ex negativo Erkenntnisse über den Zusammenhang seines schriftstellerischen und bildkünstlerischen Schaffens: Die Untersuchung stellt hier die Frage, inwiefern Grass' Literatur in einer Zeit, in der seine Betätigung als bildender Künstler abnahm, Bezüge zum anderen Medium enthält.

Die Analyse der Werkstattphasen zur ,Danziger Trilogie' einerseits sowie zum Tagebuch einer Schnecke und zum Butt andererseits ermöglicht die Betrachtung der zyklischen Arbeitsweise von Günter Grass, auf die Neuhaus hinwies, am Beispiel zweier Werketappen. ${ }^{50}$ Der mit dem Butt gesetzte Schlusspunkt ist an dieser Stelle sinnvoll, weil der Schriftsteller bildende Kunst in den folgenden literarischen Werken nicht mehr in derselben Intensität behandelte und der Stil seiner bildkünstlerischen Arbeiten nach Abschluss dieses Romans weitgehend konstant blieb. Spätere Entwicklungen in Grass' Buchkonzeption und der Gestaltung seiner Bücher, auf die sich bereits Studien von Edgar Platen und Katja Standfuss konzentrieren, ${ }^{51}$ werden im abschließenden Kapitel angesprochen und mit den hier behandelten Werken in Beziehung gesetzt.

Die erste sowie die zweite und dritte in dieser Arbeit betrachtete Schaffensphase erfordern unterschiedliche Herangehensweisen. Die Auseinandersetzung mit Grass' Ausbildungszeit, in der seine bildende Kunst und seine Literatur weitgehend beziehungslos nebeneinander existierten, fußt auf einer Rekonstruktion seiner Künstlerausbildung in Düsseldorf und Berlin sowie der zeitgenössischen kunsttheoretischen Debatten, die ihn in seinen Lehrjahren beschäftigten. Behandelt werden die frühen bildkünstlerischen Werke und die größtenteils unveröffentlichten Dichtungen, um sie im Vergleich mit Arbeiten anderer Künstler und Dichter näher zu charakterisieren und ihre Entwicklung herauszustellen. Bei der Untersuchung seiner Werke aus der Berliner Studienzeit rückt zusehends eine vergleichende Betrachtung von literarischen und bildkünstlerischen Erzeugnissen in den Mittelpunkt, die erste Motivüberschneidungen aufweisen. Wie zu zeigen sein wird, gehen Grass' Sujet-Wahl, seine bevorzugten Methoden der Bildkomposition und der ideologiekritische Impetus seines bildkünstlerischen Werkes auf die Auseinandersetzung mit der Kunst des ersten Drittels des 20. Jahrhunderts, insbesondere mit dem Surrealismus, sowie mit seinen Akademielehrern und den Debatten um die gegenständliche und gegenstandslose Kunst zurück. ${ }^{52}$

Die Analyse der beiden Arbeitsphasen innerhalb des Radius' epischer Großwerke verfolgt die Linie der Motivuntersuchung weiter. Es werden jeweils drei Motive thematisiert, die für jede der Phasen von herausragender Bedeutung sind. Deren Auswahl ergibt sich aus der Häufigkeit ihres

\footnotetext{
${ }^{50} \mathrm{Vgl}$. Neuhaus (2007).

${ }^{51}$ Vgl. Platen (2002) und Standfuss (2008). Beide postulierten mit ihren Forschungsbeiträgen die Kategorie des Text-Bild-Bandes für eine bestimmte Gruppe von Veröffentlichungen von Günter Grass. Gemeint sind die Publikationen Zunge Zeigen, Totes Holz, Fundsachen für Nichtleser, Mein Jahrhundert und Letzte Tänze, in welchen Bildern sowohl im Produktionsprozess als auch in der großformatigen Buchpräsentation ein besonders großes Gewicht zukommt. Wie im Folgenden deutlich werden soll, wurden auch die zwischen 1947 und 1977 veröffentlichten Bücher von Grass nach einem intermedialen Grundkonzept geschaffen. Wort und Bild stehen darin auch hinsichtlich der Buchgestaltung in einem engen Bezug zueinander. Eine begriffliche Unterscheidung zwischen früheren und späteren Publikationen ist $\mathrm{m}$. E. deshalb nicht gerechtfertigt.

${ }^{52}$ Einen frühen Hinweis auf die Nähe der Grass'schen Werke zum Surrealismus liefert: Hoesterey (1988), S. 89, später auch: Joch (1997), S. 22.
} 
Vorkommens in Grass' bildender Kunst, aber auch in seinen Texten verschiedener literarischer Gattungen. Die diversen Manifestationen derselben Motive in Wort und Bild, die Art, wie welches Motiv in welchem Medium umgesetzt wird und Inhalte vermittelt, werden exemplarisch innerhalb der Chronologie des Arbeitsprozesses behandelt, um Bedeutungsverschiebungen von Medienwechsel zu Medienwechsel nachvollziehbar zu machen. Eine Auflistung aller in Archiven und Publikationen zugänglichen bildkünstlerischen Motivdarstellungen wird im Motivverzeichnis dieser Arbeit für einen umfassenden Überblick und zukünftige Forschungsarbeiten zur Verfügung gestellt. Zur Einschätzung der Funktion eines in einem bestimmten Medium umgesetzten Motivs für ein in einem anderen Medium realisiertes andere stellt die rekonstruierte Chronologie des Arbeitsprozesses ein unterstützendes Argument dar. ${ }^{53}$ Ausschlaggebend jedoch ist, ob medienspezifische Eigenarten eines Artefaktes die Gestaltung eines medial differenten anderen geprägt haben könnten. Die Forschung Horst Bredekamps, in der die zentrale Bedeutung des Zeichnens als einer Erkenntnismethode im Zusammenhang mit verschiedenen wissenschaftlichen Disziplinen herausgearbeitet wird, diente der vorliegenden Untersuchung dabei als wichtige Anregung. ${ }^{54}$

Die These dieses Beitrages zum gattungsübergreifenden Schaffen von Günter Grass lautet, dass es gerade das Auffinden von Formäquivalenzen ist, das für viele Texte des Schriftstellers, wie die eingangs behandelten „Fünf Vögel“, entscheidend war. Eine genaue Betrachtung von Objekten lag ihm zugrunde und wurde durch das bildkünstlerische Schaffen des Schriftstellers befördert und darin manifest.

Bei der vergleichenden Analyse der einzelnen Zeichen in Wort und Bild wird die Terminologie der Intermedialitätsforschung genutzt, wie sie Irina Rajewsky 2002 systematisierte. ${ }^{55}$ Ausgehend von Erkenntnissen der Filmwissenschaften und der Komparatistik, die Ende der Achtzigerjahre mit Ansätzen der Intertextualität kombiniert wurden, entwickelte Rajewsky eine Klassifizierung verschiedener Intermedialitätsphänomene: des Medienwechsels, der Medienkomposition und der intermedialen Bezüge samt ihrer weiteren Differenzierungen. ${ }^{56}$ Als Literaturwissenschaftlerin setzte sich Rajewsky besonders intensiv mit Bezugnahmen der Literatur auf andere Medien aus-

\footnotetext{
${ }^{53} \mathrm{Zu}$ der in dieser Arbeit berücksichtigten Problematik der wissenschaftlichen Auseinandersetzung mit intermedialen Phänomenen vgl. Warren/Wellek (1985) hinsichtlich der Annahme einer Wechselbeziehung zwischen den Künsten allein aufgrund des identischen Produzenten und seiner Intention, aufgrund des Zeitgeistes und "gefühlter" Analogien, S. 134-142, ebenso Weisstein (1992), S. 11-31 sowie Mitchell (2008/1990) über die Notwendigkeit der Kenntnisnahme des intermedialen Charakters jedes Mediums und einer differenzierteren Betrachtung intermedialer Phänomene „über den Vergleich hinaus“, S. 136-171. Einen historischen Überblick über Fallstricke der Intermedialitätsforschung mit einem Fokus auf den Filmwissenschaften bietet Rajewsky (2002), S. 32-58. Behandelt werden: die mangelnde Berücksichtigung medialer Historizität, die Problematik der Nachweisbarkeit intermedialer Relationen und insbesondere des Einflusses eines Mediums auf ein anderes.

${ }^{54} \mathrm{Vgl}$. insbesondere Bredekamp $(2005,2005$ a, 2007, 2015).

${ }^{55} \mathrm{Vgl}$. Rajewsky (2002).

${ }^{56}$ Vgl. ebd., S. 199 und S. 201: Als Medienwechsel wird „die Transformation eines medienspezifisch fixierten Produkts bzw. Produktsubstrats in ein anderes, konventionell als distinkt wahrgenommenes Medium " bezeichnet. Die Medienkombination meint eine „Kombination mindestens zweier als distinkt wahrgenommener Medien, die im entstehenden Produkt materiell präsent sind und mit ihren je eigenen Mitteln zur (Bedeutungs-)Konstitution desselben beitragen.“ Intermediale Bezüge werden definiert als: „Verfahren der Bedeutungskonstitution eines medialen Produkts durch Bezugnahme auf ein Produkt oder das semiotische System bzw. semiotische Subsysteme eines konventionell als distinkt wahrgenommenen Mediums [...], wobei per definitionem immer nur ein Medium in seiner Materialität präsent ist."
} 
einander. Ihre zu diesem Aspekt von Intermedialität besonders detaillierten Ausführungen erwiesen sich gerade für die Beschäftigung mit Grass' Erzählwerk als erhellend, das eine Vielzahl der von ihr klassifizierten Phänomene enthält. Bei aller Berücksichtigung der generellen Verwandtschaft von sprachlichen und bildkünstlerischen Ausdrucksformen konzentriert sich Rajewskys Untersuchung auf die Analyse von markierten literarischen Auseinandersetzungen mit einem anderen Medium, wie sie in Grass' Werk durchgängig zu finden sind. Insbesondere das Betrachten der Welt aus der Perspektive von bildenden Künstlern prägt darin die Struktur der Narration und damit auch ihre Rezeption: In den Bücher wird mit dem Sehsinn die Wahrnehmungsweise betont, die für die Rezeption bildender Kunst zentral ist. ${ }^{57}$ Die von Grass gesetzten Zeichen, deren sprachlich evozierte Sinnlichkeit und Prägnanz von der Forschung bereits thematisiert wurden, werden in den Erzählwerken in ein Netz intermedialer Bezüge gespannt.

Die Untersuchung erschöpft sich nicht im Aufzeigen dieser Bezugnahmen, sondern beschäftigt sich weiter mit der Frage nach ihrer rezeptionsästhetischen Funktion. Antworten bietet der Blick auf Diskurse zur Anschauung, zur Aufklärung und zu verschiedenen Epochen der bildenden Kunst, die der Schriftsteller in seinen Texten anstieß. Grass' Auseinandersetzung mit dem Berliner Kunststreit zwischen gegenständlich und ungegenständlich arbeitenden Künstlern trug dazu bei, dass sich das anschauliche Schreiben zu einer grundlegenden Komponente seiner Literatur entwickelte. Das Sehen, im Sinne des Wahrnehmens der gesellschaftlichen Wirklichkeit, reifte in Grass' Werk zu einer Handlung von moralischer Bedeutung. Im Laufe der Jahre wurde seine Haltung durch die Beschäftigung mit der Aufklärung, mit Arthur Schopenhauers Ästhetik, mit Walter Benjamins Allegorie-Begriff sowie Claude Lévi-Strauss' und Albert Camus' Mythos-Auffassung angereichert. Zu Grass' Gegenständen gehörte dabei nicht nur das Sichtbare, sondern auch das mit anderen Sinnen erfahrbare Irrationale und Unterbewusste. Auch diese Phänomene brachte er in seinen Darstellungen und Kombination sinnlich wahrnehmbarer Gegenstände zum Ausdruck. Als Bezugspunkt diente auch hier der Surrealismus sowie später und in Verbindung mit diesem die Romantik.

Die vorliegende Arbeit vermittelt eine Zusammenschau verschiedener Aspekte der Beschäftigung des Schriftstellers und Künstlers mit bildender Kunst und Ästhetik. Vor der Folie seiner eigenen Bildkunst und seiner Mediengrenzen überschreitenden Arbeitsweise bietet die Untersuchung darüber hinaus einen tiefen Einblick in die Entwicklung seiner Poetologie.

\footnotetext{
${ }^{57}$ Vgl. ebd., S. 88. Der von Rajewsky als Teil einer Illusionsbildung angesprochene Perspektiveneinsatz wird von Elleström im Sinne einer Gemeinsamkeit beider Medien auf der Wahrnehmungsebene behandelt. Vgl. Elleström (2010), S. 11-50; vgl. ferner im selben Sammelband die Reaktion von Rajewsky auf die Kritik an ihrem konventionell wahrnehmbare Mediengrenzen berücksichtigenden Medienbegriff: Rajewsky (2010).
} 


\section{LEHRJAHRE (1947-1956): AUF DEM WEG ZU EINER BILDSPRACHE}

\section{Düsseldorf: Das Menschenbild fragmentieren}

Die Jahre 1947 bis 1952 verbrachte Günter Grass als Steinmetzpraktikant und Schüler der Kunstakademie in Düsseldorf. Während dieser ersten Hälfte seiner Ausbildung zum Bildhauer und Grafiker lernte er nicht nur von seinen Professoren, sondern ebenso von Werken überregional bekannter Bildhauer und Maler, die den verschiedenen Avantgardebewegungen des beginnenden 20. Jahrhunderts angehörten und in den ersten Jahren nach Kriegsende besonders häufig ausgestellt wurden. Sie regten ihn dazu an, sich in verschiedenen Stilen zu üben und prägten sein Kunstverständnis nachhaltig. Gleiches gilt für die Lyrik des ersten Drittels des 20. Jahrhunderts, die Grass zunächst aufnahm und in eigenen Dichtungen nachahmte, aus denen schließlich Texte eigenständigen Stils hervorgingen. ${ }^{58}$

In die besagte Zeitspanne fallen die Währungsreform, die Gründung der Bundesrepublik und das sogenannte Wirtschaftswunder. Es handelt sich um Jahre der Weichenstellung für die deutsche Gesellschaft im Allgemeinen sowie für Kunst und Kultur im Besonderen. Grass erlebte diese Etappe nicht nur als junger Künstler und Dichter, sondern behandelte sie seit 1959 literarisch immer wieder. Die Auseinandersetzung mit Kunst und Künstlern der Nachkriegszeit erhält in der Blechtrommel (1959), in den Hundejahren (1963) und noch in der Rättin (1986) viel Raum. Grass' Leben in Düsseldorf dient dabei als Steinbruch für Orts-, Milieu- und Figurenschilderungen. In letztere fließen Eigenschaften seiner Düsseldorfer Professoren Otto Pankok und Sepp Mages wie auch befreundeter Künstler ein. ${ }^{59}$ In allen drei Romanen wird Kunst in Relation zu den ökonomischen und politischen Strukturen betrachtet, in die sie eingebettet ist. Düsseldorf erhält den Status einer Chiffre für die Korrumpierbarkeit der Kunst durch Erfolg und Geld sowie für Verdrängung, Täuschung und Hochstapelei - es figuriert als „biedermeierliches Babel“ (IV 706) und „butzenscheibenverklebte Pestbeule“ (IV 706) in den "falschen Fuffzigern“ (VII 409 f.) während eines „Wiederaufbaus ohne Fundament" (XII 147). ${ }^{60}$

Grass' Studienarbeiten machen deutlich, in welchem Maße seine Schilderungen der Düsseldorfer Kunstszene auf eigenen Erfahrungen beruhen. Der in der Blechtrommel persiflierte Rückbezug der zeitgenössischen Künstlerinnen und Künstler auf Strömungen der Klassischen Moderne, vor allem auf den Expressionismus und Kubismus, erweist sich in vielen seiner Arbeiten als sein eigener.

Einen Einblick in Grass' Schaffen in Düsseldorf bieten Gipsmodelle, Zeichnungen, Aquarelle und zwei Skizzenbücher, die teils zu den Beständen des Günter Grass-Hauses in Lübeck, teils zu jenen der Günter und Ute Grass Stiftung gehören. Im Jahr 2013 wurden dem Schriftsteller ein Konvolut von rund 150 Aquarellen und Zeichnungen sowie vier Plastiken übergeben, die er 1952 in seiner Düsseldorfer Atelier-Wohnung zurückgelassen hatte. ${ }^{61}$ Grass' literarische Betätigung in seiner

\footnotetext{
${ }^{58}$ Vgl. Frizen (2010), S. 16-18.

${ }^{59} \mathrm{Vgl}$. Stallbaum (1989), Mason (1974), Neuhaus (1991) und Weyer (2009).

${ }^{60} \mathrm{Vgl}$. Neuhaus (1991).

${ }^{61}$ Beide Skizzenbücher wurden von der Günter und Ute Grass Stiftung archiviert. Einzelveröffentlichungen daraus sind zu finden in: Grass (2014), S. 18, S. 20 und S. 22 f. Das Günter Grass-Haus beherbergt einzelne
} 
Studienzeit bezeugen lose Manuskriptseiten und ein Arbeitstagebuch aus dem Jahr 1952. Sie gehören zu den Beständen des Literaturarchivs der Akademie der Künste in Berlin. ${ }^{62}$

Entscheidende Wegmarken seiner frühen Künstlerbiografie hatte Grass vor allem im Erinnerungsbuch Beim Häuten der Zwiebel (2006), zuvor im Werkstattbericht (1991) ${ }^{63}$ sowie in den Reden "Geschenkte Freiheit" (1985, XII 141-156) und "Schreiben nach Auschwitz" (Frankfurter Poetik-Vorlesung, 1990, XII 239-261) herausgestellt. Die autobiografischen Texte unterstreichen die doppelte Bedeutsamkeit der Werkphase als Etappe der frühen ästhetischen Prägung des bildenden Künstlers und Schriftstellers zum einen und als Erfahrungsschatz hinsichtlich des Umgangs mit Kriegsschuld und -scham zum anderen. Der junge Günter Grass wird dabei von dem gealterten Schriftsteller gleichsam von außen betrachtet. Er dient sich selbst als Beispiel für das Verhalten eines jungen Künstlers, der zwar davongekommen, jedoch noch nicht in der Lage war, Vergangenheitsbewältigung zu betreiben.

Die detailliertesten Angaben zu seinen Studienjahren machte Grass im neuesten dieser Texte, Beim Häuten der Zwiebel. Dabei handelt es sich nicht um eine Autobiografie nach herkömmlichem Verständnis, da Lebenserinnerungen in dieser Veröffentlichung mit stilisierten und fiktionalen Passagen verwoben sind - sie kann ebenso als "autobiografischer Roman" bezeichnet werden. ${ }^{64}$ Hinsichtlich der biografischen Fakten stellt das Buch dennoch die ergiebigste Quelle zur Rekonstruktion der von Grass am Niederrhein verbrachten Nachkriegsjahre dar, zumal sich im Archiv der Kunstakademie Düsseldorf keine Akte zum Studenten Günter Grass erhalten hat. ${ }^{65}$ Einen Überblick über die wichtigsten Stationen dieser Lebensphase wird im Folgenden den Einstieg für die nähere Betrachtung seiner Ausbildung an der Kunstakademie Düsseldorf bieten.

Nach der Entlassung aus amerikanischer Kriegsgefangenschaft 1945 hielt sich der in der Freien Stadt Danzig aufgewachsene Grass kurzzeitig an wechselnden Orten auf: in Köln-Mühlheim, im Kreis Bergheim/Erft, im Hunsrück und in Groß Giesen bei Hildesheim, wo er als Koppeljunge in einem Bergwerk der Burbach Kali-AG angestellt war. Ende 1946, Anfang 1947 traf er im niederrheinischen Fliesteden bei Bergheim auf seine aus Danzig geflüchtete Familie. Im Gepäck trug er die Erfahrung von Kampfeinsätzen in den letzten Kriegsmonaten in einer Division der Waffen-SS, die von Todesangst und dem Sterben zahlreicher, gleichermaßen junger Kameraden geprägt waren. (X 313-366)

In Fliesteden zog er zu den Eltern und der jüngeren Schwester Waltraut in eine behelfsmäßige Unterkunft, eine ehemalige Futterküche für Schweinemast. Unweit hatte sein Vater eine Anstellung als Pförtner im Braunkohle-Tagebau gefunden. Wilhelm Grass' Versuch, seinem kunst- und

kleinformatige Zeichnungen aus den Jahren 1951 und 1952 sowie eine undatierte Gipsbüste aus der Praktikumszeit. 2018 kaufte es 33 der im Jahr 2013 wiederentdeckten Bilder an. Das plötzlich aufgetauchte Konvolut wurde von Grass noch in dem kurzen Prosatext "Das soll von mir sein?" in Vonne Endlichkait in literarischer Form kommentiert: Grass (2015), S. 95 f. Eine Auswahl der Werke wurde 2016 in der Ausstellung „Don't fence me in". Frühe Bilder von Günter Grass im Günter Grass-Haus präsentiert. Vgl. zu diesen Arbeiten im Detail: Krason (2016).

${ }^{62}$ Akademie der Künste, Berlin, Günter-Grass-Archiv, Nr. 965, Nr. 181-210.

${ }^{63} \mathrm{Vgl}$. Grass $(1991,2001 \mathrm{a}, 2014)$.

${ }^{64}$ Vgl. Hinck (2008), S. 8 und Krason (2013a), S. 87.

${ }^{65} \mathrm{Im}$ Archiv der Kunstakademie befindet sich lediglich eine Sammlung mit Zeitungsartikeln über Günter Grass, die nach seinem literarischen Durchbruch veröffentlicht wurden. 
literaturbegeisterten Sohn eine Lehrstelle in der Verwaltung zu vermitteln, ließ, so vermutet Grass rückblickend in Beim Häuten der Zwiebel, seine eigenen Berufswünsche erst deutlich hervortreten. Bereits vor dem Krieg hatte er in Danzig erste Gedichte und Geschichten geschrieben, Bilder gezeichnet und an Kursen des Malers Fritz Pfuhle teilgenommen. Während der ersten Nachkriegsmonate hatte Grass wieder zu dichten und zu zeichnen begonnen:

Kann es sein, daß erst die vom Vater mir liebevoll angedrohte Bürolehre meinen Wünschen genaue Richtung gegeben hat? Mit einem Stoß gereimter und reimloser Halbzeilen - einige der Gedichte hatte des Reviersteigers Tochter säuberlich abgetippt -, dem satten Dutzend Zeichnungen, die brav ähnlich Kumpels aus der Gefangenschaft und dem späteren Barackenleben zum Motiv hatten, mehr noch mit meinen bildhaften Vorstellungen von mal miniaturhaft winzigen, dann wieder monumental gesteigerten Figuren aller Art, nackten und gewandeten, langbeinig stehenden, gestürzten, gramvoll gebeugten, auch solchen von halb tierischer, halb menschlicher Gestalt, mit figürlichem Andrang im Kopf - und weil seit eh und je inwendig reich an Figuren - wollte ich Bildhauer werden, jemand, der aus bloßer Tonerde Gestalten formt, die durch ihre rundum betastbare Anwesenheit den Raum beherrschen. (X 452, vgl. auch X 437)

Im Januar 1947, nach nur vierzehn Tagen des beengten Familienlebens, beschloss der Neunzehnjährige an der Kunstakademie Düsseldorf vorzusprechen. Dort wurde er von Joseph Enseling, Professor für Bildhauerei, darüber in Kenntnis gesetzt, dass derzeit keine Studienplätze vergeben würden, weil kein Material zum Beheizen der Ateliers vorhanden sei. Grass solle die Zeit zum nächstmöglichen Bewerbungstermin mit einem Steinmetzpraktikum überbrücken. (X 457-459)

Diesen Ratschlag befolgend, lernte er als Praktikant im Steinmetzbetrieb von Julius Göbel, Grabsteinornamente zu meißeln und eine Punktiermaschine zu bedienen. Nach einem Jahr wechselte er zur Firma Moog, wo er gemeinsam mit den Lehrlingen Kriegsschäden an den Plastiken des Düsseldorfer Hofgartens ausbesserte und ein Werk von Wilhelm Lehmbruck kopierte. (X 475 f., $486 \mathrm{f.})$

Göbel vermittelte Grass für diese Ausbildungsphase einen Schlafplatz im Caritas-Heim der Franziskanermönche im Stadtteil Düsseldorf-Rath. Unter dem Dach der Anlage waren ein Heim für männliche Obdachlose und mittellose Senioren und ein Lehrlingsheim zusammengefasst. In Pater Stanislaus, der für die jungen Bewohner zuständig war, fand der dichtende Steinmetzpraktikant einen belesenen Gesprächspartner. Dieser macht ihn mit der umfangreichen Hausbibliothek, insbesondere mit „Rilke, Trakl, einer Auswahl von Barockdichtern und allerfrühesten Expressionisten“ (X 483), zudem mit Charles Baudelaire, William Faulkner, Julien Green und Joachim Ringelnatz vertraut. ${ }^{66}$ Diskussionen über den christlichen Glauben führte Grass zudem mit dem Leiter des Heimes, Prior Fulgentius Maria Lehmann und pflegte diese Auseinandersetzungen noch bis in die späten Fünfzigerjahre hinein schriftlich weiter. ${ }^{67}$ Daneben nahm er die sich stetig erweiternden Kulturangebote der Stadt wahr, sah Ausstellungen von Marc Chagall, Ernst Ludwig Kirchner, Oskar Schlemmer, August Macke und Paul Klee sowie von regionalen Künstlern:

Die Maler der „rheinischen Sezession“, die Gruppe „Junges Rheinland“, Expressionisten, die Sammlung der ,Mutter Ey', Düsseldorfer Lokalgrößen. [...] Arbeiten von Goller, Schrieber, Macketanz, dem Bildhauer Jupp Rübsam. In Mode war ein Maler namens Pudlich. (X 503)

\footnotetext{
${ }^{66}$ Vgl. Schwartze-Köhler (2009), S. 344.

${ }^{67} \mathrm{Vgl}$. Neuhaus (1991), S. 134 f.
} 
Er besuchte außerdem Aufführungen im Düsseldorfer Schauspielhaus, das unter der Intendanz von Gustaf Gründgens große Erfolge feierte, ${ }^{68}$ hörte Konzerte im Robert-Schuhmann-Saal und profitierte ab 1950 von Rowohlts günstigen Rotationsromanen (X 483). Noch ohne entsprechende Textkenntnisse nahm Grass die verbreitete existenzialistische Grundhaltung an (X 500). Er erinnert sich, unpolitisch, egomanisch und gegen alles Ideologische, Bürgerlich-einengende ablehnend eingestellt gewesen zu sein (X 509 f., XII 243).

Zum Wintersemester 1948/1949 bewarb er sich offiziell an der Kunstakademie. Die im CaritasHeim betreuten Alten hatten ihm als Modelle für Porträtstudien gedient. Diese Zeichnungen reichte er zusammen mit weiteren Arbeitsproben ein, die im Rahmen des Steinmetzpraktikums entstanden waren. Von siebenundzwanzig Bewerberinnen und Bewerbern wurden nur zwei ausgewählt, zu denen er - auch aufgrund der gesammelten praktischen Erfahrungen - zählte. (X 496)

Grass wurde zunächst der Klasse des Bildhauers Sepp Mages zugeteilt, der für die Anfänger zuständig war, und wechselte nach zwei Jahren zu dem spätexpressionistischen Grafiker und Bildhauer Otto Pankok. Die freien Entfaltungsmöglichkeiten, die der Student zunächst an Pankoks Lehre schätzte, empfand er bald als Mangel an Führung, sodass er sich 1952 um eine Aufnahme in die Klasse des Bildhauers Karl Hartung an der Hochschule für bildende Künste in Berlin bemühte. Hartungs Arbeiten hatte er im Frühjahr 1952 in einer Düsseldorfer Galerie-Ausstellung gesehen und sich für die raumgreifenden biomorphen und gegenständlichen Formen begeistert. ${ }^{69}$ Beraten von dem niederrheinischen Künstler Ludwig Gabriel Schrieber, der mit Hartung befreundet war und den auch mit Grass später eine enge Freundschaft verbunden hat, gelang inm zu Beginn des Jahres 1953 der Wechsel in die geteilte Stadt. ${ }^{70}$

Seine Suche nach einem neuen Lehrer wurde von der Sehnsucht nach einem anderen Lebensort begleitet, denn er empfand gegen Düsseldorf zunehmend Widerwillen (X 489, 492, 509 f, 550). Zusehends verlor er sich in dem "bierseligen Altstadtbetrieb“, in welchem er gemeinsam mit den Freunden Horst Geldmacher und Günter Scholl als Jazzmusiker (am Waschbrett) auftrat. Das Trio spielte in der ungarischen Kneipe "Csikós“, die Grass später als Kulisse für den „Zwiebelkeller“ der Blechtrommel dienen sollte. Im Roman findet das Düsseldorfer Bürgertum dort auf fantastische Art und Weise zu Tränen und Erinnerung. ${ }^{71}$

Nach der Währungsreform war das Leben in der Rheinmetropole von steigendem Wohlstand, schnellem Wiederaufbau und energischem Verdrängen der jüngsten Vergangenheit geprägt. Die anfangs von den Besatzungsmächten vorangetriebene Entnazifizierung und Umerziehung, aber auch die euphorische Aufnahme jeglichen Kulturguts durch die deutsche Bevölkerung wurde nach 1948 von der Freude abgelöst, wieder ein wirtschaftlich effizienter Teil Westeuropas zu sein und

\footnotetext{
${ }^{68} \mathrm{Vgl}$. die Auflistung einzelner von Grass erinnerter Aufführungen bei Schwartze-Köhler (2009), S. 146.

${ }^{69}$ In seinem Nachruf auf Karl Hartung beschrieb Grass 1967 seine Faszination für dessen Plastiken wie folgt: „[R]uhige, zumeist liegende Formen, weibliche oder vegetative, die auf jeden Oberflächenreiz verzichteten; bis auf das endliche Maß geschliffen, beanspruchten sie Raum, zwangen sie den Beschauer zur Unruhe, boten sie rundum Ansicht." (XI 291)

70 Vgl. die Kapitel "Der dritte Hunger" und "Wie ich zum Raucher wurde“ in Beim Häuten der Zwiebel (X 455-498, 499-552) und Grass (2014), S. 7-29; Grass' handschriftlicher Brief an Hartung ist hier auf S. 36 abgedruckt.

${ }^{71}$ Ein ganzes Kapitel des Debütromans kreist um diesen besonderen Ort und trägt entsprechend den Titel "Der Zwiebelkeller".
} 
erneut auf ein breites Konsumangebot zurückgreifen zu können. Sie ging Hand in Hand mit der wachsenden Ablehnung des kommunistischen Regimes. ${ }^{72}$

Die auf diese Weise vollzogene Abkehr von der eigenen Geschichte wurde von Grass nachträglich kritisiert (XII 239-261). Die Annahme einer sogenannten Stunde Null und damit eines tatsächlichen Bewusstseinswandels der Deutschen stellte er für alle gesellschaftlichen Schichten in Abrede. Die Kontinuitäten, die der Schriftsteller stattdessen wahrnahm, thematisierte er mit Bezug auf die zügige Reintegration ehemaliger nationalsozialistischer Entscheidungsträger in die Gesellschaft. Er beschrieb zudem die Fortsetzung des Alltags der Kleinbürger und die Wiederaufnahme des kreativen Schaffens von Künstlerinnen und Künstlern nach 1945. Letzterer ist ein ganzes Kapitel des Debütromans, „Madonna 49“, gewidmet.

Auch Grass selbst hatte nach 1945, ohne einen Blick über die Schulter zu riskieren, seinen schon von Jugend an gehegten Berufswunsch zu realisieren begonnen. Im Rahmen der Frankfurter Poetik-Vorlesung erläutert er, die erste Etappe seines künstlerischen Werdegangs erscheine inm rückblickend „fragwürdig doch und am Ende gar nicht bewundernswert, weil sich meine künstlerische Entwicklung, die bald übers Gedicht zur Schriftstellerei führte, schon wieder unbeirrbar vollzog, unbeirrbar auch durch Auschwitz." (XII 242). Die Kunst, mit der er sich nach 1945 beschäftigte, stand jedoch zum nationalsozialistischen Kunstideal im Gegensatz. Bereits dem Heranwachsenden hatte sie eine wichtige Anregung zu selbständigem, kritischem Denken geboten.

\section{Das Nachleben der Klassischen Moderne in der Nachkriegszeit}

In Beim Häuten der Zwiebel erinnert Grass seine von Kindesbeinen an empfundene und nach dem Krieg unvermindert weiterbestehende Begeisterung für bildende Kunst und Literatur als Lebenskonstante. Er schildert diese Leidenschaft als eine Ausflucht aus den kleinbürgerlichen Lebensverhältnissen und als Zukunftsperspektive für die Nachkriegszeit. ${ }^{73}$

Der Aspekt der Kontinuität wird im Erinnerungsbuch besonders dadurch verdeutlicht, dass sich die Leidenschaft des Jungen und des jungen Mannes wiederholt an denselben Werken entzündet: Das Kind sammelt kleinformatige Reproduktionen von Gemälden, die es über Gutscheine aus Zigarettenpackungen bezieht. Informationen über dieselben kanonischen Werke eignet sich der Heranwachsende mit Hilfe von Knackfuß-Künstler-Monografien an. Der Student der Bildhauerei wird die Arbeiten schließlich im Original auf Autostopp-Reisen nach Frankreich und Italien wiederentdecken, so etwa Tizians Venus von Urbino, Botticellis Geburt der Venus und Sodomas Heiligen Sebastian. ${ }^{74}$

Ein zweiter Bogen wird im Erinnerungsbuch zwischen ersten Blicken auf die im „Dritten Reich“ diffamierte Avantgardekunst und ihrer Betrachtung in den Ausstellungen der frühen Nachkriegszeit geschlagen. Die Kunstlehrerin und Malerin Lilly Kröhnert zeigt dem Jugendlichen während des Krieges heimlich alte Kunstkataloge und -zeitschriften, in denen Werke von Ernst Barlach, Otto Dix, Lyonel Feininger, Karl Hofer, Paul Klee, Oskar Kokoschka und Wilhelm Lehmbruck abgedruckt

\footnotetext{
${ }^{72}$ Vgl. Abelshauser (1985), Hermand (1989), S. 36-41 und Glaser (1992), S. 139-143.

${ }^{73} \mathrm{Vgl}$. Krason (2013a).

${ }^{74} \mathrm{Vgl}$. Schade (2007) und Krason (2013a), S. 88.
} 
sind. ${ }^{75}$ Arbeiten dieser Künstler, die den Schüler noch auf recht diffuse Art faszinieren, verunsichern und die Wirkung der nationalsozialistischen Propaganda ein Stück weit unterwandern, ${ }^{76}$ sieht er während seines Studiums in Düsseldorf in Ausstellungen wieder. Noch Jahrzehnte später bleiben sie für ihn herausragende Beispiele einer Kunst, die sich mit der Wirklichkeit auseinandersetzt, wie sie die Fünfzigerjahre seiner Ansicht nach weitgehend entbehrten. ${ }^{77}$

Die in der literarischen Rekonstruktion des Erlebten in Beim Häuten der Zwiebel zwischen Grass' Kunstbetrachtung der Kriegs- und Nachkriegszeit gezogene Linie hatte ihre Entsprechung in der deutschen Rezeptionsgeschichte, die von der Kulturpolitik gelenkt wurde: Die Besatzungsmächte brachten der Bevölkerung die Kunst der Klassischen Moderne wieder ins Bewusstsein eine Kunst, die unter dem Nazi-Regime aus dem öffentlichen Raum verdrängt worden war. Nach zwölf Jahren, in denen die bildende Kunst zu großen Teilen im Dienst der staatlichen Propaganda gestanden und ,deutsche Werte' in einer naturalistischen Formensprache klassizistischen Einschlags transportiert hatte, sollte dem Publikumsgeschmack eine neue Orientierung gegeben und die Vielfalt deutscher Kunstsammlungen und Galerien wiederhergestellt werden. ${ }^{78}$ Alle vier Besatzungsmächte waren sich dem Potsdamer Abkommen gemäß darin einig, dass zum Wiederaufbau eines demokratischen Staates nicht nur die gesellschaftlichen Strukturen, sondern auch das Bewusstsein der Bevölkerung gewandelt werden müsse. Der Kultur wurde dabei eine wichtige Rolle zugesprochen. ${ }^{79}$

Die ersten Ausstellungen der Nachkriegszeit suggerierten das nahtlose Fortführen einer durch die Machtübernahme der NSDAP gewaltsam unterbundenen Kunstentwicklung. ${ }^{80}$ Museen und Galerien kauften und präsentierten vor allem Werke, die von der Ästhetik des Nationalsozialismus deutlich abwichen und deshalb als "entartet" diffamiert worden waren. Die Kuratoren konzentrierten sich - auch aus pragmatischen Gründen der Verfügbarkeit - auf bereits vor 1933 namhafte Maler und Bildhauer, die in Deutschland geblieben waren und in der „inneren Emigration" weitergearbeitet hatten. Zu diesen zählten Käthe Kollwitz, Ernst Barlach, Emil Nolde, Erich Heckel, Karl Schmidt-Rottluff, Max Pechstein, Carl Hofer, Otto Dix, Willi Baumeister, Fritz Winter und Ernst Wilhelm Nay. ${ }^{81}$ Dass aufwendige überregionale Gruppenausstellungen zunächst kaum

\footnotetext{
${ }^{75}$ Vgl. Krason (2013a), S. 88.

${ }^{76} \mathrm{Vgl}$. X 481 f.: „Nur daß mir heiß wurde, ist sicher. Sosehr hat mich, was ich zuvor nie gesehen hatte, fasziniert und zugleich entsetzt. Das alles war verboten, war „entartete Kunst“. Immer wieder hatte die Wochenschau dem Kinogänger vorgeführt, was im Dritten Reich als schön zu gelten hatte: In überlebensgroß aus Marmor gehauenen Heldengestalten überboten die Bildhauer Breker und Thorak einander mit versteinerter Muskelkraft.“ sowie XII 241: „Ein Risiko eingehend, hat sie mich mit dem Werk der Künstler Kirchner, Lehmbruck, Nolde, Beckmann entsetzt und gleichwohl infiziert. Daran hielt ich mich. Oder das ließ mich nicht los. Angesichts dieser bildnerischen Provokationen hörte die Unbeirrbarkeit des Hitlerjungen auf; nein, sie hörte nicht auf, durchlässig wurde sie an einer einzigen Stelle, hinter der sich andere, egozentrische Unbeirrbarkeit auszuwachsen begann: die dumpfe und ungenaue, dennoch beharrlich zugespitzte Verstiegenheit, Künstler werden zu wollen."

77 Grass' Kritik an einer mangelnden Auseinandersetzung mit der Realität in der Kunst der Fünfzigerjahre wird in Kapitel II.3. dieser Arbeit ausführlich behandelt.

${ }^{78} \mathrm{Vgl}$. Thomas (2003), S. 23.

${ }^{79} \mathrm{Vgl}$. Held (1981), S. 12 f.

${ }^{80} \mathrm{Vgl}$. Damus (1997), S. 25.

${ }^{81} \mathrm{Vgl}$. Hermand (1986), S. 94-96.
} 
von den Städten zu bewerkstelligen waren, hatte in vielen Präsentationen den Nebeneffekt einer Zusammenschau von regional und überregional bekannten Künstlerinnen und Künstlern. ${ }^{82}$

Der Expressionismus, der zwar von den Nationalsozialisten geächtet worden war, aber vor der Konsolidierung der faschistischen Kulturpolitik als genuin deutsche Kunst gegolten hatte, wurde durch Ausstellungen wieder bekannt. Insbesondere die Malerei der Künstlergruppe "Die Brücke“ und Werke, die im Umkreis des Künstlerzusammenschlusses „Der Blaue Reiter“ entstanden waren, wurden häufig ausgestellt. ${ }^{83}$ Die Tatsache, dass der Expressionismus sich ebenso wie der Konstruktivismus, Dadaismus, Surrealismus, Futurismus und die Neue Sachlichkeit Ende der Zwanzigerjahre bereits überlebt hatte, wurde dabei nicht reflektiert. ${ }^{84}$

In der zeitgenössischen deutschen Malerei etablierte sich zunächst ein figurativer, jedoch vom Gegenstand abstrahierender Mischstil, der zwischen der Formensprache des Verismus und Expressionismus angesiedelt war. ${ }^{85}$ Einzelne Künstler wie Otto Dix und Karl Hofer beschäftigten sich unmittelbar mit dem Kriegsleid und Maler wie Werner Heldt erhoben die allgegenwärtige Trümmerlandschaft zum Sujet. Dennoch dominierten bald zeitlose Darstellungen existentieller Lebensfragen, die etwa in den Werken von Werner Gilles mithilfe von Allegorien und Bezugnahmen auf mythologische Stoffe zum Ausdruck gebracht wurden. ${ }^{86}$

Im Unterschied zu den pathosgeladenen Figurendarstellungen des Nationalsozialismus widmete sich die Bildhauerei nach 1945 bewusst der Vermittlung eines „maßvollen Menschenbildes“. ${ }^{87}$ Oftmals in Anlehnung an die Skulptur der griechischen Archaik entstanden in Posen und Details zurückgenommene Arbeiten, als deren prägnanteste Beispiele die Werke von Gerhard Marcks angeführt werden können. Gleichzeitig gewann gegen Ende der Vierzigerjahre eine stärker vom Gegenstand abstrahierende Bildhauerei an Bedeutung. Hinzu kamen biomorphe Plastiken, die zwar in ihrer Gesamterscheinung keinem realen Gegenstand ähnelten, aber auf einzelne Ansichten und Formen von Naturobjekten rekurrierten. ${ }^{88}$

Die gegenstandslose Kunst in der Tradition Wassily Kandinskys und Paul Klees stand bis 1950 nur gleichberechtigt, nicht wie wenige Jahre später in der Bundesrepublik vorherrschend, neben der gegenständlichen Kunst. Vertreten vor allem durch den vom Bauhaus geprägten Willi Baumeister, durch Ernst Wilhelm Nay und Fritz Winter, beschäftigte sie sich in nonfigurativen Farb- und Formkombinationen oftmals mit Inhalten, die jenseits der sinnlich erfahrbaren Welt angesiedelt waren. ${ }^{89}$

In der Blechtrommel umreißt Grass satirisch das bildkünstlerische Spektrum der ersten Nachkriegsjahre aus der Perspektive seines Protagonisten: Unmittelbar nach der Währungsreform lässt Oskar Matzerath sich als Modell in der Düsseldorfer Kunstakademie beschäftigen und kommentiert die nach seinem Erscheinungsbild entstehenden expressionistischen, neoklassizistischen, kubistischen und surrealistischen Arbeiten von Professoren und Studierenden. Persiflierbar

\footnotetext{
${ }^{82} \mathrm{Vgl}$. Held (1981), S. $14 \mathrm{f}$.

${ }^{83}$ Vgl. Thomas (2002), S. 23.

${ }^{84} \mathrm{Vgl}$. Damus (1997), insbesondere S. 37.

${ }^{85}$ Vgl. Held (1981), S. 25.

${ }^{86} \mathrm{Vgl}$. Thomas (2002), S. 12-19.

${ }^{87}$ Vgl. Damus (1997), S. 71-77, hier: S. 73.

${ }^{88} \mathrm{Vgl}$. Damus (1995), S. 71-77.

${ }^{89} \mathrm{Vgl}$. Hermand (1986), S. 442.
} 
werden die einzelnen Kunstströmungen in Grass' Debütroman durch ihren von Oskar überspitzt geschilderten Schematismus. Stilelemente der Klassischen Moderne werden, den jeweiligen Lehrern folgend, von den in sich homogenen Schülergruppen weiterverwendet, woraus sich wenig differenzierte Bilder ergeben - keinem der jungen Künstlerinnen und Künstler gelingt es, Oskar in all seinen Facetten darzustellen (III 609, 612-614). ${ }^{90}$ Lediglich die ebenfalls fiktiven surrealistischen Maler "Ziege“ und „Raskolnikoff" erschaffen Werke, in welchen Oskar sich wiedererkennt (III 618). Die Konfrontation des Protagonisten mit diesen Arbeiten sorgt für einen Wendepunkt der Romanhandlung. Diese besondere Rolle surrealistischer Kunst im Erzählwerk entspricht der Wertschätzung, die der Autor ihr gegenüber als bildender Künstler ab 1954 zeigte. Wie in der vorliegenden Untersuchung noch näher erörtert werden wird, nutzte er in jenem Jahr verstärkt surrealistische Methoden der Bildkomposition und sollte sie lebenslang in einer eigenständig weiterentwickelten Form einsetzen. Sein zwischen 1954 und 1959 entstandener Roman spiegelt insofern eine damals besonders deutlich hervortretende ästhetische Präferenz des bildenden Künstlers.

Die nonfigurative Kunst wird von dem Protagonisten des Debütromans dagegen mit Verachtung gestraft (III 640). Seine Kritik, diese Strömung sei eine inhaltsleere und dilettantische, bezieht sich jedoch noch nicht auf die Kunst des Informel. Erst zu Beginn der Fünfzigerjahre trat diese nicht an den Traditionen des frühen 20. Jahrhunderts ausgerichtete Kunstströmung in der Bundesrepublik auf den Plan. Die Malerei des Abstrakten Expressionismus und des Informel, die sich in den Vierzigerjahren in den USA und in Frankreich etablierte, war seit der Gründung der Künstlergruppe Quadriga 1952 in der westdeutschen Kunst anzutreffen. ${ }^{91}$ Künstlerinnen und Künstler wandten sich im Folgenden verstärkt dem Eigenwert von Form und Farbe zu und legitimierten ihre Arbeit aus einer Teleologie der Reinheit künstlerischer Gattungen heraus, wie sie der Kunstkritiker Clement Greenberg bereits 1940 in seinem Essay „Zu einem neueren Laokoon“ formulierte. ${ }^{92}$ Die Vertreter der nonfigurativen Kunst sahen eine stetige Entwicklung von den Werken der Impressionisten über die Malerei Cézannes und die Arbeiten der Kubisten hin zu einer „puren“ Malerei, Grafik und Plastik, die von jeglichen Bezügen außerhalb ihrer selbst und damit auch von der Darstellung eines Gegenstandes entbunden sei. ${ }^{93}$ Diese künstlerische Befreiung wurde in Westdeutschland nicht nur der nationalsozialistischen Kunst gegenübergestellt, sondern diente ebenso zur Abgrenzung gegen den sozialistischen Realismus, der in Sowjetischen Besatzungszone und dann in der Deutschen Demokratischen Republik an Geltung gewann.

Die ersten umfangreichen Überblicksausstellungen deutscher Kunst, die 1946 in Konstanz und in Dresden stattfanden, präsentierten noch gleichermaßen figurative wie abstrahierende und abstrakte Werke. Komplementär zur steigenden Bedeutung der ungegenständlichen Kunst im Westen appellierten Kulturpolitiker im Osten jedoch bald an die Künstlerinnen und Künstler, gegenständliche, wirklichkeitsnahe und verständliche Werke zu schaffen. ${ }^{94}$ Ab 1948, als sich mit Währungsreform und Berlin-Blockade der Machtkampf zwischen Ost und West zum Kalten Krieg

\footnotetext{
${ }^{90}$ Vgl. III, das Kapitel „Madonna 49“, X 604-622.

${ }^{91} \mathrm{Vgl}$. Thomas (2002), S. 57-60.

${ }^{92} \mathrm{Vgl}$. Greenberg (1940/2009), S. 56-82

${ }^{93} \mathrm{Vgl}$. Damus (1997) und Greenberg (1940/2009), S. 56-81.

${ }^{94}$ Vgl. Dengler (2010), S. 30-209 und Damus (1991), S. 56.
} 
zuspitzte, wurde der Gegensatz zwischen gegenständlicher und gegenstandsloser Kunst explizit unter politischen Vorzeichen diskutiert. Während im Osten der Sozialistische Realismus zur Staatskunst erklärt wurde, lobte man die gegenstandslose Kunst im Westen für ihre Innovationskraft und die voraussetzungslose Rezipierbarkeit ihrer Farb- und Formkompositionen als demokratische Weltsprache. Ihr stand ein Großteil der Bevölkerung jedoch zunächst verständnislos gegenüber. ${ }^{95}$ Dieses Missverhältnis wurde 1950 in Darmstadt von prominenten Kultur- und Geistesschaffenden öffentlich diskutiert. Es handelte sich um die aufsehenerregendste kulturwissenschaftliche und kunsttheoretische Debatte, die in der Bundesrepublik während Grass' Studium in Düsseldorf geführt wurde.

\section{Das Darmstädter Gespräch}

Obwohl die gegenstandslose Kunst in Westdeutschland stetig an Präsenz gewann, fand das breite Publikum nur schwer zu ihr Zugang. In den ersten Jahren nach Kriegsende war noch die Kunst der Klassischen Moderne für viele Deutsche eine Herausforderung, weil ihre Sehgewohnheiten größtenteils von der naturalistischen und klassizistischen Formensprache geprägt waren, die die nationalistische Kulturpolitik in der bildenden Kunst unterstützte. Von dieser Formensprache waren gegenstandslose Arbeiten weit entfernt und galten als Werke für die intellektuelle Elite. Es verwundert deshalb nicht, dass Hans Sedlmayrs kunst- und kulturkritische Schrift Verlust der Mitte (1948) viel Zuspruch erhielt. Der Text gliedert sich in die drei Teile: „Symptome“, „Diagnose und Verlauf" sowie „Zur Prognose und Entscheidung“. Mit Rückgriff auf medizinisches Vokabular analysiert Sedlmayr darin maßgeblich Phänomene der Architektur- und Kunstgeschichte seit Ende des 18. Jahrhunderts als Merkmale des menschlichen Selbstverständnisses und des Zeitgeistes. Dabei deutet er die verfremdete Darstellung des Menschen in der Klassischen Moderne als Symptom einer gesellschaftlichen Fehlentwicklung und rechtfertigt so die „instinktive“ Ablehnung dieser Kunst durch „natürliche“ Menschen:

In verschiedenen „Richtungen“ der modernen Kunst tritt die eine oder die andere Verbindung dieser gegenmenschlichen Züge hervor, wobei grob gesehen im Kubismus die „Vertotung“, im Expressionismus das heiße Chaos, im Surrealismus die kalte Dämonie der untersten Eishölle dominiert.[...] Diese Deutung muß demjenigen, der sie noch nicht erprobt hat, als phantastisch erscheinen. Trotzdem leistet sie, ganz kalt betrachtet, das, was man von einer Theorie erwarten muß: sie erklärt eine Fülle von Tatsachen, die man bisher getrennt zu verstehen suchen muß: sie läßt alle diese "Ismen“, vom Futurismus bis zum Surrealismus (alle ein Fliehen von der oberen Realität), als nur oberflächlich verschiedene Äußerungen der gleichen erzeugenden Grundkräfte erkennen - denn das Menschliche ist in allen seinen Erscheinungen eines, seine Verneinungen aber sind viele - und läßt auch schon ihre Unterschiede bis hinein in die Einzelheiten der Technik durchschauen, die großartige Mittel zur Darstellung dieser Unwirklichkeiten entwickelt hat. Sie erklärt aber auch auf die direkteste Weise den instinktiven Widerwillen des "natürlichen“ Menschen gegen diese Bilder, der einen tiefen Grund hat und nicht als der Hohn der ihre Beschränktheit verteidigenden Banausen gegen alles Neue und Außerordentliche abgetan werden kann. ${ }^{96}$

Die Abstraktion hält Sedlmayr für eine grundlegende, wenn auch nur episodische Bedrohung der Malerei. Bereits in den Werken Cézannes sieht er die Gefahr „über der Welt der reinen Farbe die

\footnotetext{
${ }^{95}$ Vgl. zum elitären Konzept der gegenstandslosen Kunst: Hermand (1986), S. 387-400.

${ }^{96}$ Vgl. Sedlmayr (1998), S. 131.
} 
Welt des Menschen zu verlieren und den Menschen herabzusetzen". ${ }^{97}$ Als Ursache aller untersuchten Phänomene bestimmt Sedlmayr den mit dem Ende des 18. Jahrhunderts eingeläuteten „Verlust der Mitte“. Als Mitte bezeichnet er den Gottesglauben, den er aufgrund der angenommen Ebenbildlichkeit des Menschen mit Gott eng mit der Darstellung der menschlichen Figur in der bildenden Kunst verknüpft. ${ }^{98}$ Den Glaubensverlust erklärt Sedlmayr aus einem Autonomiestreben heraus, das sich gemeinsam mit dem Pantheismus und Deismus entwickelt habe und sich auch in der Auflösung des Gesamtkunstwerks hin zur Reinheit der Gattungen äußere. Drei Jahre nach Kriegsende versprach seine populäre Kulturkritik damit darüber hinaus aber nicht weniger, als eine Antwort auf die Frage nach den Gründen für die ,Katastrophe' des Zweiten Weltkrieges, ohne diese selbst zu thematisieren. ${ }^{99}$

Das erste Darmstädter Gespräch vom 15. bis 17. Juni 1950 bot den kontroversen Reaktionen, die die Publikation nach sich zog, ein Forum. Die Reden und Debatten des dreitägigen Symposiums, das parallel zu einer Ausstellung auf der Darmstädter Mathildenhöhe mit dem Titel Das Menschenbild in unserer Zeit stattfand, behandelten die zeitgenössische Auffassung vom Menschen aus der Perspektive verschiedener wissenschaftlicher Disziplinen - Theologie, Soziologie, Medizin, Biologie und Philosophie - und nahmen seine Repräsentationen in der Gegenwartskunst in den Blick. Die Eröffnungsvorträge des Schweizer Malers, Kunsttheoretikers und ehemaligen Bauhaus-Lehrers Johannes Itten und Hans Sedlmayrs markierten die beiden Pole der folgenden Debatten: Während Itten die "Möglichkeiten der Kunst" aufzeigte, sprach Sedlmayr über die ihr angeblich drohenden und von ihr ausgehenden Gefahren. ${ }^{100}$ Aus den folgenden Reden und Gesprächen lassen sich drei Hauptpositionen herauskristallisieren: Gegen Sedlmayrs konservativen Standpunkt wendete sich Willi Baumeister. Er warf Sedlmayr sowohl eine Stigmatisierung der zeitgenössischen Kunst in der Tradition der Nationalisten als auch ein generelles Unverständnis der nonfigurativen Kunst vor, die sich durchaus, und zwar in noch höherem Maße als die gegenständliche Kunst, dem Transzendenten widme. Ebenfalls konträr zu Sedlmayr, aber auch in Abgrenzung zu Baumeister verteidigte Theodor W. Adorno im Zuge des Abschlussgesprächs aller Teilnehmer die in der ungegenständlichen Kunst einvernehmlich diagnostizierten Rezeptionshürden. Die besondere Qualität dieser Werke liege gerade darin, dass sie Dissonanzen zum Strukturmerkmal erhebe. In genau dieser Form bringe sie „das Zerrissene, selber unversöhnt, unversetzt zum Ausdruck“ und sei darin zeitgemäß. ${ }^{101}$

Wie aus dem 1951 herausgegebenen Jahrbuch der Kunstakademie Düsseldorf hervorgeht, nahm die Professorenschaft der Ausbildungsstätte an dieser Debatte kaum Anteil. ${ }^{102}$ Bemerkenswerterweise war es allein Grass' zweiter Lehrer Otto Pankok, der sich in seinem Essay - jeder der Lehrenden hatte einen kurzen schriftlichen Beitrag zum Jahrbuch geliefert - zur Streitfrage von Gegenständlichkeit und Gegenstandslosigkeit äußerte. Sedlmayrs Argumentationslinie unterstüt-

\footnotetext{
${ }^{97}$ Vgl. ebd., S. 137.

${ }^{98}$ Vgl. ebd., S. 168-170.

${ }^{99}$ Vgl. Hofmann (1997) und Männig (2017), S. 100.

100 Vgl. Evers (1951), S. 28-62.

101 Vgl. ebd., S. $215 \mathrm{f}$.

102 Vgl. Trier (1985), S. 367-370., hier: S. 368 und Reuter (2014), S. 149, mit Bezug auf einen Artikel von Romain (1985), S. 419-421, hier S. 421.
} 
zend, wenn auch ohne dessen Metaphorik der Krankheit zu verwenden, verurteilte er die nonfigurative Kunst als eine buchstäblich anti-humanistische. ${ }^{103}$

Das Darmstädter Gespräch war die öffentlichkeitswirksamste Auseinandersetzung zu diesem Thema, der Diskurs mit dieser Veranstaltung jedoch noch lange nicht abgeschlossen. 1955 fand er in einem polemischen Disput zwischen Will Grohmann und Karl Hofer einen weiteren Höhepunkt. Obwohl es vor allem dieser spätere Konflikt ist, der Günter Grass intensiv beschäftigt hat, ist es in Anbetracht der Positionierung seines Lehrers Otto Pankok sinnvoll, das Darmstädter Gespräch als wichtige Vorstufe der Debatte und mittelbare Prägung des Studienanfängers im Hinterkopf zu behalten.

\section{Grass' Studium an der Kunstakademie Düsseldorf}

Als Grass im Winter 1947 an der Kunstakademie vorsprach, war die Institution noch weit davon entfernt, sich kunsttheoretischen Auseinandersetzungen widmen zu können. Das Akademiegebäude war im Zuge von Bombardierungen der Stadt am 14. und 21. März 1945 stark beschädigt worden. Phosphorgranaten hatten es in Brand gesetzt und alle Decken im östlichen Flügel des Baus zum Einsturz gebracht. Alle Anstrengungen nach Kriegsende galten deshalb zunächst der Wiederherstellung der Räume, die zur erneuten Aufnahme des Lehrbetriebs in seiner rudimentärsten Form zum Wintersemester 1945/1946 notwendig waren. ${ }^{104}$

Ewald Mataré, der als Professor 1933 von den Nationalsozialisten entlassen worden war, wurde im Herbst 1945 zum kommissarischen Direktor ernannt. Der Bildhauer forderte eine grundlegende Entnazifizierung des Kollegiums, eine Ausbildungsreform und eine spätere Wiedereröffnung der Kunstakademie, um den Studierenden eine in jeder Hinsicht angemessene Ausbildung bieten zu können. Keiner dieser Punkte stieß jedoch auf Zustimmung. Insbesondere Matarés Vorschlag, das Mindestalter der Studienanfänger auf vierzehn Jahre zu senken, um früher auf ihre Entwicklung Einfluss zu nehmen, wurde abgelehnt. Auch die Entlassung aller Professoren, die Mitglied der NSDAP gewesen waren, oder ihr zumindest nahegestanden hatten, konnte er mitunter deshalb nicht durchsetzen, weil es an alternativem qualifiziertem Personal mangelte. In den Einträgen aus den veröffentlichten Tagebüchern des Künstlers ist die Enttäuschung nicht zu überlesen:

Man hat mich mit Lob und Versprechungen geholt, und nun ist niemand da, der mir sekundierte, im Gegenteil, man will an Stelle von notwendiger Revolution Ruhe [...]. 7.12.45105

Auch rückblickend ist ihm die Beschäftigung des regimenahen Lehrpersonals ein großes Ärgernis gewesen:

Meine Hoffnung, daß die meisten Lehrkräfte sowieso bald verschwinden würden, weil ihr Abbau unter ein von den Engländern erlassenes Gesetz fiele - nach dem alle der Nazi-Partei angehörenden Lehrpersonen aus leitenden Stellungen ausscheiden müßten - wurde nachher dahin ausgelegt, daß man damit nur die Direktoren solcher Anstalten gemeint habe. So kommt es, daß nun bisher 10

${ }^{103}$ Vgl. Pankok (1951), S. 25-28 und Reuter (2014), S. 149 sowie Fasse (2018), S. 77.

${ }^{104}$ Die beiden folgenden Absätze greifen, wenn nicht anders gekennzeichnet, auf die Recherchen zurück von: Reuter (2014), S. 132 f. und S. 142-146.

105 Mataré (1997), S. 329. 
Lehrkräfte wieder eingestellt wurden, von denen 5 - also 50 \% der Partei angehörten oder ihr nahestanden! [...] Da sitzen nun also Existenzen, die mit einer wahren Gier ihre Bilder nach München in die Ausstellungen sandten, also eine Tendenz unterstützten, die gerade in der Kunst das Gegenteil erstrebt, wie nach meiner Meinung würdig.

Büderich, 2.2.1946 106

Aufgrund der mangelnden Unterstützung seiner Ideen gab Mataré seinen Posten noch vor Ablauf des Jahres 1945 auf. Als Professor für Bildhauerei blieb er weiterhin an der Akademie. Auf den Direktorenposten folgten ihm die Akademiedozenten Werner Heuser (1946-1949) und Heinrich Kamps (1949-1954). Alle drei Künstler waren von den Nationalsozialisten abgelehnt worden und galten als politisch integer. Zudem lebten und arbeiteten sie in der Nähe der Landeshauptstadt. Sie waren im Sommersemester 1946 die einzigen Neuangestellten. Weiterbeschäftigt wurden die Maler Wilhelm Herberholz, Wilhelm Schmutt, Paul Bindel, die Bildhauer Joseph Enseling und Josef Mages sowie der Grafiker Otto Coester und der Bühnenbildner Werner von Wecus. Erst 1947 wurde das Lehrerkollegium um den Grafiker und Bildhauer Otto Pankok, die Architekten Hans Schwippert und Walter Köngeter sowie um den Maler Theo Champion erweitert.

In seiner Eröffnungsrede betonte Direktor Heuser, es gelte an die künstlerische Offenheit anzuschließen, die die Kunstakademie vor 1933 charakterisiert habe. Die Akademie sollte sich an der Kunst der westlichen Nachbarländer orientieren und ihren Schülerinnen und Schülern künstlerische Grundlagen vermitteln. Ferner legte Heuser während seiner Amtszeit, wie später auch sein Nachfolger Kamps, großen Wert darauf, die handwerkliche Ausbildung der Studierenden zu vertiefen - so sollten fähige Kräfte für den Wiederaufbau gewonnen und die Absolventinnen und Absolventen gleichzeitig vor Armut bewahrt werden. Wie Günter Grass verdienten sich auch viele andere ihr Zubrot mit Ausbesserungen von Kriegsschäden an Bauwerken und Skulpturen. Die Akademie förderte zu diesem Zweck besonders die Verbindung von bildender Kunst und Architektur: Die Studierenden aller Klassen sollten ab dem dritten Semester im Rahmen von Projekten mit Architekten zusammenarbeiten. ${ }^{107}$

Davon abgesehen blieb der Lehrplan nach 1945 nahezu unverändert: Alle Akademieschülerinnen und -schüler durchliefen zunächst eine zweisemestrige Grundausbildung im Freihandzeichnen nach der Natur, in Zeichen- und Maltechnik, befassten sich mit Typografie und erhielten eine Einführung in Lithografie und Holzschnitt. Für die Studierenden der Bildhauerei folgte daraufhin ein sechssemestriges Üben im Modellieren und Holzschnitzen sowie in Stein- und Metallarbeiten. Darüber hinaus besuchten sie Kurse in Kunstgeschichte und Anatomie. ${ }^{108}$

Als Grass 1948 sein Studium begann, waren die meisten seiner Kommilitoninnen und Kommilitonen zwischen 25 und 32 Jahren alt. Ihr Kunstverständnis war damit größtenteils durch den Nationalsozialismus geformt worden. Sie hatten Kriegsdienst und Gefangenschaft erfahren und zeichneten sich gleichermaßen durch Neugier und tiefsitzende Skepsis aus. ${ }^{109}$ Das galt nach

\footnotetext{
${ }^{106}$ Ebd., S. 332.

107 Vgl. Reuter (2014), S. 143.

$108 \mathrm{Vgl}$. ebd.

${ }^{109}$ Vgl. ebd., S. 146.
} 
eigenem Bekunden auch für Grass (XI 243), und so verwundert es nicht, dass die streng akademische Ausbildung unter der Leitung von Sepp Mages nur eine kurze Übergangsphase für ihn war. ${ }^{110}$

Über den Bildhauer Josef Mages (1895-1977) ist heute nur noch wenig bekannt. ${ }^{111}$ In der Blechtrommel hatte Grass Grundzüge seiner Biografie in die Figur des formbesessenen Neoklassizisten Professor Maruhn einfließen lassen, eines fiktiven Künstlers, für den erst der politische Umbruch von 1945 eine Stagnation seines kreativen Schaffens mit sich bringt (III 610 f.). Tatsächlich hatte Mages 1936 eine monumentale Skulpturengruppe mit dem Titel Sportskameraden für das ehemalige Reichssportfeld, den heutigen Berliner Olympiapark sowie ein Gefallenendenkmal in Kaiserslautern gemäß der monumentalen Ästhetik des herrschenden Regimes ausgeführt. ${ }^{112} 1938$ wurde er an die Kunstakademie berufen und orientierte sich weiterhin an einem neoklassizistischen Stil, wie sein Bauschmuck für das Mannesmannhaus in Düsseldorf aus dem Jahr 1949 zeigt. ${ }^{113}$ Eine Publikation aus dem Jahr 1962 unter dem Titel Granitmale demonstriert dagegen eine gewandelte Formauffassung, eine Abkehr von der Antike und eine Hinwendung zu gegenstandslosen Formen und Ornamenten. ${ }^{114}$

Im Einklang mit der Annährung von bildender Kunst und Architektur, die die Studienordnung nach 1945 besonders förderte, legte der auf Denkmäler spezialisierte Mages in der Lehre einen Schwerpunkt darauf, Entwurfspraktiken aus dem Bereich der Bauplastik zu vermitteln. Im Jahrbuch der Kunstakademie von 1951 heißt es in dem Kommentar, den er der Präsentation der Arbeiten seiner Schülerinnen und Schüler voranstellte:

Alle meine bildhauerischen Arbeiten tragen die Merkmale ausgesprochener Architekturplastik. Ich lasse in ihr das im architektonischen Rahmen jeweils vorhandene Grundmotiv weiterklingen und gebe ihr einen tektonischen Charakter. ${ }^{115}$

Von dieser Besonderheit abgesehen erhielt Günter Grass bei seinem ersten Lehrer eine handwerkliche Grundausbildung. Er lernte Tonmodelle aufzubauen und schulte sich an Kopien von Gipsabgüssen aus der Antikensammlung der Kunstakademie. Bei dem Zeichnen und Modellieren nach Aktmodellen stand ein Figurentypus im Vordergrund, der sich an Plastiken Aristide Maillols orientierte. (X 502 f., X 506)

Mages betonte in einem 1959 geführten Gespräch mit der Kunsthistorikerin Anna Klapheck, dass ein bloßes Nachbilden der Wirklichkeit nicht das Ziel dieser Übungen sei. Die Studierenden sollten „keineswegs ,Akte heruntermodellieren“", sondern „ein ,dichterisches Bild' der Natur gewinnen und ihre innere Vorstellung am Modell korrigieren“. Es wurden in „kleinem, oft im kleinsten Format [...] erste Übungen von einer ,Stellung' gemacht, manchmal 8 bis 10 solcher Ver-

\footnotetext{
110 Grass' rückblickende Selbstbeschreibung deckt sich mit den Befunden einschlägiger soziologischer Studien zur „skeptischen Generation“ (vgl. Schelsky (1957)) bzw. „Flakhelfergeneration“ (vgl. Bude (1987)).

${ }^{111}$ Die wenigen vorhandenen Informationen wurden recherchiert von: Reuter (2014), S. 139 f. Geringfügige Erweiterungen bietet das Archiv der Kunstakademie Düsseldorf, das eine Sammlung von Zeitungsartikeln (in Kopie) besitzt, die zu Mages veröffentlicht wurden.

112 Zeitungsartikel vom 10. März 1940, ohne weitere Angaben, Archiv der Kunstakademie Düsseldorf, Akte Sepp Mages.

113 O. A.: „Symbol einer unverzagten Gegenwart“. In: Das Drei-Groschen-Blatt, Düsseldorf, 29. April 1949, S. 6, Archiv der Kunstakademie Düsseldorf, Akte Sepp Mages.

${ }^{114} \mathrm{Vgl}$. Mages (1962).

${ }^{115}$ Mages (1951), S. 47.
} 
suche nacheinander“. Auf diese Weise erwies sich für Mages „in welche Richtung der einzelne Schüler tendiere". ${ }^{116}$

Unter der Aufsicht von Mages entstehen 1950 Grass' Gipsmodelle für die Plastiken: Das Mädchen und Mädchen mit Apfel. Die Arbeiten wurden nach seinem Studienortwechsel nach Berlin von Bekannten verwahrt und konnten auf diese Weise nachträglich in Bronze gegossen werden (X $508 \mathrm{f}$. ).

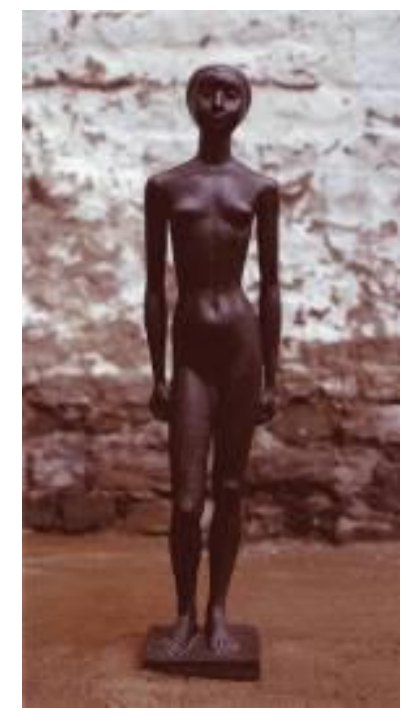

Abb. 3, Mädchen, 1950, Bronze

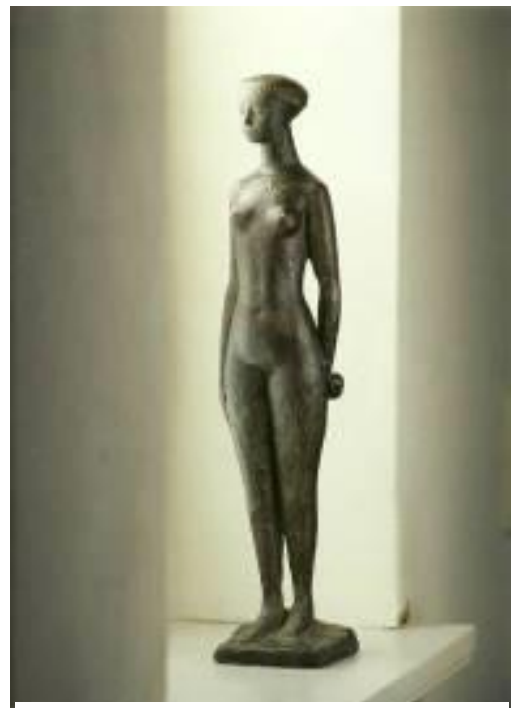

Abb. 4, Mädchen mit Apfel, 1950, Bronze

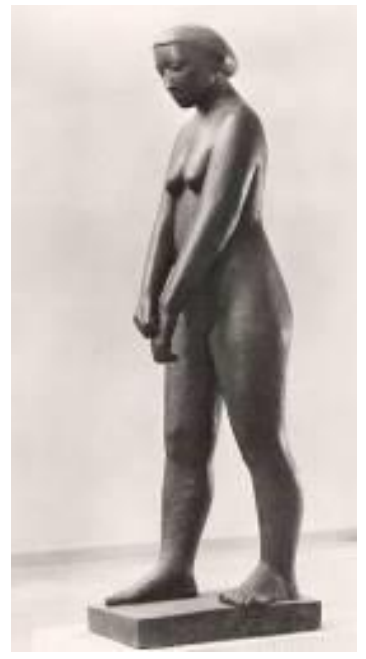

Abb. 5, Gustav Seitz, Gefesselte, 1949, Bronze

Beide Werke stellen junge Frauen in Körperhaltungen dar, die sich nur in geringem Maße in den Raum hinein entfalten. Das schlanke Mädchen (Abb. 3), das für das „Haus eines Sammlers" entworfen wurde, ${ }^{117}$ steht im Kontrapost, seine Arme fallen locker am Körper entlang herab, seinen Kopf hält es erhoben und nach vorne gewendet. Die frontale Haltung der Figur verführt nicht dazu, sie zu umschreiten. Sie scheint dazu angelegt, unmittelbar an einer Wand, nicht frei im Raum zu stehen. In dieser mutmaßlichen Anlehnung an eine Architektur könnte Grass den Weisungen seines Lehrers gefolgt sein.

Die Gestalt ist an Bauch und Brüsten naturalistisch modelliert, während ihre Gliedmaße, ihr Hals und ihr Kopf sich stereometrischen Formen, Zylinder und Kugel, annähern. Das locker ins Hohlkreuz gekippte Becken verstärkt den Eindruck einer lebensnahen, ungezwungenen Figurendarstellung.

Das Mädchen mit Apfel (Abb. 4) weist weiblichere Rundungen auf und lenkt den Blick der Betrachtenden über den hinter den Rücken gedrehten linken Arm der Figur um ihre Gestalt herum.

\footnotetext{
116 Anna Klappheck: Lehrer an der Kunstakademie, Porträts der Professoren (VII: Sepp Mages), in: Rheinische Post, 6. Mai 1959 zitiert nach Reuter (2014), S. 139.

117 Vgl. Kamps (1951), S. 146. Im Abbildungsverzeichnis des Jahrbuchs der Staatlichen Kunstakademie Düsseldorf 1948-1950, in dem Grass' Mädchen abgelichtet wurde, findet sich die Bezeichnung: „Bronzeplastik für das Haus eines Sammlers".
} 
Auch bei dieser Plastik abstrahierte der Künstler besonders von der Form des Kopfes und der Gliedmaßen. Das Werk erinnert an Gustav Seitz' Gefesselte, deren Beine sich ähnlich wie die des Mädchens mit Apfel kegelförmig zu den Füßen hin verjüngen (Abb. 5). Die geschlossene Form der Figuren und ihre gesenkten Köpfe lassen beide gleichermaßen in sich gekehrt wirken.

Bereits die schlanken Körper der von Grass dargestellten Mädchen, ihre zeichenhaft angedeuteten Gesichter und natürlichen Posen weichen von dem von Mages als vorbildlich propagierten Ideal ab. Sie entsprechen vielmehr der in der zeitgenössischen Nachkriegsplastik präsenten archaisch-reduzierten Figurengestaltung. Die relativ mageren, langhalsigen Figuren erinnern zudem noch vage an Plastiken Lehmbrucks. Grass hatte als Steinmetzpraktikant einen Torso Lehmbrucks kopiert und in Anlehnung an diese Arbeit eigene Torsi aus Sandstein geschaffen (X 485 f.). ${ }^{118}$

Mages' wenig flexible Vorgaben waren es, die Ende 1950 dazu führten, dass Grass seine Ausbildung bei inm noch mitten im Wintersemester 1950/1951 abbrach und bei Otto Pankok fortsetzte. ${ }^{119}$ In Beim Häuten der Zwiebel beschreibt Grass rückblickend den Konflikt, der zur Trennung geführt habe. Ein von ihm modellierter Frauenakt mit gespreizten Beinen sei für den Lehrer ethisch und ästhetisch nicht vertretbar gewesen:

Als es mir aber gefiel, nach etlichen stehenden Mädchen in Modellierton eine liegende weibliche Figur anzulegen, deren Oberschenkel weit auseinanderklafften, nahm Mages Anstoß an der unverborgenen Vagina und der, wie er befand vulgären Stellung, die keine "schlicht geschlossene Form“ zulasse. (X 516)

Da der Schüler seine Arbeit nicht entsprechend korrigieren wollte und auch Mages nicht einlenkte, wechselte Grass unter Vermittlung seines Lehrers in die Klasse von Otto Pankok. Zwar war der vor allem als Zeichner und Grafiker bekannte Künstler nur am Rande bildhauerisch tätig, doch die Ausbildung in seiner Klasse versprach Grass die gewünschte Freiheit:

Vielmehr schien es an der Zeit zu sein, frei von vorbildlichen Lehrzwängen den eigenen Weg oder Umweg zu suchen. Pankok war zwar kein Bildhauer, arbeitete fast nur in Schwarzweiß mit Kohle oder an Holzschnitten, galt sogar als farbenblind, zog aber Schüler an, die sich expressiv ausdrücken wollten und die, wie neuerdings ich, auf Eigensinn setzten. (X 517)

Otto Pankok (1893-1966) erwies sich im Folgenden tatsächlich als unakademischer Lehrer. Der Künstler war selbst nur für kurze Zeit an Hochschulen eingeschrieben. Sein 1912 begonnenes Studium der Malerei bei Adolf Männchen in Düsseldorf beendete er nach sechs Wochen, weil ihn dessen traditionelle Entwurfsmethoden abschreckten. Die Weimarer Kunstakademie besuchte er 1913 lediglich sieben Monate lang. Aus der Klasse von Fritz Mackensen musste er aufgrund einer Erkrankung seines Lehrers nach kurzer Zeit in die Klasse von Albin Egger-Lienz wechseln und verließ schließlich auch diese, weil die Akademie inm kein eigenes Atelier zur Verfügung stellen

\footnotetext{
118 Sie gehören zu den Arbeiten, die Grass 2013 zurückgegeben und 2015 in der Lübecker Ausstellung ausgestellt wurden. Vgl. S. 17 f. dieser Arbeit.

119 Zur Datierung des Klassenwechsels gibt es von Grass selbst zwei veröffentlichte Auskünfte, die voneinander abweichen: Während er in einem veröffentlichten Brief an Rainer Herrmann vom 27.10.1981 schreibt, er habe von Ende 1951 bis Ende 1952 bei Pankok studiert, gibt er in Beim Häuten der Zwiebel an, die Mages-Klasse bereits 1950 verlassen zu haben. Diese Version wird durch die auf 1951 datierten Reiseskizzen untermauert, die Pankoks Einfluss zeigen (vgl. X 514, XII 24 f.).
} 
konnte. Zwar waren es damit vor allem pragmatische Gründe, die ihn aus Weimar vertrieben haben, darüber hinaus lehnte er jedoch auch die Malerei von Egger-Lienz als zu dekorativ und zu wenig am Leben orientiert ab. ${ }^{120}$

Er setzte sich im Folgenden autodidaktisch mit anderen Lehrern auseinander. Sein Schaffen wurde maßgeblich von der Malerei Rembrandts, Jean-François Millets und Vincent van Goghs inspiriert. Insbesondere die Landschaftsauffassung der beiden Letztgenannten, ihre Verknüpfungen von Figur und Grund, regten ihn zu den Kompositionen seiner großformatigen Kohlezeichnungen an, in welchen er malerische Qualitäten erzeugte. ${ }^{121}$

Über Pankoks eigene, zehnjährige Lehrtätigkeit veröffentlichte die Kunstakademie Düsseldorf anlässlich seiner Emeritierung 1958 einen kurzen Essay. Darin wird hervorgehoben, er habe seinen Elevinnen und Eleven bewusst die Freiheit gelassen, eigene Vorstellungen umzusetzen und eher wortkarg als Persönlichkeit an sich inspiriert:

Wie Pankok im Leben und im Umgang mit anderen Künstlern, mit Kunstfreunden und den Verehrern seines Schaffens nicht zu haarspaltenden Diskussionen über Kunst neigt, es den Werken der Kunst überläßt, selbst zu sprechen, und den Betrachter anregt, das Erlebnis der Kunst in Geduld abzuwarten, wirkt er auch als Lehrer nicht mit vielen Worten und Erklärungen. Kurze Hinweise und Anmerkungen genügen; sie sind wirksamer, überzeugender als langatmige Begründungen, die beim Schüler vielleicht noch Zweifel bestehen lassen. Der Studierende, der die Anfangsgründe seines Studiums schon hinter sich hat, soll zunächst selbst sehen, wie er zurechtkommt; er befindet sich im Bannkreis des Meisters, der ihn durch sein Beispiel anspornt. In diesem Gewährenlassen steckt für den Schüler mehr Ermutigung als in vielem pedantischen Korrigieren, das die Eigenart verkümmern läßt. Dem jungen Menschen soll nach Pankoks Ansicht keine zeitgebundene Manier, kein Erfolgsrezept oder Modeklischee aufgezwungen werden, womit nur die Unsicherheit verdeckt wird, die auch durch ein sklavisches Kopieren des Meisters nicht überwunden werden kann. ${ }^{122}$

Aus dem letzten Satz der Beschreibung klingt an, wo der ästhetischen Freiheit der PankokSchülerinnen und -Schüler doch eine Grenze gesetzt war. In seinen kunsttheoretischen Schriften polemisierte Pankok gegen verschiedene Strömungen der Klassischen Moderne und gegen jegliche Formen des l'art pour l'art. ${ }^{123}$ Kunst sollte eine gegenständliche Verankerung im Leben haben, sei es als Stillleben, Figuren-, Tier- oder Landschaftsbild. Unterfüttert wurde diese Fokussierung von dem christlichen, konfessionell unbestimmten Glauben des Künstlers. Er vertrat damit die

\footnotetext{
${ }^{120}$ Vgl. Overbeck/Müller (1995), S. 41-52 und Pankok (1990), S. 11: „In meiner akademischen Laufbahn traf ich auch auf den Maler Egger-Lienz, der immerhin seine dünnen impressionistischen Schüler einmal mit der Nase auf Realitäten stieß. Bei aller Achtung vor ihm war er mir doch im Grunde äußerst ärgerlich. Es war mir ärgerlich, daß er von Monumentalität redete wie die Hausfrau von Butter und es meist doch nur zur vergröberten Dekoration brachte, daß er eine wichtige Seite nicht kannte, eine Seite des Lebens, die ich längst gefunden hatte. Die Materie, die Vielfalt der Oberfläche war ihm verhaßt. Anatomie hielt er für Tiefe. Er verbannte alles Einmalige, Wunderbare und nannte es Zufälligkeit. Er kannte nur das Prinzip der Form."

${ }^{121}$ Vgl. Pankok (1990), S. 8-10. In seinem autobiografischen Buch Stern und Blume bezeichnete Pankok die drei Maler als seine Wahlverwandten.

122 Kunstakademie Düsseldorf, Pankok (1958) (o. Seitenzahlen).

${ }^{123}$ Vgl. Pankok (1990), S. 8 und 36 sowie Pankok (1951). In Stern und Blume verurteilt Pankok "vielseitige“ Künstler wie Picasso, die verschiedene künstlerische Formensprachen verwenden und neue Stile entwickeln, als „Bataillonen von Pinselschwingern, die in ,Richtungen' sich bewegen und die europäischen Ausstellungen überschwemmen, gestern Futurist, heute Kubist, morgen Konstruktivist und übermorgen lebensmüder Koksschnupfer - was spricht aus innen deutlicher als eine geknebelte, schief gewachsene, ungelebte Jugend?"
} 
oben bereits behandelte konservative Position Hans Sedlmayrs. Im Jahrbuch der Kunstakademie von 1951 schreibt Pankok in seinem Essay „Unser Glaube an das Leben“:

Abstrakt malen ist ein Abgleiten ins Spiel, ein Ausweichen vor der Wahrheit in unkontrollierbare Gefilde. Der Maler abstrakter Bilder begibt sich in einen Raum, in welchem anscheinend die Freiheit herrscht, aber es ist nur die Willkür, die sich anmaßt, Freiheit zu heißen. Es ist Freiheit in einem leeren Raum, in einem menschenleeren Land. ${ }^{124}$

Pankoks Vorstellung von einem gelungenen Kunstwerk umfasste neben dem gegenständlichen Sujet die herausragende handwerkliche Ausführung eines Werkes, die er - wie später Grass - in vielen zeitgenössischen Arbeiten vermisste. Er brachte diese Auffassung in seiner autobiografischen Veröffentlichung Stern und Blume durch die allegorische Umschreibung des Gärtnerns zum Ausdruck - ein Motiv, das auch Grass 1957 für seine poetologischen Erörterungen in dem Essay „Die Ballerina“ und dem an sie anknüpfenden „Vogelscheuchen“-Komplex in abgewandelter Form nutzte. ${ }^{125}$

Als Pankok 1947 an die Düsseldorfer Akademie berufen wurde, war er bereits ein renommierter Künstler, dessen Ruf sich nicht allein auf die ästhetische Qualität seiner Arbeiten, sondern auch auf das durch sie repräsentierte politische Engagement stützte. ${ }^{126}$ Ebenso wie Mataré war auch ihm die Weiterbeschäftigung ehemaliger Nationalsozialisten an der Akademie zuwider, und er äußerte sich dazu kritisch in der Öffentlichkeit. ${ }^{127}$

Politisch aktiv wurde er jedoch schon nach dem Ende des Ersten Weltkrieges. Nachdem Pankok einen Kampfeinsatz im französischen La Bassée überstanden hatte, schloss er sich am Niederrhein der expressionistischen Künstlervereinigung „Das Junge Rheinland“ an. Die Gruppe wurde 1919 von dem Schriftsteller Herbert Eulenberg und den Malern Arthur Kaufmann und Adolf Uzarski in Düsseldorf gegründet, um für eine neue Kulturpolitik einzutreten, die Interessen der jungen Künstler aus der Region zu stärken und gemeinsam für Ausstellungsmöglichkeiten zu sorgen. ${ }^{128}$

Mit einer Reise nach Spanien 1929 rückten gesellschaftliche Randgruppen als Sujet in den Mittelpunkt seines Schaffens. Pankok empfand ihr Dasein als wahrhaftig und ursprünglich und sah darin einen positiven Gegenentwurf zum Leben in den industriell geprägten Städten. Er fertigte großformatige Kohlezeichnungen von den ärmsten und verstoßenen Bewohnerinnen und Bewohnern des Fischerdorfes Cadaquès an, hielt die Lebensgeschichten seiner Modelle schriftlich fest und veröffentlichte sie in Stern und Blume neben den grafischen Porträts. ${ }^{129}$ Nachdem er bei einer

\footnotetext{
124 Pankok (1951), S. 26.

${ }^{125}$ Vgl. Pankok (1990), S. 17. Bei Pankok heißt es: „Der Kolonist. Wer malen will, der muß es wie ein Kolonist machen. Er steckt sein Land ab und errichtet einen Zaun um seinen Bezirk. Dann muß er alles aus seinem Land reißen, was da an Unkraut wächst, mit der Axt das Gestrüpp abhauen, dann pflügen und misten. Dann kann das Pflanzen beginnen. Langsam und bedächtig. Hier einen Baum hin, da das Gemüse, da Kartoffeln. Und immer wieder schmuggelt sich Unkraut dazwischen. Da muß er wieder mit der Hacke ran, ausreißen und wieder über die Hecke kippen. Es gibt eine beträchtliche Anzahl, die nichts von Gartenbau wissen. Sie laufen herum wie die Zigeuner. Sie wissen nichts von Dünger, Hacken und Ordnung. Sie laufen herum und glauben an Zufallstreffer, planlos und wirr. Sie vermuten, die Kunst sei außen statt innen, hoffen da ernten zu können, wo sie nie säten. "Vgl. ferner Kapitel III.3. der vorliegenden Untersuchung.

${ }^{126}$ Vgl. Fasse (2018), S.75.

$127 \mathrm{Vgl}$. ebd.

${ }^{128}$ Vgl. ebd., S. 87.

${ }^{129}$ Vgl. Pankok (1930), Hofmann (1982), S. 14 und Overbeck/Müller (1995), S. 162-168.
} 
Reise nach Frankreich 1931 im Rhônetal in Fontvieille auf eine Siedlung der Sinti und Roma gestoßen war und an einem ihrer Feste teilgenommen hatte, suchte er ab Oktober 1931 auch in Düsseldorf Kontakt zu dieser Bevölkerungsgruppe. Auf dem Heinefeld, einem besitzerlosen Grundstück am Stadtrand, hatten sie ein großes Lager errichtet. Der Künstler lebte zeitweise mit ihnen zusammen und zeichnete bis 1933 eine Serie von „Zigeunerbildern“. ${ }^{130}$

Anschließend arbeitete Pankok an einem ebenfalls mit Kohle gezeichneten Passions-Zyklus. Seinen leidenden Figuren gab er dabei die Gesichter von Freunden und Bekannten, die von dem NS-Regime verfolgt wurden. Er porträtierte etwa den Maler Karl Schwesig sowie Sintiza Ringela und weitere Bekannte, die der Minderheit der Sinti und Roma angehörten. ${ }^{131}$ Die Veröffentlichung sollte 1936 im Kiepenheuer-Verlag erfolgen, wurde jedoch kurz nach dem Druck beschlagnahmt. ${ }^{132}$

1937/1938 widmete Pankok sich schließlich der am stärksten unter den Nationalsozialisten leidenden Minderheit, indem er eine Serie von sogenannten „Judenbildern“ zeichnete. Verfolgte und Misshandelte wurden auf der Grundlage von Fotografien in großformatigen Kohlezeichnungen von ihm dargestellt. ${ }^{133}$

Noch unmittelbarer setzte er seine Kunst 1950 politisch ein: Seinen Pazifismus und Christentum verbindenden Holzschnitt Christus zerbricht das Gewehr ließ er explizit gegen die deutsche Wiederbewaffnung in Umlauf bringen. ${ }^{134}$

Grass stellte im Werkstattbericht nachträglich fest, Pankok habe ihn als politisch-engagierte Persönlichkeit mehr beeinflusst, als er es als Student wahrhaben wollte. ${ }^{135}$ Pankoks Kunstauffassung persiflierte Grass in der Blechtrommel. Charakteristika seines zweiten Lehrers bilden darin die Basis für die Künstlerfigur „Professor Kuchen“, der expressionistisch arbeitet, unter Kunst „Anklage, Ausdruck und Leidenschaft“ versteht und den Anspruch verfolgt, den „Wahnsinn des Jahrhunderts" durch die Darstellung der Opfer zum Ausdruck zu bringen - ein Ziel, das der Protagonist des Romans auf diese Weise nicht für erreichbar hält. (III 609)

Dennoch sind in Grass' Schaffen verschiedene Parallelen zu demjenigen Pankoks erkennbar, auch wenn sie zum einen erst Jahre oder sogar erst Jahrzehnte nach seinem unmittelbaren Kontakt zu Pankok auftraten oder, zum anderen, Episode geblieben sind:

Pankoks humanistische Verteidigung der gegenständlichen Kunst könnte Grass beeinflusst haben. Auch wenn seine Studienarbeiten zeigen, dass er dessen Rundumschlag gegen die schnellen Stilwechsel der Klassischen Moderne nicht teilte, ist eine frühe Vorbereitung seiner späteren kritischen Haltung der ungegenständlichen Kunst gegenüber durch die Lehrzeit bei Pankok nahe-

\footnotetext{
130 Vgl. Pankok (1947): 134 Kohlezeichnungen aus dem Konvolut wurden 1947 in einer Publikation mit dem Titel „Zigeuner“ in dem von Otto und Hulda Pankok gegründeten Drei-Eulen-Verlag in Düsseldorf herausgegeben. Vgl. zu Pankoks Faszination für das einfache Leben, die nicht mit der Sozialkritik zu verwechseln ist: Overbeck/Müller (1995), S. 174-181.

${ }^{131} \mathrm{Vgl}$. Fasse (2008), S. 100-102.

132 Vgl. Overbeck/Müller (1995), S. 193-198, S. 214-223.

133 Vgl. Overbeck/Müller (1995), S. 210-213 und Hoffmann-Curtius (2014), S. 33-39.

${ }^{134} \mathrm{Vgl}$. Overbeck/Müller (1995), S. $288 \mathrm{f}$.

135 Vgl. Grass (2014), S. 7. 1997 gründete Grass in Lübeck eine „Stiftung zur Förderung der Belange von Roma und Sinti“, die hervorragende künstlerische und wissenschaftliche Arbeiten, die sich mit dem Schicksal dieser Minderheit auseinandersetzen, mit dem „Otto-Pankok-Preis“ honoriert.
} 
liegend. Darauf deuten auch Erinnerungen des bildenden Künstlers Bert Gerresheim hin, die Norbert Fasse in seinem kenntnisreichen Aufsatz über Otto Pankok zitiert. Gerresheim, der sein Studium 1956 bei Pankok begonnen hatte, charakterisiert die Klasse, der Grass bis 1953 angehörte, wie folgt:

Die waren zwar nur fünf oder sechs Jahre älter als ich, aber sie waren wegen der Kriegserlebnisse doch eine andere Generation. Sie hatten noch so eine Revoluzzer-Haltung, so eine schöpferische Unruhe hinterlassen, die ich vorfand, als ich an die Akademie kam - und der Pankok schürte das noch, durch seine Art. Er sagte: "Laßt Euch nichts vormachen vom Modernismus und all dem Chichi!" Es ging ihm immer um das eigene Erleben der Wirklichkeit. Das sollten wir finden: Den Zugang zur Wirklichkeit. ${ }^{136}$

Pankoks gesellschaftskritischen Anspruch, der sich in der Auswahl seiner Sujets spiegelte, hatte Grass im eigenen Werk lange nicht verfolgt. Erst in den intermedialen Buchprojekten um 1990 Zunge zeigen (1988), Totes Holz (1990) und Brief aus Altdöbern (1990) - prangerte auch er gesellschaftliche und ökologische Missstände in Bildern an. ${ }^{137}$

Eine stilistische Verwandtschaft mit Pankoks Grafiken ist in den Tuscheskizzen erkennbar, die Grass auf einer Auto-Stopp-Reise durch Italien (mitunter durch Rom, Florenz und Sizilien) im Sommer 1951 gefertigt hatte. Er zeichnete sie vermutlich schon im Bewusstsein, sie Pankok nach der Fahrt zeigen zu können, denn in Beim Häuten der Zwiebel berichtet er davon, wie die Schülerinnen und Schüler ihrem Lehrer zu Beginn des neuen Semesters erwartungsvoll ihre Ferienausbeute vorlegten. ${ }^{138}$ Sein Skizzenbuch enthält nur am Anfang eine Datierung: Auf der Rückseite der ersten Zeichnung ist zu lesen: „Zwischen Bozen und Verona im Regen, d. 22.5.51“. ${ }^{139}$ Die mit Feder, Pinsel und Tusche gefertigten Bilder halten Reisebeobachtungen in ausgewogenen Kompositionen fest: Landschaften, Straßenzüge sowie Genreszenen in Parks, Tanzlokalen und Kirchen. Insbesondere Geistliche - Nonnen in ihrem Habit und Pfarrer in Soutanen und breitkrempigen Hüten - werden häufig dargestellt. Das tiefe Schatten werfende Sommerlicht wird selbst zum Bildgegenstand.

In den Zeichnungen ist dabei eine Betonung von ornamentalen Formen und Strukturen zu sehen, seien es Haarlocken, Baumrinden, Pflastersteine, gemusterte Kleider oder nebeneinandergereihte Krüge. Es ist die in diesem Zusammenhang besonders an Freiheit gewinnende Linie, die an die Kohlezeichnungen Otto Pankoks erinnert.

\footnotetext{
${ }^{136}$ Zitiert nach Fasse (2008), S. $62 \mathrm{f}$.

${ }^{137}$ Vgl. S. 315 f. der vorliegenden Publikation.

138 Vgl. dazu eine Erinnerung aus Beim Häuten der Zwiebel: „Pankok nahm von meiner Reiseausbeute Zeichnungen und Aquarelle - nur flüchtig wohlwollend Kenntnis. Viele seiner Schüler kamen von weither zurück, hatten was vorzuweisen." (X 537)

139 Erst auf einer der letzten Seiten befindet sich eine auf 1953 datierte Zeichnung, die dem Motivkomplex der Hühner angehört. Da sie stilistisch von den anderen Skizzen abweicht, ist anzunehmen, dass allein dieses Huhn zwei Jahre nach dem Italienaufenthalt gezeichnet wurde.
} 


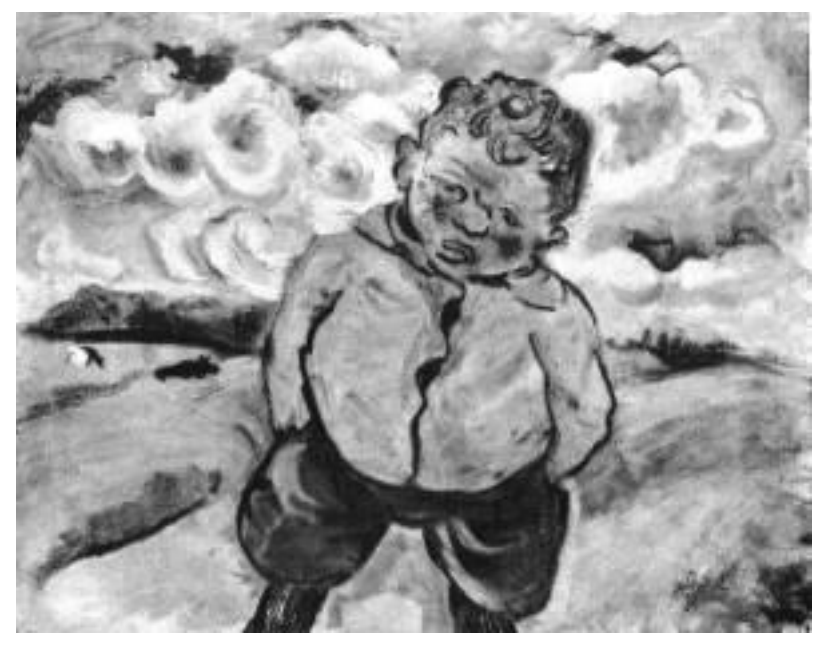

Abb. 6, Otto Pankok, Junge, 1930, Kohle
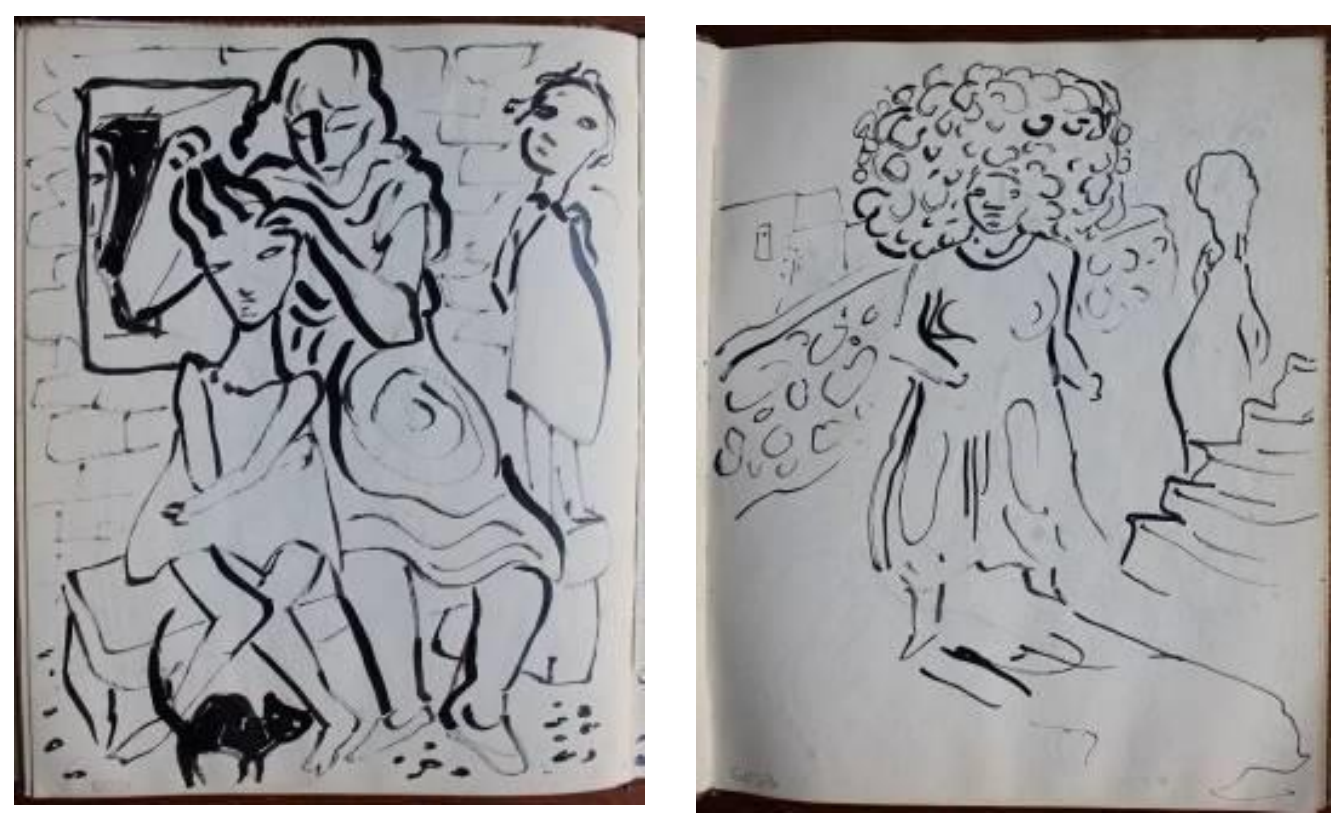

Abb. 7 und Abb. 8, Skizzenbuch, Italien, 1951, Tusche

In seinen Bildern brachte Pankok Figuren und Landschaften durch verwandte lineare Strukturen miteinander in Verbindung. So korrespondieren in der Kohlezeichnung Junge aus dem Jahr 1930 (Abb. 6) die Locken, das runde Gesicht des Kindes und die ovale Form seiner Oberschenkel mit den Umrissen der sich im Hintergrund auftürmenden Wolken.

Vergleichbare Übereinstimmungen zwischen den Bildgegenständen sind auch in Grass' Skizzen zu finden. In einer der hier abgedruckten Zeichnungen (Abb. 7), die eine Frau dabei zeigt, wie sie ein Mädchen frisiert, werden die Figuren über die Führung der breiten, sich schlängelnden Pinselstriche miteinander verbunden. Einerseits die Kleidungsfalten der Erwachsenen repräsentierend, setzen sie sich andererseits im nach oben gekämmten Haar des Mädchens fort. In einer zweiten Zeichnung nimmt der Grafiker die Formäquivalenz zwischen den Locken, die den Kopf der im Zentrum stehenden Frau umgeben, und dem unruhigen Mauerwerk der Brückenbrüstung im Hintergrund auf (Abb. 8). 
Die Berührungspunkte zwischen den Bildern des Studenten und solchen seines Lehrers sind somit weitgehend formaler Natur - die Motivauswahl des Jüngeren weist in diesen Jahren zwar eine Präferenz für das einfache, alltägliche Leben auf der Straße, aber noch keine gesellschaftskritischen Tendenzen auf.

Nach den Reiseskizzen schuf Grass 1951 Plastiken und Kohlezeichnungen. Diese zeigen keine unmittelbare Anregung durch Pankok. Stattdessen demonstrieren sie Grass' Interesse an der Formensprache der Antike und des Kubismus. Sie weisen insbesondere Parallelen zu Arbeiten Pablo Picassos und Alexander Archipenkos auf. Einen Mönchskopf aus Gips (Abb. 9), den Grass nach seiner Rückkehr aus Italien angelegt hatte, kennzeichnet ein griechisches Profil. Dieser Rückgriff auf antike Kunstwerke ist wenig überraschend, hatte Grass von seiner Reise doch gerade etruskische Kleinplastiken besonders gut in Erinnerung behalten (X 534). Die gerade Linie, die die Stirn und die Nase der Büste im Profil bilden, die scharfkantig ausgebildeten Wangenknochen der Figur und die wulstig geformten Augenlider, die die Augen in der Profilansicht nahezu erscheinen lassen, als seien sie seitlich aufgesetzt, erinnern zudem an Adaptionen antiker Gestaltungselemente in Werken Picassos, zum Beispiel an entsprechende Darstellungen in dessen Suite Vollard. Die hier abgebildete Radierung Le repos du sculpteur aus dem Jahr 1932 zeigt einen Bildhauer mit seinem Modell links neben der von ihm geschaffenen antikisierten Büste (Abb. 10). Auch Kohlezeichnungen, die Grass im Anschluss an seine Italienreise gefertigt hatte, stehen durch die antikisierte Darstellung von Gesichtern entsprechenden Arbeiten Picassos nahe. Die hier abgedruckte Zeichnung, in der ein Mädchen dargestellt ist, das sich in einem Spiegel betrachtet, zeigt eine Auseinandersetzung mit den verwendeten Gestaltungsformen (Abb. 11). Betrachterinnen und Betrachter sehen ebenso die Figur wie ihr im Spiegel erscheinendes Abbild in der Seitenansicht. Die Figurendarstellung offenbart sich auf diese Weise als zweidimensionales Artefakt. Grass' Bezugnahme auf die Kunst der Antike bewirkt nicht nur eine Universalisierung des Dargestellten und vermittelt ein Bekenntnis zu einer bestimmten Kulturtradition, sondern bringt ebenso die Auseinandersetzung mit Zwei- und Dreidimensionalität in Skulptur und Grafik zum Ausdruck.

Ein Gipstorso von Grass aus dem Jahr 1951 (Abb. 12) ist hingegen mit kubistischen Plastiken Archipenkos wie der hier abgedruckten Grünen Konkave von 1913 (Abb. 13) vergleichbar. Der von Grass modellierte Torso ist wie jene Figur aus positiven und negativen Teilformen zusammengesetzt. Die einzelnen Elemente des dargestellten Körpers werden auf diese Art voneinander abgegrenzt und hervorgehoben: Während Grass die Brust der Figur zu einer Schalenform aushöhlte, setzte er ihr links, auf der Höhe des Herzens, eine Halbkugel auf, so dass es scheint, als ob sie aus dem größtenteils abgetragenen Brustkorb freigestellt worden sei. Den Kopf der Figur flachte er hingegen zu einem Profilrelief ab. Im Gegensatz zu den Werken des aus der Ukraine stammenden Amerikaners sind die Volumina in Grass' Arbeit stärker gerundet. Sie weisen eine biomorphe Oberflächenspannung auf, wie sie Henry Moore nach 1945 in die Bildhauerei einführte. ${ }^{140}$

${ }^{140}$ Vgl. Krason (2016), S. 119. 


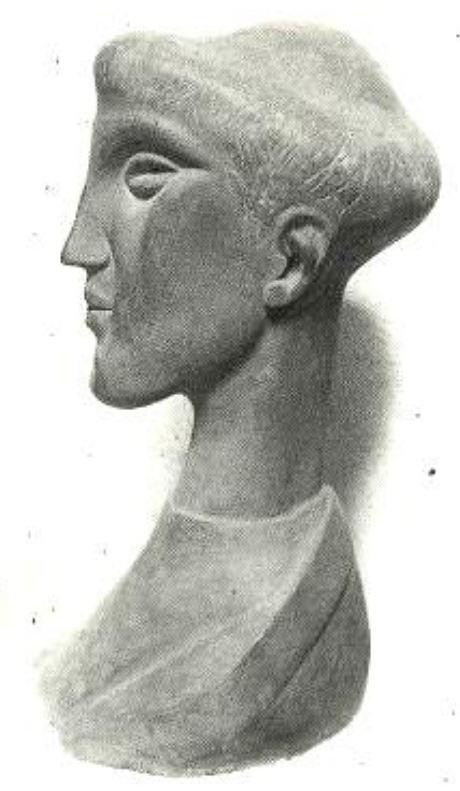

Abb. 9, Mönchskopf, 1951, Gips

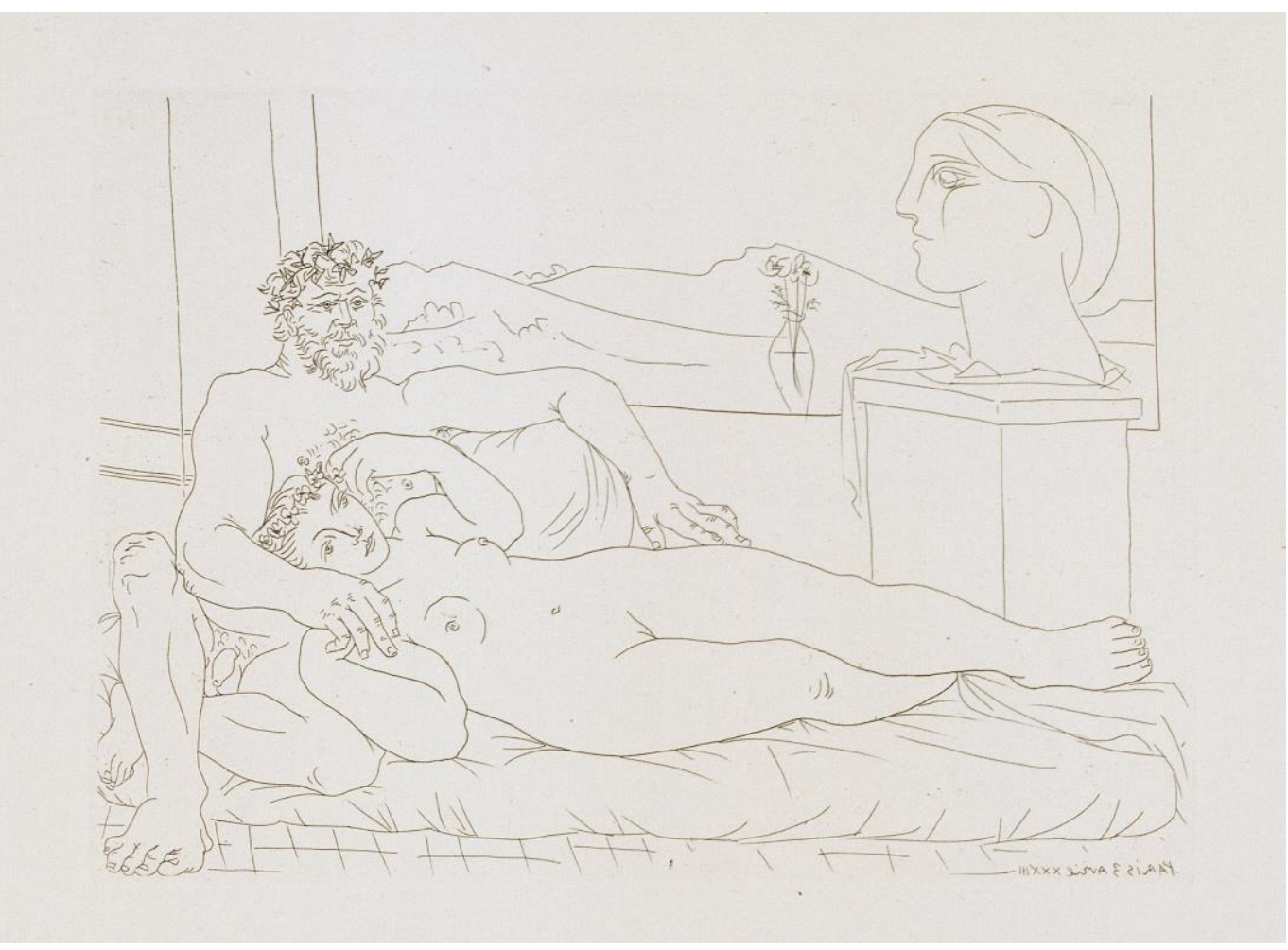

Abb. 10, Pablo Picasso, Ruhender Bildhauer, II, Suite Vollard, BI. 63, 1933, Radierung 


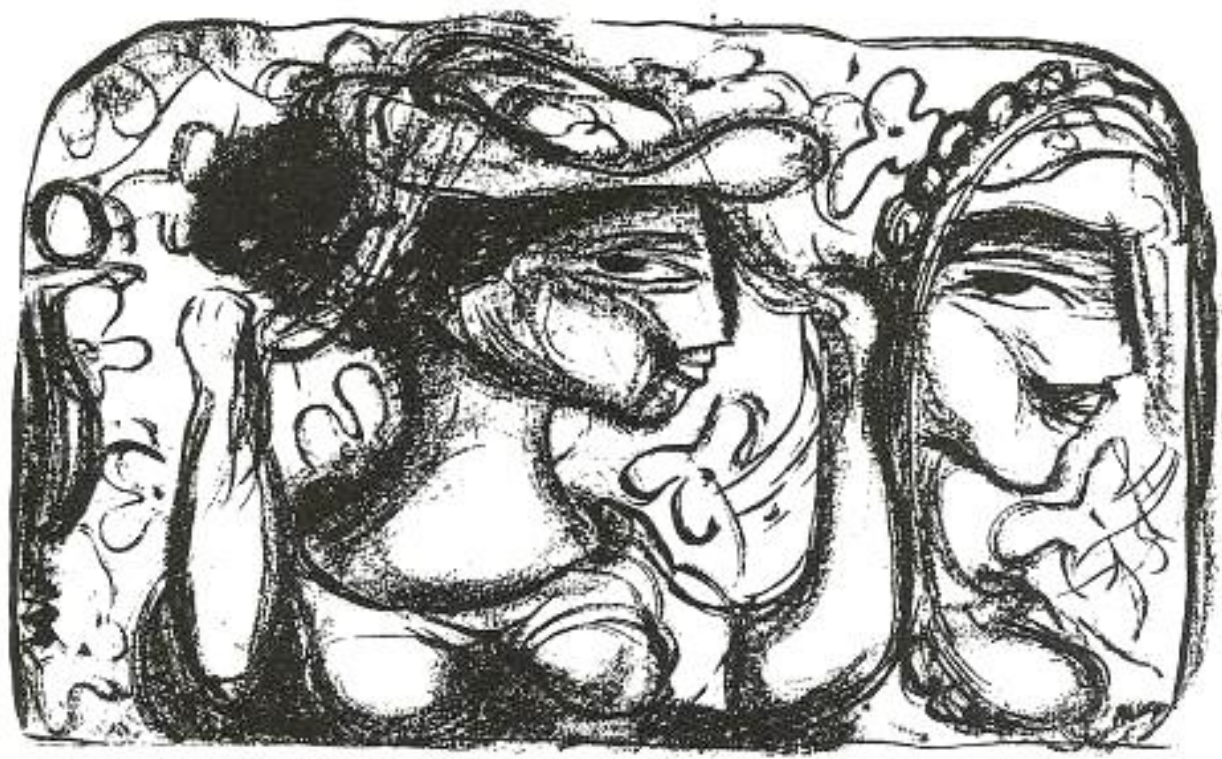

Abb. 11, Skizze, nach der Italienreise, 1951/1952, Kohle

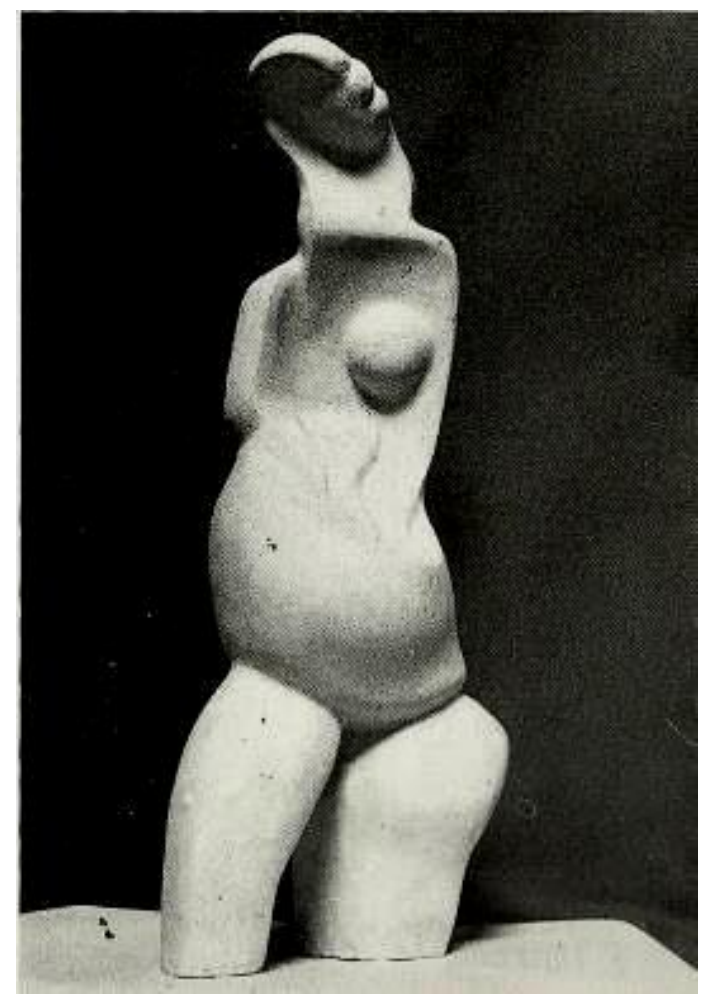

Abb. 12, Torso, 1951, Gips

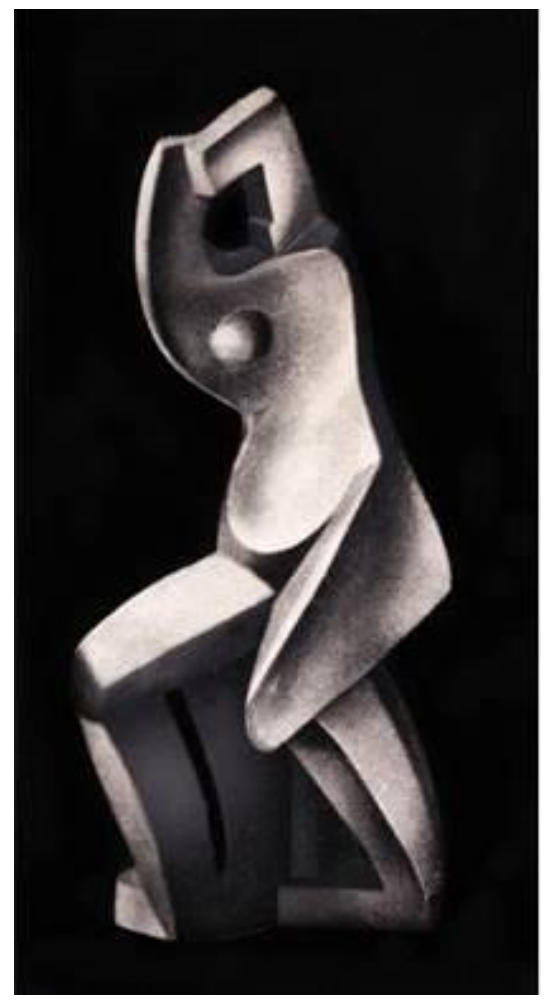

Abb. 13, Alexander Archipenko, Grüne Konkave / Frau, ihr Haar kämmend, 1913, Terrakotta 
In den Sommerferien des Jahres 1952 unternahm Grass eine zweite Studienreise, die inn nach Frankreich führte. ${ }^{141} \mathrm{Er}$ hielt sich an Küstenorten am Mittelmeer und am Atlantik, vor allem aber in Paris auf. Auch von dieser Fahrt haben sich ein Skizzenbuch und einige Aquarelle erhalten. ${ }^{142}$ Grass' Erinnerungen zufolge interessierte ihn auf dieser Reise besonders die Kunst der französischen Klassischen Moderne. Rückblickend erkannte er in seinen Arbeiten Einflüsse der Werke von Raoul Dufy, Pablo Picasso und Chaim Soutine wieder (X 546). ${ }^{143}$ In Bezug auf die Tuschezeichnungen des Skizzenbuchs leuchtet erneut ein Vergleich mit Arbeiten Picassos besonders ein: Im ersten Drittel des 20. Jahrhunderts hatte der Katalane Zeichnungen von Figuren und Genreszenen geschaffen, die auf dem Papier aus einer einzigen, nicht abreißenden Linie gebildet werden. Diese befreit sich dadurch noch stärker aus der Funktion der mimetischen Wiedergabe des Gegenstands. Die hier angeführte Kreidezeichnung Picassos (Abb. 14) zeigt einen Zirkusartisten neben einem Pferd in einer Manege. Der Kreidestrich verbindet die beiden Figuren miteinander und entwirft zugleich einen Raum um sie herum.

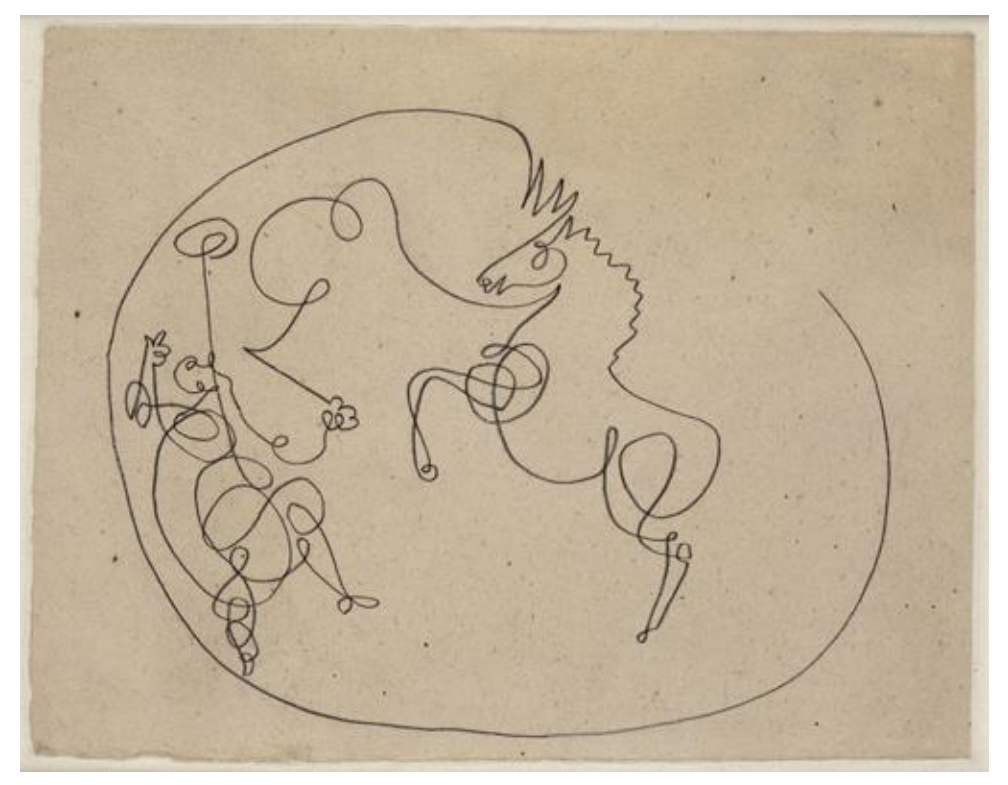

Abb. 14, Pablo Picasso, Pferd und sein jonglierender Dompteur, 1920, Kreide

\footnotetext{
${ }^{141}$ Vgl. Grass (2014), S. 19-27, X 543-547.

142 Das Skizzenbuch befindet sich im Archiv der Günter und Ute Grass Stiftung, vgl. Abdruck einzelner Skizzen und eines Aquarells bei Grass (2014), S. 18, S. 20, S. 22 f. und Grass (2001), S. 13-18.

${ }^{143}$ Vgl. Grass (2014), S. 19.
} 


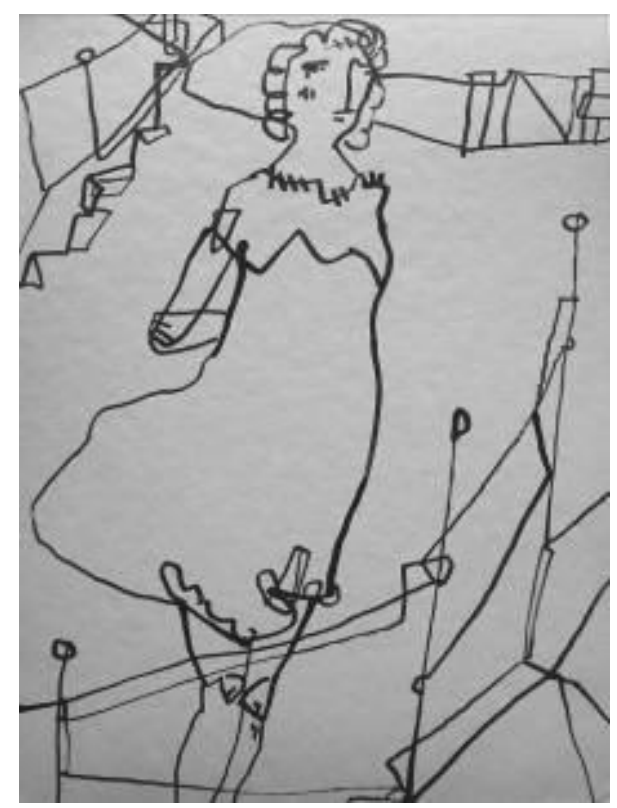

Abb. 15-17, Skizzenbuch, Frankreich, 1952,

Feder/Tusche
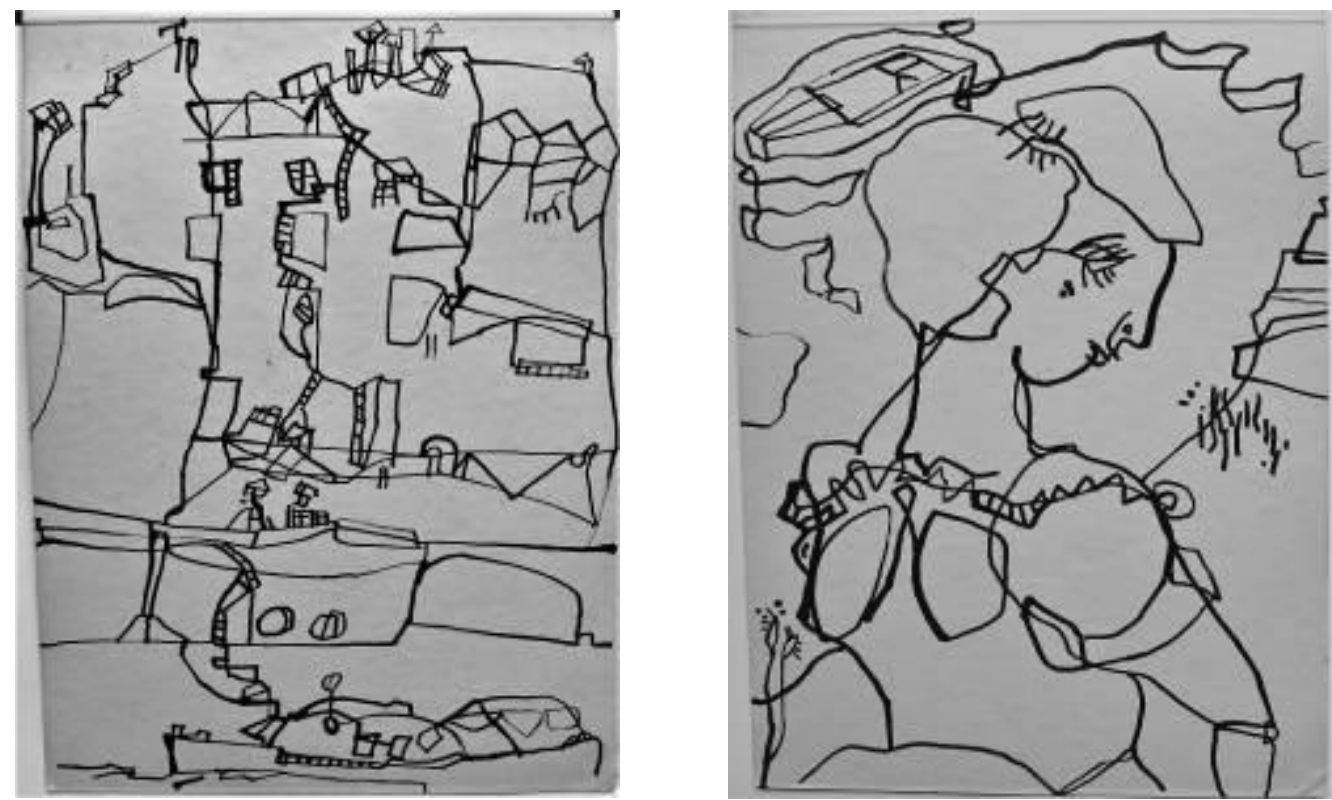

Im Vergleich zu Picasso setzt Grass die Linie auf seinen Blättern gelegentlich ab. Seine Darstellungen werden nicht isoliert in der Bildmitte platziert, sondern füllen die Skizzenbuchseiten bis zu den Rändern hin aus. Der Strich verknüpft auch hier die Figuren mit ihrer Umgebung. Bevorzugt werden wiederum Objekte dargestellt, die an und für sich linearen Charakter haben, wie Zäune, Treppen und Leinen (Abb. 15, Abb. 16). Die verkantete, nicht wie in den italienischen Skizzen fließende Linie des Grafikers fügt jedoch nicht nur zusammen, sondern seziert zugleich, indem sie zum Beispiel die Brüste, den Ärmel und die durch einen Scheitel geteilten Hälften des Haarschopfs einer jungen Frau einzeln umreißt und diesen Elementen dadurch Eigenständigkeit verleiht (Abb. 17). Dabei charakterisiert Grass die Figuren pointiert, wenn er beispielsweise den nach Art 
einer Gallionsfigur in den Luftzug gereckte Oberkörper eines Mädchens mit ihren verschämt aneinander gepressten Knien unterhalb des Kleidersaums kontrastiert (Abb. 15).

Weitere Zeichnungen, die ebenfalls 1952 auf einzelnen Blättern entstanden sind, ${ }^{144}$ weisen stilistische Zuspitzungen der Frankreich-Skizzen in zwei verschiedene Richtungen auf. Eine der Zeichnungen (Abb. 18) zeigt eine schlanke Frau, die einen Kinderwagen schiebt. Noch deutlicher als in den Darstellungen des Skizzenbuchs, da stärker von Details absehend, definiert die Line darin Teilformen ihres Körpers, ihre Beine, Arme und Brust. In einer anderen Zeichnung wird die dargestellte Person hingegen soweit verfremdet, dass einzelne Partien ihres Gesichts wie selbständige, ungegenständliche Bildelemente erscheinen: Das Porträt eines Mannes mit Melone zeigt eine in diesem Sinne surreal anmutende Deformation (Abb. 19). Es erinnert darin einerseits an Zeichnungen André Massons, in welchen Masson - bezugnehmend auf die écriture automatique - in hoher Geschwindigkeit Assoziationsreihen aus fließenden Formen auf das Papier brachte. ${ }^{145}$ Andererseits ist Grass' Zeichnung mit gesellschaftskritischen Bildern der Neuen Sachlichkeit vergleichbar, etwa mit Otto Dix' Ölgemälde Die Skatspieler von 1920 (Abb. 20). Obwohl Grass in seiner Zeichnung keine konkreten Kriegsverletzungen schildert, erzeugen die freien Interpretationen der einzelnen Gesichtspartien zusammen betrachtet eben diesen Eindruck. Sein Porträt lässt auch an Nachkriegsarbeiten von Wols und Gerhard Altenbourg denken, die in ihren verfremdenden Bildnissen mit großer Intensität psychische Krisenzustände ausdrückten. ${ }^{146}$

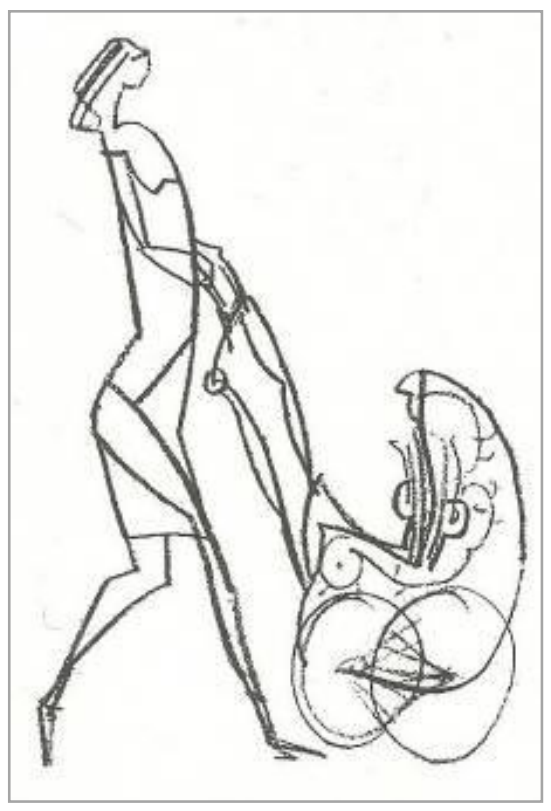

Abb. 18, Frau mit Kinderwagen, 1952, Bleistift

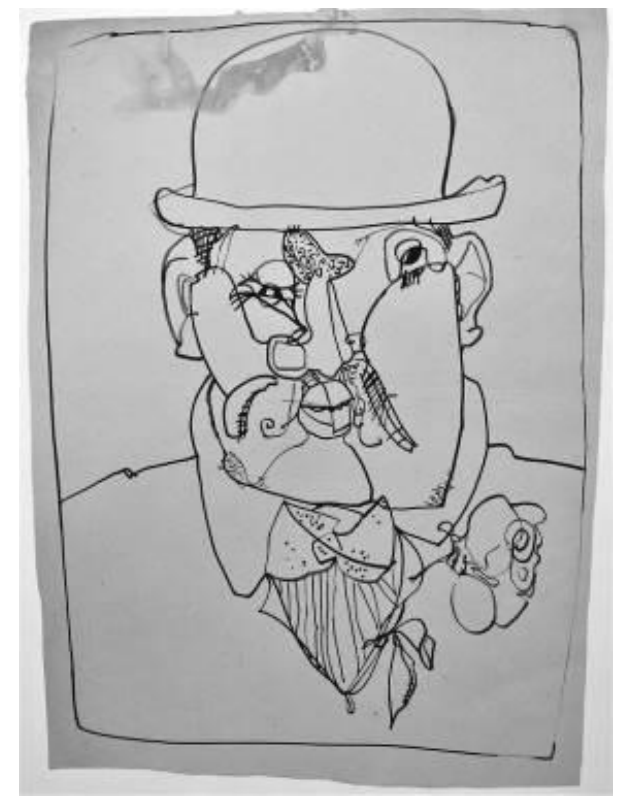

Abb. 19, o. T., um 1952, Feder/Tusche

\footnotetext{
${ }^{144}$ Vgl. Grass (2014), S. 28 f., S. 32-35.

${ }^{145} \mathrm{Vgl}$. Spies (2008), S. 55 f.

${ }^{146}$ Vgl. Beloubek-Hammer (2015), S. 51 und Hoffmann-Curtius (2014), S. 45 f. Zu den 2013 wiederentdeckten Federzeichnung von Günter Grass aus dem Jahr 1952: Krason (2016), S. 126-128.
} 


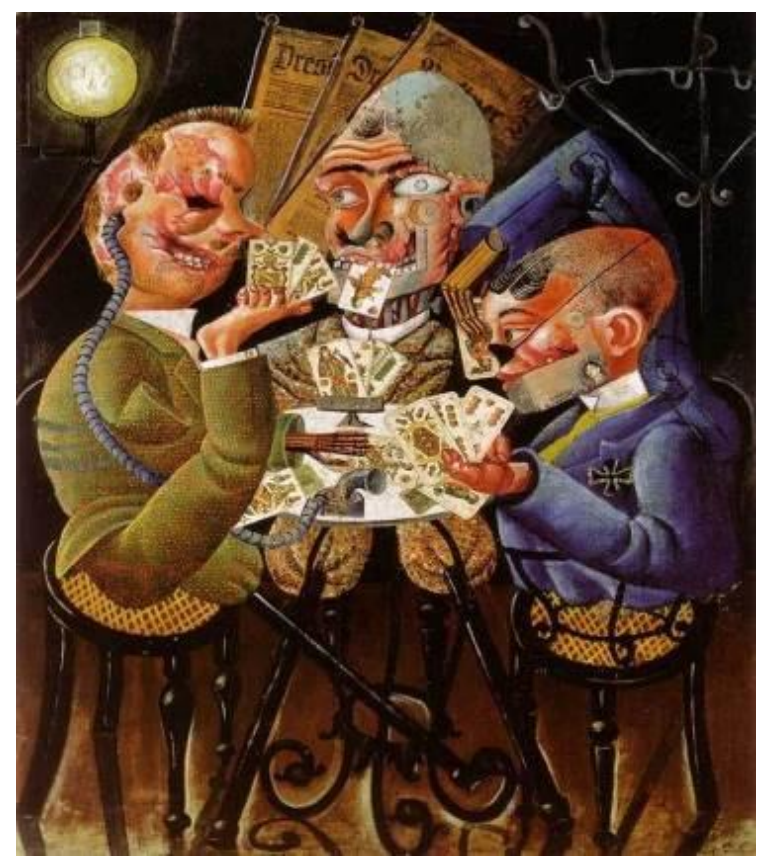

Abb. 20, Otto Dix, Die Skatspieler, 1920, Öl und Collage auf Leinwand

Ähnlich wie Grass' Tuschezeichnungen zeigen auch seine Aquarelle von 1952 Porträts, Genreszenen und Stadtansichten. Noch deutlicher als die in Frankreich entstandenen Tuschezeichnungen fragmentieren die verschiedenfarbigen Teilflächen der Aquarelle ihre Gegenstände. Diese Bilder variieren die in den Skizzenbüchern getuschten Sujets und verleihen ihnen durch die Farbigkeit mehr Tiefenraum (Abb. 21, Abb. 22). Besonders Grass' Porträts erinnern an analytisch-kubistische Werke Picassos wie das berühmte Les Desmoiselles d'Avignon aus dem Jahr 1907. Ähnlich wie Picasso hatte Grass die von ihm dargestellten Figuren aus deutlich voneinander abgegrenzten Flächen zusammengesetzt, deren Färbung nicht am wahrnehmbaren Objekt orientiert war. In Grass' Aquarell Frau mit Hut charakterisiert die rechte, violette Gesichtshälfte der Figur mittels Farbpsychologie den Gemütszustand der Dargestellten (Abb. 21). ${ }^{147}$ Gleichzeitig wird durch die Wiederaufnahme des Farbtons im Hintergrund ein kompositorisches Gleichgewicht geschaffen. Das Einbetten der dargestellten Menschen und Objekte in ein buntes Farbflächenmosaik hatte Grass nicht nur in den bekannten Arbeiten Picassos kennenlernen können, sondern ebenso in den Gemälden niederrheinischer Maler wie Bruno Goller und Ludwig Gabriel Schrieber, die ihren Stil selbst vor dem Hintergrund der kubistischen Malerei entwickelt hatten. ${ }^{148}$ Der Eindruck, den gerade Goller bei dem Studenten hinterlassen hat, sollte sich noch Jahre später bemerkbar machen. In der Bildhauerei ist unter den niederrheinischen Künstlern vor allem Ewald Mataré als weiterer Bezugspunkt für das plastische Werk von Günter Grass interessant.

\footnotetext{
147 Vgl. zu den 2013 wiederentdeckten Aquarellen aus Grass' Studienzeit in Düsseldorf: Krason (2016), S. $118-126$.

148 Vgl. Domscheit (1985), S. 81 f. und Tollowitz-Scharf (2011), S. 49, S. 101 sowie Kahmen (1981), S. 16: Daniel Henry Kahnweilers Veröffentlichung Der Weg zum Kubismus mit Reproduktionen der Bilder Braques, Légers und Picassos hatte Goller rückblickend als Offenbarung bezeichnet.
} 


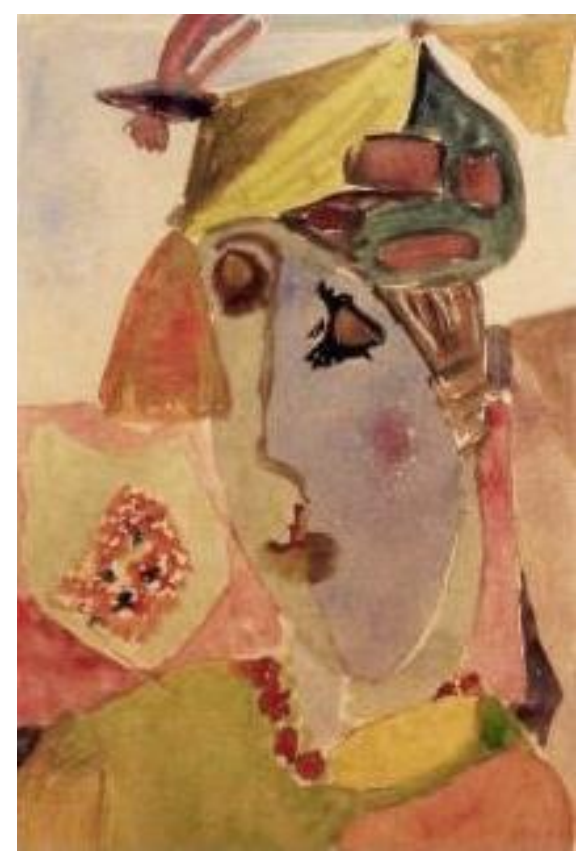

Abb. 21, Frau mit Hut, 1952, Aquarell

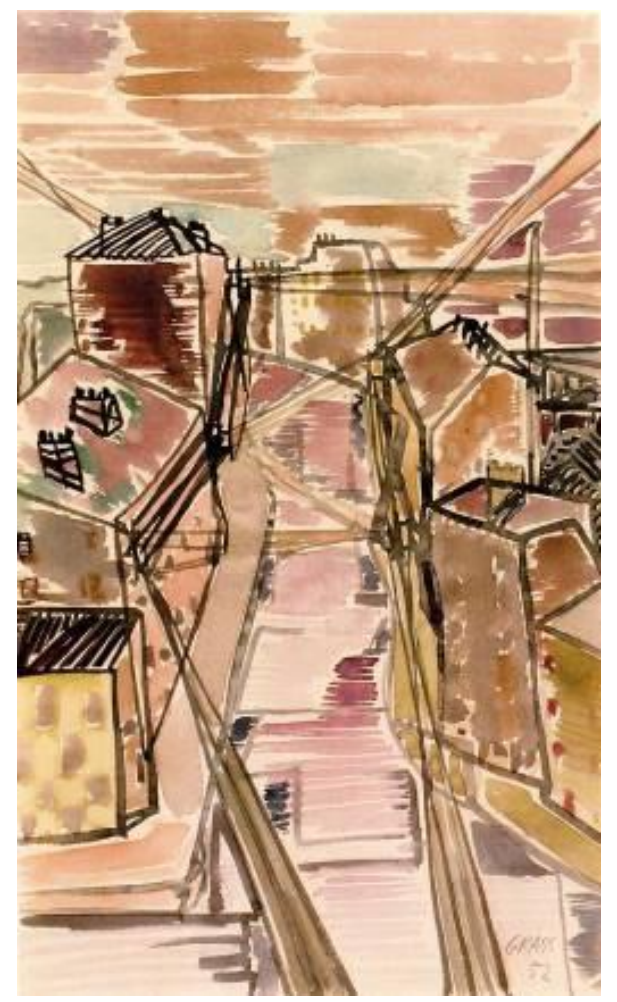

Abb. 22, Pariser Vorortstraße, 1952, Aquarell 


\section{Nachhaltige Eindrücke: Ewald Mataré und Bruno Goller}

Einigen Passagen aus Beim Häuten der Zwiebel kann entnommen werden, dass Grass sein Studium gerne bei Ewald Mataré (1887-1965) begonnen hätte. Bereits die Erinnerung daran, wie er überhaupt auf die Kunstakademie aufmerksam wurde, nämlich über einen Zeitungsartikel, der mit einem Foto von Mataré und seiner Klasse bebildert gewesen sei (X 453), deutet darauf hin, dass er die Ausbildungsstätte gerade mit diesem Bildhauer in Verbindung brachte. Nachdem seine Bewerbung akzeptiert worden war, soll er Pater Fulgentius ferner berichtet haben, dass

nun jedoch Professor Mataré leider keine weiteren Schüler aufnehmen wolle und für mich deshalb das Anfangsstudium der Bildhauerei mit dem Wintersemester bei einem gewissen, mir unbekannten Professor Mages beginnen solle [...]. (X 496)

Grass erinnerte sich, nach dem Bruch mit Sepp Mages kein Interesse mehr daran gehabt zu haben, seine Ausbildung bei Mataré fortzusetzen, weil er die anthroposophischen Theorien, die maßgeblich in dessen Lehre einflossen, ablehnte. ${ }^{149}$ Da aber auch Grass' 1952 selbstgewählter Lehrer Karl Hartung den Theorien Rudolf Steiners sehr zugetan war, ist ein Blick auf Matarés Schaffen zur Begründung der abnehmenden Bewunderung aufschlussreicher. Betrachtet man die Skulpturen Matarés aus verschiedenen Jahrzehnten, wird erkennbar, dass seine Arbeiten sich nach Ende des Krieges wandelten, sich nämlich verstärkt durch grafisch-ornamentale Strukturen auszeichneten. Die modellierten und geschnitzten eleganten Körper, die Mataré vor 1945 gefertigt hatte, sind mit den Arbeiten von Grass' zukünftigem Lehrer Karl Hartung vergleichbar und ebenso mit den späteren Tierplastiken von Günter Grass selbst. ${ }^{150}$ Die kompakte, durch die Abstraktion vom Gegenstand erzielte, geschlossene Form ist den Werken aller drei Künstler gemeinsam. Wie das folgende Kapitel zeigen wird, setzte sich Grass mit seinen Vogeldarstellungen jedoch von beiden Vorbildern durch eine Abstraktion und Verfremdung des wiedergegebenen Tierkörpers ab, die stärker zu stereometrischen Formen tendierte. Die Ähnlichkeit zwischen einem Werk wie dem Huhn von Mataré aus dem Jahr 1928 (Abb. 23) und der Henne von Grass von 1956 (Abb. 24) ist dennoch verblüffend genug, um zu mutmaßen, dass Grass' Interesse an Hartungs Kleinplastiken bereits durch eine erste positive Reaktion auf die früheren Werke des bekannten Düsseldorfer Bildhauers vorbereitet worden war.

\footnotetext{
${ }^{149} \mathrm{Vgl}$. Fitschen (2011).

${ }^{150} \mathrm{Vgl}$. Krause (1998), S. 29 f.
} 

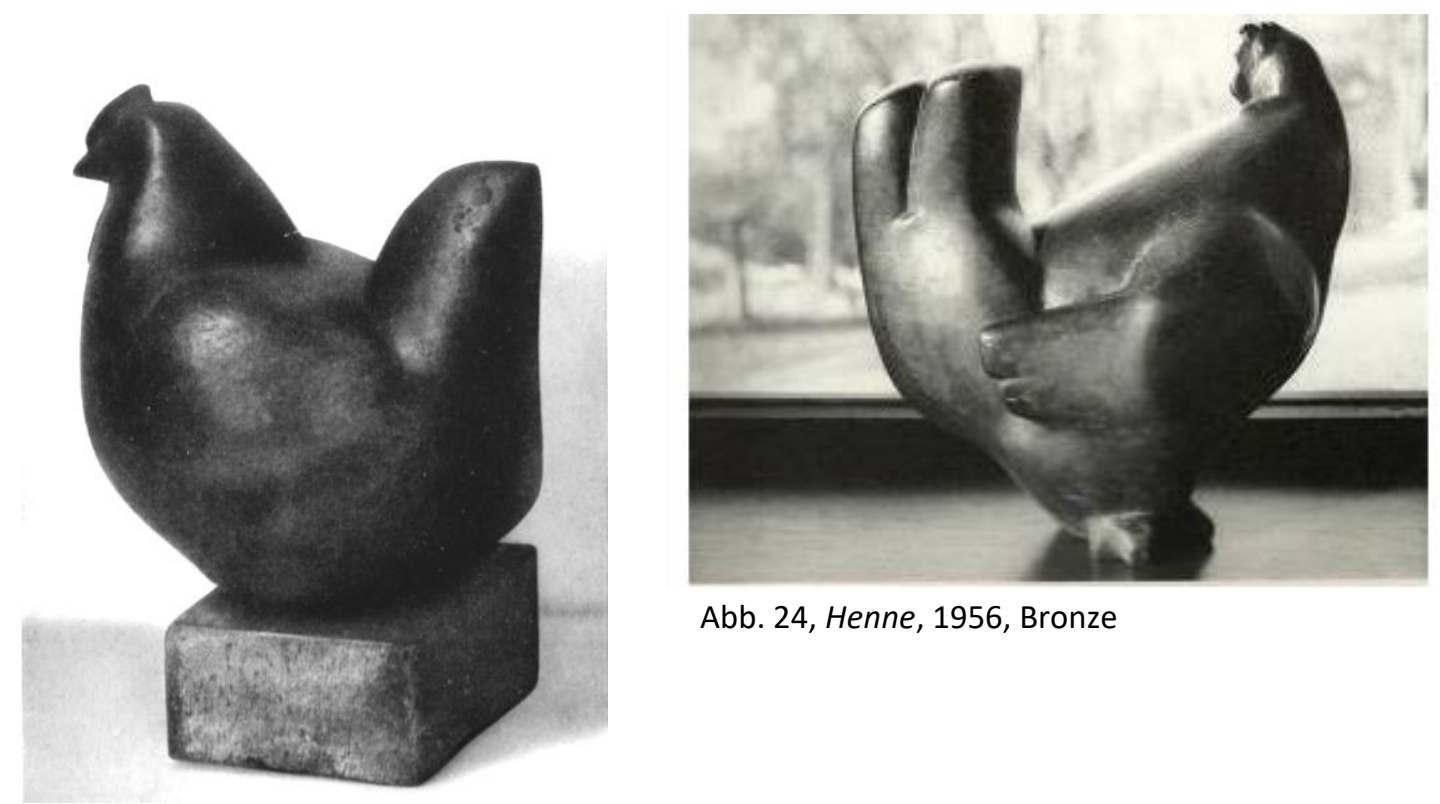

Abb. 24, Henne, 1956, Bronze

Abb. 23, Ewald Mataré, Huhn, 1928, Bronze

Der zweite niederrheinische Künstler, für dessen Werke sich Grass während seines Studiums in Düsseldorf begeisterte, ist Bruno Goller (1901-1998). ${ }^{151}$ Der von Anna Klapheck 1958 als „painter's painter“, also als ein vor allem von seinen Malerkollegen geschätzter Maler bezeichnete Goller, war seit dem Wintersemester 1949/1950 Zeichenlehrer und seit 1953 Professor für Malerei an der Kunstakademie Düsseldorf. ${ }^{152}$

Nach einer Schlosserlehre hatte er sich seit 1920 ausschließlich der Malerei gewidmet. Bereits seine frühen Arbeiten der Zwanziger- und Dreißigerjahre zeigen eine Konzentration auf Stillleben, die Merkmale des Expressionismus, Kubismus, Verismus und Surrealismus zu einem eigenständigen Stil zusammenführen. Eine Besonderheit der Goller'schen Stillleben ist die Vorliebe für Modeaccessoires als Sujets. Gollers Mutter hatte nach dem Tod seines Vaters 1904 ein Putzmachergeschäft eröffnet, sodass der Maler in seiner Kindheit und Jugend von Hüten, Schleifen, Krawatten und Handschuhen umgeben war. ${ }^{153}$ In Bildern wie dem Kleiderschrank von 1947 (Abb. 25) werden die in den Mittelpunkt gerückten und ins Ornamentale stilisierten Objekte als Bildgegenstände aufgewertet. Das Kapitel „Im Kleiderschrank“ aus der Blechtrommel (1959) korrespondiert in dieser Hinsicht ebenso mit Gollers Gemälden wie Grass' Gedicht mit dem Titel „Inventar oder die Ballade von der zerbrochenen Vase“ (1963) - Kleidungsstücke spielen darin als Abdruck und Spur des Menschen die Hauptrolle. ${ }^{154}$

Goller exponierte nicht nur in dem Bild Kleiderschrank, sondern auch in den meisten seiner anderen Werke wie Zwei Reifen (1924) (Abb. 26) oder Ohr (1956) (Abb. 27) einzelne Gegenstände, fügte sie in eine geometrisch strukturierte Farb- und Formenanordnung ein und verlieh ihnen

\footnotetext{
151 In einem unveröffentlichten handschriftlichen Manuskript zum Prosatext „Das soll von mir sein?“ aus Vonne Endlichkait (Grass (2015), S. 95), verfasst in Behlendorf am 11. Januar 2014, nennt Grass neben Picasso auch Bruno Goller als Inspirationsquelle seiner Düsseldorfer Studienzeit.

152 Vgl. Klapheck (1958), S. 25.

153 Vgl. Kahmen (1981), S. 12.

$154 \mathrm{Zu}$ Bedeutungen und Assoziationen, die mit Kleidungsstücken in der bildenden Kunst in Verbindung stehen können vgl. Wagner (2001), S. 83-91.
} 
die Erscheinung kostbarer Intarsien. Die Isolation der einzelnen Gegenstände im Bildraum macht auf einen Hintersinn der Darstellungen aufmerksam. Dieser erschließt sich oftmals vor dem Hintergrund der Archetypenlehre C. G. Jungs und der Traumdeutung Sigmund Freuds. ${ }^{155}$ Goller machte nicht nur Alltagsgegenstände, sondern auch Ziffern zu Objekten seiner Kunst, wie in dem hier abgedruckten Bild der Zahlen (1954) erkennbar ist (Abb. 28). Die ästhetische Nobilitierung des Alläglichen, das Komponieren von Objekten und Zeichen zu einer Bildsprache sollte im Folgenden auch Grass' Werk durchziehen: Von seinen Federzeichnungen zu den Vorzügen der Windhühner (1956) bis hin zu den getuschten und aquarellierten Zahlen- und Buchstabenbildern in Novemberland (1993) und in Grimms Wörter (2012). ${ }^{156}$

Abschließend bleibt festzuhalten, dass sich die erhaltene Ausbeute aus Grass' Düsseldorfer Jahren zum einen durch eine sehr deutliche Bezugnahme auf verschiedene überregional und regional bekannte Vorbilder aus dem ersten Drittel des 20. Jahrhunderts auszeichnet, von Künstlern des Expressionismus über solche des Kubismus und Surrealismus bis hin zu Malern der Neuen Sachlichkeit. Zum anderen werden dabei spezifischere Präferenzen des Studenten deutlich: Die von inm bildkünstlerisch umgesetzten Betrachtungen sind selten anekdotisch-narrativ. Sie wirken vielmehr analytisch, wenn sie Figurenkörper über die Linienführung gleichsam in Teilformen zerlegen, verbindenden Strukturen zwischen der einzelnen Figur und ihrer Umgebung auf den Grund gehen oder Einzelformen surrealistisch-assoziativ durch verwandte Objekte aus anderen Zusammenhängen ersetzen. Betrachtet man das Schaffen des Studenten von 1947 bis 1952 als Entwicklung, so fällt auf, dass die Darstellung der menschlichen Figur, die in seinen Arbeiten meist im Vordergrund steht, eine immer stärkere Aufspaltung und Deformation erfährt, die teils ein kritisches Gesellschaftsbild, teils ein gesteigertes Interesse an der form und ihrer surrealistischen Umgestaltung transportiert.

\footnotetext{
155 Vgl. Kahmen (1981), S. 67-91.
}

${ }^{156} \mathrm{Vgl}$. Detering (2016). 


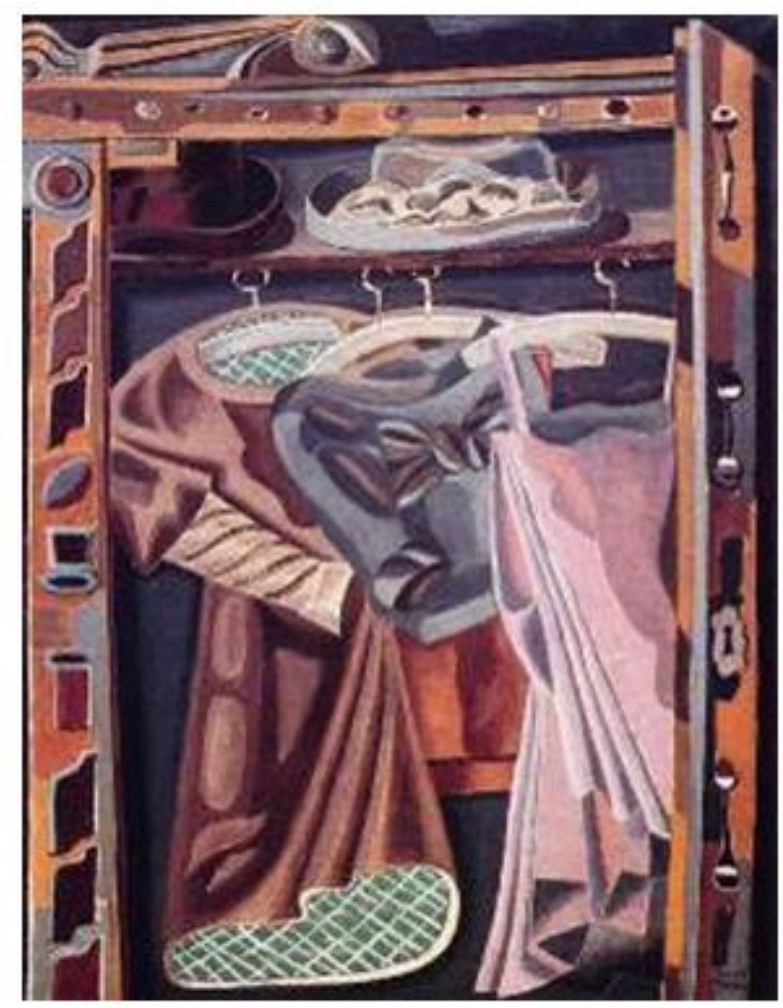

Abb. 25, Bruno Goller, Kleiderschrank, 1947, Öl auf Leinwand

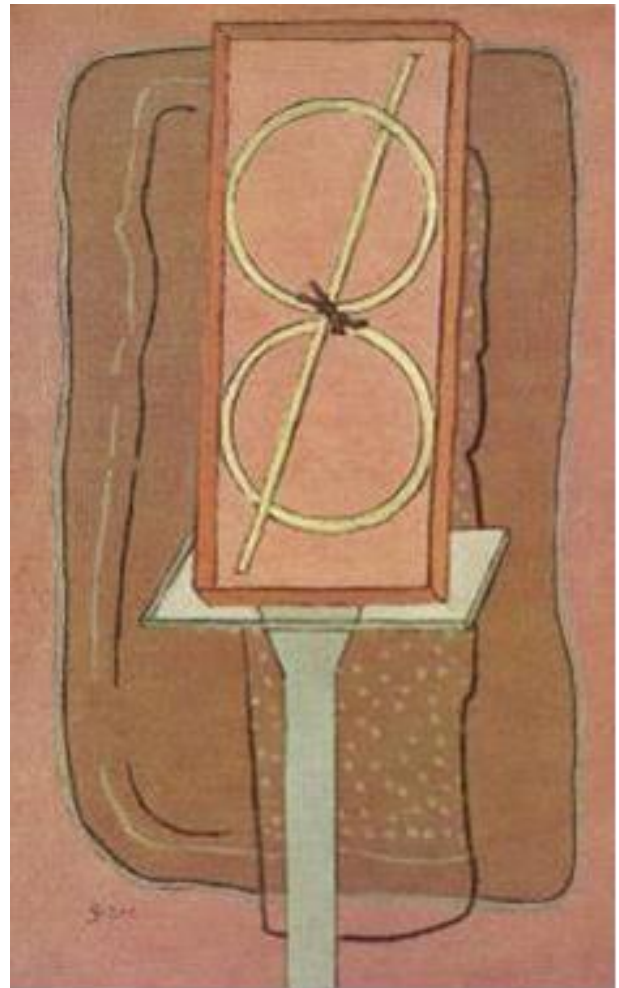

Abb. 26, Bruno Goller, Zwei Reifen, 1924 Öl auf Leinwand

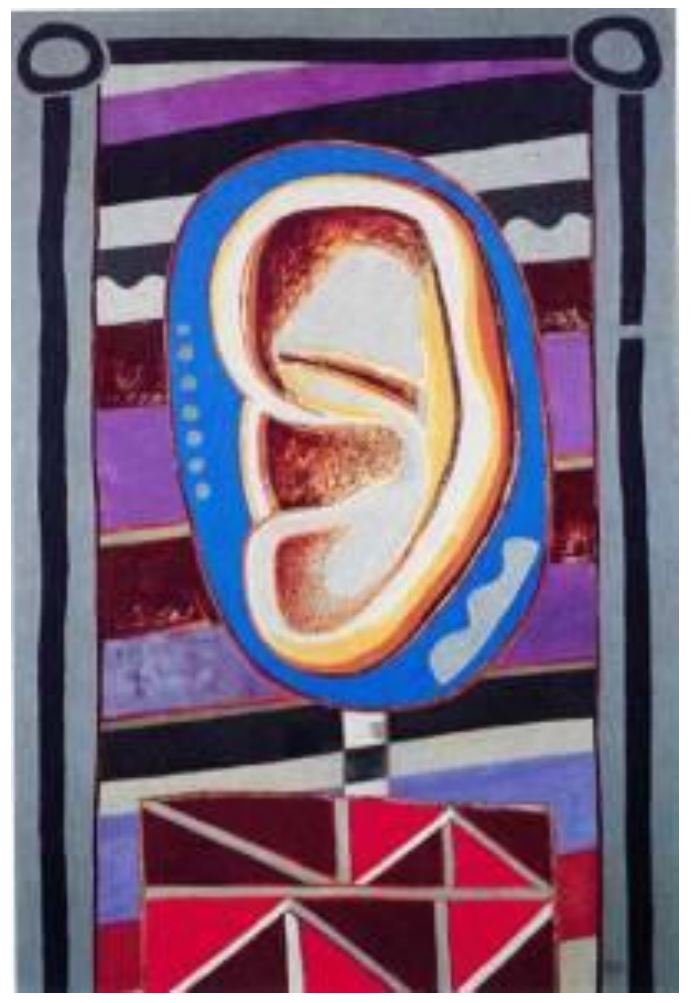

Abb. 27, Bruno Goller, Das Ohr, 1956, Öl auf Leinwand

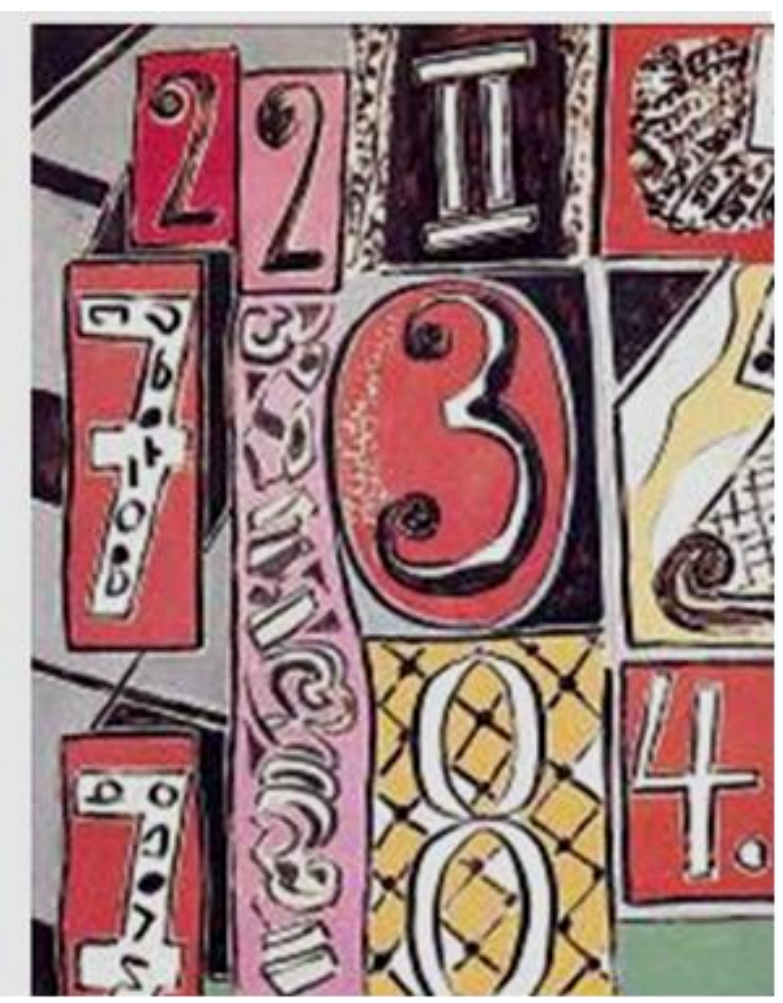

Abb. 28, Bruno Goller, Bild der Zahlen, 1954, Öl auf Leinwand 


\section{Günter Grass' Dichtungen aus der Düsseldorfer Studienzeit}

Parallel zu seiner akademischen Ausbildung hatte Grass Gedichte geschrieben. Die in Düsseldorf verfassten Texte bewahrte er auf, überließ sie dem Literaturarchiv der Berliner Akademie der Künste, veröffentlichte sie jedoch mit Ausnahme von einzelnen exemplarischen Texten für den Werkstattbericht und den Kommentarband zur Studienausgabe seiner Lyrik nicht. ${ }^{157}$

Ebenso wie sich Grass als Kunststudent an berühmten Vorbildern der Klassischen Moderne abgearbeitet hat, griff er auch zur Weiterentwicklung seines literarischen Instrumentariums auf Dichtungen aus dem ersten Drittel des 20. Jahrhunderts zurück. Er rezipierte Texte von Apollinaire, Trakl, Rilke, Ringelnatz und „miserable Lorca-Übersetzungen“ und nahm in seinen eigenen Gedichten auf sie Bezug. Diese Beziehungen und Parallelen hat Werner Frizen bereits im Kommentarband zu Grass' Lyrik exemplarisch an einigen Texten nachvollzogen. ${ }^{158}$

Die Sichtung des Düsseldorfer Arbeitstagebuchs (Mai bis Dezember 1952) ermöglicht an dieser Stelle einen Überblick über Grass' literarische Themen und Motive im letzten Düsseldorfer Studienjahr sowie einen Vergleich seiner Texte mit seinen frühen Bildwerken. Das Notizbuch enthält zweiundvierzig Gedichte, das Langgedicht „Der Säulenheilige“ und das Drama „Von einem der auszog das Fürchten zu lernen. Ein Spiel in vier Akten“.

Die Gedichte sind von einer melancholischen Grundstimmung getragen. Diese wird zum einen über die Themen Tod, Trauer und Vergänglichkeit transportiert, zum anderen über bestimmte Motive wie den Herbst und den Vogelflug. Die Texte weisen auffällig oft Beschreibungen sinnlich erfahrbarer Kontraste auf, solche von Farben, Temperaturen und Materialkonsistenzen. In folgendem Gedicht sind einige dieser Aspekte beispielhaft vereint:

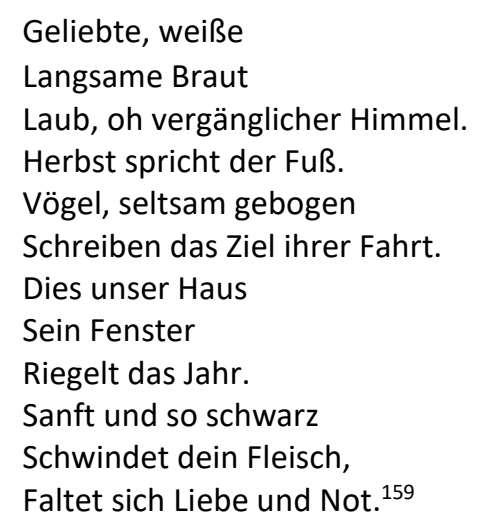

Das auffälligste rhetorische Stilmittel, auf dessen häufiges Vorkommen Grass im Werkstattbericht bereits selbstkritisch hingewiesen hat, ${ }^{160}$ sind Genitivmetaphern, die der Veranschaulichung oder Mystifizierung von Begriffen oder Phänomenen dienen (, $[\ldots .$.$] oh die feuchten Hände / Der$ Liebe ${ }^{161}$, „Regen, des Wassers / Vieldeutig Volk ${ }^{\prime 162}$ ). In seinen ersten Arbeitsproben entwirft der

\footnotetext{
${ }^{157}$ Vgl. Grass (2014), S. 19-27 und Frizen (2010), S. 16-18.

158 Vgl. Frizen (2010), S. 16-18.

${ }^{159}$ Akademie der Künste, Berlin, Günter-Grass-Archiv, Nr. 965, S. 18, hs., Transkription: V. K. Dieter Stolz sei für die kritische Durchsicht aller Transkriptionen für die vorliegende Veröffentlichung der Dissertation, für Hinweise und Korrekturen herzlich gedankt.

160 Grass (2014), S. 27.

${ }^{161}$ Akademie der Künste, Berlin, Günter-Grass-Archiv, Nr. 965, S. 19, hs., Transkription: V. K.
} 
Student archaische Landschaften, in welche er aus der antiken oder christlichen Mythologie bekanntes Personal stellt. Feuer, Eis, Gestein und verschiedene Metalle wichtige Bestandteile dieses lyrischen Inventars. In einigen Texten treten zudem animistische und surreale Sprachbilder in den Vordergrund („Ein Leuchter reitet den düsteren Tisch / Weiß fliegt der Heiland davon“163). Zwei dieser Gedichte werden in den folgenden Kapiteln eingehend behandelt werden, weil Grass sie 1954 als Anknüpfungspunkt für bildkünstlerische Arbeiten nutzte. ${ }^{164}$

Bezüge zu Grafiken und Plastiken, die Grass in den Düsseldorfer Jahren geschaffen hat, sind hingegen nicht erkennbar. Lediglich das Aufgreifen des Gesteinsmotivs könnte auf die Bildhauerei verweisen, gehörte jedoch andererseits zum Repertoire der mystischen Naturlyrik der Nachkriegsjahre. ${ }^{165}$

Ein engerer Bezug zur Bildhauerei ist in dem „Tagebuch eines Säulenheiligen“ zu finden. Das Langgedicht handelt von einem Maurer, der auf dem Marktplatz einer Stadt eine Säule fertigt und von dieser herab das Geschehen kommentiert. Wie Grass selbst 1973 in seinem „Rückblick auf die Blechtrommel - oder Der Autor als fragwürdiger Zeuge. Ein Versuch in eigener Sache", einem Beitrag zur WDR-Sendereihe Wie ich anfing, erörtert hat, erhielt die erhöhte Perspektive des Säulenheiligen für seinen Debütroman später eine herausragende Bedeutung. Für die Blechtrommel hat er sie ins Gegenteil verkehrt und den Protagonisten die Welt aus der Unterschau eines Kleinwüchsigen verlästern lassen. ${ }^{166}$

Die Figur des buchstäblich hochnäsigen Betrachters verhilft dem "Säulenheiligen“ im Unterschied zu den anderen Gedichten des Arbeitstagebuchs zu einem raueren und polemischen Ton. Trotzdem ist auch dieser Text weiterhin von Naturbeschreibungen - schließlich steht die Säule unter freiem Himmel - und altertümelnder Mittelmeerstimmung durchzogen. Einzelne Passagen weisen auf spätere Werke voraus wie zum Beispiel die Erwähnung eines Wettrennens mit einer Schnecke. Der im Text enthaltene Vers „als sie dann ankam am Ende, hatte ich vergessen, wie eine Schnecke aussah" wurde von Grass in dem Prosagedicht „Meine grüne Wiese“ (1956) fast wörtlich übernommen. Über zehn Jahre später wurde die Schnecke zum Leitmotiv von Aus dem Tagebuch einer Schnecke (1972) und zum Gegenstand der zu diesem Erzählwerk geschaffenen Zeichnungen und Druckgrafiken gewählt. ${ }^{167}$

Das ebenfalls in Düsseldorf verfasste Theaterspiel Von einem der auszog das Fürchten zu lernen basiert auf einem Märchen aus der Sammlung der Brüder Grimm. ${ }^{168}$ Es handelt von einem Bauernjungen, der den Hof seines Vaters verlässt, um die Empfindung der Angst kennenzulernen. Immer wieder begibt er sich bewusst in beängstigende Situationen, übersteht sie jedoch, ohne sich zu fürchten. Stattdessen macht er sich seine Furchtlosigkeit, bei der es sich im Grunde um rationales Denken handelt, zu Nutze und erhält auf diese Weise eine Königstochter zur Frau. Grass setzt den Märchenstoff als Theaterspiel in Versen mit geplantem Gesang um.

162 Ebd., S. 22, hs., Transkription: V. K.

163 Ebd., S. 4.

${ }^{164}$ Vgl. S. 76-80 und S. 108 f. der vorliegenden Publikation.

165 Vgl. Rühmkorf (1978).

${ }^{166}$ Vgl. Neuhaus (2010), S. 55.

167 Vgl. Kapitel V.1. der vorliegenden Untersuchung.

168 In Beim Häuten der Zwiebel hatte Grass das Kapitel, das von seinem Kriegseinsatz handelt, nach ebendiesem Märchen benannt. 
Mit diesem unveröffentlichten Text liegt Grass' erste Arbeitsprobe auf dem Gebiet des dramatischen Schaffens vor, in dem er sich wenige Jahre später weiterbewegen würde. Ebenfalls erstmals klingt in dem Drama ein Plädoyer auf Vernunft und Entdämonisierung an, das ein wichtiges Charakteristikum seines ersten Romans darstellt. Mit der Blechtrommel verfolgte er das Ziel, die entlastende Auffassung, der Nationalsozialismus sei eine mit dem Verstand nicht zu erfassende Katastrophe gewesen, zu entkräften. ${ }^{169}$

Grass' frühe bildkünstlerische Arbeiten und seine ersten Arbeitsproben in Lyrik und Dramatik weisen nur im Ausnahmefall motivische Verbindungen oder intermediale Bezüge auf. Die in den unveröffentlichten Gedichten kreierten Landschaften und Stimmungsbilder zeigen lediglich in der Betonung von Materialqualitäten eine Nähe zur bildenden Kunst.

Auffällig ist Grass' gleichermaßen im Bereich der Literatur und Kunst nachvollziehbare Orientierung an Vorbildern des ersten Drittels des 20. Jahrhunderts. Sie bereitete eine in Berlin erfolgende intensivere Auseinandersetzung mit kubistischen und surrealistischen Gestaltungsformen vor und stellt eine Grundlage für Grass' später sehr deutlich formulierte Positionierung für eine gegenständliche und engagierte Kunst dar. ${ }^{170}$ Die rege Produktivität des Studenten in verschiedenen Kulturtechniken und literarischen Gattungen bildete zudem die Basis für die folgende Annäherung der verschiedenen künstlerischen Ausdrucksformen in seinem Schaffen.

Einen Auftakt für seine eigenen Überlegungen dieser Art bildet die letzte Seite des Arbeitstagebuches von 1952, die ein Disziplinen- und Gattungsschema enthält. Mit blauer Tinte notierte Grass am oberen Bildrand drei jeweils dreizeilige Wortkolonnen. Darunter zeichnete er fünf surreal verfremdete Porträts, die den Betrachtenden frontal zugewandt sind und diese, ebenso wie den Zeichnenden und Schreibenden selbst, erwartungsvoll wie ein Publikum anschauen (Abb. 29). Den Beginn jeder Spalte bildet in der ersten Zeile jeweils eine der literarischen Gattungen und zwar von links nach rechts in der Reihenfolge, in der sie Grass 1952 am häufigsten nutzte: Lyrik, Theater und Prosa. Darunter setzte er jeweils die beiden bildkünstlerischen Techniken, die für ihn mit der jeweiligen literarischen Gattung wohl am stärksten verbunden waren: Zeichnung und Malerei fügte er zur Lyrik, Plastik und Malerei zum Theater und Zeichnung und Malerei zur Prosa. In der Kombination von Lyrik und Grafik fand Grass ab 1954 eine Möglichkeit, Literatur und bildende Kunst im kreativen Schaffensprozess und in der Buchgestaltung miteinander zu verknüpfen.

\footnotetext{
${ }^{169}$ Vgl. Rudolph (1971), S. 264.

${ }^{170}$ Vgl. Kapitel II.3. dieser Forschungsarbeit.
} 


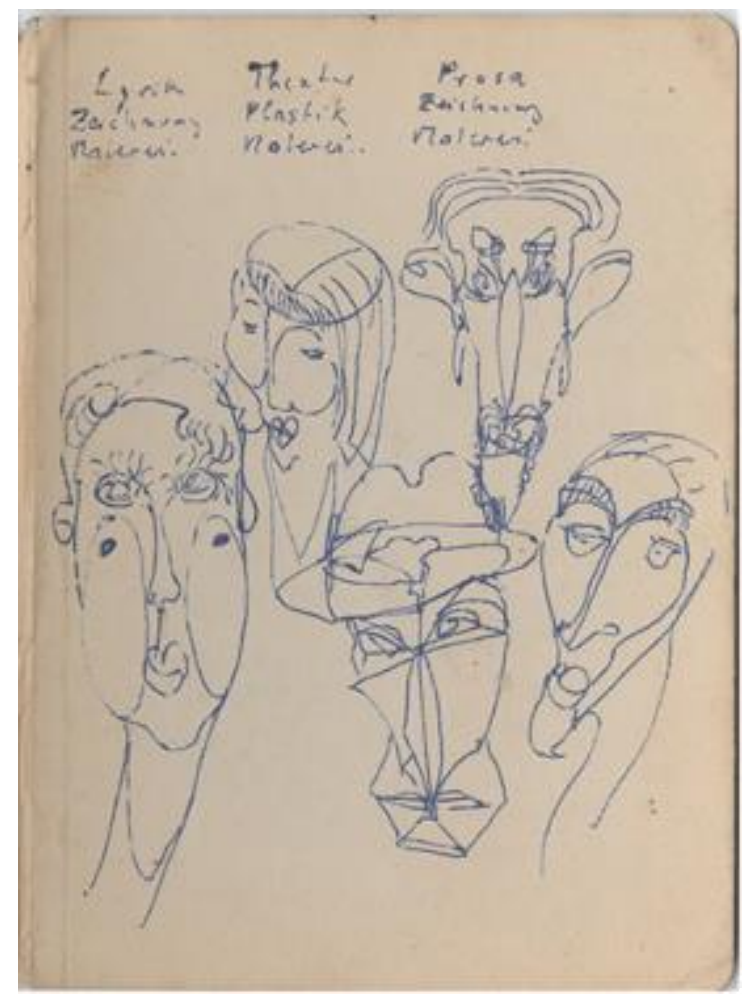

Abb. 29, Arbeitstagebuch, 1952, S. 149 (letzte Seite), blaue Tinte, Akademie der Künste, Berlin, Günter-Grass-Archiv, Nr. 965 


\section{Berlin: „Überrealität“ ins Bild setzen ${ }^{171}$}

Wie erhofft, gebärdete sich Berlin im Gegensatz zu Düsseldorf Anfang der Fünfzigerjahre nicht als „klein Paris“. ${ }^{172}$ Stärker als die meisten anderen Städte Deutschlands war ihr Anblick noch von Trümmerhalden, Häuserruinen und brachliegenden Grundstücken, also den Spuren jüngster deutscher Vergangenheit geprägt. ${ }^{173}$ Auch wenn es Westberlin ebenso wie Westdeutschland wirtschaftlich stetig besser ging, war das Wohlstandswachstum dort durch die isolierte Position der Stadthälfte und insbesondere aufgrund der Berlinblockade von 1948/1949 verzögert eingetreten. Erst 1952/1953 nahmen Industrieproduktion und Handelsumsätze zu, sodass das Gebiet nach und nach seine neue Rolle als „Schaufenster des Westens" erfüllen konnte. ${ }^{174}$

Auf der „Insel, gegen die von allen Seiten die Flut der sozialkommunistischen Meere brande$\mathrm{t}[\mathrm{e}]^{\mu 175}$ waren die Teilung des Landes und die zunehmende Frontenverhärtung zwischen Ost und West wie an kaum einem anderen Ort erfahrbar. Die nach der Blockade besonders vehemente Ablehnung des Kommunismus durch die ,Insulaner' kam auch im Bereich der Kulturpolitik in medial befeuerten Enttarnungen angeblicher Ostsympathisanten zum Ausdruck - ideologische Gefechte, die in der sowjetisch besetzten Zone unter umgekehrten Vorzeichen ihre Entsprechung hatten. ${ }^{176}$

Die mit dem Ende des Zweiten Weltkrieges einhergegangenen politischen Umwälzungen und der Beginn der Auseinandersetzungen zwischen den Siegermächten hatten sich zwischen 1945 und 1953 auch an Grass' neuer Ausbildungsstätte bemerkbar gemacht: Die 1945 gegründete Hochschule für Bildende Künste erfuhr mit Karl Hofer auf dem Direktorenposten und seinem Stellvertreter Heinrich Ehmsen im Vergleich zu ihrer Vorgängerinstitution eine grundsätzliche Neuausrichtung. Professoren, die vormals Mitglieder der NSDAP gewesen waren, wurden zu einem großen Teil entlassen und ersetzt. Im „Dritten Reich“ verfemte Vertreter der Klassischen Moderne sowie Lehrende, die sich neuer figurative und nonfigurative Elemente vereinender Mischstile bedienten, boten den Studierenden einen repräsentativen Querschnitt durch die zeitgenössische Kunst: 1947 eingestellt wurden unter anderem Max Pechstein und Karl SchmidtRottluff für die Malerei, Max Taut für die Architektur, der Kunsthistoriker Adolf Behne sowie die Bildhauerin Renée Sintenis und die Bildhauer Gustav Seitz und Waldemar Grzimek. ${ }^{177}$

Doch schon die Jahre 1949/1950 brachten erneut einen tiefgreifenden Wandel des Kollegiums mit sich. ${ }^{178}$ Heinrich Ehmsen, Gustav Seitz, Waldemar Grzimek und Oskar Nerlinger wurden auf Grund verschiedener als Annäherung an die kommunistischen Besatzer interpretierter Handlungen von dem Personalrat der HfBK aus ihren Ämtern entlassen. Auch der figurativ arbeitende Karl Hofer stand unter Verdacht, das kommunistische Regime zu befürworten, während er in Ostberlin

\footnotetext{
${ }^{171}$ Siehe Günter Grass zu seiner Lyrik in seinem kurzen Text „Der Autor sagt zu seinem Gedicht“, September 1955: XI $5 \mathrm{f}$.

172 Grass (2014), S. 29.

${ }^{173}$ Vgl. Von Buttlar/Wittmann-Englert/Dolff-Bonekämper (2013), Einführung XIII f.

${ }^{174} \mathrm{Vgl}$. Lemke (2011), $192 \mathrm{f}$.

175 Karl Friedrich Borée: Berlin. Manuskript, Deutsches Literaturarchiv Marbach, Nr. 642 153, zitiert nach: Schrott (1987), S. 15.

${ }^{176}$ Vgl. Hofmann (2004), S. 19 und Hermand (1986), S. 145-154.

177 Vgl. Schmidt (2004), S. 132.

${ }^{178}$ Vgl. Fischer-Defoy (2001), S. 30-36.
} 
als Formalist angefeindet wurde. Die Vorgänge an der von ihm geleiteten Hochschule konnte er zu seiner eigenen Bestürzung nicht verhindern. Er besetzte die freigewordenen Professorenposten schließlich unter anderen mit den Bildhauern Bernhard Heiliger, Hans Uhlmann, Karl Hartung sowie mit Ludwig Gabriel Schrieber, den Hofer an die Abteilung für Kunsterziehung in der Grunewaldstraße berief. Durch die im selben Zeitraum erfolgte Emeritierung von Renée Sintenis und Richard Scheibe verschob sich das Verhältnis der ästhetischen Positionen unter den Lehrenden in der Bildhauereisektion merklich zu Gunsten der ungegenständlichen Kunst, ${ }^{179}$ die als „Weltkunst“ zunehmend eine ausschließliche Geltung für sich beanspruchte. ${ }^{180}$

Als Grass 1953 seine akademische Ausbildung an der HfBK fortsetzte, war Schrieber der einzige verbliebene figurativ arbeitende Bildhauer unter den Lehrenden. ${ }^{181}$ Die politisch unterlegte Debatte um die Positionen der Gegenständlichkeit (assoziiert mit Nationalsozialismus / Kommunismus) und Gegenstandslosigkeit (assoziiert mit Demokratie/Kapitalismus) war mit den ersten Auseinandersetzungen innerhalb des Künstlerbundes bereits in vollem Gange. ${ }^{182}$ An den Studierenden ging sie allerdings noch weitgehend vorbei und forderte erst 1955 eine Positionierung von innen ein, nachdem der Disput sich öffentlich über die Zeitschrift Der Monat und vor allem über den Tagesspiegel auf einen verbalen Schlagabtausch zwischen Hofer und dem Kunstkritiker Will Grohmann verengt hatte. ${ }^{183}$

Der unmittelbare erste Eindruck, den Berlin im Januar 1953 auf den fünfundzwanzigjährigen Günter Grass machte, hat sich in einem kurzen unveröffentlichten Aufsatz konserviert. Der Student verfasste ihn handschriftlich am 30. Januar 1953, wohl für eine nachträgliche offizielle Bewerbung an die HfBK. ${ }^{184}$ Fasziniert hob er darin gerade die Präsenz der Vergangenheit und der politischen Konflikte in der Stadt hervor und skizzierte einen Zustand, der den Verhältnissen im durch Wirtschaftswunder und zügigen Wiederaufbau geprägten Düsseldorf diametral entgegenstand:

Berlin am 30.1.1953

Wer den westdeutschen Wiederaufbau mitansehen mußte findet daß Berlin, vor allen anderen Städten, den Krieg wohl am Besten verdaut hat. Obwohl ein nur plötzliches Hinsehen dieses kaum deutlich macht. Da ist ein Horizont von Wohnblockrückseiten der anmutet wie ein lückenhaft Gebiß. Und doch sind es gerade diese unfreiwillig eingerückten Plätze die mich erstaunen ließen. [Um?] eine ernste, lustlose Leere, breite, verschränkte Fassaden, in denen Lichter ein und aus gehen. Nie war mir so bewußt wie sonderbar wir Menschen wohnen. Nie habe ich wie hier eine Scheu empfunden, einen dieser neuen, lautlosen Plätze zu überqueren. Doch kann man Kinder sehen, die auf den Trümmerbergen rodeln. Für sie sind diese Hügel wohl zur Landschaft geworden.

\footnotetext{
${ }^{179}$ Vgl. ebd., S. 107.

${ }^{180}$ Vgl. Hermand (1986), S. 428-438, S. 476-483.

${ }^{181} \mathrm{Vgl}$. Fischer-Defoy (2001), S. 107.

182 Vgl. zu den Auseinandersetzungen innerhalb des Deutschen Künstlerbundes, insbes. zwischen Hofer und Baumeister: Fischer-Defoy (2004).

${ }^{183} \mathrm{Vgl}$. Grass in einem Gespräch mit Christine Fischer-Defoy am 22.11.1989, Fischer-Defoy (1992), S. I-5 f. und Rolf Szymanski (geb. 1928) im Gespräch mit ders. am 5.10.1989, in Fischer-Defoy (2001), S. 125.

${ }^{184} \mathrm{Vgl}$. Grass in einem Gespräch mit Christine Fischer-Defoy am 22.11.1989, Fischer-Defoy (1992), S. I-3: „Und da ist für mich der Wechsel nach Berlin - erst einmal abgesehen von Hartung und Schrieber -, diese Stadt, was ich dann in meinem Bewerbungsschreiben, das ich auch zum ersten Mal wiedergesehen habe, in diesem merkwürdigen Aufsatz schrieb [...]."
} 
- Anders als an anderem Ort [erfüllt?] sich auch hier die Ruine. Manches Haus scheint vor Jahrhunderten etwas Zertrümmerndes erlebt zu haben. Und die Gedächtniskirche, in ihrer letzten Vollendung, sollte man gewiß nie wieder umbauen. -

Gleichsam daneben, doch mit der selben [hysterischen?] Gelassenheit überschneiden sich hier politische Gegensätze. Man muß wohl ein knitterfreies Gemüt haben um zwischen all diesen Händen keine Falten zu werfen. Doch wäre es verfrüht, für mich, der ich nur kaum hinsehen durfte, dazu einen letzten Satz zu machen.

Günter Graß

Berlin-Charlottenburg. Schlüterstr. $8^{185}$

Der Neuankömmling wurde zunächst ohne formale Hürden in Hartungs Klasse aufgenommen. Die Stimmung im Klassenverband erinnerte er später als wohltuend nüchtern. Die ersten Ateliergespräche orientierten sich an praktischen Fragen wie der günstigen Lebensmittelbeschaffung (X 566). Hartung galt als strenger, um Distanz bemühter Lehrer. Wie seine Tochter Hanne Hartung rückblickend festhielt, verringerte sich der gewahrte Abstand zu seinen Schülerinnen und Schülern nur ab und an, wenn er die Klasse an Freitagabenden zum gemeinsamen Umtrunk einlud. Dabei berichtete er gelegentlich aus seiner Jugend und erzählte Anekdoten, die Grass als Stoffreservoir für seine späteren Werke gedient haben könnten. ${ }^{186}$

Dass Grass auch regelmäßig in Ludwig Gabriel Schriebers Atelier zu Gast war, störte den für seine ästhetische Toleranz geschätzten Hartung nicht. ${ }^{187}$ Besonders anregende Gespräche über Ästhetik ebenso wie über Politik wurden in der Werkstatt dieses sehr belesenen und politisch kompromisslosen Bildhauers und Malers geführt. ${ }^{188}$ Da die Studierenden in den Fünfzigern mehrheitlich die Betreuung von gegenstandslos arbeitenden Professoren präferierten, setzte sich Schriebers Klasse meist aus vier bis fünf Personen zusammen. Sein Verhältnis zu ihnen war entsprechend sehr persönlich. ${ }^{189}$

Hartung und Schrieber waren nicht nur befreundet, auch ihre Kunstauffassung überschnitt sich an zentralen Punkten. ${ }^{190}$ Die plastische Arbeit der Künstler nahm, wenn auch zeitlich versetzt - bei Hartung bereits in den Dreißigerjahren, bei Schrieber in den Vierziger- und Fünfzigerjahren -, gleichermaßen ihren Ausgang von der Verdichtung der Objektgestalt zu einer Grundform. Ihre Werke waren von Constantin Brancusi, Henri Laurens und Hans Arp zum einen und der antiken Skulptur zum anderen geprägt. Hartung wie Schrieber zielten mit ihren Arbeiten darauf ab, das zeitlose Wesen der sie umgebenden Gegenstände zum Ausdruck zu bringen. Dass Hartung im

185 Universität der Künste Berlin, Universitätsarchiv, 16 || 2515 (Studentenakte Günter Grass), Transkription: V. K., mit Dank an Dieter Stolz für Hinweise und Korrekturen.

186 Vgl. Hartung (1998), S. 22 f. Hanne Hartung berichtet insbesondere, ihr Vater habe häufig erzählt, wie Aale in seiner Jugend mit Hilfe eines abgeschlagenen Pferdekopfes gefangen wurden.

${ }^{187}$ Vgl. Fischer-Defoy (2001), S. 102.

188 Grass in einem Gespräch mit Christine Fischer-Defoy am 22.11.1989, Fischer-Defoy (1992), S. I-3: „Und von Schrieber weiß ich auch aus der Düsseldorfer Zeit, daß er bis zur Schlägerei sich mit Leuten in Düsseldorf auseinandergesetzt hat, die ihm das Malverbot damals verhängt hatten und die im ,Malkasten', der Künstlervereinigung in Düsseldorf, Ende der Vierzigerjahre schon wieder eine Funktion hatten."

${ }^{189}$ Vgl. Domscheit (1985), S. 37.

190 Die Angaben zum Werk bzw. zur Entwicklung der CEuvres von Hartung und Schrieber können sich lediglich auf jeweils eine monografische Untersuchung stützen. Zu beiden Künstlern wurden über diese Standardwerke hinaus abbildungsreiche Kataloge sowie Ausstellungsrezensionen veröffentlicht. Vgl. also hier und im Folgenden zu Schrieber: Domscheit (1985) und zu Hartung: Krause (1998). Beide Veröffentlichungen enthalten Werkverzeichnisse. 
Folgenden überwiegend biomorphe Plastiken schuf, also ungegenständliche, aber aus einzelnen Erscheinungselementen organischen Lebens konstruierte Formen herstellte, während Schrieber sich kontinuierlich der Darstellung des weiblichen Körpers widmete, hebt diese Gemeinsamkeit nicht auf. In beiden Ateliers standen das Handwerk, das "genaue Hingucken“ und die sorgfältige Umsetzung des Gesehenen im Vordergrund. ${ }^{191}$ Die Betonung der Naturbetrachtung ist für die Charakterisierung der Lehre dieser Künstler im Zusammenhang mit ihrem Schüler Günter Grass besonders wichtig. Könnte man sie anderenfalls für selbstverständlich erachten, muss sie an dieser Stelle ganz besonders hervorgehoben werden, weil Grass das bildkünstlerisch geschulte Sehen als grundlegenden Teil seiner Ausbildung bei Hartung betonte und, wie im Detail noch erörtert werden wird, in seiner Literatur thematisierte. ${ }^{192}$

Es verwundert in diesem Sinne wenig, dass Grass Hartung nicht als einen gegenstandslos arbeitenden Künstler wahrnahm. ${ }^{193}$ Wie er 1985 in einem Interview darlegte, wären beide Bildhauer für ihn als Lehrer in Frage gekommen. Hartung sei auch deshalb seine erste Wahl gewesen, weil ein Studium bei Schrieber die Einschreibung für das Lehramt voraussetzte, wozu Grass sowohl das Abitur als auch die Berufung fehlten. ${ }^{194}$

Einige Monate nach der Ankunft in Berlin, der Studentenakte zufolge am 26. März 1953, wurde Grass an der HfBK einer mündlichen Prüfung unterzogen, an welcher neben Hartung mitunter Karl Hofer und der Bildhauer Alexander Gonda teilnahmen. ${ }^{195}$ Da Grass' Bewerbungsmappe auch Gedichte enthalten hatte, driftete das von ihm als nicht sehr streng erinnerte Gespräch in den literarischen Bereich ab (X 567 f.). Während dem handschriftlich notierten Prüfungsentscheid gemäß Trakls Verhältnis zu Hölderlin im Zentrum der Diskussion stand, ${ }^{196}$ erinnerte sich Grass, vor allem über Rilke gesprochen zu haben (X 568). Ob dem angehenden Dichter und Bildhauer durch seine frühen Texte ein „Bonus“ zugekommen ist, wie er selbst in Erwägung zog (X 568), sei dahingestellt. Sicher ist, dass Hartung seinen Schüler von Beginn an auch als Lyriker sah - ein Eindruck, der sich im Folgenden nur weiter verstärkt haben kann. Schließlich soll Hartung Grass' Gedichte später Gottfried Benn, mit dem er bekannt war, zur Begutachtung vorgelegt haben. Als er seinen Schüler nach Hofers Tod 1955 bei einem Streit mit dem neugewählten Akademiedirektor Karl

\footnotetext{
191 Vgl. Domscheit (1985), S. 38. Schriebers Studierende erinnerten sich genauso wie Grass in Bezug auf Hartung besonders an dessen Weisung, das darzustellende Objekt genau zu betrachten.

192 Siehe insbesondere Grass' Nachruf auf Karl Hartung: „Genau hingucken“. Zum Tod des Bildhauers Karl Hartung. In: DIE ZEIT, 4.8.1967. (X 291-293); auf die bedeutende Rolle der Naturbeobachtung für den bildenden Künstler Grass wies im Zusammenhang mit Hartung bereits hin: Joch (1997), S. 16.

193 Grass in einem Gespräch mit Christine Fischer-Defoy am 22.11.1989, Fischer-Defoy (1992), S. I-3: „,Natur - und doch bewußt' das war sein stehender Satz, das heißt: kein Naturalismus, sondern von der Natur ausgehend, wissend, auch dort, wo er gegenstandslos wurde, hatte er im Grunde immer Naturformen, pflanzliche Formen als Vorbilder, er kam von der Natur her und war sich auch bewußt, daß wir als Menschen gar nicht in der Lage sind, Formen zu erfinden, die die Natur überbieten können."

194 Ebd.: „Ich muß es etwas relativieren: Ich wäre wahrscheinlich auch zu einem anderen Mann gegangen, der mich an die HfBK dann bei Hartung empfohlen hat, Ludwig Gabriel Schrieber, aber der war in der Grunewaldstraße, ich hatte kein Abitur, hatte auch nicht vor, es nachzumachen, und wollte auf gar keinen Fall Zeichenlehrer werden. Und dem war eine Grenze gesetzt. Aber im gewissen Sinne ist trotzdem neben Hartung auch Schrieber mein Lehrer gewesen."

195 Universität der Künste Berlin, Universitätsarchiv, 16 II 2515 (Studentenakte Günter Grass). 196 Ebd.
} 
Otto verteidigte, habe er argumentiert, der junge Mann sei ernst zu nehmen, weil er "seine Sachen" mache und „wunderbare Gedichte" schreibe. ${ }^{197}$

In der Tat hatte Grass sich während seiner gesamten Berliner Studienzeit weiterhin gleichermaßen als Bildhauer, Grafiker und Dichter betätigt. Die im Werkstattbericht ab 1954 dokumentierten Gipsmodelle, Stein- und Bronzegüsse zeigen kleinformatige Tierfiguren: verschiedene Vögel und einen Butt; in einer Ausstellungsbesprechung ist von einem Krebs die Rede. ${ }^{198}$ Zeichnend widmete sich Grass denselben Motiven, vereinzelt auch dem Mehrfigurenbild sowie mythologischen Stoffen und zeigte dabei wie schon in Düsseldorf eine Vorliebe für Stilelemente des Kubismus. Im Gegensatz zu den Plastiken weisen einige der Grafiken ab 1954 einen Einschlag ins Fantastische auf und führen damit eine zweite Tendenz aus den frühen Studienjahren fort. Sie bedienen sich surrealistischer Methoden der Bildkonzeption: der "Kombinatorik“, also der Zusammenstellung "wesensfremder Elemente auf einem innen wesensfremden Plan“, 199 und ihrer Unterkategorie, der Metamorphose. ${ }^{200}$ Wie ein Blick in Grass' Arbeitstagebücher zeigt, entstanden auf literarischem Gebiet ab 1953 zunächst weiter von Trakl, Rilke, Lorca und Arp inspirierte Gedichte, ${ }^{201}$ mit antiker Mythologie unterfütterte Epen („Palinuros“) und knappe Dramenentwürfe. 1954 bis Mitte 1956 folgten bereits erste konkrete Ansätze zur Blechtrommel202 und Motiven der Alltagswelt zugewandte Gedichte, die 1956 zur ersten eigenständigen und durch den Dichter bebilderten Lyrikpublikation, Die Vorzüge der Windhühner (1956), zusammengestellt wurden. ${ }^{203}$ In seinen Zeichnungen behandelte Grass im Zuge der Arbeit an dieser Veröffentlichung ausschließlich Motive, die er später in Metaphern und Allegorien in die lyrischen Texte bringen würde oder fand in den Grafiken eine neue Form für sprachlich vorbereitete Motive: „In ganz eigener und dinglicher Weltsicht flossen Worte und Zeichen aus einer Tinte." (X 627). Nach und nach gingen auch die Erfahrung des Zweiten Weltkrieges und die Kritik an der zu Verdrängung und Dämonisierung neigenden Nachkriegsgesellschaft in seine Werke ein. ${ }^{204}$ In Opposition zur gegenstandslosen Kunst der Fünfzigerjahre entwickelte Grass seine ideologiekritische Ästhetik eines fantastischen Realismus, der an alltägliche Objekte gebunden war.

Die folgende Analyse exemplarischer, zwischen 1953 und 1956 entstandener, bildkünstlerischer und literarischer Werke von Günter Grass vollzieht den Weg zu diesem, mit der Verknüpfung von bildender Kunst und Literatur einhergehenden und mit politischer Realität angereicherten, „eigenen Ton“ der Debütveröffentlichung nach. Voraus geht ihr eine Vorstellung der CEuvres von Karl Hartung und Ludwig Gabriel Schrieber, sodass die Arbeiten ihres Schülers anschließend zu ihnen in Beziehung gesetzt werden können.

\footnotetext{
197 Grass in einem Gespräch mit Christine Fischer-Defoy am 22.11.1989: Fischer-Defoy (1992), S. I-5.

198 Vgl. Grass (2014), S. 51-57 und Walter Höllerer (CK): „Das Knochengerüst der Dinge“, erschienen in der Frankfurter Allgemeinen Zeitung, 21. November 1955.

${ }^{199}$ Vgl. Max Ernst: Was ist Surrealismus (1934) zitiert nach Barck (1986), S. 611.

200 Vgl. Schneede (2006), S. 141-145.

${ }^{201}$ Vgl. Frizen (2010), S. 16-18.

202 Der erste Eintrag, der ganz explizit spätere Textpassagen des Debütromans vorarbeitet, ist im Arbeitstagebuch Nr. 1755 mit der Datierung 27.8.1954 zu finden.

${ }^{203}$ Archiv der Akademie der Künste, Grass-Archiv, Tagebücher Nr. 1753-1755.

${ }^{204}$ Vgl. Neumann (1994).
} 


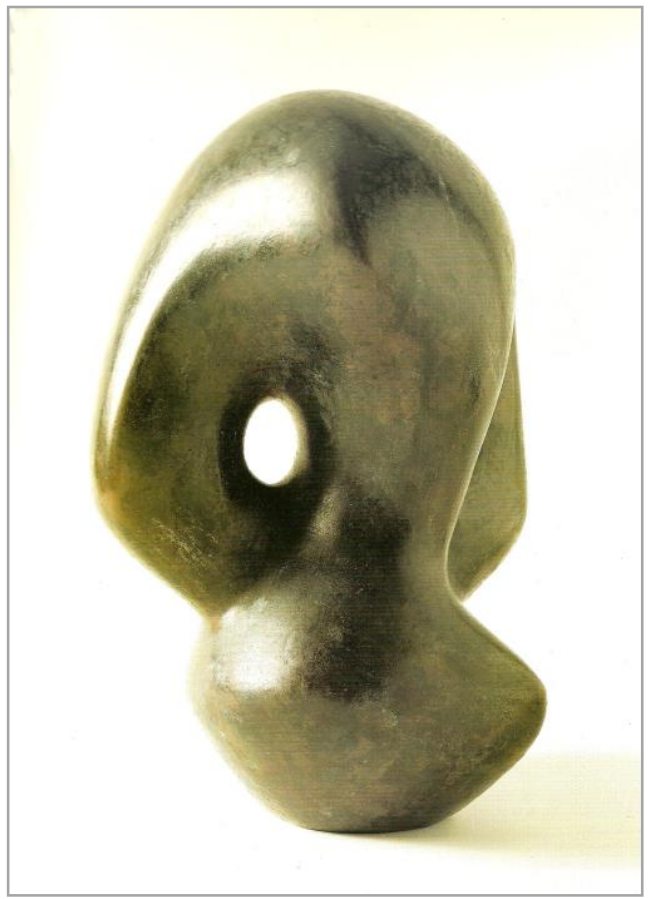

Abb. 30, Karl Hartung, Durchlöcherte Form (Abstrakte Form), 1935, Bronze

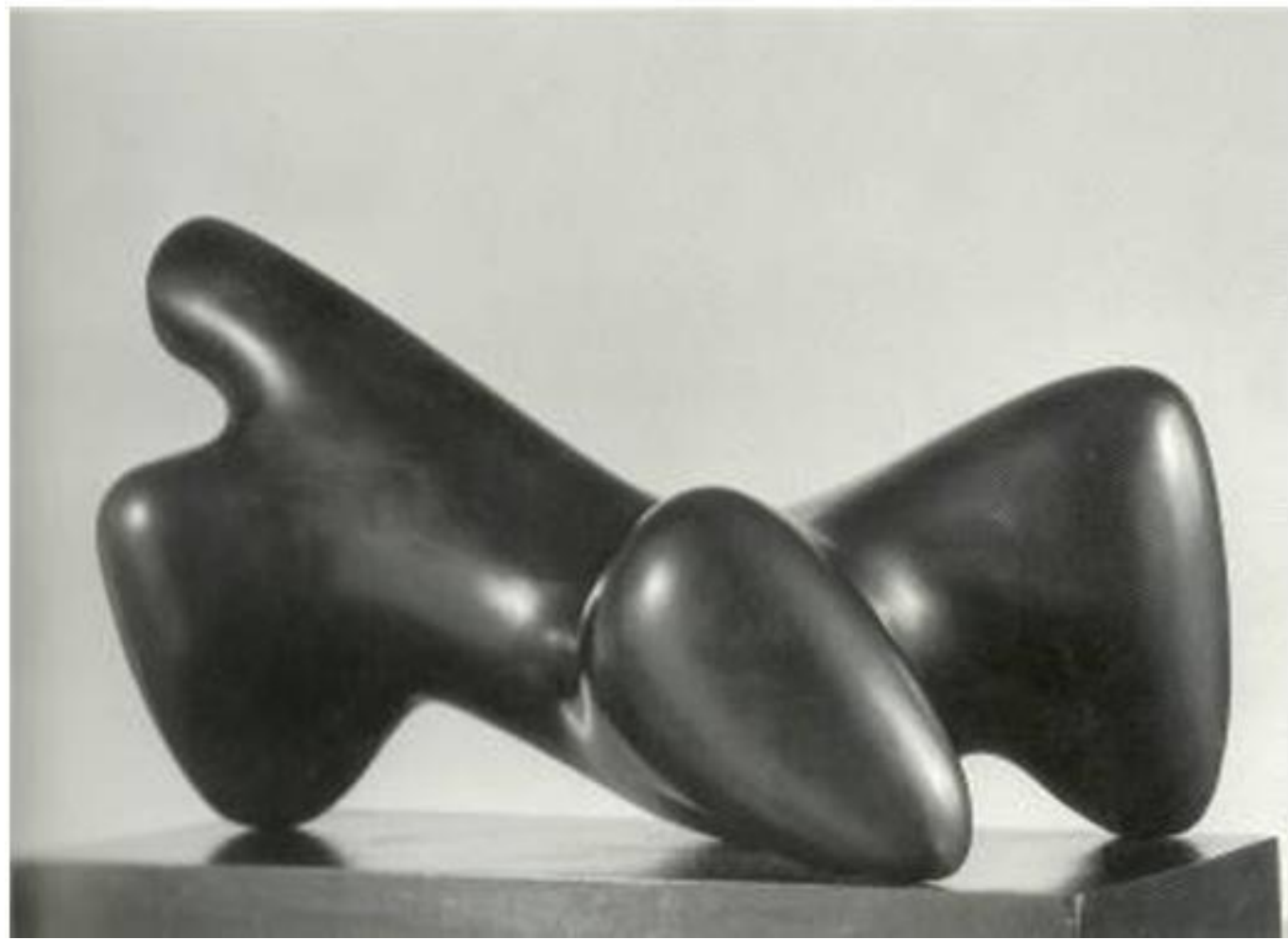

Abb. 31, Karl Hartung, Liegender, 1935/1938, Bronze 


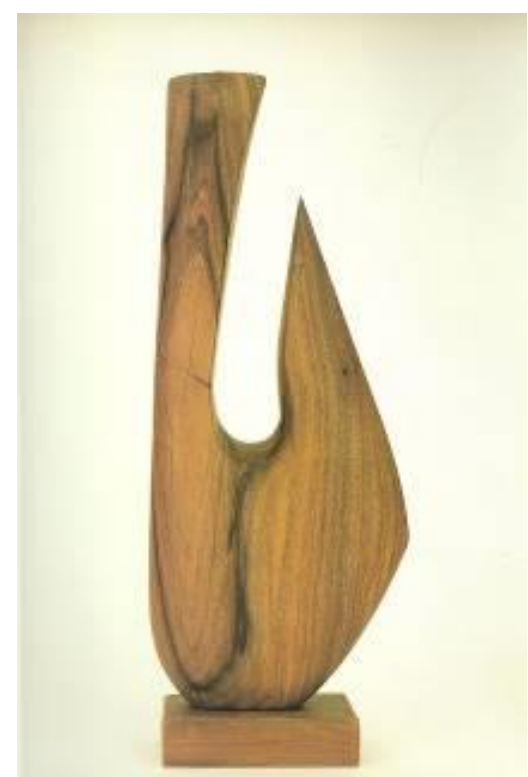

Abb. 32, Karl Hartung, Vegetative

Form, um 1939, Makassar-Ebenholz

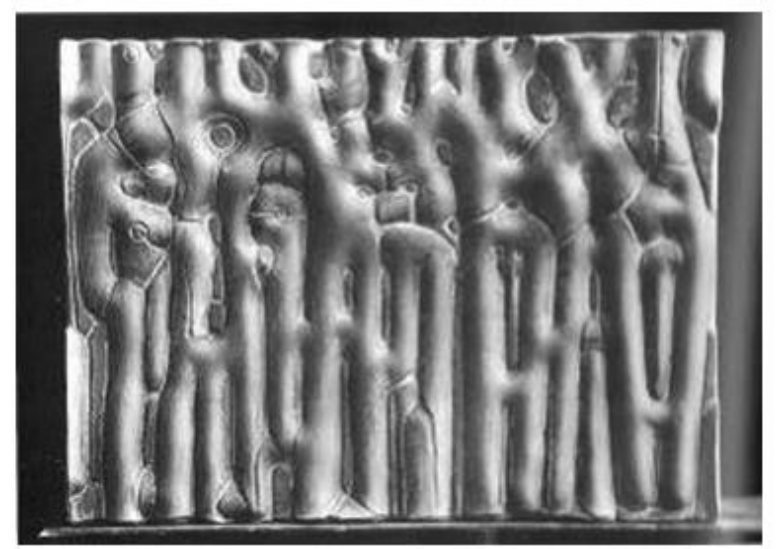

Abb. 33, Karl Hartung, Figurenwand I, 1953, Terrakotta

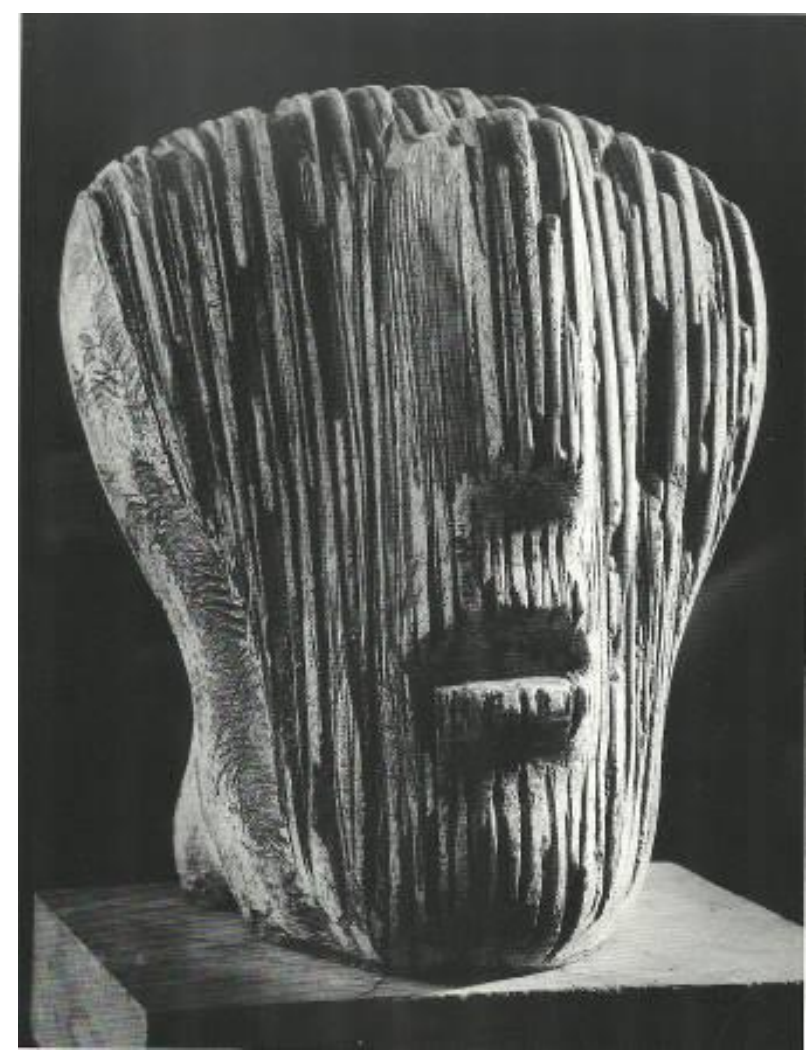

Abb. 34, Karl Hartung, Neese II, 1957, Gips/Bronze 


\section{Karl Hartung und Ludwig Gabriel Schrieber}

Karl Hartung (1908-1967) kam nach 1945 sowohl als Künstler als auch als kulturpolitischem Akteur eine vermittelnde Rolle zwischen den Standpunkten der Gegenständlichkeit und Gegenstandslosigkeit zu. Wie viele Bildhauer seiner Generation stand er zunächst unter dem Einfluss Auguste Rodins und Wilhelm Lehmbrucks und wandte sich während seines ersten ParisAufenthalts 1929 bis 1931 den Aktdarstellungen Aristide Maillols zu, die eine klarere Kompositionsstruktur und eine abstrahierende, glatte Ausarbeitung der einzelnen Körpervolumina aufweisen. Ein Aufenthalt in Florenz 1932 brachte Hartung unter anderem mit etruskischen Skulpturen in Berührung, die ihn dazu inspirierten, seine Figuren stärker zu einzelnen Grundformen zu verdichten. 1935 entstand die für Hartungs weiteres Schaffen wegweisende gegenstandslose Plastik Durchlöcherte Form (Abstrakte Form) (Abb. 30). ${ }^{205}$ Ihre Gestalt ahmt die Volumenbildung und Oberflächenspannung organischer Formen, deren Ausbuchtungen und Öffnungen, deren unregelmäßige, insgesamt aber harmonische Plastizität nach, ist jedoch nicht als Repräsentation eines bestimmten Objektes erkennbar. Zu dieser im Deutschland der dreißiger Jahre noch seltenen ästhetischen Position hatten Hartung mit großer Wahrscheinlichkeit Werke von Hans Arp und insbesondere Plastiken von Henry Moore angeregt, wie Markus Krause aufgrund der formalen Ähnlichkeit der Arbeiten annimmt. Einzelne Werke von Moore waren bereits Anfang der dreißiger Jahre in Hamburg, etwas später auch in Berlin zu sehen. Zudem ist die erste, von Herbert Read verfasste Moore-Biografie bereits 1934 veröffentlicht worden und war Hartung zugänglich. ${ }^{206}$ Vorbereitet wurde sein Weg in die Abstraktion durch Constantin Brancusis Plastiken, die er 1935 vermittelt über den Hamburger Bildhauer und Maler Richard Haizmann kennengelernt hatte. ${ }^{207}$

Bereits die Durchlöcherte Form zeichnet sich durch eine auffällige Bewegtheit aus. Diese wird von Hartung auch in seinen gegenständlichen Arbeiten entwickelt. Der 1935/1938 geschaffene und lediglich $42 \mathrm{~cm}$ hohe Liegende zeigt diese Eigenschaft sehr deutlich (Abb. 31): Seine in verschiedene Richtungen ausgreifende Form erzeugt, unterstützt von der Bronzepolitur der gekrümmten Oberfläche, den Eindruck eines pulsierenden, organischen Gebildes, was gerade im Gegensatz zur ruhenden Haltung der Figur auffällt. Wichtig wurde für den Künstler, der mit Arbeiten wie dieser auch den Lehren Rudolf Steiners folgte, zugleich der Begriff der Metamorphose. Der Prozess des Werdens und Vergehens, in dem sich ein Körper stets befindet, tritt durch die Lebendigkeit der von Hartung generierten Formen hervor. Entsprechend beschrieb Grass die Wirkung der Werke seines Lehrers in einem Nachruf als „Unruhe“ (XI 291).

Einzelne Plastiken, deren Form an pflanzliche Organismen erinnert, bezeichnete Hartung als „vegetative Formen“. Mit Arbeiten wie der hier zu betrachtenden Holzplastik, die um 1939 entstanden ist, fand er einen Ausdruck für das aufstrebende Wachstum (Abb. 32). ${ }^{208} \mathrm{Zu} \mathrm{Arp,} \mathrm{aber}$ auch zu Brancusi und Laurens nahm der Bildhauer während eines zweiten mehrwöchigen Aufenthalts in Paris 1939 persönlich Kontakt auf. Sie bestärkten inn in seiner Auffassung der Plastik, die er im „Dritten Reich“ nur im Geheimen realisieren konnte. Öffentlich präsentierte der bis zum

\footnotetext{
${ }^{205} \mathrm{Vgl}$. Krause (1998), S. 15-30, S. 65-79.

${ }^{206}$ Vgl. ebd., S. 73.

${ }^{207}$ Vgl. ebd., S. 29.

${ }^{208}$ Vgl. ebd., S. 73.
} 
Ende des Krieges nur selten als Soldat eingesetzte Hartung vor allem konventionellere Aktfiguren sowie die ab 1935 entstehenden Tierplastiken: Darstellungen von Vögeln, Rindern und Pferden. ${ }^{209}$

Nach Ende des Krieges fand Hartungs erste Einzelausstellung 1946 in der Galerie Gerd Rosen statt. Von da an stieg sein Ansehen mit großer Geschwindigkeit. Nach einigen figurativen Arbeiten surrealen Charakters entstanden in schneller Abfolge pflanzliche und organische Formen, was eine Verortung des Künstlers in nur ein einziges ästhetisches Lager verhinderte. ${ }^{210}$

Während Grass' Studienzeit in Berlin fertigte Hartung zahlreiche ungegenständliche Arbeiten an, die sich intensiv mit Hohlräumen und Negativformen befassten, aber auch abstrahierende gegenständliche Plastiken, die sich dem menschlichen Körper widmeten. Zu letzteren zählen auch Figurenreliefs wie die hier abgedruckte Figurenwand I aus dem Jahr 1953 (Abb. 33). Hartung hatte darin vertikale, wulstförmige Teilelemente dicht nebeneinandergesetzt und diese auf unterschiedlichen Höhen durch gelenkartige Verknüpfungen miteinander verbunden. Die Zusammenstellung von senkrecht ausgerichteten schmalen Körpern und runden Reliefelementen lässt ebenso an menschliche Gestalten wie an eine unbestimmte organische Struktur denken.

Ab 1954/1955 schuf Hartung häufiger Aktfiguren und Büsten, riss dabei jedoch die Oberflächen der Werke auf. Bei einigen Plastiken experimentierte er mit einer nahezu grafischen Oberflächenbehandlung der dreidimensionalen Werke. ${ }^{211}$ Das Gips-Modell für eine Bronzeplastik mit dem Titel Neese II aus dem Jahr 1957 (Abb. 34) zeigt zum Beispiel einen Kopf mit einem flächigen, dreieckig geformten Gesicht, über das vertikale, unterschiedlich tiefe Furchen gezogen wurden, die an Baumrinde erinnern. Die menschliche Physiognomie ergibt sich aus den Ausbuchtungen der Plastik wie ein zufällig von der Natur aus der Oberfläche eines Baumstamms getriebenes Bild.

Ludwig Gabriel Schrieber (1907-1975) stand in derselben bildhauerischen Tradition wie Karl Hartung, nahm davon ausgehend jedoch einen anderen Pfad - seine Skulpturen wurden zusehends realistischer. Im Gegensatz zu Hartung trat Schrieber außerdem zunächst als Maler in Erscheinung: Seine künstlerische Laufbahn begann er 1924 als Student an der Kunstakademie Düsseldorf in der Klasse für Monumentalmalerei von Jan Thorn-Prikker, die nach Thorn-Prikkers Emeritierung 1926 dessen Schüler Heinrich Campendonk übernahm. Schrieber orientierte sich an dem von ihnen vertretenen und von den Malern des „Blauen Reiter“ geprägten Expressionismus. ${ }^{212} 1925$ schloss er sich wie Otto Pankok der Künstlergruppe „Junges Rheinland“ an und beteiligte sich 1929 an den Ausstellungen der „Rheinischen Sezession“. Im Nationalsozialismus wurden sein Schaffen und seine Ausstellungstätigkeit empfindlicher eingeschränkt als Hartungs: Ab 1935/1936 erhielt er keine Künstlerhilfe mehr und wurde 1940 aus der Reichskulturkammer ausgeschlossen. Im selben Jahr wurde er eingezogen und vor allem im Ausland als Kanonier eingesetzt. Ein Aufenthalt in Griechenland brachte ihn mit der antiken Plastik in Berührung und reaktivierte den bereits früher verspürten Wunsch, Bildhauer zu werden. ${ }^{213}$ Die dazu notwendigen

\footnotetext{
${ }^{209}$ Vgl. ebd., S. 65-67.

210 Vgl. ebd., S. $80 \mathrm{f}$.

${ }^{211}$ Vgl. Lichtenstern (1993), S. 23-25 und Krause (1998), S. 154-158.

212 Vgl. Domscheit (1985), S. 15.

${ }^{213}$ Vgl. ebd., S. $18 \mathrm{f}$.
} 
Kenntnisse eignete sich Schrieber im Folgenden selbst an. Um 1941, während seiner Stationierung in Finnland, schnitzte er eine erste kleinformatige Holzplastik. ${ }^{214}$

1945 geriet der Künstler in englische Kriegsgefangenschaft, weshalb er sich bis 1946 im englischen Lager Ascot aufhalten musste. Bereits während des Krieges, vor allem aber in England entstanden zahlreiche Aquarelle, die um 1950 stärker abstrahierende, an den konstruktivistischen Gemälden Piet Mondrians orientierte Züge annahmen. ${ }^{215}$

Nach Kriegsende widmete sich Schrieber neben dem Aquarell weiter der Ölmalerei und intensivierte seine Betätigung als Bildhauer. Seine Bilder waren dabei wesentlich stärker als vor dem Krieg von der kubistischen Formensprache beeinflusst. Besonders intensiv beschäftigte er sich mit den Werken von Juan Gris und Pablo Picasso. In Reaktion auf Juan Gris' Schrift „Über die Möglichkeiten der Malerei“ (1925) hatte er 1946/1947 einen kurzen Aufsatz zu „Fläche, Form und Farbe“ verfasst. ${ }^{216}$ Einzelne Gemälde nehmen, wie Annette Domscheit anhand von Skizzen aufzeigt, explizit auf Werke Picassos Bezug. So hatte Schrieber die Körperhaltung und Profilgestaltung einer Figur aus Picassos Guernica studiert und modifiziert in zwei seiner Bilder übertragen. ${ }^{217}$ Das Gemälde Europa II (Abb. 35) setzt sich ebenso wie Guernica mit jüngsten Kriegsgeschehen auseinander und weist dabei motivische Parallelen zu Picassos Werk auf.

Schriebers Plastiken standen zunächst ebenso wie Hartungs unter dem Einfluss Brancusis, den er 1952 in Paris aufsuchte. Bei allem Interesse an der Verdichtung von Volumina war inm im Gegensatz zu Hartung im Folgenden nicht daran gelegen, aus der Anschauung der Natur neue Formen zu entwickeln. Er konzentrierte sich fast durchgehend auf den weiblichen Akt, den er 1941 bis 1952 hauptsächlich in Holz, 1952 bis Ende der Fünfzigerjahre in Gips und Ton, und schließlich in Bronze, Sand- und Kalksandstein wie auch in Stuck ausführte. Von der geschlossenen, archaisch anmutenden Figur ausgehend (Abb. 36), beschäftigte er sich anschließend mit der Darstellung bewegter Körper (Abb. 37), variierte die Behandlung der Oberflächen von glatt zu rau, nahm schließlich Abstand von der Abstraktion und versetzte seine nun detailreich modellierten Figuren in Interieurs (Abb. 38). ${ }^{218}$

\footnotetext{
${ }^{214}$ Vgl. ebd., S. 20.

${ }^{215} \mathrm{Vgl}$. Ohff (1977).

${ }^{216}$ Vgl. Domscheit (1985), S. 74-76.

${ }^{217}$ Vgl. ebd., S. $81 \mathrm{f}$.

${ }^{218}$ Vgl. ebd., S. 90-97, Abdruck im Anhang: S. 282 f.
} 


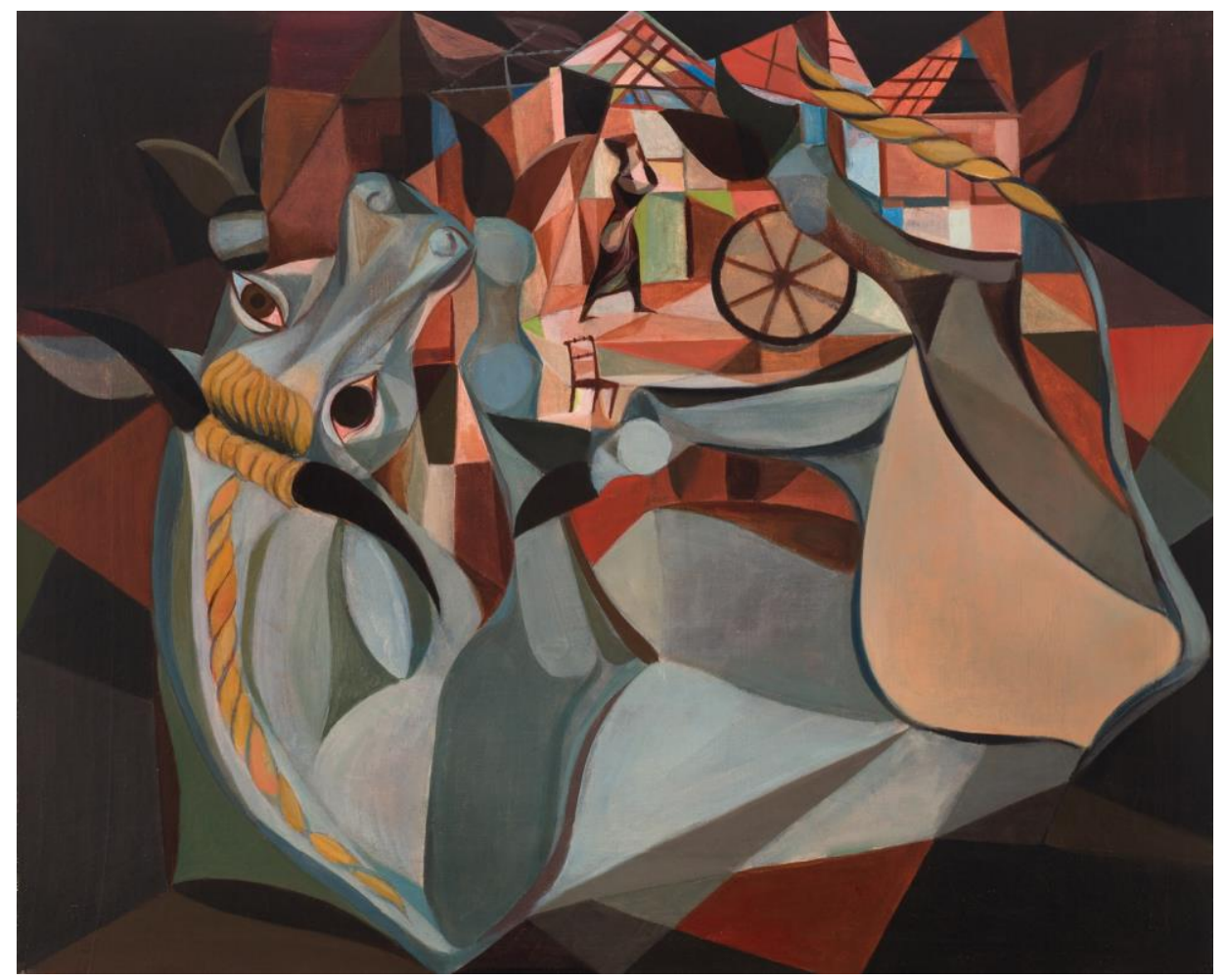

Abb. 35, Ludwig Gabriel Schrieber, Europa II, 1948, Öl auf Leinwand

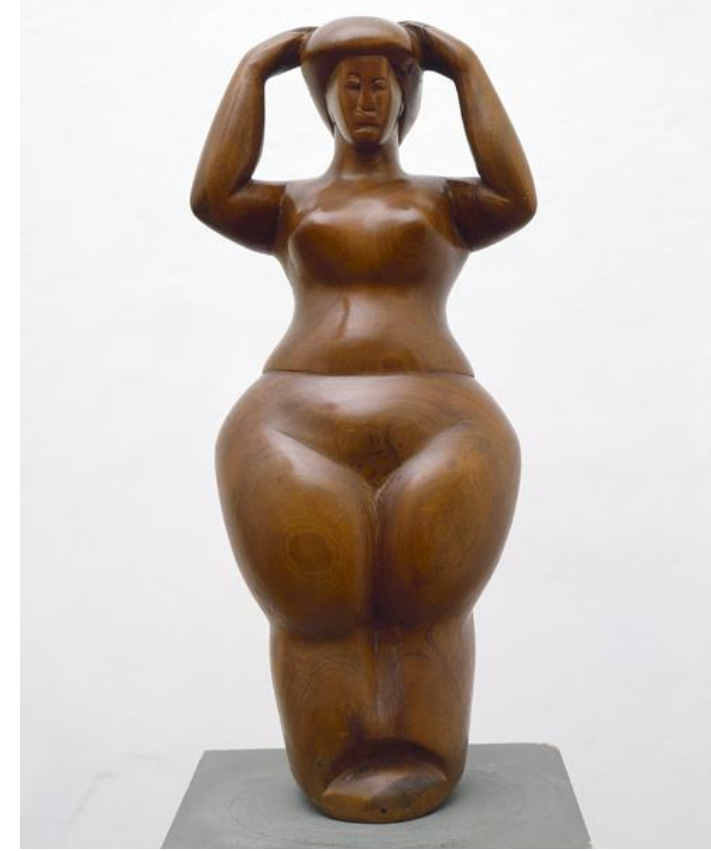

Abb. 36, Ludwig Gabriel Schrieber, Stehende mit erhobenen Armen, 1950, Nussbaum

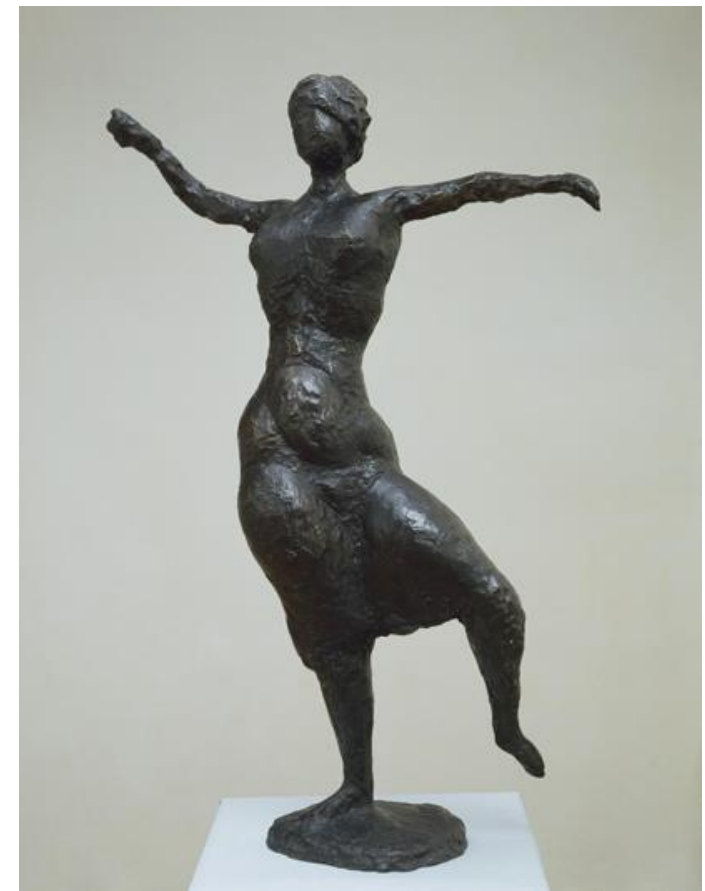

Abb. 37, Ludwig Gabriel Schrieber, Tänzerin, 1962/1963, Bronze 


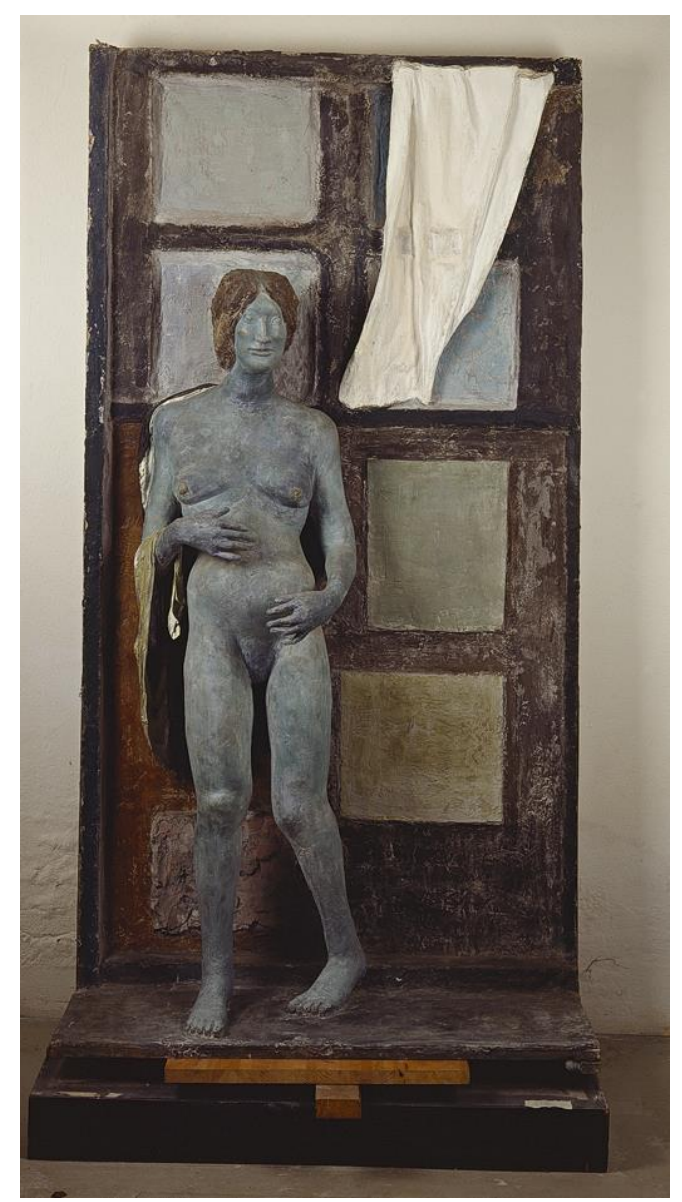

Abb. 38, Ludwig Gabriel Schrieber, Vor der Tür II, 1969, Relief, Stuck, bemalt 


\section{Grass' bildkünstlerische Arbeit an der Hochschule für Bildende Künste}

Welche Wirkung der Hochschulwechsel nach Berlin und die Konfrontation mit den Arbeiten von Hartung und Schrieber 1953 ganz unmittelbar auf Grass' bildkünstlerisches Schaffen hatten, lässt sich lediglich aus seinen Notizen und Erinnerungen rekonstruieren. Aus seinem ersten Berliner Studienjahr haben sich keine einzige Plastik und nur wenige Zeichnungen erhalten. ${ }^{219} \mathrm{Zu}$ den ersten schriftlichen Aufzeichnungen, die ein in Berlin begonnenes Arbeitstagebuch hergibt, zählt ein Gedicht, das sich den Eigenschaften der Plastik widmet:

Berlin am 7. Jan 53

Jede Kunst mache ihre Aussage.

Der Plastik doch bleibt es

vorbehalten rund, gespannt,

kurz vorm Reden doch

gerade noch stumm und voller

Geheimnis zu sein. ${ }^{220}$

Hinter dem kurzen Text könnten die biomorphen Arbeiten Hartungs stehen, die auf narrative Elemente oder traditionelle ikonografische Deutungsangebote verzichten und in diesem Sinne „stumm“ bleiben. In seinem Nachruf auf Hartung formuliert Grass entsprechend:

Langsam und gegen die leichte Hand arbeiten. Das tat Karl Hartung mit einer unnachgiebigen Strenge, die alles Anekdotische, jede erzählende Geste ausschloß und floskelhaftes Beiwerk vermied. Seine Skulpturen versagten sich die Gefälligkeit durchschimmernder Emotionen [...]. (XI 292)

Auch wenn Grass' Plastiken aus den Jahren 1954 bis 1956 wesentlich deutlicher auf ein erkennbares Objekt der wahrnehmbaren Wirklichkeiten rekurrieren als Hartungs zeitgleich entstehende Arbeiten, überschreitet auch er in diesem Medium zunächst kaum die Grenze zu einer erzählenden Form der Darstellung.

Aufschluss über das erste Berliner Arbeitsjahr gibt neben Grass' Nachruf auf Hartung eine Passage aus Beim Häuten der Zwiebel (X 566 f.). In beiden Texten beschreibt Grass die Entstehung seiner ersten Arbeiten unter Hartungs Anleitung und hebt in diesem Zusammenhang zwei wichtige Grundsätze seines Lehrers hervor: Das genaue Hinsehen sowie das von Brancusi inspirierte Anliegen, im Kunstwerk die Urform eines natürlichen Objektes herauszuarbeiten und dessen innere Struktur sichtbar zu machen. In dem 1967 veröffentlichten Nachruf schildert Grass, wie Hartung eine seiner ersten Zeichnungen kritisierte und gibt Hartungs Aufruf zur Betrachtung der Natur wieder, die allem Wildwuchs zum Trotz einer Ordnung folgt:

\footnotetext{
${ }^{219}$ Lange hat Grass weder auf den Erhalt seiner bildkünstlerischen Studienarbeiten, noch seiner Manuskripte großen Wert gelegt. Davon zeugen die erst 2013 wiedergefundenen Aquarelle, Zeichnungen und Plastiken aus der Düsseldorfer Studienzeit, die er bei seinem Umzug nach Berlin 1953 nicht mitnahm sowie der Koffer mit einem Manuskript der Blechtrommel und Zeichnungen aus den Jahren 1956 bis 1960, den Grass in Paris zurückließ und auf den erst der Germanist John Reddick 1970 im Zuge einer Recherchereise stieß. Vgl. dazu Neuhaus (2012), S. 146 und (XI 874).

${ }^{220}$ Akademie der Künste, Berlin, Günter-Grass-Archiv, Nr. 1753, ohne Paginierung, hs., Transkription: V. K. Die Zeilenumbrüche entsprechen denjenigen im handschriftlichen Text, die auch das Format des Arbeitstagebuchs vorgibt. Es ist unklar, ob Grass sie im Falle einer Veröffentlichung genauso gesetzt hätte.
} 
Meine Heringzeichnung erfuhr Kritik: „Die haben keine Gräten. Wo Sie genau hinsehen sollten, haben sie Ornamente erfunden. Ein Hering ist mehr, als Sie erfinden können. Natur - und doch bewusst." Diese vier Wörter - mehr Devise als Satz - waren das künstlerische Credo eines Arbeiters, der, überreich an Formen, Strukturen und visionären Entwürfen, der Erfinderin Natur gegenüber still wurde, hinschaute, wortkarg verzückt, als wäre er bereit gewesen, sein gesamtes Werk hinzugeben für die schöpferische Vielfalt einer Langustenschere [...]. In der Bretagne, aus verspäteter Zeitung, höre ich vom Tod meines Lehrers. Muscheln und Langustinen kaufe ich ihm zu Ehren. Genau hingucken: Dieser von allen Seiten einsehbare, langsame und genau begrenzte Ablauf: Natur - und doch bewusst. (XI 291-293)

Auch Grass' Schilderung der Entstehung seiner ersten Plastik bei Hartung in Beim Häuten der Zwiebel schließt mit demselben Credo:

Kaum angekommen, begann ich, neben einem stehenden Akt nach Modell, als freie Arbeit ein Huhn in kompakter Form anzulegen, das später mit rotbrennendem Töpferton dünnwandig in die Gipsform gedrückt und als meine erste Terrakotta gebrannt wurde [...] Nach einem seiner Korrekturgänge erzählte Hartung, sonst eher um Distanz zu seinen Schülern bemüht, von einem Besuch im Pariser Atelier des rumänischen Bildhauers Brancusi. „Als Besatzer während der Soldatenzeit“, ergänzte er korrekt. Brancusis Formsprache habe ihn beeindruckt, die "Verdichtung der Grundform". Dann wiederholte er mit Hinweis auf mein entstehendes Huhn einen seiner Standardsätze: „Natur - und doch bewußt!" (X 566 f.)

Objekte der Natur wiesen für Hartung eine vollendete innere Ordnung auf. Entsprechend legte er seinen Schülerinnen und Schülern nahe, die Gesetzmäßigkeiten der ihnen als Modell dienenden Gegenstände aufzuspüren. Ob Grass diesen Ratschlag 1953 sofort umsetzte, lässt sich aus obengenannten Gründen nicht überprüfen. Die erste erhaltene Berliner Plastik, ein Steinguss aus dem Jahr 1954, der einen Hahn darstellt, belegt allerdings die Gelehrigkeit des Schülers (Abb. 39). Zugleich werden im Vergleich mit einer Vogelfigur Hartungs die Unterschiede in der Formauffassung der beiden Bildhauer deutlich (Abb. 40):

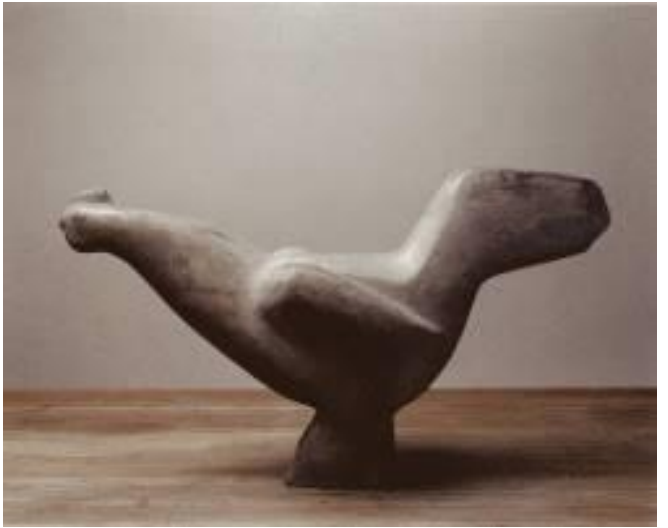

Abb. 39, Hahn, 1954, Steinguss

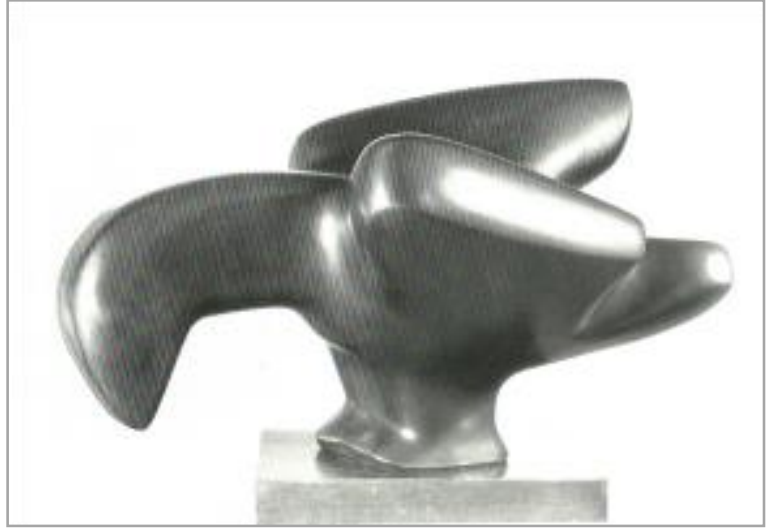

Abb. 40, Karl Hartung, Vogel, um 1937, Bronze

Grass stellt das Tier von allen Details abstrahiert in einer Körperhaltung dar, die Aufregung signalisiert. Den Kopf hat es weit nach vorne gereckt, so dass der gestreckte Hals im Profil betrachtet ein Gegengewicht zu dem schematisch-eckig wiedergegebenen Steuergefieder bildet. Der tiefste Punkt des Kopfes befindet sich nahezu exakt auf derselben Höhe wie der tiefste Punkt des 
Schwanzes. Die im Entfalten begriffenen Flügel bilden, ebenfalls von der Seite gesehen, eine Parallele zur aufstrebenden Linie des Rumpfes, während dessen hinterer Abschluss parallel zur vorderen Linie der als Trapez geformten Krallen verläuft. Aller Unruhe zum Trotz, befindet sich die Gestalt des Hahns in vollkommenem Gleichgewicht, was der Plastik eine innere Spannung verleiht. Die Gesetzmäßigkeit des Tierkörpers wird durch die stereometrische Abstraktion betont und rückt inn dabei in die Nähe eines industriell gefertigten technischen Gebildes. Den Lehrsatz „Natur - und doch bewusst!" trifft die Figur damit im Kern und zeigt zugleich weiter die in Düsseldorf aufgenommene Prägung durch den Kubismus.

Vergleicht man Grass' frühen Hahn mit der Darstellung eines Vogels von Karl Hartung aus dem Jahr 1937, so fällt auf, dass die ältere Plastik stärker von der dreidimensionalen Form her und insbesondere von der sanften Wölbung des Volumens aus angelegt ist. Die Konstruktion des Tierkörpers zielt nicht darauf ab, eine besondere Bewegung hervorzuheben; vielmehr vermittelt die weich von der Schwanzspitze über den Vogelrücken und -schnabel herunter zu den vorne leicht angehobenen Krallen fließende Umrisslinie den Eindruck eines nicht endenden Bewegungsablaufs. Das Einfangen und Transponieren dieser Lebendigkeit in das Kunstwerk stand bei Hartungs Arbeit im Vordergrund, während Grass die markante Bewegung des Tieres der betonten Ordnung seines Körpers unterwarf.

Weitere Hennen und Hähne, die Grass 1955 und 1956 schuf, zeigen gemeinsam mit entsprechenden Zeichnungen eine kubisch-sezierende Aufteilung der Körper in einzelne Volumina. Ein Huhn wie das hier abgedruckte aus dem Jahr 1955 (Abb. 41) präsentiert sich aus rückwärtiger Perspektive auf andere Art als verdichtete Form - weniger als eine Vereinfachung der gesamten Gestalt als vielmehr als Analyse und stereometrische Abstraktion einzelner Körpervolumina, wie sie sich bereits in Grass' Zeichnungen, Aquarellen und Plastiken aus den Düsseldorfer Jahren ankündigten.
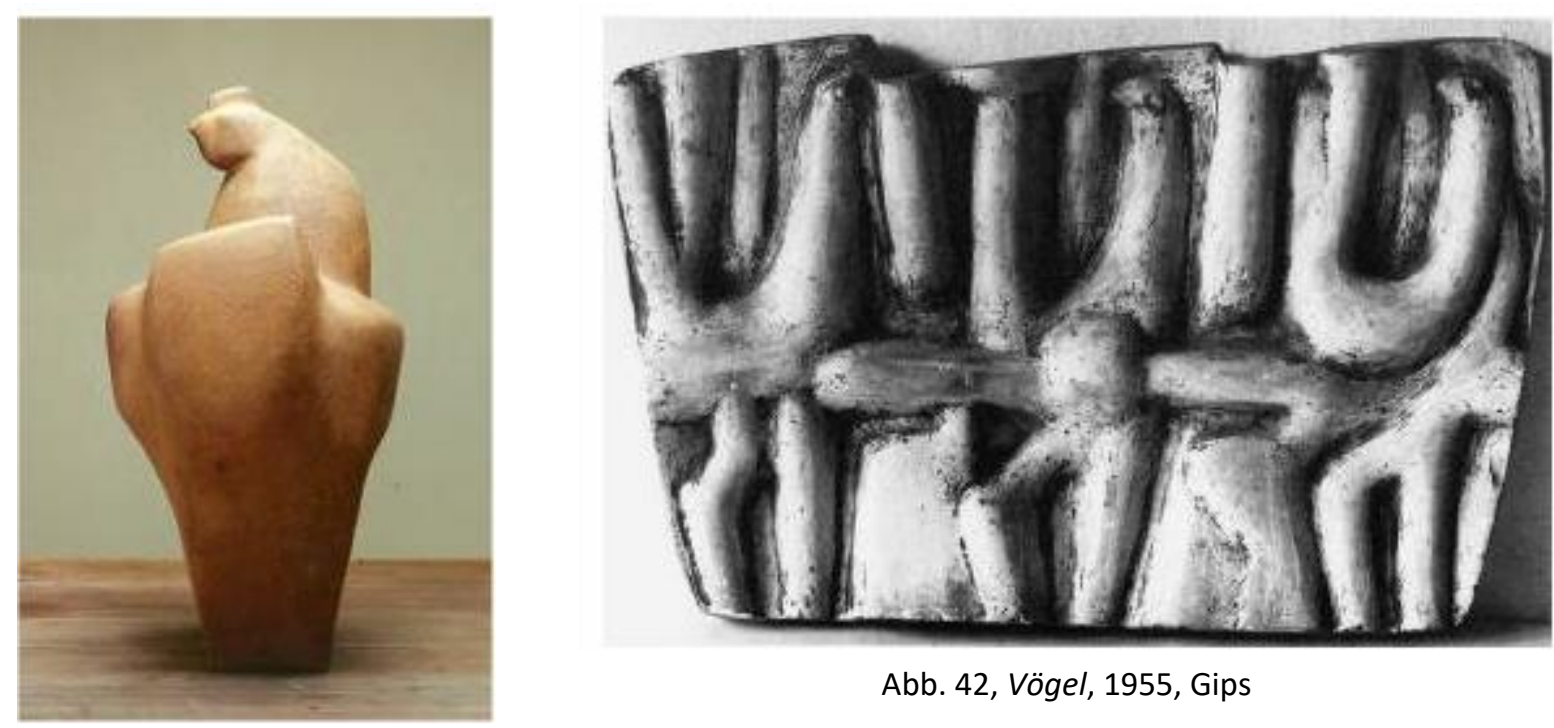

Abb. 42, Vögel, 1955, Gips

Abb. 41, Huhn, 1955, Terrakotta 
Eine Reihung einander ähnlicher Vogelkörper innerhalb einer Arbeit nahm Grass in einem Gipsrelief vor (Abb. 42), das in seiner dichten Zusammenstellung schmaler Tierfiguren an Hartungs Figurenwand erinnert (S. 59, Abb., 33). Hartungs Serie von Arbeiten, zu welchen die hier abgedruckte gehört, müssen Grass besonders aufgefallen sein, hatte er sie doch im Nachruf auf seinen Lehrer explizit erwähnt. ${ }^{221}$ Deutlicher als in Hartungs Relief ist in der Plastik des Studenten die Silhouette von Objekten, von Vogelkörpern erkennbar, zwischen welchen vertikale Formen als weitere im Hintergrund angedeutete Vögel verstanden werden können. Eine horizontale Wulst durchzieht das Relief auf halber Höhe und verbindet die Tiere miteinander. Das Element der Serie hatte Grass von da an immer wieder in seinem bildkünstlerischen Werk aufgegriffen.

Eine weitere frühe Plastik weist eine Nähe zu Hartungs Schaffen auf: Der ebenfalls 1955 entstandene Butt zeigt Grass' Auseinandersetzung mit Negativformen, die auch viele Arbeiten Hartungs aus den Fünfzigerjahren kennzeichnen (Abb. 43). Bei seiner Darstellung ließ Grass Hohlräume zwischen der Wirbelsäule und dem mit Flossen abschließenden Rand des scheibenförmigen Fischkörpers entstehen. Das Tier bietet sich auf diese Weise sowohl als unversehrtes als auch als bereits ausgenommenes Lebewesen dar und enthält damit ein zeitliches Moment, das von Grass Jahrzehnte später in seiner Literatur eingesetzt wurde. ${ }^{222}$

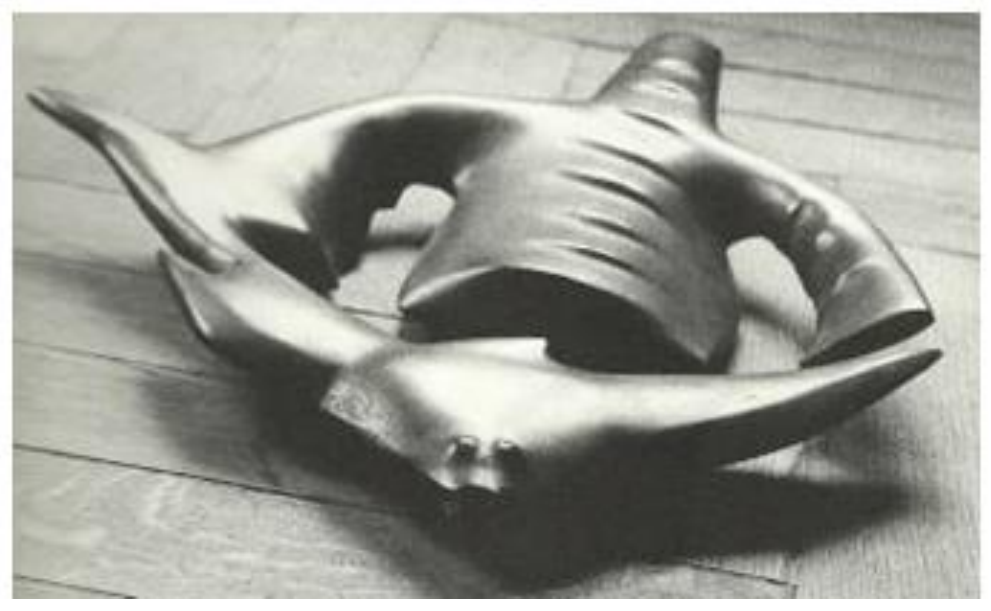

Abb. 43, Butt, 1955, Bronze

Grundsätzlich hat Grass sich, nachdem in Düsseldorf vorrangig Darstellungen von Menschen von seiner Hand entstanden waren, in Berlin dem Tierbildnis zugewandt, weil es für ihn in seiner Vielfalt an verschiedenen Spezies variantenreicher war als die menschliche Figur. Vor allem habe die Fokussierung auf das Tier aber seiner Ablehnung eines anthropozentrischen Weltbildes entsprochen. ${ }^{223}$

\footnotetext{
${ }^{221}$ Vgl. XI 292: „Seine französische Schule und sein Mißtrauen dem Ornament gegenüber hinderten ihn, symbolträchtig zu werden; und sobald ihm seine eigenen Arbeiten fremd wurden, ihn als Symbole seines organischen Zeitmaßes überragten, zeichnete er sich davon: Ab Mitte der fünfziger Jahre entstanden großformatige Blätter, die von Figurinen-Gespinsten und skeletthaften Verknotungen überzogen waren; das Heckenbild als Vorform des späteren Großreliefs."

${ }^{222} \mathrm{Vgl}$. Kapitel V.3. dieser Arbeit.

${ }^{223}$ Grass im Gespräch mit der Verfasserin am 5.12.2011: Krason (2011): [Antwort auf die Frage nach dem Charakter der Faszination für das Tiermotiv] „Vielleicht ist es bei mir eine grundsätzliche Einstellung zum Kreatürlichen - dass für mich die Tiere nicht nur gleichberechtigt neben dem Menschen stehen, dass ich
} 
Auch wenn die Sammlung der Günter und Ute Grass Stiftung zahlreiche Skizzen des Studenten aus Berliner Zoos aufweist, die sein Interesse an exotischen und mit einer bestimmten Ikonografie verknüpfbaren Tieren belegen, ${ }^{224}$ wählte er als Bildhauer ausschließlich in jedermanns Alltag präsente Wesen zum Sujet. Diese Darstellungen bieten den Betrachtenden seltener Wege in traditionelle Deutungslabyrinthe und ermöglichen ihnen stattdessen unmittelbare Zugänge über ihre eigene Lebenswelt.

Während die Gestaltung der Grass'schen Plastiken in ihrer Konzentration aufs Tierbild und in ihrer Sensibilität für formale Gesetzmäßigkeiten des natürlichen Objekts auf die Lehre Hartungs zurückgeführt werden kann, könnten die kantenreicheren kubischen Abstraktionen der Plastiken von 1955/1956 durch den Austausch mit Ludwig Gabriel Schrieber unterstützt worden sein. Da Grass, wie insbesondere die Lektüre von Beim Häuten der Zwiebel verdeutlicht, die Verehrung für zahlreiche Maler und Bildhauer mit Schrieber teilte, ${ }^{225}$ ist es nicht abwegig, auch in dessen jahrzehntelanger Beschäftigung mit der Malerei des Kubismus eine Inspirationsquelle für Grass' intensivierte Annäherung an diese Stilrichtung zu vermuten. Da sie vorrangig in der Malerei des Lehrers zum Ausdruck kam, ist von einer unmittelbaren Prägung der Grass'schen Plastiken durch selbige nicht auszugehen. Grass' zwischen 1953 und 1956 entstandenen Studienarbeiten weisen zumindest keine Ähnlichkeiten mit Schriebers Plastiken aus dieser Zeit auf, vielleicht auch aufgrund seines damals geringen Interesses für die menschliche Figur. Ein später Nachhall der zu archaischen Grundformen abstrahierten Frauengestalten Schriebers zeigte sich in Grass' Arbeiten erst sehr spät, in den Achtzigerjahren, als er die Bildhauerei nach einer jahrzehntelangen Pause wiederaufnahm. ${ }^{226}$

Früh fand er hingegen ein besonderes Gefallen an den Aquarellen des befreundeten Lehrers, denn er eiferte innen, was die Abstraktion von Bildelementen zu geometrischen Formen anbetrifft, im Jahr 1955 nach. ${ }^{227}$ Wie ein Vergleich seines Aquarells Bergsee aus dem Jahr 1955 (Abb. 44) mit Schriebers Aquarell Kleiner Kirschbaum von 1953 zeigt (Abb. 45), stellte Grass seine Landschaft im Gegensatz zu Schrieber jedoch nicht, wie vormals in Düsseldorf, als eine den ganzen Bildraum überziehende Farbfeldstruktur dar. Einzelne Elemente erinnern aller Abstraktion zum Trotz deutlich an Wiesen, Berge und Wolken, können also als Ausdruck seiner Suche nach wesensgemäßen Grundformen von Objekten verstanden werden.

den Menschen als Krone der Schöpfung nicht nur belächelt, sondern kritisiert habe, darin eine Anmaßung ohne gleichen gesehen habe. Das führte dazu. Und vielleicht auch, weil in Düsseldorf der Akademiebetrieb - und das setzte sich ja auch gewissermaßen, aber nicht so stark, in Berlin fort - sehr stark konzentriert war auf die menschliche Proportion und Figur und das Aktzeichnen. Für mich war das also auch ein Befreiungsakt, um aus diesen akademischen Zwängen herauszukommen, also das als Nebenmotiv."

${ }^{224}$ Die sechsundvierzig Tier-Skizzen aus diesem Konvolut sind nur vereinzelt, zwischen 1954 und 1957, datiert. Die Blätter zeigen neben verschiedenen, mitunter exotischen Vogelarten auch Löwen, Kamele, Eidechsen und Windhunde und ein Reh.

225 Im Erinnerungsbuch imaginiert sich der Erzähler mit den Malern Macke und Morgner um einen Tisch (X 488), ebenso mit dem Naumburger Meister (X 529 f); von einem „seit vielen Jahren anhaltenden Verhältnis zu Bildern von Mondrian" sprach Grass 1985 während einer Mitgliederversammlung der AdK: vgl. Stiftung Archiv der Akademie der Künste (1997), S. 305.

${ }^{226} \mathrm{Vgl}$. Mertens (2005), S. 61.

${ }^{227} \mathrm{Vgl}$. Grass (2014), S. 39. 


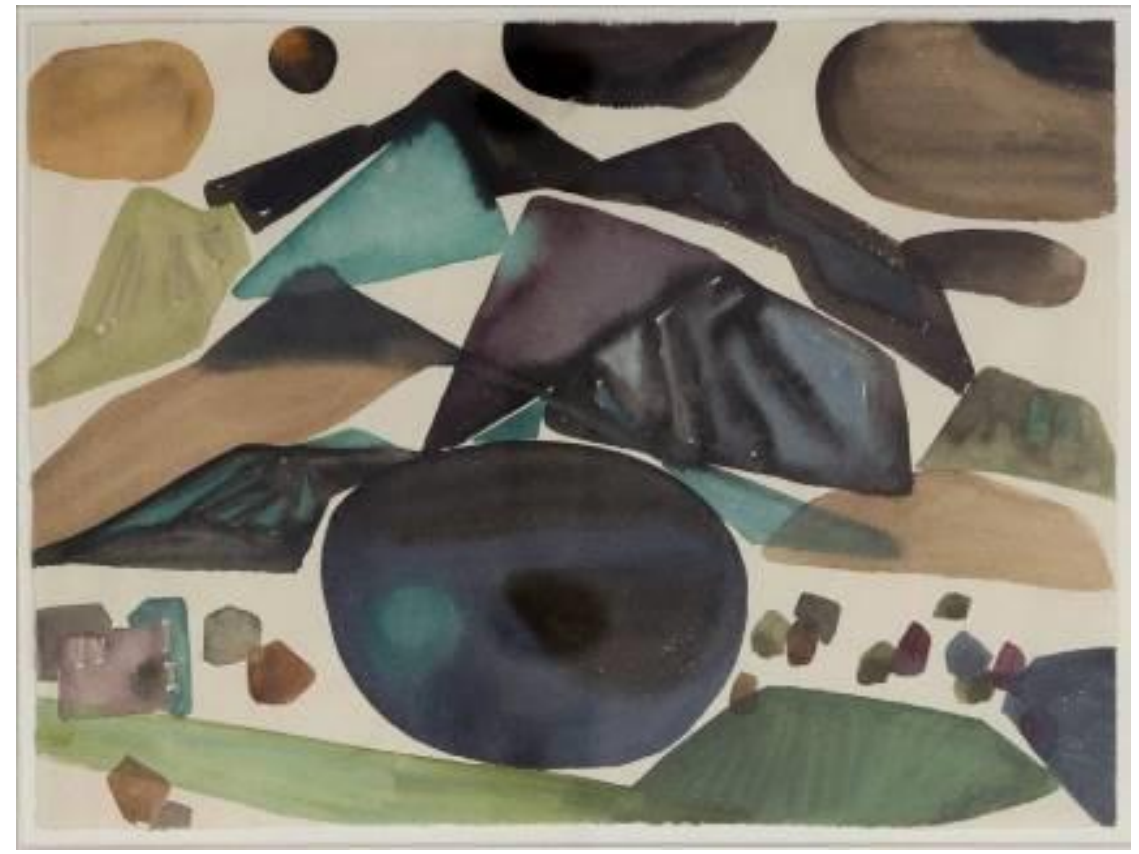

Abb. 44, Bergsee, 1954, Aquarell

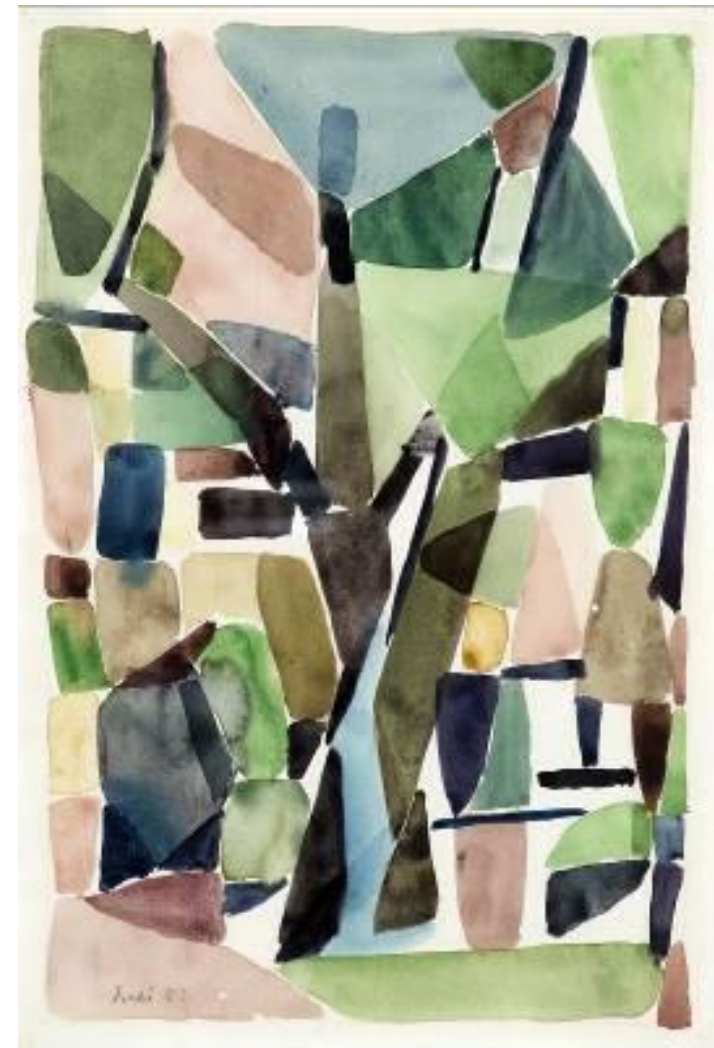

Abb. 45, Ludwig Gabriel Schrieber, Kleiner Kirschbaum, 1953, Aquarell 
1953 bis 1956 schuf Grass einige Zeichnungen und Druckgrafiken, die sich ebenso wie seine Plastiken mit der inneren Ordnung eines Objektes auseinandersetzen - oft beschäftigten ihn dabei dieselben Motive, also die bereits benannten Tierfiguren. Bei der Gestaltung griff er auf verschiedene Stilformen zurück. Am häufigsten vertreten ist eine Darstellungsweise, bei der Figuren aus Teilflächen zusammengesetzt werden, die mit verschiedenen regelmäßigen Schraffuren gefüllt sind. Diese erinnern an vegetabile Oberflächen und verleihen den Tierbildern daher einen surrealen Charakter. Zeichnungen wie der hier abgebildete Butt (Abb. 46) wirken durch die gleichmäßige Ausführung der Schraffuren wie Frottagen, die hergestellt werden, indem eine strukturierte Fläche unter das Papier gelegt und das Ornament durch den gleichmäßigen Druck des Zeichenmaterials auf den Zeichengrund sichtbar gemacht wird. Als künstlerische Ausdrucksform wurde die Frottage vor allem durch Werke Max Ernsts bekannt, der sie 1925 in Entsprechung zur écriture automatique entwickelte (Abb. 47). ${ }^{228}$ In der Plastik bediente sich Henry Moore Anfang der Fünfzigerjahre durch die Nachahmung von Blattstrukturen in Ton einer vergleichbaren Ästhetik (Abb. 48). ${ }^{229}$ In etwas schwächerem Maße als Ernsts Ausbrecher und Moores Leaf Figures erscheint Grass' Butt als surreales Mischwesen. Die schraffierten Strukturen sind in seiner Zeichnung der Gesamtgestalt des Fisches stärker untergeordnet und betonen vielmehr dessen Knochenbau in einer ornamentalen, an ein Palmenblatt erinnernden Form, die unter der transparenten Muskulatur des Tieres erkennbar ist.

\footnotetext{
${ }^{228}$ Vgl. Schneede (2006), S. 86, S. 100.

${ }^{229}$ Vgl. Lichtenstern (1993), S. 25-27.
} 


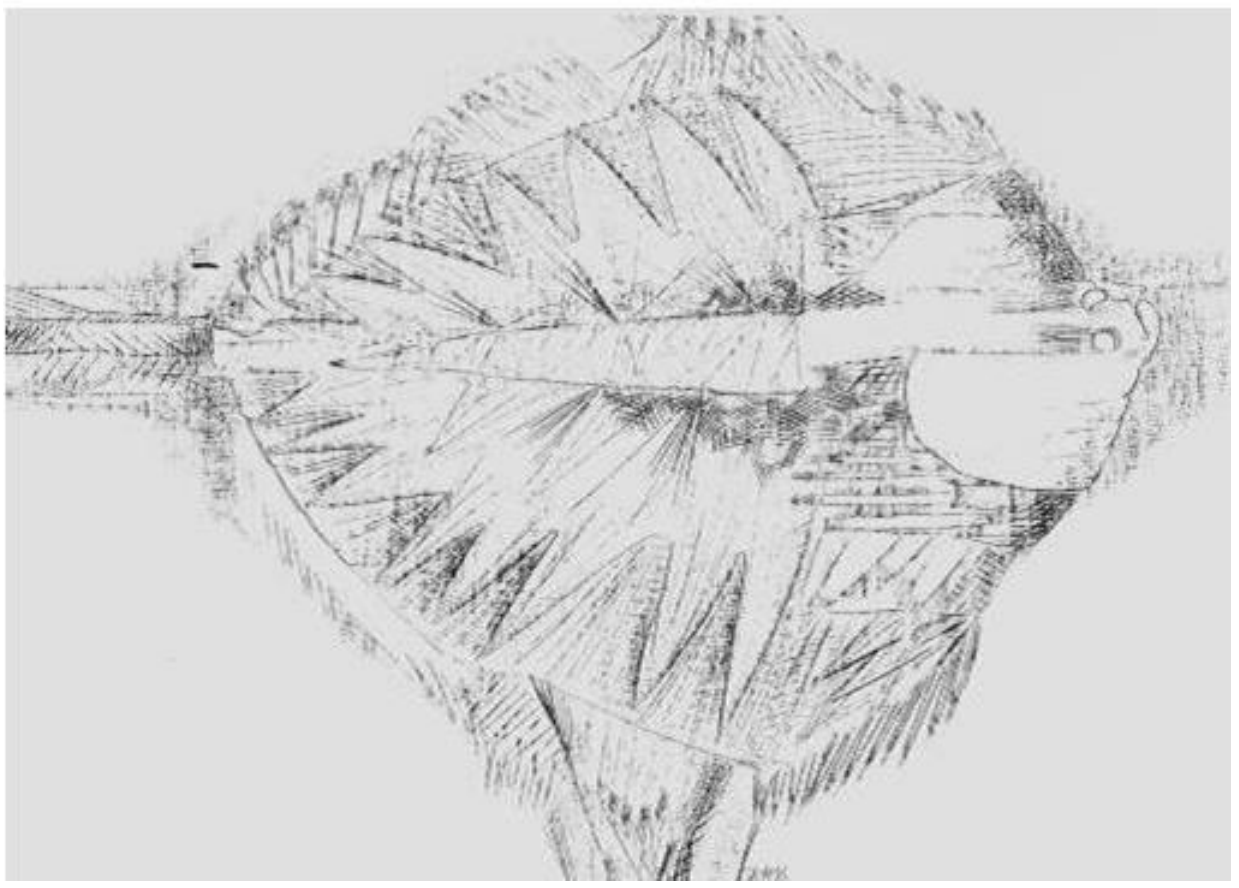

Abb. 46, Butt, 1955, Fettkohle

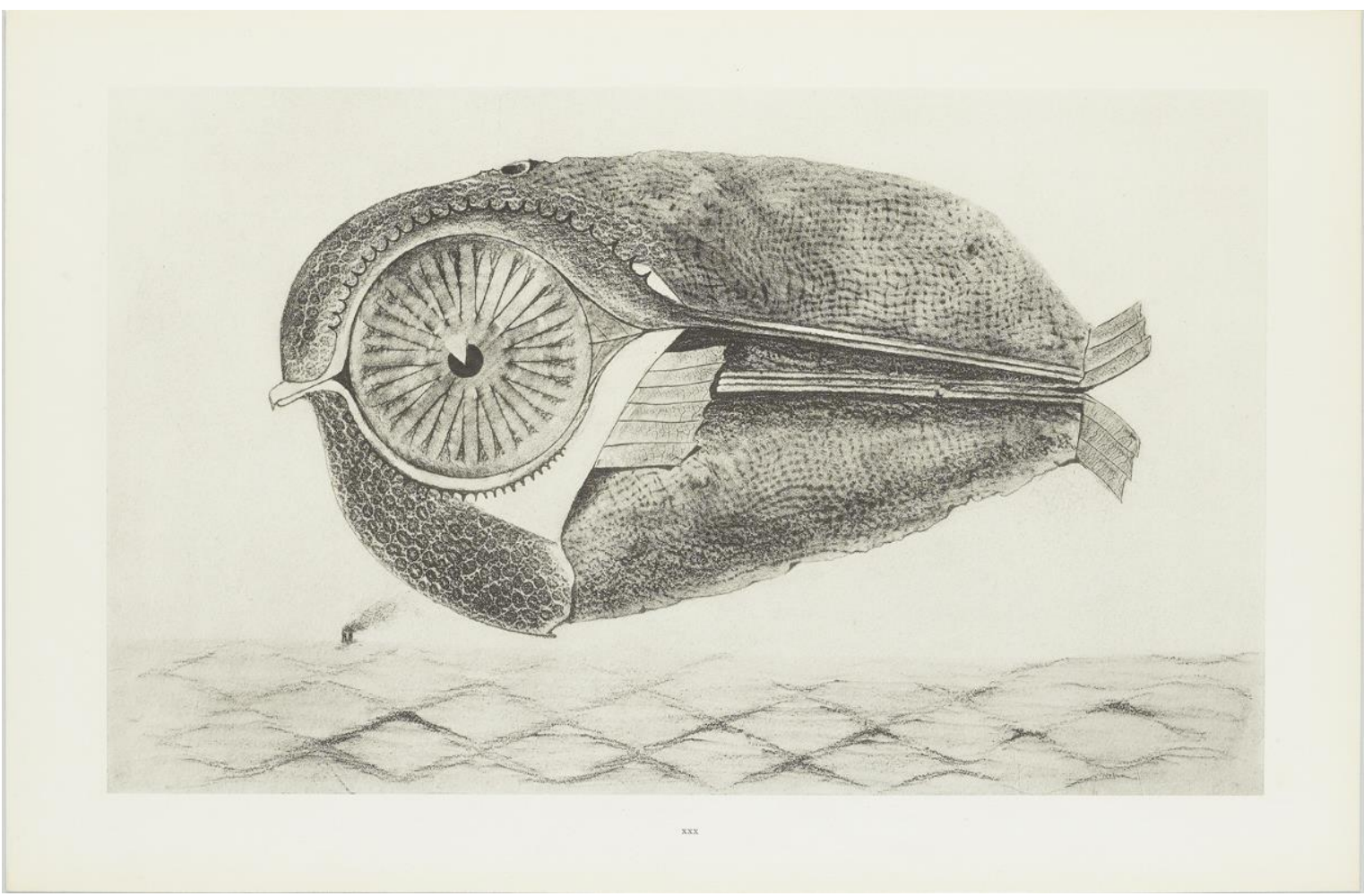

Abb. 47, Max Ernst, L'évadé (Der Ausbrecher), Blatt 30 in der Histoire Naturelle, 1926, Lichtdruck 


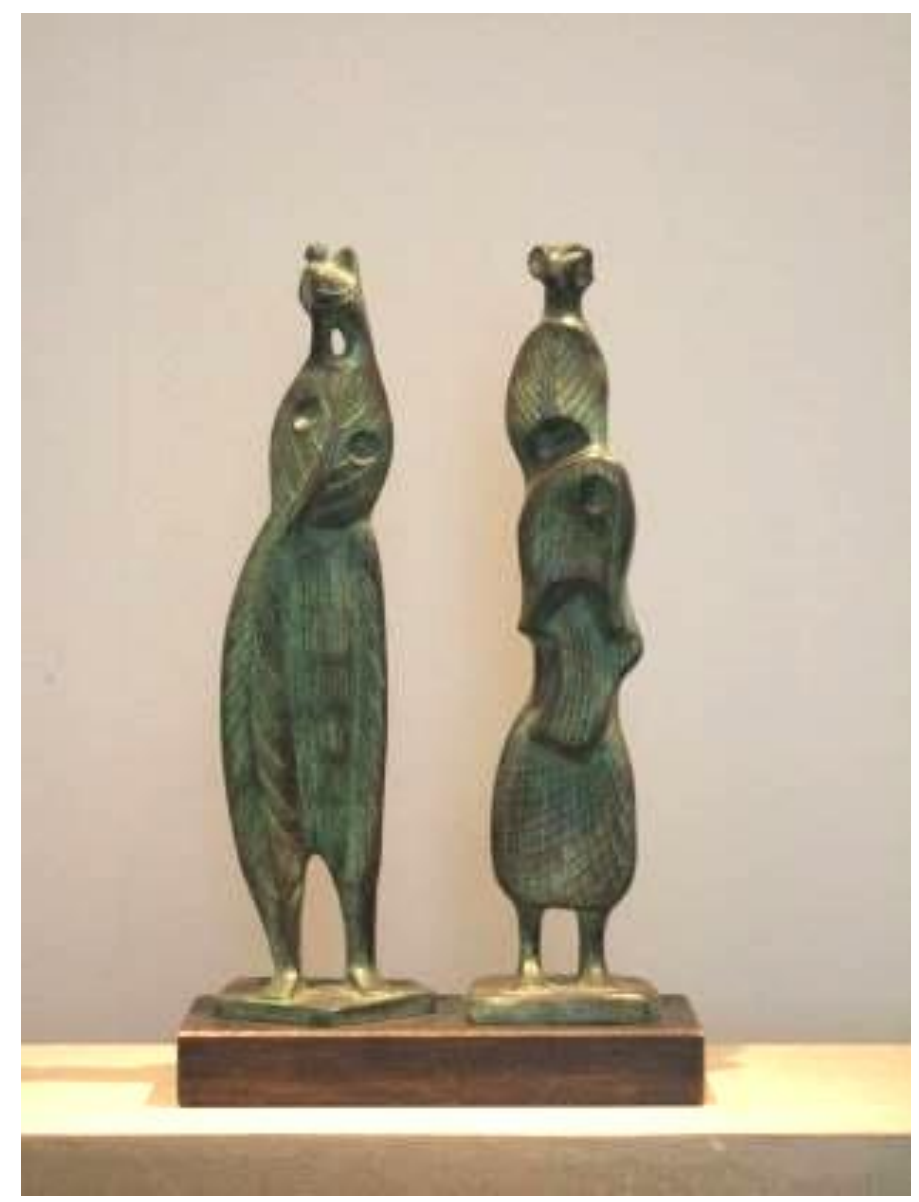

Abb. 48, Henry Moore, Leaf Figure No. 4, 1952, Bronze

Wie im Folgenden ausgeführt werden wird, schuf Grass parallel zu seinen strukturbetonten Plastiken und Grafiken Gedichte und kurze Prosatexte, bei welchen seine Aufmerksamkeit sich wie schon in Düsseldorf auf mythische Traumwelten richtete. Dazu fertigte er einzelne Skizzen und Zeichnungen, die dieselben Motive behandeln wie seine Dichtungen. Sie haben einen narrativen Charakter und weisen Parallelen zu bekannten Beispielen aus der surrealistischen Malerei auf. Die Formanalysen, die Grass mit den oben behandelten Plastiken und Zeichnungen unternahm, brachte er zur Konzeption von surrealen Objektkombinationen ein, indem er aus verschiedenen Zusammenhängen entnommene Gegenstände über Ähnlichkeiten ihrer Gestalt zueinander in Beziehung setzte. Während der intensiven Arbeit an den Vorzügen der Windhühner nutzte Grass diese Methoden der Bildkomposition weiterhin und entwarf isoliert auf den Blättern platzierte, ungewöhnliche Konstellationen alltäglicher Objekte. 


\title{
Lyrik der Jahre 1953 bis 1955 und die Annäherung zwischen Literatur und bildender Kunst
}

\author{
Berlin am 5. Jan 53 \\ Es ist die Landschaft anderen \\ Gestirns. [Niedergekommen?] \\ berstend an fremder, gläser- \\ ner Sprache. Und in die Lüfte \\ schnitten die Engel \\ nüchterne Stufen. Schnee, \\ weicher, [fettiger?] Schnee \\ wogt auf dem sauren \\ Acker. Wälder, gekrümmt \\ zum Sprung zittern und \\ fürchten des Jägers Signal. \\ Erwartung lange bis uns der \\ Tod einst gelingt. ${ }^{230}$
}

Dieses unveröffentlichte Gedicht, das der Kunststudent in Berlin als erstes verfasste, bekräftigt die rückblickende Einschätzung des Schriftstellers, Berlin habe inm „nicht unmittelbar" Realität beigebracht. ${ }^{231}$ Der Student wendete sich in seinen Texten keineswegs der städtischen Ruinenlandschaft zu. Im oben zitierten Gedicht entwarf er stattdessen, wie schon in seinen Düsseldorfer Dichtungen, eine magische Landschaft, die von Engeln, Jägern und Todessehnsucht erfüllt ist und als Resonanzraum für den emotionalen Zustand des lyrischen Ich dient. Auch die folgenden, den Arbeitstagebüchern zu Folge noch bis Ende Februar 1954 entstandenen Texte beschreiben ähnliche Szenarien und zeigen eine Vorliebe des Dichters für Materien aller Aggregatszustände und Härtegrade, von Kristallen über Eis bis hin zu Wachs.

Einige der zu Beginn des Jahres 1953 im Tagebuch niedergelegten Arbeiten enthalten Verse, die aus dem 1955 veröffentlichten Gedicht von Günter Grass, „Lilien aus Schlaf“, seinem ersten publizierten lyrischen Text, bekannt sind. ${ }^{232}$ Das Gedicht befand sich unter den Arbeiten, die seine Schwester Waltraut Grass und seine erste Frau Anna Grass im Herbst 1954 in seinem Namen für den Lyrikwettbewerb des SWR einreichten. Es sollte inm den dritten Preis des Wettbewerbs und die Aufmerksamkeit der Gruppe 47 einbringen und damit seiner literarischen Karriere den Anstoß geben. Der Text, dessen Akteur sich zwischen Wachen und Schlafen, zwischen Bewusstsein und Traum sowie zwischen Leben und Tod bewegt, bündelt viele auf verschiedene handschriftlich notierte Gedichte verteilte Motive und Formulierungen von 1953 und ist daher repräsentativ für Grass' lyrische Produktion des ersten Jahres in Berlin:

LILIEN AUS SCHLAF

Zwischen den Lilien aus Schlaf

Müht sich des Wachenden Schritt.

Wüßt er die Zahl nur

\footnotetext{
230 Akademie der Künste, Berlin, Günter-Grass-Archiv, Nr. 1753, ohne Paginierung, hs., Transkription: V. K. Die Zeilenumbrüche entsprechen denjenigen im handschriftlichen Text, die auch das Format des Arbeitstagebuchs vorgibt. Es ist unklar, ob Grass sie im Fall einer Veröffentlichung genauso gesetzt hätte.

${ }^{231}$ Vgl. Grass (2014), S. 37.

232 Veröffentlicht wurde „Lilien aus Schlaf“ erstmals in den Akzenten, 2. Jg., 1955, H. 3, S. 259 f. In seinen ersten Gedichtband Die Vorzüge der Windhühner hatte Grass es 1956 nicht aufgenommen.
} 
Das findige Wort

Könnte er der Wolke

Den Regen befehlen.

Trockenes Horn.

Lachenden Tieres trockenes Horn

Spießt du der Liebenden

Traurige Zettel.

O ihrer Tage schnelle Verträge.

Es ist ein Kommen und Gehen

Zwischen den Lilien aus Schlaf.

Es ist ein Lachen tief unterm Schnee.

Denn auf der Lichtung

Zwischen der Schlafenden

Wechselnder Lücke

Hastet der Sand.

O du der Erde alter Verdruß

Wenn sich der Tote bewegt.

Es war ein Tier und ein Stern,

Die trauernd so sprachen.

Es war ein Schlitten überm Kristall

Schön und mit Schwermut bespannt.

Es ist ein Lachen tief unterm Schnee.

Der Venus Blut käuflich in grauen Tabletten.

Magernde Sterne

Jagen die Dichter.

O diese Rufe im Schnee,

Ringe aus Gold und Geschrei,

Punkt

In der Landschaft aus Horn.

Es ist ein Kind darüber erwacht.

Es sah durch die Nähte der Nacht

Atemlos eilig

Die Zeit.

Der Venus Blut käuflich in grauen Tabletten.

Mit Gedichten wie diesen reihte Grass sich 1953 noch in die Gruppe von Dichterinnen und Dichtern ein, die Peter Rühmkorf zehn Jahre später in seinem vielzitierten Resümee zur Nachkriegsliteratur tadelte. Am Beispiel von Walter Höllerers Anthologie Transit. Lyrikbuch der Jahrhundertmitte (1956) kennzeichnete Rühmkorf die Dichtung der frühen Fünfziger als eine Lyrik, die steckengeblieben sei „beim Andenkengeschäft, Museum, in der Petrefaktensammlung“. Ihre „archaische Landschaft" sei besiedelt von Gestalten des frühen Christentums: „Einsiedler, Pilger, Eremiten und andere seltsame Heilige deuteten den Vogelflug, lasen die Schattenspur, wiesen die Fährte. “233 Mit dieser auf die Trümmerliteratur folgenden Tendenz kehrte die Dichtung den Bemühungen um eine Revision der deutschen Lyrik wieder den Rücken und zog sich, mitunter Gottfried Benn folgend, zeitweise in die Höhen eines ästhetischen Elfenbeinturms zurück. ${ }^{234}$ Grass

\footnotetext{
${ }^{233}$ Vgl. Rühmkorf (1978), S. 20 ff. Grass selbst wird von Rühmkorf bemerkenswerterweise nicht im Zusammenhang mit Höllerers Anthologie erwähnt; im Gegenteil stellt der Verfasser Grass mit seinen neuen Gedichten der Vorzüge als Experimentalrealisten der in Transit vertretenen Lyrik positiv gegenüber.

${ }^{234} \mathrm{Vgl}$. Vormweg (1980), S. 13.
} 
war in Höllerers Veröffentlichung unter anderem mit seinem poetischen Erstling vertreten, bezeichnenderweise unter der Rubrik "Dunkel - Innere Landschaft“ ${ }^{235}$

Wie schon die in Düsseldorf entstandene Lyrik des Bildhauerdichters weist auch "Lilien aus Schlaf" auf bekannte Vorbilder zurück. ${ }^{236}$ Hinsichtlich der Verwendung von starken Farb- und Temperaturkontrasten erinnert es etwa an Georg Trakls „Winternacht“. ${ }^{237}$ Die apokalyptischen, aus dem bloßen „Gerüst aus Horizont und Fläche“ gebildeten Landschaften und die Betonung von Schlaf und Traum als Gegenpol zu einem rationalisierten und kommerzialisierten Alltag lassen sich zugleich als Hinwendung zur Bildwelt des Surrealismus deuten. ${ }^{238}$ So bezeichnete Harald Hartung Grass' erstpubliziertes Gedicht als "surrealistisches Gesellenstück", dass sich „ornamentalsurrealistischer Metaphorik und preziöser Abstraktionen" bediene. ${ }^{239}$ Bereits in den ersten Nachkriegsjahren erfassten Maler wie Heinz Trökes, Mac Zimmermann und Franz Radziwill die Gegenwart durch einen fantastischen Realismus, während unter den Literaten Hermann Kasack, Hans Erich Nossack und Hans Wörner Vergleichbares boten. Ihren Werken gemeinsam ist die Konstruktion innerer Welten, die die zeitgenössische Realität, die unter dem Eindruck jüngster unverarbeiteter Schrecken stand, mit besonderer Betonung des Unterbewussten zum Ausdruck bringen. ${ }^{240}$

Grass hatte den Surrealismus unter den in der Nachkriegszeit vertretenen Kunstströmungen für diejenige gehalten, die die Stimmungen und Zustände jener Jahre am angemessensten darzustellen vermochte. Dies geht zumindest aus seinen Beschreibungen der Düsseldorfer Künstlerkreise in der Blechtrommel (1959) hervor, in der die fiktiven surrealistischen Maler "Ziege" und „Raskolnikoff“ im Jahr 1949 die treffendste Darstellung des Protagonisten Oskar Matzerath anfertigen und der Romanhandlung damit zu einem entscheidenden Wendepunkt verhelfen (III 618622). Aber nicht nur seine 1953 niedergelegte Lyrik und der ab 1954 verfasste Debütroman, sondern auch einige seiner seit 1954 entstandenen Bildwerke bekräftigen diese Einschätzung.

Bildende Kunst und Literatur gingen im Surrealismus bekanntermaßen stets eine enge Bindung ein. Als Grass ab 1954 seine Texte und Bilder zusammenführte, konnte er sich innerhalb eines Kunstbetriebs, der gerade die Trennung der Gattungen zu einer konsequenten historischen Entwicklung erklärte, vor allem auf diese Kunstströmung berufen. Tatsächlich ist seine Bezugnahme auf den Surrealismus gerade in vielen Arbeiten, die Mitte der Fünfzigerjahre entstanden sind, deutlich erkennbar. Unter Grass' Bildwerken von 1954 befindet sich eine Federzeichnung mit dem Titel Skizze frei nach Dalí, die sich, dieser Bezeichnung entsprechend, von den mit schmelzenden Körpern, Uhren und anderen Vanitasmotiven versehenen Kompositionen des Surrealisten inspiriert zeigt (Abb. 49).

\footnotetext{
${ }^{235} \mathrm{Vgl.} \mathrm{Höllerer} \mathrm{(1956).}$

${ }^{236}$ Vgl. Frizen (2010), S. 16-18.

${ }^{237}$ Vgl. Trakl (2012), S. 71.

${ }^{238}$ Vgl. zu „Landschaft und böse Ahnung“ als Element der „neuen Ikonografie“ des Surrealismus: Schneede (2006), S. $145 \mathrm{f}$.

${ }^{239} \mathrm{Vgl}$. Hartung (1984), S. 154.

${ }^{240} \mathrm{Vgl}$. Hermand (1986), S. 180-189.
} 


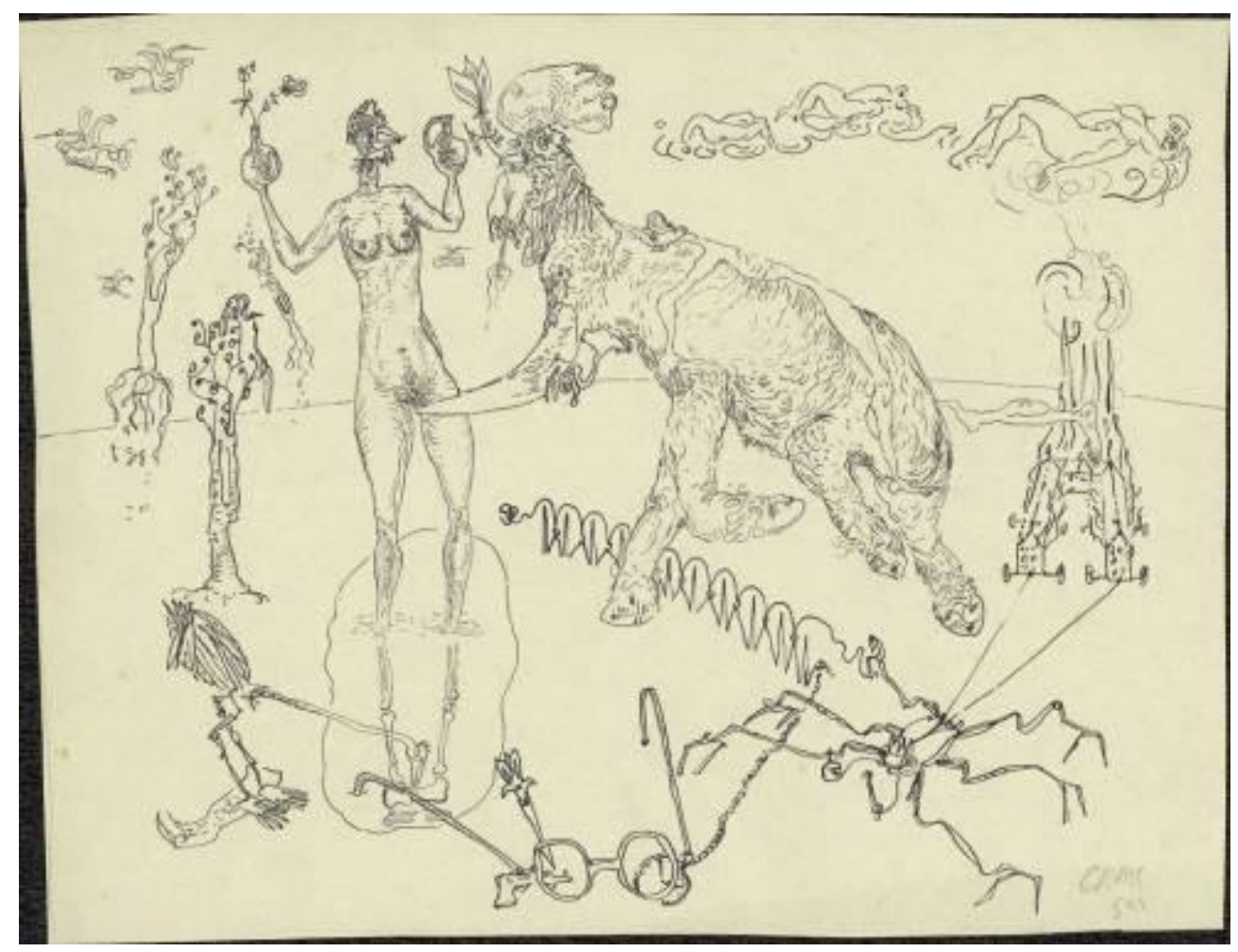

Abb. 49, Skizze frei nach Dalí, 1954, Feder/Tusche

In der Zeichnung spielt sich vor einer kargen Landschaft Merkwürdiges ab: Nahezu in der Mitte des Bildes ist eine nackte Frau zu sehen, die mit beiden Füßen in einer Wasserlache steht und den Betrachtenden zugewandt ist. An Stelle eines menschlichen Kopfes ruht der eines Huhns auf ihrem Hals. Ihre erhobenen Arme gehen statt in Hände in Vasen über, in welchen Lilien stehen. Um die Figur herum bilden verschiedene Objekte eine halbkreisförmige Begrenzung. Ein großes Tier ist dabei, sie zu überqueren und steuert von rechts auf die Unbekleidete zu. Es handelt sich um einen Vierbeiner, dessen Körper an den eines Elefanten erinnert. Auch diese Gestalt trägt jedoch keinen passenden Kopf auf ihren Schultern, sondern den eines Hahns. Die Sohlen seiner Füße zeigen weibliche Gesichter. Aus der Brust des Tieres ragt ein spitzes Horn, mit dem es auf die Scham der Vogelfrau deutet. Subtiler erotisch konnotiert ist das weiter oben dargestellte Handlungselement: Mit seinem Schnabel legt das Tier eine weitere Lilie, gleichermaßen Reinheits- und Todessymbol, in das Gefäß der Frau.

Vollends von Tod und Vergänglichkeit geprägt sind die Bildelemente in der unteren Hälfte des Blattes: Im unbewegten Gewässer spiegelt sich nicht der Leib der darin stehenden Frau, sondern lediglich ihr Skelett. Ein knochiger Stelzvogel, der mit behandschuhten Krallen auf einem beschriebenen Blatt steht, pickt zielsicher an die Stelle der Reflexion, an der sich eigentlich das Abbild der weiblichen Scham zeigen sollte. Zugleich weist sein an einem langen, dürren Hals hängender Kopf auf einen ebenso langen Brillenbügel, dessen Ende in die Wasserlache ragt. Er gehört zu einer überdimensional-großen Brille im Vordergrund, hinter deren linkem Glas die kriminalistisch anmutende Zusammenstellung von Dolch und Pistole zu sehen ist; hinter dem rechten Brillenglas ruht das Ziffernblatt einer Taschenuhr. Die gerade Linie ihrer Kette führt zu einer zaunartigen Spur, die eine ebenfalls überdimensionierte Spinne (zu sehen rechts im Bild) hinterlassen 
zu haben scheint. Ihre feingliedrigen Beine ähneln hinsichtlich ihrer Struktur der Uhrenkette. Die Spinne ist mit Reichskleinodien ausgestattet, also kein gewöhnliches Tier. An zwei Fäden zieht der Monarch sein brennendes Schloss dem Wasser entgegen. Was da brennt, ist nicht das Gebäude allein; Leidenschaft ist augenscheinlich auch hier im Spiel: Zum einen kulminiert der aufsteigende Rauch zu Formen, die nackten Liebespaaren ähneln, zum anderen scheinen die Flammen einen Mann buchstäblich zum Schmelzen gebracht zu haben. Nur mehr eine weiche Hülle seines Körpers liegt auf dem Rücken des Urtieres auf, während einer seiner Füße noch in Flammen steht. Komplementär zur lustvollen Himmelfahrt rechts oben, lösen sich links oben Bäume aus dem Erdboden, um sich am Himmel, so der durch die sequenzielle Anordnung erzeugte Eindruck, in Vögel zu verwandeln.

Die Kohärenz dieser Ketten von Bildelementen beruht vor allem auf den Gegensatzpaaren, zu welchen sie sich ordnen lassen: Mensch und Tier, Feuer und Wasser, Himmel und Erde, Liebe und Tod werden in den durch Formanalogien und Metamorphosen zusätzlich miteinander verbundenen Bildelementen realisiert. Die das Blatt dominierenden Motive weisen eine symbolische Bedeutung auf, die jedoch nicht über kulturelles Vorwissen erschlossen werden muss, sondern bereits im Bild angelegt ist: Der Hahn als Sinnbild sexueller Potenz und als lautstarker Verkünder des Übergangs zwischen Nacht und Tag fügt sich zum Beispiel durch die von ihm vollzogenen Bewegungen in diese Rollen. Dass der Künstler die einzelnen Elemente der Darstellung nur im oberen Bildbereich einer einheitlichen Perspektive unterwarf und auf das Einhalten natürlicher Größenverhältnisse verzichtete, unterstreicht die Eigenständigkeit der einzelnen Objekte, verstärkt den Eindruck von ihrer Gegensätzlichkeit und verleiht der Zeichnung den Charakter eines Bildrätsels.

Grass' Darstellung erinnert an Salvador Dalís Gemälde Traum, verursacht durch den Flug einer Biene um einen Granatapfel, eine Sekunde vor dem Aufwachen aus dem Jahr 1944 (Abb. 50). Gemeinsame Motive stellen eine Verbindung zwischen Grass' Skizze und diesem Werk des Surrealisten her: Hier wie dort bestimmen weibliche Akte, verfremdete Dickhäuter und Waffen die Komposition. Das Thema beider Arbeiten lässt sich mit dem Topos von Eros und Thanatos umreißen. Zu seiner Darstellung kombinieren Grass und Dalí in vergleichbarer Weise Gegenstände aus disparaten Zusammenhängen und fantastische Metamorphosen in einer weiten, kaum ausgestalteten Landschaft. 


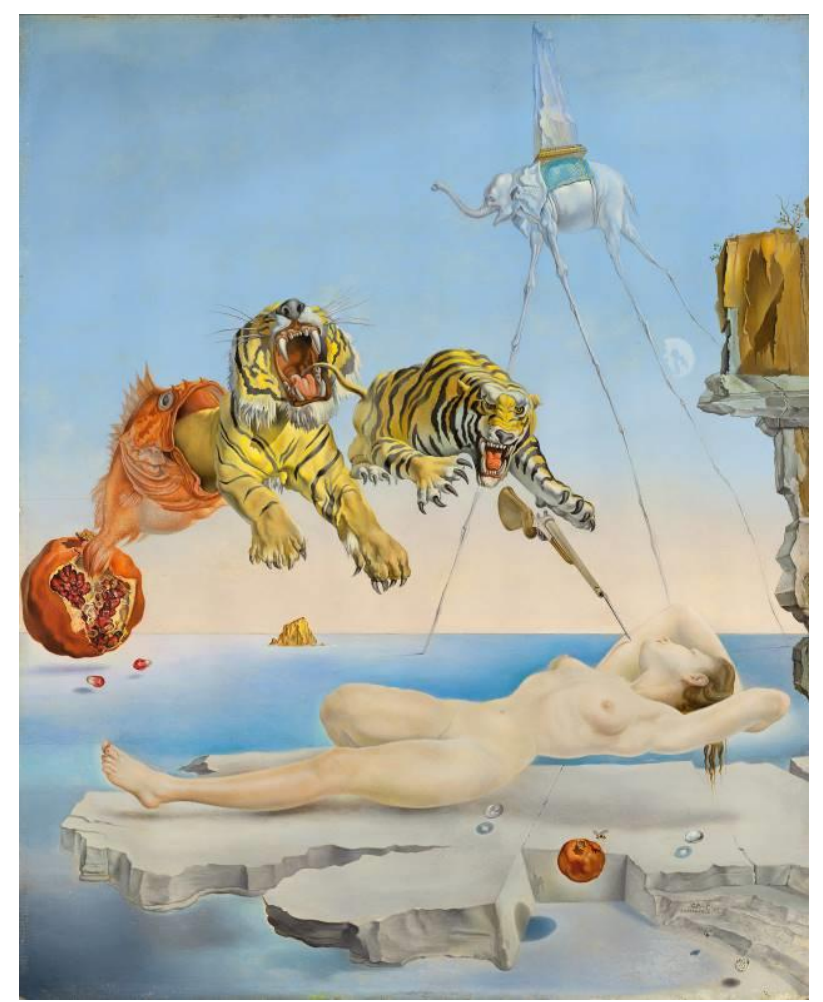

Abb. 50, Salvador Dalí, Traum, verursacht durch den Flug einer Biene um einen Granatapfel, eine Sekunde vor dem Aufwachen, 1944, Öl auf Holz

2011 erläuterte Grass in einem Gespräch, es sei das freie Spiel mit Motiven, "auch der erzählerische Umgang mit ihnen, die Bildergeschichte" gewesen, das ihn an den Werken Dalís, aber auch Marc Chagalls und Max Ernsts gereizt hätte. ${ }^{241}$

Mit der Lyrik des Studenten steht die Skizze Frei nach Dalí in engem Zusammenhang. Sie beschäftigt sich mit einzelnen Motiven aus „Lilien aus Schlaf“, mit dem gehörnten Tier, den Lilien und der Venus, ist vor allem jedoch ein grafisches Gegenstück zu dem unveröffentlichten Düsseldorfer Gedicht „Der Löschteich“ (1952). Handschriftlich in eines der Arbeitstagebücher eingetragen, ${ }^{242}$ ist es nicht vollständig lesbar. Es kann jedoch festgestellt werden, dass die in der Zeichnung nebeneinander platzierten oder metamorph miteinander verbundenen Objekte im Gedicht als Metaphern konstruiert sind. Im Gegensatz zur Zeichnung ist hier eine eindeutige Leserichtung vorgegeben. Lebewesen und Gegenstände werden durch ihre Integration ins Versgefüge in ihrer Bedeutung und ihrem Verhältnis zueinander näher bestimmt:

\footnotetext{
${ }^{241}$ Grass im Gespräch mit der Verfasserin am 5.12.2011: Krason (2011).

${ }^{242}$ Akademie der Künste, Berlin, Günter-Grass-Archiv, Nr. 965, hs., S. 74, einzige Datierung am Anfang: Paris, Mai 1952.
} 
Feuriger ElefantenHahn

Dir glaubte Venus

Dass sie ein Huhn war.

In den Vasen ihrer Hände

Birgt sich deren schwarze,

[Zirkusdüsternde?]

Elefantenvase.

Trockenes Untier

Dass du mit meiner Abwehr

Dich wälzest

In schielenden [Fratzen?]

Mit den lachenden Köpfen

Meiner vier [?] Bräute

Beschlag ich den Kummer deiner Füße

Still nur ihr streitenden Vögel

Müssen die Bäume nicht fliegen

Das ihr noch [leitet?]

Unbekümmert nur

König Spinne

Zum Löschteich zieht er

Sein brennendes Schloß

Unbekümmert noch ihr

Im Bett des [?] Prunkes

Zeigt nun das eine Geschlecht

Glashelles zum Löschteich

Kam Vogel Tod.

Plündert der Venus

Beinernes Abbild. ${ }^{243}$ [Hervorhebungen V. K.]

Der Dichter hatte seine im Mai 1952 notierten Metaphern also 1954 unter Verwendung surrealistischer Kompositionsmethoden ins Bild gesetzt. Andere Grafiken aus den Berliner Jahren zeigen ebenfalls einen surrealistischen Ansatz: Eine Reihe von Feder-, Pinsel- und Bleistiftzeichnungen etwa fertigte Grass 1955 zu seiner kurzen Erzählung „Meine grüne Wiese“ (1955) an, die er nach einer in den Semesterferien des Vorjahres unternommenen Spanienreise geschrieben und veröffentlicht hatte. ${ }^{244}$ Die in diesem Zusammenhang entstandenen Darstellungen der Protagonistin Pepita, hier exemplarisch in einer Bleistiftzeichnung zu sehen (Abb. 51), erinnern in ihren fantastischen Motivzusammenstellungen an bestimmte Arbeiten Dalís aus den Dreißigerjahren.

In Grass' Erzählung stirbt Pepita eines ungewöhnlichen Todes, an der Verwundung durch einen Hummer, den sie sich selbst an die Brust setzt. Die Zeichnung zeigt eine junge Frau mit ebendiesem Tier im Haar. Der Hummer schmiegt sich an die Rundung ihres Oberkopfes und wird der Dargestellten auch durch einen ähnlich starren Blick anverwandelt. Zum einen bedient sich der Dichter auf diese Weise der ins Mittelalter zurückreichenden Tradition, Märtyrer mit einem auf ihre Todesart hinweisenden Attribut darzustellen, zum anderen nähert er sich auch hier surrealistischen Werken an. Genauso wie Dalí fügte er zwei aus unterschiedlichen Kontexten stammende Objekte über eine Formanalogie zusammen und brach bewusst mit konventionellen Seherfahrun-

243 Ebd. Transkription: V. K., mit Dank an Dieter Stolz für Hinweise und Korrekturen.

${ }^{244}$ Erstdruck in: Akzente, 2. Jg., 1955, Heft 6, S. 528-534. 
gen. Ein vergleichbares Werk Dalís besteht aus einem Kunststoff-Hummer, den der Künstler anstelle eines Telefonhörers auf einen Telefonapparat setzte (Abb. 52). Auf eine Idee Dalís hin hatte die Designerin Elsa Schiaparelli nach demselben Prinzip einen „Schuhhut“ entwickelt, einen Damenhut in Form eines hochhackigen Schuhs, dessen Fußbett dem Hinterkopf seiner Trägerin auflag. ${ }^{245}$ Aus der Zusammenarbeit von Dalí und Schiaparelli ging ferner 1937 der Entwurf eines weißen Abendkleides mit aufgemaltem Hummer hervor, der Grass ganz unmittelbar zu der tödlichen Wendung seiner Erzählung angeregt haben könnte, denn seine durch die scharfen Scheren des Hummers ums Leben kommende Protagonistin trägt ein weißes Kleid (Abb. 53). ${ }^{246}$

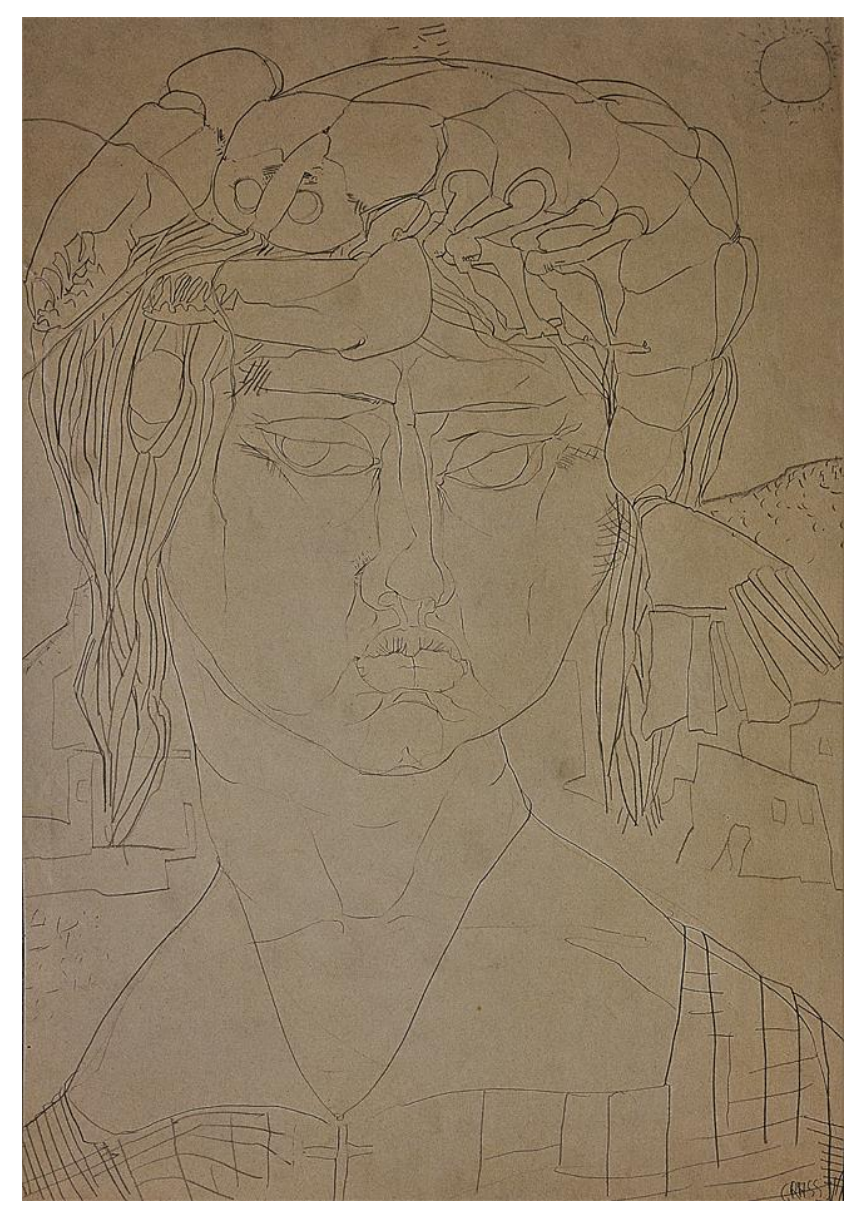

Abb. 51, Pepita, 1955, Bleistift

${ }^{245}$ Ein solcher Hut aus den Jahren 1937-1938 befindet sich in der Sammlung des Metropolitan Museum of Art, New York, Inv. 1974.139: https://www.metmuseum.org/art/collection/search/83437, letzter Zugriff am 9.2.2019.

${ }^{246}$ Vgl. Baudot (1997), o. Paginierung. 


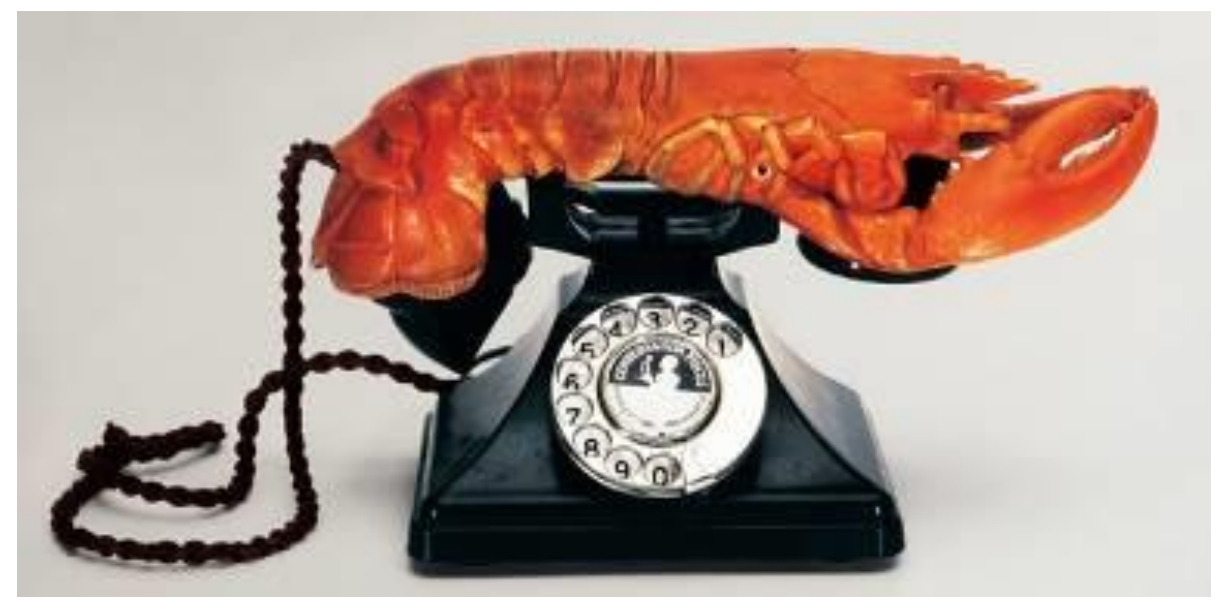

Abb. 52, Salvador Dalí, Hummertelefon/ Hummer- oder aphrodisisches Telefon, 1936, Metall, Kunststoff, Glas

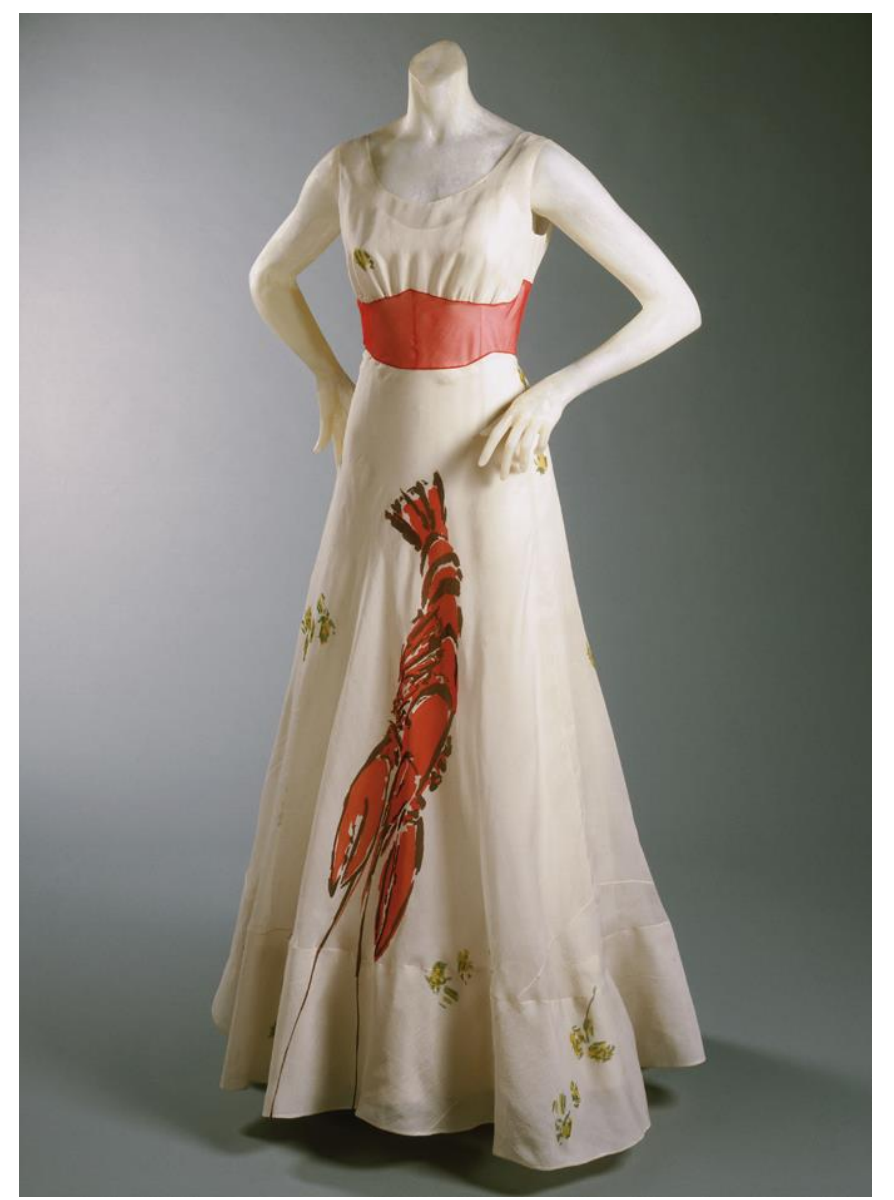

Abb. 53, Elsa Schiaparelli in Zusammenarbeit mit Salvador Dalí, Abendkleid, 1937, bemalte Seide, synthetisches Pferdehaar 
Seine Gestaltung des Frauenbildnisses ist hinsichtlich ihrer Symmetrie und der von Details absehenden Linienführung hingegen mit Porträts von Picasso vergleichbar - beide Eigenschaften der Darstellung lassen die Figur zeitlos und universell wirken. ${ }^{247}$

Dass Grass sich lange und intensiv mit Picassos Werken befasst hat, belegt neben seinen eigenen Hinweisen ${ }^{248}$ und der Ähnlichkeit stilistischer Elemente zwischen den Zeichnungen Picassos aus den Zwanzigerjahren und Grass' 1952 entstandenen Skizzen auch ein Arbeitstagebuch aus seiner Berliner Studienzeit. 1956 verfasste er ein mehrseitiges Gedicht zu Picassos Gemälde Guernica, zudem ein weiteres auf den Katalanen bezugnehmendes Gedicht, das mit dem Vers „Bei Ebbe in Hamburg“ beginnt und vermutlich mit Grass' Besuch einer Picasso-Ausstellung in Verbindung steht. ${ }^{249}$ Da keiner der handschriftlich festgehaltenen Texte vollständig entzifferbar ist, können sie zwar nicht in die Analyse einbezogen werden, zeugen aber von dem außerordentlichen Interesse, das der Student den Werken des Katalanen entgegenbrachte. Für Grass' Schaffen konnte Picasso auch deshalb eine besondere Bedeutung gewonnen haben, weil der weltbekannte Künstler sich in den Zwanzigerjahren wieder der figurativen Malerei zugewandt hatte, statt von der kubistischen Malerei zur gegenstandslosen überzugehen. Womöglich hatte Grass sich in Bezug auf Picasso auch mit Ludwig Gabriel Schrieber ausgetauscht, dessen Gemälde ebenfalls von Picasso inspiriert waren. ${ }^{250}$

Surreale Kompositionen und Metamorphosen nahmen in Grass' bildkünstlerischem und literarischem Werk seitdem einen festen Platz ein. Bereits seit Ende 1954 bettete er sie jedoch nicht als vielgliedrige Assoziationsketten in Traumlandschaften, sondern legte überraschende Konfrontationen von Alltagsgegenständen in einem weitgehend ungestalteten Bildraum an. Im Gespräch charakterisierte er diesen neuen Ton seiner Gedichte rückblickend als nüchterner und kontrollierter:

Diese Fülle von Genitiv-Metaphern, das desperate Gegenstände mit Hilfe des Genitivs ins Verhältnis zueinander Setzen, kam mir sehr beliebig vor und wurde beliebig. Ich bin dann auf eine eher nüchterne Art der Lyrik gekommen. In Die Vorzüge der Windhühner kann man das auch genau beobachten. ${ }^{251}$

Im Sinne einer Lockerungsübung, aber auch als Methode scheint die Bildsprache des Surrealismus eine wesentliche Anregung für die lyrischen und grafischen Objektzusammenstellungen des Debütbandes gewesen zu sein. Diese Phase beschreibt der erste poetologische Text des Autors mit dem Titel „Der Autor sagt zu seinem Gedicht“, der am 3. September 1955 in der Frankfurter Neuen Presse veröffentlicht wurde. In der ersten Hälfte des Essays gibt der Dichter Deutungshinweise zu seinen preisgekrönten „Lilien aus Schlaf“ und formuliert in der zweiten seine Dichtungsauffassung. Er verpflichtet seine Lyrik darin dem Ziel, mit Hilfe ungewöhnlicher, über formale Ähn-

\footnotetext{
${ }^{247}$ Vgl. Dreher (1982), S. 123.

248 In seinen autobiografischen Texten nennt Grass Picasso als Inspirationsquelle: vgl. X 546, XII 242.

249 Akademie der Künste, Berlin, Günter-Grass-Archiv, Nr. 1755, S. 189-195, hs., Eintrag: Hamburg, 21.4.1956 („Picasso“) und Hamburg, 22.4.1956 („Bei Ebbe in Hamburg“). An die Besichtigung einer PicassoAusstellung in Hamburg während seiner Studienzeit erinnerte sich Grass 1990 in seiner Frankfurter PoetikVorlesung (XII 242).

${ }^{250} \mathrm{Vgl}$. S. 62 der vorliegenden Untersuchung.

${ }^{251}$ Grass im Gespräch mit der Verfasserin am 5.12.2011: Krason (2011).
} 
lichkeit statt über Logik aufgebauter Metaphern und Allegorien eine "neue Realität“ darzustellen; für seine rhetorischen Figuren legt er wie vormals die Surrealisten die visuell und akustisch wahrnehmbare Alltagswelt als Quelle fest. Als Kernelement der Gedichte benannte er das Fragment und damit das aus konventionellen Zusammenhängen gerissene Einzelobjekt:

Denn setzt das Gedicht nicht erst dort an, wo der alles erklärende Finger der Logik nicht mehr hinreicht? Die letzten Beziehungen zwischen Schlüssel und Schloß, der Augenblick, da das Ohr zur Muschel wird, am Strand liegt und den Lärm des Sandes vernimmt, das fast Unsagbare gehört dem Gedicht. Immer wieder wird es der Vogelflug sein, der den Lyriker zum Nachzeichnen zwingt, der Regen, der auf eine Trommel schlägt, diktiert ihm, die Großstadtstraße, in deren Fluß Neonschrift zu Versen wird und der Atem des Zeitungsverkäufers sind sein Anliegen.

Das Gedicht beginnt immer beim Torso. Das soll heißen, es genügt, eine Planke am Strand zu finden und ein Stück vom Ruder, um ein Schiff nachzuweisen, um nach Amerika zu segeln. Nicht nur der Dichter weiß ein Fragment derart zu ergänzen. Mancher hat schon bewußt oder unbewußt einen verlassenen Regenschirm gesehen und sich sogleich den Besitzer dazu gedacht. Die Sprache kann dieses alles, hält dieses aus. Jedes Wort hat seine Tragfähigkeit, man kann es bepacken, mit einem oder mit doppeltem Sinn versehen, kann es auf ein Podest stellen. Es wird nun eine neue Realität verkünden, eine Überrealität. So kann es kommen, daß der Dichter Schwäne an der Wäscheleine sieht und weiße Blumen Persil nennt. Die Sprache erlaubt es inm, sie ist für das Gedicht geschaffen, will das Gedicht. (XI 5 f.)

Wie die folgenden Ausführungen zeigen werden, führte Grass die bildkünstlerisch geprägte, alogische Assoziationskraft in seiner Lyrik jedoch nach und nach stärker mit rationalen Strukturen zusammen.

\section{Die Vorzüge der Windhühner (1956) - erste Betrachtung}

Den Arbeitstagebüchern gemäß schrieb Grass das erste Gedicht zu den Vorzügen der Windhühner im Juli 1954 („Rundgang“), die anderen folgten Ende 1954 bis Anfang 1956. ${ }^{252}$ Genitivmetaphern, apokalyptische Landschaften und mythologische Stoffe sind aus diesen Texten verschwunden. Sie beziehen ihr Motivrepertoire nun, wie in "Der Autor sagt..." beschrieben, aus dem Leben und enthalten häufiger Motivverknüpfungen, die durch visuell vorstellbare Formanalogien gestützt werden. Wie Brigitte Zissel-May überzeugend herausarbeitete, wird der Aspekt des Visuellen in den Gedichten der Vorzüge der Windhühner besonders hervorgehoben, indem einzelne Beobachtungen ohne eine Einordnung des Beobachteten in funktionale oder kausale Zusammenhänge geschildert werden. ${ }^{253}$ Obgleich Objekte und Ereignisse ähnlich wie in der surrealistischen oder auch dadaistischen Poesie aus ihren gewohnten Kontexten gelöst und auf ungewöhnliche Art kombiniert werden, ergeben sie schlüssige Allegorien und Metaphern für Zustände, Ereignisse und Begriffe. ${ }^{254}$ Die Gedichte thematisieren in existenzialistischem Tenor das Leben angesichts des unvermeidlich bevorstehenden Todes und setzen sich kritisch mit der Idee einer "reinen“ Liebe, mit der Institution der Kirche und mit dem Glauben an eine Erlösung nach dem Tod auseinander; einzelne Texte deuten eine Beschäftigung mit dem Holocaust an. Darüber hinaus veranschaulichte

\footnotetext{
${ }^{252}$ Akademie der Künste, Berlin, Günter-Grass-Archiv, Nr. 1753 und Nr. 1755, hs.

${ }^{253}$ Vgl. Zissel-May (1974), S. 107. Zissel-May charakterisiert diesen „Blick“ des lyrischen Ich auf die Welt als einen kindlichen, der die Texte in eine märchenhafte Stimmung einbettet.

${ }^{254} \mathrm{Vgl}$. ebd., S. 27 und S. 47.
} 
Grass seine Dichtungsauffassung in poetologischen Gedichten. ${ }^{255}$ Obwohl der "grimmige Idylliker" in diesen programmatischen Texten einen von Welt und Geschichte befreiten Schaffensraum des lyrischen Ich konstruierte, wird darin, wie auch in den anderen Gedichten des Bandes, die außerhalb dieser Idylle drohende Realität bereits mitangedeutet. ${ }^{256}$

Im frühen Herbst 1955, einige Monate nach seiner ersten Lesung bei dem Frühjahrstreffen der Gruppe 47, schloss Grass einen Vertrag mit dem Luchterhand-Verlag ab. Mit seinem Lektor Peter Frank vereinbarte er, dass sein erster Gedichtband zusammen mit einigen seiner Federzeichnungen veröffentlicht werden sollte. Bereits im Zuge der Niederschrift der ersten Gedichte waren Bilder entstanden (X 625). Die erhaltenen Zeichnungen wurden den Datierungen zufolge von Mitte 1955 bis zum Frühling des Jahres 1956 angefertigt. Dabei schuf Grass weitaus mehr Bilder als schlussendlich abgedruckt wurden. Dreiundzwanzig Originalzeichnungen sind öffentlich zugänglich. ${ }^{257}$ Bei diesen handelt es sich bis auf eine Ausnahme um nicht abgedruckte Varianten. Ihren Weg zwischen die Buchdeckel fanden insgesamt acht Federzeichnungen, zwei weitere auf die Vorder- und Rückseite des Umschlags. ${ }^{258}$ Sofern eine Datierung Auskunft gibt, sind die verwendeten Arbeiten zu einem großen Teil 1956 entstanden. Ein Vergleich der im Band neben die Gedichte gestellten Bilder mit den ungedruckten Werken zeigt, dass erstere durch eine stärkere Fragmentierung und Abstraktion der Form charakterisiert sind, sich auf eine geringe Zahl an Objekten konzentrieren und durch grafische Leitmotive miteinander korrespondieren.

Die Skizzen aus dem Jahr 1955, in welchen mehrere Bildelemente miteinander kombiniert werden, lassen noch eine stärkere Verwandtschaft mit der oben behandelten surrealistischen Zeichnung von 1954 erkennen. In diesen früheren Arbeiten, von denen einige zu nicht mehr erhaltenen Textfassungen entstanden sind (das Dargestellte ist in diesen Fällen keinem der gedruckten Gedichte eindeutig zuzuordnen, auch wenn der Bildtitel das Gegenteil verspricht), setzt Grass dem Alltag entnommene Motive scheinbar beziehungslos nebeneinander. In Einzelfällen wie der hier abgedruckten Skizze zu einer nicht mehr erhaltenen Version des Gedichts „Unfall“ (Abb. 54) leiten Pfeilsymbole die Betrachtenden durch die Anordnung, was den zeichenhaften Charakter der dargestellten Objekte noch weiter verstärkt.

\footnotetext{
255 Vgl. Stolz (1994), S. 23-54.

256 Vgl. Frizen (2010), S. 34-37 und Hermand (1986), S. 409-428; angesprochen sind hier besonders die Gedichte „Die Vorzüge der Windhühner" und "Credo“.

257 Diese Blätter gehören zur Sammlung des Günter Grass-Hauses. Dass sich weitere Zeichnungen in Privatbesitz befinden, ist sehr wahrscheinlich, da Grass gerade unter den Dichterfreunden der Gruppe 47 in der zweiten Hälfte der Fünfzigerjahre zahlreiche Abnehmer für seine Bilder gefunden hat. Vgl. Jürgs (2002), S. 111.

${ }^{258}$ Einzelne abgedruckte Zeichnungen in: Grass (2014), S. 51-57.
} 


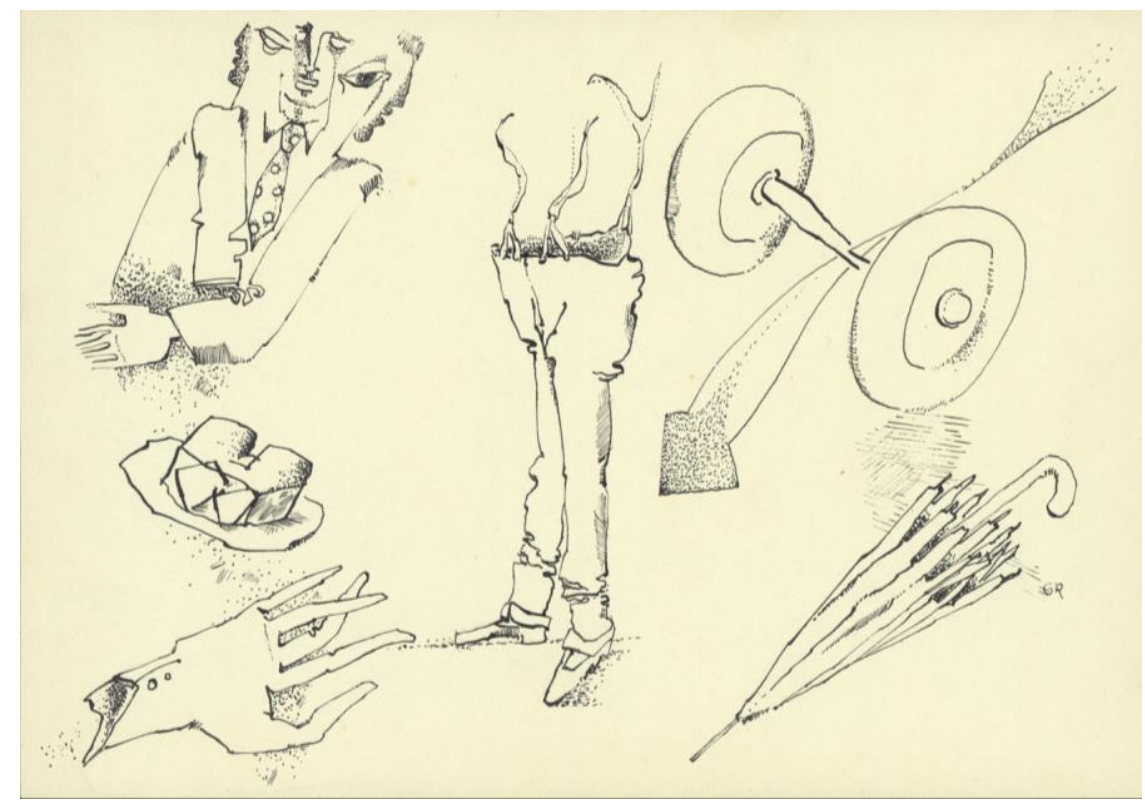

Abb. 54, Skizze zum Gedicht „Unfall“, 1955, Feder/Tusche

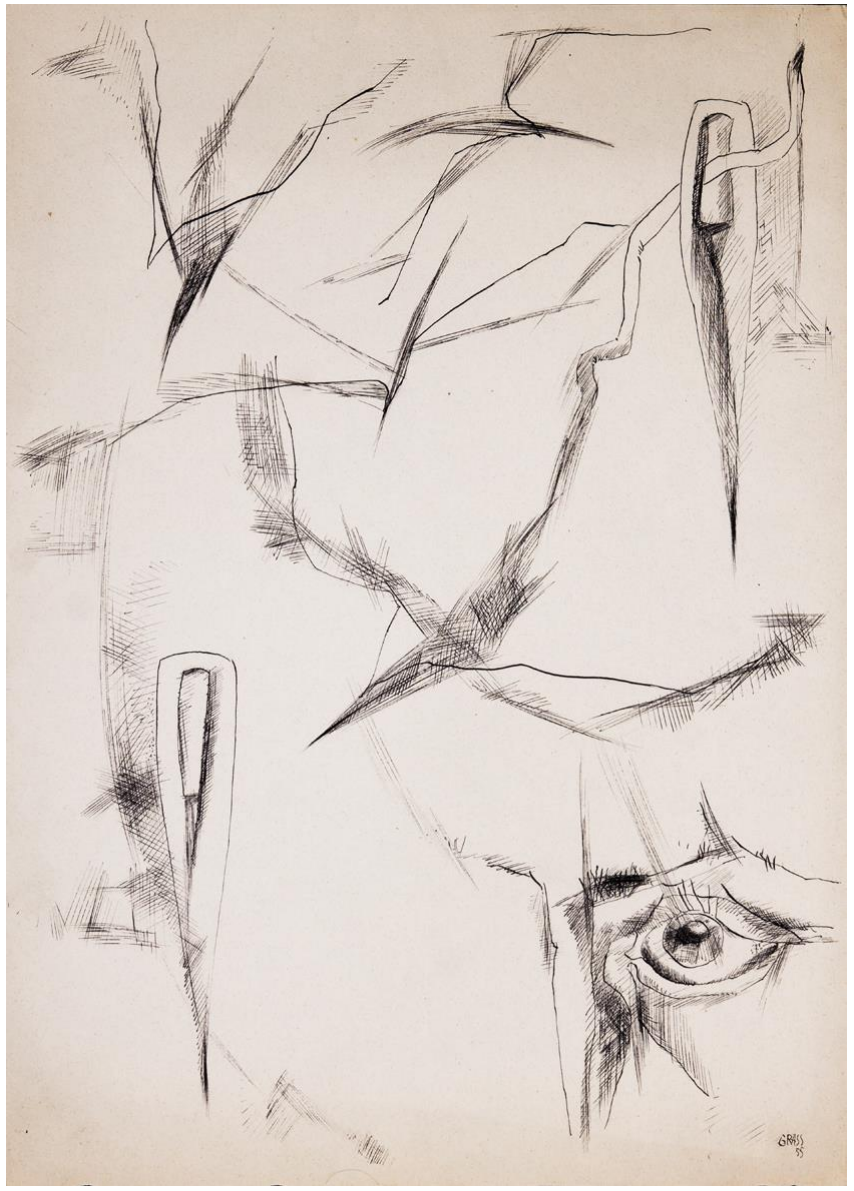

Abb. 55, Skizze zum Gedicht „Vogelflug“, 1955, Feder/Tusche 
Auf typische Elemente der surrealistischen Ikonografie, auf eine mysteriöse landschaftliche Kulisse und Freud'sche Symbolik, wurde weitgehend verzichtet. Weiterhin bedient sich der Künstler jedoch der Kombinatorik, wie sie literarisch zum Beispiel durch Lautréamonts kühne Metaphern aus den Chants de Maldoror (,,beau comme la rencontre fortuite sur une table de dissection d'une machine à coudre et d'un parapluie") angeregt und visuell von Man Ray in Szene gesetzt worden ist. Er hatte das Zusammentreffen von Nähmaschine und Regenschirm auf einem Seziertisch in Fotografien festgehalten. ${ }^{259}$

Eine der unveröffentlichten Grass'schen Skizzen entstand zu dem Gedicht „Vogelflug“ (Abb. 55). Im Gegensatz zu der oben behandelten Zeichnung sind die Motive hier mit Elementen eines lyrischen Textes deckungsgleich, so dass die Zeichnung und das Gedicht miteinander verglichen werden können. Die Grafik ist ein Beispiel dafür, wie Grass Motivverknüpfungen, auf welchen ein Text aufbaut, in einer Zeichnung realisierte, indem er äußerliche Ähnlichkeiten zwischen verschiedenen Objekten betonte und das Sehen selbst mitthematisierte. Unter Berücksichtigung des Textes wird besonders deutlich, welcher Logik seine Objektkombinationen folgen.

Die Federzeichnung zeigt rechts unten den Ausschnitt eines Gesichts: ein geöffnetes linkes Auge und darum herum angedeutet ein Nasenrücken und Augenbrauen. Auf der Höhe der Iris ansetzende und von dort diagonal nach linksoben verlaufende Schraffuren deuten die Blickrichtung an. Über diesem Fragment rahmen zwei mit den Spitzen nach unten zeigende Nähnadeln das Dargestellte: Unregelmäßige Linien zwischen den Nadeln werden von Schraffuren überlagert, die die Form von fliegenden Vögeln haben. Das am deutlichsten erkennbare Tier ist so positioniert, als befände es sich auf dem Flug zwischen den überdimensional großen Nadeln von rechts nach links im Bild. Die Steuerfedern dieses Vogels gehen in ein sich schlängelndes Band über, das seinen Weg bereits durch das rechte Nadelöhr gefunden hat. Die sich auf diese Weise aus dem Arrangement der einzelnen Bildelemente und den darin präsenten Metamorphosen ergebende Narration findet ihre Entsprechung im Gedicht:

\author{
VOGELFLUG \\ Über meiner linken Braue \\ liegen Start und Ziel \\ für immer begründet. \\ Wenn sie beginnen, \\ die Fläche Blau überbrücken, \\ der Mittag, die lautlose Kurve sie aufnimmt. [...] \\ Unter den Bögen, wenn sie das Nadelöhr finden, \\ die Risse vernähen und keinen Durchblick gewähren. \\ Wenn sie sich nähern und auf die Stirn deuten, \\ erkenne ich, dass es Schwalben sind.- \\ Bald wird es regnen. [... $]^{260}$
}

\footnotetext{
${ }^{259}$ Vgl. Man Ray, Hommage à Lautréamont, 1935, Fotografie, Collection Juliet Man Ray (Man Ray Trust). Die Fotografie ist abgedruckt im Kat. Ausst. Frankfurt a. M. (2011), S. 28.

${ }^{260}$ Grass (1956), S. 5.
} 
Mit der grafischen Zusammenstellung von Blick, Vogelflug und Nähvorgang visualisiert die Skizze grundlegende Textbausteine. Zwei im Gedicht als Wahrnehmungsetappen hintereinander gereihte Eindrücke, das Beobachten eines als "Vernähen“ beschriebenen Prozesses und das Erkennen eines Schwalbenflugs in demselben, werden in der Grafik simultan neben- und übereinandergesetzt. Die Zeichnung verdeutlicht, dass der sprachlich formulierten Assoziation eine visuell vorstellbare Analogie zugrunde liegt, nämlich diejenige zwischen der Linie, als die das träge Auge die schnelle Bewegung eines Vogels wahrnimmt und einem während des Nähens geschwungenen Faden.

Eine 1956 entstandene Bleistiftskizze zeigt eine andere Variante des visuellen Vergleichs von Vogelbewegung und Nähvorgang (Abb. 56): Dargestellt ist eine Nähmaschine zwischen einem Vogel und einer Frau. Beide rahmende Gestalten nehmen eine Körperhaltung an, die sich der Form der Maschine annähert. Die Darstellung fokussiert also eine Ähnlichkeit zwischen dem Nähen und dem Vogelkörper.

Sowohl der Vogelflug als auch die Nähbewegung können als Metaphern für das Schreiben gedeutet werden. ${ }^{261}$ Dass die Tierdarstellung auf beiden Blättern gerade mit dem Motiv des Nähens verbunden wird, geht also auf den poetologischen Inhalt des Gedichts zurück. Grass' Zeichnungen unterstreichen jedoch, dass die visuell vorstellbare Ähnlichkeit der Motive im Gedicht für ihn eine entscheidende Rolle spielte. Da die Entstehungsreihenfolge von Wort und Bild in diesem Fall nicht rekonstruierbar ist, könnte der Dichter seinen Text mit Hilfe der Zeichnungen formuliert, oder nachträglich nach einer grafischen Darstellungsform gesucht haben, die den visuellen Aspekt der Dichtung veranschaulicht. Dass er abschließend keine der Zeichnungen im Gedichtband abdrucken ließ, mag daran liegen, dass die in „Vogelflug“ beschriebene Äquivalenz auf einer Bewegung beruht und diese von Grass im Medium der Grafik nicht treffend dargestellt werden konnte. Die herausragende Rolle, die die visuelle Wahrnehmung im Gedicht "Vogelflug" spielt, wird im Zusammenhang mit dem Vogelmotiv in Kapitel III.1. noch eingehend behandelt werden. Gleiches gilt für die Darstellung der Windhähne und -hühner, die den Umschlag des Lyrikbandes dominieren. Seine Rückseite wird vorab an dieser Stelle kurz beleuchtet, um an der Federzeichnung zu zeigen, auf welche Art Grass Formäquivalenzen in einer Zeichnung einsetzte, die im Gedichtband tatsächlich veröffentlicht wurde (Abb. 57).

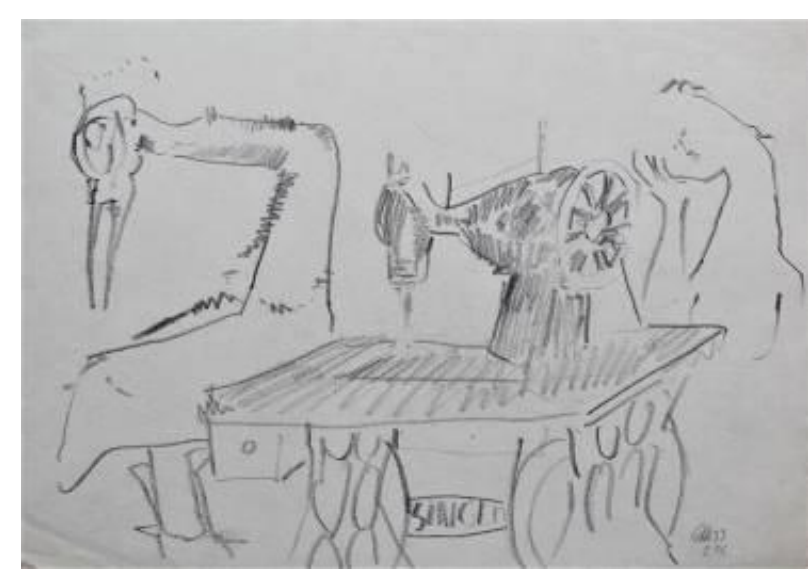

Abb. 56, o. A., Februar 1956, Bleistift

${ }^{261}$ Vgl. Scheffer (2007), S. 9-27. 


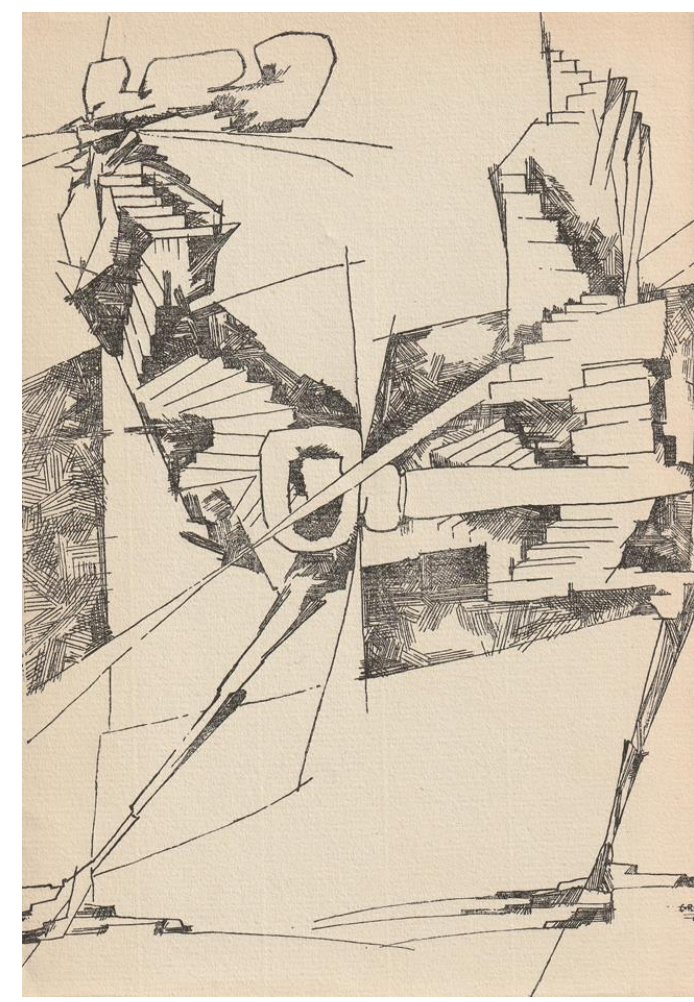

Abb. 57, Die Vorzüge der Windhühner, BerlinFrohnau/Neuwied am Rhein 1956, Umschlag, Rückseite

Die für die Rückseite des Buchumschlags verwendete Darstellung zeigt Motive, die im programmatischen ersten Gedicht des Bandes, „Die Vorzüge der Windhühner“, als bildgebende Elemente von Metaphern des Allegorischen zu finden sind. Die Verbindung von Gedicht und Zeichnung wird in diesem Fall besonders betont, da sich dieser Text auf der vorderen Innenseite des Umschlags befindet.

Das Bild zeigt einen Hahn in der Seitenansicht. Seine Silhouette wird durch schmale gewundene Treppenaufgänge gefüllt, die sie vertikal in zwei Läufen durchziehen. Dem Tier ist waagerecht ein Schlüssel so vorgesetzt, dass sich sein Griff an der Stelle befindet, an der sein oberes Flügelgelenk vorstellbar wäre. Der Schlüsselbart stellt den Übergang zum rechten Treppenlauf her, der in die Konturen des Schwanzgefieders übergeht. Die gesamte Gestalt wurde vor drei scharf umrissenen, abwechselnd schraffierten und unschraffierten Flächen postiert, die an Stellwände erinnern. Weil der Bauch, der Rücken und das Hinterteil des Vogels nicht durch Umrisse konturiert sind, ergibt sich eine Verzahnung zwischen dem Tier und diesen Flächen. Die Darstellung greift insofern auch auf kubistische Gestaltungselemente zurück.

Im Gedicht „Die Vorzüge der Windhühner“, in dem Geflügel als Sinnbild für Grass’ Dichtung genutzt wird, stehen drei Verse in enger Beziehung zu dieser Zeichnung. Wie der gesamte Text antworten auch diese Zeilen auf die Frage, warum das lyrische Ich den Windhühnern so zugeneigt ist:

Weil sie die Tür offenlassen, der Schlüssel die Allegorie bleibt, die dann und wann kräht. ${ }^{262}$

${ }^{262}$ Grass (1956), Umschlag, vordere Innenklappe. 
Die durch Geflügel repräsentierte Dichtung wird in den drei Versen als interpretationsoffen und allegorisch gekennzeichnet. In die Metapher des Schlüssels gekleidet, kann die Allegorie sowohl als Bedeutungserweiterung (Aufschließen) als auch als -verengung (Abschließen) interpretiert werden. Die Dichtung, die verschiedene Deutungswege eröffnet, wird in der Zeichnung durch die Kombination des Hahns mit den beiden Treppenläufen und den hinter ihm gestaffelten Flächen (Türen) vermittelt. Krähender Hahn und Schlüssel bilden die anschauliche Seite der im Text ausformulierten Metaphern des Allegorischen, indem sie ihre Bildspender grafisch verwirklichen. Hahn, Schlüssel und Treppen werden über die Ähnlichkeit ihrer Form miteinander verzahnt.

Vergleicht man die Federzeichnung mit einer im Vorjahr entstandenen Hühnerplastik von Günter Grass (S. 67, Abb. 41), fällt die Ähnlichkeit hinsichtlich der Darstellung der Steuerfedern ins Auge. Während die Plastik als stereometrische Abstraktion von der Gestalt des Hahns ausgeführt ist, ging der Künstler mit seiner Grafik einen Schritt weiter und kombinierte die aus der Betrachtung gewonnene Form mit einer anderen, die mit ihr assoziiert werden kann. Nachdem der Bildhauer sich ausgiebig mit der Körperform des Tieres auseinandergesetzt hatte, nutzten Grafiker und Dichter in diesem Fall die aus der plastischen Arbeit gewonnenen Beobachtungen zur Auffindung sinnstiftender Analogien.

Das Betrachten der Zeichnung ergänzt die Lektüre: Die semantische Verbindung der Motive des Textes leuchtet im Anschluss an die Bildbetrachtung auch visuell ein. Diese Kooperation der beiden Medien wird durch die stilistische Gestaltung der Zeichnung unterstützt, die alle Federzeichnungen des Bandes gemeinsam haben. Die dargestellten Gegenstände sind darin aus einzelnen, über das Objekt hinaus gezogenen Linien zusammengesetzt, die sie eher zweidimensional in die Fläche einbetten, als dass sie die Illusion von Volumen hervorbringen. In einigen Fällen werden die Gegenstände kubistisch in Teilflächen zerlegt und neu zusammengesetzt. In ihrer Flächigkeit und betonten Freisetzung der Linie nähern sich die Bilder der Typografie der gedruckten Texte an.

Andere im Gedichtband verwendete Zeichnungen erzeugen Bedeutungen, indem sie Objekte aus unterschiedlichen Kontexten in überraschenden Zusammenstellungen zeigen, ohne dass Formäquivalenzen einen Übergang zwischen den Bildelementen herstellen. Zu dem Gedicht „Bohnen und Birnen“ schuf Grass eine Federzeichnung, die eine Spinne in einem leeren Weinglas zeigt (Abb. 58). Das Dargestellte hat eine direkte Entsprechung im Text. Genau in der Mitte des Gedichtes bringt die Beschreibung dieses ,Stilllebens' einen Zustand des Rückzugs zum Ausdruck:

BOHNEN UND BIRNEN

Bevor die grünen Dotter welken -

die Hennen brüten einen frühen Herbst -,

jetzt gleich, bevor die Scherenschleifer

den Mond mit hartem Daumen prüfen, der Sommer hängt noch an drei Fäden, den Frost verschließt ein Medaillon, noch eh die Hälse nackt, vom Nebel halb begriffen, bevor die Feuerwehr die Astern löscht und Spinnen in die Gläser fallen, um so der Zugluft zu entgehen, vorher, bevor wir uns verkleiden, 
in ärmliche Romane wickeln,

laßt uns noch grüne Bohnen brechen.

Mit gelben Birnen, einer Nelke,

mit Hammelfleisch laßt uns die grünen Bohnen,

mit schwarzer Nelke und mit gelben Birnen,

so wollen wir die grünen Bohnen essen,

mit Hammelfleisch, mit Nelke und mit Birnen.

Der im Gedicht angekündigte, durch den Winter bedingte Rückzug erschließt sich für Betrachterinnen und Betrachter aus der Kombination und der Form der dargestellten Bildelemente: des auf Windstille angewiesenen Spinnentieres, das sich an seinem vertikal gespannten Faden in den konkaven, auch sexuell als weiblich konnotierten Schutzraum abseilt. Ebenso wie der Vogelflug kann auch die Fadenproduktion der Spinne als Metapher für das Schreiben gedeutet werden, was in der Zeichnung besonders einleuchtet, weil der Faden der Spinne als betonte Linie unter den zahlreichen Linien der Zeichnung als Ausdrucksform des Grafikers wie des Dichters hervorgehoben wird. ${ }^{263}$ Die surreale Vergrößerung der Spinne in der Federzeichnung erlaubt es, gleichermaBen das Tier und die Gesamtanordnung der Szene zu erkennen. Die Bedeutung des Bildes leuchtet unmittelbar ein, ist zeitlos, allgemeingültig und der Alltagswelt entnommen, wodurch sie für die Betrachtenden in besonderem Maße nachvollziehbar ist. Auch in dieser Zeichnung werden die Gegenstände aus geraden, sich überlagernden und kreuzenden Linien zusammengesetzt. Wie besonders an den Umrissen des dargestellten Weinglases erkennbar ist, wird die Illusion von Dreidimensionalität auf diese Weise unterbunden und die Zeichnung damit dem Text angenähert. Der sich aus dieser Gestaltungsweise ergebende Konstruktionscharakter des Dargestellten verdeutlicht darüber hinaus, dass es sich bei den Darstellungen um Artefakte, um eine von dem Zeichner hergestellte Realität handelt.

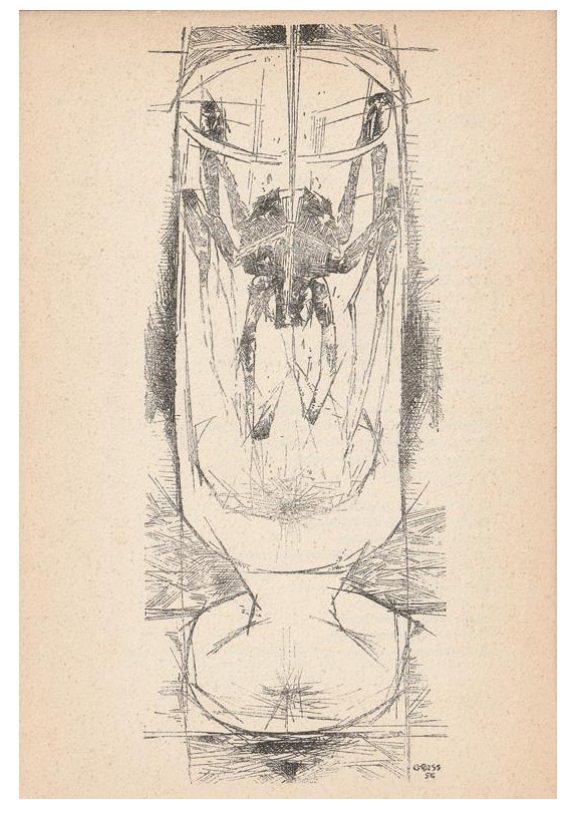

Abb. 58, Die Vorzüge der Windhühner, Berlin-Frohnau/ Neuwied am Rhein 1956, S. 6

\footnotetext{
${ }^{263}$ Vgl. zur Spinne und ihrem Netz als einem Sinnbild für Künstler und Kunst auf der Grundlage der Meta-
} morphosen Ovids: Michalski (2010), S. 60-64. 
Die generelle Annäherung von Wort und Bild in den Vorzügen der Windhühner wird durch den Verlagskommentar bekräftigt. Der Paratext auf der Innenseite des hinteren Umschlagtitels legt Rezipientinnen und Rezipienten des Buches ausdrücklich nahe, Wort und Bild zueinander in Verbindung zu setzen. Im Flattersatz gehalten, lehnt sich der Text an die im Buch versammelte Lyrik an:

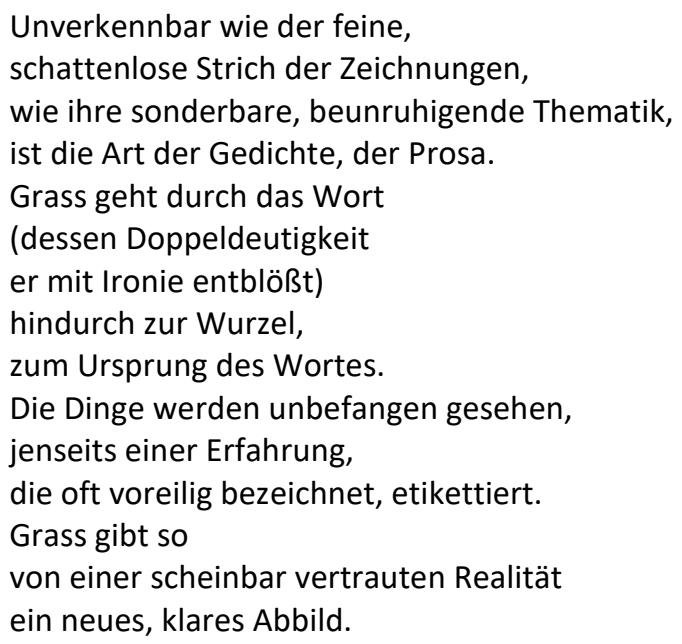

In diesem Kommentar wird die Ästhetik der intermedialen Veröffentlichung erläutert: Texte und Bilder lösen gleichermaßen einzelne Objekte aus ihren Kontexten und Funktionszusammenhängen und kombinieren sie in einer Weise, die neue Bedeutungszusammenhänge schafft. Wie exemplarisch gezeigt werden konnte, stehen in den Gedichten Kompositionen im Mittelpunkt, die visuell durch die Erscheinung ihrer Form unmittelbar einleuchten und in Gegenüberstellungen, kubistisch anmutenden Verzahnungen, surrealistischen Metamorphosen und Überblendungen zueinander in Beziehung gesetzt werden. Die Konzentration auf das alltäglich Sichtbare, die eine Loslösung von Objekten aus ihren üblichen Zusammenhängen befördert („Die Dinge werden unbefangen gesehen"), wird durch die beigefügten Federzeichnungen des Dichters hervorgehoben.

Mit seinen figurativen Grafiken und Plastiken bewegte sich Grass zusehends außerhalb des nonfigurativ dominierten, zeitgenössischen Kunstmarkts. Je mehr er gegen Ende seines Studiums als bildender Künstler Fuß zu fassen versuchte, desto stärker betraf ihn die Mitte der Fünfzigerjahre ihren Höhepunkt erreichende Debatte über gegenständliche und gegenstandslose Kunst, die bereits im Darmstädter Gespräch einen Vorläufer hatte. ${ }^{264}$ Erst nachträglich, am deutlichsten in seinem Erinnerungsbuch, stellte Grass fest, dass sein Beharren auf der figurativen Bildkunst den weiteren Verlauf seiner Karriere mitbestimmte:

Das hatte Folgen: nur in Einzelausstellungen, und immer abseits der wechselnden Moden, konnte sich mein künstlerisches Werk behaupten; so blieb es randständig bis heute. (X 588)

Der Berliner Kunststreit hatte auch über Grass' Karriereverlauf als bildender Künstler hinaus Konsequenzen für sein Schaffen: Zusammen mit der frühen Prägung durch die Klassische Moderne während des Studiums in Düsseldorf bot er für Grass den Ausgangspunkt um bestimmte ästhetische Positionen mit ethischen Haltungen zu koppeln. Seine Gedanken hierzu formulierte er nicht 
unmittelbar. Er brachte sie erst ab 1957 zu Papier und nahm sie von da an wiederholt, mit wechselnden Schwerpunkten auf. Die entscheidenden Stationen dieser Auseinandersetzung zeichnet der folgende Exkurs nach. Er bildet den theoretischen Hintergrund für die darauffolgenden Motivanalysen. 


\section{Exkurs: Gegenständlichkeit und Moral}

Spätestens seit Ende des Jahres 1954 kombinierte Grass in seiner Lyrik Schilderungen alltäglicher Objekte aus disparaten Zusammenhängen miteinander. Gleiches gilt für die ab Mitte 1955 im Zusammenhang mit den Gedichten entstandenen Zeichnungen. In die Periode dieses Umbruchs fällt die Debatte zwischen dem Kunstkritiker Will Grohmann und dem Akademiedirektor Karl Hofer. Die innerhalb des Künstlerbundes bereits seit Jahren geführte Diskussion um die Geltung von gegenstandsloser und figurativer Kunst geriet 1955 ins Zentrum der öffentlichen Aufmerksamkeit.

Der Kunsthistoriker Will Grohmann war 1948 von Dresden nach Westberlin gezogen und von Karl Hofer an die HfBK berufen worden. Neben seiner Lehrtätigkeit verfasste Grohmann, der bereits in der Weimarer Republik publizistisch als Vermittler der Avantgarden in Erscheinung getreten war, Kritiken für Die Neue Zeitung - ein von den amerikanischen Besatzern herausgegebenes Blatt. In seinen Artikeln trat Grohmann in der ersten Hälfte der Fünfzigerjahre immer deutlicher als Förderer der gegenstandslosen Kunst in Erscheinung. ${ }^{265}$

Hofer dagegen stand dieser Kunst kritisch gegenüber. Er befürchtete die Entwicklung des Nonfigurativen zu einer beliebigen, „reinen unmenschlichen Artistik“ und vertrat damit eine konservative Position, die mit den Ausführungen Hans Sedlmayrs vergleichbar ist. Hofer brachte seine Meinung ab 1950 in Reden und Essays zum Ausdruck. ${ }^{266}$ Obzwar seine Einstellungs- und Ausstellungspolitik als Hochschuldirektor und Präsident des Künstlerbundes von seiner persönlichen Haltung weitgehend unbeeinflusst blieb, lösten seine öffentlichen Äußerungen angesichts der von inm bekleideten Ämter Befremden unter den gegenstandslos arbeitenden Künstlern aus. Der Konflikt eskalierte 1954/1955 mit dem Übergang auf die Presse-Bühne:267

In einer Ausgabe der Zeitschrift Constanze wurde Hofer 1954 mit der angeblich im Rahmen eines Interviews gefallenen Bemerkung zitiert: „Als ich dahinter kam, wie einfach es ist, gegenstandslos zu malen, hat mich diese Art Malerei nicht mehr interessiert. “268 Tatsächlich handelte es sich um einen stark gekürzten und zugespitzten Auszug aus Hofers Biografie Aus Leben und Kunst von 1952. ${ }^{269}$ Willi Baumeister, Ernst Wilhelm Nay und Fritz Winter traten nach der Veröffentlichung aus dem Künstlerbund aus und wurden in dieser Entscheidung nachdrücklich und nicht uneigennützig von Will Grohmann unterstützt. ${ }^{270}$ Sowohl Hofers Bemühungen, eine Richtigstellung in der Constanze zu erwirken als auch sein Versuch, die Künstler zur Rückkehr zu bewegen, scheiterten. 1955 verfasste er für die Zeitschrift Der Monat einen Aufsatz zur "Situation der bildenden Kunst". Der seit Jahrzehnten zwischen ideologisch-politischen Fronten stehende und aufgrund dessen von den Vorgängen besonders empfindlich getroffene Hofer beklagt darin nicht nur die Intoleranz der Nonfigurativen gegenüber den Figurativen, sondern greift zugleich die „Skribenten" der gegenstandslos arbeitenden Künstler und damit vor allem Will Grohmann polemisch an,

\footnotetext{
265 Vgl. Bode (2013).

266 Zitiert nach Fischer-Defoy (2004), S. 284.

${ }^{267}$ Vgl. Kat. Ausst. Leipzig (2004), S. 162-171.

268 Die Ausgabe wurde am 12.11.1954 veröffentlicht.

269 Hofer (1952).

${ }^{270} \mathrm{Vgl}$. zu den Auseinandersetzungen innerhalb des Deutschen Künstlerbundes, insbes. zwischen Hofer und Baumeister: Fischer-Defoy (2004).
} 
indem er den Kunstkritiker und seine Kreise mit Goebbels und dem „Nazistaat" vergleicht. Für einen zweiten Abdruck im Tagesspiegel wurde auch dieser Text des Hochschuldirektors zusätzlich radikalisiert, nämlich um relativierende Passagen gekürzt. Zudem änderte die Redaktion den Titel in: „Der Mut, unmodern zu sein“, womit sie dem Verfasser bereits einen rückwärtsgewandten Standpunkt zuschrieb. Grohmann, der zumindest phasenweise selbst unter dem „Dritten Reich“ gelitten hatte, formulierte eine scharfe Replik unter der Überschrift „Respekt vor den Tatsachen“, die in derselben Zeitung erschien. Es folgten zwei weitere Artikel von beiden Seiten, wobei der rhetorisch gewandtere Kritiker gestärkt aus der Fehde hervorging. Hofer zog entsprechende Konsequenzen und gab seinen Direktorenposten auf. Kurz nach dem Rücktritt starb er an den Folgen eines dritten Schlaganfalls. ${ }^{271}$

Die Studierenden der HfBK registrierten den schon seit Jahren schwelenden Konflikt zwischen den Positionen der Gegenständlichkeit und Gegenstandslosigkeit erst mit der Veröffentlichung von Hofers Beitrag im Monat, hatten seine Brisanz jedoch auch nach Hofers Tod noch nicht in ihrem ganzen Ausmaß erfasst. ${ }^{272}$ Proteste löste die Wahl des neuen Hochschuldirektors, des Architekten Karl Otto aus, der zuvor Direktor der Kunstgewerbeschule in Hannover gewesen war. Grass beteiligte sich an der Organisation eines Studentenstreiks. An die Motive erinnerte er sich 1989 wie folgt:

Wie nach einem Mann wie Hofer, der in jedem Fall Maßstäbe setzte, solch eine Null kommen konnte, so empfanden wir es. [...] Da mag sicher auch mit eine Rolle gespielt haben, jedenfalls was mich betraf, daß dieser Otto von den Formgebern her kam und wir Angst hatten, daß mit einem Mann dieser Art wir deformiert werden in so eine Zulieferungswerkstatt für die formgebende Industrie. [...] es war ein großes Durcheinander, eine große Wut gegen diese Entscheidung [...], ich weiß nur, daß wir alle aufgewühlt waren und diesen Otto verhindern wollten. ${ }^{273}$

Stärker mit den Inhalten der Debatte konfrontiert wurde Grass, als seine für die Ausstellung des Deutschen Künstlerbundes im Jahr 1956 eingereichten Zeichnungen mit der Begründung abgelehnt wurden, sie seien zu gegenständlich. ${ }^{274}$ Obwohl Hartung seinem Meisterschüler selbst die Bewerbung nahegelegt hatte und nach dem Tod Hofers zum Vorsitzenden des Künstlerbundes ernannt worden war, konnte er sich in der Jury nicht erfolgreich für dessen Arbeiten einsetzen. Die in Düsseldorf präsentierte Schau, in der auch Werke von Hartung und Schrieber gezeigt wurden, berücksichtigte zwar figurative Arbeiten, jedoch vor allem solche von arrivierten älteren Künstlern. Unter den jüngeren bildeten Vertreter des Tachismus einen bewusst gesetzten Ausstellungsschwerpunkt, der, wie das Presseecho bescheinigte, die jüngsten Tendenzen der zeitgenössischen Kunst spiegelte. ${ }^{275}$

\footnotetext{
${ }^{271}$ Der Ausgang des Berliner Kunststreits wirkte sich positiv auf die Popularität gegenstandsloser Ausdrucksformen bei den Kunstschaffenden aus. Einen Überblick über den Verlauf der Debatte bieten in ausführlicherer Form zahlreichen Dokumentationen. Ich stütze meinen kurzen Abriss auf Kat. Ausst. Leipzig (2004), S. 128-171 und Kat. Ausst. Berlin (1987), S. 161-201.

${ }^{272}$ In einem Gespräch mit Christine Fischer-Defoy am 22.11.1989 sagte Grass, er sei als Student nicht auf die Idee gekommen, dass Hofer über dem Konflikt gestorben sein könnte: „er war ein alter Mann, und es ist mir eigentlich auch erst später bewußt geworden, daß das so einen Zusammenhang hatte." VgI. Fischer-Defoy (1992), S. I-6.

${ }^{273}$ Ebd., S. I-5 f.

${ }^{274}$ Vgl. Grass (2014), S. 63.

${ }^{275}$ Vgl. Maiser (2007), S. 236-240 und Kat. Ausst. Düsseldorf (1956).
} 
Für Grass führte die Entscheidung zum Rückzug aus dem Kunstbetrieb. Er wendete sich zunächst verstärkt Gedichten und Theaterspielen zu und fertigte begleitend zu diesen Arbeiten Zeichnungen an. ${ }^{276}$ Die zweitaufwendigere Bildhauerei geriet von da an für Jahrzehnte ins Hintertreffen. Im August 1956 verließ er Berlin zusammen mit seiner ersten Ehefrau Anna Grass Richtung Paris, wo die Tänzerin sich dem klassischen Ballett widmen und er an seinem ersten Roman arbeiten wollte (X 632). ${ }^{277}$ Erst in der französischen Hauptstadt, aus der zeitlichen und geografischen Distanz heraus, schrieb er über den Berliner Kunststreit und zwar bezeichnenderweise im Rahmen eines poetologischen Essays.

"Der Inhalt als Widerstand" (XI 16-22) lautet der Titel des Textes, der sich im Zusammenhang mit der Debatte als Auflehnung gegen die zeitgenössischen Tendenzen der Gegenstandslosigkeit lesen lässt. Veröffentlicht wurde der Aufsatz im Mai 1957 in den Akzenten des Freundes und Förderers Walter Höllerer und gliedert sich in drei Teile: Während die erste essayistische Passage vor dem Hintergrund des Diskurses um Gegenständlichkeit und Gegenstandslosigkeit in der bildenden Kunst das Verhältnis von Form und Inhalt in allen Künsten behandelt, wendet sich der zweite, in dramatischer Form verfasste Teil mit dem Untertitel „Ein misstrauischer Dialog" gegen die von Grass selbst bis 1953/1954 vertretene, auf Naturbeschreibungen, unterbewusst gesteuerte Mechanismen und kühne Genitivmetaphern setzende Poesie. ${ }^{278}$ Der dritte Teil der Abhandlung, „Der Phantasie gegenüber", beschäftigt sich essayistisch mit dem Gegensatz von Fantasie und Realismus, in dessen Spannungsfeld sich die neuen Texte des Verfassers bewegten.

Der für den Zusammenhang des Kunststreites mit der Poetologie von Günter Grass interessante erste Textteil reibt sich zu Beginn an einem Satz aus Wassily Kandinskys 1937 publizierter Schrift Zugang zur Kunst:

Kandinsky sagte: „Die richtig herausgeholte Form drückt ihren Dank dadurch aus, daß sie selbst ganz allein für den Inhalt sorgt." (XI 16)

Form und Inhalt wurden von Grass in dieser Aussage als identisch begriffen. Dieses Äquivalenzverhältnis wird im Text durch eine Umstellung des Satzes in Frage gestellt:

Schütteln wir ihn, den Satz; seinem Sinn nach müßte er es vertragen: „Ein richtig herausgeholter Inhalt drückt seinen Dank dadurch aus, daß er selbst ganz allein für die Form sorgt." Da nun auch diese Umkehrung nicht so recht stimmen will, da sich über Form und Inhalt, Inhalt und Form nicht in einem Satz sprechen läßt, [...] soll hier versucht werden, zwischen mehreren Satzzeichen Mißtrauen auszubreiten, ja Mißtrauen zwischen Form und Inhalt zu säen. (XI 16)

Darauf folgt die Gegenposition des Verfassers: Im ersten Schritt wird der Inhalt als Herausforderung für den sich schriftlich oder bildkünstlerisch ausdrückenden Künstler beschrieben. Das überbordende gestalterische Talent des Schriftstellers, Malers oder Bildhauers wird durch diesen „Widerstand“ diszipliniert. Der kreative Schaffensprozess stellt sich dabei als handwerkliche Anstrengung dar, die darauf abzielt, einem bestimmten Inhalt eine bestimmte Form zu verleihen. Zur

\footnotetext{
${ }^{276}$ Vgl. Abdruck bei Grass (2014), S. 66-73, die Zeichnungen befinden sich im Besitz des Günter GrassHauses. Ursprünglich hatte Grass eine Veröffentlichung der Federzeichnungen im Rahmen einer Veröffentlichung seiner ersten drei Theaterspiele geplant.

${ }^{277} \mathrm{Vgl}$. ebd., S. 63.

${ }^{278}$ Vgl. Hartung (1984), S. 156.
} 
Veranschaulichung dient das Beispiel des figurativ arbeitenden Bildhauers Aristide Maillol, der mehrere Künstlergenerationen und, wie oben bereits erörtert, auch Karl Hartung und Ludwig Gabriel Schrieber prägte:

Und eine Tugend mehr nennen heißt, jener zu gedenken, die sich da abplagten und gegen den Inhalt schrieben, malten oder sich, wie Maillol, Jahr für Jahr dasselbe rundliche Mädchen ansahen, um der formenden Hand zu helfen, um eine Kniescheibe deutlich zu machen und einen Halswirbel so einzubetten, daß nur die wahren Halswirbelfetischisten ihn entdecken.- (XI 16)

Im zweiten Schritt werden Form und Inhalt als die beiden unverzichtbaren Bestandteile eines literarischen oder visuellen Kunstwerks beschrieben, die sich zeitlich und proportional in einem angemessenen Verhältnis zueinander befinden müssten, damit ein ästhetisches Produkt zustande kommen kann. Der Moment der Inspiration wird dabei allegorisch als Attentat dargestellt:

\begin{abstract}
Form oder Formgefühl hat man, trägt es wie eine Bombe im Köfferchen, und es bedarf nur eines Zünders - nennen wir inn Story, Fabel, roter Faden, Sujet oder auch Inhalt -, um die Vorbereitungen für ein lange geplantes Attentat abzuschließen und ein Feuerwerk zu zeigen, das sich in rechter Höhe, bei günstiger Witterung entfaltet; mit dem dazugehörigen Knall, einige Sekunden nachdem das Auge etwas zu sehen bekam. Denn - und alle Attentäter, auch jene literarischer Herkunft, mögen mir hier zustimmen - bleibt der Zünder oder der Inhalt zu lange im Köfferchen, wird voreilig, vorzeitig entschärft, ist das Verhältnis zwischen Bombe und Zündung unverhältnismäßig, kurz, wird mit Kanonen auf Spatzen oder mit Spritzpistolen auf Pottwale geschossen, lacht das noch zu benennende Surrogat der vormals so leicht zu belustigenden Götter. (XI 16 f. Hervorhebung V. K.)
\end{abstract}

Der Inhalt aktiviert also demnach erst das Formgefühl und dieser „Anschlag“ kann erst gelingen, wenn „das Auge etwas zu sehen“ bekommt, der bildende Künstler oder Dichter also visuell angeregt wird.

In einem dritten Schritt werden Konstellationen beschrieben, in welchen das Verhältnis von Form und Inhalt aus dem Gleichgewicht geraten ist. Zunächst werden kurz die „Formverächter" genannt, die dem Inhalt eine zu große Bedeutung beimessen. Der Inhalt wird im Folgenden als ein besonders schwer zu entdeckendes Objekt umschrieben - schwer zu entdecken, weil es auf den ersten Blick allzu alltäglich scheint:

Ein echter Inhalt, das heißt ein widerspenstiger, schneckenhaft empfindlicher, detaillierter, ist schwer aufzuspüren, zu binden, obgleich er oftmals auf der Straße liegt und zwanglos tut. Inhalte nutzen sich ab, verkleiden sich, stellen sich dumm, nennen sich selbst banal und hoffen dadurch, der peinlichen Behandlung durch Künstlers Hand zu entgehen. (XI 17)

Die „inhaltsfeindlichen“ Künstler, denen sich ein gutes Drittel des Textes widmet, hätten ihre Einstellung aus Frustration heraus erworben: Sie seien entweder nicht in der Lage gewesen, einen Inhalt ausfindig zu machen oder nicht fähig, inn angemessen zu behandeln. Auf diese stereotype konservative Polemik - im Grunde formulierte Grass hier eine weitere Radikalisierung der in der Constanze verzerrt abgedruckten Meinung Hofers - folgt eine als direktes Zitat markierte Persiflage der Ansprüche und Positionen jener Künstler, die unschwer als die „Gegenstandslosen“ zu erkennen sind: ${ }^{279}$

${ }^{279}$ Vgl. Hermand (1986), S. 413-416, S. 476-483. 
Wenn Künstlers Hand eine Zeitlang gesucht hat, doch leer blieb oder Gefundenem nicht geschickt genug war, schimpft Künstlers Mund über Inhalte, und Künstlers Kopf erinnert sich ureigenster, formaler Fähigkeiten und Qualitäten. „Es kommt nicht auf das Was an nur auf das Wie. Der Inhalt stört nur, ist Konzession, fürs Publikum, die Kunst will die Form an sich, die Kunst ist zeitlos, muß Raum und Zeit überwinden, hat schon überwunden, nur die im Osten, die machen noch auf sozialen Realismus [...]." - Was kann man nicht alles machen, wenn man Phantasie hat. Neue Perspektiven, Konstellationen, Strukturen, Aspekte, Akzente; und alles noch nie dagewesen. (XI 17)

Mit dieser Kritik schließt sich der Kreis zum Eingangsverweis auf Kandinsky, in dessen Tradition sich die „inhaltsfeindlichen“ Künstler sahen. ${ }^{280}$ Zugleich wird die Erörterung zum Verhältnis von Form und Inhalt mit den eindeutigen Verweisen auf die Nonfigurativen innerhalb eines bestimmten Diskurses positioniert. Das Plädoyer für eine Kunst und Literatur, die die Form und die dem Leben entnommenen Inhalte gleichermaßen als eigenständige Aspekte des Kunstwerks wichtig nimmt, erweist sich damit als Reaktion auf den in Berlin ausgetragenen Konflikt. ${ }^{281}$

Die Koppelung einer poetologischen mit einer kunsttheoretischen Auseinandersetzung hat gemeinsam mit der Verwendung von Allegorie und Personifikation noch einen anderen Effekt: Grass' Poetologie wird anschaulich und die Selbstauskunft des Dichters darüber hinaus zum Exempel für ihre stilistische Umsetzung. Der abstrakte Begriff des Inhalts nimmt als rundliches Mädchen, als Halswirbel, als Bombenzünder und als Straßenmüll Gestalt an. Zwar wird er noch nicht explizit als Gegenstand benannt, aber als solcher beschrieben und behandelt. Wenn der Inhalt als Widerstand bezeichnet wird, kündigt sich darin, in der ursprünglichen Bedeutung des Wortes („Widerstand“ als etwas, das etwas Anderem entgegensteht), bereits der Gegenstand an.

In einem kurzen Text aus dem Jahr 1958, erschienen im Sammelband Lyrik unserer Zeit. Gedichte und Texte, führte Grass diese noch ausstehende begriffliche Substitution zu Ende. In dem kurzen Beitrag „Über das Schreiben von Gedichten“ (XI 23) wird der Inhalt nicht nur durch verschiedene Objekte repräsentiert, sondern explizit und ausschließlich als Gegenstand bezeichnet. Zudem fügte Grass der poetologischen Bedeutungsebene dieser Veröffentlichung auch eine produktionsästhetische hinzu: Ausführungen über das Beschreiben, Zeichnen oder Modellieren eines Inhalts werden nicht mehr vergleichend nebeneinandergesetzt, sondern als einander bedingende Arbeitsabläufe in der Werkstatt des mehrfachbegabten Künstlers und Dichters angeführt. Sie werden nun auch genauer spezifiziert, denn der Dichter gibt Objekte nach eigener Aussage nicht mimetisch wieder, sondern unterzieht sie einer Analyse, nimmt sie auseinander, um sie in einer neuen, spannungsreichen Konstellation wieder zusammenzufügen. Die Zielsetzung dieses Programms, im Zusammenhang mit welchem zum ersten Mal auch der Terminus „Realismus" fällt, ist eine ideologiefreie Darstellung des Wahrgenommenen:

In meinen Gedichten versuche ich, durch überscharfen Realismus faßbare Gegenstände von aller Ideologie zu befreien, sie auseinanderzunehmen, wieder zusammenzusetzen und in Situationen zu bringen, in denen es schwerfällt, das Gesicht zu bewahren, in denen das Feierliche lachen muß, weil die Leichenträger zu ernste Miene machen, als daß man glauben könnte, sie nehmen Anteil.

\footnotetext{
280 Vgl. ebd., S. 402.

281 Vgl. Mertens (2005), S. 87. Zu dieser Erkenntnis kam bereits Mertens, schloss daraus jedoch, bei „Der Inhalt als Widerstand“ handele es sich „nicht um die poetische Selbstreflexion eines beginnenden Schriftstellers, als die der Aufsatz oft verstanden wurde", sondern um ein politisches Statement. Dem ist zu widersprechen, da der ästhetische Diskurs und die poetologischen Ausführungen aller drei zur Veröffentlichung gehörenden Texte sie, wie oben beschrieben, maßgeblich kennzeichnen.
} 
Oft kommt mir mein anderer Beruf entgegen und erlaubt, den zu fixierenden Gegenstand von allen Seiten zu zeichnen. Erst dann erfolgt die Niederschrift des Gedichts. Die Aufgabe des Versemachens scheint mir darin zu bestehen, klarzustellen und nicht zu verdunkeln; doch muß man manchmal das Licht ausknipsen, um eine Glühbirne deutlich machen zu können. (XI 23)

Eine ethische Dimension gegenständlichen Arbeitens, wie sie 1950 bereits von Grass' Lehrer Otto Pankok und vehementer von Hans Sedlmayr unter religiösen Vorzeichen dargelegt worden war, entfaltete Grass selbst in diesen essayistischen Texten noch nicht. Seine literarischen Werke bringen jedoch diese Ebene seiner Ästhetik ab 1959 zum Ausdruck. Konzentriert formulierte Grass diesen Zusammenhang in dem Gedicht "Diana oder die Gegenstände“, das er in seinem zweiten Gedichtband Gleisdreieck (1960) zusammen mit einer Fettkreidezeichnung publizierte (Abb. 59). ${ }^{282}$

Über eine Doppelseite erstreckt sich die Darstellung einer monumentalen, in ihren Proportionen gestauchten Frauenfigur. Ihren Körper richtet sie in Schrittstellung nach rechts, ihrem ausgestreckten linken Arm folgend. In ihrer übergroßen linken Hand hält sie eine Armbrust. Ihren Kopf wendet die Göttin zurück zu dem über ihrer Schulter hängenden Köcher, nach dem sie mit ihrer Rechten greift. Obgleich die Darstellung sich eindeutig an der berühmten Diana von Versailles orientiert (Abb. 60), entspricht die gezeichnete Frauenfigur nicht dem antiken griechischen Ideal. Nicht die Schönheit und Eleganz eines athletischen Frauenkörpers wird betont, sondern die Entschlossenheit und die Massivität, die sich in Dianas markanter Geste realisiert und die durch die abstrahierende Gestaltung der Glieder und die energische Umrisszeichnung hervorgehoben wird. Hinsichtlich des Stils erinnert die Darstellung an Frauengestalten der neoklassischen Phase im Werk Picassos wie seine Deux femmes courant sur la plage / Zwei laufende Frauen am Strand aus dem Jahr 1922 (Abb. 61). ${ }^{283}$

\footnotetext{
282 Vgl. Stolz (1994), S. 56.

$283 \mathrm{Zu}$ dem in seinem Widerspruchsreichtum vergleichbaren Klassizismus Picassos vgl. Cowling (1988): Picassos Hinwendung zu antiken Formen ab 1914 wurde stets durch Übertreibungen und Verzerrungen konterkariert. Cowling deutet seinen „Kolossalstil“ schlüssig als Ausdruck von antikischer Melancholie angesichts der Kriegstragödie und als Teil seiner Auseinandersetzung mit Nietzsches Konzept des Dionysischen.
} 


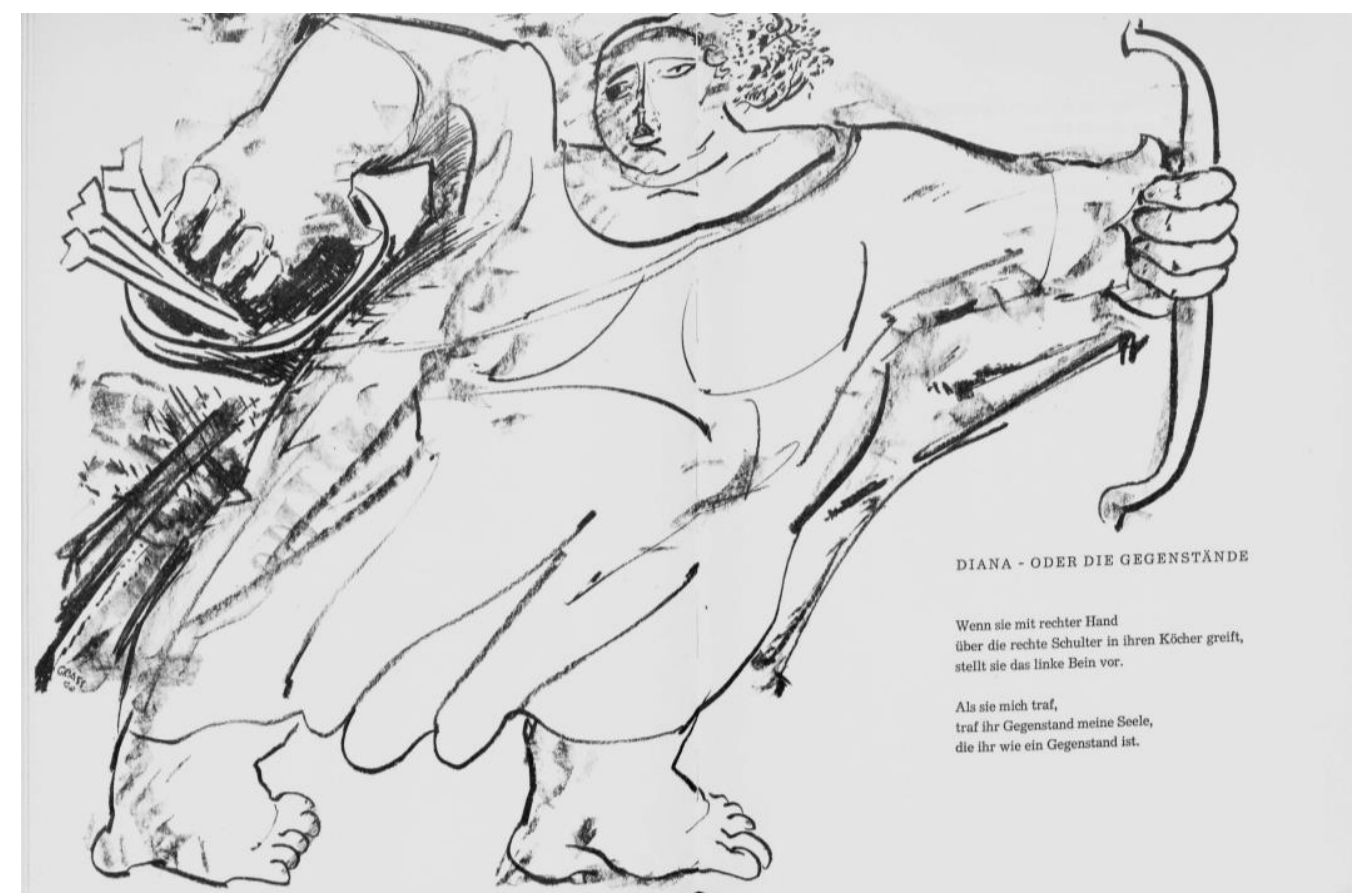

Abb. 59, Gleisdreieck, Darmstadt 1960, S. 72 f.

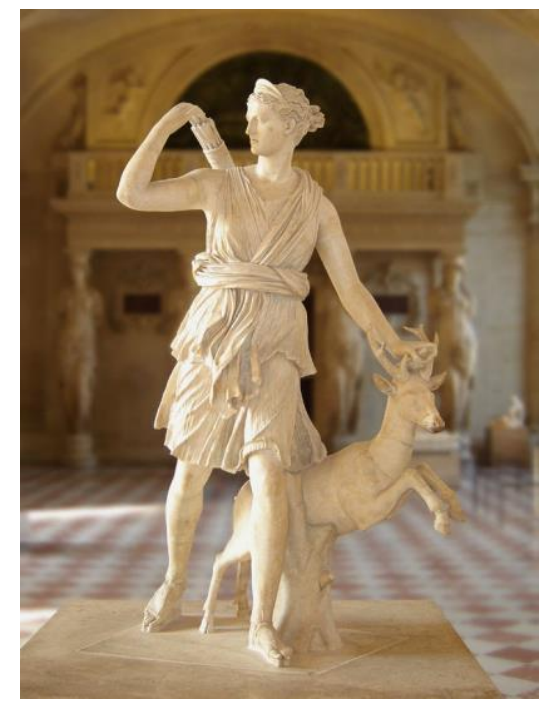

Abb. 60, Nach Leochares, Artemis, Göttin der Jagd, genannt „Diana von Versailles", erste Hälfte des zweiten Jh. n. Chr. (Kopie, Original: 340-320 v. Chr.), Marmor

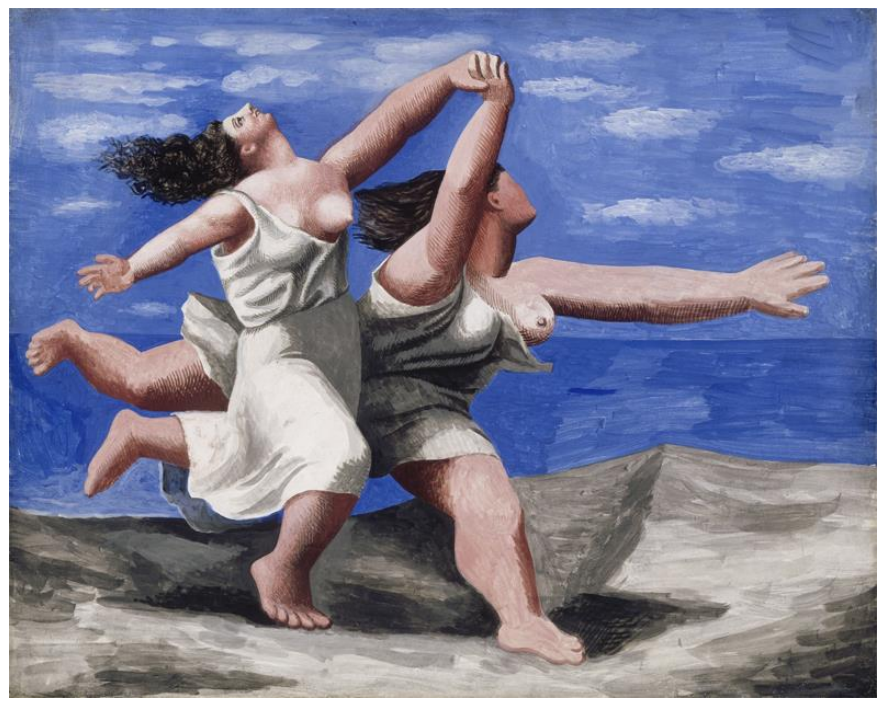

Abb. 61, Pablo Picasso, Zwei laufende Frauen am Strand, 1922, Öl auf Leinwand 
Grass' Gedicht nimmt in der ersten und vierten Strophe in Form einer Ekphrasis unmittelbar auf die griechische Darstellung Dianas und damit auch auf seine eigene Zeichnung Bezug und begründet mit ebendieser ästhetischen Materialisierung der Jagdgöttin, weshalb gerade sie, im Gegensatz zu anderen Ideen, für ihn „gegenständlich“ sein kann:

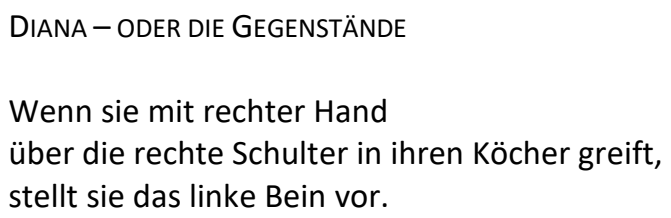

Doch du, Diana, mit deinem Bogen bist mir gegenständlich und haftbar.

Das Gedicht vollzieht nach, wie das lyrische Ich der in der Plastik anschaulich gewordenen Göttin zur Beute wird. Dianas Eigenschaften werden abwechselnd zu Standpunkten des lyrischen Ichs thematisiert, sodass Ähnlichkeiten zwischen beiden deutlich werden: Genauso wie das lyrische Ich zeigt sich auch die Göttin ausschließlich von "Gegenständen der Natur" beeindruckt; ihnen wird die "schattenlose Idee“ gegenübergestellt. Ein empiristischer Standpunkt wird auf diese Weise an einem Kunstwerk veranschaulicht, ohne Begriffe und Ideen per se aus dem Interessensgebiet des Iyrischen Ichs auszuschließen. Die figurative Kunst leistet die Veranschaulichung, die für den Sprechenden allerdings unverzichtbar ist, um sich mit ihnen auseinanderzusetzen, weil sie nur so Teil der wahrnehmbaren Wirklichkeit werden. ${ }^{284}$

Diana ist dem lyrischen Ich als Artefakt nicht nur "gegenständlich", sondern auch "haftbar". Mit diesem letzten, dem juristischen Bereich entlehnten Wort erhält die Plastik eine ethische Di-

\footnotetext{
${ }^{284}$ Wie bereits Zissel-May treffend hervorhob, ergibt sich dabei über die Art des Kunstwerks, die Darstellung einer Göttin, eine Parallele zwischen Grass' Ästhetik und der Funktionsweise des Mythos: „So wie im Mythos das Gegenstandslose konkret Gestalt annimmt, so wird in der Grass'schen Lyrik das GedanklichAbstrakte vergegenständlicht." Vgl. Zissel-May (1974), S. 165 und Stolz (1994), S. 61.
} 
mension: Sie bezieht sich erkennbar auf etwas, ist darin überprüfbar und weniger sie als der Künstler, der sie erschaffen hat, ist für das Dargestellte zur Verantwortung zu ziehen. Diese Beobachtung wird nicht als allgemeingültige Aussage formuliert, sondern ausdrücklich als Auffassung des Sprechenden, der damit ein poetologisches Statement setzt.

In Form einer Gesellschafts- und Kulturkritik brachte Grass seine Meinung in aller Deutlichkeit erst sehr viel später zum Ausdruck: in der Rede "Geschenkte Freiheit", die er während seiner Amtszeit als Präsident der Akademie der Künste am 8. Mai 1985 anlässlich des vierzigsten Jahrestages der deutschen Kapitulation vortrug. Der Schriftsteller hatte darin die in der Bundesrepublik nach der Währungsreform in Kraft getretenen Verdrängungsmechanismen angeprangert. Einen Schwerpunkt legte er auf die Rolle der Künste in den Fünfzigerjahren, die sich der Auseinandersetzung mit Gegenwart und Vergangenheit durch die Tendenz zur Gegenstandslosigkeit beziehungsweise zu einer mystizistischen Naturlyrik entzogen hätten. Seine Auffassung vermittelte Grass aus seiner persönlichen Erfahrung, aus der Erinnerung an seine Studienjahre in Berlin heraus:

Als ich im Januar 1953 als junger Bildhauer nach Berlin kam, liefen die Künste Gefahr, ins Unverbindliche abzudriften. Wenn in der Literatur herkömmliches Gräserbewispern preiswürdig war und Autoren wie Wolfgang Koeppen und Arno Schmidt im Abseits blieben, stand in der bildenden Kunst die Moderne ganz vorn; freilich nur dann, wenn sie sich gegenstandslos anbot. Von all dem Häßlichen, das man glücklich hinter sich zu haben meinte, sollte möglichst nichts zu erkennen sein. Chiffren, ja. Ornamente, gewiß. Auch Materialien, Strukturen die Menge, die reine Form. Nur Überdeutliches nicht, nichts, das als Bild schmerzte. Kein Dix, kein Kirchner, kein Beckmann zwang das erlebte Grauen ins Bild.

Der heftige, bis in den Künstlerbund hineingetragene Streit zwischen dem "gegenständlichen“ Maler Karl Hofer und Will Grohmann, dem Apologeten der „Gegenstandslosigkeit", bedeutete Mitte der fünfziger Jahre mehr als im Kunstbereich übliche Polemik: Es ging auch um das Wahrnehmen oder Übersehen der Wirklichkeit in einem Land, das geschlagen, geteilt war, dessen zu verantwortende Last Völkermord hieß und das dennoch oder deshalb im Begriff war, alles zu verdrängen, ich sage gegenstandslos zu machen, was die Vergangenheit heraufbeschwören und die Flucht nach vorne behindern konnte.

Eine merkwürdige Avantgarde tat sich zusammen: die des stromlinienförmigen technischen Fortschritts im Zeichen wirtschaftlicher Zuwächse und die der alle Wirklichkeit aussparenden Großformate [...] pompös betitelte Unverbindlichkeiten, die sich der Wiederaufbauarchitektur und dem Zeitgeist fügten. Indem in der DDR zeitparallel der „sozialistische Realismus“ alles andere als Realität gestaltete, wurde, trotz gegensätzlicher Ismen, ein gesamtdeutscher Konsens gefunden: Die Gegenstandslosigkeit triumphierte. Wer hier oder drüben in Bildern Zustände spiegelte, sich am Realen rieb, wurde ausjuriert. Nicht Carl Hofer, Will Grohmann behielt das letzte Wort. Was heute kurios anmutet, war damals herrschende Gegebenheit: Während innenpolitisch die Restaurierung obrigkeitsstaatlicher Machtverhältnisse Fortschritte machte, ließ sich eine unkritische Avantgarde, die sich allenfalls formalen Widersprüchen aussetzte, nach außen als Zeugnis neudeutscher Modernität und Weltoffenheit vorweisen. (XII 149 f., Hervorhebung V. K.)

Grass' Meinung nach spiegelte sich sowohl in der Ästhetik der Gegenstandslosigkeit als auch in ihrer allgemeinen Popularität in den Fünfzigerjahren das gesamtgesellschaftliche Bestreben, die Vergangenheit und ihre allzu gegenwärtigen Konsequenzen zu verdrängen. Wieder kommt dem Sehsinn bei dieser Argumentation eine wichtige Rolle zu: Das Sehen und das Darstellen des Gesehenen wird als Bedingung gesellschaftlich verantwortungsbewussten Handelns beschrieben. Hinsichtlich des "Wahrnehmens" der Wirklichkeit macht Grass zwischen Leben und Kunst keinen Unterschied. Zu der Schärfe, mit der er seine Auffassung formulierte, trug vielleicht bei, dass er 
sich in seinem eigenen Schaffen zeitgleich so eingehend mit ökonomischen und ökologischen Krisen beschäftigte wie nie zuvor: Nachdem 1980 Kopfgeburten oder die Deutschen sterben aus erschienen war, folgte 1986 Die Rättin als episches Großwerk und darauf in kurzen Abständen Zunge zeigen (1988) und Totes Holz (1990). In seiner Polemik gegen die "epigonalen" Gegenstandslosen der Nachkriegszeit ließ Grass womöglich deshalb - in Anbetracht der großen Verantwortung, die er dem Künstler als einem Augenzeugen katastrophaler Zustände zusprach - keinen Raum für Differenzierungen.

In den ersten Nachkriegsjahren hatte es durchaus Versuche gegeben, Kriegsleid und Zerstörung ins Bild zu setzen, doch hinterließen diese Werke ästhetisch keinen nachhaltigen Eindruck und verschwanden auch aus diesem Grund bald von der Bildfläche. Die Ausstellungen des Künstlerbundes zeigten in der ersten Hälfte der Fünfzigerjahre durchaus Werke expressionistischer Meister. Dass Arbeiten von Max Pechstein und Otto Dix, die zu der Künstlergeneration gehörten, an die Grass als Kunststudent in Düsseldorf Anschluss suchte, 1953 nicht in die Schau aufgenommen wurden, lag, so die Auswertung der DKB-Dokumentation von Myriam Maiser, daran, dass die von ihnen eingereichten Werke ästhetische Schwächen aufwiesen und in ihrer Qualität stark gegen die früheren Arbeiten der Maler abfielen. Ihre abgelehnten Gemälde wiesen im Übrigen keinen gesellschaftskritischen Gehalt auf. ${ }^{285}$ Die grundsätzliche Problematisierung des Kulturschaffens nach Ausschwitz, wie sie in Deutschland seit 1949 am einflussreichsten von Adorno geleistet worden war, ${ }^{286}$ wurde von Grass in seiner Rede nicht erörtert, sondern mit einem Rückgriff auf die figurative Kunst der Zwischenkriegsjahre aufgehoben.

1985 löste die Auffassung des Akademiepräsidenten unter den bildenden Künstlerinnen und Künstlern jedoch vor allem deshalb Empörung aus, weil er der gegenstandslosen Kunst jegliches gesellschaftskritische Potenzial abgesprochen hatte. Weder nahm Grass die Bemühungen und den Anspruch der Nonfigurativen zur Kenntnis, sich den herrschenden politischen Ideologien durch neue Ausdrucksformen entziehen zu wollen, noch zollte er der intellektuellen Leistung der abstrakten Kunstsprachen Anerkennung, Inhalte durch gegenstandslose Formen zum Ausdruck zu bringen. Im Umkehrschluss stellte er die Gegenständlichkeit als notwendiges Kriterium eines politisch relevanten Kunstwerks dar.

Ähnlich wie im Fall Hofer wurden die Äußerungen des Schriftstellers besonders vehement kritisiert, weil er sie in einer repräsentativen Funktion, als Akademiepräsident vortrug - die Kritik äußerten besonders diejenigen, die sich durch inn repräsentiert sehen mussten, die Mitglieder der Akademie der Künste. Bei der 63. Mitgliederversammlung vom 8. bis zum 10. November 1985 bildete Grass' Rede deshalb einen Punkt auf der Tagesordnung. Eberhard Roters, Leiter der Abteilung bildende Kunst, formulierte im Namen der bildenden Künstlerinnen und Künstler eine Kritik an der "Geschenkten Freiheit", und damit zugleich auch an Grass' Kunstverständnis, das in der Akademie bereits vor dem 8. Mai diskutiert worden war:

Wir sind der Auffassung, daß die Sprache des Mediums bildende Kunst von Günter Grass nicht begriffen worden ist. Wir möchten unsere Bedenken dagegen äußern, daß dieses Mißverständnis vom

\footnotetext{
${ }^{285}$ Vgl. Maiser (2007), S. 138-146.

${ }^{286}$ Vgl. zur Rezeption der einschlägigen Texte Adornos und ihrer Aussagekraft für die Debatten um Abstraktion und Gegenständlichkeit in der Nachkriegszeit: Godfrey (2007), S. 9-11.
} 
Präsidenten öffentlich ex kathedra als allgemeinverbindliche Erkenntnis vorgetragen wird, [...] das Mißverständnis in der Auffassung, daß die gesellschaftliche Verpflichtung der bildenden Kunst sich im Grunde genommen allein in der gegenständlichen moralischen Allegorie äußern könne und der daraus folgenden Unterstellung, nicht-figurative und nicht-erzählerische Kunst, mit anderen Worten, die sogenannte ungegenständliche Kunst sei von vornherein unverbindlich und experimentiere allein im Ästhetischen, so daß sich der Künstler, der ungegenständlich arbeitet, letztlich gesellschaftlich verantwortungslos verhalte. Dem ist zu widersprechen. Um es kurz zu machen: Da die bildenden Künstler, ihrer Eigenart gemäß mehr dazu geneigt sind, sich visuell zu äußern als verbal, haben die Mitglieder auf ihrer heutigen Abteilungssitzung ihr Meinungsbild in einem Gesamtkunstwerk zusammengefaßt, ich muß dazu sagen, ich habe noch nie so eine lustige Abteilungssitzung erlebt! ${ }^{287}$

Bei dem „Gesamtkunstwerk" handelte es sich um eine für den Schriftsteller gebastelte Blindenarmbinde, die ihm unverzüglich überreicht wurde. ${ }^{288}$ Grass, der das Geschenk mit Humor entgegennahm, verteidigte seine Meinung, die nicht pauschal gegen alle gegenstandslose Kunst gerichtet gewesen sei und auf die besonderen gesellschaftspolitischen Umstände in den Fünfzigerjahren in der Bundesrepublik Bezug genommen habe:

Weder in dem Hoferschen Aufsatz, noch in meinen Worten erschöpft sich mein Verständnis von gegenständlicher Kunst, ich nenne unter anderem Kirchner und Beckmann, auch gegenständliche moralische Allegorien. Ich will mich jetzt nicht zurückziehen und in drei Punkten antworten, aber ein Hörapparat und ein Lesegerät wäre vielleicht ihrer Abteilung zu wünschen.[...] Ich habe zum Beispiel ein starkes, schon seit vielen Jahren anhaltendes Verhältnis zu Bildern von Mondrian, ich habe sehr viel für die Bilder von Wols übrig [...], aber ich habe sehr viel gegen diese epigonalen Bewegungen, die es in den fünfziger Jahren in der Bundesrepublik en masse gegeben hat, und die haben den Ton bestimmt, und die paßten in die Landschaft, und in diesem Zusammenhang hatte ich, wenn sie so wollen, meine Polemik eröffnet. 289

Das von Grass in der angegriffenen Rede formulierte Gegenbild zu den gegenstandslosen „epigonalen Bewegungen“, das Ideal einer figurativen Kunst, die „das Grauen ins Bild" gezwungen hätte oder zumindest „Zustände spiegelte“ drängt die abschließende Frage nach einer Verortung der Arbeiten auf, die Grass selbst in dieser Zeit schuf. Zweifellos waren seine Plastiken und Grafiken gegenständlich und stellten gerade vor dem Hintergrund der gegenstandslosen Kunst der Fünfzigerjahre ein Bekenntnis zur Realität dar. In der Konzentration auf das alltägliche Tier als Sujet ist ferner eine Zivilisationskritik angedeutet. ${ }^{290}$ Dennoch: Bis zur Entstehung der ersten gattungsübergreifenden Text-Bild-Kompositionen erfüllten seine Arbeiten die von ihm Jahrzehnte später selbst als Ideal postulierten Kriterien eines engagierten Kunstwerks nicht. Erst im Zusammenhang mit den Vorzügen der Windhühner begann er sich in Wort und Bild mit aktuellen gesellschaftlich relevanten Themen auseinanderzusetzen. In der ,Danziger Trilogie' kam die deutsche Vergangenheit ausdrücklich ins Spiel. In Verbindung mit ihr flossen Querverweise auf eine ethische Bewertung der zeitgenössischen bildenden Kunst in die Werke ein. Sowohl für Grass' Bilder als auch für

287 Vgl. die transkribierten Tonbandaufzeichnungen in: Stiftung Archiv der Akademie der Künste (1997), S. 304.

288 Anwesend waren bei dieser Abteilungssitzung am 8./9. November 1985: Joseph Beuys, Max Bill, Rupprecht Geiger, Mathias Goeritz, Erwin Heerich, Gerhard Hoehme, Werner Hofmann, Horst Egon Kalinowski, Fritz Koenig, Heinz Mack, Arnulf Rainer, Eberhard Roters, Bernard Schultze, K. R. H. Sonderborg, Daniel Spoerri, Rolf Szymanski, Fred Thieler, André Thomkins (in der Nacht zum 9.11. verstorben) und Heinz Trökes. Vgl. ebd, S. 303.

${ }^{289} \mathrm{Vgl}$. ebd., S. 305.

${ }^{290}$ Vgl. S. 81 dieser Untersuchung. 
seine Literatur blieb das Sehen dabei eine unerlässliche Bedingung und ein literarisches Motiv mit Signalwirkung. ${ }^{291}$ Obwohl sich über Grass' Verständnis der gegenstandslosen Kunst streiten lässt, konnte eine Blindenbinde gerade für ihn kein angemessenes Geschenk darstellen.

${ }^{291}$ Kniesche wies zu Recht darauf hin, dass diese Verwendung des Motivs in Heinrich Bölls „Bekenntnis zur Trümmerliteratur“ (1952) einen unmittelbaren Vorläufer gefunden haben könnte. In dessen Essay heißt es: „[...] man schien uns zwar nicht verantwortlich zu machen dafür, daß Krieg gewesen, daß alles in Trümmern lag, nur nahm man uns offenbar übel, daß wir es gesehen hatten und sahen, aber wir hatten keine Binde vor den Augen und sahen es: ein gutes Auge gehört zum Handwerkszeug des Schriftstellers." Vgl. Böll (1952), S. 58 und Kniesche (2002), S. 8. 


\section{MOTIVWANDERUNGEN IM UMKREIS DER, DANZIGER TRILOGIE' (1959, 1961, 1963): ZWISCHEN ARTISTIK UND GESELLSCHAFTSKRITIK}

\section{Vögel: Geflügelte Zeichen einer neuen Ästhetik}

Die Vogelfigur ist das erste Motiv, das Grass mehrfach zwischen verschiedenen künstlerischen Ausdrucksformen wandern ließ und variierte:292 Nachdem er sich 1951 bis 1952 in lockeren Tuschezeichnungen und seit 1953 in Plastiken, Kreidezeichnungen und Druckgrafiken mit Hähnen und Hühnern beschäftigt hatte, waren von 1954 an auch langgestreckte Stelzvögel in den verschiedenen Kunstgattungen hinzugekommen. 1954 bis 1956 zeichnete der Grafiker zudem Metamorphosen aus Vogel- und Frauenkörpern, wobei ihm sowohl surrealistische Bildwerke als auch der mythologische Stoff "Leda und der Schwan“ als Inspirationsquelle dienten.

In seiner Lyrik behandelte Grass diverses Geflügel vereinzelt schon ab 1951, verwendete es aber erst in den Gedichten zu den Vorzügen der Windhühner (1956) als poetologisch bedeutsames Motiv. Beschreibungen des Haushuhns verknüpfte er im Titelgedicht des Bandes mit spezifischen Kennzeichen seiner Dichtung. Das Vogelmotiv im Allgemeinen nutzte Grass zudem als Sinnbild für Kunst und Künstler und griff dabei mitunter auf traditionell mit dem Motiv in Verbindung stehende Bedeutungen zurück. ${ }^{293}$ Ab 1957 leitete es zu anderen Elementen seines Motivschatzes über: Zu Nonnen und Vogelscheuchen, die er ebenso in Zeichnungen realisierte wie in der Blechtrommel (1959) und in den Hundejahren (1963).

Dass Geflügel von Grass ab 1960 auch in andere als poetologische Zusammenhänge gestellt wurde, machte bereits Benedikt Engels in seiner Untersuchung zum lyrischen Umfeld der ,Danziger Trilogie' deutlich. ${ }^{294}$ Im bebilderten Lyrikband Gleisdreieck sind sie Teil einer kritischen allegorischen Auseinandersetzung mit religiös-spekulativem Denken. In Zeichnungen aus den späten Siebzigerjahren können sie als sinnbildliche Darstellung der aggressiven Konfrontation interpretiert werden. Die vorliegende Analyse konzentriert sich auf die Medienwechsel von den studentischen, fast ausschließlich bildkünstlerischen Arbeiten hin zu den Dichtungen der Vorzüge der Windhühner, zu welchen wiederum Tierzeichnungen und Plastiken entstanden sind. Die Medienkompositionen aus lyrischen Texten und Zeichnungen in Grass' erstem Gedicht- und Kurzprosaband bieten sich zur rezeptionsästhetischen Analyse der Wechselwirkungen zwischen grafischen und sprachlichen Realisierungen des Vogelmotivs an. Wie oben im Zusammenhang mit Grass' Entwicklung als bildender Künstler und Dichter in Berlin erörtert worden ist, wird die visuell wahrnehmbare Erscheinung von Dingen in diesen Texten verstärkt evoziert und durch die Visualisierung derselben Motive in den beigefügten Federzeichnungen zusätzlich hervorgehoben. Wie im Folgenden zu zeigen sein wird, fällt diese Art der Annäherung von Wort und Bild in Zusammenhang mit dem Vogelmotiv ganz besonders ins Auge. Es ist gerade das ausgiebig studierte Sujet des

\footnotetext{
292 Eine erste Zusammenstellung der bildkünstlerischen veröffentlichten Vogeldarstellungen bis 1986 leistete: Hille-Sandvoss (1987), S. 84-96. Eine Aktualisierung bietet das Motivverzeichnis der vorliegenden Studie. ${ }^{293} \mathrm{Vgl}$. zum Vogel als einem Symbol des Geistes, der Seele und der Idee: Lurker (1988), S. 773 f.; zum Vogelmotiv in poetologischen Darstellungen vgl. Scheffer (2007), S. 9-27.

${ }^{294} \mathrm{Vgl}$. Engels (2005), S. 33-36, S. 74-82. Die von Engels in seine Untersuchung einbezogenen Vogeldarstellungen werden im Motivverzeichnis angeführt.
} 
bildenden Künstlers, an dem eine von der visuellen Wahrnehmung ausgehende Ästhetik in Wort und Bild in Erscheinung tritt. Erste bildkünstlerische Umsetzungen des Motivs schuf Grass bereits in seiner Düsseldorfer Studienzeit.

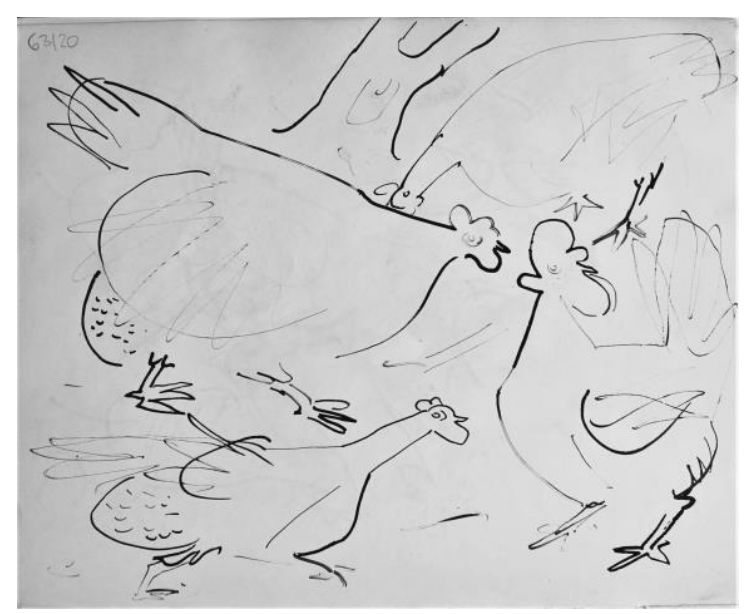

Abb. 62, Skizzenbuch, Italien, Sommer bis Frühherbst 1951, Feder/Tusche

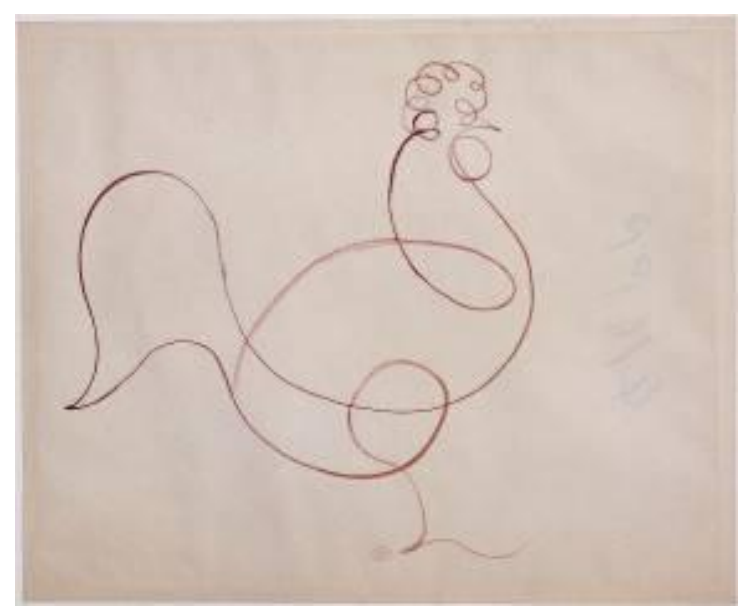

Abb. 64, Pablo Picasso, Coq/Hahn, 1918, Gouache

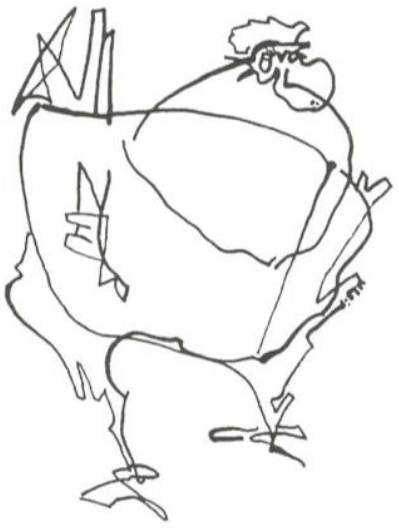

Abb. 63, Huhn, 1952, Feder/Tusche 


\section{Hühner, Hähne und Stelzvögel oder: Mimesis, Abstraktion und Metamorphose}

Während der Autostopp-Reisen durch Italien im Sommer 1951 und durch Frankreich Mitte des Jahres 1952 fertigte Grass die ersten Skizzen von Hühnern und Hähnen an. ${ }^{295}$ Arbeiten wie die hier abgelichtete von 1951 haben den Charakter von Verhaltensstudien (Abb. 62). Das vorliegende Blatt zeigt drei Hühner im Streit, in devoten wie dominanten Posen, und belegt damit Grass' Interesse am Gebaren der Tiere. Die sprichwörtlich gewordene „Hackordnung“ einer Hühnerschar könnte Grass aufgrund der Ähnlichkeit zu den sozialen Mechanismen menschlicher Gemeinschaften interessiert haben. ${ }^{296}$

Die ein Jahr später in größerer Zahl geschaffenen Skizzen, wie die hier als Beispiel angeführte Darstellung aus dem Jahr 1952 (Abb. 63), sind im Gegensatz zu den früheren Zeichnungen durch einen Strich geprägt, der eckige und spitz zulaufende Formen besonders akzentuiert. Wie Grass' andere in Frankreich entstandene Skizzen werden auch die Geflügeldarstellungen aus wenigen Linien gebildet, die kaum unterbrochen sind und in dieser Hinsicht Ähnlichkeit mit Zeichnungen Picassos aufweisen (Abb. 64): Der Vergleich des Grass'schen Geflügels mit einem von Picasso gezeichneten Huhn aus dem Jahr 1918 zeigt das Anliegen beider Künstler, ihre Figuren aus möglichst wenigen Linien zu konstruieren. Erkennbar sind jedoch auch Unterschiede zwischen den Zeichnungen: Picasso stellt das Tier durch eine einzige, sich fließend rundende Linie dar, deren Schleifen und Kurven sich am Hals und Bauch des Vogelkörpers deutlich ornamental von einer mimetischen Darstellung lösen. Die von Grass gezeichneten Vögel werden durch die Linienführung hingegen deutlicher in Einzelformen aufgespalten, die einander transparent überlagern. Seine HuhnDarstellung setzt sich aus dem unregelmäßigen Oval des Rumpfes, dem fast zum Kreis verkürzten Hals sowie den Details des Kopfes und der Beine zusammen. Der Freiheit seiner Linienführung zum Trotz wird in diesen Bildern eine bestimmte Körperhaltung der Tiere naturnah wiedergegeben. Verglichen mit Picassos Figur liegt der Schwerpunkt der Darstellungen von Günter Grass stärker auf dem Aspekt der Analyse des Objektes als auf dem Spannungsverhältnis zwischen der ornamentalen Linie und dem Erfassen des Gegenstands.

Das Sujet wählte der Student zunächst aus der Gelegenheit heraus, da Hühner und Hähne sich inm während des Wartens auf Mitfahrgelegenheiten als Modelle anboten, wie der Schriftsteller in Beim Häuten der Zwiebel erinnert (X 548). Die Studien von 1952 haben unmittelbar zu den ersten Hühnern geführt, die Grass ein Jahr später in Berlin in Ton modellierte (X 566). Mit diesen Artefakten erhob Grass ein profanes Nutztier zum bildkünstlerischen Sujet.

Unter den im Jahr 1952 niedergeschriebenen Gedichten des Arbeitstagebuches spielt das Vogelmotiv noch eine untergeordnete Rolle. Lediglich in zwei lyrischen Texten tritt es in den Vordergrund. In beiden sind die Tiermotive Teil surrealer, kühner Metaphern: In dem bereits behandelten Gedicht "Der Löschteich“ wird das Motiv des Hahns in ein aus Vogel- und Elefantenkörper zusammengesetztes Phantasiewesen integriert. ${ }^{297}$ Das folgende unveröffentlichte Gedicht bestimmen „des Himmels gläserne Hühner", ein Hahn, der singend den kommenden Tag ankündigt und „der Blume verwandt[e]“ Tiere:

\footnotetext{
${ }^{295}$ Ein Skizzenbuch aus dem Jahr 1951 und eines aus dem Jahr 1952 befindet sich im Besitz der Günter und Ute Grass Stiftung.

${ }^{296} \mathrm{Vgl}$. Appleby (2004), S. 75.

${ }^{297}$ Vgl. S. 76-89 dieser Forschungsarbeit.
} 
Ach dem behutsamen Fleisch

Pflückten des Himmels gläserne Hühner

Alle die kleinen Gelüste.

Früh im Gebälk seines glücklichen Raumes

Singt schon der Hahn.

Tiere, der Blume verwand[t]

Weiden den kommenden Tag.

Langsame Braue der Engel

Doppelt geschweift. ${ }^{298}$

Ebenso wie in „Der Löschteich“ werden Hühner und Hähne in Verbindung mit sexuellen Konnotationen in die Morgenszenerie eingebracht. Hier jedoch werden sie zugleich in ein doppeldeutiges Sinnbild eingespannt, denn als den Himmel bewohnende, körperlos-transparente Wesen, die es auf das Entfernen fleischlicher Gelüste abgesehen haben, werden sie in eine Existenzform transponiert, die der von Engeln vergleichbar ist. In der Metapher werden einander widersprechende Elemente - das profane fluguntaugliche Huhn, dessen Bewegung des Aufpickens von "kleinen Gelüsten" einen Akt moralisch-sittlicher Reinigung vermittelt, und die himmlische Sphäre - in einer Genitivkonstruktion zusammengefasst. Die Identität von "Tieren, der Blumen verwandt", mit Hühnern ergibt sich assoziativ über die kelchförmigen Körper der bodenständigen Vögel und damit über eine Form, die Grass in seinen Tierplastiken durch stereometrische Abstraktionen besonders hervorhob (S. 67, Abb. 41).

Als Bildhauer thematisierte er nicht nur Hühner, sondern auch Hähne in unterschiedlichen Körperhaltungen, 1954 in zwei Steingüssen (Abb. 65, Abb. 66). Deutlicher als in Grass' Skizzen ist an ihnen ein Spannungsverhältnis zwischen der Wiedergabe einer natürlichen Bewegung und der harmonischen Struktur ihrer Gestalt erkennbar. Die grafischen Darstellungen der Vögel aus dem Jahr 1954 zeigen dagegen die Tendenz, die Figur und ihr Umfeld über eine ornamentale, von der tatsächlichen Beschaffenheit eines Tierkörpers unabhängige Binnenschraffur miteinander zu verbinden. Die hier abgedruckte Radierung zeigt exemplarisch die Vernetzung zwischen einem Lebewesen und seiner Umgebung, die bereits in den von Pankok und Picasso angeregten Reiseskizzen der Jahre 1951 und 1952 angestrebt war. (Abb. 67)
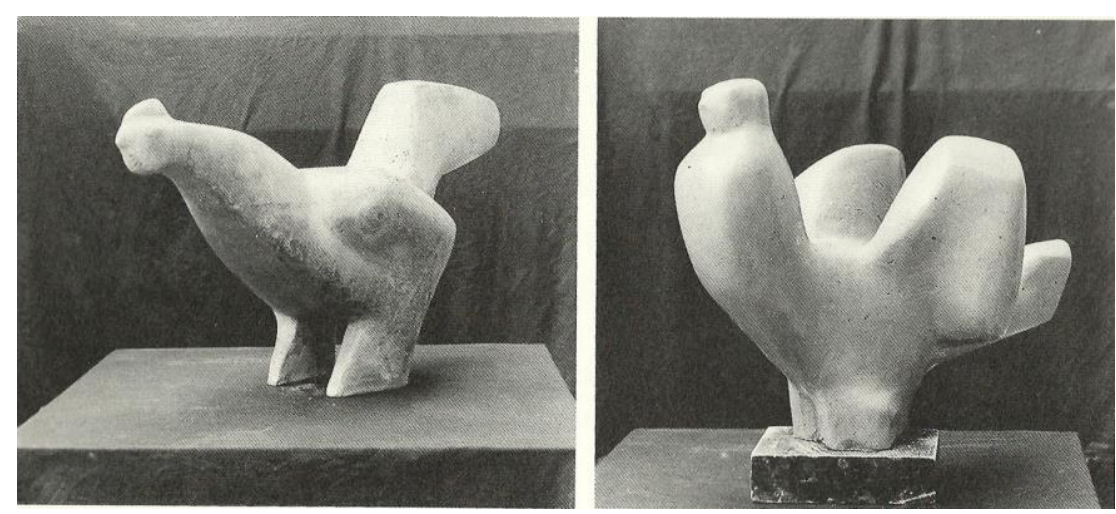

Abb. 65, Abb. 66, Huhn, 1954, Steingüsse

${ }^{298}$ Akademie der Künste, Berlin, Günter-Grass-Archiv, Nr. 965, S. 15, hs., Transkription: V. K. 


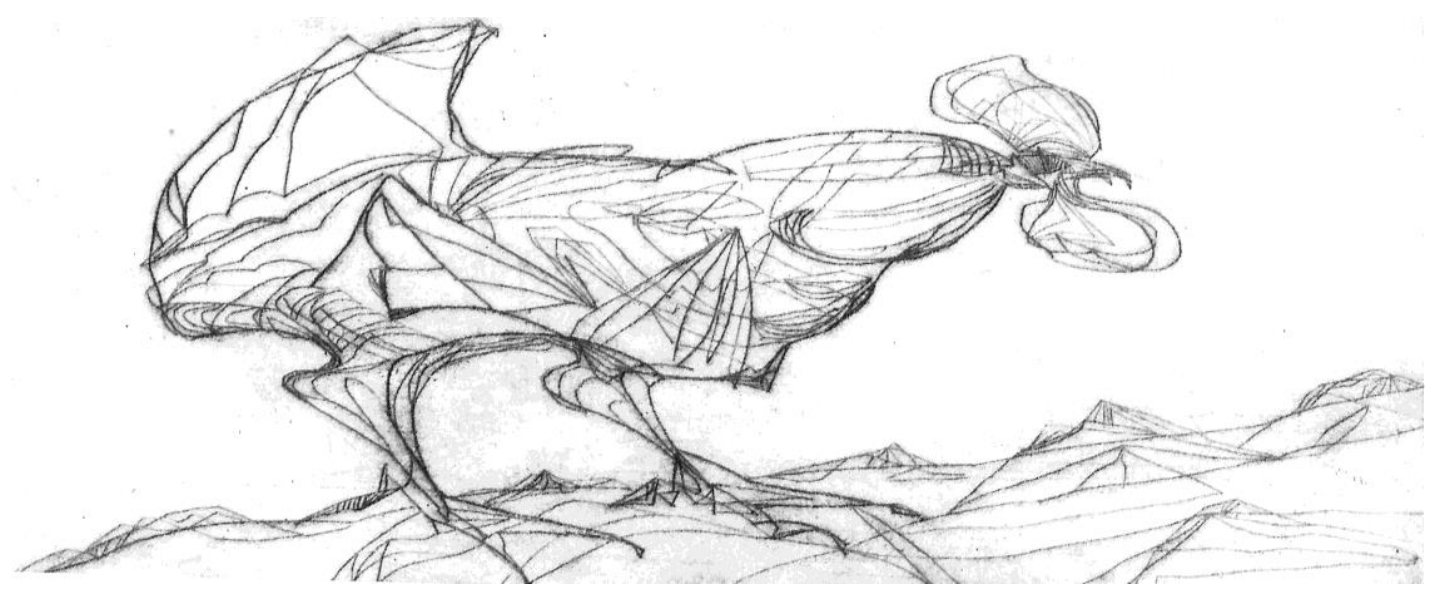

Abb. 67, Hahn im Gebirge, 1954, Radierung

Ab 1954 gestaltete Grass auch schlanke, langbeinige Vögel mit großen Schnäbeln. In einer unnatürlich aufrechten Haltung dargestellt, erinnern sie häufig an menschliche Figuren. Feder- und Kohlezeichnungen aus dem Jahr 1954 visieren eine Assimilation der Proportionen von Vogel- und Menschenkörpern an. Zwei Zeichnungen zeigen dieses Verschmelzen beispielhaft (Abb. 68, Abb. 69). Es wird in den Arbeiten verstärkt, indem die Beine der Tiere in einer für Vögel unüblichen Position dargestellt werden, wenn sie das Spielbein grazil vor das gestreckte Standbein führen. Während der Stelzvogel in der Tuschezeichnung durch eine einzige Linie gestaltet wird (Abb. 68), zeigt inn die Fettkreidezeichnung in einer Zusammensetzung aus schraffierten Formen und Flächen (Abb. 69). Wie zum Vergleich hatte Grass die beiden Arbeiten nachträglich auf einem Passepartout nebeneinander angebracht. Die Kreidezeichnung wirkt zweidimensionaler, da sie aus deutlich konturierten Flächen zusammengesetzt ist, die weniger Volumen suggerieren als die verschlungenen Linien der Federzeichnung. Zudem erscheint die Kohlezeichnung surrealer als ihr Gegenstück, da die Binnengliederung der Teilflächen, die den Vogelkörper generieren, an Oberflächen von Laubblättern erinnern. Es handelt sich um eine mit diesem Kontrast spielende Figurenkonstruktion, die Grass auch an anderen Sujets zur Anwendung brachte. ${ }^{299}$ Eine Tuschezeichnung zu einem Ballettentwurf aus dem Jahr 1955 zeigt die Annäherung zwischen Menschen und Tieren noch deutlicher (Abb. 70): Eine Tänzerin und ein Stelzvogel führen darin synchron nebeneinander eine Arabeske aus.

${ }^{299}$ Vgl. S. 71 der vorliegenden Untersuchung. 

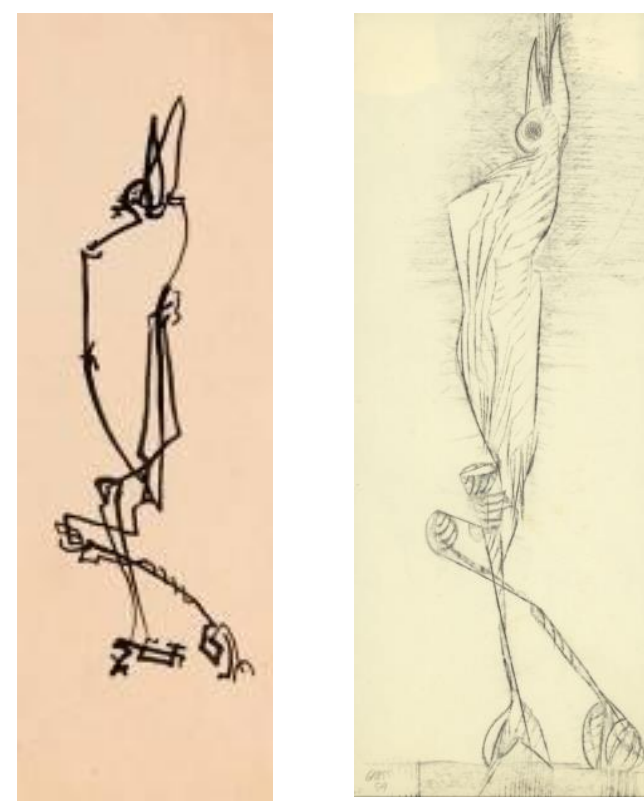

Abb. 68, Vogel, 1954, Feder/Tusche

Abb. 69, Vogel, 1954, Fettkreide

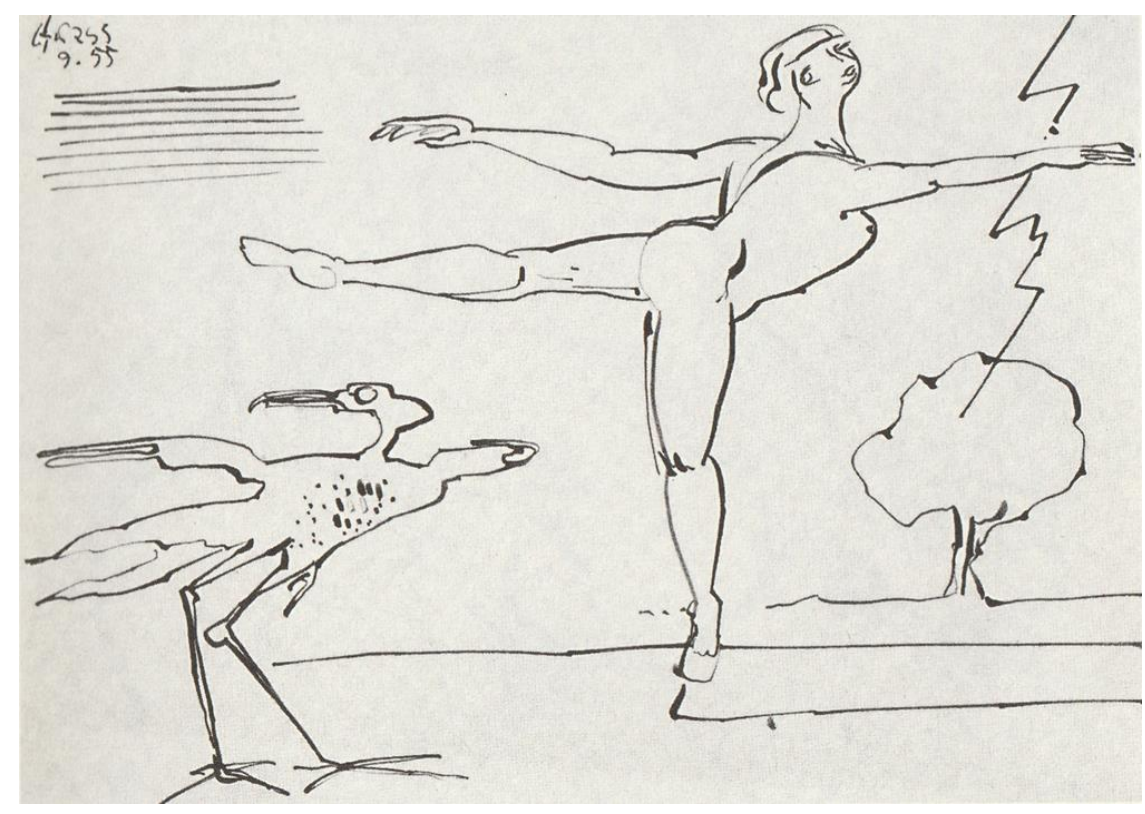

Abb. 70, Skizze für ein Ballettlibretto, 1955, Feder/Tusche 
Annäherungen zwischen Vogel- und Menschenkörpern gestaltete Grass zudem in Metamorphosen, denen der unter anderem bei Euripides und in Ovids Metamorphosen festgehaltene Mythos „Leda und der Schwan“ als Grundlage diente. Die Überlieferung spricht so: Um die mit Tyndareus, dem König Spartas, verheiratete Leda zu verführen, verwandelt sich Zeus in einen Schwan. In dieser anmutigen Gestalt lässt sich der Gott von einem Adler verfolgen, um das Mitleid der Begehrten zu erregen. Wie erwartet, versucht sie das Tier zu beschützen, woraufhin Zeus sie überwältigt und schwängert. Kurze Zeit darauf mit ihrem Gemahl schlafend, empfängt Leda wundersamer Weise auch von Tyndareus Nachwuchs, den sie in zwei Eiern austrägt: die Halbgötter Helena und Pollux sowie die Sterblichen Kastor und Klytaimnestra. ${ }^{300}$

Der Stoff wurde in der bildenden Kunst häufig zur Ausgestaltung erotischer Szenen genutzt. Eine der bekanntesten Interpretationen des Mythos' zeigt den Schwan zwischen den Beinen der nackten Leda dabei, wie er an ihren Brüsten herauf zum Kuss drängt. Mensch und Tier werden in diesem Werk von Peter Paul Rubens, das nach einem Wandgemälde von Michelangelo geschaffen wurde, kunstvoll ineinander verflochten (Abb. 71). Von Leonardo da Vinci stammt ursprünglich eine Komposition, die nur in Kopien überliefert ist, wie in der hier abgedruckten „Spiridon-Leda“ von Francesco Melzi (Abb. 72). ${ }^{301}$ Leda steht Betrachterinnen und Betrachtern darin frontal und gänzlich unverdeckt gegenüber. Während der verhältnismäßig große Schwan, dessen Kopf bis an ihre Schultern reicht, sie mit einem seiner Flügel umfasst, legt Leda beide Arme um seinen Hals und zieht inn zärtlich zu sich heran.

An Grass' Darstellungen fällt im Gegensatz zu diesen bekannten Werken auf, dass sie weniger eine erotische Spannung transportieren, als vielmehr die vergleichende Konfrontation der tierischen mit der menschlichen Körperform sowie deren Vereinigung in den Mittelpunkt rücken. In einer Tuschezeichnung aus dem Jahr 1955 sind die Frau und der aufrecht neben ihr stehende Vogel ähnlich wie in dem Gemälde nach Leonardo nahezu gleich groß dargestellt (Abb. 73). Die Flügel des Tieres umfangen die Nackte auch hier, während züngelnde Federn auf die Scham der Frau weisen. Die Dargestellte selbst scheint dem Tier gegenüber keineswegs aufgeschlossen: Ihren Blick wendet sie von ihm ab und schafft, indem sie ihre Hand wie zur Fütterung vor seinen Schnabel hält, eine räumliche Grenze zwischen sich und dem Vogel. Die beiden Körper werden einander auf diese Art deutlich, wie zum Vergleich, gegenübergestellt.

Eine weitere Zeichnung von Grass aus dem Jahr 1956 (Abb. 74) zeigt Leda und den Schwan dagegen in einer engen Umarmung. Die Konturen der Frauendarstellung kreuzen die Umrisslinien der Vogelfigur, sodass ihre Gestalt oberhalb der Stirn nach kubistischer Manier in den Hals des Tieres überzugehen scheint. Der zeitgenössisch geschnittene Hut, den Grass' aktualisierte Leda trägt, weist eine biomorphe, an eine Versteinerung erinnernde Oberfläche auf. Diese setzt sie auch über die formale Durchdringung der Figuren hinaus zum knochigen Kopf des Tieres in Beziehung.

\footnotetext{
${ }^{300}$ Vgl. Schneider (2005), S. 408-412.

${ }^{301}$ Leonardo soll das Gemälde 1508 geschaffen haben. Es wurde jedoch zerstört und ist nur noch in Kopien wie der hier abgedruckten von Francesco Melzi, der sogenannten Spiridon-Leda, ehemals in Besitz der Gräfin Spiridon, erhalten. Vgl. Schneider (2005), S. 408-412.
} 
Noch augenfälliger ist die Anverwandlung von Frau- und Vogelkörper in einer Zeichnung aus dem Jahr 1955: Die linke Seite des darin präsentierten Porträts bestimmt ein Vogelkopf, während die rechte Seite einen Teil eines Frauenkonterfeis zeigt (Abb. 75). Obwohl der Kopf der Figur nahezu frontal ausgerichtet ist, wird an der menschlichen Seite des Antlitzes die antikisierte Profillinie besonders betont. Daran angefügt ist der Vogelkopf in der Seitenansicht, so dass sein Schnabel formidentisch einen der beiden Frauenzöpfe verdeckt, die in der Aufsicht wiedergegeben sind. Die Verbindung der beiden Wesen wird zudem dadurch betont, dass das Vogelauge nahezu an der Stelle platziert ist, an der sich bei einem rein menschlichen Porträt das rechte Auge der Frau befunden hätte. Die multiperspektivische Darstellung der Figur wie auch die Art der Zusammenführung beider Gestalten kann auch in diesem Fall als eine Konsequenz der Grass'schen Beschäftigung mit dem Kubismus betrachtet werden. Das griechische Profil verleiht der Figur einen überzeitlichen, mythischen Charakter.

Die behandelten Metamorphosen zwischen Vogel und Mensch setzen die Annahme einer engen Verwandtschaft zwischen Mensch und Tier voraus, die Grass' Weltbild maßgeblich kennzeichnete. ${ }^{302}$ Der auf einer körperlichen Vereinigung und Zeugung basierende und symbolisch aufgeladene Stoff „Leda und der Schwan“ war nicht nur formal-ästhetisch für den Grafiker interessant, sondern bot gleichzeitig die Möglichkeit, ihn literarisch zur dichterischen Selbstreflexion zu nutzen.

Grass arbeitete zu Beginn des Entstehungsjahres der Zeichnungen, dem Arbeitstagebuch nach am 20. Januar 1955, auch an einem Gedicht zu „Leda und der Schwan“, von dem nur die ersten Verse lesbar sind. ${ }^{303}$ Es liegt nahe, dass er den Mythos, ebenso wie vor ihm Hölderlin, Mallarmé und Rilke, für eine poetologische Auseinandersetzung nutzen wollte. ${ }^{304}$ Abgeleitet von dem Apollo-Mythos gilt der Schwan seit der Antike als Symbol des Dichters und der Dichtung. ${ }^{305}$ Diese Konnotationen dürften für Grass besonders interessant gewesen sein, weil auf ihrer Basis der Moment der poetischen Inspiration - die „Befruchtung“ der poetischen Sprache (verkörpert von Leda) durch den Dichter (verkörpert durch den Schwan) - veranschaulicht werden konnte. Grass' Methode der ungewöhnlichen Kombination von Figuren und Objekten in grafischen Bildern und Metaphern passte zudem per se sehr gut zu diesem Stoff. Die programmatischen Gedichte der Vorzüge belegen, dass das Formulieren der eigenen Schaffensprinzipien für Grass um 1955 ein wichtiges Anliegen war. In den meisten von ihnen spielen zwar keine Schwäne, jedoch andere Vögel eine entscheidende Rolle. ${ }^{306}$

\footnotetext{
302 Vgl. S. 68 f. dieser Arbeit.

${ }^{303}$ Akademie der Künste, Berlin, Günter-Grass-Archiv, Nr. 1755, S. 154.

${ }^{304} \mathrm{Vgl}$. Schneider (2005), S. 408-412.

${ }^{305} \mathrm{Vgl}$. ebd.

${ }^{306}$ In Gleisdreieck spielt der Schwan eine entscheidende Rolle für Grass' eigene dichterische „Vermessung“, nämlich im poetologischen Gedicht: „Racine läßt sein Wappen ändern“, Grass (1960), S. 58.
} 


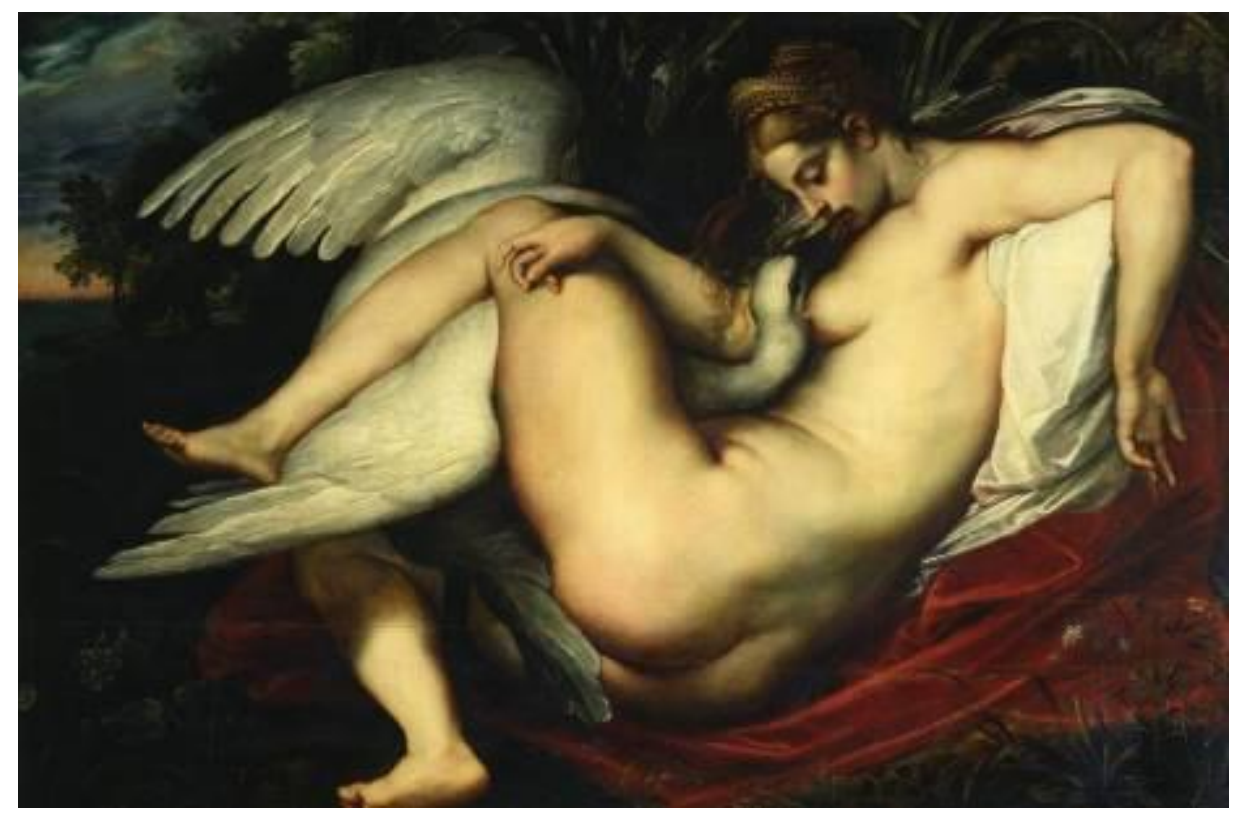

Abb. 71, Peter Paul Rubens, Leda mit dem Schwan, 1598-1600, Öl auf Eichenholz

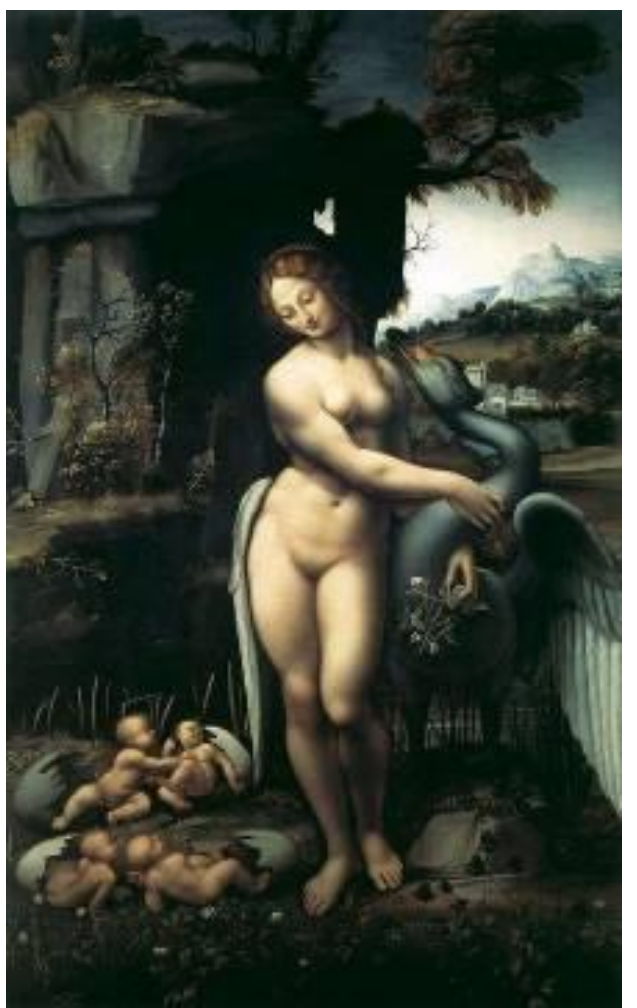

Abb. 72, Francesco Melzi nach Leonardo da Vinci, Leda und der Schwan, 1505-1518, Öl auf Holz

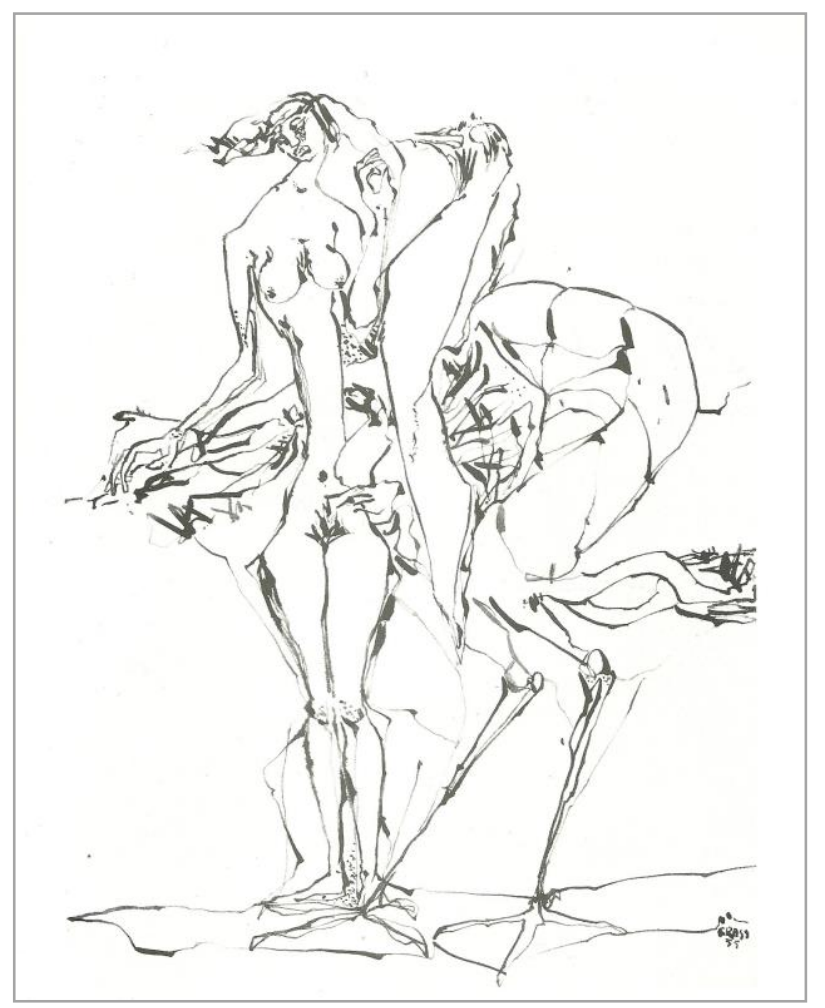

Abb. 73, Frau mit Vogel/Leda, 1955, Feder/Sepia 


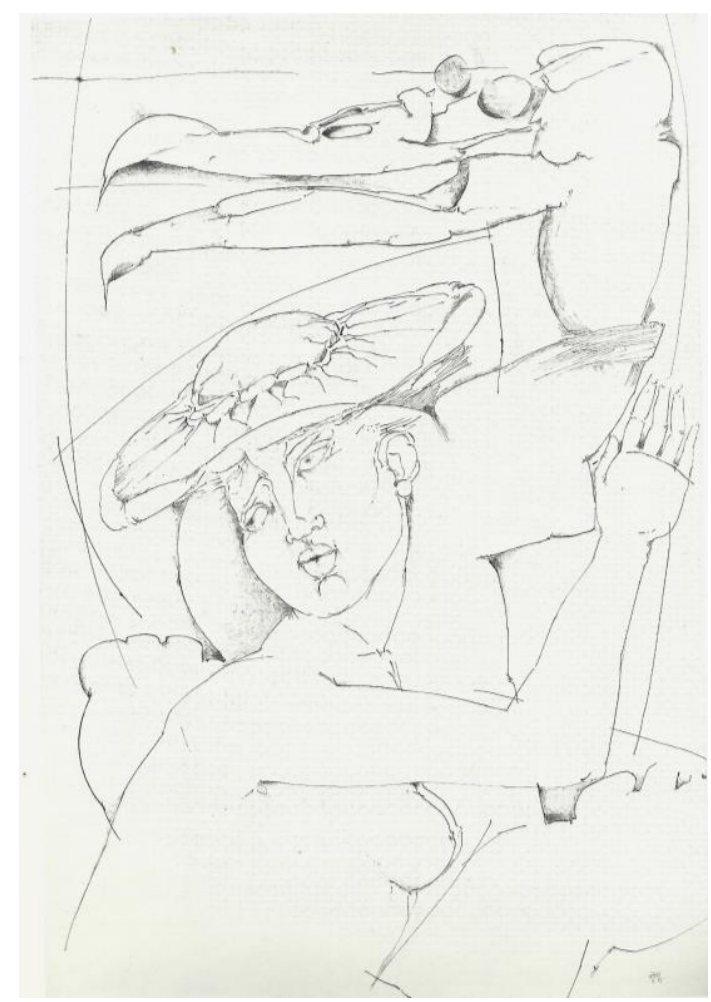

Abb. 74, Leda, 1956, Feder/Tusche

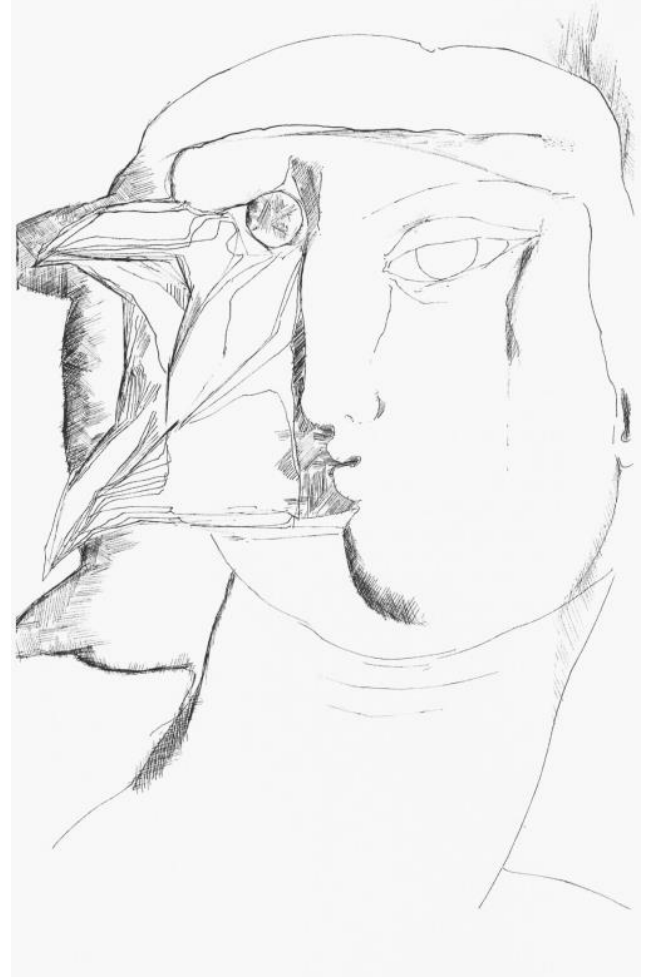

Abb. 75, Mädchen- und Vogelkopf, 1955, Feder/Tusche

\section{Die Vorzüge der Windhühner (1956) - zweite Betrachtung}

Das Vogelmotiv als Sinnbild der Literatur und Kunst wird in Grass' Debütveröffentlichung sehr häufig bemüht - zum einen bezeichnet als "Windhuhn“, zum anderen schlicht als Vogel benannt. Bei der ersten Bezeichnung handelt es sich um eine zwischen "Windei" und "Wetterhahn" angesiedelte Wortneuschöpfung, die als wegweisende, aber noch unausgereifte Idee verstanden werden darf ${ }^{307}$ und zugleich in Anlehnung an Kafkas "Lufthunde“ ein poetologisches Signal darstellt. Im Fragment „Forschungen eines Hundes“ werden Lufthunde als Wesen beschrieben, die - Künstlern vergleichbar - ein zweckfreies Dasein genießen. ${ }^{308}$ Natürlich ist das in Kapitel II.2. bereits in Auszügen zitierte programmatische Titelgedicht „Die Vorzüge der Windhühner“ für diesen Motivkomplex von besonderer Bedeutung, ferner auch die lyrischen Texte "Vogelflug", „Beobachtet beim Attentat", „Bauarbeiten“, „V der Vogel“, „Streit“ und das Prosagedicht „Fünf Vögel“. Einige dieser Texte sind in Grass' Arbeitstagebuch in früheren Varianten erhalten, sodass ihre Genese teilweise datiert werden kann: „Beobachtet beim Attentat“ hielt Grass bereits am 13. März 1955

\footnotetext{
307 Vgl. Kurz (1969), S. 239, Stolz (1994), S. 23 und Frizen (2010), S. 168 f.

${ }^{308}$ Grass hatte sich im Entstehungszeitraum der Vorzüge nach eigener Aussage von Kafkas Texten anregen lassen, im Gedichtband weist der Text „K der Käfer“ ganz explizit auf die Vorbildfunktion des Prager Schriftstellers hin. Vgl. Frizen (2010), S. 187 f. Insbesondere die wissenschaftlichen Beiträge der Fünfzigerjahre hatten Kafkas „Lufthunde“ aus dem Fragment Forschungen eines Hundes als Allegorie der Kunst und Literatur respektive ihrer Erzeuger gedeutet. Der Text stellt m. E. nicht nur für die Figur der „Windhühner“, sondern auch für die in der Publikation enthaltene Kurzprosa „Fünf Vögel“ einen wichtigen Bezugspunkt dar. Vgl.: Kafka (2008), S. 65-69, zur Rezeptionsgeschichte des Kafka-Textes, Berg (2010), S. 330-336. Vgl. ferner S. 124 der vorliegenden Forschungsarbeit.
} 
fest, auch die Zeichnung dazu entstand 1955. „Fünf Vögel“ schrieb er wenige Monate später, am 16. Mai 1955, und auch die Zeichnung, die in der zweiten Auflage der Publikation zusammen mit dieser kurzen Geschichte veröffentlicht wurde, entstand im selben Jahr. Das Gedicht "Streit“ notierte er am 18. November 1955. Zum Titelgedicht ist nur ein vage auf das Jahr 1955 datiertes Manuskript erhalten, das im Werkstattbericht veröffentlicht wurde. ${ }^{309}$

In Abweichung zur Druckfassung, der zufolge es zu den wesentlichen Eigenschaften der „Windhühner" gehört, dass sie „die Tür offenlassen“ aber „der Schlüssel die Allegorie bleibt, die dann und wann kräht" heißt es in der handschriftlichen Fassung, dass "der Schlüssel die Allegorie bleibt / die dann und wann gackert“. Ein Hahn wurde somit erst später durch das Verb „krähen“ in die Hühnerschar des Gedichts integriert, womöglich im Zuge der Arbeit an der Umschlaggestaltung, in der die Darstellung eines Hahns von 1956 auf der Rückseite den Hühnern auf der Vorderseite als Pedant gegenübersteht.
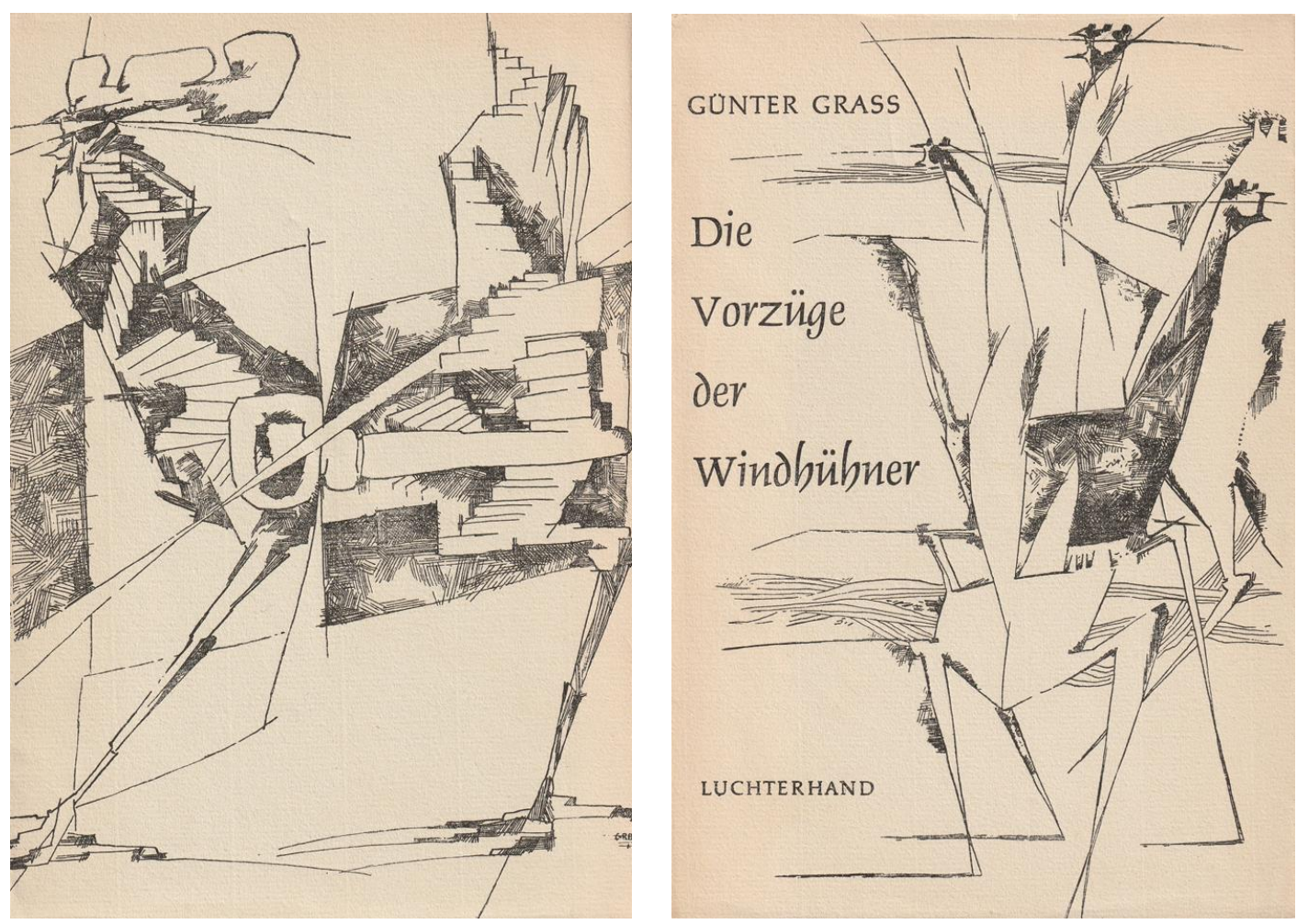

Abb. 76, Die Vorzüge der Windhühner, Berlin-Frohnau/Neuwied am Rhein 1956, Umschlag 
Beide Federzeichnungen des Buchumschlags (Abb. 76) präsentieren Tiere und Objekte, die den Betrachterinnen und Betrachtern aus dem Alltag vertraut sind bzw. waren auf entstellte Weise. Als grafische Entsprechung zum titelgebenden und maßgeblich in die Poetologie des Bandes einführenden Gedicht geben sie auf den ersten Blick Auskunft über das ästhetische Programm des Urhebers:

Der vordere Umschlagteil zeigt drei durch den Buchtitel als "Windhühner" benannte Tiere auf einer nicht näher definierten Ebene. Ihre Körper sind so flächig wiedergegeben, als bestünden die Figuren aus Papier, das zu überlangen Hälsen gefaltet ist und zu Rümpfen, die sich in den Raum hinein öffnen. Dennoch weisen die aufgeregt umherblickenden Gestalten Erkennungsmerkmale der Nutztiere auf: Hühnerschnäbel, Kämme und die typische gedrungene Torsoform. Die Umrissund Konstruktionslinien der gezeichneten Windhühner laufen, wie auch in den anderen Darstellungen des Bandes, in die Fläche hinein aus. Sie heben hervor, dass es sich um grafisch hergestellte Artefakte handelt und betonen ihre Zweidimensionalität, die sie der Typografie des Bildtitels annähert.

Die Rückseite des Umschlags füllt seitlich gewendet ein Hahn, der wie die Windhühner ohne konkrete Ausgestaltung eines Bildraums auf dem Papier platziert ist. Wie bereits im vorausgehenden Kapitel erörtert, bringen verschiedene Bildelemente, die von den Umrissen des Tieres umfangen werden, gemeinsam den allegorischen Aspekt der Dichtung zum Ausdruck: Die Schlüssel Symbole der Erkenntnis und metaliterarische Sinnbilder der Allegorie ${ }^{310}$ - und die gewundenen Treppengänge vermitteln den Eindruck, dass die Tierfigur Bedeutungen aufweist, die es buchstäblich zu erschließen gilt.

Das programmatische Gedicht „Die Vorzüge der Windhühner" benennt die herausragenden Eigenschaften der fantastischen Tiere, die sich das lyrische Ich auf seinem Grundstück hält. Wie in den Umschlagzeichnungen und in der sonderbaren Tiergattung des "Windhuhns" im Buchtitel werden in diesem Text verschiedene semantische Felder zusammengeführt: Die Beschreibung realer Hühner wird mit den Vorzügen literarischer Kunstwerke verwoben. Verbunden wird dabei auch hier scheinbar Gegensätzliches: Verhaltensweisen des Geflügels mit den Kennzeichen einer Dichtung, die ihre Inhalte aus Träumen bezieht („Traumrinden“), nicht sklavisch an den üblichen Sprachgebrauch gebunden ist („Buchstaben [...], die der Briefträger jeden Morgen vor meiner Tür verliert"), sich fruchtbar mehrt und von der spontanen Inspiration beflügelt wird („Zugluft"/,Ostwind“). ${ }^{311}$ Grass' poetologische Ausführungen werden also in eine allegorische Figurendarstellung gekleidet:

\footnotetext{
${ }^{310}$ Vgl. Neubauer-Petzoldt (2008), S. 328-330.

${ }^{311}$ Vgl. Stolz (1994), S. 25 und May (1974), S. 102.
} 


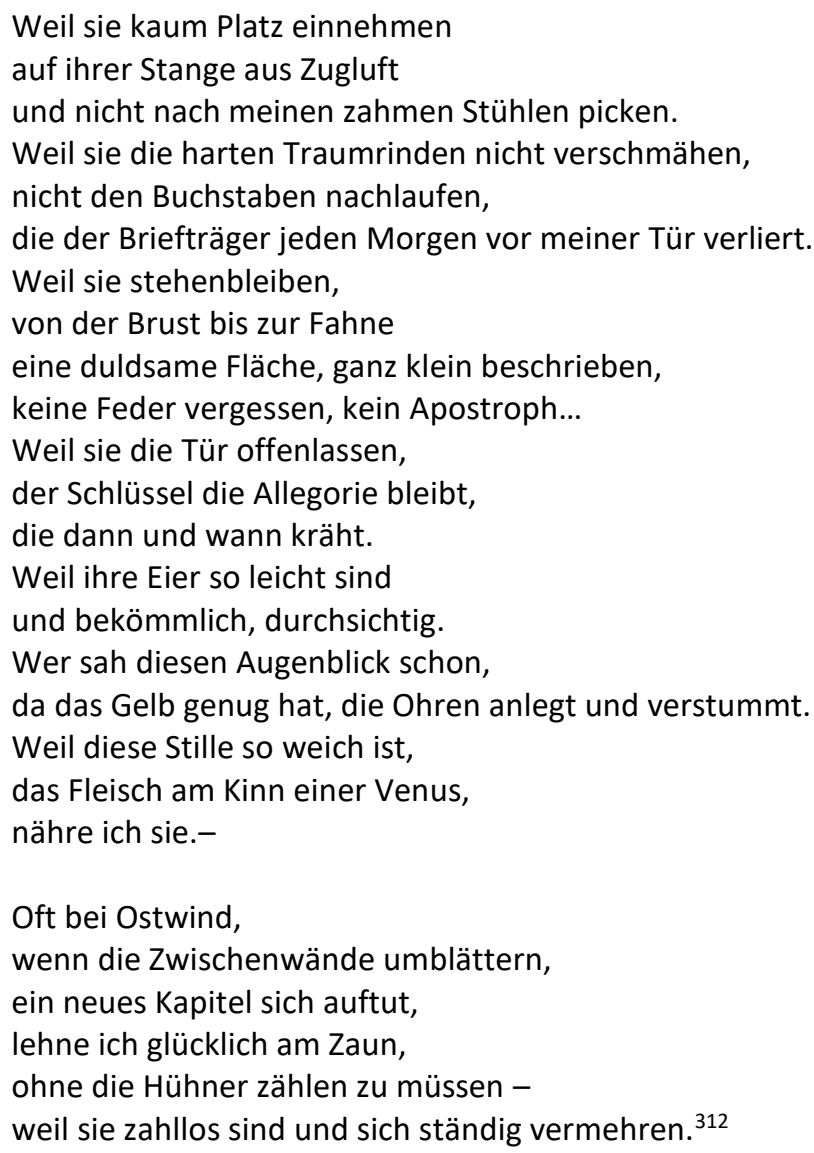

Mit der Kenntnis des Textes auf die Grafiken zurückblickend: Die Merkmale des literarischen Kunstwerks, das in diesem Gedicht angepriesen wird, setzt der bildende Künstler durch die stilistische Verfremdung der Figurenkörper und durch ihre Kombination mit anderen Motiven um. Die einzelnen Bildelemente nehmen in ihrer räumlich-isolierten Darstellung zeichenhaften Charakter an und werden visuell zu einer Bildsprache verknüpft. Die Zeichnung der Rückseite hebt dabei den optisch vorstellbaren Zusammenhang zwischen den Bildspendern der einzelnen Metaphern hervor, die das Gedicht mittels seiner Struktur leistet. Die visuell vorstellbare Harmonie der literarischen Motive, die durch Formäquivalenzen hergestellt wird, leuchtet bei der bloßen Lektüre des Gedichts nur mit äußerst viel Phantasie ein. Wird der durch die Ähnlichkeit verschiedener Teilformen gegebene Zusammenhang der einzelnen Motive jedoch in der Grafik zur Kenntnis genommen, eröffnet sich die Bildstruktur auch den Leserinnen und Lesern des Textes.

Wie fruchtbar und flexibel das Motiv des Geflügels für Grass war, zeigen weitere 1955 und 1956 entstandene Zeichnungen, die eine ähnliche Komposition aufweisen wie das rückwärtige Umschlagbild: Der Hahn steht auch in diesen Bildern in der Seitenansicht im Mittelpunkt, wird jedoch zusammen mit jeweils anderen Motiven dargestellt. Die Arbeiten verdeutlichen, dass gerade der Hahn dem Grafiker aus seiner Form heraus zahlreiche Anknüpfungspunkte bot.

Aus einer Federzeichnung von 1956 mit dem Titel $A B C$ geht eine poetologische Botschaft des Arrangements noch etwas deutlicher hervor, als aus der oben behandelten Umschlaggrafik. Sie

${ }^{312}$ Vgl. Grass (1956), Umschlag, vordere Innenklappe. 
zeigt motivische Bezüge zu Grass' oben behandelter surrealer Skizze frei nach Dalí aus dem Jahr 1954 (S. 77, Abb. 49) und zu seinem Gedicht "Lilien aus Schlaf" (1954). Sowohl in der Skizze als auch im lyrischen Text spielen Hähne und Hörner eine entscheidende Rolle. Die Zeichnung aus dem Jahr 1956 zeigt einen Hahn, dessen Brustgefieder von der den Rezipienten abgewandten Seite aus von zwei spitzen Hörnern aufgespießt wird (Abb. 77). Sie durchstoßen zugleich einige Blätter mit der Aufschrift ABC und heften sie somit an den Körper des Tieres. Auch diesem Hahn wurde zudem an Stelle des linken Flügels ein Schlüssel angesetzt. Der Schlüsselbart geht in eine Treppe über, welche auf diesem Blatt von einer Stadtansicht umfangen wird.

Durch das Einbeziehen eines Schriftzugs wird das Tier pars pro toto mit Literatur in Verbindung gebracht. Der Pfeil, der den Kopf des Hahns von hinten durchdringt, erinnert an eine Wetterfahne, auf die ein Wetterhahn für gewöhnlich gestellt wird. Mit ihrer Spitze gibt sie die Richtung an, in die der Wind weht. In der Zeichnung in den Schnabel des Hahns verschoben, könnte der Pfeil die vorgestellte Dichtung als eine kennzeichnen, die auf aktuelle Umstände reagiert.

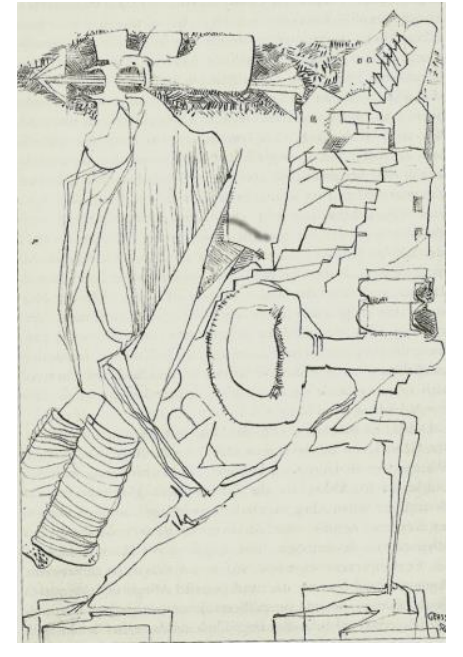

Abb. 77, ABC, 1956, Feder/Tusche

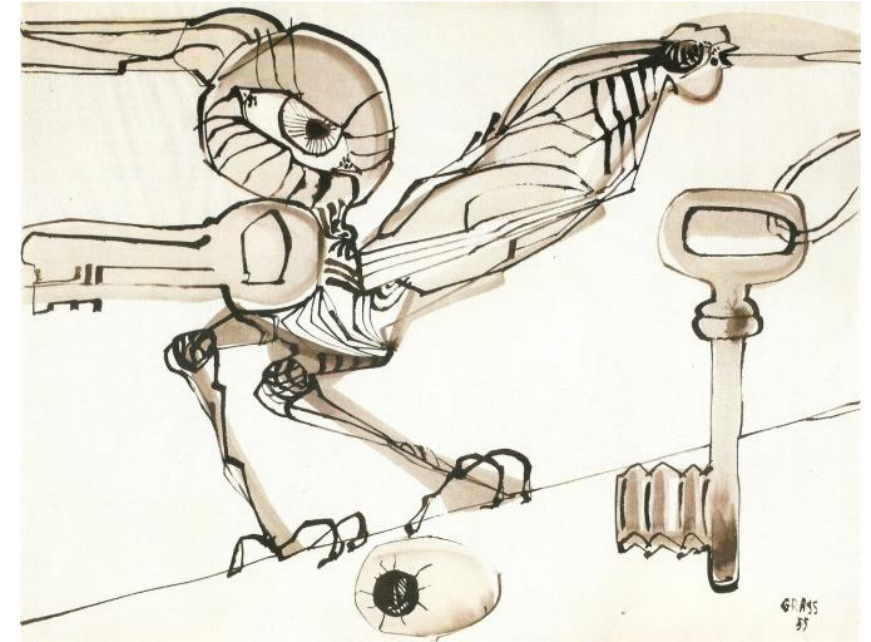

Abb. 78, Huhn mit Ei und Schlüssel, 1955, Feder/Tusche, laviert

Eine ähnlich komponierte Zeichnung mit dem Titel Huhn mit Ei und Schlüssel aus dem Jahr 1955 betont dagegen den Aspekt des Sehens. Sie zeigt ein von einem Pfeil unmittelbar in den Schnabel getroffenes, an einer ansteigenden Bodenfläche festgekralltes Huhn (Abb. 78). Dieser Vogel ist offenkundig Widerständen ausgesetzt. Ein Schlüssel liegt dem Rumpf des Tieres nun an Stelle des Steuergefieders an. Das Schultergelenk des linken Flügels ersetzt ein geöffnetes, von einem Kreis gerahmtes Auge. Die Zeichnung enthält darüber hinaus Gegenstücke zu diesen Elementen: Unterhalb der Bodenlinie, direkt unter den gekrümmten Zehen des Huhns, wurde ein Ei platziert, das ein Loch aufweist - die schwarze Öffnung und die um den Schalenrand angedeuteten Risse lassen es wie einen freiliegenden, geäderten Augapfel erscheinen. Rechts neben dem Huhn, parallel zum rechten Bildrand, ist ein Schlüssel dargestellt, der nur wenig kleiner ist als das Tier. Ein angedeutetes Schlüsselband verläuft zum Bildrand hin. Sowohl das geöffnete Auge als auch der Schlüssel stellen Erkenntnissymbole dar. Indem die leere Eierschale, der Ursprung der Henne, zugleich als 
Auge erscheint, könnte das erkenntnisbedingende Sehen als Herkunft des Tieres bzw. im übertragenen Sinne das Sehen als Ursprung der Kunst verstanden werden. Der zweite, der gesamten Zeichnung den Größenverhältnissen nach vorangestellte Schlüssel, lässt sich als Wink an die Betrachterinnen und Betrachter interpretieren, die gesamte Anordnung als ein Rätsel anzunehmen.

Die Formverwandtschaften, die auch diese Zeichnung als verbindende Gelenke zwischen einzelnen Bildelementen nutzt - hier also die Ähnlichkeiten zwischen Ei, Augapfel sowie zwischen Schlüssel und Flügel - sind ein wichtiges Strukturelement der Gedichte der Vorzüge der Windhühner. Es fällt auf, dass sich gerade die um das Vogelmotiv kreisenden Texte unter den prägnantesten Beispielen für dieses Schema befinden. Im oben bereits kurz behandelten "Vogelflug" - dem Text, der unmittelbar auf das Titelgedicht folgt, das auf der Innenseite des Umschlages platziert ist - wird die Betrachtung einer Vogelformation für eine phänomenologische und zugleich poetologische Auseinandersetzung genutzt. Sie soll an dieser Stelle im Zusammenhang mit dem Vogelmotiv näher erörtert werden.

Wie der Titel des Gedichts ankündigt, beschreibt das lyrische Ich in diesem Text einen Vogelflug. Die ersten Verse konzentrieren sich auf die visuelle Wahrnehmung des Vorgangs. Geschildert wird, auf welche Art die Vögel das Sichtfeld des lyrischen Ich durchkreuzen und welche Assoziationen ihre Bewegungen vor verschiedenen Hintergründen auslösen. Die Tiere werden erst im neunzehnten Vers als Schwalben benannt - erst dann, aus geringerer Distanz, kann der Betrachter sie als solche erkennen. Auf diese Beobachtung folgt eine meteorologische Einschätzung, eine Deutung des Schwalbenflugs:

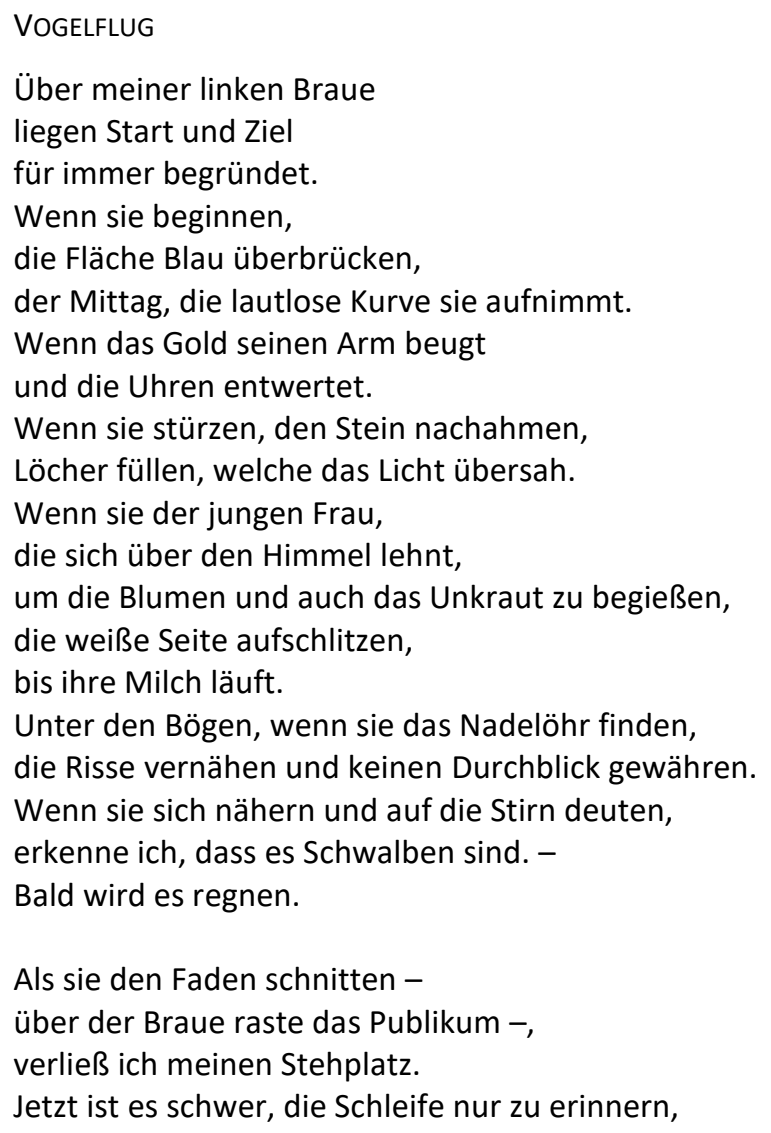




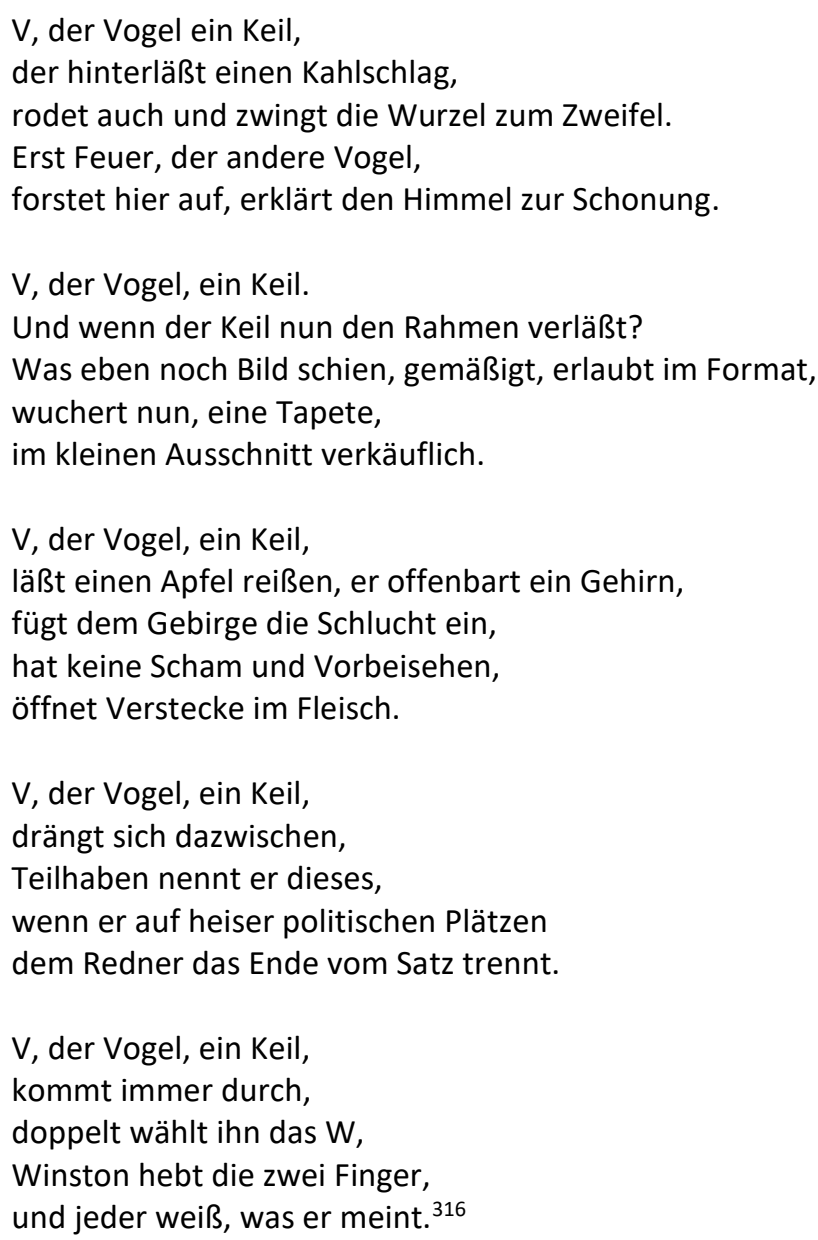

Die Form eines Buchstabens wird auch in einem anderen Text, dem direkt vorangehenden „K, der Käfer" zum Ausgangspunkt. Auch das handschriftlich festgehaltene, aber nicht veröffentlichte Gedicht „S der Schwan“, das Grass' Auseinandersetzung mit dem Leda-Stoff zuzuordnen ist, war in vergleichbarer Art entworfen worden. ${ }^{317}$ Indem Grass die Ikonizität und den Assoziationsreichtum von Buchstaben betonte, wies er auf die gemeinsame Wurzel von Bild und Schrift hin. Dem erstgenannten Gedicht „K der Käfer“ wird eine Zeichnung vorangestellt, die den auf dem Rücken liegenden Buchstaben K und einem ebenfalls auf dem Rücken liegenden Käfer durch das Übereinandersetzen der beiden Objekte ihre Ähnlichkeit bescheinigt (Abb. 79).

Dass Buchstaben Grass in dieser Zeit als grafische Formen besonders beschäftigt haben, belegt auch die Federzeichnung mit dem Titel Lingua, die ebenfalls 1955 entstanden ist: Sprache wird in diesem Bild durch den Schriftzug „Lingua“ repräsentiert, der an Materialität gewinnt, indem er in der Darstellung wie eine Papiergirlande von einer Schere in seine Bestandteile zerschnitten wird (Abb. 80). Grass' Zeichnungen und Texte erinnern in ihrer Betonung der Bildhaftigkeit von Buchstaben an Werke der visuellen Poesie des beginnenden 20. Jahrhunderts wie solche Apollinaires, die er nach eigener Aussage intensiv gelesen und betrachtet hat. Buchstäblich näher liegt ein Bezug zu den Gemälden Bruno Gollers, die Grass während seiner Studienzeit in Düsseldorf ebenfalls sah und schätzte. Unter ihnen befanden sich Ölbilder, in welchen Ziffern wie plastische Bildobjek-

${ }^{316} \mathrm{Vgl}$. Grass (1956), S. 56 f.

${ }^{317}$ Vgl. Akademie der Künste Berlin, Günter-Grass-Archiv, Nr. 1755, S. 154. 
te eines Stilllebens innerhalb ornamental gestalteter, gemalter Bildrahmen arrangiert worden waren (vgl. S. 48, Abb. 25).

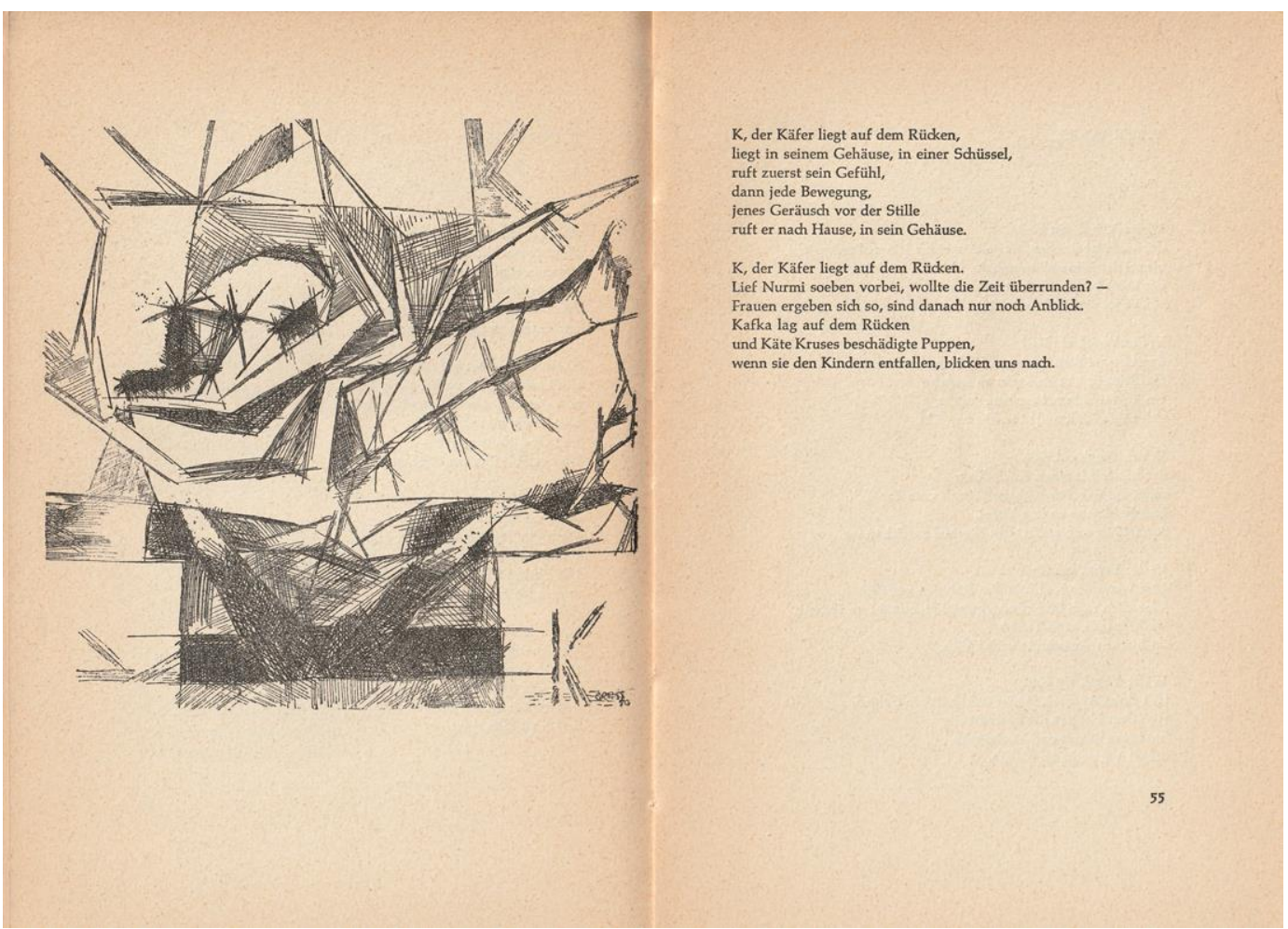

Abb. 79, Die Vorzüge der Windhühner, Berlin-Frohnau/Neuwied am Rhein 1956, S. 54 f.

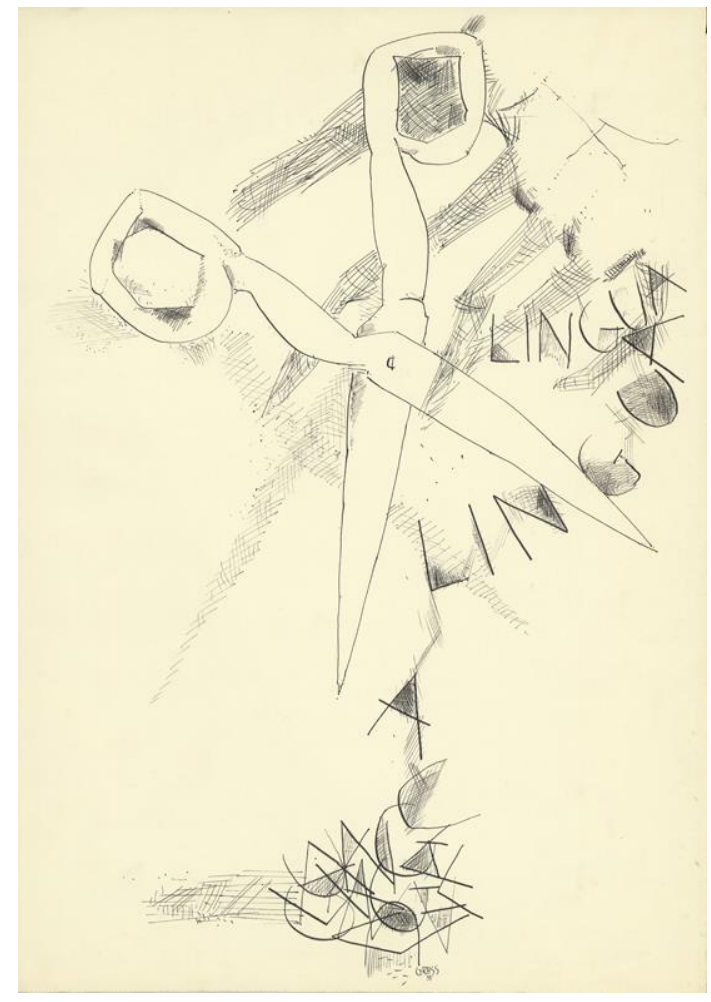

Abb. 80, Lingua, 1955, Feder/Tusche 
Die Kombinationen von formverwandten Elementen bestimmt auch die narrative Struktur des einzigen Prosatextes der Vorzüge der Windhühner mit dem Titel „Fünf Vögel“. ${ }^{318}$ Wie bereits am Eingang der vorliegenden Studie angeführt, spielt das Vogelmotiv auch hier eine entscheidende Rolle: Die kurze Erzählung berichtet in drei Abschnitten, den Kapiteln „Herkunft“, „Viele Berufe“ und „Ziel“, von der Bildung ihrer titelgebenden Protagonisten. Verwandlungen der fünf schlanken Vögel in andere ähnlich schlanke Objekte treiben die Handlung voran. In aller Kürze sei sie wiedergegeben: Auf ein abgesprochenes Zeichen hin steigt ein fünfpfähliger Zaun in den Himmel „Hier begann die große Reise, die dauernde Wandlung, welche am Ende das Ei meint". ${ }^{319}$ Der Zaun wird zur Vogelformation, die bald den Wunsch hat, einen Beruf auszuüben und dazu den Platz und die Funktion zweckdienlicher Dinge einnimmt. Die Tiere scheitern bald an ihren neuen Aufgaben und freuen sich deshalb über ein Visum für das vorgebliche Land der Freiheit, für Amerika, wo sie als Zaun einem freiheitsliebenden Bauern zum Opfer fallen. In den Boden Virginias gerammt, kündigen die zwischen Nützlichkeit und l'art pour l'art schwankenden, zeugungsfähigen und fruchtbaren Wesen eine Nachfolge in Form von „eindrucksstarken“ Eiern an.

Darauf, dass in dieser Allegorie von der Dichtung die Rede ist, deuten bereits vorab die Gedichte hin, die das Vogelmotiv am Beginn der Publikation als poetologische Metapher etablieren: "Die Vorzüge der Windhühner" und „Vogelflug“. Im Prosagedicht wird die Vogelformation mit einem Text verglichen: Vor dem sommerlichen Himmel sagt der transformierte Zaun seine „Sprüche her" und weist damit eine Gemeinsamkeit mit dem Abschluss des Gedichtes "Vogelflug" auf. ${ }^{320}$ Schließlich kann wie schon im programmatischen Titelgedicht und seinen "Windhühnern" in „Fünf Vögel“ ein Bezug zu Kafkas „Lufthunden“ als entsprechende Markierung gelesen werden. Im Prosafragment Forschungen eines Hundes werden Lufthunde im Sinne von Künstlern bzw. Dichtern thematisiert, die keinem „Beruf" nachgehen und deren Werke von Zwecklosigkeit und Irrationalität geprägt sind - so einer der maßgeblichen Zugriffe der Germanistik der Fünfzigerjahre. ${ }^{321}$ Die besondere Betonung der Anzahl der Vögel in Grass' Text, die sich mit der Anzahl der Finger einer menschlichen Hand in Verbindung bringen lässt, kann zudem gemeinsam mit der intermedialen Gestaltung des Gedichtbandes und den im Text enthaltenden intermedialen Bezüge als Hinweis auf das bildkünstlerische Schaffen und den bildenden Künstler verstanden werden.

\footnotetext{
${ }^{318}$ Grass (1956), S. 39-42.

${ }^{319}$ Ebd., S. 40.

${ }^{320}$ Ebd., S. 5, S. 39.

${ }^{321}$ Vgl. Kafka (2008), S. 66 f.: „Es sollte einen Hund von allerkleinster Art geben, nicht viel größer als mein Kopf, auch im hohen Alter nicht größer und dieser Hund, natürlich schwächlich, dem Anschein nach ein künstliches, unreifes, übersorgfältig frisiertes Gebilde, unfähig, einen ehrlichen Sprung zu tun, dieser Hund sollte wie man erzählte, meistens hoch in der Luft sich fortbewegen, dabei aber keine sichtbare Arbeit machen sondern ruhen. [...] Aber viel wunderbarer ist für mein Gefühl die Unsinnigkeit, die schweigende Unsinnigkeit dieser Existenzen. Im Allgemeinen wird sie gar nicht begründet, sie schweben in der Luft und dabei bleibt es, das Leben geht weiter seinen Gang, hie und da spricht man von Kunst und Künstlern, das ist alles. Aber warum, grundgütige Hundeschaft, warum nur schweben diese Hunde? Was für einen Sinn hat ihr Beruf? Warum ist kein Wort der Erklärung von ihnen zu bekommen? Warum schweben sie dort oben, lassen die Beine, den Stolz des Hundes, verkümmern, sind getrennt von der nährenden Erde, säen nicht und ernten doch, werden angeblich sogar auf Kosten der Hundeschaft besonders gut genährt." Die Wortfolge „säen nicht und ernten doch“ ist ein Bibelzitat, das Vögel kennzeichnet (Mt 6,26). Vgl. zur Rezeptionsgeschichte des Kafka Textes: Berg (2010), S. 330-336.
} 
Die dem Schema des Bildungsromans folgenden Etappen des Prosagedichts entwickeln sich über Assoziationen zu der visuell wahrnehmbaren Form des gestreckten Vogels. Nach ihrer Geburt aus dem Zaunpfahl übernehmen die Protagonisten die Aufgaben von Baukränen, Telefonund Schiffsmasten sowie von menschlichen Fingern. Die Wandlung der Tierfiguren in andere Gegenstände respektive der Einsatz der Vögel anstelle von Objekten, die eine ähnliche Grundform aufweisen wie sie, wird für das Prosagedicht zum konstitutiven Element.

Die nun nicht nur wie in der Lyrik Metaphern verknüpfende, sondern eine ganze Handlung generierende Kombinatorik erinnert an bekannte surrealistische Filmprojekte wie Un chien andalou (1929) von Luis Buñuel: Schon zum einprägsamen Auftakt des Kurzfilms schneidet ein vorbeitreibendes Wolkenband den Vollmond ebenso wie anschließend eine Rasierklinge einen Augapfel. Wie bereits im vorangehenden Kapitel für den Debütband insgesamt festgestellt, ${ }^{322}$ gilt jedoch auch für die "Fünf Vögel“, dass ihre strukturgebende Methode zwar dem Surrealismus entlehnt ist, aber dennoch gezielt dazu eingesetzt wird, eine bestimmte Idee zu schildern: Das Konzept einer spielerisch-assoziativen Dichtung, die aller Freiheit zum Trotz Anfang und Ziel in der fruchtbaren Bodenständigkeit ihrer Motive und Inhalte findet.

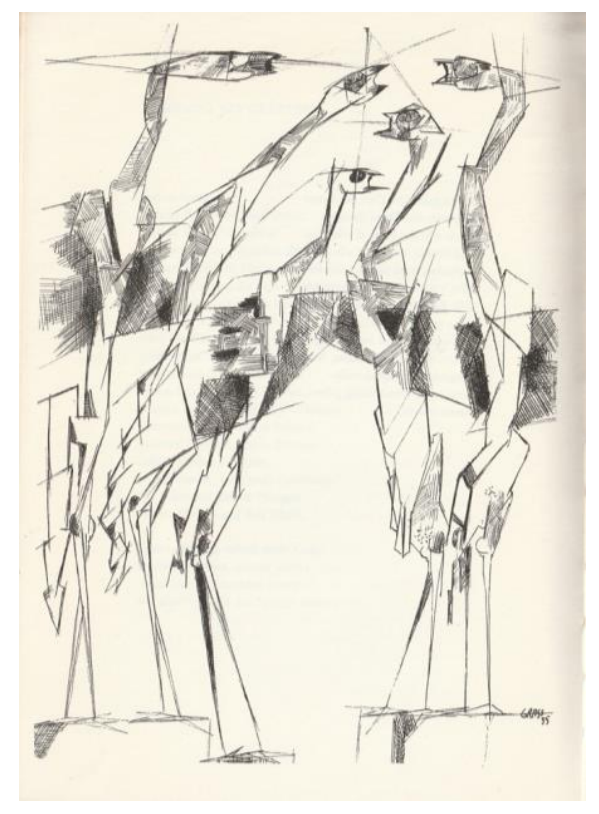

Abb. 81, Federzeichnung aus: Die Vorzüge der Windhühner, Berlin-Frohnau/Neuwied am Rhein 1956,2 . Auflage, 1963, S. 38

Wie in der Einleitung dieser Arbeit kurz beleuchtet wurde, hatte Grass 1955 auch Zeichnungen und eine Plastik geschaffen, die enge Bezüge zum Prosagedicht „Fünf Vögel“ aufweisen. In allen drei Medien setzte er sich mit dem Vogelmotiv auseinander. Wie im Folgenden erläutert werden soll, zeigt jede der Arbeiten dabei eine Betonung der Charakteristika, die für das Medium, in dem die beiden anderen realisiert wurden, besonders kennzeichnend sind. Grass näherte auf diese Weise Zeichnung, Plastik und Erzählung einander an. 
Die Federzeichnung, die fünf Vögel zeigt, entstand 1955 (Abb. 81). Sie wurde dem Prosagedicht in der zweiten, veränderten Auflage des Gedichtbandes von 1963 beigefügt. ${ }^{323}$ Fünf schlanke Vögel sind auf dem Blatt nebeneinander gereiht und erinnern in dieser Anordnung an Grass' von Hartung inspiriertes Relief. ${ }^{324}$ Wie in den anderen Federzeichnungen zur Debütpublikation sind die Gestalten auch hier in eine Struktur aus sich in den Raum verlängernden Konstruktionslinien gespannt und harmonieren durch ihre so betonte Zweidimensionalität mit dem gedruckten Text der Buchseiten. Dunkel schraffierte, rechteckige Felder verbinden die Vögel miteinander und erinnern an die im Prosagedicht beschriebene „Herkunft" der Wesen in der Form des Zauns. Gleichzeitig sind auch die gezeichneten schlanken Figuren durch ihre Anzahl, Position und Verbundenheit mit der menschlichen Hand assoziierbar. Die in die Länge gestreckten Torsi der Vögel verleihen ihnen zudem nahezu menschliche Proportionen. Alle fünf stehen auf Sockeln, sodass die Figuren von einem gleichsam in Stein gehauenen, unbewegten Zustand in der unteren Bildhälfte in einen lebhaft-bewegten Zustand in der oberen Bildhälfte übergehen.

Geht die Federzeichnung dem Text in der Publikation voran, verstärken sich medienspezifische Aspekte des einen Artefakts jeweils im anderen: Der Text lässt im Bild das narrative Moment in den Vordergrund treten, also die darin angedeutete Wandlung von einer Form in die andere. Die Zeichnung hebt dagegen auch für Leserinnen und Leser hervor, dass die Struktur der Erzählung auf einer nur visuell vorstellbaren Grundform beruht. Die anthropomorphisierende Streckung und Körperhaltung der Wesen im Bild und ihre Assoziierbarkeit mit der menschlichen Hand unterstreicht zudem die Interpretation der Erzählung als künstlerischen Bildungsweg. Die Podeste, auf welchen die Vögel stehen, erinnern zudem an Skulpturensockel, womit ein Bezug zu der womöglich parallel entstandenen Plastik geschaffen wurde. In der Bildkomposition ist damit ein Übergang von plastischen, statischen Gebilden zu bewegten und zweidimensional konstruierten Wesen hergestellt.

Der Bronzeguss aus dem Jahr 1955 zeigt ebenfalls eine stark in die Vertikale gedehnte und leicht nach vorne gebeugte Gestalt mit langem Hals, die lediglich auf Grund des kleinen Vogelkopfes mit kurzem Schnabel und der zu einem einzigen Fuß zusammengezogenen Krallen als Vogel erkennbar ist (Abb. 82). Der Torso der Figur ist wie im Fall der gezeichneten Tiere auf einen schmalen, länglichen Streifen mit deutlich ausgearbeiteten Kanten reduziert. Nur am Übergang vom Hals zum Körper gewinnt er an Volumen (Abb. 83). Ihren Kopf hält die Figur zudem starr geradeaus gerichtet, sodass sie für die Betrachtenden vor allem im Profil interessant wird. Flügel werden auch in dieser Darstellung kaum hervorgehoben. In ihrer Zweidimensionalität nähert sie sich den Vögeln der Grass'schen Zeichnungen an.

Durch die starke, über die Abstraktion von der natürlichen Erscheinung weit hinausgehende Verfremdung des Vogelkörpers unterscheidet sich die Arbeit deutlich von den frühen SteingussHähnen des Bildhauers und erst recht von vergleichbaren Tierbildern von der Hand Karl Hartungs oder Constantin Brancusis. Grass' Geschöpf weist sich durch die an Volumen reduzierte und verfremdete Form als Realisierung einer abstrakten Idee aus. Nicht umsonst schreibt Grass in Beim Häuten der Zwiebel über diese Arbeit, dass sie „langgestreckt einem Vogel gleicht" (X 630), also

\footnotetext{
${ }^{323}$ Grass (1963a), S. 38.

${ }^{324}$ Vgl. S. 67, Abb. 42 der vorliegenden Untersuchung.
} 
nicht eigentlich einen solchen darstellt. Wie schon bei den gezeichneten Vögeln fällt auch an der Plastik auf, dass es nicht die herausragende Eigenschaft des realen Vogels, das Fliegen ist, das betont wird, wie zum Beispiel im Fall des Vogels im Raum von Brancusi (Abb. 84), dessen Fokus gerade auf dem Aufschwingen des Tieres in die Schwerelosigkeit liegt. Stattdessen handelt es sich ebenso wie bei dem plastischen und grafischen Geflügel von Günter Grass bei seinem bronzenen Vogel um ein Wesen mit Bodenhaftung, das im Zusammenhang mit dem Prosagedicht an die ursprüngliche Pfahlform der Protagonisten und ihre menschliche Seite erinnert.

Alle drei Arbeiten demonstrieren folglich mit anderen Mitteln die Verwandtschaft des vogelartigen Wesens mit anderen Geschöpfen und Objekten. Die bildkünstlerischen Werke und der Text enthalten zudem intermediale Bezüge - besonders deutlich wurden jeweils die Eigenschaften an ihnen hervorgehoben, die für die jeweils andere Kulturtechnik und für andere bildkünstlerische Gattungen kennzeichnend sind.
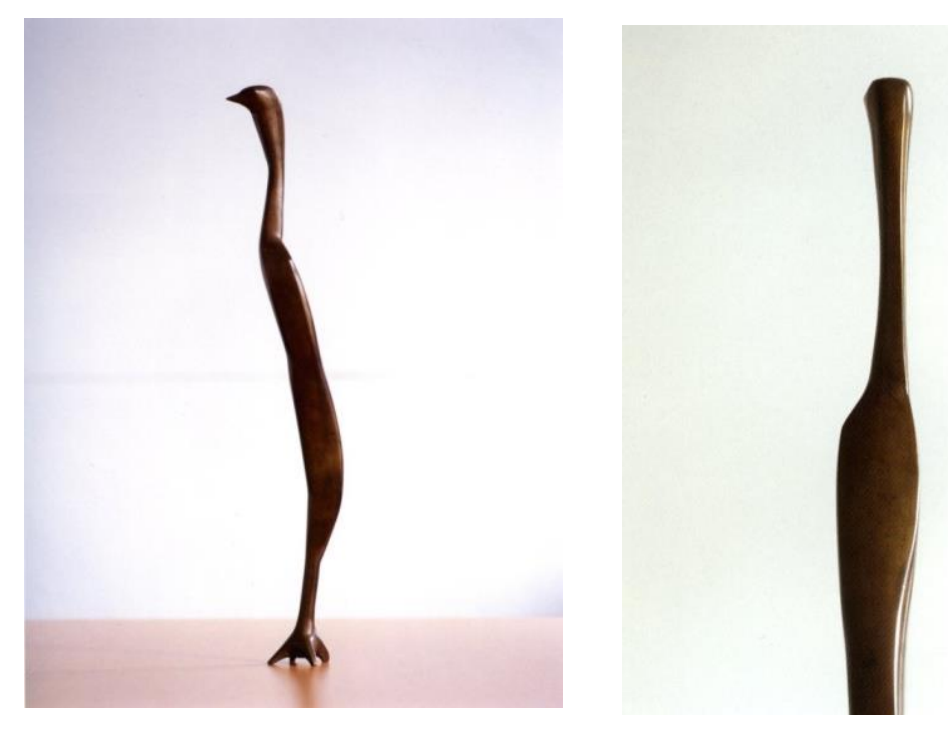

Abb. 82 und Abb. 83, Vogel, 1955, Bronze

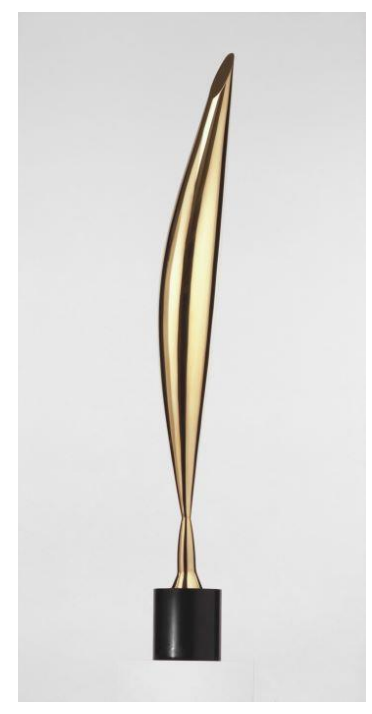

Abb. 84, Constantin Brancusi, Vogel im Raum, um 1924, polierte Bronze, schwarzer Marmor 
Während die bis zu diesem Punkt behandelten Texte den Vogel im Sinne eines betrachteten Objektes thematisieren, wird in dem Gedicht „Beobachtet beim Attentat“ die Perspektive umgekehrt. Der Blick des Vogels auf ein Ereignis wird beschrieben und zeigt das Gesehene auf eine besondere Weise. Es handelt sich in gesteigerter Form um ein Sehen, das kaum Korrespondenzen zwischen den Dingen herstellt. Die daraus hervorgehende emotionslose Art der Schilderung steht zu den beobachteten Vorgängen im Kontrast. Der Vogelblick fällt auf eine Gewalttat, zeichnet diese jedoch so nach, dass alle daran beteiligten Menschen und Dinge gleichrangig erscheinen. Dabei entfalten Gegenstände und Abstrakta in Form von Personifizierungen ein Eigenleben:

BEOBACHTET BEIM ATTENTAT

Es ist so schwer, den Platz zu überqueren.

Des Vogels Blick,

die Kälte ohne Wimper

und Neugierde an Zäunen lang,

dahinter Rauch und zwischen nassen Hüten

das trockne Foto einer Frau.

Wär es im Keller zwischen Pferd und Zaudern,

die Treppe hätte nicht gelacht

und dreimal ihren Hals gebogen.

Es öffnete der General.

Er nannte pausenlos die Summe,

die Zahl brach ab,

des Vogels Blick, als niemand in den Spiegel sah, gewann im Blei die Müdigkeit vorm Schlaf.

Verwirrt vergaßen beide Mörder

den Atem aus der Uhr zu nehmen,

das Fenster wie ein Hemd zu öffnen,

die Zahl zu heben,

die im Spiegel brach. ${ }^{325}$

Die dem Text beigefügte Zeichnung gibt das scheinbar starre, irislose Auge eines Vogels wieder, das sich unmittelbar auf Betrachterinnen und Betrachter richtet und diese damit selbst zum Gegenstand der Betrachtung macht (Abb. 85). Sie werden auf diese Weise in die Position der fiktiven Attentäter gerückt, die ebenfalls dem Blick eines Vogels ausgesetzt sind. Im Bild wird das Moment zusätzlich dadurch hervorgehoben, dass das kreisrunde Auge besonders dicht von Linien umschlossen wird. Die Augenzeugenschaft des Vogels wird sieben Jahre später in den Hundejahren (1963) und $1977 \mathrm{im} \mathrm{Butt} \mathrm{auf} \mathrm{vergleichbare} \mathrm{Art} \mathrm{thematisiert.} \mathrm{Krähen} \mathrm{haben} \mathrm{in} \mathrm{diesen} \mathrm{Romanen} \mathrm{die}$ Funktion stummer Zeugen und Beobachter von Gräueltaten. ${ }^{326}$ Ihre mitleidlose Betrachtung impliziert kühle Objektivität. Zudem ist ihre Perspektive naturgemäß flexibel, sodass Ereignisse auch über verschiedene Handlungsorte hinweg verfolgt werden können. Die distanzierte und distanzierende, in der Forschung mitunter als „inszenierte Naivität" bezeichnete Perspektive ist es, die auch den Protagonisten der Blechtrommel, den kleinwüchsigen Oskar auszeichnet. ${ }^{327}$ In einem der von Grass gemalten Entwürfe zum Titelbild seines Debütomans wird dessen Blick auf ähnliche Art betont wie der Blick des Vogels in der Federzeichnung zu „Beobachtet beim Attentat“. Es ist ein

\footnotetext{
${ }^{325}$ Vgl. Grass (1956), S. 26.

${ }^{326} \mathrm{Vgl}$. Cepl-Kaufmann (1975), S. 15.

${ }^{327}$ Vgl. Fischer (1992).
} 
vergrößertes, kreisrundes Auge, verstärkt durch die Wiederholung im Rund der Trommel, das der in Plakafarbe gepinselte Trommler auf die Betrachtenden richtet (Abb. 86).

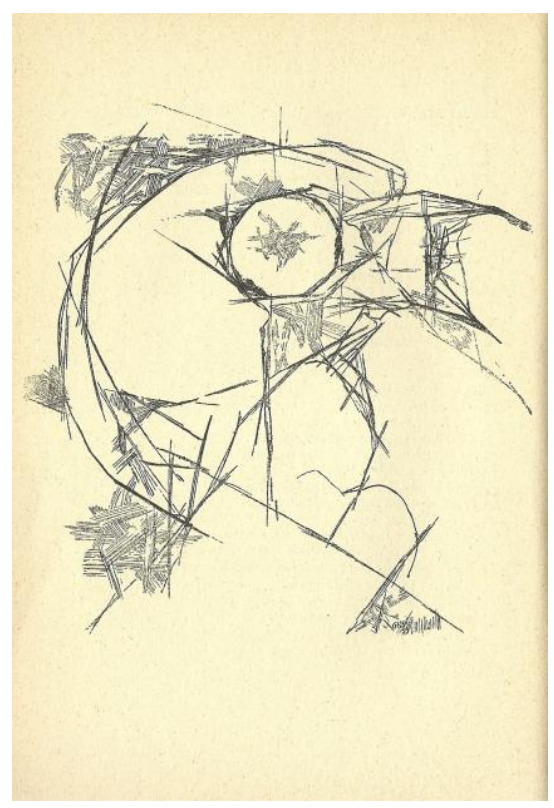

Abb. 85, Die Vorzüge der Windhühner, Berlin-Frohnau/Neuwied am Rhein 1956, S. 26

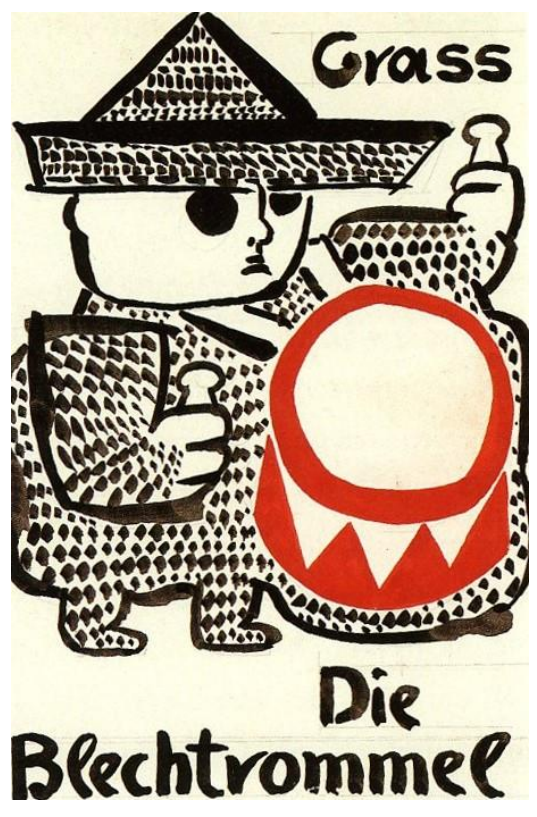

Abb. 86, Umschlagentwurf für Die Blechtrommel, 1959, Plakafarben

Verschiedene Vögel, die Grass als bildender Künstler auf ihr Verhalten hin beobachtet, auf die Gesetzmäßigkeiten ihrer Gestalt hin analysiert und unter Verwendung kubistischer und surrealistischer Methoden dargestellt hat, werden in den Vorzügen der Windhühner zum poetologischen Hauptmotiv. Das Vogelmotiv eignete sich aufgrund seiner visuellen Erscheinung und den sich aus Kultur- und Literaturgeschichte speisenden Deutungsangeboten als Anknüpfungspunkt für Analogien und Assoziationsreihen, die zur Veranschaulichung poetologischer Programme genutzt werden konnten. Die Ähnlichkeiten zwischen den Dingen, die Grass wahrnahm und zur Konstruktion von Allegorien und Metaphern nutzte, werden durch die Federzeichnungen im Gedichtband besonders hervorgehoben - gerade dort, wo der Text selbst sie nur andeutet. Die besondere, als visuell und antirational konzipierte Wahrnehmung des lyrischen Ich spielt dabei eine wichtige Rolle, denn sie nähert die Texte den beigefügten Zeichnungen an. Grass' Grafiken und Plastiken selbst kommen dem gedruckten Wort durch ihre zur Zweidimensionalität tendierende Gestaltung entgegen. In der Verwendung des Vogelmotivs als Sinnbild der freien Kunst und der Dichtung sowie ihrer Erzeuger treten diese Eigenschaften besonders deutlich und besonders häufig hervor. Die mit dem Motiv verbundene Symbolik wird zu Eigenschaften und Gestaltmerkmalen des Tieres in Verbindung gesetzt. 


\section{Übergänge: Von Vögeln zu Nonnen und Vogelscheuchen}

In der Metapher des In-den-Himmel-Kommens fand Grass einen Berührungspunkt zwischen dem Motiv des Vogels und dem von inm spätestens ab 1957 grafisch und literarisch behandelten Nonnenmotiv. Im Gedicht "Theater", das um 1957 verfasst und 1960 in Gleisdreieck veröffentlicht wurde, heißt es:

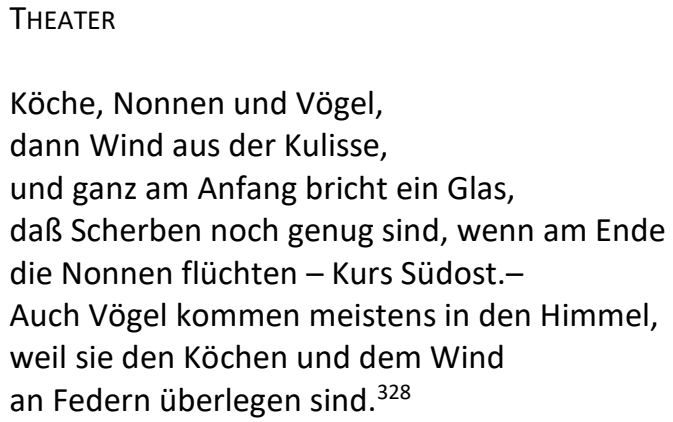

Indem das im übertragenen Sinne gemeinte In-den-Himmel-Kommen der Nonnen mit dem buchstäblichen Aufschwung der Vögel in die Luft in Eins gesetzt wird, persiflierte der Dichter den mit dem Sprachbild verbundenen Kinderglauben.

Grafisch werden Nonnen und Vögel (und auch die Köche) über eine optisch wahrnehmbare Analogie miteinander in Verbindung gesetzt, wie die Zeichnung, die Grass in der unteren Hälfte der Manuskriptseite platzierte, veranschaulicht (Abb. 87): Alle drei Figuren stehen über die weiße Farbe ihrer Kleidung bzw. ihres Gefieders miteinander in Verbindung. Zudem weisen sowohl die Mütze des Koches als auch die Flügelhaube der Nonne und der Hals des Vogels eine ähnlich schmale und längliche Form auf. Inhaltlich stehen die drei Figuren auch über eine Opfer-TäterBeziehung miteinander im Verhältnis: Es ist der Koch, der es sowohl auf das Fleisch des Vogels als auch der Nonne abgesehen hat.

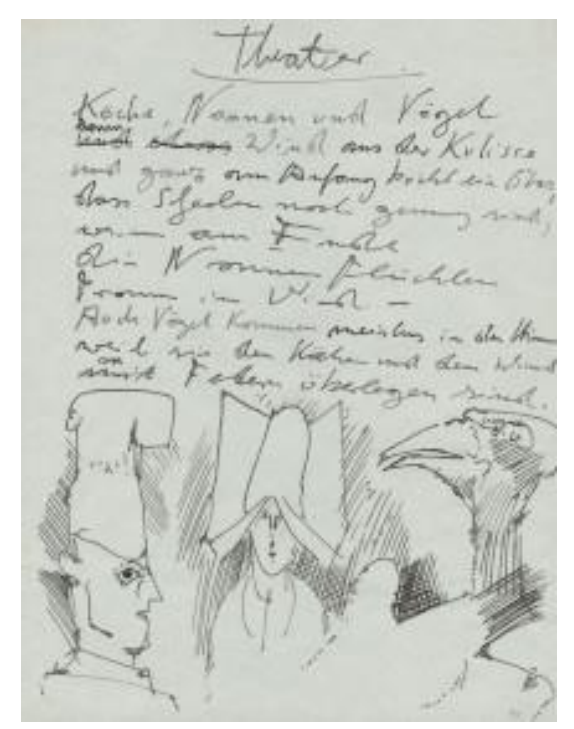

Abb. 87, Manuskript zum Gedicht „Theater" mit Zeichnung, um 1957, Bleistift, Akademie der Künste, Berlin, Günter-Grass-Archiv, Nr. 948

${ }^{328}$ Grass (1960), S. 49. 
Ein Plakat, das für eine Ausstellung von Günter Grass in der Kreuzberger Galerie „zinke“ wirbt, nutzt eine seiner Federzeichnungen als Motiv, das einen Vogel mit einer Nonnenhaube auf dem Kopf darstellt und so den Spott noch weitertreibt (Abb. 88). Die Verkleidung des Vogels als Nonne, profaniert und karikiert die "Flügelhaube" der Geistlichen ebenso wie ihren Wunsch, in das Reich Gottes aufzusteigen. Kritisiert wird damit nicht der Glaube an sich, sondern die verklärende religiöse Metaphorik.

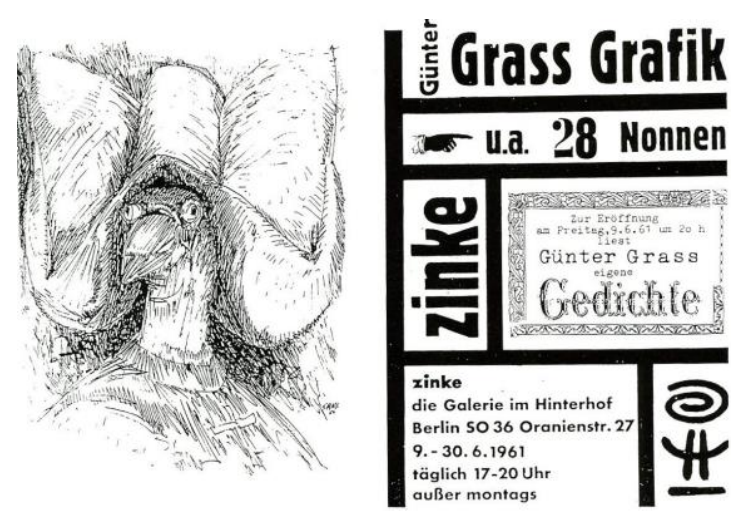

Abb. 88, Ausstellungsplakat, „zinke“, 1961

Eine Beziehung zwischen Nonnen und Vögeln eröffnet ebenfalls Die Blechtrommel. Im dritten Teil des Romans, der in der Nachkriegszeit spielt, erhalten Leserinnen und Leser einen Einblick in die Verdrängungsmechanismen der Düsseldorfer Bohème. Im Kapitel „Der Zwiebelkeller" ist dem berüchtigten tränentreibenden Zwiebelschneiden eine Beschreibung der besonderen Lebensgewohnheiten des Wirtes Schmuh vorangestellt. Dieser fährt, wenn es ihm schlecht geht, in die Rheinauen, um dort auf Spatzen zu schießen, wobei er sich erholt und im Gegenzug zur Versorgung der Vögel beiträgt:

Schmuh war ein guter Schütze, womöglich war Schmuh auch ein guter Mensch; denn wenn Schmuh Sperlinge schoß, verwahrte er zwar in seiner linken Jackentasche die Kleinkalibermunition, seine rechte Jackentasche jedoch war prall von Vogelfutter, das er nicht etwa vor dem Schießen, sondern nach dem Schießen - niemals schoß Schmuh mehr als zwölf Sperlinge an einem Nachmittag - mit großzügigen Handbewegungen unter die Spatzen austeilte. (III 685)

Wie die Vorgänge im Zwiebelkeller, das tränenlösende Knollenhacken und Oskars infantilisierendes Trommeln, wird auch das maßvolle Töten von Tieren als Vorgang der Schuldverdrängung und Erleichterung angeführt. ${ }^{329}$ Zudem kann die moralische Irrationalität des gleichermaßen tötenden wie auch nährenden Wirtes stellvertretend für weitaus schwerwiegendere ethische Inkonsequenzen in Teilen der Nachkriegsgesellschaft gelesen werden.

Im darauffolgenden Kapitel nämlich, „Am Atlantikwall oder es können die Bunker ihren Beton nicht loswerden“, bildet Schmuhs spektakulärer Tod den Übergang zu einer anderen Erschießungsszene: Der Wirt erliegt der Versuchung, sich nicht auf die Tötung von zwölf Sperlingen zu beschränken, und erschießt einen dreizehnten. Während der folgenden Autofahrt, so scheint es

\footnotetext{
${ }^{329}$ Vgl. III 706: „Ich aber fand [...] in den Zwiebelkeller zurück, wo Schmuh immer noch in die Hände klatschte, mit nassen Hosen X-beinig neben der Hühnerleiter stand und sich in Tante Kauers Kindergarten ähnlich wohl zu fühlen schien wie auf den Rheinwiesen, wenn er als erwachsener Schmuh auf Sperlinge schoß."
} 
zumindest, rächen sich die verbleibenden Vögel, indem sie mit vereinten Kräften gegen die Windschutzscheibe seines Wagens steuern und einen tödlichen Unfall herbeiführen. Noch während des Begräbnisses wird Oskar von einer Veranstaltungsagentur als Solotrommler angeworben. Um das Angebot zu überdenken, unternimmt er eine Reise, bei der eine Szene aus Kriegszeiten, thematisiert im Kapitel „Beton besichtigen - oder mystisch barbarisch gelangweilt", aufgefrischt wird: Oskar und sein Reisebegleiter Lankes erinnern sich, wie letzterer als ehemaliger Obergefreiter den normannischen Strand, an dem eine Gruppe Nonnen Krabben für einen Kindergarten sammelte, mit einem Maschinengewehr räumte, die Geistlichen also ebenso erschoss wie Schmuh die Sperlinge. Nonnen und Vögel figurieren auch hier, ähnlich wie im obengenannten Gedichtmanuskript, gleichermaßen als Opfer.

Wie bereits in den Gedichten der Vorzüge erschließt sich die Verwandtschaft zwischen diesen beiden Motiven äußerlich über eine visuelle Analogie. Anfang der Sechzigerjahre fertigte der Künstler großformatige Tusche- und Kreidezeichnungen von Nonnen und Vögeln wie die hier präsentierten Arbeiten an (Abb. 89, Abb. 90). Die beiden exemplarisch herangezogenen Tuschezeichnungen zeigen jeweils eine große Gruppe dunkler uniformer Gestalten in schräger Aufsicht. Die Gemeinsamkeit der Darstellung liegt darin, dass beide Figurentypen als Gruppe gleichförmiger, dunkler Gestalten präsentiert werden. Während die Vögel, in breiten Pinselstrichen skizziert, wenige individuelle Kennzeichen aufweisen, ergibt sich die Gleichförmigkeit der Geistlichen durch ihren Habit und die in der Zeichnung vorgenommene Abstraktion von Details.

Vögel spielen auch in Grass' zweitem Romanepos, den Hundejahren, eine wichtige Rolle. Das Werk, das mitunter ein „Handbuch zum Bau von Vogelscheuchen“ darstellt, sollte zunächst den Titel „Amsel, Drossel, Fink und Star“ tragen. ${ }^{330}$ Auch hier werden Nonnen und Vögel bzw. Krähen über die Parallele von schwarzer Figur auf weißem Schnee zueinander in Beziehung gesetzt. Die den Schnee "verunreinigenden“ Vögel weisen auf die Vision einer Orgie voraus, an der Nonnen beteiligt sind. ${ }^{331}$

Darüber hinaus spielen Vögel noch eine weitaus wichtigere Rolle in den Hundejahren. Als poetologisches Motiv werden sie in diesem Erzählwerk zwar von Vogelscheuchen abgelöst, stehen mit innen aber in engem Zusammenhang. ${ }^{332}$ Die Arbeiten des jungen Vogelscheuchenbauers Eddi Amsel, von dem in der Untersuchung zum Vogelscheuchenmotiv noch eingehend berichtet werden wird, erzeugen Panik unter den Tieren, die sich durch die Formation des Vogelfluges als eine Form der Schrift vermittelt. In den Hundejahren beschreibt Grass explizit bildhaft, wie Amsel unter freiem Himmel an seinen Vogelscheuchen arbeitet, die er als Kunstwerke versteht, und dabei von seinem Freund Walter Matern unterstützt wird:

Ein Bild, stellvertretend für viele und farbige Situationen junger Freundschaft auf dem Lande, zwischen feststehenden Figuren des Landlebens - Bauer, Knecht, Pastor, Lehrer, Posthalter, Hausierer, Käsereibesitzer, Inspektor des Milchgenossenschaftsverbandes, Forsteleve und Dorftrottel - hielt sich in seiner Einmaligkeit viele Jahre lang, ohne fotografiert zu werden: Irgendwo in den Dünen, den Strandwald mit seinen Schneisen im Rücken, arbeitet Amsel. Ausgebreitet und übersichtlich geord-

${ }^{330}$ Der Entwurf befindet sich unter den Faksimiles in Kiwus/Trautwein (2002), eine alternative Fassung ist abgedruckt bei Stolz (2010), S. 228, Abb. 14.

${ }^{331} \mathrm{Vgl}$. Harscheidt (1976), S. 401-404.

${ }^{332}$ Vgl. Engels (2005), S. 130. 
net liegen Bekleidungsstücke verschiedener Machart. Keine Mode herrscht vor. [...] Und zwischen all den Vorräten, überraschend behände: Eduard Amsel. Schwitzt, tritt barfuß auch Stranddisteln, merkt aber nichts, stöhnt, grunzt, kichert bißchen, pflanzt hier eine Bohnenstange, wirft ihr quer eine Dachlatte dagegen, wirft Draht hintendrein - er bindet ja nicht, sondern wirft aneinander, und es hält wunderbar -, [...] und ist gleich darauf [...] steuerbord seines verlorenen Haufens, der mehr und mehr zur vogelscheuchenden Gruppe wird; denn aus den Dünen, dem Strandhafer, den Kiefern des Strandwaldes hebt es gewöhnliche und - ornithologisch gesehen - seltene Vögel. Ursache und Wirkung: zu einer Wolke, hoch über dem Arbeitsplatz des Eduard Amsel, ballt es sie. Mit Vogelschrift schreiben sie ihre Angst immer enger, steiler und krauser durcheinander. Dieser Text birgt die Wurzel Krah, treibt den Waldtaubenzweig Marukruh, hört, wenn er aufhört, mit Pih auf, hat Uebü, viel Oekk, das Stockenten-Räätsch und das Ochsengebrüll der Rohrdommeln als Ferment. Keinen Schrecken gibt es, der, von Amsels Produktion gefördert, nicht Ausdruck fände. (IV 197-199)

Eine von vielen Spielarten der Wechselwirkung von bildender Kunst und Literatur findet auf diese Weise Eingang in die Handlung der Hundejahre. Wie schon in den Vorzügen der Windhühner repräsentieren Vögel an dieser Stelle das Schreiben und die Dichtung. Sie reagieren auf die Menschen und ihre Eigenarten, die der bildende Künstler durch ausgesuchte Zusammenstellungen von Gegenständen in seinen Artefakten pointiert zum Ausdruck bringt. Ihre Angst wird durch den Schriftsteller zu einem Schriftbild verdichtet.

Bei der Gestaltung des literarischen Vogelmotivs, das in besonderem Maße auch ein Motiv des bildenden Künstlers war, betonte Grass damit auch in diesem Fall ihre visuell vorstellbare Gestalt. Während er in seinen sprachlichen Darstellungen der Tiere immer wieder auf den Sehsinn rekurriert, enthalten seine Manifestationen des Nonnenmotivs, wie nun gezeigt werden soll, darüber hinaus Bezüge zu Werken der bildenden Kunst.

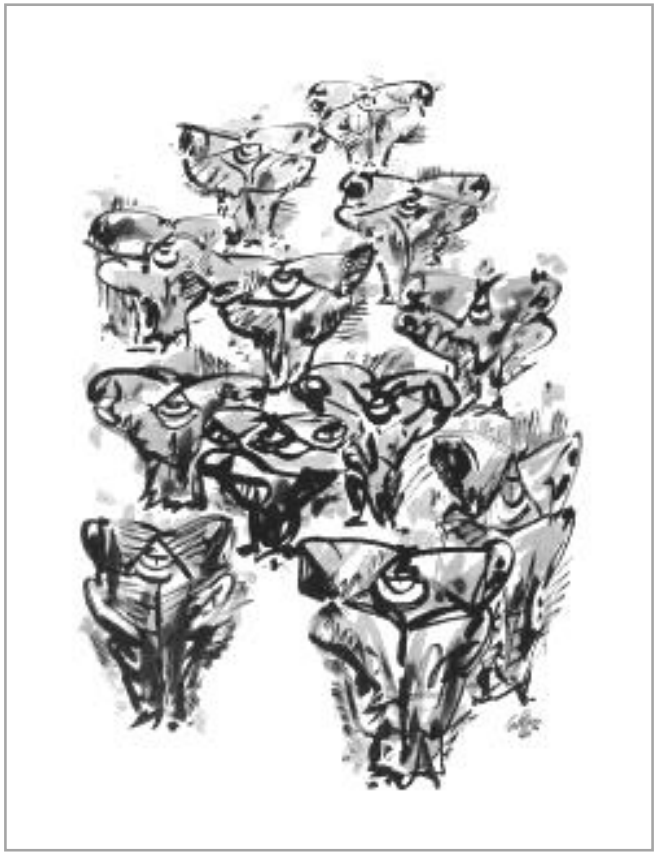

Abb. 89, Ein Pulk Nonnen, 1961, Pinsel/Tusche, laviert

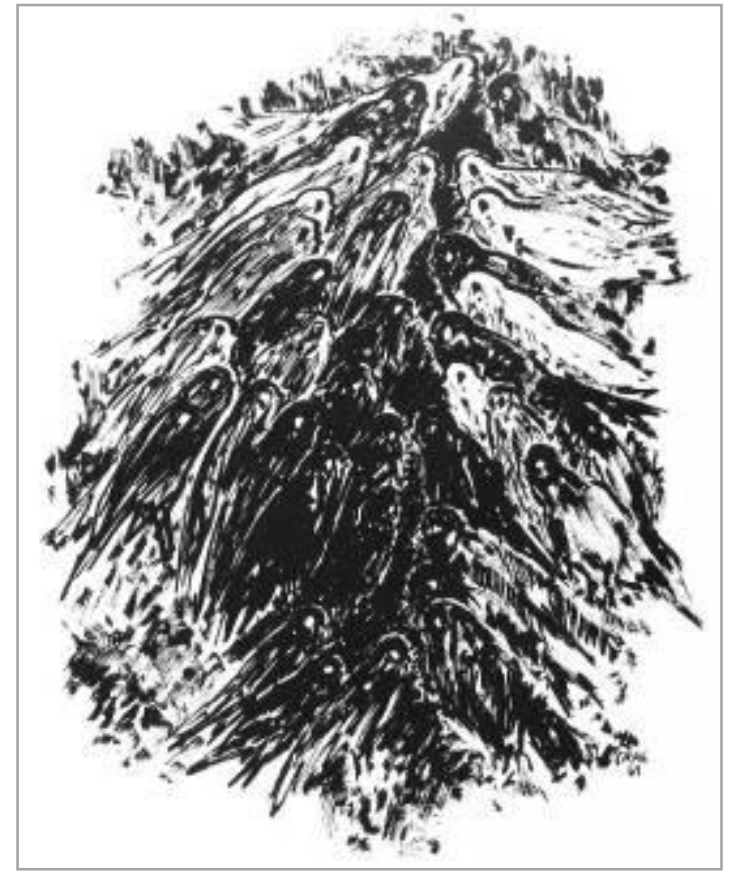

Abb. 90, Versammlung, 1961, Pinsel/Tusche 


\section{Nonnen: Verkörperte Ideologiekritik}

Sind Hühner und Vögel in der ersten Hälfte der Fünfzigerjahre besonders häufig in Grass' bildkünstlerischem CEuvre vertreten, so gilt dasselbe für Nonnen zwischen 1955 und $1963 .{ }^{333}$ Sein Umgang mit diesem Motiv bietet das vielleicht schlüssigste Beispiel dafür, wie der Schriftsteller und Grafiker die äußere Erscheinung einer Figur zur komprimierten Darstellung ideologiekritischer Zusammenhänge nutzte. In Texten und Grafiken realisierte er sie als Zeichen zur Repräsentation von Widersprüchen der katholischen Sittenlehre, der ästhetischen Askese und der katholischen Kirche als einer der Ideologie des „Dritten Reichs“ in die Hände spielenden Organisation. ${ }^{334}$

Nicht alle Nonnen-Manifestationen in Zeichnungen, Manuskripten und Publikationen sind datiert und viele von ihnen dürften dem Veröffentlichungsdatum der literarischen Werke zufolge parallel oder in kurzen Abständen nacheinander entstanden sein. Zum ersten Mal griff der Schriftsteller das Motiv im Rahmen des Theaterspiels Hochwasser (UA 1957) auf. Die erste handschriftliche Fassung der entsprechenden Passage entstand am 7. August $1955 .{ }^{335} \mathrm{Ab}$ dem 9. September 1956 integrierte Grass das Nonnenmotiv in seinen poetologischen Essay „Die Ballerina“ (1956). ${ }^{336}$ Geistliche und Tänzerin werden darin gleichermaßen als Sinnbild einer auf alle künstlerischen Ausdrucksformen bezogenen Ästhetik der Askese gestaltet. Weitere Anmerkungen zu diesem Begriff hielt Grass in seinem Arbeitstagebuch am 28. Oktober 1956 fest. ${ }^{337}$ Sein programmatisches Gedicht "Askese“ ist demnach wahrscheinlich in unmittelbarer zeitlicher Nähe entstanden, wurde jedoch erst 1960 im Gedichtband Gleisdreieck veröffentlicht. ${ }^{338}$ Passend zur Maxime der ästhetischen Enthaltsamkeit fertigte Grass 1957 kontrastarme Bleistiftzeichnungen von Vinzentinerinnen an.

Zwischen 1956 und 1958 schrieb er darüber hinaus den Einakter Noch zehn Minuten bis Buffalo (UA 1958), in dem sich bereits die auf zwei Kapitel verteilte Nonnenpassage der Blechtrommel (1959) mit den darin virulenten ästhetischen Diskursen ankündigt. ${ }^{339}$ Ein Jahr nach dem Debütroman publizierte Grass im Gedichtband Gleisdreieck den Zyklus „Zauberei mit den Bräuten Christi“" der viele der hier angesprochenen Aspekte in verdichteter Form enthält. Diese Texte wurden zusammen mit drei Fettkreidezeichnungen des Autors veröffentlicht. ${ }^{340}$

Im Gegensatz zum Komplex der Vögel fällt die intensivste bildkünstlerische Behandlung der Nonnen nicht in die Anfangs-, sondern in die Schlussphase der Auseinandersetzung mit diesem

\footnotetext{
${ }^{333}$ Vgl. das Motivverzeichnis dieser Arbeit sowie die Zusammenstellung der bis 1986 publizierten NonnenGrafiken bei Hille-Sandvoss (1987), S. 114-124.

${ }^{334}$ Das Kapitel folgt weitgehend dem Aufbau und den Thesen meines 2013 publizierten Aufsatzes zum Nonnenmotiv im Werk von Günter Grass. Während der 2013 veröffentlichte Text die literarischen Quellen ausführlicher behandelt, widmet der vorliegende den bildkünstlerischen Arbeiten mehr Aufmerksamkeit. Vgl. Krason (2013b).

${ }^{335}$ Akademie der Künste, Berlin, Günter-Grass-Archiv, Nr. 1755, S. 92.

336 Ebd., S. 202-225. Erstabdruck: Akzente, 1956, S. 532-539, dann als Einzeldruck bei der Friedenauer Presse: Grass (1963) sowie in den Werkausgaben (XI 8-15).

${ }^{337}$ Akademie der Künste, Berlin, Günter-Grass-Archiv, Nr. 1755, S. 234. Die Passage ist nur teilweise entzifferbar.

${ }^{338}$ Grass (1960), S. 56.

${ }^{339} \mathrm{Vgl}$. Stolz (2010), S. 86; Variante zum Theaterspiel abgedruckt in: ebd., S. 211-227. Vgl. zum Verhältnis der alternativen Dramenfassung und der Blechtrommel: Neuhaus (2010), S. 14.

${ }^{340}$ Vgl. Grass (1960).
} 
Motiv: Zwischen 1960 und 1963, parallel zur Manuskriptarbeit an der Novelle Katz und Maus (1961) und an den Hundejahren (1963), entstand eine Serie großformatiger Tuschezeichnungen zu den Geistlichen. Ausstellungen dieser Arbeiten fanden 1961 und 1962 in Berlin statt, in der Kreuzberger Galerie „zinke“ und in der Akademie der Künste. ${ }^{341}$

Die Beschäftigung des Schriftstellers und bildenden Künstlers mit den „Bräuten Christi“ steht mit den kirchenkritischen Tendenzen um 1960 in engem Zusammenhang. Die katholische Kirche war in Westdeutschland auch nach dem Ende des Zweiten Weltkrieges sehr präsent, musste jedoch allmählich ihre opportunistische Haltung im „Dritten Reich“ und ihre konservativen Sittlichkeits- und Moralvorstellungen rechtfertigen. Unter den Schriftstellern waren es besonders Heinrich Böll und Carl Amery, die die Institution angriffen. Mit ihren Auffassungen konnte sich Grass noch vor der Veröffentlichung von Bölls kirchenkritischem Roman Billard um halbzehn (1959) und Amerys Streitschrift Die Kapitulation oder der Katholizismus heute (1963) im Rahmen der Treffen der Gruppe 47 vertraut machen. Er selbst beschäftigte sich nicht nur als katholisch getaufter und erzogener Zeitgenosse mit dem Thema. ${ }^{342}$ Seine Auseinandersetzung hatte, wie seit der Publikation von Beim Häuten der Zwiebel (2006) bekannt ist, besondere Ereignisse im engsten Familienkreis zum Anlass:

Kniende, fliegende, hüpfende und Richtung Horizont gegen den Wind kreuzende, als Äbtissinnen dominierende und zu eucharistischen Kongressen versammelte, einzelne und paarweis bis auf die Flügelhaube entkleidete Nonnen verdanke ich dem Unglück meiner Schwester, die glaubensfromm der organisierten Heuchelei auf den Leim ging und als Novizin Raffaela den Gelübden entgegenbangte [...]. (X 579)

Waltraut Grass war 1953 in ein Aachener Kloster eingetreten, jedoch schnell enttäuscht von dem geringen Stellenwert, den die soziale Arbeit im Orden hatte und von den dort herrschenden rigiden Verhaltensregeln. Da die zuständige Novizenmeisterin starken Druck auf die Dreiundzwanzigjährige ausübte, konnte sie sich erst mit der Unterstützung ihres Bruders zum Austritt durchringen. Dieser biografische Hintergrund wird nicht nur in Form allgemeiner Religionskritik in Grass' Werke Eingang finden, sondern auch in Form eines unmittelbaren Hinweises: Der in Hochwasser erwähnten Oberin gab er denselben Namen wie der realen Aachener Geistlichen.

Ein anderer Grund für Grass' aufkeimendes Interesse an den „Bräuten Christi“, war sein Gefallen an der Tracht einer bestimmten Ordensgemeinschaft, so die Erinnerungen des Schriftstellers in Beim Häuten der Zwiebel: Die voluminösen und von bretonischen Hauben abgeleiteten traditionellen Kopfbedeckungen der Vinzentinerinnen fielen ihm 1954 in einem Kölner Krankenhaus sowie ab 1956 in Paris auf. Sie regten Grass besonders als Grafiker zu Assoziationen an. ${ }^{343}$ In den Kreide- und Tuschezeichnungen setzte er sich dann ab 1960 vor allem mit den Schwarz-WeißKontrasten von Ordensgewändern und mit ihrer Volumenbildung auseinander.

Wie im Folgenden zu zeigen sein wird, wurde auch bei der Darstellung dieses Motivs der Vergleich zwischen der sichtbaren Gestalt der Nonne in ihrem Habit und anderen mit ihr assoziierba-

\footnotetext{
${ }^{341}$ Vgl. Kat. Ausst. Berlin (1979), insbes. S. 20-24 und o. A.: Eintrag in der Rubrik „Personalien“. In: Der Spiegel 10 (7. März 1962), S. 96.

${ }^{342} \mathrm{Vgl}$. Neuhaus (1988).

${ }^{343}$ Vgl. ebd., S. 442.
} 
ren Gegenständen wichtig. Der Dichter und Grafiker nahm ihre Erscheinung zum Ausgangspunkt, um das Motiv mit verschiedenen Bedeutungen aufzuladen. Während er sich zunächst zeitgleich in verschiedenen Medien den Themen der sittlichen Enthaltsamkeit und der ästhetischen Askese widmete, wurden diese ab 1958 zusammengeführt und mit einer Kritik am Verhalten der Kirche während des Zweiten Weltkrieges verbunden. Die Kombination von Zeichnungen und Texten machen diese Zusammenhänge ebenso deutlich wie die eingebetteten Ekphrasen bildkünstlerischer Nonnendarstellungen in der Prosa.

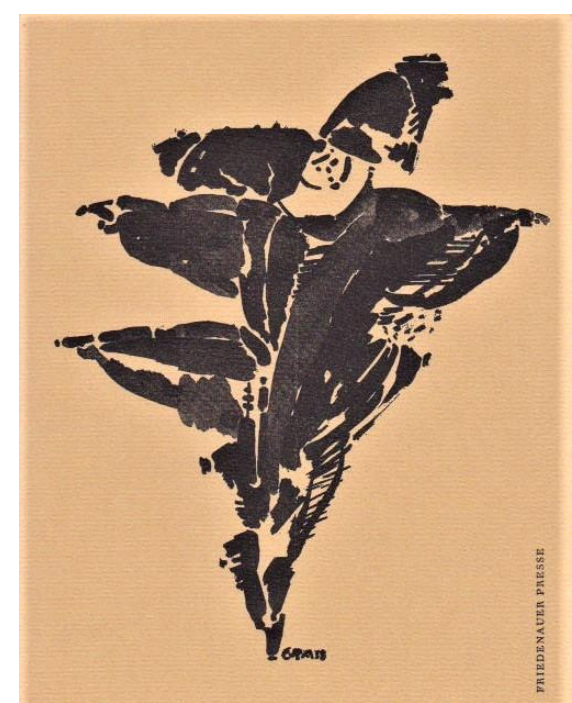

\section{Günter Grass Die Ballerina}

Abb. 91, Die Ballerina, Berlin 1963, 2. Auflage, 1965, Umschlag, Titelbild

\section{Religion und Ästhetik: die Nonne als Sinnbild der Askese}

Zwei frühe Texte deuten bereits darauf hin, in welche Richtung sich Grass' langjährige Beschäftigung mit der „Braut Christi“ bewegen sollte. In den die Nonne betreffenden Passagen beider Werke wird der Begriff der Askese unter Berücksichtigung von jeweils anderen Aspekten fokussiert. Während der Schriftsteller inn im Dreiakter Hochwasser (UA 1957) in seiner religiössittlichen Komponente thematisierte, erhob er Enthaltsamkeit im Essay „Die Ballerina“ zu einer ästhetischen Maxime. Literarisch und bildkünstlerisch schritt Grass damit die gesamte Spannweite der Begriffsbedeutung aus: von dem aus dem Griechischen abgeleiteten „technischen oder künstlerischen Verfertigen“ über die bei Xenophon und Epiktet thematisierte leibliche Ertüchtigung bis hin zu Entsagung und Verzicht im Dienste der Tugend und des Glaubens. ${ }^{344}$

Das im Januar 1957 an der neuen bühne der Johann-Wolfgang-Goethe-Universität in Frankfurt am Main uraufgeführte Theaterspiel fingiert Gespräche der Bewohnerinnen und Bewohnern eines mehrstöckigen Hauses, das durch erhöhten Wasserstand kurzzeitig von dem Rest der Welt abgeschnitten ist. Die Art des titelgebenden Naturphänomens und der Name des Hausvaters,

\footnotetext{
${ }^{344}$ Vgl. Hauser (1971).
} 
Archibald Noah, machen hinter dem Wohnhaus die Arche und hinter dem Hochwasser die Sintflut erkennbar. Zu den in diesem allegorischen Sinne Erretteten zählt das Rattenpaar Perle und Strich, das sich die Zeit auf dem Dach mit dem Erzählen von Geschichten vertreibt. Eine davon handelt von der Nonne Alfons Maria. ${ }^{345}$ Wie Strich berichtet, zieht sich die Geistliche regelmäßig in den Klosterkeller zurück, um dort ungestört ihre nackten Beine betrachten zu können. Die erfolglose Unterdrückung der eigenen Körperlichkeit wird mit dieser Geschichte hervorgehoben und ins Lächerliche gewendet:

STRICH: [...] Die kam nämlich manchmal runter, schloß ab von innen, immer hübsch vorsichtig, dann hob sie sich die Kutte hoch, schnapp, schnapp, ließ die Wollsocken runter und guckte sich ihre Beine an. Ich sag dir, wenigstens zehn Minuten saß die immer so und guckte.

PERLE: Wird halb so schlimm gewesen sein.

STRICH: Schlimm? Weiß waren die, weiß wie 'ne Made. Von unten bis dahin wo's aufhört, und lauter Sommersprossen drauf. [...] Später sind dann die Pfaffen runtergekommen mit so ein paar blassen Chorknaben und haben geweihräuchert und geweihwassert. War 'ne verdammte Schande.

PERLE: Warum denn?

STRICH: Du kannst fragen. Von wegen mir natürlich. Haben gedacht, ich wäre so eine Art Geist, der den Nönnchen unter die Kutten saust. [...]

PERLE: Und die mit den Sommersprossen?

STRICH: Die hatten sie doch schon vorher versetzt, was weiß ich, wohin. Muß wohl dolle Dinger gedreht haben. Man hört ja oft die dunkelsten Geschichten über Klöster. (II 36 f.)

Positiv wird die angestrebte Enthaltsamkeit der Nonne dagegen in Grass' frühem poetologischen wie kunsttheoretischen Essay „Die Ballerina“ angeführt, den der Autor in Walter Höllerers Auftrag für die Novemberausgabe der Akzente von 1956 schrieb. Der Text setzt sich in fünf Abschnitten mit dem Verhältnis von Natur und Kunst auseinander. Stellvertretend für alle Künste wird darin der Ausdruckstanz dem klassischen Ballett gegenübergestellt. Kunst müsse sich, so die Schlussfolgerung der Argumentation, nach Grundsätzen und Regeln vollziehen, um die wahrnehmbare Realität angemessen zu repräsentieren und diese nicht etwa „möglichst natürlich“ imitieren. Die Disziplin der Balletttänzerin wird mit der Askese der Nonne verglichen:

Die Ballerina lebt, einer Nonne gleich, allen Verführungen ausgesetzt, im Zustand strengster Askese. Dieser Vergleich darf deshalb nicht überraschen, da alle auf uns gekommene Kunst stets Ergebnis konsequenter Beschränkung und nie genialischer Maßlosigkeit war. Auch wenn zeitweise Ausbrüche ins Unerlaubte zu denken gaben und geben, der Kunst sei alles erlaubt, erfand sich immer, und gerade der beweglichste Geist, Regeln, Zäune, verbotene Zimmer. (XI 11)

Die Bedeutung der Passage wurde von Grass noch fünf Jahre später in einer separaten Ausgabe des Essays hervorgehoben, indem er den Textauszug auf die Innenseite des Umschlages platzieren ließ und den literarischen Vergleich in einer Tuschezeichnung umsetzte, die als Titelbild Verwendung fand (Abb. 91). Die Gegenüberstellung von grafischem und literarischem Bild erfolgt damit in vergleichbarer Weise wie zuvor in den Vorzügen der Windhühner, wo das gleichnamige Gedicht auf die vordere Innenklappe des Umschlags gesetzt worden war. Die Zeichnung zur separaten Ballerina-Publikation zeigt eine Nonne in einer Ballettpose, der Arabeske, und irritiert durch die

${ }^{345}$ Vgl. bezüglich der Namensgebung zu Ehren des heiligen Alfonso Maria de Liguori: Stolz (2010), S. 76. 
Widersprüchlichkeit zwischen klassischem körperbetontem Tanz und der ihn ausführenden, von ihrem wallenden Gewand verhüllten Schwester.

Ist die Askese der Geistlichen vor allem durch ihre sexuelle Enthaltsamkeit gekennzeichnet und die der Tänzerin durch ihre körperliche Disziplin, wird die Selbstbeschränkung des Schriftstellers im „Ballerina“-Essay konkret als ein Verzicht auf abgegriffene Beschreibungen und als eine Konzentration auf das sinnlich Wahrnehmbare charakterisiert. Der Dichter sollte sich zu seinem Gegenstand verhalten wie ein Briefmarkensammler zu seinem „,begehrten Viereck“, das er

[...] prüfend ins Licht hält, um Zahnung und Wasserzeichen deutlich zu haben. Krone und Lächeln der bunten Königin, so wohlgelungen die Miniatur sein mag, beeinflussen niemals sein wertendes Auge.

(XI 8)

Wenn die handwerkliche Vervollkommnung des Kunstwerks ferner mit der moralischen Vervollkommnung des Geistes verglichen wird (XI 12), erhebt Grass die Kunst zu einer antimetaphysischen Ersatzreligion. Weiterverfolgt wird damit eine Linie, die bereits in einigen Gedichten des ersten Gedichtbandes ihren Ausgangspunkt hatte, maßgeblich in dem Gedicht "Credo" (I 41). ${ }^{346}$

Die poetische Selbstdisziplinierung nimmt in dem Gedicht „Askese“ - wie Grass selbst rückblickend bemerkt, mit einiger Verzögerung - auf Adornos Diktum von 1951 Bezug. Anstelle der häufig als Verbot interpretierten Aussage, nach Auschwitz ein Gedicht zu schreiben, sei barbarisch, bietet Grass' Gedicht Gebote, die das „Schreiben nach Auschwitz“ (so der Titel der 1990 von Grass gehaltenen Frankfurter Poetik-Vorlesung, XII 239-261) auszeichnen sollten. Der mutmaßlich 1957 entstandene und 1960 veröffentlichte Text fordert einen skeptischen Umgang mit Religion und Nationalismus. Dazu nutzt er eine Metaphorik, die sowohl dem Bereich der bildenden Kunst als auch dem des handschriftlichen Schreibens entlehnt ist: ${ }^{347}$

ASKESE

Die Katze spricht.

Was spricht die Katze denn?

Du sollst mit einem spitzen Blei

die Bräute und den Schnee schattieren,

du sollst die graue Farbe lieben,

unter bewölktem Himmel sein. [...]

Die Katze spricht.

Was spricht die Katze denn?

Du solltest die Marine streichen,

die Kirschen, Mohn und Nasenbluten,

auch jede Fahne sollst du streichen

und Asche auf Geranien streun. [...]

\footnotetext{
${ }^{346}$ Vgl. Neuhaus (1988), S. 111 und Stolz (1994), S. 38-45.

${ }^{347}$ Vgl. Günter Grass deutete den Text aus dem Abstand von über dreißig Jahren heraus wie folgt: „Es galt, den absoluten Größen, dem ideologischen Weiß oder Schwarz abzuschwören, dem Glauben Platzverweis zu erteilen und nur noch auf Zweifel zu setzen, der alles und selbst den Regenbogen graustichig werden ließ. Und obendrein verlangte dieses Gebot Reichtum neuer Art: Mit den Mitteln beschädigter Sprache sollte die erbärmliche Schönheit aller erkennbaren Graustufungen gefeiert werden. Das hieß, jene Fahne zu streichen und Asche auf Geranien zu streuen. Das hieß, mit spitzem Blei, der von Natur her für Grauwerte steht, quer über jene Wand, ,wo früher pausenlos das grüne Bild das Grüne wiederkäute', als mein Gebot das Wort Askese zu schreiben." (XII 246)
} 
Und an die Wand, wo früher pausenlos

das grüne Bild das Grüne wiederkäute,

sollst du mit deinem spitzen Blei

Askese schreiben, schreib: Askese.

So spricht die Katze: Schreib Askese. (I 90)

Mit einem Bleistift soll also die Reinheit der Farbe Weiß und damit die Unschuld in Zweifel gezogen werden. Die durch die Farbe Rot gekennzeichneten Motive der Leidenschaft, des vom Mohn geförderten Schlafes und des Schmerzes sowie die nationalen Symbole und die mit Geranien assoziierbare Idylle seien entsprechend zu „streichen“. Mit den „Bräuten“, die in diesem Gedicht mit dem Bleistift bearbeitet werden sollen, können nun sowohl die weltlichen gemeint sein als auch Nonnen, die Grass in anderen Gedichten als „Bräute Christi“ (I 86 f.) bezeichnete und welchen er sich 1957 zeichnend gewidmet hat. Wie im Gedicht „Askese“ wird ihre Unschuld auch in den grafischen Darstellungen in Zweifel gezogen. Die in Hochwasser formulierte Satire über die missglückte Verneinung des sommersprossigen Nonnenfleisches bringt Grass auch in diesen Zeichnungen zum Ausdruck.

Bei den erhaltenen Blättern aus diesem Zeitraum handelt es sich um vier Darstellungen einer jungen Nonne mit der traditionellen Haube des St. Vinzenz-Ordens auf dem Kopf. Einige von ihnen sind im Archiv des Günter Grass-Hauses zugänglich, andere befinden sich in Privatbesitz oder wurden in Bildbänden abgedruckt. ${ }^{348}$ Gemäß der in „Askese“ mit dem Vokabular des zeichnenden und schreibenden Künstlers zum Ausdruck gebrachten Enthaltsamkeit sind die mit Bleistift gezeichneten Porträts äußerst kontrastarm. Stets handelt es sich um denselben, durch eine längliche Gesichtsform und volle Lippen gekennzeichneten Typ. Das hier abgedruckte Brustbild zeigt ein Mädchen seitlich mit ihrem Oberkörper zu Betrachterinnen und Betrachtern positioniert, ihnen ihr Gesicht im Dreiviertelprofil zuwendend (Abb. 92). Die leicht gesenkten äußeren Augenwinkel, der nach innen gekehrte Blick, die geschürzten Lippen und der gerundete Rücken lassen die Dargestellte betrübt oder zumindest lethargisch wirken. Die im Verhältnis zum schmalen Gesicht und dem schlanken gebeugten Körper sehr große, hohe und weit ausladende Haube scheint wie eine Bürde auf ihr zu lasten. ${ }^{349}$

\footnotetext{
${ }^{348}$ Vgl. das Verzeichnis der erhaltenen Nonnendarstellungen im Motivverzeichnis.

${ }^{349} \mathrm{Vgl}$. Hille-Sandvoss (1987), S. 114 f.
} 

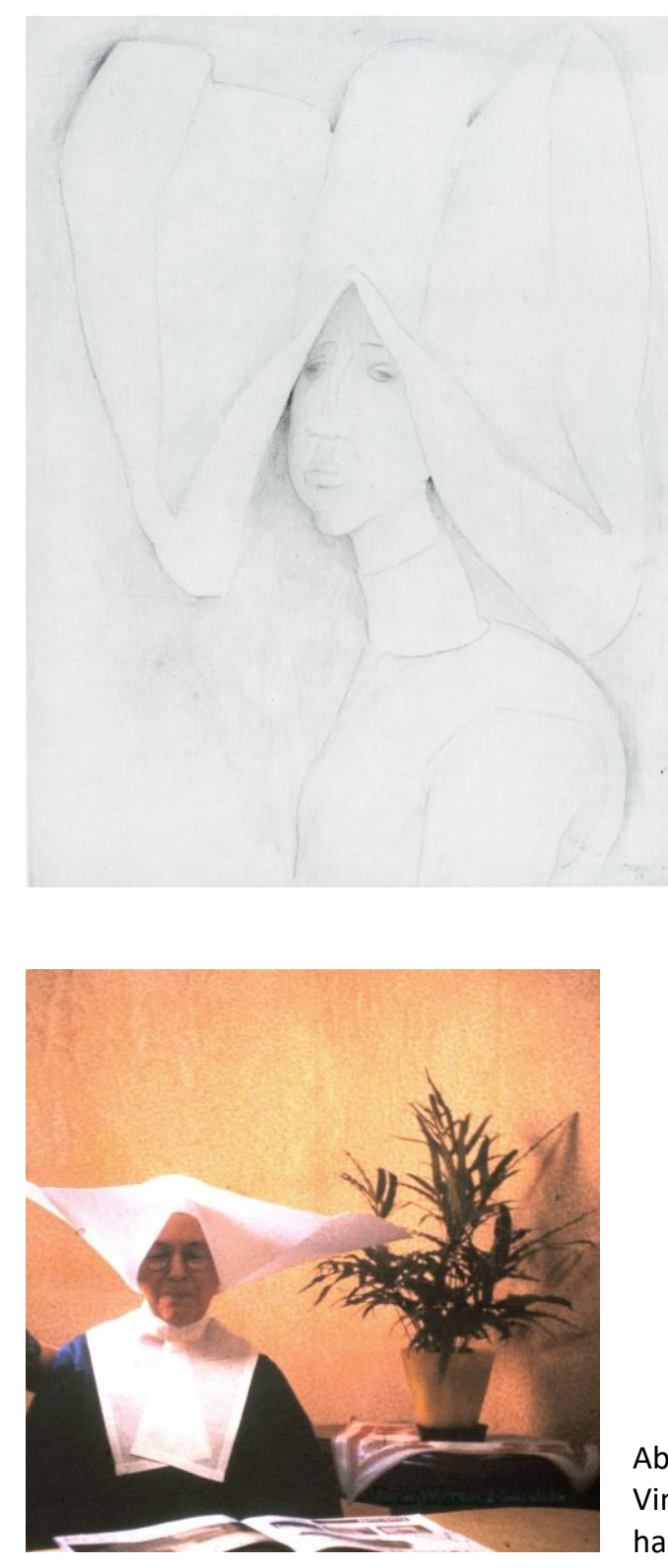

Abb. 92, Schwester Agneta, 1957, Bleistift und Kohle
Abb. 93, Maria Wichłacz-Musielak,

Vinzentinerin Jean Gabriel Batke mit Flügelhaube, 1961, Fotografie

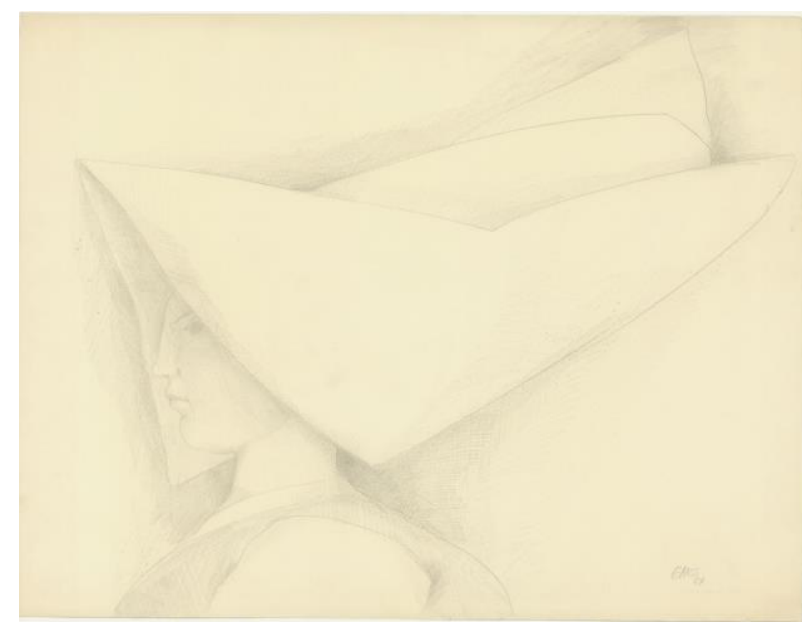

Abb. 94, Vinzentinerin, 1957, Bleistift 
Es fällt auf, dass die jungen Frauen in Grass' Nonnen-Porträts ihre Haube, im Gegensatz zur üblichen Tragweise der Kopfbedeckung (Abb. 93), weit in die Stirn geschoben haben. Auf diese Art ist der Haubenzylinder fast in seiner ganzen Höhe, ohne Verkürzung sichtbar und kann aufgrund dieser besonderen Abweichung als Phallussymbol und damit als Sinnbild der unterdrückten Sexualität interpretiert werden. Freuds Traumdeutung, in welcher der Hut an sich in diesem Sinne verstanden wird, könnte Grass hier als Anregung gedient haben. ${ }^{350}$ Zu männlichen Gliedern erweiterte Kopfbedeckungen und verformte Köpfe hatte der Grafiker zudem später in noch eindeutigerer Form in andere Darstellungen eingebracht, um den Geschlechtstrieb der thematisierten Figuren sichtbar zu machen. Mit den Nonnen ist Grass' Darstellung des Heiligen Antonius vergleichbar, die er 1960 zu dem Gedicht "Anton“ schuf, das im Lyrikband Gleisdreieck veröffentlicht wurde. Der Oberkopf des Heiligen ähnelt darin dem männlichen Genital, während im Gedicht das Scheitern der Sublimierung fleischlicher Lust behandelt wird. ${ }^{351}$

Die Verbindung einer weiblichen Figur mit der Andeutung eines Gliedes kann einerseits als Manifestation der unterdrückten Sehnsucht nach dem Geschlechtsverkehr mit einem Mann verstanden werden oder andererseits als eine, dem Vorurteil gemäß, durch das Klosterleben beförderte Neigung zur Bi- oder Homosexualität. Die phallisch konnotierte Darstellung der Flügelhaube wäre demnach als Ausdruck einer angenommenen Vermännlichung der Nonne zu deuten. Für diese Interpretation spricht, dass Grass der Aachener Oberin Alfons Maria in seinem Erinnerungsbuch aufgrund ihres Namens als „bisexueller Instanz" gedachte (X 580). In Lithografien aus dem Jahr 1981 zu dem Kapitel „Vatertag“ des Butt stellte er die lesbischen Protagonistinnen der Passage mit Pilzhüten auf dem Kopf dar, deren Spitzen die Form männlicher Glieder haben. ${ }^{352}$ Der Titel der exemplarisch behandelten Zeichnung, Schwester Agneta, macht die erste Deutung einer Verkörperung unterdrückter Sexualität durch die Haubenform wahrscheinlich. „Agneta“ lautet der Name der Figur einer verführten Novizin in der Blechtrommel, deren Rolle im nächsten Unterkapitel näher erörtert werden wird.

Eine Assoziation der Haube mit einem ganz anderen Objekt, mit einem Segelschiff, kann sich für den Grafiker bei der Betrachtung der Kopfbedeckung im Profil ergeben haben (Abb. 94). Der Zylinder der Haube erinnert in der Seitenansicht an einen Schiffsmast mit gesetztem Segel, unter welchem sich der Schiffsrumpf befindet. Eine weibliche Personifikation eines militärischen Schiffes, die mit der Nonnenfigur in Verbindung steht, hatte der Schriftsteller und Künstler in anderen Arbeiten entworfen, die zwischen 1957 und 1959 entstanden sind. Sie sollen im Folgenden behandelt werden.

\footnotetext{
${ }^{350}$ Vgl. zum Hut als Phallussymbol: Freud (1914), S. 137; dass die Bildwelt von Günter Grass häufig Verweise auf die Psychoanalyse enthält, erwähnte bereits: Joch (1997), S. 19.

${ }^{351}$ Vgl. Grass (1960). Zur Interpretation von „Anton“ vgl. Stolz (1994), S. 76 f., ferner zu Kopfbedeckungen im bildkünstlerischen Grass-Werk: Dreher (1982), S. 123.

352 Ohsoling (2007a), L 16. Vgl. S.353, Abb. 192 dieser Arbeit.
} 


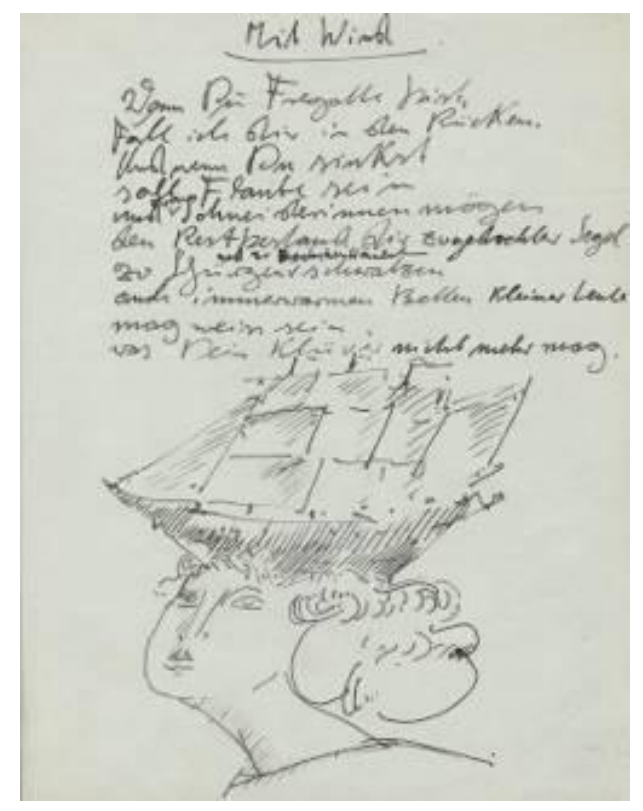

Abb. 95, Manuskript und Zeichnung zum Gedicht „Mit Wind“, um 1957, Tusche, Akademie der Künste, Berlin, Günter Grass-Archiv, Nr. 533

\section{Ästhetik und Ethik: die Nonne als Gegenstand der Kunst und des (un)moralischen Handelns}

In einem Manuskript des unveröffentlichten Gedichts „Mit Wind“ (ca. 1957), ${ }^{353}$ in einer Variante des Einakters Noch zehn Minuten bis Buffalo (1958) und in der Blechtrommel (1959) beschäftigte sich Grass mit Figuren, die zwischen Nonnen und Schiffen changieren. Vor allem die alternative Theaterspielfassung thematisiert die Nonne erstmals zugleich als sexuelles Wesen und als Repräsentantin der katholischen Kirche im Sinne einer Organisation, die sich im „Dritten Reich“ mit dem herrschenden Regime arrangiert hat. Die Schlussfassung des Stücks selbst bereitet die Figur der Nonne zudem als Gegenstand der ästhetischen Reflexion vor. In der Blechtrommel werden diese drei Aspekte zusammengeführt. Die gattungs- und medienspezifischen Eigenschaften der Vorgängerwerke, ihre dramatische und grafische Form, werden bei dieser Transformation berücksichtigt. Die frühen Theaterspiele und Zeichnungen tragen damit entscheidend zum dichten Geflecht intermedialer Beziehungen in Grass' Debütroman bei.

Die obere Hälfte des Gedichtmanuskripts „Mit Wind“ nimmt der zehnzeilige lyrische Text ein (Abb. 95). Die untere Hälfte füllt das Bildnis einer jungen Frau. Ihr als Dreiviertelporträt dargestelltes Gesicht, der schlanke lange Hals und der leicht gebeugte Rücken erinnern an die oben behandelten Bleistiftzeichnungen von Nonnen. An Stelle einer Flügelhaube trägt die Dargestellte die Miniatur eines Schiffes mit gesetzten und im Wind gespannten Segeln auf dem Kopf. Das halblange, in Wellen gelegte Haar in ihrem Nacken bildet ein kompositorisches Gegengewicht zu diesem surrealen Aufbau. Eine ähnliche Frisur, aus voluminösem Kunsthaar und Fregattenmodell bestehend und als „La belle poule“ („Die schöne Henne“) oder „Fregatte“ bezeichnet, wurde von Marie Antoinette getragen und von Perückenmachern und Friseuren bis ins 20. Jahrhundert überliefert. ${ }^{354}$

\footnotetext{
353 Das Manuskript ist abgedruckt bei: Stolz (2010), S. 228, Abb. 14.

${ }^{354}$ Fotografien der Frisur sind abgedruckt in: Kat. Ausst. Los Angeles (2018), S. 375 und S. 383.
} 
Das lyrische Ich des Gedichtes gibt sich selbst als Wind zu erkennen. Es richtet seine Worte an ein konkretes $\mathrm{Du}$, eine auf diese Weise personalisierte Fregatte, die in der unten abgebildeten Frauenfigur visualisiert wird und daher auch bei der Lektüre des Textes besondere Aufmerksamkeit erfährt: „Wenn Du Fregatte bist, / Fall ich dir in den Rücken. Und wenn Du sinkst / soll Flaute sein / und alle Schneiderinnen mögen dem Restbestand dir zugedachter Segel / zu Schürzen und zu Häubchen [schwatzen?] [...]." Sprachlich ist damit ein vager Bezug zwischen (Flügel)haube und Segel, zwischen Nonne und Fregatte hergestellt. In der undatierten Variante zum Theaterspiel Noch zehn Minuten bis Buffalo wurde diese über die äußere Form vermittelte Annäherung von Nonne und Fregatte ebenfalls zum Ausdruck gebracht.

Grass hat sich dem Einakter vermutlich zwischen 1956 und 1957 gewidmet. Im Jahr 1958 wurde das Stück in den Akzenten abgedruckt und im Schauspielhaus Bochum uraufgeführt. Da die im Literaturarchiv der Akademie der Künste erhaltenen Manuskriptfassungen nicht datiert sind und die Protagonisten Pempelfort und Krudewil von Grass auch in anderen Texten und Textentwürfen bemüht wurden, ist eine genauere Rekonstruktion der Werkgenese nicht möglich. Die von Dieter Stolz im Kommentarband zu Grass' Theaterspielen unter dem Titel „Dünenlandschaft“ abgedruckte Fassung des Stücks zeigt stärkere Ähnlichkeiten mit einschlägigen Passagen der Blechtrommel als mit dem abgedruckten Noch zehn Minuten bis Buffalo, sodass diese Variante zeitlich eher nach 1958 verortet werden kann. ${ }^{355}$

Zunächst deshalb zur Druckfassung des Theaterspiels: Im Zentrum des aufgeführten Einakters steht eine Fregatte, die wie im bebilderten Gedichtentwurf in Gestalt einer Frau auftritt. Die Dialoge der Protagonisten Krudewil und Pempelfort geben Auskunft darüber, dass sie vormals in ihrem Dienst bei der "christlichen Seefahrt" standen, dann jedoch meuterten und sich nun auf dem Weg nach Buffalo befinden. Die Helden sind augenscheinlich Sinnestäuschungen erlegen, denn die Lokomotive, die sie ihrer Auffassung nach gerade in das Land ihrer Träume bringt, bewegt sich nur in ihrer Fantasie. Für das Theaterpublikum steht sie rostig und fest auf einer weiten Wiese. Die frühere Dienstherrin, die dem Paar plötzlich und gleichermaßen als Schiff und "Dame“ erscheint, tatsächlich aber nicht mehr als eine Kuh ist, löst in den Meuterern Angst und Ehrfurcht aus und kann sie unversehens zur Rückkehr bewegen.

Dieser Aktion wird eine Nebenhandlung voran und zur Seite gestellt, die eine poetologische und kunsttheoretische Komponente ins Spiel bringt und dem Rezipienten von Beginn an eine Unterscheidung der im Mittelpunkt stehenden Ereignisse in tatsächliches Geschehen und Einbildung der Protagonisten ermöglicht: Ein von seiner freien Assoziationskraft beflügelter Maler, Professor Kotschenreuther, diskutiert mit einem Kuhhirten, dem seinen Sinnen fest vertrauenden Axel, über seine Kunst. Anlass des Gesprächs ist ein Bild, das Kotschenreuther unweit der Hauptereignisse malt. Mit einer Staffelei auf der Weide positioniert, widmet er sich, so scheint es, einer Kuh. Diese bildet er jedoch als Fregatte ab, was den Hirten irritiert:

\footnotetext{
355 Vgl. zur Werkgenese und oben genannten Rekonstruktionsproblemen: Stolz (2010), S. 86; die zweite Fassung des Stücks wurde abgedruckt in: ebd., S. 211-227. Zum Verhältnis zur Blechtrommel siehe: Neuhaus (2010), S. 14.
} 
AXEL: Na ja, Sie als Professor - man wundert sich. Da kommen Sie nun jeden Morgen her, sehen sich die Kühe an, messen herum, als wenn Sie was verstehen vom Vieh und hätten vor, 'ne Sterke zu kaufen, und dann und dann...

KOTSCHENREUTHER: Na?

AXEL: Dann machen Sie 'n Schiff draus.

KOTSCHENREUTHER: Eine Fregatte.

AXEL: Auf jeden Fall ' $n$ Segelschiff.

KOTSCHENREUTHER: erhebt sich, vergleicht das Bild mit der Landschaft: Du mußt dich mehr einordnen. Tauchen, unter den alten Wertungen durchschwimmen und dann: neue Aspekte, nervöse Instrumente, hellhörige Apparate, ein jungfräulicher Erdteil... Vor allen Dingen mußt du diese dummen Titel über Bord werfen. Kuh, Schiff, Professor, Butterblume. Alles Täuschungen, Komplexe. Wenn du zu deiner Kuh Schiff sagst oder auch nur Dampfer, meinst du, da macht sie sich was draus?

AXEL: Da können Sie vielleicht recht haben. - Aber das Auge? Wenn ich nun sehe und sehe da die Kuh und hier ein Schiff...

KOTSCHENREUTHER: Das ist ja der Fehler. Du betrachtest die Dinge zu sehr mit dem Intellekt. Einfach bleiben, ganz von vorne anfangen. Zuerst war das Schiff. Daraus hat sich dann später die Kuh entwickelt und aus der Kuh das Schachspiel, dann wurden die Pyramiden gebaut, später kam der Journalismus und mit ihm die Eisenbahn - wer weiß, was morgen sein wird. - Bringe mir Segelsaft, ich habe Durst. (II 125 f.)

Die betont irrationalen Eingebungen folgende Kunst Kotschenreuthers, die parallel zur Haupthandlung ab und an thematisiert wird, bildet die Angstvorstellungen der Meuterer ab. Sein ästhetisches Programm wird als Äquivalent zum wenig zielführenden Handeln der Protagonisten konstruiert. Schließlich bringt Axel am Ende des Theaterspiels noch einmal den unwirklichen Charakter der von Kotschenreuther, Pempelfort und Krudewil heraufbeschworenen Fregatte zum Ausdruck und kurz darauf die Lokomotive zum ersten Mal in diesem Stück tatsächlich ins Rollen:

AxEL schüttelt langsam den Kopf: Wie die Bremsen sind sie [Pempelfort und Krudewill, die auf ,Fregattes' Rücken davongetragen werden] hinter den Kühen her. Er nähert sich mit Eimer und Zigarre der Lok. [...] Kommen, scheuchen die Kühe und wollen nach Buffalo. Als wenn unsereins nicht auch mal. Hab zwar keine Verwandten dort, aber so für zwei Tage, warum nicht? - Er kichert, raucht, die Maschine stößt Dampf aus, heult, setzt sich in Bewegung. (II 138 f.)

In der alternativen Fassung des Theaterspiels sind es nicht helldunkel gescheckte Rinder, die die Fantasie eines verängstigten Gespanns in Gang setzen, sondern in denselben Kontrasten gekleidete Nonnen. Pempelfort und Krudewil sind zudem in dieser Textversion keine flüchtigen Seefahrer, sondern zwei ehemalige Soldaten, die nach dem Ende des Zweiten Weltkrieges ihren alten Stützpunkt in der Normandie am Atlantikwall wieder einnehmen und sich an die Invasion von 1944 erinnern. Die Handlung wird nun als eine Konsequenz der Kriegserfahrung geschildert.

Zunächst erscheint eine junge Nonne namens Agneta am Strand und lässt sich widerstandslos und mit Vergnügen von Pempelfort im Bunker verführen. Daraufhin geht sie im Meer schwimmen, wo andere, ebenfalls wundersamer Weise auftauchende Nonnen zu ihr stoßen. Alle Schwestern verwandeln sich während des Bades in Segelschiffe. Unter der Leitung einer Oberin alias „Fregatte“, kehrt die Gruppe an Land zurück und erobert Pempelfort und Krudewil sowohl in militärischer als auch in erotischer Hinsicht:

[A] uf der Düne erscheint die Oberin in Admiralsuniform mit weissem Sonnenschirm und Zigarre. Auf dem Kopf trägt sie über dem Admiralshut das Modell einer Fregatte. In gleicher Aufmachung begleiten sie links und rechts die sechs ehemaligen Nonnen. [...] 
KRUDEWIL (Schwach) Es ist wie damals bei der Invasion, eine momentane Schwäche hindert mich, die notwendigen Schritte zu tun. [...]

PEMPELFORT Sir, wir übergeben uns bedingungslos.

FREGATTE Die Korvette Agneta längsseits!

AGNETA (Neben Fregatte) Käpten?

FREGATTE Führen sie die Meuterer in den Bunker. Das Verhör beginnt in wenigen Minuten.

AGNETA Werde die Burschen mal hart anfassen Käpten. - Los Jungs, zeigt mir noch einmal euer gemütliches Wochenendhäuschen.

PEMPELFORT (Zu Krudewil) Es steht zu befürchten, lieber Freund, dass man uns als Mörtel verwendet, um die Schiessscharten dieser im Grunde uneinnehmbaren Festung zu vermauern. ${ }^{356}$

Die Nonne dient in dieser Fassung des Stücks als Projektionsfläche für verdrängte Schuldgefühle, sexuelle Tabus und Minderwertigkeitskomplexe, und zwar sowohl nationaler als auch persönlicher Art. Die Niederlage in der Normandie von 1944 wird von den Helden in der Vorstellung von einer Nonneninvasion erneut durchlebt und mit Traumata auf anderen Gebieten in Verbindung gebracht. Die Assoziation einer religiösen mit einer militärischen Gruppe macht zugleich eine kirchenkritische Deutung des Textes möglich, denn die Ähnlichkeit der Form von Flügelhauben und Segeln sowie von religiösen und militärischen Uniformen ist als Ausdruck der "Gleichschaltung" von Kirche und Staat im „Dritten Reich“ deutbar.

Im dritten Buch der Blechtrommel wird die Szenerie aus der "Dünenlandschaft" in abgewandelter Weise aufgegriffen. Grass gestaltet zu dieser Passage zudem ein Gegenstück im zweiten Buch des Romans. Die Protagonisten der Episoden sind nun zwei Künstler: der trommelnde Oskar Matzerath und der malende Obergefreite Herbert Lankes. Vermittelt über diese Figurenkonstellation wird auch die kunsttheoretische Diskussion aus dem Einakter Noch zehn Minuten bis Buffalo in erweiterter Form in die Haupthandlung integriert.

Seinen dramatischen Vorläufern entsprechend ist das Kapitel „Beton besichtigen - oder mystisch barbarisch gelangweilt" (III 431-454) als Einakter verfasst. Er spielt am Vortag der Invasion in der Normandie und behandelt einen Ausflug, den Oskar gemeinsam mit einer Gruppe von Liliputanern, Mitgliedern der nationalsozialistischen Unterhaltungskompanie, an den Atlantikwall unternimmt. Sie treffen dort auf den Obergefreiten Lankes, der vor dem Kriegseinsatz als Künstler ungegenständliche Werke geschaffen hat und nun seinen Bunker in freien Stunden mit „strukturellen Schrägformationen" versieht. Ein Wortwechsel zwischen Lankes und dem Anführer der Liliputaner, Meister Bebra, thematisiert die Reliefs des Obergefreiten satirisch. Der Jargon der zeitgenössischen Kunstkritik der Fünfzigerjahre wird darin persifliert: ${ }^{357}$

BEBRA nach gründlichem Studium: Erstaunlich! Welch ein Formenreichtum, welch strenge Ausdruckskraft!

LANKES: Strukturelle Formationen könnte man die Stilart nennen.

BEBRA: Und hat ihre Schöpfung, das Relief oder Bild einen Titel?

LANKES: Sagte doch schon: Formationen, von mir aus auch Schrägformationen. Is ne neue Stilart. Hat noch keiner gemacht.

BEBRA: Dennoch, und gerade weil Sie der Kreator sind, sollten Sie dem Werk einen unverwechselbaren Titel geben... [...]

LANKES: Na wenn sie mir so kommen. - Also Lankes hat sich gedacht: Wenn hier mal Schluß ist. Und einmal ist hier ja Schluß - so oder so - dann bleiben die Bunker stehen, weil Bunker immer stehen

\footnotetext{
${ }^{356}$ Vgl. Stolz (2010), S. 225 f. Das Zitat folgt dem Manuskript in Rechtschreibung und Zeichensetzung.

${ }^{357} \mathrm{Vgl}$. Hoesterey (1988), S. 79.
} 
bleiben, auch wenn alles andere kaputtgeht. Und dann kommt die Zeit! [...] Und die Jahrhunderte kommen und gehen darüber hinweg wie nix. Aber die Bunker bleiben, wie ja auch die Pyramiden geblieben sind. Und dann, eines schönen Tages kommt ein sogenannter Altertumsforscher und [...] sagt sich: Guck mal einer an. Interessant. Möchte fast sagen, magisch, drohend und dennoch von eindringlicher Geistigkeit. Da hat sich ein Genie, womöglich das einzige Genie des zwanzigsten Jahrhunderts eindeutig und für alle Zeit ausgesprochen. - Ob das Werk auch einen Namen hat? [...] $\mathrm{Na}$, da steht geschrieben: Herbert Lankes, anno neunzehnhundervierundvierzig. Titel: MYSTISCH, BARBARISCH, GELANGWEILT.

BEBRA: Damit dürften sie unserem Jahrhundert den Namen gegeben haben. (III 440-442)

Auf diese Persiflage, die Grass' 1957 formuliertem Angriff auf die gegenstandslose Kunst entspricht, folgt der Auftritt einiger Nonnen. Die Geistlichen aus dem benachbarten Kloster sammeln, in besonderem Maße auf Gott vertrauend, entlang der Verteidigungslinie am Strand Muscheln für den von ihnen betreuten Kindergarten und lassen sich mit Regenschirmen von dem Wind über den Strand treiben. Die Schwestern erweisen sich durch dieses risikofreudige Verhalten als außerordentlich weltfremd. Aus der Gruppe sticht die junge Novizin Agneta heraus, die Lankes bereits bekannt ist und, wie ihr allegorisch auslegbarer Wortwechsel mit der Oberin, Schwester Scholastika, zum Ausdruck bringt, den Wind ebenso wenig unter Kontrolle hat wie ihre Begierden:

SCHOLASTIKA: Kehren Sie um, mein Kind! Schwester Agneta!

AGNETA: Ich kann ja nicht! Das läuft von alleine!

SCHOLASTIKA: Dann beten Sie, Schwester, für eine Umkehr!

AGNETA: Für eine schmerzensreiche?

SCHOLASTIKA: Für eine gnadenreiche!

AGNETA: Für eine freudenreiche?

SCHOLASTIKA: Beten Sie, Schwester Agneta!

AGNETA: Ich bete ja, immerzuhu. Aber es läuft immer weiter! (III 447 f.)

Wohl aufgrund der angespannten militärischen Situation meint Lankes' Vorgesetzter Herzog, im Nonnenpulk eine Bande verkleideter Angreifer zu erkennen und befiehlt dem Obergefreiten, den Strand mit dem Maschinengewehr zu räumen (III 448). Nach kurzem Zögern gehorcht Lankes wider besseren Wissens bzw. Sehens, während Oskar und die Liliputaner das Grammophon lauter drehen, aus dem der Song The Great Pretender ertönt. Wie die Regieanweisungen informieren, fliegen daraufhin "fünf Nonnen mit Regenschirmen gen Himmel". Noch deutlicher als in Noch zehn Minuten bis Buffalo stellt Grass in der Blechtrommel damit Kunst in ein spiegelbildliches Verhältnis zum menschlichen Verhalten. Die Art der von Lankes und Oskar ausgeübten künstlerischen Tätigkeit, gegenstandslose Kunst und Unterhaltungskunst, werden in diesem Kapitel mit der folgenschweren Abwendung der Künstler von der Realität parallelgeführt. Auch die Nonnen, zwar keine Künstlerinnen, aber Gläubige, bedienen sich dabei desselben Verhaltensmusters, indem sie das offensichtliche Kriegstreiben in ihrer nächsten Umgebung ignorieren. Mit der Verortung der Romanhandlung am Vortag der Invasion von 1944 und mit der Schuld, die die künstlerisch tätigen Protagonisten in dieser Zeit auf sich laden, erhält die Episode eine historische und ethische Dimension, die sie in der Druckfassung von Noch zehn Minuten bis Buffalo noch nicht hatte.

In der Blechtrommel treffen Oskar und Lankes nach dem Krieg während eines Karnevalsfests der Kunstakademie Düsseldorf erneut zusammen. Die Rheinmetropole ist als Ort des Wiedersehens in vielerlei Hinsicht nicht zufällig gewählt. Nicht nur hatte Grass sein Studium in Düsseldorf begonnen, sondern dort ebenfalls den Künstler kennengelernt, der ihn bei der Ausgestaltung der 
Figur des Herbert Lankes inspirierte: den für seine Stilvariationen und sein aufbrausendes Temperament bekannten Maler Herbert Zangs (1924-2003). ${ }^{358}$

Oskar und Lankes beschließen, noch einmal an die Normandie-Küste zu reisen. Diese Episode bestimmt das Kapitel „Am Atlantikwall oder es können die Bunker ihren Beton nicht loswerden“ (III 707-727). Wie darin deutlich wird, erinnert sich Lankes ausgesprochen ungern, weder an die Invasion noch im Allgemeinen: „Passé ist ein Lieblingswort bei Lankes. Er pflegt die Welt in aktuell und passé einzuteilen“ (III 718). Dennoch vollzieht er die damaligen Ereignisse auf Anregung der Oskar'schen Trommelei hin bis zum entscheidenden Punkt nach. In diesem Moment lässt der kleinwüchsige Musiker, der die Vergangenheit mit Hilfe des Trommelns höchst realistisch heraufbeschwören kann, die Novizin Agneta erneut mit ihren Schwestern am Strand erscheinen. Das Mädchen beginnt ein Gespräch mit den beiden Männern, während die anderen Frauen sich wie vormals vom Wind treiben lassen. Der bildende Künstler gerät daraufhin ins Träumen und beschreibt die Nonnen, wie zuvor sein Vorgesetzter, als Schiffe:

\footnotetext{
"Dat sind keine Nonnen, dat sind Segelschiffe."

"Segelschiffe sind weiß", gab ich zu bedenken.

„Dat sind schwarze Segelschiffe“. Mit Lankes konnte man schlecht diskutieren. „[...] Morgen früh wachen die Tommys auf, gucken aussem Fenster, was sehen sie: Fünfundzwanzigtausend Nonnen, bis über die Toppen beflaggt, und schon kommt die erste Breitseite..."

„Ein neuer Religionskrieg!“ half ich ihm. Das Flaggschiff müsse Maria Stuart heißen oder De Valera oder, noch besser, Don Juan. [...] Die Invasion könnte beginnen: England hat aufgehört, eine Insel zu sein! Lankes wurde das Gespräch zu politisch. (III 721)
}

Nach diesen Beobachtungen vergeht sich Lankes erneut, nun auf andere Art, an Agneta und setzt damit die von Oskar angedeutete Parallele zwischen militärischer und erotischer Eroberung um. Ebenso wie Pempelfort in der "Dünenlandschaft" zieht sich der Obergefreite, eindeutige Absichten verfolgend, mit der Novizin in den Bunker zurück. Im Gegensatz zu ihrer Namensvetterin im Dramenentwurf macht diese Agneta im Anschluss an die "Besichtigung" einen verstörten Eindruck. Das folgende Bad, von dem sie nicht zurückkehrt, kann deshalb als Selbstmord interpretiert werden. Während Oskar den Vorgang besorgt beobachtet, wendet sich Lankes ab und interessiert sich vielmehr für die Ausbeute, die er zukünftig mit seiner Kunst aus dem Erlebten schlagen könnte. Die von inm in diesem Sinne formulierte Assoziationskette macht zudem deutlich, dass er die Begründung des Oberleutnants zur Tötung der Nonnen übernommen hat, um sich vor sich selbst zu rechtfertigen:

Auf den Bunker stieg ich und überblickte den durch die Flut näher herangeworfenen Strand. [...] „Laß sie schwimmen, und komm endlich vom Bunker runter!“ Ich blickte hinter mich und sah Lankes ausgestreckt qualmen. [...] Als ich vom Beton sprang, öffnete Lankes die Maleraugen und sagte: „Das gibt ein dolles Bild: Flutende Nonnen. Oder: Nonnen bei Flut.“ „Du Unmensch!“ schrie ich. "Und wenn sie nun ertrinkt?“ Lankes schloß die Augen: „Dann heißt das Bild: Ertrinkende Nonnen.“ „Und wenn sie zurückkommt, dir vor die Füße fällt?" Mit offenen Augen sprach der Maler sein Urteil: „Dann wird man sie und das Bild eine gefallene Nonne nennen.“ Er [...] malte, während sie noch in die offene See hinausschwamm, mit grobem, knolligem Fuß Bilder in die Luft, gab sogleich Formate an, betitelte sie: Flutende Nonnen. Nonnen bei Flut. Ertrinkende Nonnen. Fallende Nonnen. Fünfundzwanzigtausend Nonnen. Querformat: Nonnen auf der Höhe von Trafalgar. Hochformat: Nonnen besiegen Lord Nelson. Nonnen bei Gegenwind. Nonnen bei Segelwind. Nonnen gegen den Wind

${ }^{358}$ Vgl. Cremer-Bermbach (1996), S. 30 und Kat. Ausst. Gdańsk (2013), S. 50-56. 
kreuzend. Schwarz, viel Schwarz, kaputtes Weiß und Blau auf Eis gelegt: Die Invasion, oder: Mystisch, barbarisch gelangweilt - sein alter Betontitel aus Kriegszeiten. Und alle diese Bilder, Hochformate und Querformate, malte der Maler Lankes, als wir ins Rheinland zurückkehrten, fertigte ganze Nonnenserien an, fand einen Kunsthändler, der auf die Nonnenbilder scharf war, stellte dreiundvierzig Nonnenbilder aus, verkaufte siebzehn an Sammler, Industrielle, Kunstmuseen, auch an einen Amerikaner, veranlaßte Kritiker, ihn, Lankes, mit Picasso zu vergleichen [...]. (III 726 f.)

Lankes' malerische Auseinandersetzung mit seinen Opfern führt folglich nicht zu einem Schuldeingeständnis. Ebenso wenig wie Oskar wird er durch seine Kunst geläutert. Beide schlagen aus schmerzlichen Erfahrungen anderer Profit, machen mit ihrer Kunst jedoch Unsichtbares sichtbar. Die Werke des ehemaligen Obergefreiten sind Ausdruck seiner durch Kriegserlebnisse geprägten Phantasien und bringen unterbewusste Mechanismen ans Licht. Sowohl im Theaterspiel Noch zehn Minuten bis Buffalo als auch in der Blechtrommel veranschaulicht bildende Kunst Kotschenreuthers „Fregatte“ und Lankes' in die Luft imaginierte Invasionsserie - die gleichzeitig über die Romanaktion vermittelten Traumata der Protagonisten. Die Verfahrensweise beider fiktiver Künstler, deren Grundlage die visuelle Assoziation ist, diente auch Grass für zahlreiche Bildwerke als Ausgangspunkt.

Im Debütroman ist der hier beleuchtete Bezug auf die bildende Kunst Teil einer ganzen Kette vergleichbarer Erwähnungen von Grafiken und Plastiken. In Zitaten, Beschreibungen und Besprechungen fremdmedialer Erzeugnisse spiegeln sich die von Oskar schriftlich dargelegten Ereignisse - er ist schließlich der fiktive Autor einer fiktiven Autobiografie - in einer anderen Form: ${ }^{359}$ Oskars Pfleger Bruno, der sein Zuhörer ist und zeitweise sogar die Niederschrift der durch den Insassen einer Heil- und Pflegeanstalt diktierten Texte übernimmt, bildet deren Protagonisten in „Knotengeburten" ab, in aus Fäden geknoteten Figuren, denen Gips Halt gibt. Oskar selbst steht, wie bereits im ersten Kapitel dieser Arbeit thematisiert, nach Ende des Krieges für kurze Zeit in der Düsseldorfer Kunstakademie für verschiedene Klassen Modell. Die Beschreibungen der entstehenden Kunstwerke vermitteln ein Kaleidoskop verschiedener Ansichten dieser Figur und bieten zugleich einen Einblick in verschiedene Kunstströmungen der frühen Nachkriegszeit (III 604-622, 640 f.).

Die auf diese Weise vorgenommene Parallelführung des Erzählens und Schreibens mit anderen Formen der ästhetischen Präsentation haben zwei Effekte: Zum einen modifizieren sie die Wahrnehmung des gesamten Textes, indem sie bestimmte Zusammenhänge verdichten, sie den Lesenden quasi-visuell vor Augen stellen und das Tempo des Handlungsflusses verändern, nämlich hemmen. Zum anderen können die Beschreibungen des bildkünstlerischen Fertigungsprozesses, eines Bildes oder einer Plastik, in Anbetracht der Parallelführung zum ebenfalls thematisierten Erzählen und Schreiben als poetologische Einschübe interpretiert werden. Wie schon in seinem kurzen Text „Über das Schreiben von Gedichten“ (1958, XI 23) nutzte Grass in der Blechtrommel die Beschreibung von bildender Kunst und bildkünstlerischem Schaffen zur Veranschaulichung seiner Gedanken über das Erzählen.

${ }^{359}$ Der folgende Argumentationsstrang wurde von mir bereits detaillierter ausgeführt in: Krason (2009). 

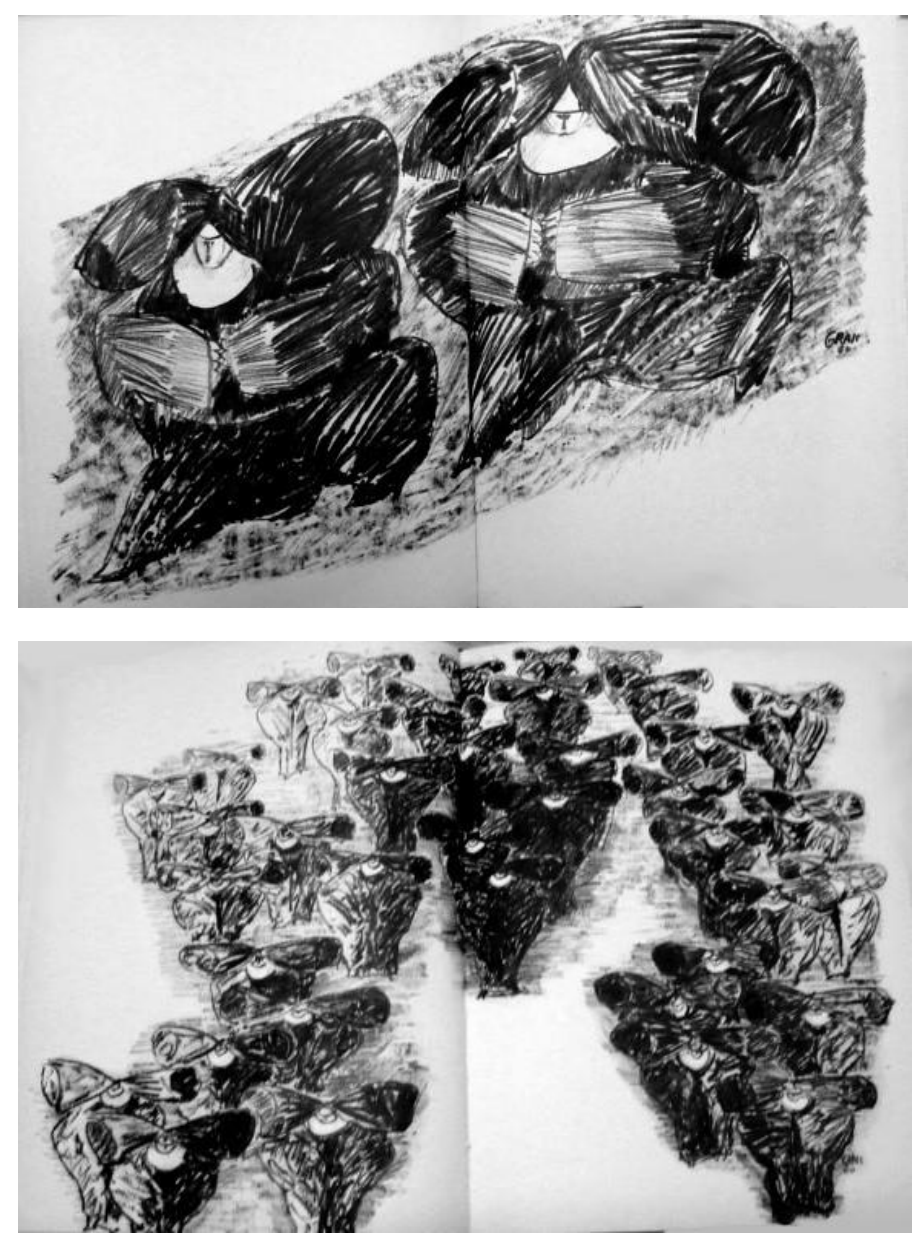

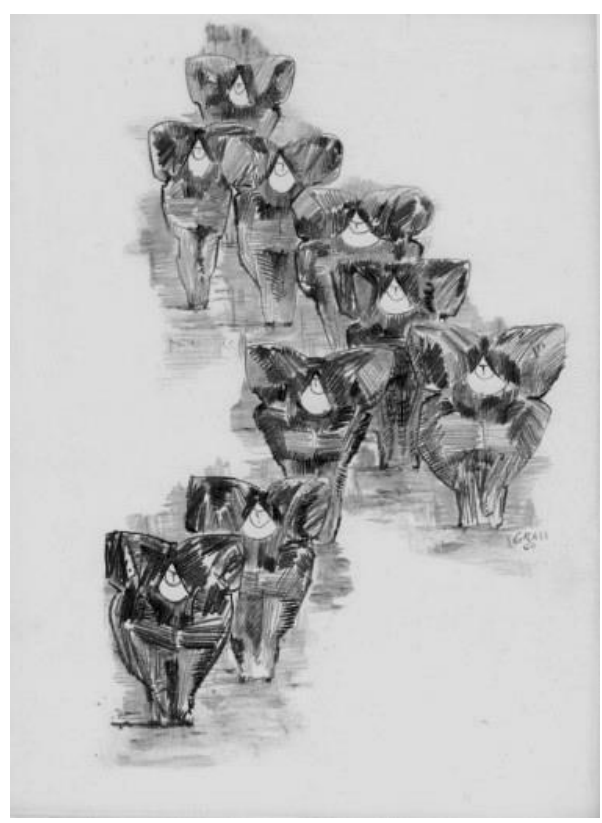

Abb. 96-98, Gleisdreieck, Darmstadt 1960, S. 46 f., S. 48 , S. 53 f. (im Uhrzeigersinn)

\section{Von intermedialen Bezügen zu Medienkompositionen: Gleisdreieck (1960)}

Die in der Blechtrommel über Lankes' Visionen hergestellten Bezüge zur bildenden Kunst sind in den vermutlich parallel oder vielleicht sogar noch vor dem Prosatext geschriebenen NonnenGedichten nicht enthalten. ${ }^{360}$ Statt dessen werden den Texten im Gedichtband Gleisdreieck (1960) grafische Bilder zur Seite gestellt. Die von dem fiktiven Künstler Lankes angekündigten Werke, von deren Anlehnung an Picasso und ihrem reißenden Absatz auf dem Kunstmarkt Oskar aus der Rückschau berichtet, wurden von Grass selbst ein Jahr nach der Veröffentlichung des Romans realisiert. ${ }^{361}$ Die Assoziation von Nonnen mit einer Segelschiff-Flotte wird dabei ins Bild gesetzt. Der Gesamtgestaltung des Gedichtbandes folgend, fertigte Grass seine Bilder mit Fettkreide an statt, wie Lankes es plante, in Farbe („Schwarz, viel Schwarz, kaputtes Weiß und Blau auf Eis gelegt" (III 725-727)). Allein die Nonnen sind in Gleisdreieck, ihrer intensiven bildkünstlerischen Behandlung durch den Schriftsteller ab 1960 gemäß, in drei Bildern vertreten (Abb. 96-98). Alle anderen Motive des Bandes werden nur ein oder zwei Mal grafisch interpretiert.

360 Die nur wenigen erhaltenen Manuskripte zu den lyrischen Texten sind nicht datiert, werden von Neuhaus aber auf das Jahr 1957 geschätzt. Die Annahme, dass die Gedichte vielleicht vor der entsprechenden Passage des Debütromans entstanden sind, geht auf die von Grass selbst beschriebene Arbeitsweise zurück: Die ersten Ansätze zu seinen epischen Werken seien meist in der Lyrik zu finden. In vielen Fällen ist diese Vorgehensweise auch am erhaltenen Material belegbar. VgI. dazu insbesondere Kapitel III.3. der vorliegenden Forschungsarbeit.

${ }^{361}$ Vgl. Hille-Sandvoss (1987), S. 118. 
Die unverwendeten wie die verwendeten Zeichnungen zu dieser Textsammlung entstanden erst im Veröffentlichungsjahr. ${ }^{362}$ Sie wurden alle in derselben Technik, mit demselben Material und in demselben Stil gezeichnet: Wie für die Nonnenbilder nutzte Grass auch für die Anfertigung der restlichen Illustrationen Fettkreidestifte. Aus ihrer Verwendung ergibt sich zwangsläufig eine kontrastreiche und expressive Darstellung, die ohne zierliche Details auskommen muss.

Die Arbeiten bilden nicht nur als Serie in sich eine Einheit, sondern stehen auch mit den Gedichten in einem engen Verhältnis. Berührungspunkte zwischen der Gedicht- und der Bildersammlung im Allgemeinen finden sich zunächst erneut in der Wahl der Gegenstände, die Grass zum lyrischen und grafischen Thema macht. Noch in stärkerem Maße als schon in den Federzeichnungen zu den Windhühnern konzentrierte er sich in dieser Bildfolge auf einzelne alltägliche Gegenstände sowie auf Tiere und Figuren, die die Seiten meist ohne die Andeutung eines Bildraums füllen. Die Gedichte umkreisen diese Motive und bedienen sich alltagssprachlicher Wendungen und Kinderreime. Auch wenn der Schriftsteller seine Texte nicht geradezu ,kahlschlagartig' reduzierte, ist der Bezug zu dieser früheren Literaturströmung nicht zu übersehen. Günter Eichs berühmte „Inventur" wird in Grass' zweitem Gedichtband zu einem „Inventar" (vgl. das gleichnamige Gedicht ( 74)). Der Vorgang des Ordnens und Aufzählens wird also durch dessen Endprodukt ersetzt, das in seiner Zusammenstellung betrachtet und weiterverwendet werden kann. Der Reduktion auf alltägliche Motive entspricht das für die Bilder gewählte Zeichenmaterial, das die Darstellungen skizzenhaft wirken lässt. Der Titel auf dem Umschlag des Gedichtbandes wurde entsprechend in Handschrift gestaltet. Der metaphysikkritische Tenor, der der Reduktion auf den sicht- und fassbaren Gegenstand zu entnehmen ist, teilt sich in programmatischen Gedichten wie den oben bereits behandelten "Askese“ und „Diana oder die Gegenstände“ mit. Die im Gedichtband dargestellten menschlichen Figuren erinnern nicht nur im Fall der Zeichnung zu „Diana" an solche der klassizistischen Phase Picassos, in der sich der Katalane um 1920 wieder einer den Gegenstand eindeutig erkennbar abbildenden Formensprache zuwandte und menschliche Körper in Anlehnung an die Kunst der Antike monumentalisierte, ohne sie zu idealisieren. ${ }^{363}$

Grass' abstrahierte Figuren erhalten mit ihren zu Strichen und Punkten reduzierten Gesichtern etwas Kindliches. Insofern ähneln sie den Werken der „Kreuzberger Bohème“ (Abb. 99, Abb. 100), einer Künstlerszene, in die Grass nach seiner Rückkehr aus Paris 1959 kurzzeitig eintauchte und in deren Forum, der Galerie „zinke“, er aus seinen Texten las und seine Nonnenbilder ausstellte. ${ }^{364}$ Die 1958 von Günter Bruno Fuchs, Robert Wolfgang Schnell und Günter Anlauf gegründete Galerie schien, so Schnells Erinnerung, mit ihrer figurativen Kunst und ihrem sekundären (und schnell aufgegebenen) Ziel der Arbeiterbildung im Westen wie aus der Zeit gefallen:

Wir sind in den Jahren 58/59 [...]. Die kulturpolitische Hilflosigkeit der Kalten Krieger ließ alles hochleben, was sich von Figur, Thema, Gegenstand und konkretem Inhalt entfernte, obwohl es das gar nicht gibt. Das sollte die Antwort auf die Kulturpolitik des bekämpften Bereiches, vornehmlich der DDR sein, wo man gerade um den Realismus stritt, vor allem wie und auf welche Art er sozialistisch sein könnte oder müßte [...]. Mehr dem poetischen Wesen der Kunst anhängend, d. h. ihre politische

362 Im Archiv des Günter Grass-Hauses befinden sich 16 Zeichnungen/Skizzen von Günter Grass, die zu Gleisdreieck entstanden sind.

${ }^{363} \mathrm{Vgl}$. Cowling (1988), insbes. S. 35.

${ }^{364} \mathrm{Vgl}$. Kat. Ausst. Berlin (1979), insbes. S. 20-24. 
Haltung an der friedliebenden Kreativität messend, waren sich Günter Bruno Fuchs, Anlauf und ich einig, eine - unsere - Art von Kunst zu zeigen, deren Erlebnis ins Phantastische, Realistische, Ironische, Traumhafte, in eine Welt gelebten Friedens führte, fern von äußerlicher Polemik. ${ }^{365}$

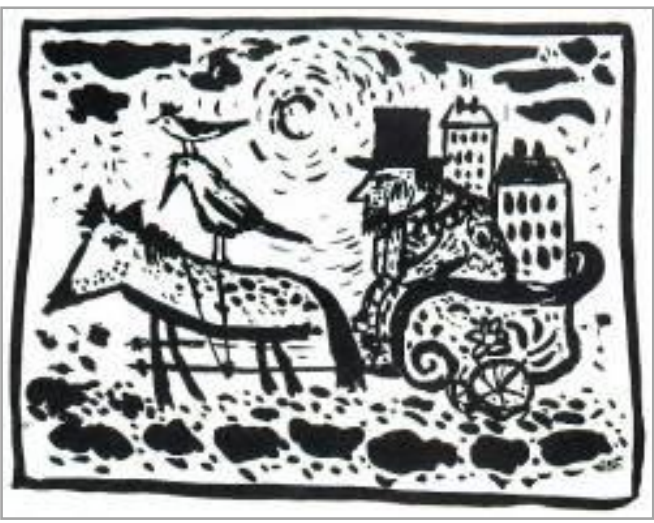

Abb. 99, Günter Bruno Fuchs, Eine schwere Last, 1961, Pinsel/Tusche

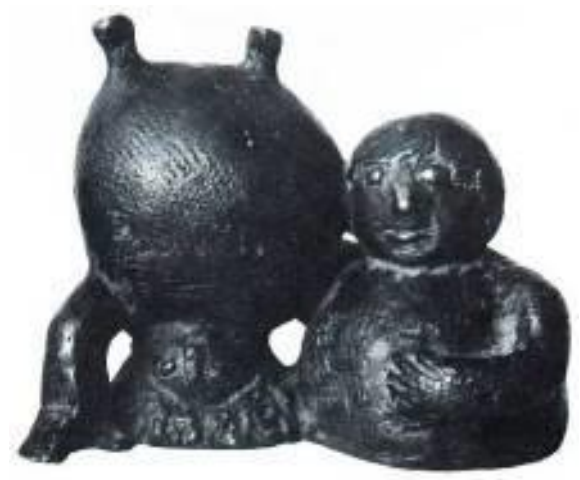

Abb. 100, Günter Anlauf, Meine Freunde Fuchs und Schnell, o. A., Bronze

Neben einem solchen Einschlag ins Phantastische, Ironische und Naive zeigen viele der Grass'schen Zeichnungen eine Anlehnung an den Kubismus und vervollständigen die Figuren mittels paralleler Schraffuren zu kantigen, geschlossenen Volumen, wie gerade an den NonnenBildern erkennbar ist. Die Objekte spreizen sich nicht mehr wie in den Zeichnungen zum ersten Gedichtband analytisch in einzelne Flächen auf, sondern wirken durch die Reduktion auf geschlossene plastische Formen eindeutiger und sind leichter erfassbar.

Die erste Nonnendarstellung aus Gleisdreieck (Abb. 96), die unmittelbar auf den Gedichtzyklus „Aus dem Leben der Puppe Nana“ folgt, zeigt über eine Doppelseite erstreckt zwei schwarzgewandete Ordensschwestern, die sich diagonal von dem linken unteren zum rechten oberen Bildrand erheben. Wie die Ausrichtung ihrer Fußspitzen zeigt, fliegen sie dabei rückwärts in die Höhe, wie von einem Luftzug getrieben, der sich in ihren Kleidern sowie den zu den Seiten der Köpfe propellerartig geblähten schwarzen Schleiern verfängt und sich grafisch als gleichmäßig hell schraffiertes, ebenfalls diagonal verlaufendes Band manifestiert. Beide Nonnen haben die Hände vor ihrem Körper zusammengeführt. Ihre Gesichter sind identisch und im Gegensatz zu den Vinzentinerinnen von 1957 rein schematisch angedeutet.

Die auf das erste Bild folgende Seite füllt eine zweite Zeichnung aus. Sie zeigt neun kleine, in gleicher Körperhaltung und auf gleiche Art zu Dreiecksformen abstrahierte, versetzt hintereinander gestaffelte Nonnenfiguren vor schraffiertem Hintergrund (Abb. 97). Auf der gegenüberliegenden Seite beginnt der Gedichtzyklus „Zauberei mit den Bräuten Christi“, der aus fünf Texten besteht, mit den Gedichten „Aus himmlischen Töpfen“ und „Theater". Er wird auf den folgenden Seiten mit "Vorsicht", „Keine Taube“ und „Die Nonnen“ weitergeführt und von einem dritten Nonnenbild abgeschlossen, das ein Gegenstück zur zweiten Zeichnung bildet (Abb. 98). ${ }^{366}$ Diese dritte querformatige Arbeit wird auf einer Doppelseite präsentiert und zeigt ebenfalls eine Grup-

\footnotetext{
365 Ebd., S. 11.

${ }^{366}$ Grass (1960), S. 46-53.
} 
pe von Nonnen. Es sind nun weitaus mehr Frauenfiguren als in der vorangehenden Grafik dargestellt: Rund vierzig Schwestern wurden darin hintereinander gestaffelt. In drei parallel zueinander gesetzten Schlangen durchziehen sie das Bild vertikal. Im Gegensatz zum zweiten Nonnenbild ist die dritte Zeichnung im Ausschnitt abgedruckt, sodass die Figuren darin größer erscheinen. Hintereinander betrachtet erzeugen diese beiden den Zyklus umschließenden Zeichnungen den Eindruck, als würden die Schwestern sich nicht nur vermehren, sondern den Betrachtenden auch näherkommen. Die Zusammenstellung solcher Bilderpaare, die mal prozessual, mal über die Graustufen kontrastiv zueinander im Verhältnis stehen, verwendete Grass auch zur Bebilderung anderer Gedichte des Bandes, nämlich der Texte: „Die Ballade von der schwarzen Wolke“, „Die Vogelscheuchen“, „Aus dem Leben der Puppe Nana“, „Köche und Löffel“ sowie "Der amtliche Tod".

Alle drei Nonnen-Bilder visualisieren Vorgänge, die literarisch in den letzten beiden Gedichten des Zyklus', "Keine Taube“ und „Die Nonnen“, thematisiert werden und bereits aus der Blechtrommel bekannt sind: ${ }^{367}$ Das gutgläubige Treiben der Nonnen im Wind und die nach ihrer Tötung ganz buchstäblich umgesetzte Himmelfahrt sowie Lankes' Wahrnehmung der Nonnen als Schiffsflotte. Im Gedicht „Keine Taube“ wird blinder Glaube im Vergleich zum gemächlichen Rückwärtsflug der gezeichneten Nonnen drastischer ausgestaltet - in einer Brutalität, die die Einleitung des Gedichtes durch die Form eines Witzes nur stärker hervorhebt:

KEINE TAUBE

Es begegneten sich eine Möwe

und eine Nonne.

Und die Möwe

hackte der Nonne die Augen aus.

Die Nonne aber hob ihren Schleier, lud wie Maria den Wind ein, segelte blind und davon. -

$[\ldots]$

Die Blindheit, die der Maler und Obergefreite Lankes in der Blechtrommel an den Tag legt, wird in der Lyrik den Nonnen zugeschrieben. Diese Ähnlichkeit in der Charakterisierung bildet die Brücke zwischen den Figuren und verdeutlicht, weshalb gerade Nonnen als Sujet eines bildenden Künstlers eingebracht werden und Diskurse um Ethik und Ästhetik entfachen. Die geringe Aufmerksamkeit, die Lankes der Realität zeitweise entgegenbringt, steht in Analogie zum Verhalten der Schwestern. Auch in der ersten Hälfte des Gedichts „Die Nonnen“ wird die Problematik des unhinterfragten Gottvertrauens behandelt, lediglich ohne Rückgriff auf die Metaphorik der Blindheit:

DiE NONNEN

Sie sind nur für den Wind gemacht.

Sie segeln immer, ohne auch zu loten.

Was ihnen himmlisch Bräutigam,

heißt andernorts Klabautermann.

${ }^{367}$ Vgl. Stolz (1994), S. 78 f. und Engels (2005), S. 89-105. 
In der zweiten Hälfte des Textes ergreift das lyrische Ich explizit das Wort und nimmt die Perspektive des Nonnenzeichners ein, der die „Bräute Christi“ betrachtet und mit einer Flotte Segelschiffe assoziiert:

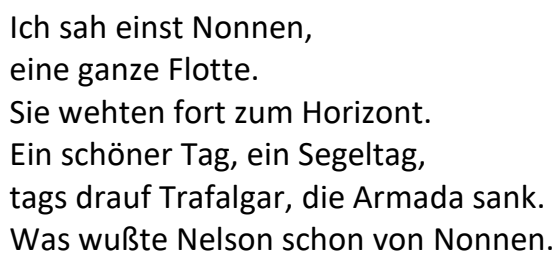

Sowohl das grafische als auch das literarische Nonnenmotiv weisen in Gleisdreieck auf die formale Analogie zwischen Nonnensilhouette und Schiffskörper hin. Die Zusammenführung beider Medien im Gedichtband vermittelt, dass die visuell erfahrbare Ähnlichkeit von Objekten die gemeinsame Wurzel der Arbeiten ist.

Die drei ersten Gedichte aus der „Zauberei“ wenden sich vor allem dem Thema der Unschuld der Geistlichen zu, die gleichermaßen durch die eigene Fleischeslust wie durch die Lust der Verführer gefährdet ist. Sie „schöpfen ab“, was dem „himmlischen Bräutigam“ versprochen war. Wie weiter oben bereits erörtert, wurde dieser Aspekt des Motivs, der die sexuelle Askese der Nonnen betrifft, schon im Jahr 1957 von Grass thematisiert. Das mit einer Zeichnung versehene Gedichtmanuskript zu „Theater" (S. 130, Abb. 87) zeigt eine Nonne in der unteren Bildhälfte mit der gleichen Kopfhaltung und Positionierung der Flügelhaube wie in den 1957 gefertigten Bleistiftzeichnungen der Vinzentinerinnen. Die „Zauberei“ fasst somit einen Großteil der Grass'schen Auseinandersetzungen mit dem Motiv zwischen 1956 und 1960 zusammen. 


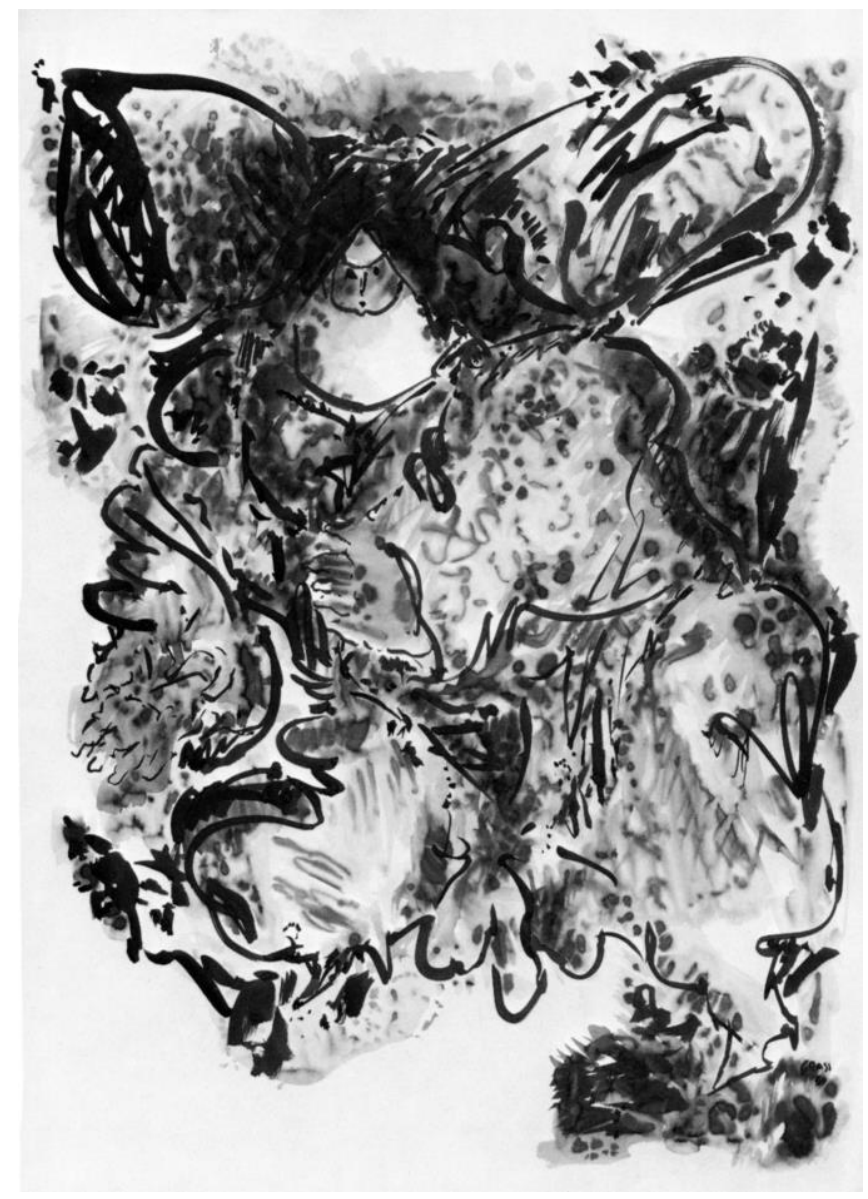

Abb. 101, Hüpfende/Springende Nonne, 1960, Pinsel/Tusche, laviert

\section{Naivität und Satire: Tuschezeichnungen zwischen 1960 und 1963}

Ab 1960 widmete sich Grass dem Nonnenmotiv nicht nur im Rahmen der bildkünstlerischen Gestaltung für Gleisdreieck. Auf dasselbe Jahr sind auch erste großformatige, mit Tusche gefertigte Pinselzeichnungen datiert, die das Sujet behandeln. In den folgenden beiden Jahren entstehen weitere Werke dieser Art. Die Größe der Blätter, die zwischen A3- und A1-Formaten angelegt sind, und die Tatsache, dass die Nonnen, meist einzeln dargestellt, die gesamte Bildfläche füllen, verleihen ihnen eine Monumentalität, wie sie in der bildenden Kunst vor allem Madonnen und Göttinnen zukam. Auf diesem Podest können sich die „Bräute Christi“ jedoch nicht lange halten, da auch diese Bilder satirisch Widersprüche der katholischen Lehre und Kirchenorganisation aufdecken, die vor allem durch die Darstellungen der Ordenstracht und ritueller Handlungen aufgezeigt werden.

Die Kernthemen der Bildserie sind zum Teil mit denjenigen aus dem Gedichtband Gleisdreieck deckungsgleich: Die im Zölibat unterdrückte Sexualität, der unhinterfragte „blinde“ Glaube sowie die Nähe von religiöser und politischer Ideologie, die über die Ähnlichkeit der Form von Schiffen und Nonnen in ihren traditionellen Gewändern vermittelt wird. Die neue Darstellungstechnik führt jedoch noch andere Aspekte mit sich.

Die Verwendung von Pinsel und Tusche an Stelle von Fettkreide ermöglicht eine weichere und nuancierte Gestaltung von Umrissen. Volumen wird nicht mehr durch Parallelschraffuren erzeugt, 
sondern vor allem durch lavierte Flächen und Flecken sowie durch expressiv ausgeführte Linienknäuel. Am differenziertesten treten die Möglichkeiten der Pinselzeichnung in dem Bild Hüpfende Nonne in Erscheinung (Abb. 101). Die schwebende Nonne ist hier nicht wie in Gleisdreieck als wuchtige, geschlossene Gestalt dargestellt, sondern scheint sich von unten her aufzulösen: Die Frauenfigur setzt mit dem rechten, bereits in der Luft verharrenden Bein zum Sprung an. Sie wird durch breite, geschwungene und skizzenhaft unterbrochene Linien umrissen. Das Volumen ihrer Haube und des hier geblähten und da in Falten gestauchten Kleides wird durch mal spärlicher, mal dichter getupfte Flecken wiedergegeben. Der Nonne wird in dieser Darstellung erneut eine zweifache sexuelle Orientierung unterstellt, denn der Schritt in den Himmel entblößt einen dreiteiligen Zipfel zwischen ihren Beinen. ${ }^{368}$

Noch etwas klarer tritt die geschlechtliche Ambiguität der Figur in der Zeichnung mit dem Titel Kniende Nonnen hervor (Abb. 102): Die beiden mit gefalteten Händen nebeneinander betenden Figuren skizzierte der Grafiker hier fast ausschließlich linear mit wenigen Binnenschraffuren. Die über die Umrisse besonders stark hervortretenden und überdimensional vergrößerten Oberarme und Oberschenkel erinnern zusammengenommen an männliche Glieder.

Betende Nonnen interessierten den Künstler auch im folgenden Jahr. Diese Darstellungen, für die an dieser Stelle eine repräsentative Zeichnung ausgewählt wurde (Abb. 103), betonen ohne sexuelle Anspielungen das Volumen der Ordenstracht. Dem auffällig weit gebauschten Gewand werden der bescheidene Gestus des Betens und das zarte Betpult kontrastierend gegenübergestellt.

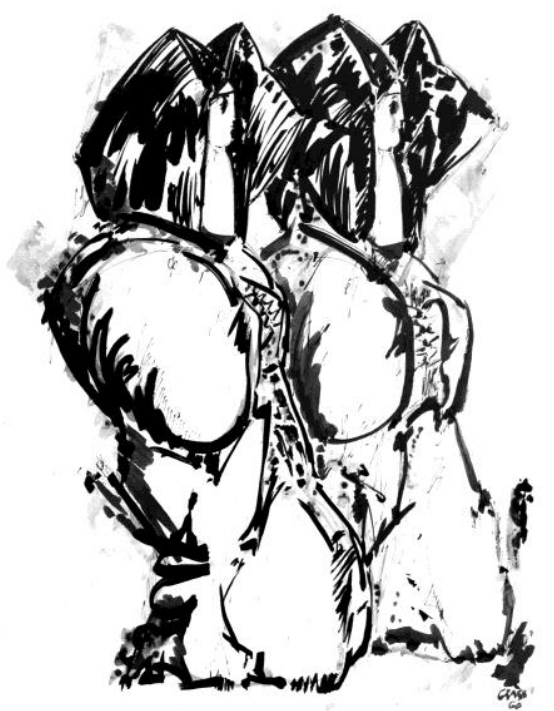

Abb. 102, Knieende Nonnen, 1960, Pinsel/Tusche, laviert

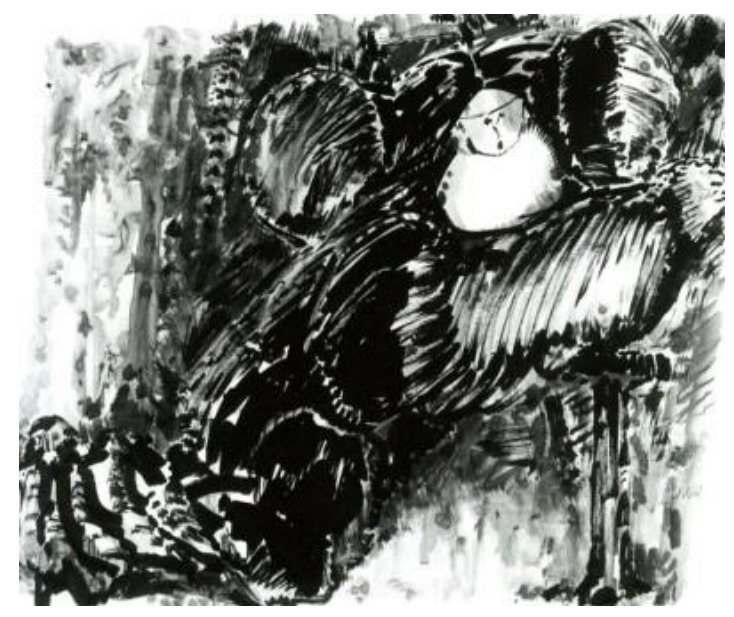

Abb. 103, Betende/Knieende Nonne, 1961, Pinsel/Tusche, laviert

${ }^{368} \mathrm{Vgl}$. Hille-Sandvoss (1986), S. 119 und Joch (2000), S. 15. 


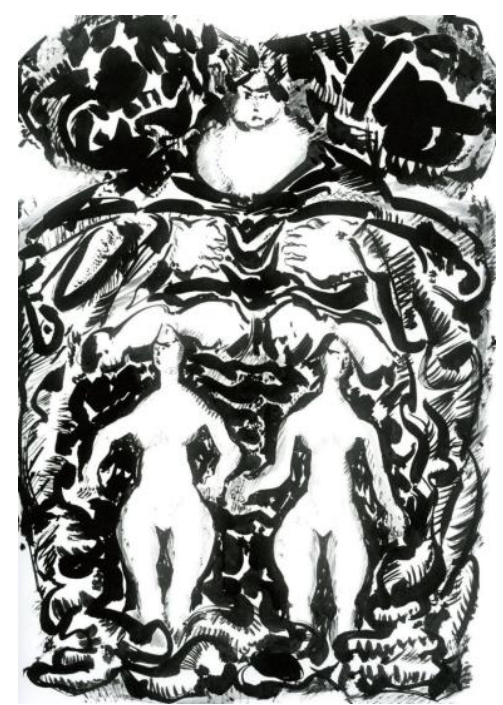

Abb. 104, Äbtissin kleidet zwei Novizinnen ein, 1961, Pinsel/Tusche, laviert

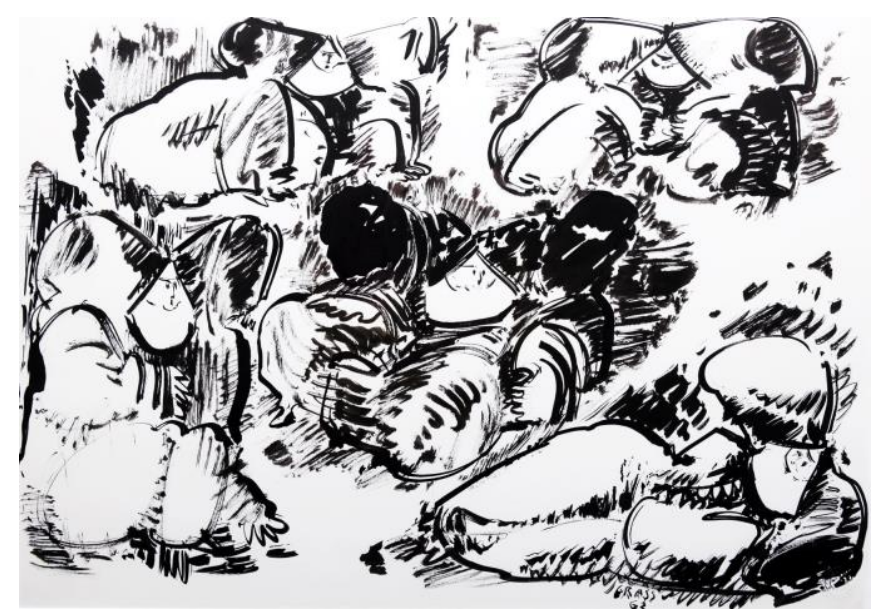

Abb. 105, Ruhende Nonnen, 1962, Pinsel/Tusche, laviert

Ein weiteres und in den Bildern des zweiten Gedichtbandes noch nicht behandeltes Thema ist die Einkleidung, also das traditionelle Ritual, bei welchem den Novizinnen, die ihr Gelübde abgelegt haben, das Nonnengewand angelegt wird. Stets wird bei Darstellungen wie der hier abgedruckten eine einzelne schwarz gewandete Ordensschwester aufs Engste in das Blatt eingepasst (Abb. 104). In unproportionierter Verkleinerung stehen vor ihr zwei Frauenfiguren nebeneinander und den Betrachterinnen und Betrachtern zugewandt. Das Gesicht der gewaltigen Nonne ist wütend verzerrt. Ihr schwarzes Kleid ist aus gekräuselten Linien zusammengesetzt und dient nicht nur als Hintergrund für die als helle Silhouetten ausgestanzten und hilflos zur Seite blickenden Novizinnen, sondern umfängt sie seitlich und an den Füßen. Die aus der Ikonografie der Schutzmantelmadonna bekannte Darstellungsweise der Fürsorge erhält in diesem Bild einen bedrohlichen, die Nonne selbst einen dämonischen Charakter. Die ungewöhnlichen Größenverhältnisse der Figuren bringen die Hierarchie zwischen einer Novizenmeisterin und ihren Zöglingen in grotesker Überspitzung zum Ausdruck. Denis Diderots Roman La religieuse (1796), in dem die Leidensgeschichte der Nonne Suzanne Simonin und insbesondere ihre Auseinandersetzung mit einer grausamen Äbtissin im Mittelpunkt steht, könnte Grass neben den Erfahrungen seiner Schwester Waltraut zu Darstellungen dieser Art angeregt haben. ${ }^{369}$

Der verhüllte Nonnenkörper in Posen, die traditionell zur Darstellung nackter weiblicher Körper gewählt wurden, wird zum Thema einer weiteren Gruppe von Bildern. Diese setzen die Schwestern in typischen Aktposen in Szene (Abb. 105). Gerade die hier abgedruckte Arbeit verdeutlicht, dass Grass' Zeichnungen zum einen eine kirchenkritische Botschaft transportieren und zum anderen formale Interessen des Grafikers zum Ausdruck bringen. Die Ruhenden Nonnen zeigen seine Freude an der Darstellung stoffverhangener Körper. Das Volumen der Figuren wird präzise herausgearbeitet und erhält durch das Spannen der Stoffe um die Frauenkörper erneut eine nahezu stereometrische Gestalt.

${ }^{369}$ Vgl. Diderot (1796/1797). 
Die Auseinandersetzung mit Grass' Nonnenmotiven zeigt, wie sehr sowohl ihre grafischen als auch ihre literarischen Manifestationen auf der Formäquivalenz zwischen ihrer Gestalt und anderen Objekten beruht: Die Nonne als Zeichen der sexuellen Enthaltsamkeit wurde durch die Überblendung der Figurendarstellung mit der Form des männlichen Geschlechts erarbeitet. Grass' Kirchenkritik kam durch die Ähnlichkeit der Gestalt von Nonnenhauben und Segelschiffen zum Ausdruck. Während das Vogelmotiv, das der Dichter bereits als Schüler der HfBK intensiv behandelt hatte, zur Veranschaulichung poetologischer Prinzipien Verwendung fand, diente die gezeichnete und beschriebene Nonne gleichermaßen als gesellschafts- und metaphysikkritisches Zeichen und als Gegenstand eines kunsttheoretischen Diskurses um Kunst und Moral nach 1945. Die surrealistischen Methoden der Bildfindung, die Grass bereits während seines Studiums für sich entdeckte, fanden sowohl in seinen Zeichnungen als auch in seinen Texten weiter Verwendung. Für die Gestaltung des Vogelscheuchenmotivs sollten allerdings andere Praktiken wichtiger werden: An Stelle von Kombinatorik und Metamorphose rückten vor allem Objektmontagen und ihre Mechanisierung in den Vordergrund. 


\section{Scheuchen: Spiegelbilder des Deutschen}

Vogelscheuchen treten in Grass' Werk am prominentesten im zweiten Roman der ,Danziger Trilogie', den Hundejahren (1963), in Erscheinung. Das Anfertigen dieser Objekte ist die bevorzugte Ausdrucksform der herausragenden Künstlerfigur des Erzählwerks, Eddi Amsel. Seine besonderen Scheuchen sind bildkünstlerische Arbeiten und Gebrauchsgegenstände in einem. Amsels erste Figuren entstehen ab 1922 im Danziger Umland. Der Künstler ist in dieser Zeit noch ein Kind. Als junger Mann wird er sich auf mechanisch betriebene Objekte verlegen und während des Krieges als Ballettmeister an einem Vogelscheuchenballett arbeiten. Nach 1945 wird er Vogelscheuchen seriell in einem ehemaligen Kalibergwerk produzieren lassen, das ebenso als Fabrik wie als Museum der deutschen Mentalität, Geschichte und Ideologien fungiert. ${ }^{370}$

Ebenso wie seine epischen Manifestationen der Nonnen bereitete Grass die der Scheuchen vorab in anderen literarischen Gattungen und Zeichnungen vor. ${ }^{371}$ Bislang unbeachtetes Archivmaterial lässt an dieser Stelle eine relativ präzise Rekonstruktion der Entwicklungsstationen des Motivs zu: ${ }^{372}$ Den Anfang machte die erste Fassung des Gedichts „Die Vogelscheuchen“, die Grass am 4. April 1956 in sein Arbeitstagebuch eintrug. Es wurde 1960 im illustrierten Gedichtband Gleisdreieck in einer anderen Version veröffentlicht. ${ }^{373}$ Der Schriftsteller bezeichnete das Gedicht rückblickend als „Komplexvorform“ seines Romans. ${ }^{374}$ Zwischen dem 7. und dem 11. April 1956 notierte er in demselben Tagebuch erste Ideen für ein Ballett mit Gesangseinlagen in drei Akten, das ebenfalls den Titel Die Vogelscheuchen tragen sollte. Einige Monate darauf schrieb Grass in Paris den bereits im vorangehenden Kapitel erwähnten Essay „Die Ballerina“, der neben dem Nonnenmotiv den Gegensatz zwischen klassischem Ballett und Ausdruckstanz thematisiert und darüber hinaus mit dem Motiv der Scheuche in Zusammenhang steht. An einem Exposé und einem ersten Libretto zum Vogelscheuchen-Ballett schrieb der Schriftsteller vermutlich parallel zu diesem Aufsatz. ${ }^{375}$

Über die Inszenierung des Stücks beriet Grass ab 1957 mit seiner ersten Ehefrau, der Tänzerin Anna Grass, dem Choreografen und Tänzer Marcel Luipart sowie etwa ab 1962 mit dem Komponisten Aribert Reimann. Einen Eindruck von seinen frühen Vorstellungen zur visuellen Erscheinung der Vogelscheuchen vermitteln Zeichnungen aus den Jahren 1957 bis 1960.

\footnotetext{
${ }^{370}$ Die Assoziation des Museums formulierte Grass im Gespräch mit Zimmermann. Vgl. Grass/Zimmermann (1999), S. 97.

${ }^{371}$ Zur Entwicklung des Prosamanuskriptes der Hundejahre vgl. Neuhaus (2010a), S. 11-13. Zur Genese des Balletts Die Vogelscheuchen im Detail, aber ohne Berücksichtigung der Aufzeichnungen von Günter Grass im Literaturarchiv der Akademie der Künste Berlin vgl. Weyer (2007), S. 131-144. Die erste Auflistung von gezeichneten Vogelscheuchen findet sich bei: Hille-Sandvoss (1987), S. 98-103, aktualisiert im Motivverzeichnis dieser Arbeit.

${ }^{372}$ Akademie der Künste Berlin, Günter-Grass-Archiv, Nr. 1755; Nr. 49 und Nr. 50 enthalten zwei undatierte Fassungen des abgeschlossenen Librettos und ein Exposé.

${ }^{373}$ Grass (1960).

${ }^{374} \mathrm{Vgl}$. Tank (1973), S. $167 \mathrm{f}$.

${ }^{375}$ Am 29.3.1957 teilte Grass in einem Brief an Dr. Heinz Schöffler vom Luchterhand Verlag mit, dass er kurz davor sei, ein Theaterspiel für eine neue Sammelpublikation fertigzustellen, die das Vogelscheuchen-Ballett enthalte. Die Publikation wurde für den folgenden Herbst des Jahres 1958 geplant. Vgl. Weyer (2007), S. 132. Anna Grass' Erinnerungen zufolge fiel der Entschluss, das Libretto auf die Tanzhandlung zu kürzen, erst im Jahr 1969. Vgl. Grass (1991a), S. 106.
} 
Die Aufführungspläne konkretisierten sich jedoch erst 1969, als der Intendant der Deutschen Oper in Berlin auf das „Vogelscheuchen-Team“ zukam. ${ }^{376}$ Grass blieb dabei weiterhin ausschließlich für das Libretto zuständig. Für die Aufführung im Oktober 1970 arbeitete er es zu einer zweiten, wesentlich kürzeren Fassung um, aus welcher er die Gesangseinlagen ausschloss. ${ }^{377}$

Mit der Arbeit an den Hundejahren begann Grass unmittelbar nach der Veröffentlichung der Blechtrommel 1959. Er konzipierte das zweite Romanprojekt zunächst unter dem Titel Kartoffelschalen. Einen Handlungsschwerpunkt koppelte er aus dem entstehenden Roman aus und veröffentlichte diesen Text als Novelle unter dem Titel Katz und Maus (1961). Den Hauptteil des Romanmanuskripts entwickelte er anschließend zu den Hundejahren (1963) weiter. ${ }^{378}$ Einen späten Schlusspunkt der Beschäftigung mit den Vogelscheuchen setzte er mit über einhundert Radierungen, die der Neuausgabe des Buches zum fünfzigsten Jubiläum seiner Erstpublikation beigefügt wurden. ${ }^{379}$ Die Grafiken entstanden in den Jahren 2010 bis 2013. Einen ersten Anlauf zu diesen Arbeiten bilden bereits fünf Radierungen aus dem Jahr 1990. ${ }^{380}$

Die folgenden Betrachtungen widmen sich zunächst der Wanderung des Vogelscheuchenmotivs von der Lyrik zur Dramatik und beschäftigen sich dann mit seiner grafischen Umsetzung von 1957 bis 1960 sowie in besonderem Maße mit der Transformation und Integration dieser verschiedenen Arbeiten in den Prosatext. Nicht nur flossen die Bedeutungen, die das Motiv im Zuge seiner wiederholten Bearbeitung mit den Jahren aufnahm, in die Hundejahre ein, auch auf die zuvor bei ihrer Verwirklichung in Anspruch genommenen literarischen Gattungen und Medien wies Grass durch intermediale Bezüge in seiner Prosa hin. Es wird zu zeigen sein, wie sich seine Poetologie in der Ästhetik seiner fiktiven Künstlerfigur spiegelt. ${ }^{381}$

\section{Ein Aufstand in Etappen: Von der Lyrik zur Ballettoper}

Bereits im ersten unveröffentlichten Entwurf des Gedichts „Die Vogelscheuchen“ vom 4. April 1956 wird das Motiv der menschenähnlichen Schreckgestalt deutlich umrissen. Der Text kommt der Druckfassung von 1960 sehr nahe. Zwar sind die Verse noch nicht in Strophen gegliedert, die sparsam verwendeten Satzzeichen markieren jedoch deren spätere Abschlüsse. In die untenste-

\footnotetext{
${ }^{376}$ Vgl. Grass (1991a), S. 106.

377 Für die Gestaltung der Kostüme war Lieselotte Erler verantwortlich. Das Bühnenbild entwarf Erich Kondrak. Zeichnungen und Notizen von Marcel Luipart sind im Theatermuseum Wien archiviert, Fotografien der Aufführung von Ilse Buhs lagern im Theatermuseum München. Eine Auswahl an Presseartikeln ist ferner im Kölner Tanzarchiv zugänglich. Zur Beteiligung von Günter Grass vgl. auch das Grass-Zitat im Artikel: Collani: Ab heute flattern die Vogelscheuchen. In: Berliner Zeitung, 7.10.1970: „,Ich schreibe ein BallettLibretto ganz gerne', schmunzelt Grass, ,ich genieße es, zwischen meinen größeren Arbeiten auf drei Seiten Prosa etwas vorzulegen und dann zuzusehen, was die anderen damit machen." Nach der Aufführung sagte Grass: „Ich könnte mir vorstellen, daß meine Vogelscheuchen auch andere Choreografen reizen könnten." Zitiert nach Weyer (2007), S. 135, S. 140.

${ }^{378} \mathrm{Vgl}$. Neuhaus (2010a), S. 11.

379 Der Roman wurde 2013 in drei leinengebundenen Bänden im Steidl Verlag herausgegeben. Vgl. Grass (2013).

380 Die fünf Radierungen, die sich alle auf eine Passage des zweiten Buches beziehen (den Einbruch von SAMännern in den Garten des Künstlers), wurden auf einem Blatt gedruckt. Eine Vorzeichnung befindet sich in der Sammlung des Günter Grass-Hauses Lübeck. Vgl. Ohsoling (2007), R 253-257.

${ }^{381}$ Bereits Reddick wies darauf hin, dass Amsels Kunst Grass' eigene Poetologie und dessen Auffassung einer gesellschaftspolitisch engagierten Literatur verkörpert. Vgl. Reddick (1975), S. 239. Weiter ausgeführt bei Stallbaum (1989), S. 137.
} 
hende Transkription wurden zur besseren Lesbarkeit an entsprechender Stelle Leerzeilen eingezogen:

\section{VOGELSCHEUCHEN}

Ich weiß nicht ob man Erde kaufen kann

ob es genügt wenn man vier Pfähle

mit etwas Rost dazwischen und Gestrüpp

im Sand verpflanzt und Heimat dazu sagt.

Ich weiß nicht was die Stare denken

sie flattern manchmal auf zerstäuben

und tun so als würde man sie verscheuchen

als seien Vogelscheuchen

und Luftgewehre fast bereit zur Saat.

Sind Vogelscheuchen Säugetiere

es sieht so aus als ob sie sich vermehren

indem sie nachts die Hüte tauschen

in manchem Garten stehen drei

schon stehen in meinem Garten drei

verneigen sich und winken tun höflich

und drehen sich und zwinkern in die Sonne

und reden reden zum Salat.

Ich weiß nicht was das Unkraut will

ich weiß nicht was die Blattläuse bedeuten

es ist sehr schwer dem Garten zu befehlen

selbst Vogelscheuchen tun oft nicht was ich will

oft fürchte ich es könnte was bedeuten

denn wenn man schweigt hört man Konservendosen

und Löffel wie zum Aufstand läuten.

Ich weiß nicht was die alten Jacken

und Hosentaschen von uns wissen

Ich weiß nicht wer in alten Hüten brütet

welchen Gedanken was entschlüpft

und flügge wird und läßt sich nicht verscheuchen

nur noch von Vogelscheuchen werden wir behütet. ${ }^{382}$

In fünf Strophen konstruiert das lyrische Ich systematisch eine Gartenszenerie. Zugleich bringt es mit der wiederholten Einleitung „Ich weiß nicht, was“ zum Ausdruck, dass die beschriebenen Phänomene von ihm nicht erklärt oder kontrolliert, lediglich benannt und in Frage gestellt werden können: Die erste Strophe thematisiert das umzäunte Stück Land, um das es im Folgenden gehen soll. Ungewiss ist, ob dessen Umzäunung und Benennung als „Heimat“ es wirklich zum Besitz des Gärtners machen können. Die zweite Strophe widmet sich Staren, die den Himmel über dem Garten bevölkern und ihrem Verhältnis zu den darin aufgestellten Vogelscheuchen: Festgestellt wird, dass die Vögel sich nur aus freien Stücken gelegentlich aus dem Garten erheben, da Vogelscheuchen im Grunde keine Vogelscheuchen seien. Die Gestalten wirken, so die dritte Strophe, sehr

\footnotetext{
382 Akademie der Künste Berlin, Günter-Grass-Archiv, Nr. 1755, S. 178 f., hs., Transkription: V. K. Seite 177 enthält bereits einen ersten, auf den 4. April 1956 datierten Entwurf des Gedichts, der jedoch nur aus wenigen Versen besteht und hier deshalb nicht als eigenständige erste Textfassung benannt wird.
} 
lebendig, wenn sie sich nachts scheinbar vermehren und durch selbstständige Bewegungen zusehends Menschen ähneln: Sie verneigen sich, winken, drehen sich, zwinkern und reden. In ihrer unkontrollierbaren Aktivität drohen sie, die Gartenidylle zu zerstören: Die Scheuchen läuten „wie zum Aufstand".

In der letzten Strophe werden die wichtigsten Bestandteile der Figuren, wird die Kleidung angesprochen. Jacken, Hosentaschen und Hüte scheinen ein Eigenleben zu führen, das aus ihrer vormals unmittelbaren Nähe zum menschlichen Körper abgeleitet werden kann. Der letzte Vers „nur noch von Vogelscheuchen werden wir behütet“ folgt dem besorgten Hinweis auf sich womöglich unter einem Hut entfaltende Gedanken, die vogelgleich "flügge“ werden und sich nicht verscheuchen lassen. Er wird von einem resignativen Unterton getragen, der ex negativo zum Ausdruck bringt, dass auch keine andere, höhere Macht dem Menschen Schutz bieten wird. Von Vogelscheuchen selbst ist hingegen nicht mehr als ein Hut für sich entfaltende Gedanken zu erwarten. ${ }^{383}$

Sofern man den Garten, wie schon in Grass' früherem programmatischen Gedicht „Die Vorzüge der Windhühner", als Metapher für den ästhetischen Spielraum des Künstlers verstanden wissen will, kann die aus dem Gedicht extrahierbare Handlung als poetologische Allegorie gedeutet werden. ${ }^{384}$ Als Sinnbild der Poesie war der Garten bereits in der Literatur der Romantik präsent und stand um 1900 als Metapher für den von der Alltagswelt abgeschirmten Wirkungsbereich des Ästheten. ${ }^{385}$ Die ,Werkstatt' in Grass' Gedicht gerät aus den Fugen, weil das lyrische Ich Begriffe und die damit verbundenen Funktionszuweisungen zu den gehüteten Gegenständen ebenso andeutet, wie in Zweifel zieht. Vor allem sind es die Vogelscheuchen, die sein von der restlichen Welt isoliertes ästhetisches Konzept von Innen unterwandern: Mit der Natur, mit Sonne, Salat und selbst mit den Vögeln im Bunde stehen die Gestalten den Abgrenzungsversuchen des weltabgewandten Künstlers gegenüber. Gleichzeitig gehören sie zum Inventar seines kreativen Schaffensraums und ersetzen die Kunstfiguren der „Windhühner" aus dem Gedichtband von 1956.

Die Vogelscheuchen geben sich „realer und gegenständlicher" als ihre Vorgänger. ${ }^{386}$ Sie zeichnen sich durch Eigenschaften aus, die sie als Sinnbild einer Kunst erkennbar machen, die die empirisch erfahrbare Wirklichkeit unmittelbarer thematisiert: Die Figuren repräsentieren Menschen. Es handelt sich jedoch nicht um plastische Nachbildungen menschlicher Körper, sondern um Kompositionen aus Kleidung und zweckentfremdeten Alltagsgegenständen, die ihrer Form nach einzelnen Körperteilen ähneln. Natur wird daher durch ein artifizielles Arrangement repräsentiert. Zudem können die Assemblagen als Ausdruck einer empiristischen Auffassung vom Menschen ge-

383 Dieter Stolz fokussiert in seiner Analyse der Druckfassung des Gedichts diesen metaphysikkritischen Aspekt, und seine Interpretation wird durch die hier vorgestellte handschriftliche Version gestützt. Die besagte Strophe verliert nämlich ihre exponierte Schlussposition erst in der Druckvariante. Sie wird darin hinter der zweiten eingefügt, so dass die Scheuchenrevolution den Text abschließt. Das Gefühl einer Bedrohung, die das lyrische Ich formuliert, erfährt eine Steigerung zum Ende hin. Vgl. Stolz (1994), S. 91.

${ }^{384}$ Engels bietet ausgehend von der poetologischen Deutung des Gartens eine ausführliche Analyse der Schlussversion. Die nähere Betrachtung des Vogelscheuchenmotivs und der ihm in diesem Gedicht zugeschriebenen Eigenschaften wird jedoch erst in der vorliegenden Untersuchung ergänzt. Vgl. Engels (2005), S. 130-133.

${ }^{385} \mathrm{Vgl}$. Ananieva (2012), S. 141-144.

${ }^{386}$ Vgl. Engels (2005), S. 133. 
deutet werden - also als Ausdruck einer bewusst auf dessen äußere Hülle beschränkten und auf Spekulationen über sein Gefühlsleben verzichtenden Betrachtung.

Die poetologische Verwendung dieses im weitesten Sinne bildkünstlerischen Motivs im Gedicht schlägt eine Brücke zwischen den Medien. Dass Grass gerade jenen Text im April 1956 zum Entwurf einer Ballettoper ausweiten konnte, leuchtet auch aus diesem Grund sofort ein. Die Motive der Vogelscheuche und des Gartens sind räumlich-visuell umsetzbar und die notwendigen Parameter - Akteure, Handlung und Handlungsort - in den „Vogelscheuchen“ bereits angelegt.

In seinen Tagebuchnotizen zu einer dreiaktigen Ballettoper ergänzte Grass das lyrische Personal um eine Gärtnerstochter und eine einzelne handlungsbestimmende Vogelscheuche. Er integrierte eine Liebesgeschichte und einen Generationenkonflikt in den Disput zwischen Gärtner und Scheuchen und entwarf mit dem "Reich der Vogelscheuchen“ einen weiteren Handlungsort. Der umzäunte Garten wird bereits schriftbildlich unterkellert:

1.)

$$
\text { Vor Hannover - }
$$

Vogelscheuchen, Einakter. Oper.

Garten, Vogelscheuche gesucht, Gärtner

mit Tochter.

Duett Gärtner und Tochter über das Leben

hinter dem Gartenzaun. Vogelbal[l]ett.

Arie des Gärtners über die angefressenen Kirschen

Auftritt des jungen Mannes

Trio über den Gartenzaun hinweg

Der junge Mann als Vogelscheuche allein mit dem Vogelbal[I]ett.

[...?] Duett Tochter u. Vogelscheuche

Gärtner über den Umgang mit Vogelscheuchen

Trio über das Recht auf Liebe

Flucht der Vogelscheuche mit Tochter.

Arie und Lamento des Gärtners

Bal[l]ett der Vögel

2.)

Tochter und Vogelscheuche [fliehen?]

im Duett über den Sinn der Vogelscheuche.

Weg zum Reich der Vogelscheuchen.

Im Reich d. Vogelscheuchen Chor.

und Vogelscheuchen gegen die Tochter.

Arie der Tochter zwischen [?]

Der Schlaf der Vogelscheuchen

[...?] Die Tochter singt die Vogelscheuchen in den Schlaf

Arie des Mannes: Ich bleibe [wach?].

[...?] Die Tochter flieht

[...?] Lamento,

[...?] Vogelscheuchen

Der Gärtner allein mit den Vögeln

3.) $[\ldots ?]$

[...?] d. Tochter als Vogelscheuche

Arie des Gärtners über den Sinn des Gartens.

Duett Vater und Tochter über die Kleidung

Lamento der Tochter über den [?] Geliebten 
Spottlied des Vaters.

Auftritt der Vogelscheuchen, [?]

des Gärtners mit [?]

[?] Entführung [...?]

zu den Vogelscheuchen [gehörende?] Tochter.

Arie und Lamento des Gärtners

[?] Finale der Vögel.

*387

Aus den lesbaren Notizenpassagen des Dreiakters ist folgende Handlung rekonstruierbar: Ein Gärtner sucht eine Vogelscheuche für seinen Garten, den er gemeinsam mit seiner Tochter pflegt, denn Vögel haben sich über den Kirschbaum hergemacht. Seine Tochter und die eingesetzte Vogelscheuche verlieben sich, verlassen den Garten und betreten das „Reich der Vogelscheuchen“. Die Gärtnerstochter singt diese jedoch in den Schlaf und kehrt zu ihrem Vater zurück. Die Schreckgestalten folgen ihr und entführen sie, woraufhin sich das Mädchen in eine Vogelscheuche verwandelt. In den später entstehenden Libretti wird der Vater bei dem Versuch, die Vögel zu verscheuchen, selbst zur Vogelscheuche.

Grass' Aufzeichnungen enthalten neben der vorgesehenen Handlung auch die Themen der geplanten Lieder. Diese widmen sich Motiven, die bereits im Vogelscheuchen-Gedicht von großer Bedeutung waren: Dem Garten, den Vogelscheuchen und der Kleidung, neu hinzu kommt in den Liedern die Liebesthematik. In das erste Libretto mit Liedtexten fügte der Schriftsteller einzelne Verse des Vogelscheuchen-Gedichtes unmittelbar ein, integrierte also die dichten lyrischen Passagen in eine weiterentwickelte dramatische Handlung. ${ }^{388}$

Analog zu Grass' Gedicht kann auch das geplante Ballett, ausgehend von der Interpretation des Gartens als realitätsfernem ästhetischen Spielraum, als kunsttheoretische bzw. poetologische Reflexion gedeutet werden. ${ }^{389}$ Wieder sind die Scheuchen als Gegenpol zu einer weltabgewandten Ästhetik lesbar. Die dramatische Form erlaubt eine prozessuale Erweiterung der im Gedicht nur angedeuteten Aktion zur dreischrittigen Dialektik: die Präsentation der Welt des Gärtners im ersten und der gegensätzlichen Welt der Vogelscheuchen im zweiten Schritt sowie die Konfrontation und Überwältigung des Gärtners durch die Vogelscheuchen im dritten Schritt. Der im lyrischen Text angedeutete "Aufstand“ wird in der geplanten Ballettoper tatsächlich ausgeführt und mündet in der Transformation eines Menschen in eine Vogelscheuche. Auch darüber hinaus verschiebt sich das Mächteverhältnis zwischen Gärtner und Scheuchen weiter zugunsten der Kunstfiguren: Außerhalb des eingezäunten Gartens existiert ein ganzes Vogelscheuchen-Reich, eine

\footnotetext{
${ }^{387}$ Akademie der Künste Berlin, Günter-Grass-Archiv, Nr. 1755, S. 184 f., hs., Transkription: V. K., Dieter Stolz sei auch an dieser Stelle für Hinweise und Korrekturen gedankt.

${ }^{388}$ Vgl. Akademie der Künste Berlin, Günter-Grass-Archiv, Nr. 50, Libretto mit Gesang, „Erster Akt / 3. Seite und 4. Seite", Typoskript. Während der Gärtner die Vogelscheuche einkleidet, singt er folgendes Lied (S. 4): „Es ist gefährlich, / seine Jacke wegzugeben. / Man sollte es sich dreimal überlegen, / bevor man seine Hose / verschenkt. / Nicht ohne Folgen kann es bleiben, / so jemand seinen Hut, seinen behutsamen Hut / vom Scheitel hebt und sagt: / Hebe dich fort von mi[r], Hut. / Du hast mich lange genug - behütet. / Ich weiss nicht, was in alten Hüten brütet, / geheimnisvoll in mürben Nähten knackt. / Ich weissnicht, was die alten Jacken, / die Hosentaschen von uns wissen. / Könnt es nicht sein, dass wir uns so verraten, / wenn unsre Kleider unters Volk geraten?"

${ }^{389}$ Vgl. Stallbaum (1989), S. 141 und Engels (2005), S. 135-140. Beide Forscher widmen sich der in den Roman aufgenommenen Beschreibung des Balletts, das in den Hundejahren als Projekt des Vogelscheuchen-Künstlers Eddi Amsels alias Haseloff bezeichnet wird.
} 
eigene Gesellschaft, während das isolierte "Leben hinter dem Zaun“ nur eine kleine Enklave bildet.

Im Gegensatz zum poetologischen Gedicht, in welchem die Dichtung selbst auf ihr Verhältnis zur Realität ausgelotet wird, ist es im Ballett entsprechend der Tanz, der hinsichtlich seiner Beziehung zur wahrnehmbaren Umwelt auf dem Prüfstand steht. Fragt man sich, welche tänzerischen Ausdrucksformen Grass bei der Konzeption seines Gegensatzpaares konkret im Sinn hatte, ist ein Blick in den im September 1956 begonnenen „Ballerina“-Essay aufschlussreich: Der Autor stellt darin die natürliche Gebärde des Ausdruckstanzes der ornamentalen Bewegung des klassischen Balletts gegenüber, um abschließend seine Vorstellungen von einer perfektionierten Form des zeitgenössischen Tanzes zu formulieren. ${ }^{390}$ Auch wenn seine Betrachtungen dabei insgesamt von einem ironischen Unterton getragen werden, gilt seine Bewunderung zunächst dem von Gesetzmäßigkeiten bestimmten klassischen Ballett. ${ }^{391}$ Disziplin und eine ästhetisch-reflektierte Formensprache finden den Zuspruch des Autors, der sich mitunter darin äußert, dass er diese Aspekte für andere künstlerische Ausdrucksformen, vor allem für die Literatur, zum Vorbild erhebt (XI 14 f.). Der Ausdruckstanz wird hingegen für die willkürliche Darstellungsweise individueller Gefühle kritisiert:

Feind und todernstes Gegenteil der Ballerina ist die Ausdruckstänzerin. Während die Ballerina ihren Körper nach festen Regeln bewegt und dabei lächelt, als sei ihr die Belanglosigkeit in die Mundwinkel gepinselt, tanzt die Ausdruckstänzerin mit ihrer schwierigen Seele und rührt ihre Glieder dazu, als sei ihr privates und obendrein krummes Knie Anlaß genug, das achtel Parkett und halbvolle Ränge zwei Stunden zu fesseln. (XI 10)

Der Tanz, der das "formvollendete" klassische Ballett übertreffen und damit ablösen könnte, würde aus einer "Ehe“ zwischen Marionette und Ballerina hervorgehen. Der Text lehnt sich mit diesen Ausführungen an Heinrich von Kleists Aufsatz "Über das Marionettentheater" an. Der mechanische Tanz der Puppe wird darin dem menschlichen übergeordnet, weil der Mensch, nachdem er von den Früchten des Baumes der Erkenntnis gegessen habe, nicht mehr zu natürlichen, also von dem Bewusstsein seiner selbst befreiten Bewegungen in der Lage sei. Es gibt, so die Konklusion in Kleists Essay, nur zwei Rückwege in den „Stand der Unschuld“392. Grazie er-

\footnotetext{
${ }^{390}$ Die erste Fassung des Aufsatzes vom 9.9.1956, die Grass ebenfalls in seinem Arbeitstagebuch festgehalten hat, trägt die Überschrift "Gebärde gegen Ornament“. Vgl. Akademie der Künste Berlin, Günter-GrassArchiv, Nr. 1755, S. 200. Die Beschäftigung des Autors mit dem Ausdruckstanz stand mit der Ausbildung seiner ersten Ehefrau in enger Verbindung. Anna Grass hatte in Berlin bei einer der bekanntesten Vertreterinnen des Ausdruckstanzes, Mary Wigman, studiert und war im Sommer 1956 nach Paris gegangen, um wie viele Tänzerinnen ihrer Generation - ihre Ausbildung durch Kenntnisse des klassischen Balletts zu ergänzen. Der Ausdruckstanz wurde nach Kriegsende nicht mehr als zeitgemäß empfunden und feierte nur mehr letzte Erfolge im Rahmen einzelner Aufführungen von herausragenden Künstlerinnen wie Wigman. Wichtige Entwicklungen des Balletts waren hingegen durch die Anpassung an nationalsozialistische Vorstellungen von einem „Deutschen Ballett" am „Dritten Reich“ vorbeigegangen, sodass es Tänzerinnen und Tänzer in der Nachkriegszeit zur Ausbildung nach Paris, London und New York zog. Zur Geschichte des Ausdruckstanzes nach $1945 \mathrm{vgl}$. Müller/Stöckemann (1994), S. 30.

${ }^{391}$ Zu Günter Grass' Verwendung der Ironie in diesem Text vgl. unter der Überschrift „Tradition and Parody": Mason (1974), S. 17-40.

${ }^{392}$ Teile des Aufsatzes wurden vor Beginn der Uraufführung des Triadischen Balletts von einem Schauspieler rezitiert. Vgl. Scheper (1988), S. 54.
} 
scheint in dem Körper, „der entweder keins, oder ein unendliches Bewusstsein hat, d. h. in dem Gliedermann, oder in dem Gott. “393

Als konkretes Vorbild für eine auf diese Weise gesteigerte Künstlichkeit wird von Grass zum einen die Puppe angeführt, die Oskar Kokoschka bei einer Schneiderin in Auftrag gab, um sich über die Trennung von seiner Geliebten Alma Mahler hinweg zu trösten. Zum anderen, und mit Bezug auf den Tanz vor allem, wird auf das Triadische Ballett Oskar Schlemmers hingewiesen, von dem in dieser Arbeit weiter unten noch ausführlich die Rede sein wird. An Schlemmers Choreografien wird die Formelhaftigkeit ihres Bewegungsrepertoires hervorgehoben, die der des klassischen Balletts ebenbürtig sei, sowie die Kühnheit seiner Kostümentwürfe:

Erst wenn es gelingen sollte, aus all den Experimenten - und bisher wurden nur Experimente gezeigt - gleichstarke Formeln der tänzerischen Bewegung zu kristallisieren, welchen gleich dem Ballett alle Zufälligkeit abgeht, wird sich die Ballerina zum letzten Mal verbeugen.

Vielleicht zeigt sich dann die große, ganz und gar künstliche Puppe. In seinem Traktätchen über das Marionettentheater weist Kleist auf sie hin. Kokoschka ließ sich solch ein unempfindliches Mädchen schneidern, in Schlemmers Triadischem Ballett machten kühn entworfene Figurinen den ersten, wichtigen Schritt. Vielleicht werden sich beide vertragen und eine Ehe eingehen, die Marionette und die Ballerina. (XI 15)

Versucht man Grass' eigene Ballettentwürfe mit Hilfe seines Ballerina-Essays weiter zu entschlüsseln, so findet man eine Entsprechung zum realitätsfernen Garten im klassischen Tanz ${ }^{394}$ und die „Ehe" der Marionette mit der Ballerina in der Liebesbeziehung zwischen der Vogelscheuche und der Gärtnerstochter wieder. Während der Essay die herbeigesehnte neue Tanzkunst jedoch nur durch ihre reflektierte Formensprache und die Beispiele von betont künstlichen Darstellungen des Menschen charakterisiert, setzt sein Ballett mit dem Motiv der Vogelscheuche einen neuen Akzent. Mit ihm wird, wie oben beschrieben, eine Kunst ins Leben gerufen, die die Charakterisierung des Menschen durch eine Assemblage von Alltagsgegenständen zu ihrem Thema macht.

Die Welt der Schreckgestalten wird in den Libretti näher geschildert. In der mutmaßlich Ende der Fünfzigerjahre entstandenen ersten Fassung des Stücks als Ballettoper entwirft Grass folgende Szenerie: Kleiderständer sind auf der Bühne im Halbkreis angeordnet. Die Vogelscheuchen bewegen sich zwischen ihnen in einer "Springprozession“. Am Bühnenrand ist ein Pavillon vorgesehen, in dem die Gärtnerstochter und ihr Geliebter - er stellt sich hier als „Präfekt" des Vogelscheuchen-Reichs heraus - gemeinsam mit drei Vogelscheuchen positioniert sind. Letztere stimmen ein Lied an, das sie als Repräsentanten einer zusammengebrochenen Gesellschaft kennzeichnet, die aus dem Entstehungszeitraum des Librettos heraus als westdeutsche Nachkriegsgesellschaft erkennbar wird. Das Lied greift die Bewegung des Kreises bzw. des "Kreiselns" wiederholt auf und nimmt damit Bezug auf die Prozession der Tänzergruppe in der Bühnenmitte. Vor allem charakterisiert es jedoch die Gemeinschaft der Scheuchen näher:

I. und 2. Vogelscheuche: Es kreiseln Kreislaufstörungen in siebenundzwanzig Bäuchen.

${ }^{393}$ Kleist (2001, Erstausgabe des Aufsatzes: 1810), S. 345.

${ }^{394} \mathrm{Vgl}$. XI, S. 11: „Auch wenn zeitweise Ausbrüche ins Unerlaubte zu denken gaben und geben, der Kunst sei alles erlaubt, erfand sich immer, und gerade der beweglichste Geist, Regeln, Zäune, verbotene Zimmer. So ist auch der Raum unserer Ballerina beschränkt [...]". 


\begin{tabular}{|c|c|}
\hline & $\begin{array}{l}\text { Wir leben von Erklärungen } \\
\text { im Reich der Vogelscheuchen. }\end{array}$ \\
\hline Dritte Vogelscheuche: & $\begin{array}{l}\text { Auch spielen wir Schwermut und Einsamkeit } \\
\text { und schnitzen uns Pferdchen aus gelbem Neid. } \\
\text { Einst ritten wir, als wir noch grün, } \\
\text { die Hengste aus Chrom und Benzin. }\end{array}$ \\
\hline I. und 2. Vogelscheuche: & $\begin{array}{l}\text { Erstickten den Stein, versüssten das Salz. } \\
\text { Wir schnitt[e]n der Ziege das Meckern vom Hal[s] } \\
\text { Wir schrieben der Katze mit Kreide ans Haus } \\
\text { Töte die Maus, töte die Maus. }\end{array}$ \\
\hline Alle drei Vogelscheuchen: & $\begin{array}{l}\text { Wir dienten einst im Staatsarchiv, } \\
\text { Doch mit dem Staat da ging es schief. } \\
\text { Wir dienten einst der Industrie, } \\
\text { die Industrie brach sich das Knie. } \\
\text { Einst sangen wir im Kirchen chor } \\
\text { bis sich der Kirchentext verlor. } \\
\text { Nun schwanken alle Währungen, } \\
\text { wir haben Kreislaufstörungen, } \\
\text { der Kreisel funktioniert nicht mehr, } \\
\text { zwar kreiselts noch, doch krieselts sehr. } 395\end{array}$ \\
\hline
\end{tabular}

Während die Vogelscheuchen im Gedicht, von ihren grundlegenden Bestandteilen abgesehen, nicht näher beschrieben werden, stellt sie das Libretto als grotesk deformierte Vertreter der deutschen Nachkriegsgesellschaft dar. Im Vogelscheuchenmotiv der Ballettoper überlagern sich somit zwei Bedeutungen: Die Verkörperung einer realistischen Ästhetik, die - dem „Ballerina“-Essay gemäß - durchdachten Gesetzmäßigkeiten folgt und ein mittels ebendieser Ästhetik erzeugtes Gesellschaftsporträt.

Präsentiert wird eine Gemeinschaft, die durch ein Ereignis in ihrer Entwicklung zurückgeworfen wurde, weshalb sie neidvoll auf ihre Umwelt blickt (2. Strophe). Ihr Verhalten wurde in der Vergangenheit von Dominanz, Brutalität und Aggression bestimmt (3. Strophe). Einige Säulen dieser Gesellschaft - Archiv, Industrie und Kirche - sind eingebrochen und ihr innerer Antrieb wurde gestört. Einzig von „Erklärungen“ sollen diese Wesen noch leben (1. Strophe), was im Zusammenhang mit der selbstverschuldeten Situation als Suche nach Rechtfertigungen verstanden werden kann. Diese zweite Seite des Vogelscheuchenmotivs erweitert die Deutungsmöglichkeiten des Balletts: Nicht nur wird in diesem Stück damit die weltabgewandte (Tanz-)Kunst von einer weltzugewandten überwältigt, sondern zugleich ein bewusst zurückgezogen lebender Mensch von der Nachkriegsgesellschaft. Ästhetik und Ethik werden auf diese Weise auch in dieser Arbeit miteinander verwoben: Der Rückzug in ein von der Außenwelt separiertes Idyll hat weder für die Kunst noch für das Leben Bestand.

Das zweite, gesanglose Ballett-Libretto, das vermutlich erst Ende der Sechzigerjahre entstanden ist, vermittelt durch die Regieanweisungen, dass die zuvor in den Liedern enthaltenen Informationen nun visuell realisiert werden sollten. Die Vogelscheuchen offenbaren sich durch ihre

\footnotetext{
${ }^{395}$ Akademie der Künste, Berlin, Günter-Grass-Archiv, Nr. 50, Libretto-Fassung mit Gesang, „Zweiter Akt / Seite zwei“, Typoskript.
} 
jeweilige Erscheinung als Spiegel der Gesellschaft: Die Kunstfiguren treten dem Figurenverzeichnis zufolge als „General, Richter, Priester, Turner, Mediziner, Student und Fahne[n]träger“ auf. Aus dem Bühnenarrangement wird der Pavillon entfernt. Er ist nun überflüssig, da keine Sänger mehr vorgesehen sind. Stattdessen bestimmt ein mechanisches Möbel den Raum, das die Einbindung der Scheuchen in einen fremdbestimmten Kreislauf suggeriert: „In der Mitte des Halbkreises steht ein thronähnlicher Automat, an dem sich Zahnräder, Pendel, Zeiger bewegen. Es knarrt, läutet, knallt, klingelt und pfeift. ${ }^{\text {" }} 96$ Auch mit diesem Element wird eine vormals über das Lied und den Tanz vermittelte Information allein visuell umgesetzt und neu akzentuiert: Das als innerer Antrieb der Figuren besungene mechanische Kreiseln wird nun in einen Apparat verlegt. Eine technische und damit als zeitgenössisch konnotierte Kraft motiviert und strukturiert das Leben im Scheuchen-Reich.

Diese und weitere Kennzeichnungen der Vogelscheuchen, die gleichermaßen als Repräsentanten einer der Realität zugewandten, reflektierten Gesetzmäßigkeiten folgenden Kunst und als Abund Zerrbilder einer bestimmten Menschengruppe interpretiert werden können, sind Grass' Zeichnungen zum Ballettprojekt aus den Jahren 1957 bis 1960 zu entnehmen.

\section{Bewegte Vogelscheuchen im grafischen Bild}

In zwei Interviews berichtete Günter Grass, er habe die Vogelscheuchen parallel zur Niederschrift des Ballettlibrettos in zahlreichen Grafiken festgehalten. ${ }^{397}$ Bei den wenigen zugänglichen Zeichnungen scheint es sich also nur um einen Teil der insgesamt angefertigten Arbeiten zu handeln. ${ }^{398}$ Zwischen 1957 und 1960 geschaffen, gehen sie Grass' zweitem Libretto voraus. Seine grafischen Darstellungen von Vogelscheuchen legte er ohne Andeutung einer Handlung oder eines Bühnenbildes im Querformat als Gruppenbilder an. Wie schon in einigen seiner Zeichnungen, die Vögel thematisieren und Mitte der Fünfzigerjahre entstanden sind, ordnete Grass die Vogelscheuchen in diesen Werken parallel zur Bildfläche nebeneinander. Die Kompositionen erinnern deshalb an Kostümpräsentationen auf schmaler Bühne, an Reliefs oder an mit Puppen bestückte Schaufenster. Auf die bei tatsächlichen Vogelscheuchen üblichen kreuzförmigen Gerüste verzichtete der Grafiker und erlaubte sich auf diese Weise einen größeren Gestaltungsspielraum. Drei hinsichtlich der Merkmale Abstraktion, Repräsentation und Mechanisierung für die Bildgruppe exemplarische Zeichnungen werden im Folgenden näher betrachtet.

Bei einer der frühesten Vogelscheuchen-Darstellungen handelt es sich um eine lavierte Tuschezeichnung aus dem Jahr 1957 (Abb. 106). Sie zeigt vier Figuren, die sich auf schlanken stelzenartigen Beinen halten. Gestalten mit länglichen und runden Torsi wechseln sich rhythmisch ab: Den Oberkörper der Scheuche am linken Bildrand bildet ein Ornament aus rippenartig übereinander geordneten, eckigen und gebogenen Linien, dessen Struktur sich in der Verdrehung ihrer Beine fortsetzt. An Stelle von Armen ragen mehrere Linien unmittelbar aus ihrem Brustkorb nach oben. Den Kopf der Figur bedeckt ein Hut. Die benachbarte Gestalt zu ihrer Linken setzt sich aus einem locker als ovaler Umriss skizzierten Rumpf, einem eiförmigen, kahlen und bärtigen Kopf

\footnotetext{
${ }^{396}$ Vgl. Akademie der Künste Berlin, Günter-Grass-Archiv, Nr. 50, Libretto-Fassung ohne Gesang, Erster Akt, S.1, Zweiter Akt, S. 2, Typoskript.

${ }^{397}$ Ebd. und Grass/Zimmermann (1999), S. 238.

${ }^{398} \mathrm{Vgl}$. die im Motivverzeichnis enthaltene Auflistung der Vogelscheuchen-Darstellungen von Günter Grass.
} 
sowie einem ungewöhnlich gestalteten Arm zusammen. Aus einer Kugel und einer Keule bestehend, weist er zur huttragenden Scheuche zurück und blickt in ihre Richtung. Die dritte Vogelscheuche vollzieht mit ihrem schmalen Körper eine Zickzackbewegung nach. Herausfordernd nähert sie sich dabei ihrem linken Nachbarn, einer Figur mit rundem Rumpf und kahlem Kopf, deren kurze Arme abwehrend vor dem Körper erhoben sind. Die linke Hand dieser Scheuche ist vor dem kreisrunden Torso geballt, als bediene sie sich seiner als Klangkörper; ihre Rechte ist senkrecht nach oben gerichtet, als wolle sie ihr Gesicht dahinter verbergen.

Die Körper der Gestalten sind auf diesem Blatt zum Großteil auf nonfigurative, teils geometrische Formen reduziert, die sie zwar voneinander unterscheiden, aber nur in geringem Maße näher individualisieren. Sie sind mittels gleicher Abstände und Formwiederholungen so sorgfältig ins Blatt gefügt, dass sie auf den ersten Blick fast wie eine Reihe typografischer Symbole wirken. Die menschliche Anatomie wird der gegenstandslosen Komposition nahezu untergeordnet.

Andere Zeichnungen aus dieser Motivserie deuten geometrische Formen lediglich an und kombinieren sie verstärkt mit Abbildern identifizierbarer Gegenstände. Es handelt sich vor allem um Kopfbedeckungen, die die Vogelscheuchen einer gesellschaftlichen Gruppe oder einer Zeit zuordnen. So tragen die beiden mittleren Figuren in einer Skizze, die im März 1957 entstanden ist, Krone und Wehrmachtshelm (Abb. 107). Die militärisch gekleidete Figur hat den rechten Arm schräg nach oben gestreckt, eventuell wird ein "deutscher Gruß“ angedeutet. In dieser Zeichnung stehen die Scheuchen bereits als Gruppe aus verschiedenen Typen zusammen, wie sie das zweite Libretto in Bezug auf das „Reich der Vogelscheuchen“ ausführlicher vermittelt.

Die Bewegung der Scheuchen wird besonders in einer Kohlezeichnung aus dem Jahr 1960 (Abb. 108) hervorgehoben. Jeweils drei der hier präsentierten sechs Figuren durchdringt eine horizontale Linie. Beide schneiden sich in der Bildmitte, die vertikal durch zwei weitere gebogene Linien betont wird. Es scheint, als seien die Gestalten auf zwei von mehreren angedeuteten Stangen aufgezogen, die wie Speichen eines Rades an der vertikalen Mittelachse angebracht sind. Einerseits sind die Rümpfe der Scheuchen auf diese Weise fest an eine mechanische Vorrichtung gebunden, andererseits können sie mit ihren Gliedmaßen gerade aus diesem Grund freier hantieren. Stärker als auf jedem anderen Blatt führen die dargestellten Figuren weit vom Körper wegführende Bewegungen aus: Arme werden in V-Form oder im rechten Winkel erhoben und Beine seitlich abgespreizt. Die Kennzeichnung als Bewegung im Gegensatz zur Pose erfolgt mit Hilfe von Schraffuren, die eine Richtung oder einen Radius bezeichnen. Der auf dem Blatt angedeutete Automat unterlegt der grotesken, fremdbestimmten Mobilität der Scheuchen zusammen mit dem Titel Mechanische Vogelscheuchen eine konkrete Ursache, die in Grass' zweitem Libretto mittels der Regieanweisungen und eines Liedes bzw. durch einen freistehenden „Automaten-Thron“ angedeutet wird.

Es fällt auf, dass die Bestandteile der Scheuchen (Jacken, Hosen, Löffel, Dosen), die ihren besonderen Assemblage-Charakter ausmachen, in den Zeichnungen nur sehr sparsam, nämlich durch Hüte angedeutet werden, um die Figuren als Repräsentanten einer bestimmten Berufsgruppe, eines Standes oder einer Zeit zu kennzeichnen. Die Freiheit, die das Motiv der Vogelscheuche bietet, nutzte der Grafiker, indem er den Ausdruck der Gestalten durch groteske Bewegungen und durch die Abstraktion von Körpervolumen steigerte. Seine Zeichnungen ergänzen die 
literarische Darstellung der Vogelscheuchen damit um eine nähere Charakterisierung mit grafischen Mitteln. Aber widersprechen die nahezu ins Geometrische überzeichneten, auf das Allgemeine abzielenden Formen nicht geradezu der aus dem Gedicht und dem Ballett herausgearbeiteten Abbildfunktion der Vogelscheuchen?

Wie im Folgenden erörtert wird, legen sowohl die drei vorgestellten Zeichnungen als auch Grass' Kommentare in Interviews und Essays konkrete Inspirationsquellen für die verfremdenden Aspekte der Darstellungen nahe: Die abstrahierenden Kostüme des Triadischen Balletts von Oskar Schlemmer, dem der Schriftsteller bereits im „Ballerina“-Essay große Anerkennung ausgesprochen hatte und dessen Werk in den Fünfzigerjahren eine Renaissance erfuhr, ${ }^{399}$ sowie die mobilen Figuren des Mechanischen Theaters von Harry Kramer, den Grass in Paris kennenlernte, dienten inm für die Ausgestaltung seiner Kunstfiguren als Vorbilder. Aus dem Vergleich der Arbeiten Schlemmers und Kramers mit Grass' Scheuchen in Wort und Bild wird deutlich, aus welchem Interesse heraus er einzelne Aspekte ihrer Werke übernommen haben könnte, und weshalb sie anschließend nur in abgewandelter Form in die Hundejahre Eingang fanden.

${ }^{399} \mathrm{Vgl}$. Krystof (1994), S. 56 f. 


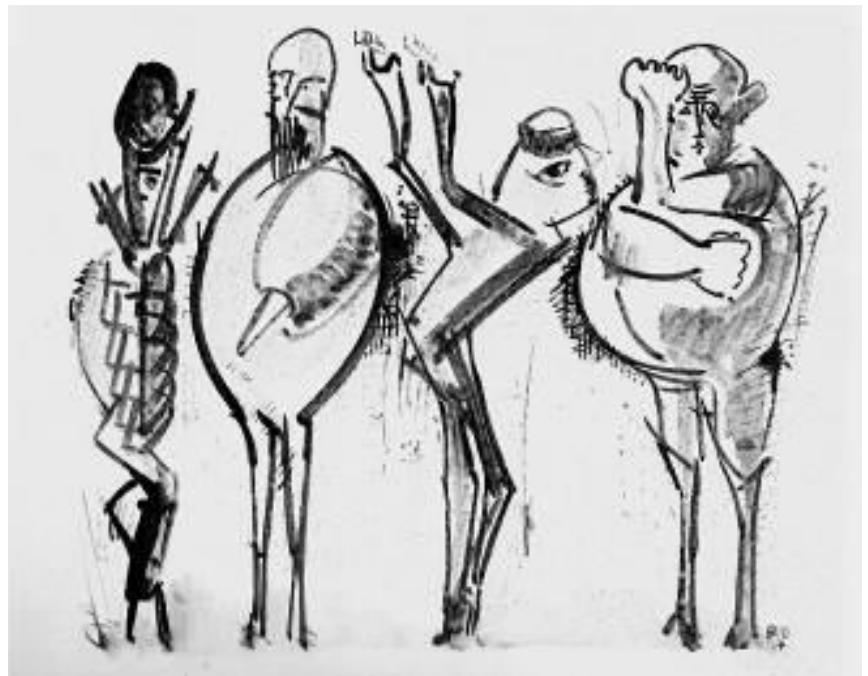

Abb. 106, Skizze zum Ballett Die Vogelscheuchen, 1957, Pinsel/Tusche, laviert

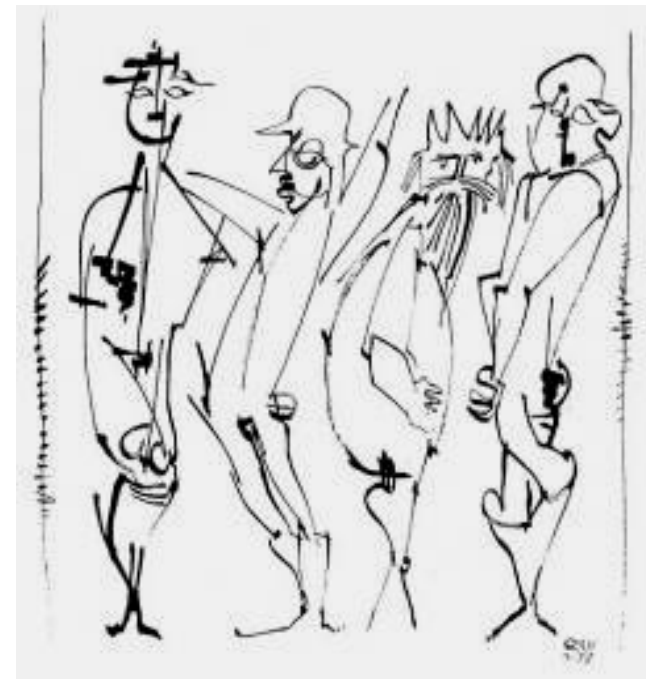

Abb. 107, Skizze zum Ballett Die Vogelscheuchen, 1957, Feder/Tusche

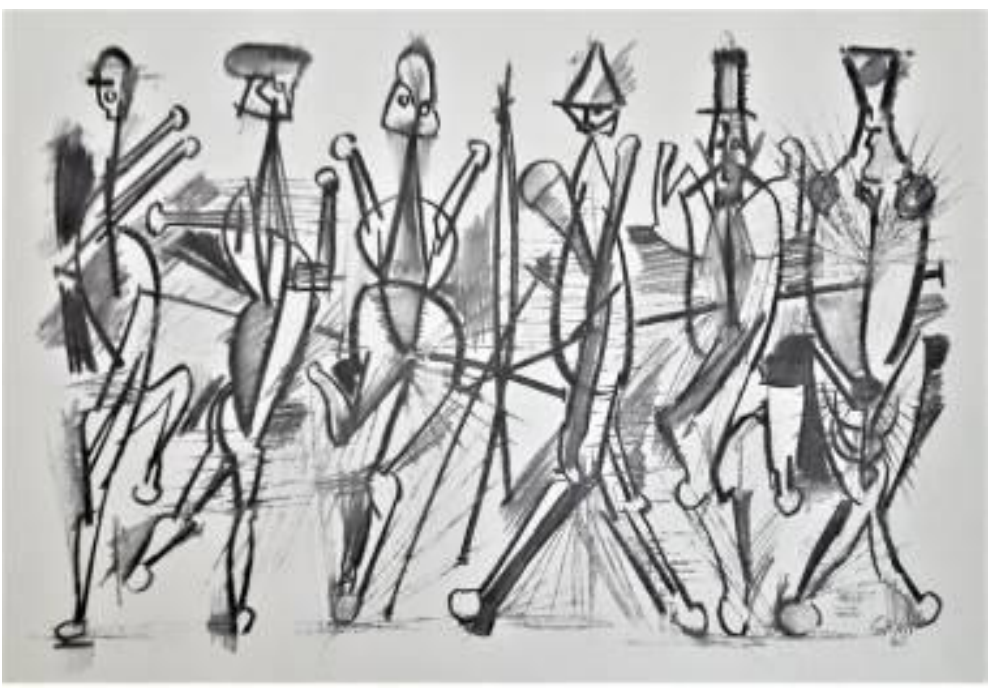

Abb. 108, Mechanische Vogelscheuchen, 1960, Fettkreide 


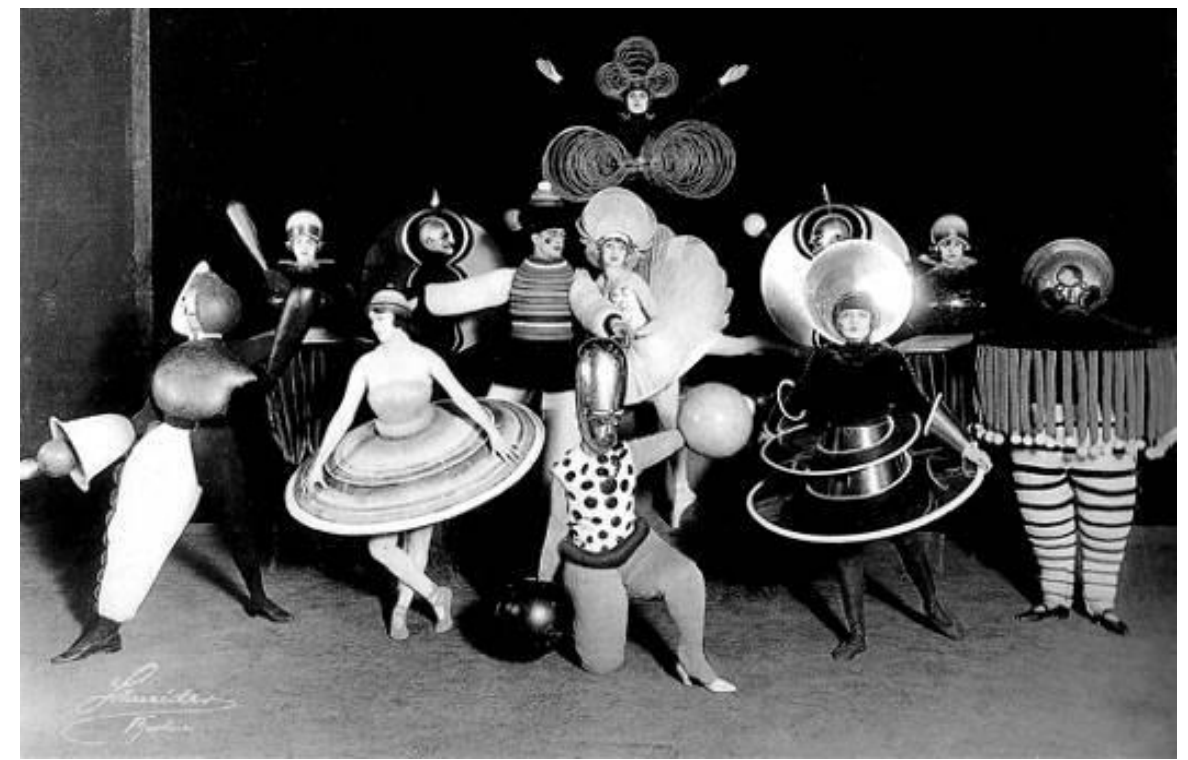

Abb. 109, Oskar Schlemmer, Das Triadische Ballett, Figurinen als Teil der Revue Wieder Metropol, im Metropol -Theater, Berlin, 1926

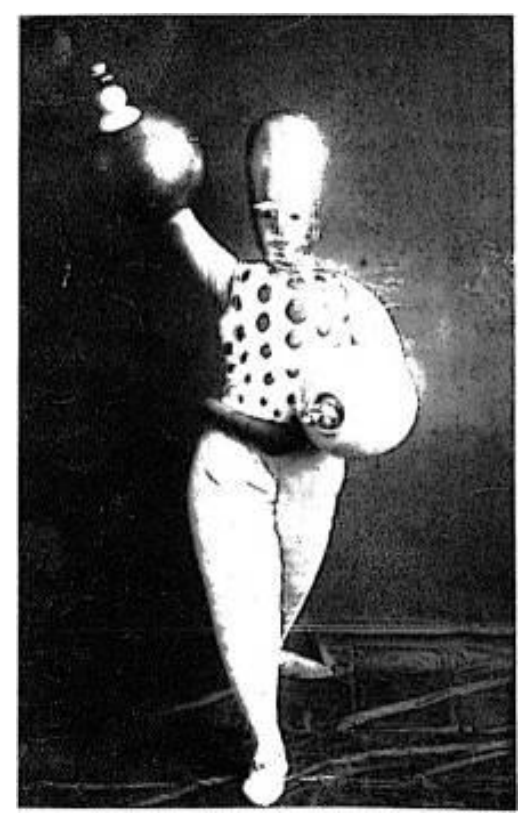

Abb. 110, Oskar Schlemmer, Das Triadische Ballett, Figurine mit Kugelhänden, Gelbe Reihe, 1922 


\section{Abstraktion und Mechanisierung - Oskar Schlemmer und Harry Kramer}

Vor allem Grass' Darstellung von vier Vogelscheuchen in einer der Tuschezeichnungen von 1957 (Abb. 106) zeigt Anklänge an die voluminösen, wattierten und kaschierten Kostüme des Malers, Bühnen- und Kostümbildners Oskar Schlemmer (1883-1943) für das Triadische Ballett (Abb. 109). Grass' Figur mit Kugelarm ähnelt besonders einer Figurine mit dem Titel „Kugelhände“ (Abb. 110), einem Kostüm, das Schlemmer aus den Grundformen des menschlichen Körpers ableitete, sodass es entfernt an eine Gliederpuppe erinnert. ${ }^{400}$

Ab 1912 hatte Schlemmer damit begonnen, Entwürfe zu einer neuen Art der tänzerischen Präsentation zu entwickeln, die gleichermaßen die Choreografie, die Kostüme und das Bühnenbild mit einbezog. ${ }^{401}$ Das Projekt ging aus seiner Ablehnung des Ausdruckstanzes hervor. Es war das Anliegen des Künstlers, Tanzformen aus analytischen Prinzipien zu deduzieren, statt darin Gefühlen intuitiv und individuell Ausdruck zu verleihen. Das 1922 uraufgeführte Stück wird nicht durch eine Handlung strukturiert, denn das Triadische Ballett erzählt keine Geschichte. Die titelgebende Zahl unterteilt es in drei Akte, die jeweils von einer Farbe und einer Grundstimmung geprägt sind: 1. Zitronengelb (heiter-burlesk), 2. Rosa (festlich-getragen) und 3. Schwarz (mystisch-phantastisch).

In die Gestaltung der Kostüme und der Choreografie flossen zwei Aspekte ein, die den modernen Tanz seit Mitte der Zwanzigerjahre stark prägten:402 Abstraktion und Mechanisierung. Folgende Innovationen sollten dazu beitragen, Tänzer und Bühnenraum in ein harmonisches Verhältnis zueinander zu setzen: Schlemmers Kostüme verpuppten die Körper seiner Tänzer zu stereometrischen Formen. Gleichzeitig reduzierten sie deren Bewegungen auf mechanisch wirkende Gesten. Ein Jahr nach der Erstaufführung des Balletts arbeitete Schlemmer die im Zuge der Kostümgestaltung gewonnenen Erkenntnisse zu einer Gestalttheorie aus, die er 1924 unter dem Titel Mensch und Kunstfigur veröffentlichte. ${ }^{403}$ Der Künstler beschreibt darin vier Arten von Bühnenkostümen: Sie sollen 1. „Gesetzen des umgebenden kubischen Raums" folgen, 2. den „Funktionsgesetzen des menschlichen Körpers“ entsprechen, 3. den „Bewegungsgesetzen des menschlichen Körpers im Raum“ unterliegen oder 4. „metaphysische Ausdrucksformen als Symbolisierung der Glieder des menschlichen Körpers" darstellen.

Insgesamt verfolgte Schlemmer das Ziel, den Tänzerinnen und Tänzern gerade durch die Kostüme, die nur kontrollierte Bewegungen zuließen, neue und präzisere Ausdrucksmöglichkeiten zu bieten und sie auf diese Art von menschlicher Unzulänglichkeit zu befreien. Präsentiert werden sollte „ein Gleichnis, ein Symbol menschlicher Gestalt" , ${ }^{404}$ das aus der Betrachtung des Menschen deduziert war. An Stelle des menschlichen Organismus setzte er „die mechanische Kunstfigur: Automat und Marionette“. ${ }^{405}$ Auch für dieses Konzept war Heinrich von Kleists Aufsatz „Über das

\footnotetext{
${ }^{400}$ Vgl. Scheper (1988), S. 39 f.

${ }^{401} \mathrm{Vgl}$. grundlegende Informationen zum Triadischen Ballett in diesem Kapitel folgen: Scheper (1988); Kat. Ausst. Düsseldorf (1994), darin insbes. Michaud (1994); Krystof (1994), Müller (1994a) und Zimmermann (2007).

402 Vgl. Postuwka (1999), S. 25-28 und Zimmermann (2007), S. 136-156.

${ }^{403}$ Vgl. Schlemmer (1974, Erstausgabe: 1927), S. 16 f.

${ }^{404}$ Schlemmer zitiert nach Zimmermann (2007), S. 160.

${ }^{405}$ Schlemmer (1974, Erstausgabe: 1927), S. 16 f.
} 
Marionettentheater" eine wichtige Inspirationsquelle: Die Figuren des Triadischen Balletts sollten die Anmut der Kleist'schen Marionette erreichen.

Grass lobt Schlemmers Projekt in seinem Ballerina-Essay als entscheidenden ersten Schritt zu einer Reform des zeitgenössischen Tanzes, weil es dem klassischen Ballett "gleichstarke Formeln tänzerischer Bewegung“ entgegensetzen könne, denen „alle Zufälligkeit abgeht“. Es ist also anzunehmen, dass Grass auch für sein eigenes Ballett nach Methoden suchte, um Repräsentationen des Menschen der deutschen Nachkriegsgesellschaft zu schaffen, die systematisch künstlich, nicht natürlich abbilden sollten - und das, obwohl seine Ästhetik im Gegensatz zu Schlemmers seit 1955 zugleich eine starke Bezugnahme auf das individuell Wahrnehmbare enthielt. Grass' Kompositionen aus stark abstrahierten, sogar nonfigurativen Formen und eindeutig identifizierbaren Objektdarstellungen scheint sich aus diesem im Grunde widerspruchsvollen Anliegen zu speisen.

Einen ähnlichen Kompromiss ging Schlemmer selbst ein, als er sich 1928 der Gestaltung von tanzenden Vogelscheuchen nach einem Libretto von Hanns Frömbgen widmete. Es ist lediglich das Motiv der Scheuche, nicht die Handlung, die Gemeinsamkeiten mit Grass' „Vogelscheuchen“Libretti aufweist. ${ }^{406}$ Am 14. November 1928 wurde das Stück am Hagener Kammertanztheater uraufgeführt. ${ }^{407}$ Auch Schlemmer stellte für seine Kostüme stereometrische Formen und Darstellungen bestimmter Gebrauchsgegenstände zusammen. Die Figur des Ritters komponierte er zum Beispiel aus glatten Kegeln, Schrauben und konkreten Objekten wie einer Teekanne, einem Ofenrohr und einem Boxhandschuh (Abb. 111).

Interessanterweise gestaltete Grass seine gezeichneten Vogelscheuchen im Vergleich zu Schlemmer sogar noch abstrakter. Die einige Jahre später veröffentlichten Hundejahre machen jedoch deutlich, dass diese Art der Visualisierung von Grass in seiner Prosa nicht aufgegriffen wurde - vielleicht, weil sie die besondere Materialität der Figuren nicht vermittelte und zu wenige Informationen über Grass' besondere "Modelle" transportierte. Eine Präsentationsform der Figuren, die das Wesen der Menschen, die sie verkörpert, verdichtet zum Ausdruck bringt, spielte für die Vogelscheuchen der Hundejahre jedoch noch eine wichtige Rolle. Eddi Amsel alias Goldmäulchen alias Haseloff abstrahiert bei der Gestaltung seiner bewegten und tanzenden Figuren zwar nicht von der Erscheinung und den Eigenschaften des menschlichen Körpers und Organismus' wie Schlemmer, fertigt seine Scheuchen zuletzt aber dennoch so, dass sie einzelne Merkmale des Deutschen verkörpern: Diese Figuren kennzeichnen vor allem typische, wiederholt ausgeführte Bewegungen. Die Wurzeln dieser analytischen Vorgehensweise sind in Grass' Beschäftigung mit dem Anliegen und der Systematik des Triadischen Balletts zu erkennen.

Auch auf die Mechanik der Grass'schen Figuren im Vogelscheuchen-Reich könnte Schlemmers Projekt anregend gewirkt haben. Die Darstellung einer augenscheinlich maschinenbetriebenen, statt lediglich mechanisch anmutenden Figur, verweist jedoch noch stärker auf die Arbeiten Harry

\footnotetext{
${ }^{406}$ Vgl. Scheper (1988), S. 183 f.

407 Vgl. Stamm (1994), S. 258 f. Das Werk ist im Handbuch des Tanzes von Viktor Junk enthalten, das Grass für die Verwendung des Ballettvokabulars in den Hundejahren nutzte, allerdings ohne Erwähnung der Mitwirkung Schlemmers. Vgl. Harscheidt (1976), S. 504. Harscheidt hat wörtliche Parallelen zwischen den Hundejahren und dem Handbuch nachgewiesen. Das Werk verzeichnet neben den „Vogelscheuchen, Pantomime mit Worten von Guntheim, Hagen 1928“ auch „Die Vogelscheuche, Ballett von Max Terpis, nach der Musik von Max de Falla“ sowie Der Liebeszauber: s. Junk (1930), S. 251.
} 
Kramers (1925-1997). Im Werkstattbericht hebt Grass hervor, dass die Figurinen des Tänzers und bildenden Künstler seinen Vogelscheuchen „zur Mechanik verholfen“ hätten. ${ }^{408}$

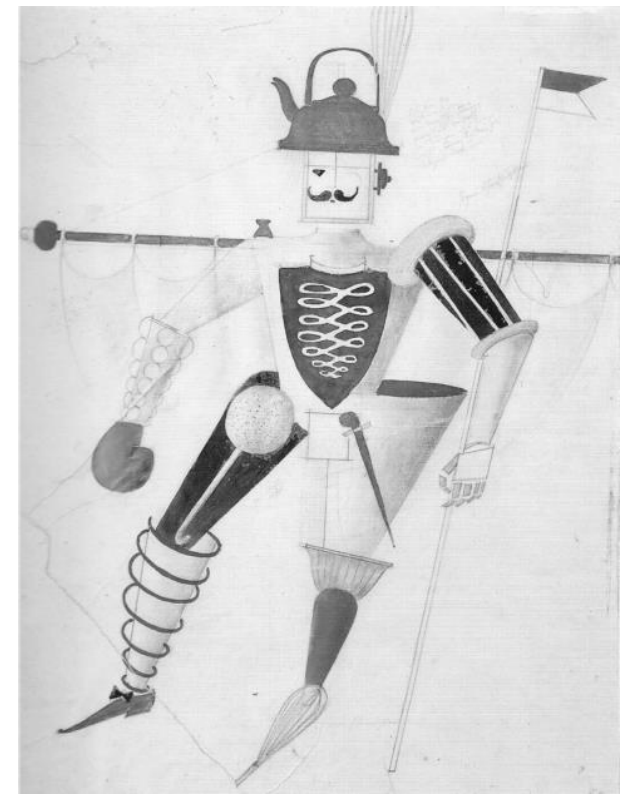

Abb. 111, Oskar Schlemmer, Vogelscheuchen, Der Ritter, 1928, Bleistift, Aquarell, Gold- und Silberbronze auf weißlichem Maschinenbütten, auf Karton aufgezogen

Der Schriftsteller hatte Kramer in Paris über seine erste Ehefrau kennengelernt, die sich mit Helga Brauckmeyer, der Partnerin und späteren Gattin Kramers, anfreundete. Nachdem Brauckmeyer 1955 ein Engagement im Tanzrevue-Ensemble der Bluebell Girls angenommen hatte, folgte ihr Kramer im Januar 1956 von Berlin nach Paris. Noch in Berlin hatte er seit 1952 unter dem Eindruck des Kleist'schen Essays an einer neuen Form des Marionettentheaters gearbeitet. ${ }^{409}$

Erste Figurinen entstanden zwischen 1953 und 1955 und orientierten sich an Gemälden von Paul Klee, Joan Miró und Henry Moore. Entsprechend wurden sie von Kramer stärker als Kunstwerke, denn als Marionetten aufgefasst. Sie bestanden aus leichten Pappmaschee- oder HolzKörpern, aus Draht, aber auch aus einzelnen Gebrauchsgegenständen. 1955 brachte der Künstler sein erstes Figurenensemble in einem Stück mit dem Titel 13 Szenen in der Berliner Galerie Springer zu der konkreten Musik Wilfried Schröpfers in Bewegung. Er entwickelte eine neue „Theater-

\footnotetext{
${ }^{408}$ Vgl. Grass (2014), S. 75: „In Paris angekommen, setzte, nach langwieriger Wohnungssuche, Anna ihre Ballettausbildung fort, und ich legte im Heizungsraum unserer Zweizimmerwohnung Plastiken an, die bald eintrockneten, denn die Arbeit am Prosamanuskript unter wechselnden Titeln - Der Trommler, Der Blechtrommler, schließlich Die Blechtrommel - ließ dem Bildhauer keine Zeit. Doch Zeichnungen für BallettLibretti, Die Vogelscheuchen, Die Gans und fünf Köche entstanden, wobei die gezeichneten Vogelscheuchen später vom ersten bis zum zweiten Buch den Roman Hundejahre bevölkerten. In einer LithographieWerkstatt auf dem rechten Seineufer entstanden erste Zeichnungen auf Stein. Die schwierige Freundschaft mit Paul Celan, die praktische Freundschaft mit Harry Kramer, dessen mobile Figuren meinen Vogelscheuchen zur Mechanik verhalfen."

${ }^{409}$ Kramer (1990), S. 34: „Um seine Freundin ein wenig aufzuheitern, bastelte der Tänzer eine Puppe und ließ sie an Bindfäden baumeln. [...] Das Ganze wäre eine Episode geblieben und im Ofen gelandet, hätte nicht eine schlaue Kundin angesichts des süßen Meisterwerks mit Kleist-Zitaten um sich geworfen. Wie nicht anders zu erwarten, verglich sie den unvollkommenen Tänzer mit der vollkommenen Marionette. [....] Auf dem Heimweg in der S-Bahn faßte er den Entschluß, das Marionettentheater zu revolutionieren und damit der Unsterblichkeit etwas näher zu kommen."
} 
form“, der - ebenso wie dem Ballett Schlemmers - „Dialog und Pointe fremd“ waren. Seine Figuren bezeichnete Kramer damals als "Chiffren einer einmal fixierten unabänderlichen Erfahrung", die nach der "Gesetzmäßigkeit der Träume" abliefen und den Betrachter - mit Musik und Lichteffekten arrangiert - unmittelbar und sinnlich affizierten. ${ }^{410}$

Bereits dieser Künstlerkommentar Kramers und seines Mitarbeiters Wolfgang Ramsbott verrät enge Bezüge zu den unterbewusst gesteuerten Assoziationsreihen der Surrealisten zum einen und der Einsicht in die Absurdität der empirisch wahrnehmbaren Welt der Existenzialisten zum anderen. ${ }^{411}$ Insbesondere ergeben sich Überschneidungen zwischen den Manifesten Kramers/ Ramsbotts und den Vorstellungen Albert Camus zum „absurden Kunstwerk“, die der Philosoph im Mythos des Sisyphos formulierte - einem Text, den auch Günter Grass in den Fünfzigerjahren rezipierte und in den Sechzigerjahren zu seinem politischen Programm erhob. ${ }^{412}$ Kramer zielte wie Camus darauf ab, die Welt, „die mathematisch darstellbar, sinnlich aber nicht mehr erfahrbar" sei, durch eine „spektakuläre“ Kunst wieder in den „Bereich der menschlichen Empfindungen“ zu bringen: „Uns bleibt, das Hirn zum Brennspiegel zu machen, der die ganze Phantastik dieses Vorgangs zu Bildern bündelt. “413

In Paris arbeitete Kramer bis 1959 an einer zweiten Figurengruppe für das Stück Signale im Schatten. Diesen Figuren setzte er zum Teil Motoren ein und arbeitete mit Rampen und Schranken, die sie genau kontrollierte Bewegungen ausführen ließen.
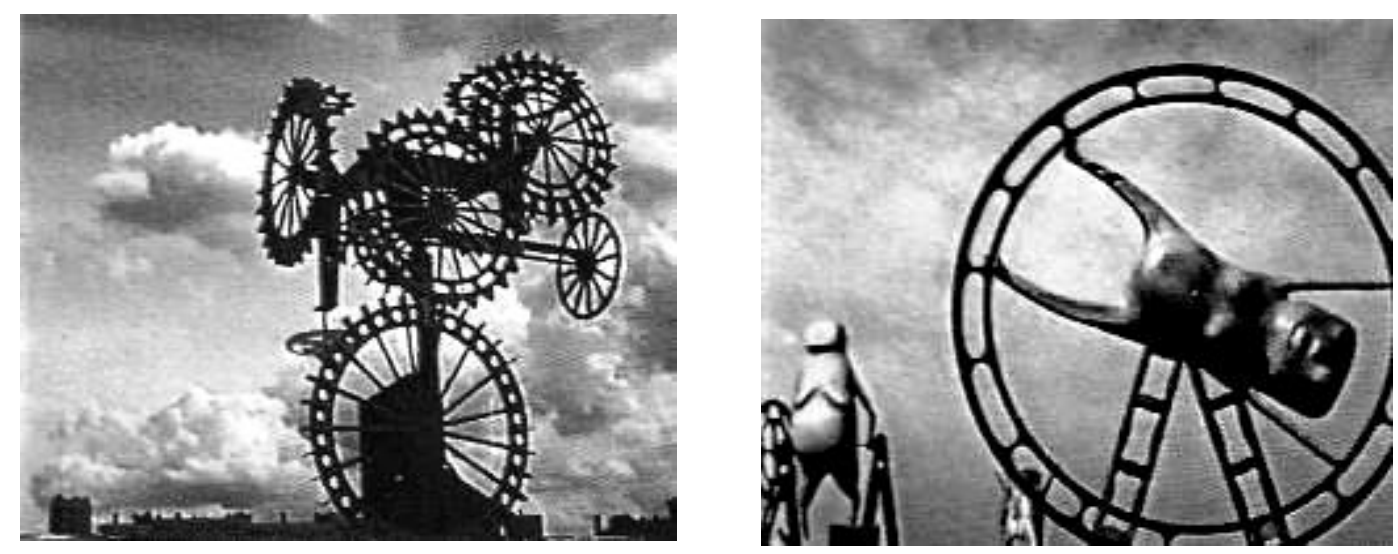

Abb. 112 und Abb. 113, Harry Kramer und Wolfgang Ramsbott, Stills aus dem Film Die Schleuse, 1961

\footnotetext{
${ }^{410}$ Kramer/Ramsbott (1990).

${ }^{411}$ Vgl. Metken (1990), S. 61, ferner Jappe (1990), S. 82-92.

412 Über Grass' Camus-Rezeption gibt der mit Grass Biografika ausgestattete Erzähler des Romans Kopfgeburten oder Die Deutschen sterben aus (1980) Auskunft (X 84 f.).

413 Kramer/Rambsbott (1990), S. 76. Vgl. Camus (2012), S. 118 f.: „Der Ausdruck beginnt, wo das Denken aufhört. Bei jenen Jünglingen mit leeren Augen, die die Tempel und die Museen bevölkern, ist ihre Philosophie in Gebärden umgesetzt."
} 
Kramers Aufführungen wurden auf Filmspulen konserviert - gemeinsam mit Ramsbott inszenierte er sie auch für die Kamera und verlieh seinen wie traumwandelnd durch das Bild gleitenden und um die eigene Achse rotierenden Figuren durch Untersicht und Nahaufnahmen Monumentalität (Abb. 112, Abb. 113). ${ }^{414}$

Der mechanische Apparat, den Grass in der Kohlezeichnung von 1960 skizzierte und in sein zweites Libretto aufnahm, erinnert an Vorrichtungen des „Mechanischen Theaters". Im Unterschied zu Kramers Präsentation werden die Bewegungselemente im Text jedoch in eine Handlung eingebunden. Sie charakterisieren eine ganz bestimmte Gesellschaft anhand ihrer wie fremdgesteuert wirkender Mechanismen. In den Hundejahren bilden Sprungfedern und Motoren die Grundlage für die Beweglichkeit der Kunstwerke Eddi Amsels. Sie ermöglichen es dem Künstler, einzelne Individuen und Typen der Gesellschaft durch charakteristische, nämlich stets wiederkehrende Bewegungen zu beschreiben.

\section{Vogelscheuchen als Kunstwerke im Roman}

Die zweifache Funktion des Vogelscheuchenmotivs als Sinnbild einer neuen Ästhetik zum einen und als Spiegel der Nachkriegsgesellschaft zum anderen entwickelte der Schriftsteller in den Hundejahren weiter. Indem er die Vogelscheuchen in seinem Roman als Werke eines bildenden Künstlers thematisierte, konnte er die zuvor nur fragmentarisch angedeuteten Inhalte nun ausführlich behandeln: Vorgestellt werden ein Überblick über rund vierzig Jahre der Auseinandersetzung Eddi Amsels mit seinem Gegenstand anhand exemplarischer Beispiele, ein Einblick in seine Arbeitsweise sowie die von dem fiktiven Künstler schriftlich fixierten ästhetischen Grundsätze, die erstaunlich genau mit späteren Aussagen von Günter Grass über seine eigene Bildkunst übereinstimmen. ${ }^{415}$ Die Ästhetik Amsels wird im Roman nicht als abgeschlossenes, statisches Programm vorgestellt, sondern als langjährige Entwicklung.

Auch wenn die Hundejahre viele Themen und Handlungsstränge bündeln, mitunter die Geschichte einer ambivalenten, von wechselseitiger Abhängigkeit und Schuld geprägten Freundschaft sowie eine Erzählung „vom Verfall einer Hundefamilie“416 umfassen, tritt das mal ernstgenommene, mal persiflierte Muster des Künstlerromans darin am kontinuierlichsten hervor. ${ }^{417}$ Das Leben und Wirken des halbjüdischen Vogelscheuchenkünstlers Eddi Amsel, der im Laufe der Zeit seine Identität wechseln und mindestens noch auf die Namen Haseloff, Goldmäulchen und Brauksel/Brauxel/Brauchsel hören wird, bildet die Basis des Buches.

Der Erzählfiktion nach gibt er es selbst als dreiteiligen Prosatext bei Autoren in Auftrag, die gemeinsam mit inm in der Freien Stadt Danzig aufgewachsen sind. Es soll am 4. Februar 1962 anlässlich des zehnjährigen Bestehens seiner Firma als Festschrift veröffentlicht werden. Der Herausgeber übernimmt die Niederschrift des ersten, „Frühschichten“ genannten Teils, der die Jahre 1917 bis 1927 thematisiert, in eigener Person. Der angehende Schriftsteller Harry Liebenau schreibt den zweiten, in den Jahren 1922 bis 1945 situierten Teil unter dem Titel „Liebesbriefe“

\footnotetext{
${ }^{414}$ Kramers Nachlass, darunter auch seine Filme, wird im documenta archiv der Stadt Kassel aufbewahrt.

415 Vgl. Reddick (1975), S. 239 und Stallbaum (1989), S. 137.

${ }^{416} \mathrm{Vgl}$. Neuhaus (2010a), S. 29.

${ }^{417}$ Vgl. zur Rolle der Kunst und des Künstlers in den Hundejahren: Reddick (1975), S. 239 und Stallbaum (1989), S. 125 f.
} 
und der Schauspieler und Rundfunksprecher Walter Matern, dem Amsel als Jugendlicher aufs Engste freundschaftlich verbunden war, den dritten Teil, die „Materniaden“. Diese behandeln den Zeitraum zwischen 1946 und 1957. Das Werk soll dem ersten Federführenden zufolge später „als Handbuch für wirksame Vogelscheuchen gelesen werden“ (IV 192) - die Entwicklung einzelner Arbeiten treibt auch die Handlung voran.

Sein Schaffen lässt sich grob in fünf Phasen unterteilen, von welchen die erste ausführlich von inm selbst, die drei folgenden aus beobachtender Distanz von Harry Liebenau und die letzte von Walter Matern wiedergegeben werden. Der Herausgeber stützt seine Erinnerungen auf ein Arbeitstagebuch, ein „Diarium“, das kommentierte Zeichnungen seiner Werke, ästhetische Theorien und Abrechnungen enthält. Grass' Text rekurriert damit bereits auf der Handlungsebene in vielfältiger Form kontinuierlich auf die bildende Kunst, in vielen Passagen ebenfalls auf das Ballett. Bildkünstlerische Werke werden den Leserinnen und Lesern zudem in Bildbeschreibungen vor Augen geführt, die teilweise mit direkten und indirekten Zitaten von realen Werken der bildenden Kunst unterfüttert werden. Die Künstlerfigur als fiktiver Schriftsteller, der seine eigene, von einer starken Sensibilität für das Visuelle geprägte Perspektive auf die Welt vermittelt, rechtfertigt zudem die Verdichtung bestimmter Erzählpassagen zu Bildern.

Die Scheuchen der ersten Phase baut Eddi Amsel als Kind und Jugendlicher in den Jahren 1923 bis 1939. Der gerade Fünfjährige hat zunächst keine Absicht, seine Figuren im Hinblick auf eine bestimmte Funktion herzustellen. Erst nachdem anderen Dorfbewohnern auffällt, dass seine Arbeiten als Vogelscheuchen wirksam werden, treten sie nicht nur als Kunstwerke, sondern auch als Gebrauchsgegenstände in Erscheinung und werden damit zugleich ökonomisch verwertbar. Ebenso wie im Gedicht werden der Begriff und die Auffassung davon, was eine Vogelscheuche ist, in Frage gestellt und so ihr Doppelcharakter als Kunstwerk und Gebrauchsgegenstand offenbart.

Amsel setzt die Gestalten zunächst aus Fundstücken zusammen, die die Weichsel nach einem Hochwasser ans Ufer spült. Der Künstler bindet diese Objekte nicht zusammen ",' sondern wirft aneinander, und es hält wunderbar" (IV 198) - ein Arbeitsvorgang, der das Erscheinungsbild der Vogelscheuche als Assemblage zusätzlich unterstreicht. Die Gestalten vermitteln zudem eine besondere Agilität, die an ihre Charakterisierung im „Vogelscheuchen“-Gedicht erinnert:

Seine Scheuchen schienen lebendig zu sein und waren, wenn man ihnen lange genug zuschaute, schon während des Entstehens, auch als Torso, wenn sie abgerissen wurden, ganz und gar lebendig: Über den Deich spurteten sie, Deichläufer winkten, drohten, griffen an, schlugen zu, grüßten von Ufer zu Ufer, ließen sich vom Wind tragen, unterhielten Gespräche mit der Sonne, segneten den Fluß und seine Fische [...]. (IV 193 f.)

Die Ursache ihrer nicht zu leugnenden Wirksamkeit gegenüber Vögeln und Menschen wird ebenfalls genau bezeichnet, sie liegt in den "gut beobachteten Details“:

Wenn all diese vergänglichen Bauwerke immer wieder Fleiß und Anteil der Phantasie des Baumeisters verrieten, war es dennoch Eduard Amsels wacher Sinn für die vielgestaltete Realität, war es sein über feisten Wangen neugieriges Auge, das seine Produkte mit gutbeobachteten Details ausstattete, funktionieren ließ und zu vogelscheuchenden Produkten machte. (IV 193)

Amsels besonders ausgeprägter Sehsinn wird im Roman durchgehend hervorgehoben: Hinweise auf den genauen Blick des Künstlers, seine „zusammengekniffenen Äugelchen“, die Menschen 
und Ereignisse als würdige Sujets auswählen, machen nicht nur die enge Bindung der daraufhin entstehenden Werke an die wahrnehmbare Welt deutlich, ${ }^{418}$ sondern sind zugleich ein Signal für die Leserinnen und Leser, das Folgende aus seiner Perspektive wahrzunehmen. Sie erhalten buchstäblich einen Einblick in die Sichtweise des bildenden Künstlers, die literarisch simuliert wird.

Amsels Vogelscheuchen entstehen „nach dem Vorbild des Menschen“ (IV 191), so der wichtigste Grundsatz des Künstlers. Alle seine Modelle werden der „Natur entnommen“. Nachträglich erweitert Amsel den Satz um eine Beobachtung, die an den metaphysikkritischen Tenor des „Vogelscheuchen“-Gedichtes anknüpft, indem sie verdeutlicht, dass er sich bei seinen Darstellungen bewusst auf die äußere Erscheinung seiner Umwelt beschränkt: ${ }^{419}$ „Alles, was sich ausstopfen läßt, gehört der Natur an: die Puppe etwa“ (IV 206 f.). Zehn Jahre später wird der reale Künstler Günter Grass über sich schreiben: „Alle Gegenstände der Natur, auch die ausgestopften, sind mir Modell.“ (XI 864)

Der heranwachsende Eddi Amsel fertigt ganz konkret „Figuren des Landlebens" (IV 197), „altpreußische Götter" (IV 224) und "Gestalten aus dem Bodensatz der osteuropäischen Geschichte" (IV 227), wobei nicht unerwähnt bleibt, dass auch für die Gestaltung von „Grenadieren, Füsilieren, Gefreitenkorporale[n], Standartenjunker[n] und Officiers", einzelne Bauern Modell stehen (IV 216). Dabei zielen die aus Objekten zusammengefügten Kunstwerke nicht darauf ab, die ihm bekannten Personen sklavisch zu imitieren. ${ }^{420}$ Amsels letzte Scheuche aus Kindertagen ist die Darstellung eines Vogels als Vogelscheuche, ein Paradoxon. In der von dem Künstler festgehaltenen Anleitung zum Bau des „Großen Vogels Piepmatz“ heißt es: „Mit Teer und Pech bestrichene Lumpen müssen von außen, und wenn genug da ist, auch von innen, mit großen und kleinen Federn beklebt werden. Aber unnatürlich, nicht natürlich.“ (IV 257). Jedem seiner Werke geht zudem ein kreativer Einfall voraus, der sprachlich als eine assoziative Reihung von visuellen Eindrücken wiedergegeben wird (IV 397). ${ }^{421}$

Bei der Darstellung der beobachteten Menschen vollbringt Amsel eine Abstraktionsleistung, indem er für sie charakteristische Gesten betont. Noch während der pummelige Junge von Gleichaltrigen verprügelt wird, gelingt inm "das sachliche Wahrnehmen typischer Bewegungen“ (IV 195), die er wenig später in einer Vogelscheuche umsetzen kann: „Zwei drei Tage nach solch einer Prügelei [...] fand sich im Strandwald, zwischen den Dünen oder direkt am Strand, beleckt von der See, dieselbe Prügelszene in einer einzigen vielarmigen Vogelscheuche abgebildet." (IV 195 f.). Noch effektvoller wird Amsel solche Beobachtungen in seine mechanischen Vogelscheuchen integrieren.

Die ersten Figuren dieser Art sind die "Windmühlennonnenscheuche" und die "Windmühlenritterscheuche", zu welchen der Künstler durch die Legende von den 12 Nonnen und den 12 Rit-

\footnotetext{
${ }^{418}$ Vgl. Reddick (1975), S. 240 f.

${ }^{419} \mathrm{Vgl}$. Mason (1974), S. 74.

${ }^{420}$ Während Amsels Vogelscheuchen für Mason von Beginn an abstrahierende, nicht mimetisch abbildende Arbeiten darstellen, sind sie für andere Forscher, auch aufgrund von Amsels intensiver Naturbeobachtung, naturalistische Kunstwerke: Vgl. Mason (1974), S. 24 und dagegen Stallbaum (1989), S. 137 und Engels (2005), S.139.

${ }^{421}$ Vgl. Stallbaum (1989), S. 89.
} 
tern zu Kreuzburg und durch eine Bockwindmühle angeregt wird (IV 229-240). ${ }^{422}$ Die Geschichte, laut welcher Geister von zwölf Rittern und Nonnen immer wieder an Vollmond zu Orgien zusammentreffen und anschließend Buße tun, inspiriert inn zu einem sich geißelnden Vogelscheuchenpaar, einer Nonne und einem Ritter, in die Windmühlenflügel eingebaut sind, und die, gleich der Nickelswalder Mühle, die der Familie von Amsels Freund Matern gehört, auf einem Bock sitzen:

Wir nehmen leise Elektromotoren: Windmühlennonne schwingt Windmühlengeißel... [...] Nach Skizzen im Diarium fertigte er einen Windmühlenritter und eine Windmühlennonne, ließ beide mit kostümgerechtem Rutenzeug auf dem Bock sitzen und dem Wind gehorchen [...]. (IV 240)

An Kramers rotierende Figuren erinnernd, verdeutlicht das mechanische Kreisen die Zwangsläufigkeit der Handlung und ihre stetige Wiederholung. Passend zur Legende bringt das Scheuchenpaar Sünde und Buße in ihrer zyklischen und im Grunde absurden Abfolge zum Ausdruck.

Die Jahrzehnte später für das Vogelscheuchenbergwerk des erwachsenen Künstlers geplanten Windmühlennonnenscheuchen sind zusätzlich von der Bildwelt eines anonymen Grafikers inspiriert. Die genannten Titel und Formate verweisen auf die im vorangehenden Kapitel dieser Arbeit behandelten Nonnendarstellungen, die Grass 1962 in der Akademie der Künste ausgestellt hatte und die in anderen Varianten auch als Kohlezeichnungen dem Gedichtband Gleisdreieck (1960) beigefügt wurden: ${ }^{423}$

Endlich sind die Grafiken angekommen. Brauksel hat sie sogleich unter Glas legen und hängen lassen. Mittelgroße Formate: „Nonnenanhäufung zwischen dem Kölner Dom und dem Kölner Hauptbahnhof. Eucharistischer Kongreß München. Nonnen und Krähen und Krähen und Nonnen." Dann die großformatigen Blätter, DIN A1, schwarze Tusche, zum Teil ausgezogen: Einkleidung einer Novizin; Große Äbtissin; Hockende Äbtissin - ein gelungener Wurf. Fünfhundert DM verlangt der Künstler. Angemessen, durchaus angemessen. Das Blatt kommt sogleich ins Konstruktionsbüro. (IV 240)

An dieser Stelle werden also nicht die Zeichnungen des Schriftstellers zitiert, die Vogelscheuchen darstellen, etwa die oben behandelten Gruppenbilder. Erwähnt werden stattdessen Zeichnungen, die den mit den Scheuchen anvisierten Menschentyp auf kritische, teilweise satirische Art darstellen und dem Künstler daher als Vorstufe zu seinen noch pointierteren dreidimensionalen Darstellungen dienen.

Auch wenn die Zeichnungen im Roman nicht explizit als Arbeiten des realen Günter Grass benannt werden, verweisen die Bildzitate darauf, dass die Nonnenvogelscheuchen im Medium der Grafik vorbereitet wurden und führen auf diese Weise Romangenese und Erzählfiktion zusammen. Leserinnen und Lesern, die mit Grass' bildkünstlerischen Arbeiten vertraut sind, werden sie durch die Erwähnung zudem in Erinnerung gerufen. Indirekt lassen die sich mechanisch peitschenden Windmühlennonnen zudem an barocke Tischuhren der Geißelung Christi denken frühe Automaten, auf welche Harry Kramer und andere Künstler, die sich mit der kinetischen Plastik beschäftigten, in den Fünfzigerjahren Bezug genommen haben. ${ }^{424}$

\footnotetext{
${ }^{422}$ Vgl. Neuhaus (2010a), S. 186: Die Volkssage geht zurück auf: Die 12 Ritter und die 12 Nonnen zu Kreuzburg, in: Die Volkssagen Ostpreußens, Litauens und Westpreußens, gesammelt von W. J. A. von Tettau und J. D. H. Temme, Berlin 1837.

${ }^{423}$ Vgl. Hille-Sandvoss (1987), S. 119.

${ }^{424} \mathrm{Vgl}$. Kramer/Ramsbott (1990), S. 78 f.; eine Abbildung einer solchen Tischuhr befindet sich in der Kasseler Hochschulzeitung PUBLIK, J. 3, Nr. 9, 16.7.1980, S. 6.
} 
Die außergewöhnliche Wirkung der Amsel'schen Vogelscheuchen wird ebenfalls bereits in den „Frühschichten“ behandelt. Dem Künstler fällt schon früh auf, dass seine Arbeiten, „wenn sie nur intensiv genug der Natur entnommen waren“, nicht nur Vögeln, sondern auch Menschen "die ländlich ruhige Gangart stören konnten“ (IV 215). Nachdem Walter Materns Großmutter nach der Betrachtung des besonders furchterregenden "Großen Vogels Piepmatz" der Schlag trifft, beschließt Amsel seine Arbeit vorerst einzustellen.

Die zweite Schaffensphase setzt ein, als Eddi Amsel um 1935 den von Otto Weininger verfassten antisemitischen Bestseller Geschlecht und Charakter erbt und ein zerrissener Bratenrock seine Fantasie anregt. Die Lektüre und Umkehrung des Weininger-Textes unterlegt Amsels Scheuchen und samt ihrer Wirkungsweise eine Theorie, die der Künstler nutzen will, um die Wirksamkeit seiner Figuren zu intensivieren. Weininger, selbst Jude, wie er in einer Fußnote seines Textes kundtut, hatte in seiner pseudobiologisch und pseudopsychologisch argumentierenden Schrift die Zugehörigkeit zum Judentum als negative „psychische Eigenart “425 definiert. Sofern man sich ihrer Kennzeichen bewusst werde, könne man sie überwinden. Der Antisemitismus sei eine Projektion, die dem Antisemiten dabei helfe, eigene abstoßende Eigenschaften zu erkennen und sich auf diesem Wege von ihnen zu befreien. Generell könnten „Arier“ die Auseinandersetzung mit Juden nutzen, um „jüdische“ Merkmale ihres eigenen Charakters auszumerzen. Als Projektionsfläche, als welche Weininger die Angehörigen seiner eigenen Religionsgemeinschaft erkennen will, sieht Amsel von da an auch seine Vogelscheuchen. Sie sollen aber nicht etwa angebliche jüdische Eigenarten repräsentieren, sondern tatsächliche menschliche Unarten, zum Beispiel den Nationalsozialismus. Der Erzähler Harry Liebenau lässt Amsel eine für diese Idee entscheidende Passage mit Quellenangabe zitieren:

\footnotetext{
"Geschlecht und Charakter", dreizehntes Kapitel, Seite 405: „... und es ist, vorläufig gesprochen, vielleicht die welthistorische Bedeutung und das ungeheure Verdienst des Judentums kein anderes, als den Arier immerfort zum Bewußtsein seiner Selbst zu bringen, ihn an sich (,an sich' fettgedruckt) zu mahnen. Dies ist es, was der Arier dem Juden zu danken hat; durch ihn weiß er, wovor er sich hüte: vor dem Judentum als Möglichkeit in ihm selber. (IV 389)
}

Amsels Kunstfiguren vereinen spätestens an diesem Punkt beide von Kleist aufgezeigte Wege zu einer „Rückkehr in den Stand der Unschuld“:426 Die Bewusstseinslosigkeit in der mechanischen Bewegung der Kunstfigur zum einen und das Forcieren einer Erkenntnis der Betrachterin oder des Betrachters über sich selbst zum anderen. Unter der produktiven Umkehrung des antisemitischen Weininger-Textes vollendet der Künstler zahlreiche Scheuchen. Die ersten Gestalten, die Amsel in seinem Atelier an der Decke nebeneinander aufreiht, scheinen sich im Gespräch miteinander zu befinden, eine "amorphe und dennoch diskutierende Gesellschaft", die an Grass" frühe Tuschezeichnungen zum Vogelscheuchen-Ballett erinnert. ${ }^{427}$ Diese in der Isolation der Werkstatt entstandenen „Atelierpflanzen und Zimmerlinden“ (IV 394) misslingen jedoch mangels einer unmit-

\footnotetext{
425 Weininger (1920, Erstausgabe 1903), S. 401.

${ }^{426}$ Vgl. Kleist (2001, Erstausgabe 1810), S. 345: „Mithin, sagte ich ein wenig zerstreut, müßten wir wieder von dem Baum der Erkenntnis essen, um in den Stand der Unschuld zurückzufallen? Allerdings, antwortete er; das ist das letzte Kapitel von der Geschichte der Welt."

${ }^{427} \mathrm{Vgl}$. Hille-Sandvoss (1987), S. 101.
} 
telbaren Verbindung zur wahrnehmbaren Wirklichkeit: „Weiningers Text blieb Papier. Perfektion ermüdete" (IV 393).

Es ist ein aggressionsgeladenes Ereignis, eine Schlägerei zwischen Walter Matern und dem Jungvolk, die den Künstler ergänzend zu Weiningers Text inspiriert und den Beginn seiner dritten Schaffensphase markiert. Er baut Vogelscheuchen von nun an explizit nach dem Bild der Deutschen. Wie Amsel alias Goldmäulchen viele Jahre später formuliert "[...] ist es mit Vorzug das deutsche Volk, das, mehr noch als das jüdische, alles Zeug in sich hat, der Welt eines Tages die Urvogelscheuche zu schenken." (IV 849). Die neuen Figuren entstehen aus benutzten SAUniformen, Symbolen und Reproduktionen aus der Bildgeschichte der deutschen Kultur. Das Material wird nun nicht mehr aneinander „geworfen“, sondern genäht und geklebt:

\begin{abstract}
Und auf die Rupfenhemden nähte er manchmal mit weitem, dann mit pingeligem Stich das entsetzliche Braun in Lappen, als Schönheitspflästerchen. Er fragmentierte aber auch das Armbindenrot und die sonnenstichtollen Bauchschmerzen des Hakenkreuzes. Er fütterte mit Kapok und Sägemehl. Er suchte und fand in Illustrierten und Jahrbüchern Gesichter, etwa das grobkörnige Foto des Dichters Gerhart Hauptmann, oder das glatte Schwarzweiß eines populären Schauspielers jener Jahre: Birgel, oder Jannings. Er heftete Schmeling und Pacelli, den Bullen und den Asketen, unter den Mützenschirm der Braunmützen. Er machte aus des Völkerbundes Hochkommissar einen SA-Mann Brand. Er scheute sich nicht, an Reproduktionen nach alten Stichen so lange herumzuschnipseln und mit Solingens Schere gottähnlich zu wirken, bis Schillers kühnes Profil oder des jungen Goethe Dandy-Haupt irgendeinem Opfer der Bewegung, Herbert Norkus oder Horst Wessel, Gesicht gaben. Amsel verhackstückte, spekulierte, kuppelte und gab den Jahrhunderten Gelegenheit, sich unter SA-Mützen zu küssen. (IV 406)
\end{abstract}

Die letzten Modelle, die aus Amsels Atelier hervorgehen, konzentrieren sich bei den Versatzstücken deutschen Bildungsguts auf den Stoff des Nibelungenliedes sowie auf die Künstler, die ihn maßgeblich als deutschen Nationalmythos etablierten:

[...] Eddi Amsel hat allen Schweinsblasen-Gesichter geklebt. Reproduktionen nach Bildern des Malers Schnorr von Carolsfeld, der, wie bekannt sein sollte, der Nibelungen Not gemalt hat, spenden die Personalien: der finstere SA-Mann Hagen von Tronje; die SA-Männer Vater und Sohn, Hildebrand und Hadubrand; der lichte SA-Sturmführer Siegfried von Xanten; der sensible Obersturmführer Gunther; der allzeit lustige Volker Baumann; und drei Recken, die aus der Nibelungen Not Kapital geschlagen hatten: der edle Hebbel von Wesselburen, Richard der Wagner und jener Maler, der mit mattem Nazarenerpinsel der Nibelungen Nöte konterfeit hatte. (IV 423)

Die an den Scheuchen angebrachten Abbildungen der Fresken Schnorr von Carolsfelds (Abb. 114) sind aus der königlichen Residenz Ludwigs I. in München bekannt und waren durch fotografische Reproduktionen und druckgrafische Varianten in einer illustrierten Fassung des Textes weit verbreitet. $^{428}$

\footnotetext{
${ }^{428}$ Vgl. Nowald (1978), S. 27-33: Julius Schnorr von Carolsfeld hatte zwischen 1827 und 1867 an Fresken zum Nibelungenlied gearbeitet, die die fünf repräsentativen Empfangsräume der königlichen Residenz Ludwigs I. in München schmücken sollten. Er verteilte den Stoff auf einen „Saal der Hochzeit“, einen „Saal des Verrats", einen "Saal der Rache" und einen "Saal der Klage“. Dem Ensemble war zudem ein "Saal der Helden" vorangestellt. Hier wurden den Betrachtenden alle Akteure der sich im Folgenden entfaltenden Legende in monumentalen Gruppenbildern vorgestellt. Reproduktionen dieser Fresken finden sich in den Zwanzigerjahren z. B. in der Prachtausgabe: Die Nibelungen-Sage nach den Fresko-Gemälden von Julius Schnorr von Karolsfeld in der Königlichen Residenz zu München, photographiert im Auftrage seiner Majestät König Ludwig II. von Bayern, München 1921, dort: Abb. 2-8.
} 
Die SA-Scheuchen kennzeichnen nicht nur ihre Uniform und ihre Masken, sondern ebenso Hitlergruß und Marschschritt. Erneut werden Figuren durch eine prägnante, hier politisch bedeutsame Bewegungsfolge charakterisiert, die eventuell bereits in Grass' Skizze zum VogelscheuchenBallett vom März 1957 vorbereitet wurde (S. 170, Abb. 107).

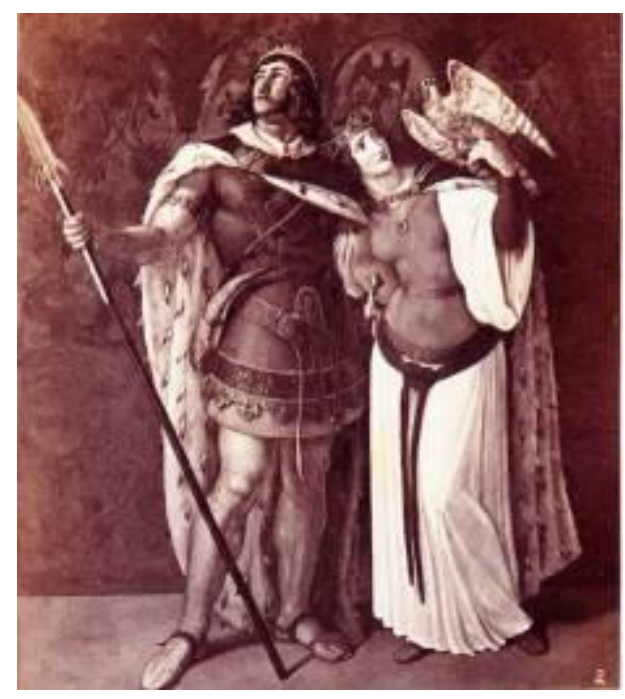

Abb. 114, Julius Schnorr von Carolsfeld, Fresko aus der Münchner Residenz, dem „Saal der Helden“, Siegfried und Kriemhild, 1827-67, Fotografie aus dem Jahr 1921

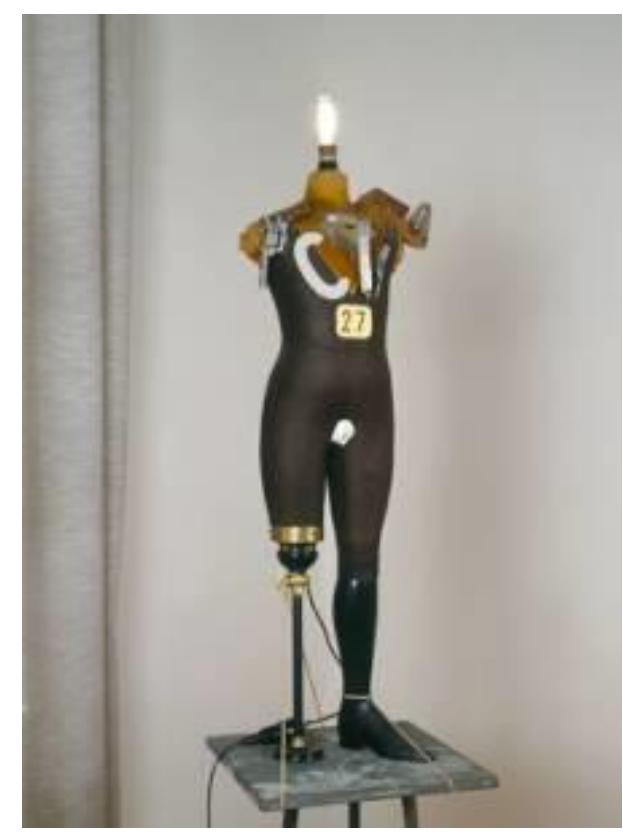

Abb. 115, George Grosz und John Heartfield, Der wildgewordene Spießer Heartfield (elektro-mechanische Tatlin-Plastik), 1920, Rekonstruktion Michael Sellmann 1988, Installation (Schneiderpuppe, Revolver, Klingel, Messer und Gabel, „C", „27", Gebiss, schwarzer Adlerorden, EK II, Osram Glühbirne) 
Die von Amsel aus verschiedenen Materialien montierten Figuren erinnern indirekt an reale Kunstwerke, die tatsächlich in den Jahren zwischen den beiden Weltkriegen entstanden sind, ${ }^{429}$ wie solche von George Grosz und John Heartfield - etwa an das dadaistische Gemeinschaftsprojekt Der wildgewordenen Spießer John Heartfield aus dem Jahr 1920 (Abb. 115). Die Beschäftigung des Kunstakademiestudenten Grass mit der Kunst des ersten Drittels des 20. Jahrhunderts findet damit auch in den fiktiven Kunstwerken der Hundejahre ein Echo. Amsels Vogelscheuchen verbinden auf vergleichbare Weise Elemente der deutschen Populär- und Nationalkultur zu spöttischen Spiegelbildern des Deutschen. Wo Grosz/Heartfield ein Verdienstkreuz aus dem Ersten Weltkrieg mit einer Kriegsversehrten-Prothese und bourgeoisem Wohninventar zusammenfügen, schließlich an Stelle einer geistigen Erleuchtung eine profane technische setzen, kombiniert Amsel blutige Uniformen mit bildgewordenem und auf bürgerlicher Kultur gegründetem Nationalstolz.

Die Entstehung der Werke macht jedoch die moralische Ambivalenz deutlich, die Eddi Amsel als Künstlerfigur kurz vor Beginn des Zweiten Weltkrieges auszeichnet. Die Vorbereitungen, die Amsel für die Anfertigung der SA-Scheuchen trifft, zeigen, dass der Künstler zu den politischen Zuständen persönlich keine Position bezieht. Das notwendige Material für seine Figuren, die Uniformen, erhält Amsel über seinen besten Freund Walter Matern, den er zu diesem Zweck davon überzeugt, in die nationalsozialistische Kampforganisation einzutreten. Er stellt sich zudem selbst als SA-Scheuche dar, „zeigt sich verliebt in seine neue Schöpfung“ (IV 407) und erwidert den deutschen Gruß seiner Schreckgestalten in der Rolle des „Führers“ (IV 425).

Genauso wie dem Blechtrommler Oskar, mit dem Amsel kurz vor dem Bau der SA-Scheuchen die Köpfe zusammensteckt (bei der Herstellung selbst trägt er rotweiße, also mitunter auf Oskars Trommel rekurrierende Kleidung (IV 421)), ist inm ein scheinbar naiver, moralisch nicht wertender Blick eigen, der die Realität und ihre Widersprüche bloßlegt. Der Künstler erläutert, er wolle „Pfundskerle wie Schweinehunde, gemischt und gewürfelt, wie nun mal das Leben spiele, mit künstlerischen Mitteln produzieren“ (IV 408), womit er wieder einer späteren selbstreflexiven Aussage des bildenden Künstlers Günter Grass sehr nahekommt. ${ }^{430}$ Genauso wie Amsel spricht auch Grass seinen Bildern keine weltverbessernde Wirkung zu. Gleichwohl zeigen die Reaktionen, die Amsels Scheuchen auslösen, dass dessen Figuren die nationalsozialistische Ideologie unterwandern.

Der manipulierte Matern fühlt sich durch die neuen Scheuchenkreationen provoziert (eine der frühen SA-Scheuchen ist auch ein Porträt seiner selbst) und organisiert einen Schläger-Trupp, mit dessen Hilfe er in den Garten des Künstlers eindringt. Die echten SA-Männer werden wie mechanische Figuren beschrieben, sodass die Ähnlichkeit zwischen Amsels Vogelscheuchen und ihren Vorbildern auch aus den Beschreibungen der letztgenannten hervorgeht. Die Gruppe prügelt Amsel scheinbar zu Tode und rollt ihn im Schnee zu einem Schneemann. Aus ihm geht Amsel wundersamerweise als athletischer Jüngling hervor. Er verlässt die Stadt, um als Ballettmeister für die Berliner Propagandakompanie tätig zu werden. Die Handlung des Vogelscheuchen-Balletts

\footnotetext{
${ }^{429}$ Eine erste Assoziation der Vogelscheuchen dieser Entwicklungsphase mit der von den Nazis verfemten Kunst der Avantgarde findet sich bei: Mason (1974), S. 53.

${ }^{430}$ Vgl. Grass' kurzen Text „Bilder können die Welt nicht verändern“ (1972). Insbesondere die Passage: „Die Frage nach der gesellschaftlichen Relevanz meiner Zeichnungen ist mir uninteressant. Bilder können die Welt nicht verbessern, allenfalls die Widersprüche ihrer Wirklichkeit darstellen." (XI 864)
} 
erscheint im Roman bereits an dieser Stelle in einer Variation: Auch wenn Amsels ästhetische Produkte mitnichten realitätsfern sind, lebt und arbeitet der Künstler selbst zurückgezogen und ist in die um ihn herum stattfindenden politischen und sozialen Vorgänge nicht involviert. Da er sich mit der Realität nur ästhetisch, nicht ethisch auseinandersetzt, trifft ihn Materns Reaktion auf dieser Ebene völlig unerwartet. Ebenso, wie der Gärtner der Ballettoper sich am Schluss des Stücks in eine Vogelscheuche verwandelt, passt Amsel sich an das faschistische Regime an, indem er seine Kunst in den Dienst der Kriegspropaganda stellt.

Die vierte Entwicklungsetappe der Vogelscheuchen, kann von dem Erzähler Harry Liebenau nur durch Briefe seiner Freundin Jenny wiedergegeben werden. Jene als Kind vor allem mit Eddi Amsel befreundete Ballerina wird von dem nun als Ballettmeister unter dem Namen Haseloff agierenden Künstler für sein Berliner Tanzensemble angeworben. Durch Jennys Beschreibung findet Grass' Handlungsballett Eingang in den Roman (IV 581-588). Geprobt wird unter wechselnden Titeln: „Die Vogelscheuchen“, „Der Aufstand der Vogelscheuchen“, „Die Gärtnerstochter und die Vogelscheuchen“ (IV 582). Der Ballettmeister, der in seinem Keller an mechanischen Figuren arbeitet, versucht seinen Tänzern perfekte, nahezu automatische Bewegungen beizubringen, was im Zusammenhang mit dem Genre des Balletts an Schlemmers Triadisches Ballett zurückdenken lässt. Die Handlung des Stücks ist mit derjenigen der beiden Libretti von Günter Grass identisch.

Ebenso wenig wie die dramatischen Entwürfe des Schriftstellers sagt Jennys Brief Näheres über die visuelle Gestaltung der einzelnen Scheuchenfiguren aus. Sie beschreibt jedoch die im Stück entworfene Unterwelt detaillierter als eine Zusammensetzung aus gesellschaftlichen Typen der Danziger Kulturgeschichte. Während die grotesken Bewegungen und mechanischen Apparaturen aus Grass' vorangehenden Arbeiten in den Roman Eingang finden, gelangen abstrahierende Kostüme wie diejenigen Schlemmers nicht ins beschriebene Bild. In Bezug auf die in das Bühnenbild integrierten Automaten wird ein anderes reales Werk der bildenden Kunst zitiert: Paul Klees Zwitscher-Maschine aus dem Jahr 1922 - eine Ölpause, die einen Automaten zeigt, der aus vier an einer Kurbel befestigten Vögeln besteht. Ihre geöffneten Münder, die teils unbestimmte grafische Formen freigeben, suggerieren zusammen mit dem oben rechts im Bild notierten Titel, dass das Drehen der Kurbel sie zum Singen bringt (Abb. 116). Es entstand in Anlehnung an einen Vogelautomaten des Deutschen Museums in München. ${ }^{431}$ Erneut wird Amsels alias Goldmäulchens Kunst also mit einem realen Werk der Klassischen Moderne hinterlegt.

\footnotetext{
${ }^{431}$ Vgl. Henkel (1997), S. 123 und Glozer (1997). Bei der Maschine handelt es sich um ein Spielwerk mit Vogelstimmen, erbaut von Blaise Bontemps, Paris, um 1875. Es befindet sich seit 1911 im Bestand des Deutschen Museums in München. Lange war es für die gelungene Imitation der Tiere berühmt.
} 


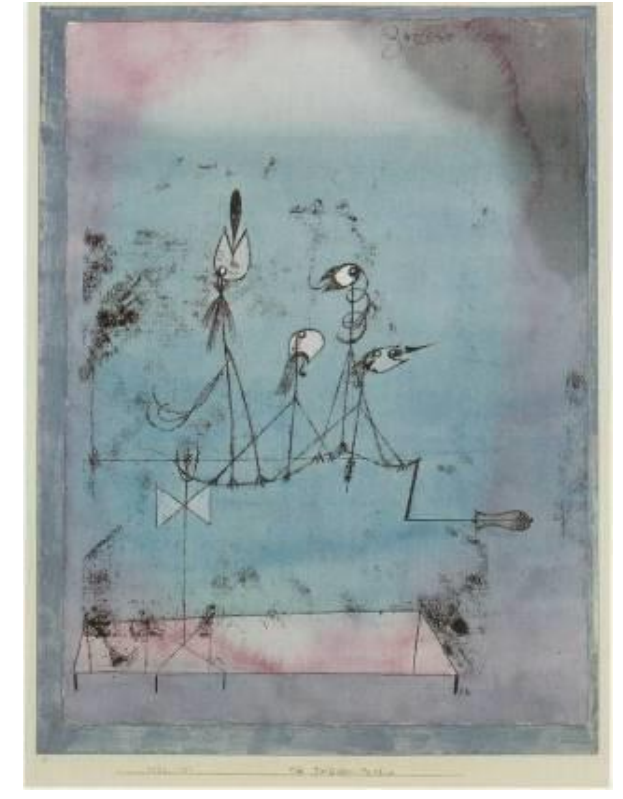

Abb. 116, Paul Klee, Zwitscher-Maschine, 1922, Ölpause, Aquarell und Stift/Tinte auf Papier, aufgezogen auf Karton, The Museum of Modern Art, New York, Erwerb 564.1939, (C) 2019. Digital image, The Museum of Modern Art, New York/Scala, Florence

Das Ballett wird den Lesenden über einzelne Typenbezeichnungen und Kulissen-Beschreibungen hinaus durch den Erzählduktus sehr anschaulich vor Augen gestellt. Jenny, die ähnlich wie Amsel, die Gabe besitzt, „Dinge zu ersehen, trocken und abklopfbar" (IV 527), berichtet gleichsam simultan von dem Stück und fügt die Bezeichnungen der Tanzschritte in ihre Beschreibung ein:

Natürlich verliebt sich die junge hübsche Gärtnerstochter - also ich - in die junge sprungkräftige Vogelscheuche: Pas de deux zwischen den Rhabarberstauden des alten bösen Gärtners - süßes Adagio, gemessenes Führen: Attitude en promenade. Gespielte Scheu, Zurückweichen, Ergebung und Entführung der Gärtnerstochter über den Zaun, abermals mit Grand jeté. Wir beide - der kleine Fenchel macht übrigens den jungen Mann - gehen nach rechts ab. (IV 582 f.)

Das Ballett wird damit nicht nur erwähnt, sondern im Modus seiner Wahrnehmbarkeit simuliert. Indem auch Jennys Leben und Karriere im zweiten Teil der Hundejahre detailliert von Harry Liebenau beschrieben und kommentiert wird, zudem Exkurse ihres Ziehvaters Brunies über die Ballettkunst an sich Auskunft geben, wird das klassische Ballett als künstlerische Disziplin im Roman ebenfalls thematisiert.

Der Bericht der Ballerina wird in das in mehreren Anläufen im Märchenduktus eingeleitete Finale der „Liebesbriefe“ integriert, das nahezu im Zentrum des Romans angesiedelt ist. Es markiert im Handlungsablauf zugleich das Ende des Zweiten Weltkrieges. Zur Aufführung kommt Amsels Stück nicht mehr. Nachdem es ohnehin auf Anweisung des Reichspropagandaministeriums gründlich umgeschrieben werden sollte (es sei zu „sinister und anzüglich“ geraten (IV 586)), zerstört eine Bombe das Kostümdepot und beendet die Karriere der Primaballerina, die bei der Explosion ihre Zehen verliert.

Das Werk im Werk reflektiert einzelne Facetten des Schaffens von Eddi Amsel. Konsequent wird angemerkt, dass der Choreograf schon seit seiner Kindheit an dem Stück „herumbastelte“ (IV 582) und mit dem Gedanken spiele, die Rolle des Gärtners selbst zu übernehmen (IV 585). Grundlegend für die Beziehung des Balletts zu Amsels Schaffen als Vogelscheuchenbauer ist natürlich 
die Figur der Vogelscheuche selbst, als seine bevorzugte Kunstform, die hier nicht nur als mechanisches Abbild einzelner Menschen fungiert, sondern zu einem weiten kulturhistorischen Panorama zusammengestellt wird. Einzelne Figurentypen, die Amsel in seiner Jugend als Scheuchen realisiert hat, ziehen dabei wie in einer Revue an den Lesenden vorbei und verlängern das im tatsächlichen Libretto angelegte Gesellschaftsbild in vergangene Jahrhunderte hinein. Wie weiter oben bereits erwähnt, steht das Ballett in engem Zusammenhang mit dem Überfall auf Eddi Amsel: Der Einbruch der Vogelscheuchen in den Garten im Ballett stellt eine Parallele zum Einbruch der SA-Männer in Amsels Kunstwelt dar. Dass der Künstler das Ereignis in seinem Ballett behandelt, bringt zum Ausdruck, dass er sich nun auf einem erhöhten Reflexionsniveau befindet.

Ebenso wie in Grass' realem Ballettlibretto kommt neben der ethischen Komponente der Handlung die ästhetische zum Tragen. Der Antagonismus einer realitätsfernen und einer weltzugewandten Ästhetik wird im fiktiven Ballett der Hundejahre vor allem dadurch näher definiert, dass die Tänzerin Jenny, die die Gärtnerstochter spielt, im Roman als klassische Ballerina par excellence vorgestellt wird. Da ihre Charakterisierung mit der Beschreibung der disziplinierten Tänzerin in Grass' Essay genau übereinstimmt, ${ }^{432}$ interpretieren Klaus Stallbaum und Benedikt Engels das Stück vor der Folie des Aufsatzes. ${ }^{433}$

Die fünfte Scheuchen-Phase ist mit einem erneuten Wechsel der Identität des Künstlers und mit seiner Rückkehr zur mechanischen Vogelscheuchenfigur verbunden. Aus seiner Arbeit am Vogelscheuchenballett überträgt er die Komposition einzelner Figuren zu einem Vogelscheuchenreich in sein neues Projekt. Als Fabrikant, der nun unter den Namen Goldmäulchen und Brauchsel auftritt, lässt er Scheuchen industriell unter Tage fertigen und im In- und Ausland verkaufen. Während die einzelnen in Danzig gebauten Vogelscheuchen bestimmte Menschen ",bedeuteten“, stellt das Bergwerk ein kleinteiliges und zugleich umfassendes Porträt der Nachkriegsgesellschaft, ihrer ideologischen und historischen Prägung dar. Wie Schlemmer die Figuren des Triadischen Balletts gestaltet auch der fiktive Künstler seine Werke nach analytischem Prinzip. Amsels Scheuchen repräsentieren menschliche Grundemotionen, religiöse und politische Doktrinen, prägende historische Ereignisse und Philosophien, die er im Verhalten der Nachkriegsdeutschen erkannt hat. Die Produktionsstätte verteilt sich auf zweiunddreißig Firstenkammern eines ehemaligen Kalibergwerks, das nicht nur der Herstellung der Figuren, sondern auch ihrer Präsentation dient. Walter Matern, der seine Vergangenheit und die in den Jahren der Vorkriegs- und Kriegszeit aufgeladene Schuld vehement verdrängt, wird als erster Besucher durch die Katakomben geführt. Sie repräsentieren nicht nur entscheidende Merkmale seiner Persönlichkeit, sondern erinnern inn zugleich auch an seine Vergangenheit - nicht umsonst ist Amsels Fabrik in die Tiefe gebaut. Grass bediente sich mit dieser Konstruktion eines bekannten Sinnbilds für die Erinnerung. ${ }^{434}$ Mit der in Talsohlen und Firstenkammern gegliederten Anlage des Bergwerks kann ferner nicht nur Dantes Hölle assoziiert werden, sondern ebenso ein bekannter unterirdischer Friedhof, die Franziskaner-

\footnotetext{
${ }^{432} \mathrm{Vgl}$. Neuhaus (2010a),

${ }^{433} \mathrm{Vgl}$. Engels (2005), S. 136-138, vorsichtiger Stallbaum (1989), S. 140. Beide Forscher stellen eine Verbindung zwischen den Vogelscheuchen (als Repräsentanten der Menschen) und dem Ausdruckstanz (als einem Medium menschlicher Emotionen) her. Wie weiter oben erörtert, bilden die Scheuchen die Wirklichkeit jedoch in artifizieller Form ab: durch Selektion, Montage und Mechanisierung.

${ }^{434}$ Vgl. Paaß (2009), S. 163-176.
} 
gruft im sizilianischen Palermo, in der die Toten zwischen dem 16. und 18. Jahrhundert balsamiert und festlich gekleidet, nach Beruf und Rang bestattet wurden. Grass hatte die Gruft noch vor Fertigstellung des Manuskripts 1963 besucht und Zeichnungen von den dort untergebrachten Mumien angefertigt. ${ }^{435}$

Dem didaktischen Impetus des Projekts zum Trotz bleibt auch Brauchsels Gesamtkunstwerk moralisch mehrdeutig: Einerseits erfüllen das Bergwerk im Allgemeinen und die exportierten Scheuchen im Besonderen weiterhin den Zweck, ihren Betrachterinnen und Betrachtern einen Spiegel vorzuhalten, sie zu läutern oder sie zumindest dazu zu bringen, sich zu erinnern. Brauchsels genereller Wunsch, einen Beitrag zur Aufklärung des Menschen leisten zu wollen, ist nicht zu bezweifeln. ${ }^{436}$ Gleichzeitig sind die scheuchenden Kunstwerke ebenso wie ihr Hersteller ökonomisch in die Gesellschaft eingebunden, die sie kritisieren.

Im Laufe der Jahre gelingt es dem Künstler, die Wirksamkeit seiner Vogelscheuchen immer weiter zu erhöhen, indem er die verschiedenen menschlichen Eigenschaften, die sie vermitteln, differenzierter herausarbeitet und den Figuren durch mechanische Bewegung bzw. durch ihre Einbettung in ein Ballett ein Eigenleben verleiht. Zudem steigert er ihre Effizienz, indem er den Rahmen, in dem sie betrachtet werden können, optimiert: Zunächst stehen die Vogelscheuchen, ihrer konventionellen Funktion gemäß, auf dem Feld. Als Figuren seines Balletts sollen sie auf einer Bühne auftreten, sodass das Publikum auf sie fokussiert ist. Abschließend wird jeder Gast des Vogelscheuchen-Bergwerks genötigt, die Arbeiten des Künstlers in einer bestimmten Reihenfolge zu begutachten und das an eine Architektur gebundene Gesamtkonzept intellektuell und physisch wahrzunehmen.

In den Hundejahren entwickelte Grass das Motiv der Vogelscheuche nicht nur episch weiter, sondern brachte frühere Manifestationen des Motivs mit Verweis auf ihre jeweilige literarische Gattung oder ihr Medium in den Roman ein: Vogelscheuchen werden als dreidimensionale Kunstwerke Eddi Amsels beschrieben, zu welchen Grass' Federzeichnungen eine wichtige Vorlage bildeten. Andere Ekphrasen werden durch direkte und indirekte Vergleiche mit bekannten realen Werken der Kunstgeschichte angereichert. Grass' Ballettstück findet in Form einer Aufführungsbeschreibung, samt Erwähnung einzelner Tanzschritte, Eingang in den Roman. Bildende Kunst, darstellende Kunst und Tanz, werden darüber hinaus durch Reflexionen des fiktiven Künstlers, Einblicke in Ateliers und Ballettsäle thematisiert. Ferner werden Amsels Blick auf seine Inspirationsquellen und die kenntnisreiche Perspektive der Balletttänzerin auf eine Ballettprobe sprachlich konstruiert.

Ebenso wie das Gedicht und das Ballett die Vogelscheuchen als Sinnbild einer neuen Ästhetik einführen, welche darauf abzielt, Natur durch eine höchst künstliche Form wiederzugeben, sind auch Grass' epische Vogelscheuchen Teil einer poetologischen Allegorie. Durch den Wechsel zwischen der Wiedergabe einer Handlung und der Beschreibung einer Vogelscheuche oder eines

435 Vgl. dazu den Dokumentarfilm von Sigrun Matthiesen: ,Spätschicht' - Günter Grass bei der Arbeit an Radierungen zu Hundejahre, 2013: Matthiesen (2013).

${ }^{436}$ Vgl. Cepl-Kaufmann (1975), S. 65: Der Forscherin zufolge durchzieht den Roman das „Erklärungsmodell Vogelscheuche“, das abschließend auf einen Urtyp, auf „das deutsche Volk“ hin stilisiert wird. Vgl. Neuhaus (2010 a) S. 24, Mundt (1989), S. 114 und Schilling (2002), S. 108. 
Tanzes, die das zuvor Beschriebene auf andere Art vermitteln, wird dieser Bedeutungshorizont akzentuiert. Mit der kontinuierlichen Erwähnung anderer Mediensysteme im Prosatext wird ein Muster aus Grass' erstem Roman erneut aufgenommen: Amsels Scheuchen und sein Ballett spiegeln ebenso Teile der Handlung wie schon die Knotenfiguren des Krankenpflegers Bruno in der Blechtrommel die von Oskar Matzerath erinnerten und ertrommelten Situationen auf ihre Art zum Ausdruck bringen. ${ }^{437}$ In den Hundejahren gewinnt diese Art der Reflexion nur mehr an Komplexität, denn innerhalb der Erzählfiktion ist der Herausgeber der „Festschrift“ zugleich der Verfasser ihres ersten Teils und seine Tätigkeit als bildender Künstler und Ballettmeister ihr Gegenstand.

Da die Vogelscheuchen-Kunst und das Ballett im Roman intensiv aus verschiedenen Perspektiven beleuchtet werden, ist auch die Ausbeute der allegorischen Lesart eine besonders reichhaltige: Beschrieben wird eine Kunst, die den Menschen, in all seiner Widersprüchlichkeit und der Absurdität seiner Existenz thematisiert. Die Darstellung erfolgt nicht „natürlich“, sondern über Kunstfiguren, die aus originalen Objekten montiert sind, sich mechanisch bewegen und Personen auf diese Weise durch typische Bewegungen charakterisieren. Sie zielen auf eine Läuterung der Betrachtenden ab, die sich, in einem Ähnlichkeitsverhältnis zu den Scheuchen stehend, in ihnen erkennen sollen. Gleiches gilt für die fiktive „Festschrift“ wie für den Roman Hundejahre, der den Lesenden einen Einblick in den kleinbürgerlichen deutschen Kosmos bietet und aus Versatzstücken der Danziger Kulturgeschichte komponiert ist. Die verschiedenen selbstreflexiven Darstellungen, die Grass im Vorfeld der Hundejahre in diversen Medien, bezogen auf Dichtung, Tanz und bildende Kunst, fertigte, werden in seinem Erzählwerk zusammengeführt und veranschaulichen, wie schon der „Ballerina“-Essay, dass für den Verfasser für alle Disziplinen ein im Grundsatz identisches Programm gilt.

Amsels Scheuchen sind Repräsentationen der Menschen in seiner Umgebung, später, auch auf dem Gebiet des Tanzes, des Deutschen an sich. Dasselbe leistet Grass' Roman durch die Thematisierung seiner Arbeiten, verstärkt durch Zitate aus der bildenden Kunst und Wahrnehmungssimulationen. Die explizite Erwähnung und das Erwecken der Illusion anderer Medien führen nicht nur zu einer Verdichtung der Handlung an einzelnen Stellen, sondern steigern auch ihre Anschaulichkeit, da verschiedene visuell gestaltende Kunstformen imaginiert werden. Die Verdichtung der Handlung zu einem literarischen Bild, entspricht Camus' Vorstellung von einem absurden Kunstwerk, das nicht versucht, die Welt zu erklären, sondern im Gegenteil darum bemüht ist, ihre Widersprüche anschaulich aufzuzeigen:

\footnotetext{
Die großen Romanciers sind philosophische Romanciers, das heißt das Gegenteil von ThesenSchriftstellern. So Balzac, Sade, Melville, Stendhal, Dostojevskij, Proust, Malraux, Kafka, um nur einige von ihnen anzuführen. Aber gerade die Entscheidung, eher in Bildern als in Beweisführungen zu schreiben, offenbart ein gewisses Denken, das ihnen gemeinsam ist, das von der Nutzlosigkeit eines jeden Erklärungsprinzips und von der lehrreichen Botschaft des sinnlich wahrnehmbaren Erscheinens überzeugt ist. ${ }^{438}$
}

Die illustrierte Jubiläumsausgabe der Hundejahre erweitert die durch intermediale Bezüge charakterisierte Prosa zu einer Medienkomposition, also einer Zusammenstellung von tatsächlich in ver-

\footnotetext{
${ }^{437}$ Vgl. Krason (2009).

${ }^{438}$ Vgl. Camus (2012), S. 120 f.
} 
schiedenen Medien realisierten Arbeiten. Amsels Vogelscheuchen werden nun nicht mehr nur beschrieben, sondern grafisch neben dem Text dargestellt.

Angesichts der nahezu widerspruchsfreien Erweiterung und Integration des lyrischen Vogelscheuchen-Motivs ins Ballett und des Balletts in den Roman, fällt der Bruch zwischen Grass' frühen Vogelscheuchen-Zeichnungen und den Beschreibungen des Vogelscheuchen-Balletts aus den Hundejahren besonders ins Auge. Zwar werden im Roman Zeichnungen von Vogelscheuchen erwähnt, aber nichts spricht dafür, dass Amsel sich bei ihrer Gestaltung einer abstrahierenden Formensprache bedient. Auch hinsichtlich des Balletts des erwachsenen Choreografen ist nicht von stereometrischen, an das Triadische Ballett Schlemmers erinnernden Kostümen die Rede, gleichwohl die Tänzerinnen und Tänzer sich nach dem Vorbild mechanischer Figuren zu bewegen lernen.

Amsels Vogelscheuchen abstrahieren zwar von ihrem Gegenstand, der Künstler vollzieht diese Abwandlung ins Zeitlos-Allgemeingültige jedoch durch eine analytische Selektion des Gesehenen und durch die mechanische Wiederholung bestimmter Bewegungen. Die visuelle Überprüfbarkeit der extrahierten Details und Gesten eines Modells gewährleistet den erwünschten Erkenntnisgewinn. Grass' an die Kostüme Schlemmers erinnernde gezeichnete Entwürfe treten im Rahmen der Arbeit an den Vogelscheuchen als ein schnell verworfener Lösungsansatz in Erscheinung, der jedoch mittelbar, über die analytische Auseinandersetzung mit den Formen des menschlichen Körpers, zu einer anderen Darstellungsform ,des Deutschen` führt.

Wenn auch die konkreten Bezüge auf das Triadische Ballett in Grass' bildkünstlerischem Werk eine Besonderheit darstellen, sind abstrakte, der Bildsprache des Kubismus verwandte Formen für viele seiner Bildwerke der Fünfzigerjahre charakteristisch. Es ist auffällig, dass sich dieser den Traditionen der Klassischen Moderne verpflichtete Stil nach Abschluss der Hundejahre verliert. Bereits die 1965 entstehenden Tuschezeichnungen zu Ingeborg Bachmanns Ein Ort für Zufälle, die im folgenden Kapitel behandelt werden, geben einzelne Gegenstände und Figuren einer Komposition wieder, ohne eine Grundform aus ihnen abzuleiten, oder die Gestalt in verschiedene Perspektiven aufzubrechen. Zunehmend mimetisch und detailliert werden einzelne Objekte von Grass im Folgenden dargestellt, während er ihre überraschende Zusammenstellung beibehält.

Obwohl weder die in den Hundejahren beschriebene Technik der Montage noch die mechanische Belebung von dreidimensionalen Objekten in Grass' reale Bildwerke eingingen, scheint die Betonung der Materialität und die von Amsel praktizierte Darstellung des speziellen aber repräsentativen Details für den realen Grafiker und Bildhauer überzeugender geworden zu sein, als das Abstrahieren von einem Gegenstand. Nicht nur Grass' Bilder sprechen dafür, dass die Veröffentlichung der Hundejahre 1963 mit einem Wandel der eigenen Ästhetik zusammenfällt. Auch seine eigenen Aussagen lassen darauf schließen, dass viele Elemente seiner Auffassung als bildender Künstler in die Gestaltung der Amsel'schen Kunsttheorie eingeflossen sind bzw. gleichzeitig mit ihr entwickelt wurden. Einige der bereits angeführten, auf die fiktive Kunst Amsels bezogenen Grundsätze werden von Grass in seinem kurzen Text „Bilder können die Welt nicht verbessern“, veröffentlicht im Zeit-Magazin vom 17. November 1973, nahezu wörtlich für das eigene Schaffen übernommen. 
Vergleicht man eine der Vogelscheuchen-Darstellungen aus dem Jahr 1957 (Abb. 117) mit einer Radierung zur Jubiläumsausgabe der Hundejahre (Abb. 118), wird deutlich, dass sich Grass' bildende Kunst gleichermaßen wie sein Text auf die mimetische Wiedergabe des einzelnen Gegenstands konzentriert. Alle Elemente der Scheuchenkörper, die in der Zeichnung aus den Fünfzigern geometrisch umrissen wurden, werden nun als tatsächlich identifizierbare Objekte präsentiert, wie sie auch der Roman benennt. Aller Mimesis zum Trotz bleiben das Dargestellte selbst, die lebendigen Vogelscheuchen, eine surreale Erweiterung der Wirklichkeit. Die Zusammensetzung der Scheuchen aus Fundsachen erhält die zuvor im Vordergrund stehende Kombinatorik als Detail des Scheuchenkörpers. In den Arbeiten der folgenden Jahre sollte diese „Konfrontation des Gegenständlichen“ wieder zu einem Hauptinstrument seiner Arbeitsweise werden.

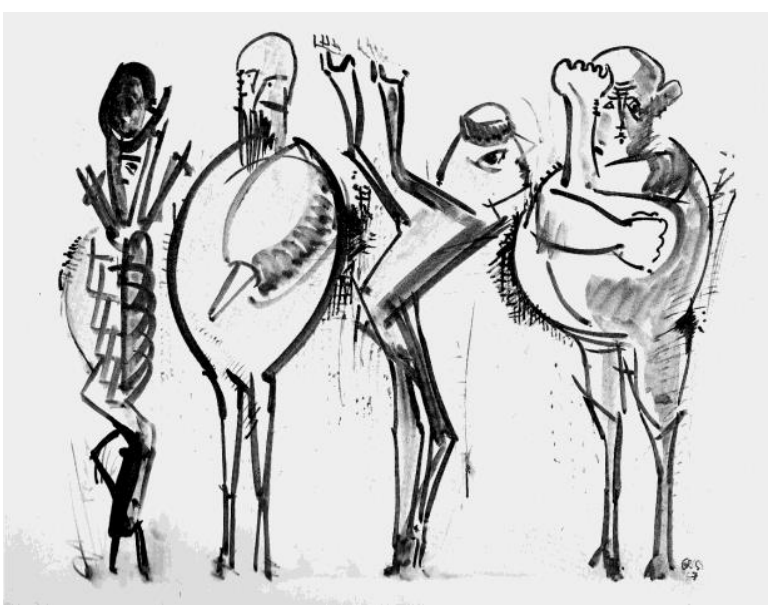

Abb. 117, Skizze zum Ballett Die Vogelscheuchen, 1957, Pinsel/Tusche, laviert

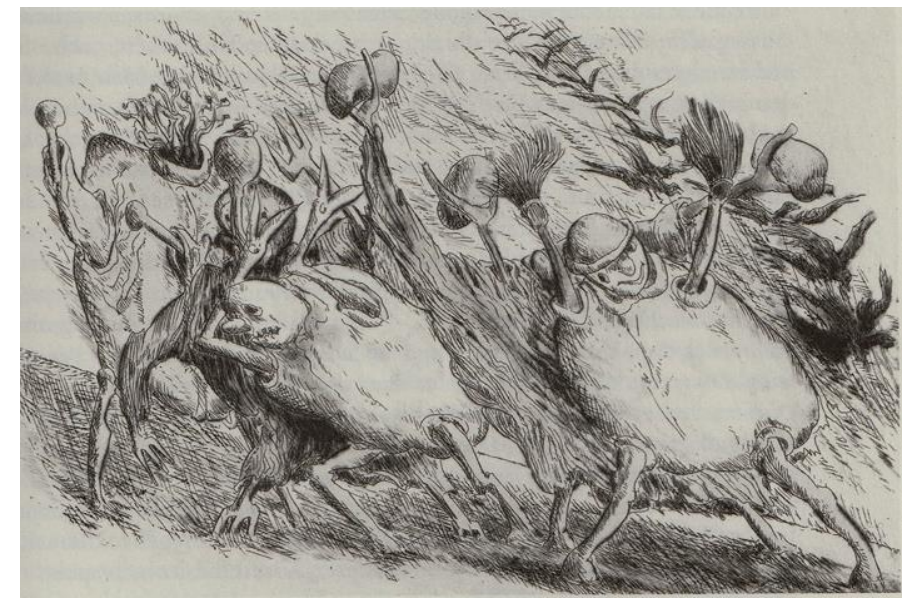

Abb. 118, Hundejahre, Göttingen 2013, dreibändige illustrierte Jubiläumsausgabe, Bd. 1, S. 49 


\section{PAUSE MIT UNTERBRECHUNGEN (1963-1969)}

In den Hundejahren wurde der Einbruch politischer Wirklichkeit in das Leben eines Künstlers literarisch ausführlich behandelt. Nach Abschluss der ,Danziger Trilogie' stand bis zum Wahlsieg der SPD bei den Bundestagswahlen von 1969 das politische Engagement in Grass' Leben im Vordergrund. ${ }^{439}$ Unmittelbar dahinter blieb das Schreiben mit Theaterspielen präsent, die von dem zeitgenössischen politischen Geschehen und dem Spannungsverhältnis zwischen Kunst und Politik geprägt wurden: POUM - oder die Vergangenheit fliegt mit (1965), Die Plebejer proben den Aufstand (UA 1966) und Davor (UA 1969). Zudem publizierte Grass den Gedichtband Ausgefragt (1967) und den Roman örtlich betäubt (1969). Die bildende Kunst rückte dagegen in den Hintergrund. Für das Zeichnen wurde es, so erinnert der Schriftsteller in seinem Werkstattbericht, „nicht mehr still genug". ${ }^{440}$ Veröffentlicht wurden lediglich einige Bleistiftzeichnungen zur Lyrik, Buchumschläge zu den oben genannten Publikationen, zu der amerikanischen Ausgabe von Reinhard Lettaus Sammlung absurder Kurzgeschichten Obstacles $(1965)^{441}$ sowie dreizehn Federzeichnungen zu Ingeborg Bachmanns Ein Ort für Zufälle (1965).

Warum also überhaupt eine Auseinandersetzung mit den Jahren 1963 bis 1969 im bildkünstlerischen Schaffen von Günter Grass? Zum einen, weil die ersten Zeichnungen des Grafikers zu einem fremden Text und damit zu einer von innen losgelösten Poetologie ihre Beschaffenheit noch klarer zeigen, als die Bilder, die in Verbindung mit seiner eigenen Literatur entstanden sind. Zum anderen bestätigt Grass' zeitweiliger Rückzug aus der grafischen und plastischen Bilderwelt, der mit einer Enthaltsamkeit von fantastischen Einfällen, bilderzeugenden Stilfiguren und Bezügen zur bildenden Kunst in seinen Texten einherging, ${ }^{442}$ den engen Zusammenhang von Kunst und Literatur in seiner Werkstatt. Darüber hinaus bilden das politische Engagement und die mit ihm in Verbindung stehende Auseinandersetzung mit Vernunft und Aufklärung eine wichtige Grundlage für die im nächsten Kapitel beleuchteten Motivkomplexe. Ein aufklärerischer Anspruch ist bereits in Grass' Literatur der Sechzigerjahre erkennbar und wird gegen Ende des Jahrzehnts durch eine starke Betonung der empirischen Erfahrung ergänzt, die im Tagebuch einer Schnecke in einer erneuten Hervorhebung des Sehens und in der Integration der bildenden Kunst in sein Werk zum Ausdruck kommt.

\footnotetext{
${ }^{439}$ Bereits im Zuge seiner Wahlkampfreise im Frühjahr und Sommer 1969 begann Grass mit der Arbeit am Tagebuch einer Schnecke und setzte sie nach dem Wahlsieg intensiv fort, während er sich politisch lediglich an einzelnen Projekten beteiligte. Der bewusste Rückzug aus dem politischen Geschehen erfolgte 1972 und wurde von Grass in einer Rede auf einer Tagung der Sozialdemokratischen Wählerinitiative in Bonn am 16./17. Dezember 1972 verkündet. Vgl. Köbel (2013), S. 979-984. Zu Grass' Bemühungen, seit 1969 aktiv an der Regierungsarbeit mitzuwirken, vgl. ebd., S. 1109-1119.

440 Grass (2014), S. 131.

${ }^{441}$ Die deutsche Erstausgabe wurde 1962 unter dem Titel Schwierigkeiten beim Häuserbauen, 21 Geschichten über absurde - oder besser gesagt normale Situationen, die ins Absurde kippen veröffentlicht.

${ }^{442}$ Wie Cepl-Kaufmann in ihrer weiterhin grundlegenden Studie zu Wechselbeziehungen von Literatur und Politik in Grass' Gesamtwerk aus dem Jahr 1975 herausarbeitete, gehen „die zunehmende Aufnahme aktuell politischer Themen und die Zunahme politischer Tätigkeit“ in Grass' zwischen 1965 und 1972 veröffentlichten Werken „einher mit der Reduktion des Fiktionsgrades und dem Ansteigen des Abstraktionsgrades“. Vgl. Cepl-Kaufmann (1975), S. 140.
} 


\section{Ingeborg Bachmann: Ein Ort für Zufälle (1965)}

Bachmanns Erweiterung ihrer 1964 gehaltenen Büchner-Preis-Rede „Deutsche Zufälle“ reflektiert drei Jahre nach dem Bau der Mauer das „beschädigte Berlin“ wie ein Zerrspiegel. Das nationalsozialistische Erbe gelangt darin immer wieder an die Oberfläche des städtischen Lebens. ${ }^{443}$ Bei ihrem zwischen Essay und „Prosagroteske" changierenden Text ${ }^{444}$ handelt es sich jedoch weniger um eine Analyse der herrschenden gesellschaftlichen und politischen Zustände, als um eine Darstellung der zerstörerischen Auswirkungen einer grundlegenderen „Disharmonie“ des Ortes Berlin auf seine Bewohnerinnen und Bewohner, die zugleich Patienten einer Heilanstalt sind. Das buchstäblich Verrückte der Perspektive der so Betroffenen vermittelt der abwechselnd erlebende und beobachtende Erzähler, ${ }^{445}$ indem er bekannte Berliner Schauplätze und tagespolitische Ereignisse verfremdet. ${ }^{446}$ Die Schriftstellerin nahm mit diesem Text auf die Thematik des Wahnsinns in Georg Büchners Lenz Bezug und schuf zugleich eine Ankündigung ihres "Todesarten“-Projekts, das verschiedene Formen der Gewalt am Individuum, „sublime Verbrechen der modernen Gesellschaft", umkreisen sollte. ${ }^{447}$ Bachmanns ursprünglicher Einstieg in die Rede wurde auf der Rückseite des Buches abgedruckt und charakterisiert es als:

Topografie und Diagnose eines Krankheitsbildes. Zufälle, die sich nicht nur aus jetzigen Eigenarten der Einzelnen ergeben, sondern schon viel früher kollektiv von ihnen ausgegangen sein können und nun förmlich von außen den Rückweg antreten nach innen, als, alte' Zufälle, als Verformung, als Wahn, in der Perspektive des Lenz - so wie ihn Georg Büchner beschrieb -, der auf dem Kopf ging. ${ }^{448}$

Die Publikation des Textes als Quartheft durch Klaus Wagenbach sollte dessen im Vorjahr gegründeten Berliner Verlag unterstützen. Die Rede wurde von der Autorin um vier berlinspezifische Passagen ergänzt, so dass sie abschließend aus sechsundzwanzig Abschnitten bestand. ${ }^{449}$ Für eine separate Veröffentlichung war die Schrift dennoch recht kurz, weshalb Bachmann, der Verleger und Grass beschlossen, der Publikation Zeichnungen des Schriftstellers beizufügen. ${ }^{450}$ Alle Beteiligten erarbeiteten gemeinsam die gestalterische Komposition des Bandes. In der Veröffentlichung betonen im Umfang variierende Leerzeilen, Leerseiten und Grass' Zeichnungen die Gliederung der Prosa in eigenständige Teile. ${ }^{451}$ Miteinander verbunden sind die Schilderungen durch die Wiederholung einzelner Themen, Motive und Figuren sowie gerade durch die den Text kontinuierlich durchziehende Diskontinuität. ${ }^{452}$

Grass' dreizehn Federzeichnungen illustrieren die alogisch aufgebauten Handlungsstränge nicht, sondern präsentieren sich, lediglich auf einzelne Motive und Strukturen des Textes bezug-

\footnotetext{
${ }^{443}$ Vgl. Bannasch (2002), S. 178.

${ }^{444} \mathrm{Zu}$ der in der Rezeption immer wieder problematisierten Gattungsfrage vgl. Däufel (2013), S. 9-32. Den wegweisenden Terminus der „Prosagroteske“ führte für Ein Ort für Zufälle ein: Bartsch (1982), S. 81 f., S. 84. ${ }^{445}$ Vgl. Bannasch (2002), S. 178.

${ }^{446}$ Zur Aufschlüsselung von realen Ereignissen aus dem politischen Berlin vgl. Schlinsog (2005), S. 124-133.

${ }^{447}$ Vgl. Bannasch (2002), S. 176 und Schlinsog (2005).

448 Bachmann (1965), Buchumschlag, Rückseite.

${ }^{449}$ Vgl. Däufel (2013), S. 63.

${ }^{450}$ Vgl. Wagenbachs Nachwort zur Ausgabe von 1999: Bachmann (1999).

${ }^{451}$ Vgl. Däufel (2013), S. 105.

452 Vgl. ebd., S. 112-117.
} 
nehmend, als selbständiger visueller Kommentar. ${ }^{453}$ Bei den gezeichneten Motiven handelt es sich teilweise um solche, die der Grafiker bereits im Umkreis der ,Danziger Trilogie' und insbesondere zu den Vorzügen der Windhühner (1956) und Gleisdreieck (1960) zur Darstellung gebracht hatte. Sie weisen auf die in den ersten Gedichtbänden schreibend und zeichnend behandelten Themen der existentiellen Bedrohung sowie den in Berlin besonders spürbaren Ost-West-Konflikt zurück. ${ }^{454}$ Durch motivische Rückgriffe auf das eigene Werk und beibehaltene Konzeptionsschemata betonte Grass die Eigenständigkeit seiner Arbeiten gegenüber Bachmanns Text und setzte diesem eigene, gleichsam grafisch dargebotene Metaphern entgegen.

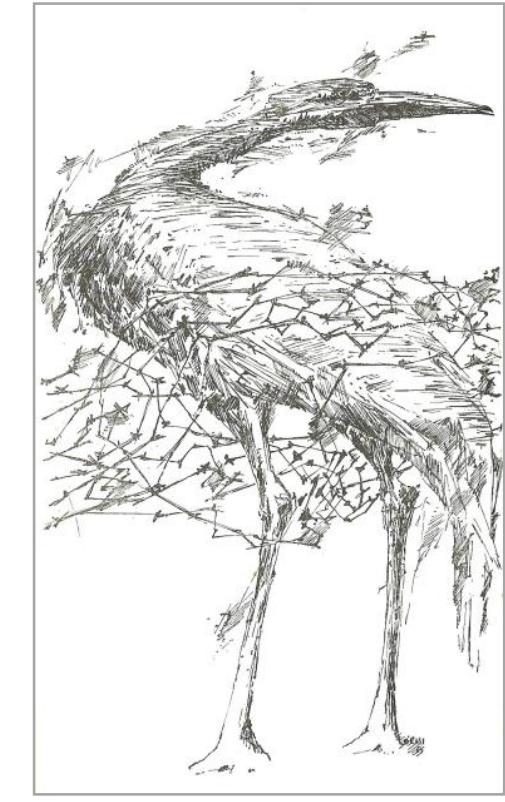

Abb. 119, Ingeborg Bachmann, Ein Ort für Zufälle, mit 13 Zeichnungen von Günter Grass, Berlin 1965, S. 6

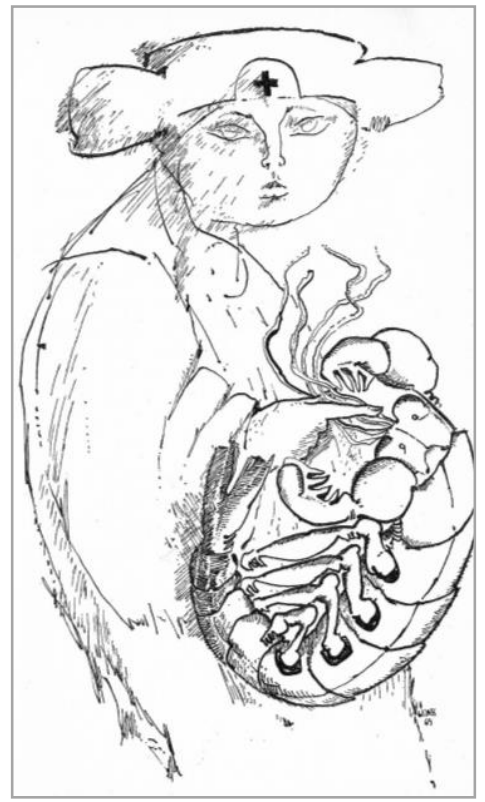

Abb. 120, Ingeborg Bachmann, Ein Ort für Zufälle, mit 13 Zeichnungen von Günter Grass, Berlin 1965, S. 31

Exemplarisch seien zwei Darstellungen angeführt, die Motive realisieren, die in dieser Arbeit weiter oben bereits behandelt wurden. Die erste zeigt einen in Stacheldraht verfangenen Stelzvogel, der gleich zu Beginn des Textes die von außen und innen eingeschränkte Freiheit eines Subjekts repräsentiert (Abb. 119). Das Vogelmotiv figuriert in den Vorzügen als Sinnbild der zweckfreien Kunst und Künstler und ist auch unabhängig von dieser Referenz als Symbol der unabhängigen Entfaltung verständlich. In der Federzeichnung von 1965 hält der mit diversen Grenzziehungen im öffentlichen Raum assoziierbare Stacheldraht die Beine und die Flügel des Tieres unter Androhung von Schmerzen in Schach. Die Haltung des Vogels vermittelt zudem eine Bewegungsunfähigkeit, die aus seinem Streben in entgegengesetzte Richtungen resultiert: Während Körper und Fußgelenke der Figur zur linken Bildseite hingewendet sind, ist der Hals des Tieres scharf nach rechts gebogen.

\footnotetext{
${ }^{453}$ Vgl. ebd., S. 131.

${ }^{454}$ Vgl. ebd., S. 131-139.
} 
Das zweite Beispiel zeigt eine Krankenschwester, die einen Hummer unter ihrer Brust hält (Abb. 120). Das Motiv erinnert an die oben behandelte Erzählung "Meine grüne Wiese“, in der sich die weibliche Hauptfigur, ein junges Mädchen in einem weißen Kleid, von den Scheren eines Krebstiers tödlich verletzen lässt. Die Zeichnung gemahnt entsprechend an die zu diesem Text entstandenen „Pepita“-Zeichnungen sowie an Passagen aus der Blechtrommel, in welchen Krankenschwestern eine ambivalente - zwischen einschläfernder Geborgenheit und sexueller Anziehungskraft schwankende - Wirkung auf Oskar ausüben wie auch an eine ähnlich konnotierte Federzeichnung von 1957, die eine Krankenschwester mit einem Aal zeigt. ${ }^{455}$ Die auffällige Rundung des Frauenkörpers, die die über Rücken und Nacken und bis in den Haaransatz hinein geführte Linie generiert, findet in der ovalen Wölbung des Tierkörpers ein Echo, so dass die gesundheitsfördernde Angestellte und das mit scharfen Scheren ausgestattete Krustentier eine neue, in sich widersprüchliche Einheit bilden.

Im Kontrast zu Grass' eigenen literarischen Motiven und Metaphern beruhen die Sprachbilder Bachmanns nicht auf eng zusammengeführten Gegensätzen. In Ein Ort für Zufälle kommt das Motiv des Vogels nicht vor. Krankenschwestern spielen zwar eine wichtige Rolle, da doch Berlin in diesem Text als Heilanstalt präsentiert wird, und ihre berufliche Funktion im Widerspruch zu ihrem als grausam geschilderten Verhalten steht ${ }^{456}$ - dieser Gegensatz wird jedoch nicht, wie so oft in Grass' Motivwelt, anhand ihrer Erscheinung demonstriert. ${ }^{457}$

Der grundlegende Zusammenhang zwischen Text und Bild ergibt sich deshalb aus den übergeordneten Themen, im Fall der angeführten Beispiele: der erzwungenen Eingrenzung sowie dem Spannungsverhältnis von Verletzung und Heilung. Die Vereinbarkeit der Grass'schen Kompositionen mit Bachmanns Prosa belegt die universelle Aussagekraft der Zeichnungen. In Kombination mit Ein Ort für Zufälle erhalten sie einen auf Berlin bezogenen Akzent.

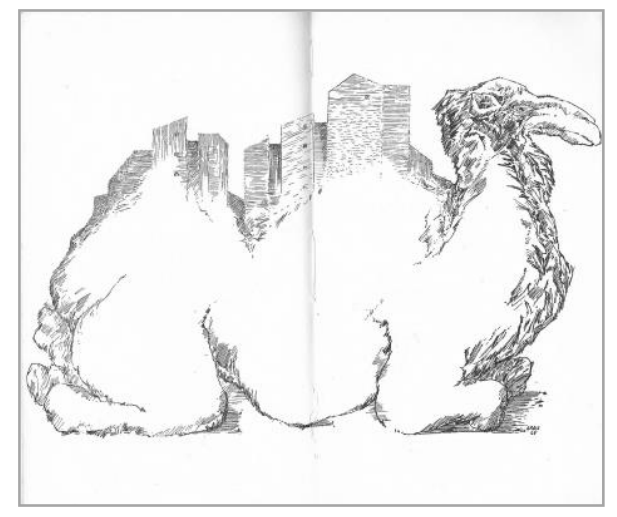

Abb. 121, Ingeborg Bachmann, Ein Ort für Zufälle, mit 13 Zeichnungen von Günter Grass, Berlin 1965, S. 60 f.

\footnotetext{
455 Vgl. die Federzeichnung Krankenschwester mit Aal, 1957 in Grass (2014), S. 83; vgl. dazu den entscheidenden Hinweis bei Däufel (2013), S. $137 \mathrm{f}$.

${ }^{456} \mathrm{Vgl}$. Bachmann (1965), S. 30, auf der der Zeichnung gegenüberliegenden Seite: „Die Patienten, denen Spaziergang verordnet ist, wollen trotzdem hinunter ans Wasser, aber die Schwester befiehlt allen, stehenzubleiben, steigt allein über den Baum, sieht nach, hebt die Äste, schaut, ob Blut an den Ästen ist, ob der Baum jemanden getötet hat."

${ }^{457}$ Ein gutes Beispiel sind die in der Blechtrommel aus Oskars Perspektive beschriebenen Krankenschwestern: Ihre weiße Arbeitskleidung wird mit den Rotkreuzbroschen kontrastiert, die sie an ihren Häubchen tragen. Der Erzähler entwickelt aus diesem visuellen Gegensatz die Assoziation von Heilung und Schlaf auf der einen Seite und erotischer Leidenschaft auf der anderen. (III 199 -201)
} 
Umgekehrt wirken Grass' Bilder auf die Rezeption des Textes ein. Unterstützt allein die Lokalisierung der Prosahandlung in Berlin den politischen Charakter seiner Arbeiten, so heben zahlreiche seiner Zeichnungen, die den Widerspruch der Teilung von etwas im Grunde Unteilbarem betonen, den politischen Kontext stärker hervor, in dem die Prosa angesiedelt ist. ${ }^{458}$ Auch im Fall jener Bildgruppe ist der Bezug der Grafiken zum Text nicht illustrativ: Eine prominent in der Mitte des Bandes auf einer Doppelseite platzierte Zeichnung zeigt zum Beispiel ein ruhendes Kamel mit zwei Höckern, die im oberen Bereich in Berliner Stadtkulissen übergehen (Abb. 121). Das Bild folgt auf den dreiundzwanzigsten Abschnitt, auf die einzige Passage, die eine Erlösung von Berlin verspricht, denn auf den Rücken von Zirkuskamelen gelangen die Patientinnen und Patienten aus der Stadt:

Die Kranken haben nur auf die Kamele gewartet, gehen auf die Kamele zu, stellen sich unter ihren Schutz. Die Felle riechen inbrünstig nach Wüste, Freiheit und Draußen, jeder geht mit seinem Kamel und kommt ungehindert weiter, querfeldein geht's, durch den Forst, man schwimmt mit dem Kamel durch die Gewässer. Das Kamel scheut kein Wasser, es hört keinen Pfiff, keinen Rettungswagen, keine Sirene, keine Nachtglocke, keinen Schuß. Noch einen Forst, dann wieder ein Forst. Im Sand wird das Kamel immer schneller. Ein letzter Forst. Man ist draußen. ${ }^{459}$

Es folgen eine leere Doppelseite, die die im Text vermittelte Befreiung unterstreicht, und Grass' Zeichnung auf der nächsten Doppelseite. Seine Darstellung greift das Tiermotiv zwar auf, gestaltet es jedoch nicht als Sinnbild der Freiheit, sondern vorrangig als solches des geteilten Berlins: Das Kamel bewegt sich nicht, es hat es sich vielmehr bequem gemacht und die Stadt mit den für sie typischen freigestellten Brandmauern auf zwei Höcker verteilt in sich aufgenommen. Diese Umdeutung kann nicht allein als Repräsentation der Teilung verstanden werden, sondern darüber hinaus auch als Verdichtung des von Bachmann aufgebauten Kontrastes von Wüste (Utopie) und Berlin (Dystopie) sowie als Aufhebung jedes Erlösungsgedankens. Zur Prosa steht die Grafik damit nur kurzzeitig im Widerspruch: In Ein Ort für Zufälle ist die Flucht nach „draußen“ lediglich ein Ausflug in die märkische Wüste. Bereits mit dem nächsten Abschnitt befinden sich die Leserinnen und Leser wieder in Berlin: „Der Holzstoß ist errichtet am Kurfürstendamm, Ecke Joachimstalerstraße. ${ }^{4460}$

\footnotetext{
${ }^{458}$ Bachmann (1965), S. 49, S. 53, S. 60 f., S. 67.

${ }^{459}$ Ebd., S. 57 f.

${ }^{460}$ Ebd., S. 63.
} 


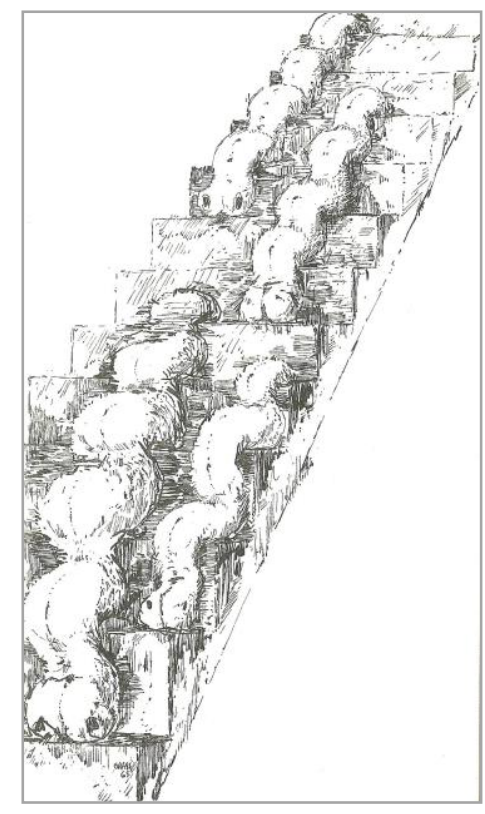

Abb. 122, Ingeborg Bachmann, Ein Ort für Zufälle mit 13 Zeichnungen von Günter Grass, Berlin 1965, S. 17

Ein weiteres grafisches Sinnbild veranschaulicht die im Text präsente Kritik am rasanten westdeutschen Konsumfortschritt. Es ist besonders bemerkenswert, weil es eine Komposition präsentiert, mit der sich Grass noch Jahre später eingehend beschäftigen sollte. Das Bild zeigt über eine Rolltreppe gleitende Raupen (Abb. 122) und bereitet auf diese Weise die ab 1968 zum Tagebuch einer Schnecke geschaffenen Zeichnungen und Sprachbilder vor, die den "Stillstand im Fortschritt" emblematisch ins Bild setzen. Das Schleichen der Raupen konterkariert die schnellere Bewegung der Rolltreppe.

In Bachmanns Prosa verschwimmen die Grenzen zwischen Krankenhaus und KaDeWe, in das nun alle Kranken respektive Konsumentinnen und Konsumenten drängen: Nachdem die große Euphorie verklungen ist, hören die Leute

wenigstens auf zu johlen und sind nur noch lustig, die Dekoration wird abgerissen und von den obersten Stockwerken geworfen, die Rolltreppen sind verklemmt, die Lifts sind schon ganz vollgestopft mit Schals und Kleidern und Mänteln, die alle mitsollen, aber die dicken Kassiererinnen stecken mitten drin, sind am Ersticken und rufen: das muß alles bezahlt werden, das werdet ihr noch bezahlen! $!^{461}$

Im beigefügten Bild wurde folglich eine eigenständige Ausdrucksform der Fortschritts- und Konsumkritik entworfen, die lediglich im Motiv der Rolltreppe einen Berührungspunkt mit dem Text aufweist.

Verglichen mit den Zeichnungen zu den Vorzügen der Windhühner und Gleisdreieck enthalten Grass' Bilder von 1965 seltener expressiv oder kubistisch anmutende Formbildungen. Sie konzentrieren sich mehrheitlich auf eine mimetische Wiedergabe der einzelnen Gegenstände, nehmen jedoch die Fantastik der Prosa durch spannungsreiche Kombinationen und ihre grotesken Übertreibungen in Form von irrealen Maßstabsverhältnissen der dargestellten Objekte auf. ${ }^{462}$

${ }^{461}$ Ebd., S. 16.

462 Vgl. Bannasch (2002), S. 178. 
Bachmanns Text ähnelt hinsichtlich dieser Wirklichkeitsverfremdung Grass' Lyrik und Kurzprosa der Fünfzigerjahre. Da seine eigenen Gedichte aus den Jahren 1966 und 1967 wie auch die zu innen entstandenen Zeichnungen einen wesentlich realistischeren Charakter haben, erscheint seine grafische Auseinandersetzung mit Ein Ort für Zufälle als Reminiszenz an eine vertraute, aber für das eigene literarische Werk zeitweise verabschiedete Ausdrucksweise.

Grass' Interesse für Ein Ort für Zufälle hing nicht nur mit der Wertschätzung diesem Text gegenüber und der Freundschaft zu Bachmann zusammen, die die Jahre 1963 bis 1965 in Berlin verbrachte. ${ }^{463}$ Der politische Kern ihrer Prosa - deutsche Teilung, mangelnde Vergangenheitsbewältigung und Konsumüberwältigung in Berlin - beschäftigte ihn ebenso wie sie. In das ereignisreiche Jahr 1961 fiel der Beginn seiner politischen Aktivität, die ihren Anlass zunächst im Ost-WestKonflikt und der Errichtung der Mauer hatte.

\section{Grass' politisches Engagement in den Jahren 1961 bis 1965}

Im Rahmen des fünften Schriftstellerkongresses der DDR in Ostberlin, im Mai 1961, hatte Grass die Einschränkung des Zugangs zu internationaler Literatur in der DDR kritisiert. ${ }^{464}$ Kurz nach Beginn des Mauerbaus, am 14. August 1961, verfasste er einen offenen Brief an Anna Seghers in ihrer Funktion als Präsidentin des Deutschen Schriftstellerverbandes in der DDR, worin er sie dazu aufforderte, gegen die sich weiter konkretisierende Teilung des Landes zu protestieren. Ein Schreiben an die Institution des Deutschen Schriftstellerverbandes setzte er gemeinsam mit Wolfdietrich Schnurre auf und überreichte es gemeinsam mit ihm persönlich in Ostberlin an den ersten Sekretär der Vereinigung, Erwin Strittmatter. ${ }^{465}$

Grass' Eintritt ins Wahlkampfgeschehen ist ebenfalls auf das Jahr 1961 datiert. Seinem Engagement ging die Sympathie für Willy Brandt voraus. Der Kanzlerkandidat der SPD wurde von Adenauer in dessen Regensburger Wahlrede vom 14. August 1961 hinsichtlich seiner Integrität und Glaubwürdigkeit angegriffen. Indem der amtierende Bundeskanzler von „Brandt alias Frahm“ sprach, wies er abfällig auf die Emigration des SPD-Politikers während des Zweiten Weltkrieges hin, die mit dem selbstgewählten Namenswechsel von Frahm zu Brandt einherging, sowie implizit auf dessen außereheliche Geburt. ${ }^{466}$ Grass stieß dieser Ausfall zutiefst ab und ließ inn noch vor dem ersten persönlichen Kontakt zu Brandt Partei für den Politiker ergreifen.

Im Mai 1961 hatte Brandt Hans Werner Richter darum gebeten, unter Schriftstellerinnen und Schriftstellern anzufragen, wer zu einem vertraulichen Gespräch bereit wäre, bei dem es um einen intensiveren Austausch zwischen den Geistesschaffenden und der Politik, und insbesondere um eine Unterstützung der SPD durch die Intellektuellen im bevorstehenden Wahlkampf gehen sollte. Richter, der als politisch engagierter Gründer der Gruppe 47 für diese Mittlerrolle prädesti-

\footnotetext{
463 Grass (2014), S. 131: „Da wohnten wir schon in Berlin-Friedenau. Ab Beginn der sechziger Jahre und weit in dieses Jahrzehnt hinein war Berlin ein literarischer Ort. [...] Uwe Johnson wohnte um die Ecke, Enzensberger nicht weit entfernt. Fremd und verletzt kam, immer wie auf der Flucht, Ingeborg Bachmann auf kurzen Besuch vorbei. (Sie bewohnte salonartige Räume in jener inzwischen aufgemöbelten Villa im Grunewald, Königsallee, in deren Keller Anna und ich Anfang der fünfziger Jahre gehaust hatten.).“

${ }^{464}$ Vgl. Kölbel (2013), S. 1066.

${ }^{465}$ Vgl. Schlüter (2010), S. 23 und Essig (2000), S. 288.

${ }^{466}$ Vgl. Kölbel (2013), S. 1079.
} 
niert war, ${ }^{467}$ wendete sich zunächst nicht an Grass, weil er bei dem nach der Veröffentlichung der Blechtrommel als Bürgerschreck verschrienen Dichter mehr anarchistisches Potenzial als realpolitisches Interesse vermutete. ${ }^{468}$ Nachdem Grass von dem ohne ihn in Bonn geführten Gespräch erfuhr, beschwerte er sich bei Richter und wurde zur Fortsetzung des Dialogs im September eingeladen. Als sich Brandt am Ende dieser zweiten Runde erkundigte, wer sich im Wahlkampf für die SPD engagieren würde, etwa durch Korrekturen von Wahlreden, war Grass der einzige Freiwillige. Er machte im Folgenden Verbesserungsvorschläge für Brandts Texte und begleitete ihn auf einzelnen Wahlkampfreisen. ${ }^{469}$

Auch wenn Brandt im Oktober 1961 Adenauer unterlag, war Grass' politisches Interesse nachhaltig geweckt: Im Bundestagswahlkampf von 1965 verstärkte er seinen Einsatz. Gemeinsam mit Richter und Wagenbach initiierte er den „Wahlkontor", an dem eine Gruppe deutscher Schriftsteller derselben Generation, darunter Peter Härtling und Hubert Fichte, mitwirkte. Ihr Ziel war es, der SPD mit Verbesserungsvorschlägen und Ideen für Reden und Werbekampagnen unter die Arme zu greifen und eine stabilere Brücke zwischen „Macht und Geist“ (Weber) zu schaffen, ohne sich von der Partei vereinnahmen zu lassen. Grass beteiligte sich zudem erstmals durch Wahlreden, in welchen er ohne Absprache mit der SPD auch eigene Schwerpunkte setzte. ${ }^{470}$

Grundtenor seiner Ansprachen war ein Appell an die Bürgerinnen und Bürger, ihre gesellschaftliche Verantwortung als Wählende wahrzunehmen und sich bei ihrer Entscheidung ihres Verstandes zu bedienen. Grass legitimierte sein politisches Wirken als Intellektueller, indem er sich auf die literarische Tradition der deutschen Aufklärung berief, die mit ihren Werken eine nationale Literatur begründet habe, bevor überhaupt eine deutsche Nation existierte. Das Gedankengut der Aufklärung wies er zudem als Basis sozialdemokratischen Denkens aus: ${ }^{471}$

Denn Wahlen sind Appelle an die Vernunft jedes einzelnen. Kühl gilt es abzuwägen. Nicht strahlendes Weiß und düsteres Schwarz stehen zur Wahl, sondern mehrere Grautöne. [...]

[S]ollte unser Bundeskanzler immer noch meinen, es habe der Schriftsteller ausschließlich der holden Poesie zu dienen, er möge sich fernhalten der angeblichen Geheimwissenschaft Politik, dann bin ich bereit Ludwig Erhard einigen Nachhilfeunterricht in deutscher Geschichte zu erteilen.

Wer Ohren hat, höre: Bevor es überhaupt eine deutsche Nation gab, gab es, seit Klopstock und Lessing, eine deutsche Literatur. Als in diesem Lande zu Beginn des achtzehnten Jahrhunderts noch mittelalterliche scholastische Denkspiele jeden Fortschritt hemmen wollten, hat der Hallenser Philosoph Christian Wolff der Aufklärung die erste Gasse gebahnt. Als die Herrschenden in diesem Land ihren separatistischen Klein- und Großkriegen nachgingen, schrieb der schwäbische Pietist Friedrich Karl Moser im Jahre 1765 seine aufklärende und bahnbrechende Schrift „Vom deutschen Nationalgeist". Der Schwabe Schubart, die Brüder Stolberg und der Balladendichter Bürger stehen neben Klopstock, Lessing und Herder am Anfang unserer immer noch jungen literarischen Tradition. Denn Deutschland ist, hundert Jahre vor Bismarck, durch deutsche Schriftsteller und Philosophen, die den Geist der Aufklärung durch dieses Land wehen ließen, kraft der Sprache gereinigt worden. [...] Alleine schon deshalb votieren meine Sympathie und mein Vertrauen für die Sozialdemokraten. Die SPD mit ihrer reformistischen Tradition fußt auf Vernunft und Aufklärung. [...]

\footnotetext{
${ }^{467}$ Vgl. ebd., S. 1063 f.: 1956 hatte Richter mit Schriftstellern der Gruppe 47 bei München, in der Sportschule Grünwald, einen politischen Debattierkreis gegründet, den „Grünwalder Kreis“. Dieser hatte nur kurze Zeit Bestand.

${ }^{468}$ Vgl. ebd., S. 1065.

${ }^{469} \mathrm{Vgl}$. ebd., S. 1067.

${ }^{470}$ Vgl. Münkel (2011), S. 197.

${ }^{471}$ Vgl. Braun (2005), S. 40-46.
} 
Wann endlich wird auch in unserem Land das Zeitalter der Aufklärung beginnen? Wann wird die Ignoranz endlich den Ministersessel räumen und der Vernunft Platz machen? (XI 124-136)

Grass' Auseinandersetzung mit den Begriffen der deutschen Aufklärung ging über diese Appelle und Traditionsbekundungen hinaus zunächst nicht weiter in die Tiefe. ${ }^{472}$ Vernunftgeleitetes politisches Handeln wurde in seinen Reden als ein Handeln ohne Einfluss von Emotionen sowie als Heilmittel gegen ideologische Parolen und Tendenzen charakterisiert und entsprach damit seiner bereits in den Fünfzigerjahren ausgebildeten erkenntniskritischen Ästhetik. ${ }^{473}$ Der Rückblick auf die jüngste deutsche Vergangenheit, auf die Vereinnahmung durch den Nationalsozialismus, war inm dafür, sowohl in den Fünfziger- als auch in den Sechzigerjahren, das entscheidende Argument: „Noch nie bestand Anlaß, angesichts von Politikern oder Parteien in Begeisterung zu geraten. Unsere Geschichte lehrt es uns schmerzhaft.“ (XI 123)

\section{Politik und bildende Kunst im Grass-Werk der Sechzigerjahre}

Grass' politische Aktivität von 1961 bis 1965 spiegelt sich inhaltlich und stilistisch in den daraufhin entstandenen literarischen Texten. Der Einakter POUM - oder die Vergangenheit fliegt mit (1965) inszeniert einen Flug von Berlin nach Stuttgart, den Brandt und seine engsten Mitarbeiter gemeinsam mit Günter Grass 1961 auch real anlässlich einer Wahlkampfveranstaltung unternahmen. Entworfen wird hier ein Porträt des SPD-Spitzenkandidaten Brandt, ${ }^{474}$ in dem dessen umsichtige Handlungsweise und intensive Auseinandersetzung mit der Diffamierung durch Die Kandidaten (1961) von Hans Frederik besonders hervorgehoben werden. Frederiks Schmähschrift behandelte mitunter Brandts Einsatz für die Partido de Unificatión Marxista (POUM) während des Spanischen Bürgerkrieges und sollte inn als Vaterlandsverräter und Kommunist brandmarken. Grass' Stück zeigt die Bewunderung „des Schriftstellers“ für Brandt als hartnäckigen „Schwerarbeiter" und die Bemühungen des Dichters, den Kanzlerkandidaten mit eigener Sprachfertigkeit zu unterstützen. Veröffentlicht wurde der Einakter in dem 1965 von Richter herausgegebenen Sammelband Plädoyer für eine neue Regierung oder Keine Alternative, womit die dem Werk zugrunde liegende Absicht offenkundig wird. ${ }^{475}$

Ist POUM damit Teil des Wahlkampfes, befasst sich das Trauerspiel Die Plebejer proben den Aufstand (UA 1966) am Beispiel des Arbeiteraufstandes vom 17. Juni 1953 in wesentlich komplexerer Form mit dem Verhältnis von Kunst und politischer Wirklichkeit. Bertolt Brechts CoriolanBearbeitung samt ihren Vorlagen von Livius, Plutarch und Shakespeare und das Aufbegehren der

\footnotetext{
472 Vgl. Cepl-Kaufmann (2002), S. 122-131.

${ }^{473} \mathrm{Vgl}$. Zimmermann (1999).

${ }^{474}$ Vgl. Stolz (1994) und ders. (2010), S. 122. Hier findet sich der Hinweis auf das zum Einakter abgedruckte Vorwort im Sammelband Plädoyer für eine neue Regierung oder Keine Alternative: „Weil der Anlaß vier Jahre zurückliegt, weil alles und nichts im Flugzeug passierte, weil schnelle Vorwärtsbewegung und fleißiges Rückblicken im Widerstreit lag - Stillstand in zweitausend Meter Höhe - obgleich wir nicht abstürzten, sondern am soundsovielten September 1961 auf dem Flugplatz Stuttgart glatt aufsetzten, auch weil ich nicht anders kann, wird das Porträt des Regierenden Bürgermeisters von Berlin, Willy Brandt, zum Einakter werden."

${ }^{475}$ Vgl. Stolz (1994), S.222-226 und ders. (2000) S. 46-48, $122 \mathrm{f.}$
} 
Arbeiter in Ostberlin werden in dem vieraktigen Theaterspiel parallel geführt, ${ }^{476}$ wenn Grass einen mit biografischen Fakten aus dem Leben Brechts ausgestatteten "Chef" eine Coriolan-Probe am 17. Juni 1953 in Berlin durchführen lässt. Grass' Stück zeigt einen Künstler zwischen den Stühlen, zwischen eigenen und fremden Erwartungen. Während der "Chef" in seiner Coriolan-Fassung die Plebejer und Tribunen aufwerten will, kann er sich in der Realität weder zur Unterstützung der Arbeiter noch der Staatsdiener durchringen, weil ihn keine Position vollends überzeugt. Seine ursprüngliche Absicht, das geprobte „Lehrstück“ auf die Bühne zu bringen und auf diese Art „das Publikum klüger" zu machen (II 364), scheitert an seiner Auseinandersetzung mit dem tatsächlichen Aufstand. Zumindest vorläufig: Die Einsicht in die gegebenen Verhältnisse lassen den "Chef" erkennen, dass „wir, zum Beispiel, den Shakespeare nicht ändern können, solange wir uns nicht ändern" (II 424). ${ }^{477}$

Aktuelle politische Realität dringt mit dem Gedichtband Ausgefragt auch erstmals merklich in Grass' Lyrik ein. Die mehrheitlich im Frühjahr und Sommer 1966 geschriebenen Texte sind in drei wie folgt betitelte Gruppen geordnet: „Ausgefragt“, "Mein großes Ja bildet Sätze mit kleinem Nein" und „Zorn Ärger Wut", wobei vor allem die letztgenannte Gruppe politische Themen aufnimmt und bestimmte Formen politischer Aktivität kritisch thematisiert. Stets in Bezug zur westlichen Wohlstandsgesellschaft stehend, beschäftigen sich die Texte mit aktuellen Krisen und Gefahren wie dem Kalten Krieg, der nuklearen Aufrüstung und dem Vietnamkrieg sowie mit der deutschen Kriegsschuld, mit Revanchismus und Heimatverlust. Polemisch angegriffen werden "ohnmächtige" Proteste und politische Lyrik genauso wie Ostermärsche, die sich bereits in ihrer singulären Aktivität erschöpften, während die Teilnehmenden vor langfristiger politischer Partizipation zurückscheuten. ${ }^{478}$ Aus der in den ersten beiden Teilen des Bandes unternommenen Standortbestimmung des lyrischen Ich ergibt sich das Bekenntnis zu einer ideologiefreien Grundhaltung, die dem Sprechenden das Wahrnehmen von Widersprüchen und "Grauwerten" abfordert und entsprechend Kompromisse notwendig macht. ${ }^{479}$

Wie der Titel Ausgefragt ankündigt, sind Grass' Gedichte teilweise in dialogischer Form gehalten. Sie enthalten nur wenige der bekannten Sinnbilder aus seinem um 1960 entwickelten Motivrepertoire in Gestalt von Gegenständen, Tierfiguren oder Gesellschaftstypen. Treten sie auf, sind sie wesentlich leichter zu dechiffrieren, als in vorhergehenden Veröffentlichungen. ${ }^{480}$ Bereits der Klappentext zum Band deutet die neue Tonart an:

Die Sprache von Günter Grass ist nüchterner geworden. Sie drängt aus der Metapher heraus; gemessen an Erfahrungen und Einsichten, die sich täglich ausfragen, ist jeder Vergleich eine Antwort zu viel, eine Frage zu wenig. ${ }^{481}$

\footnotetext{
${ }^{476}$ Vgl. Grass' Rede „Vor- und Nachgeschichte der Tragödie des Coriolanus von Livius und Plutarch über Shakespeare und Brecht zu mir", Rede zum 400. Geburtstag Shakespeares in der Akademie der Künste Berlin, April 1964 (XI 58-84).

477 Vgl. Stolz (1994), S. 226-239 und ders. (2010), S. 48-56 und S. 133-135.

${ }^{478} \mathrm{Vgl}$. Cepl-Kaufmann (1975), S. 153-160.

${ }^{479}$ Vgl. Frizen (2010), S. 64-74.

${ }^{480}$ Vgl. Stolz (1994), S. 98.

${ }^{481}$ Grass (1967), Klappentext.
} 
Mit der selbstverordneten Metaphern-Diät geht auch eine Reduktion an gezeichneten Bildern für die Buchgestaltung einher. Waren den einundvierzig Gedichten der Vorzüge der Windhühner zehn Zeichnungen beigefügt worden und kamen auf fünfundfünfzig Gedichte in Gleisdreieck siebzehn Bilder, sind es in Ausgefragt zu sechzig lyrischen Texten lediglich elf. Die sprachliche Ernüchterung geht ferner mit einer Kontrastarmut der Bleistiftzeichnungen einher, die an diejenige der NonnenBilder aus dem Jahr 1957 erinnert. Die Metapher der Farbe Grau und die feinen Schattierungen als Ausdruck von Skepsis werden in diesen Darstellungen wiederaufgenommen. Betrachtet man die ungelenke Linienführung und Volumenbildung der nun ausschließlich mimetisch abbildenden Einzelobjekte in den Zeichnungen, wird nachvollziehbar, weshalb Grass selbst nicht mit ihnen zufrieden war und sie rückblickend als "leblos" und „starr" bezeichnete. ${ }^{482}$ Umso deutlicher tritt hier die Kombination und Konfrontation von Bildelementen in ihrer Zeichenhaftigkeit hervor.

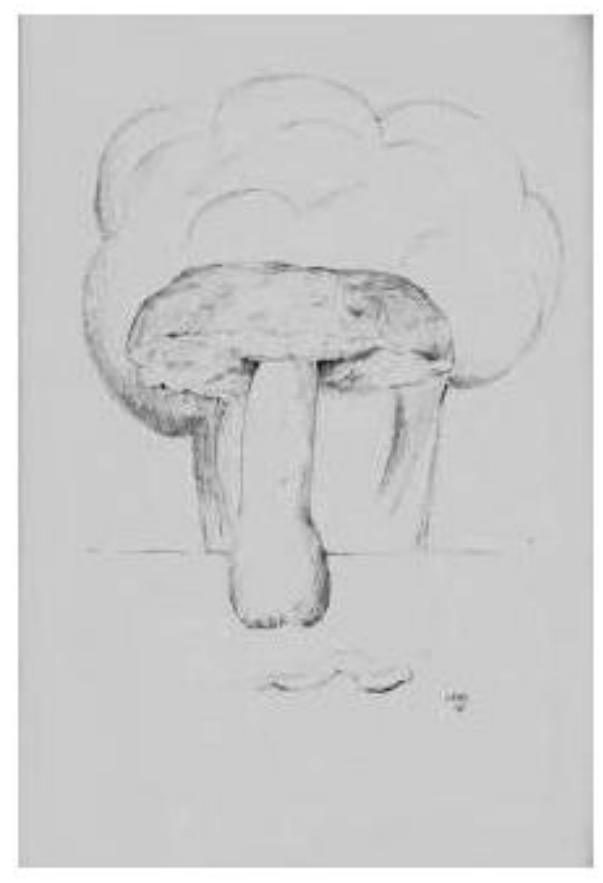

Abb. 123, Ausgefragt, Darmstadt 1967, S. 84

Die 1966 und 1967 entstandenen Arbeiten zeigen einzelne Objekte in einem engen Bildausschnitt. Meist sind allägliche Gegenstände dargestellt, selten surreale Zusammenstellungen. Die Bilder visualisieren einzelne Motive der Texte und betonen ihre Anlehnung an optisch erfahrbare Objekte. Das wohl plakativste Beispiel bildet die Zeichnung eines Pilzes vor dem Hintergrund einer ähnlich geformten Atomwolke; unter beiden krümmt sich eine Made im Erdreich (Abb. 123). Im dazugehörenden Gedicht "Gemüsetest" dienen Beschreibungen von Gemüsesorten der allegorischen Veranschaulichung gesellschaftlicher und politischer Zu- und Missstände; es handelt sich vor allem um eine Auseinandersetzung mit der durch den Kalten Krieg und die Kuba-Krise ins gesellschaftliche Bewusstsein gerückten atomaren Bedrohung und mit den Protesten gegen diese:

${ }^{482}$ Grass (2014), S. 131. 


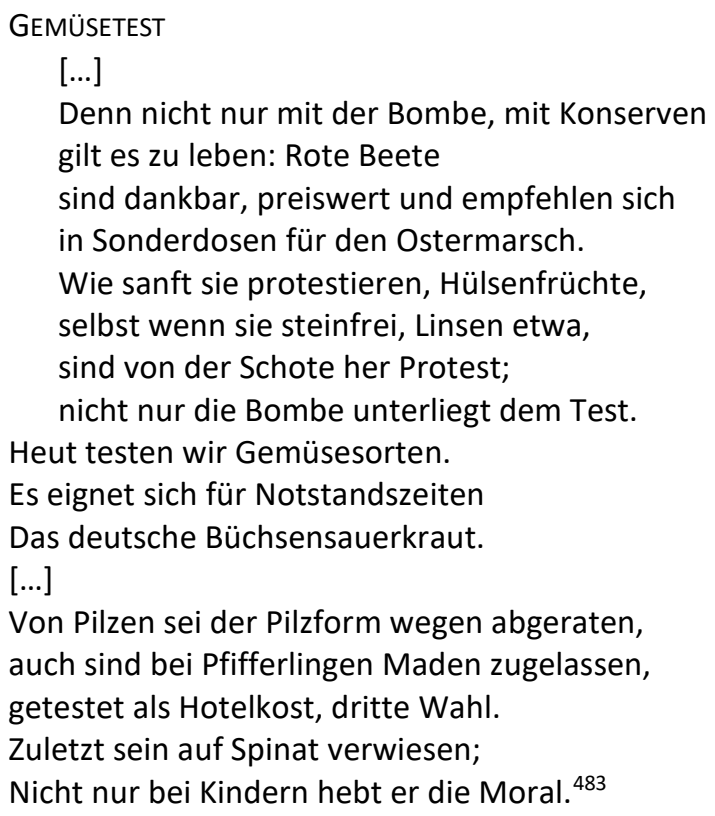

Die Zeichnung macht den sensus allegoricus überdeutlich. Sie veranschaulicht, dass nicht nur der kausale Zusammenhang von nuklearer Verseuchung und der Speicherung radioaktiver Strahlung im Pilz, sondern auch die Formanalogie, die in den Versen angesprochen, aber nicht weiter ausformuliert wird, für eine Verzahnung der Bedeutungsebenen sorgt.

Zwei der Themen, die Günter Grass nach den Bundestagswahlen von 1965 besonders beschäftigten, sollten auch in seinem Roman örtlich betäubt eine herausragende Rolle spielen: der Umgang mit der deutschen Kriegsschuld und der seit der Gründung der APO in sein Blickfeld geratene Widerstreit zwischen verbalem Abwägen und radikalem Handeln. Diese Themen manifestierten sich Mitte der Sechzigerjahre in konkreten politischen Ereignissen: Nach der Bildung der Großen Koalition 1966 unter Kurt Georg Kiesinger, dessen frühere Einbindung in den Machtapparat der NSDAP wiederholt für Empörung gesorgt hatte, stand die SPD als mitregierende Partei in Verruf, nicht nur die Politik der CDU, sondern auch ihren moralisch vorbelasteten Kanzler zu legitimieren. Grass selbst hatte deshalb öffentlich vor einer Großen Koalition gewarnt ${ }^{484}$ und in den eigenen Reihen auch Karl Schiller privat dazu aufgefordert, sich zu seinen Verstrickungen im „Dritten Reich" zu bekennen. Gerade seine öffentlichen Anklagen in jenen Jahren verstärkten später das Maß der Kritik an Grass selbst, als er in Beim Häuten der Zwiebel (2006) erstmals darüber schrieb, Mitglied der Waffen-SS gewesen zu sein. Die Anklagenden nahmen wenig Rücksicht darauf, dass Grass im Gegensatz zu Kiesinger und Schiller einer anderen Generation angehörte und wenige Monate vor Kriegsende im Alter von siebzehn Jahren ohne eigenes Zutun der Waffen-SS zugewiesen worden war. ${ }^{485}$

Ebenso kritisch, wie der Schriftsteller sich mit Kiesinger und der großen Koalition auseinandersetzte, beschäftigte er sich auch mit der Außerparlamentarischen Opposition, die

\footnotetext{
483 Grass (1967), $85 \mathrm{f}$.

${ }^{484} \mathrm{Vgl}$. dazu besonders die offenen Briefe an Willy Brandt vom 26.11.1966 und 28.11.1966 sowie an Kurt Georg Kiesinger am 30. November 1966.

$485 \mathrm{Vgl}$. Kölbel (2013), S. 1081 f., Dokumentation der Mediendebatte nach der Veröffentlichung von Beim Häuten der Zwiebel: Kölbel (2008).
} 
Mitte der Sechzigerjahre aus der Studentenbewegung hervorging. Ihre Parolen waren ihm zu selbstgefällig, zu planlos radikal und zu gewaltverherrlichend, ihre Themen zu wenig an der Realpolitik orientiert. ${ }^{486}$

Diese Kontroversen bestimmen den Roman örtlich betäubt (1969). Schon vorab, ab 1966, konzipierte Grass die Geschichte des Generalfeldmarschalls Krings, der sein militärisches Scheitern während des Zweiten Weltkrieges nicht verwinden kann, als Theaterstück. ${ }^{487}$ Noch Jahrzehnte nach Kriegsende spielt Krings im Sandkasten seine „verlorenen Schlachten“ nach und versucht sie nachträglich zu gewinnen. Seine Unternehmungen führen nicht zum Ziel, da seine Tochter Sieglinde mit ebenbürtiger Vehemenz gegen ihn antritt. In den Prosatext ging der Plot des Theaterspiels als Nebenhandlung ein. Sie wird in örtlich betäubt von einem Studienrat für Deutsch und Geschichte, Eberhard Starusch, während einer langwierigen Zahnbehandlung erinnert. Krings figuriert dabei als ehemaliger Schwiegervater des Patienten in spe, dessen manischer Kampf gegen Tochter "Linde“ ihre Beziehung zu Starusch zerstört hat.

Der mittlere Teil der Romanhandlung wurde von den Studentenunruhen von 1967/1968 inspiriert: Staruschs Lieblingsschüler Philipp Scherbaum möchte aus Protest gegen den Vietnam-Krieg seinen geliebten Dackel vor dem Café Kranzler auf dem Berliner Kudamm verbrennen und so das politische Bewusstsein der „kuchenfressenden Pelztiere“ (V 184) wecken. Der Studienrat versucht inn in zahlreichen Gesprächen von seinem Vorhaben abzubringen und schlägt inm vor, seine Überzeugungen stattdessen als Chefredakteur der Schülerzeitung durchzusetzen. Lange zurückliegende, antifaschistische Jugendaktionen Staruschs, der sich im Roman bald als Weiterentwicklung der Figur des siebzehnjährigen Bandenführers Störtebecker aus der Blechtrommel erweist, werden den beiden Möglichkeiten des Engagements von Scherbaum gegenübergestellt. Der Einfluss des Zahnarztes, eines vernunftgeleiteten, an langsamen Fortschritt glaubenden Stoikers, führt schließlich dazu, dass Scherbaum von der Dackelverbrennung absieht und die Redaktion der Schülerzeitung übernimmt.

Die unmittelbare Übertragung der zeitgenössischen gesellschaftlichen Diskurse in die Literatur brachte Grass in der deutschen Literaturkritik vehemente Ablehnung ein. Noch vor Abschluss des Romans hatte der Schriftsteller die Scherbaum-Handlung als Theaterspiel adaptiert und unter dem Titel Davor zur Aufführung gebracht. ${ }^{488}$ Dass die didaktisch-aufklärerische Intention und der dialektische Charakter des Werkes darin noch deutlicher hervortreten, als im Prosatext, beförderte die kritische Aufnahme des Buches. Als "Gesprächsangebot", das in seinen Dialogen die praktische Vernunft selbst zum Thema macht und in den Dienst der Aufklärung stellt, ${ }^{489}$ wurde es kaum ernstgenommen. Kritisiert wurde stattdessen der wie im Gedichtband Ausgefragt auch im Roman zum Vorschein kommende nüchternere Ton des Schriftstellers, der im Vergleich zum „barocken“ Stil und fantastischen Realismus der erfolgreichen ,Danziger Trilogie' weitgehend als Mangel empfunden wurde: Grass spreche über einen Stoff, statt ihn zu evozieren. ${ }^{490}$

\footnotetext{
${ }^{486}$ Vgl. Kölbel (2013), S. 1083-1094.

487 In Sechs Jahrzehnte befindet sich der Abdruck eines Arbeitsplans zu Verlorene Schlachten vom 3.1.1966: Grass (2014), S. 136 f.

${ }^{488}$ Vgl. Stolz (1994), S. 239-252 und ders. (2010), S. 57-65, 154 f. sowie Grass (2014).

${ }^{489} \mathrm{Vgl}$. Zimmermann (1999), S. 303.

${ }^{490}$ Vgl. Arnold (1997), S. 110-120; im Vergleich zur positiven Aufnahme in den USA: Durzak (1971).
} 
Dabei handelt es sich keineswegs um ein Werk, das ganz auf Anschaulichkeit und Fantastik verzichtet. Intermediale Bezüge sind auch in diesen Roman integriert, allerdings vor allem solche zum Film. In der Zahnarztpraxis soll ein Fernsehgerät den Patienten von seinem Schmerz ablenken - soweit die allegorische Medienkritik. Die „Mattscheibe“ dient aber zugleich als Projektionsfläche für die Fantasien und Erinnerungen des Erzählers, die entsprechend als Film, teilweise das Medium imitierend, geschildert werden (V 16 f, 24-26, 36 f., 42-44, 45-48, 49-51, 81-85, 122129). Indem der Erzähler Geschehnisse in bewegten Bildern wiedergibt, wird zudem der dramatische Charakter der Vor- und Nebenarbeiten zum Buch, die oben skizzierten „verlorenen Schlachten" des Generalfeldmarschalls Krings, in die Prosa integriert.

Bezüge zur bildenden Kunst enthält der Roman dagegen nur vereinzelt. Dem Erzähler wird zwar kein aktives Künstlertum, immerhin aber ein abgebrochenes Kunstgeschichtsstudium angedichtet (V 27), sodass er nicht nur kanonische Werke der barocken Genremalerei von Adriaen Brouwer zum Thema der Zahnbehandlung zitieren (V 72), sondern im dritten Teil des Buches auch glaubwürdig ein Gleichnis aus dem Leben des Danziger Malers Anton Möller erfinden kann, das an dessen Jüngstes Gericht (1603/zerstört 1945) angelehnt ist.

Möllers Darstellung der Personifikation der Sünde, die eine gewölbte, transparente und das Licht reflektierende Haube auf dem Kopf trägt, ist, so Starusch innerhalb der Erzählfiktion, Ausdruck eines Dreiecksverhältnisses zwischen dem Maler, seinem geliebten Modell und seiner Verlobten. Die Geliebte habe für die „Sünde“ Modell gestanden. Um es seiner aufgebrachten Verlobten recht zu machen, habe Möller nachträglich ein Porträt der Bürgertochter auf den Körper des Bauernmädchens gesetzt, es schließlich aber mit Hilfe der reflektierenden Kopfbedeckung vor hämischen Blicken schützen müssen. Staruschs Gleichnis ist damit als eine Allegorie des lebensweltlichen und ästhetischen Kompromisses zu verstehen (V 272-274). ${ }^{491}$

örtlich betäubt bereitet mit dieser an den Schluss gesetzten intermedialen Auseinandersetzung eine Vorgehensweise des Tagebuchs einer Schnecke (1972) und des Butt (1977) vor. Im erstgenannten Buch werden die Hauptthemen des Werkes abschließend in einer Rede zu Dürers Melencolia I gebündelt. In letzterem wird mittels einer erotischen Dreiecksbeziehung, an der ebenfalls der Maler Möller beteiligt ist, das Stilmittel der Allegorie anschaulich charakterisiert.

Andere Verweise auf bildende Kunst oder bildkünstlerische Schaffensvorgänge sind in örtlich betäubt nicht zu finden. Diese werden von Grass erst in den nächsten beiden Prosaprojekten eingebracht, zu welchen er Zeichnungen geschaffen hatte. Entsprechend sollte in dem darin vertieften Diskurs um Vernunft und Aufklärung die Rolle der empirischen Anschauung wieder hervorgehoben werden. Im Tagebuch einer Schnecke, einem Werk, das sich bewusst in die Tradition der Aufklärung, in die Tradition Georg Christoph Lichtenbergs und Michel de Montaignes stellt, 492 werden Einsichten explizit aus sinnlicher Erfahrung gewonnen. Deren Gegenstand ist wiederum der Wahlkampf von 1969.

\footnotetext{
${ }^{491}$ Vgl. Neuhaus (2010), S. 134.

492 Vgl. Zimmermann (1999), S. 304-312.
} 


\section{Günter Grass und der Wahlkampf von 1969}

Als eine verbesserte Ausführung des "Wahlkontors deutscher Schriftsteller" formulierte Grass gemeinsam mit dem Historiker Eberhard Jäckel und Siegfried Lenz im Zuge einer Wahlkampfreise durch Schleswig-Holstein für die Landtagswahlen von 1967 die Idee einer „Bürgerinitiative“, aus der 1969 die „Sozialdemokratische Wählerinitiative“ hervorgehen sollte. Bürgerinnen und Bürger konnten sich darin bundesweit in organisierten Regionalbüros im SPD-Wahlkampf engagieren. Neben den bereits im "Wahlkontor" durchgeführten Beteiligungsformen wurde das Magazin dafür umgesetzt, in dem die Aktivisten Artikel zu verschiedenen politischen Themen, Politikerporträts, aber auch Karikaturen und Comics unterbrachten. ${ }^{493}$

Organisiert wurde zudem eine Tour von insgesamt sechzig Wahlveranstaltungen, die Grass bundesweit zwischen dem 19. März und 26. September mit seinen Auftritten bestritt. ${ }^{494}$ Im Vergleich zum Wahlkampf von 1965 befand sich Grass nun in einer anderen Situation: Mit seinem Engagement waren die Medien bereits vertraut; er musste es nicht rechtfertigen und konnte sich stattdessen auf die bereits gesammelten politischen Erfahrungen berufen. Der Tenor seiner Reden war 1969 weitaus weniger emphatisch als noch 1965. Weiterhin beschwor er die Vernunft, jedoch nicht mehr im Sinne eines Aufrufs zur politischen Beteiligung. Angesichts der Studentenunruhen von 1967/1968 appellierte Grass besonders an eine Mäßigung in Bezug auf radikale Einstellungen und Handlungen. Wie in den literarischen Werken der Sechzigerjahre kann auch in seinen Reden von 1969 eine sprachliche Ernüchterung und eine Konzentration auf politische Inhalte festgestellt werden. Sie enthalten weder Anspielungen auf das eigene literarische Schaffen oder Rechtfertigungen der eigenen politischen Aktivität durch Hinweise auf seine Vorbilder in der Literaturgeschichte noch rhetorische Volten. ${ }^{495} \mathrm{Im}$ Tagebuch einer Schnecke dagegen verknüpft Grass die Erfahrungen aus seiner Wahlkampfreise mit einer Schilderung der Flucht der Danziger Juden aus der Freien Stadt während des Zweiten Weltkrieges auf gewohnt bildreiche Weise. Zum ersten Mal erhebt er eines seiner Tiermotive zu einem zentralen Element, das Handlungsstränge und grundlegende Begriffe in Wort und Bild miteinander verbindet.

\footnotetext{
493 Vgl. Münkel (2011) und Marchand (2011).

${ }^{494} \mathrm{Vgl}$. Schlüter (2011), S. 10.

${ }^{495}$ Vgl. Braun (2008), S. 46-50.
} 

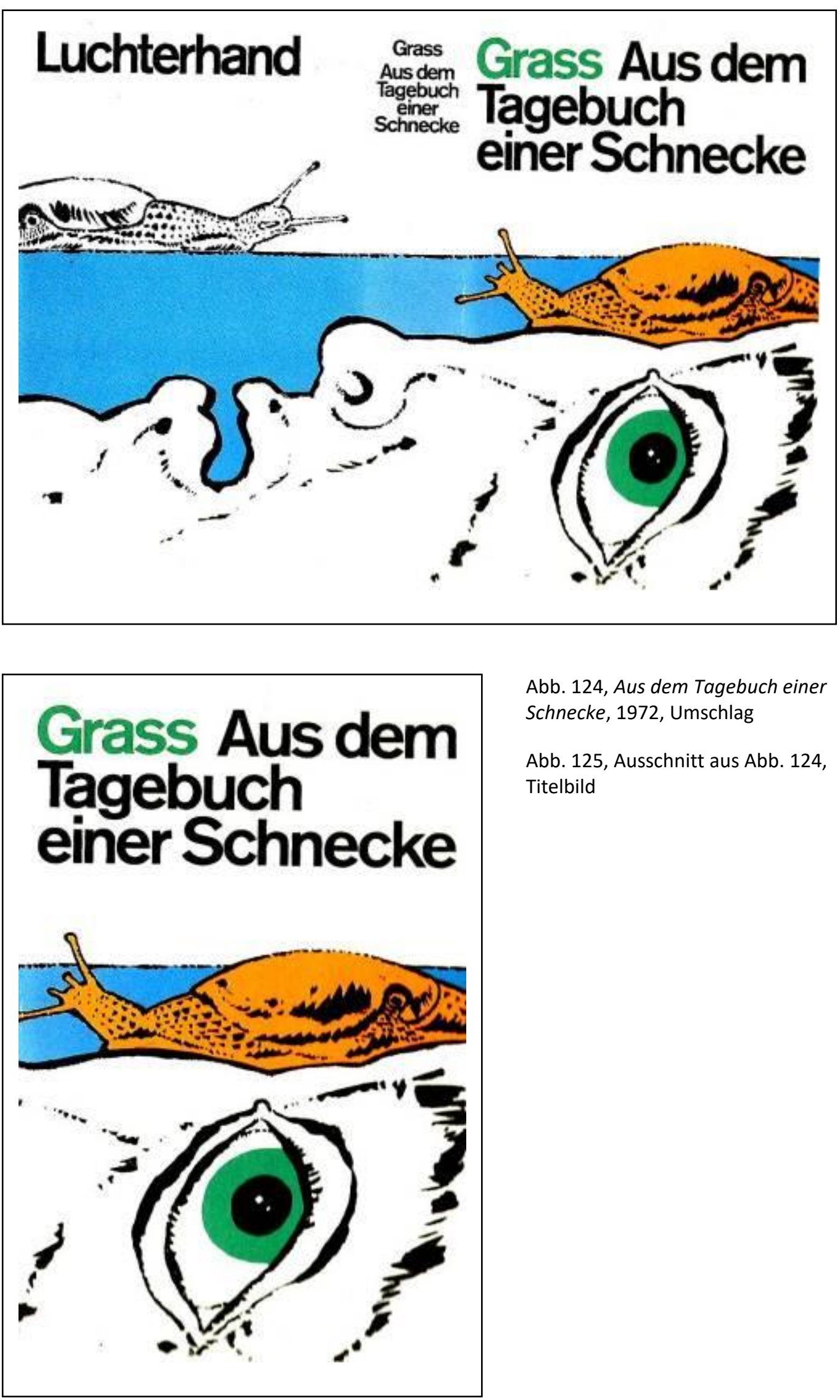

Abb. 124, Aus dem Tagebuch einer Schnecke, 1972, Umschlag

Abb. 125, Ausschnitt aus Abb. 124, Titelbild 


\section{MOTIVWANDERUNGEN IM UMKREIS DES TAGEBUCHS EINER SCHNECKE (1972) UND DES BUTT (1977): BESTÄTIGUNG IN JEDER EPOCHE}

\section{Schnecken: „Aufklärung der Vernunft mit den Mitteln der Aufklärung“ “996}

Der von Grass gestaltete Buchumschlag zu Aus dem Tagebuch einer Schnecke aus dem Jahr 1972 bietet sich als Zugang zum entsprechenden Werk, zu dessen Ästhetik und seinem Schlüsselmotiv an. Neben dem grundlegenden Handlungsschema transportiert die Darstellung auch die immense Bedeutung des Sehens im Prosatext. Das Schneckenmotiv wird dazu offenkundig in einen engen Bezug gesetzt (Abb. 124).

Über Vorderseite, Rücken und Rückseite der Erstausgabe zieht sich ein einziges Bild, in welchem die dargestellten Objekte auf weißem Papier mit kräftigen schwarzen Linien umrissen und nur drei Teilflächen farbig gefüllt sind. Die Komposition ist horizontal in raumschaffende Schichten, in Vordergrund, Mittelgrund sowie den Hintergrund mit eingefügtem Text, unterteilt. Das untere Bilddrittel wird durch die Darstellung eines nach oben gewendeten Gesichts im Profil bestimmt. Im Ausschnitt vergrößert, füllt es die Bildfläche in ihrer gesamten Breite. Das linke, weit geöffnete grüne Auge der Figur ist im Gegensatz zu ihrer Darstellung in früheren Entwürfen ${ }^{497}$ nicht zentralperspektivisch, sondern in der Aufsicht wiedergegeben und somit unmittelbar auf die Betrachtenden gerichtet. Der Mund der Figur ist leicht geöffnet. Unmittelbar über dem Auge, auf der im antikisierten Profil nur leicht angedeuteten Nasenwurzel, sitzt eine orange gefärbte Wegschnecke. Ihr Körper ist parallel zur Bildfläche nach links gerichtet. Ihren Kopf mit ausgezogenen Fühlern hat sie von den Betrachterinnen und Betrachtern ab und in das Bild hinein gewendet. Hinter ihr erstreckt sich eine hellblau kolorierte und damit als Wasser gekennzeichnete Fläche, die durch eine exakt gezogene schwarze Horizontlinie begrenzt ist. Darauf kriecht ein zweites, etwas kleineres Weichtier von links nach rechts ins Bild und befindet sich damit, nach oben versetzt, über dem Mund der Figur.

Die einander auf getrennten Wegen entgegenkommenden Gastropoden visualisieren eine das Buch maßgeblich bestimmende Dialektik: Die in der Zeichnung angedeuteten langsamen Bewegungen, die sich parallel zueinander in Nähe und Ferne vollziehen, können in Bezug auf den Text als Repräsentationen seiner Erzählstränge in Gegenwart und Vergangenheit gedeutet werden. Das Zuwenden der beiden Tiere zueinander, das nahezu spiegelbildlich erscheint, deutet auf die Relation zwischen den beiden Handlungslinien hin. Thematisiert werden in der Prosa auf der einen Seite das Wahlkampfjahr 1969, in dem Grass als unabhängiger Redner in der gesamten Bundesrepublik für die Kanzlerkandidatur Willy Brandts eintritt und die Person des politisch engagierten Schriftstellers, bildenden Künstlers und Familienvaters Günter Grass, der erstmals innerhalb der Erzählfiktion als Ich-Erzähler figuriert. Dieser berichtet auf der anderen Seite über die Vertreibung der Danziger Juden während des Zweiten Weltkrieges und setzt sie mit der größten-

\footnotetext{
${ }^{496}$ Siehe Günter Grass nachträglich über Aus dem Tagebuch einer Schnecke in: Grass/Zimmermann (1999), S. 122.

497 Vgl. das Motivverzeichnis der erhaltenen und/oder reproduzierten Zeichnungen zum Komplex der Schnecken in der vorliegenden Veröffentlichung. Die erste Zusammenstellung publizierter Schneckenmotive von Grass bot Hille-Sandvoss (1987), S. 232-257.
} 
teils erfundenen Geschichte Hermann Otts, genannt „Zweifel“, in Verbindung - eines Lehrers, der die jüdische Gemeinde in der Freien Stadt unterstützt, dann als politisch Verfolgter den Krieg im Keller eines Fahrradhändlers überlebt und währenddessen eine Liebesbeziehung mit dessen depressiver, oder vielmehr melancholischer, Tochter eingeht. Da das Werk nach dem Vorbild von Georg Christoph Lichtenbergs Sudelbüchern als eine Sammlung von Erinnerungen, Geschichten, Einfällen und Gedichten konzipiert wurde, ${ }^{498}$ konnten beide Zeitebenen locker miteinander verzahnt werden. Als Adressaten der Aufzeichnungen treten immer wieder die Kinder des Erzählers in Erscheinung, denen der Holocaust ebenso anschaulich erklärt werden soll wie die politische Gegenwart und das Leben des Vaters. Dabei wird die Scham angesichts der deutschen Schuld als Motivation für das Engagement des Autor-Erzählers als Schriftsteller und als Bürger deutlich. In Grass' Umschlag muss die Farbe der Schnecke im Vordergrund, das leuchtende Orange, bei Erscheinen des Buches auf dessen zeitgenössische politische Inhalte verwiesen haben, denn es handelt sich um die Farbe, die die SPD 1969 für ihr Marketingmaterial nutzte (V 444 f.).

Den oberen Abschluss des Einbandes bilden die den Verlag, den Verfasser und den Buchtitel benennenden Schriftzüge. Auf den Vornamen des Schriftstellers wurde verzichtet. Der Nachname auf dem Titelbild ist - abweichend vom restlichen schwarzen Schriftzug - in demselben Grün gehalten, wie das Auge der Figur im Vordergrund. Noch deutlicher wird der Zusammenhang in dem auf die Vorderseite des Umschlags begrenzten Bildausschnitt, in dem das Auge die gesamte untere Bildhälfte einnimmt (Abb. 125).

Grass' Einbandgestaltung kann als Programm einer Poetologie gedeutet werden, die sich der Sinnlichkeit verschrieben hat: Autor und Sehsinn werden über die Farbgestaltung zueinander in Verbindung gesetzt. Die Positionierung der Schnecke über dem Auge rückt das Sehen in unmittelbare Nähe zum Fühlen, das mit der Wiedergabe des feuchten Kriechtieres auf bloßer Haut hervorgehoben wird. Beide Sinne, der visuelle noch unvermittelter als der taktile, treten gegenüber dem durch den antikisierten Kopf repräsentierten humanistischen Denken in den Vordergrund.

Bei der Schnecke handelt es sich um das erste Tiermotiv, das ein episches Werk von Günter Grass in vielfacher Hinsicht durchzieht: Es repräsentiert darin die Lebensphilosophie des Erzählers, ist Bildspender der wichtigsten Metaphern des Buches und besetzt als Sammelobjekt des Biologieund Deutschlehrers Hermann Ott einen Platz in der Handlung - diese Schnecken sind, wie es im Tagebuch heißt, „beispielhafte, prinzipielle und solche, die wirklich vorkommen“ (V 499).

Wie schon Vögel, Nonnen und Scheuchen von Grass als bildendem Künstler gestaltet und durch intermediale Bezüge im Text an ihre bildhaften Manifestationen zurückgekoppelt wurden, zeichnete er auch die Schnecken parallel zur Entstehung des Tagebuchs von 1969 bis 1972 und beschrieb sie im Text explizit als visuell vorgestellte und gezeichnete. Unterlegt wird dieser Umgang mit der Schnecke zum einen mit Verweisen auf Schopenhauers Aufwertung eines auf der Anschauung beruhenden Denkens und zum anderen mit der immer wieder thematisierten Beschäftigung des Erzählers mit Albrecht Dürers Melencolia I und mit der Stilfigur der allegorischen Sinngebung, die teils durch die Brille Walter Benjamins betrachtet wird. Anlass der Auseinandersetzung mit dem Kupferstich ist ein Vortrag zum 500. Jubiläum des Dürer-Geburtstages im Mai 1971, den Grass bereits 1969 vorzubereiten beginnt. Die tatsächlich gehaltene Rede unter dem

${ }^{498}$ Vgl. Neuhaus (2010), S. 136. 
Titel "Vom Stillstand im Fortschritt. Variationen zu Albrecht Dürers Kupferstich Melencolia I" wurde dem Tagebuch zum Abschluss angefügt.

Mit seinen Schneckendarstellungen kehrte Grass zu einer eingehenden Auseinandersetzung mit dem Tiermotiv zurück, die sich zu Beginn der Fünfzigerjahre in Berlin sowohl in seiner Lyrik und Kurzprosa als auch in seinen Plastiken und Grafiken manifestierte. Die Verwendung des Schneckenmotivs im Besonderen stellt ebenfalls einen Rückgriff auf das studentische Frühwerk dar. Bereits im Entwurf zum Langgedicht "Tagebuch eines Säulenheiligen“ aus dem Jahr 1952 hatte Grass es literarisch aufgegriffen und in dem Kurzprosatext „Meine grüne Wiese“ (1955) weiter ausgestaltet. ${ }^{499}$

In dem nur im Düsseldorfer Arbeitstagebuch niedergelegten Gedicht figuriert die Schnecke als Metapher für das Glück, das das lyrische Ich zu erreichen versucht. Auf dieser Verfolgungsjagd büßt der Sprechende jede Vorstellung von der Gestalt seines Ziels ein. ${ }^{500}$ Dieser Gedanke wird in „Meine grüne Wiese“ wiederaufgenommen und erweitert. Die Schnecke bleibt, wie das in Versen gehaltene Ende des Textes erweist, ein Sinnbild für vage definierte Heilsversprechen:

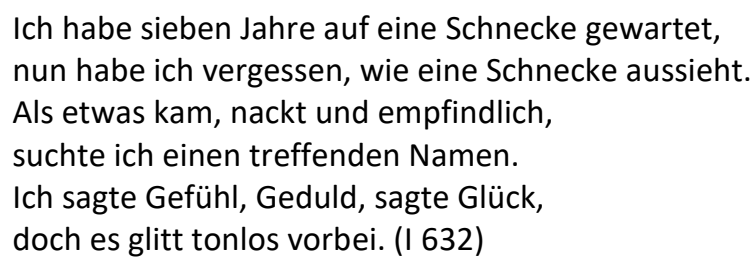

Die sich bedächtig vorwärts bewegende Schnecke wird darüber hinaus konkreter als ein Wesen beschrieben, dass gerade durch die nachgiebige Weichheit seines Körpers unverletzlich ist. Sie wird im Zusammenhang mit einer Zukunft erwähnt, die von jeglicher Brutalität und Radikalität Abstand nimmt. Den Konterpart zur Schnecke bildet in "Meine grüne Wiese" die sich selbst tö-

\footnotetext{
${ }^{499}$ Vgl. ebd., S. 141.

„Hätt ich nicht Angst vor

Reichtum und Glück, Ich wollt noch

alle restlich betrügen. Ich baut mir

ein Schiffchen aus steifem Papier, einst paßt ich nicht auf, es segelte faltig davon. Schade ich hatt es noch gar nicht beladen. Morgen doch, [?] lehre [?] Fortschritt lies ich den Hut an die [?], gieß inn voll Wind und lasse ihn [steigen?]. Sollt es gelingen knöpf ich mir Kopf und Kragen [darunter?]. Ich will noch allen in den Schornstein gucken. --- Ich lief einem Hund nach, doch er hatte zwei Beine mehr als ich. Ich [?] auch die Schnecke, als sie dann ankam am Ende, hat ich vergessen wie eine Schnecke aussah."
}

${ }^{500}$ Akademie der Künste Berlin, Günter-Grass-Archiv, Nr. 965, S. 54, hs, Transkription: V. K. Dieter Stolz sei für Korrekturen gedankt. Die Zeilenumbrüche folgen denjenigen im Arbeitstagebuch: 
tende Pepita, deren weißes Kleid sich blutrot färbt, und deren Name, an das schwarzweiße Textilmuster erinnernd, sinnbildlich für radikale Gegensätze steht: ${ }^{501}$

Fast möchte ich sagen, doch ohne als Prophet zu gelten, die Schnecke hält ihre Fühler in ein kommendes Jahrhundert. Es wird dieses eine vorsichtige Zeit sein, ein Zurücknehmen aller Beschuldigungen, ein Jahrhundert ohne jene äußerste Farbe, in die Pepita sich kleidete. (I 632)

Die ab 1957 von Grass in dem programmatischen Gedicht „Askese“ und in Nonnenzeichnungen entwickelte Metaphorik der grauen Ideologie- und Metaphysikfeindlichkeit deutet sich somit auch in jenem frühen Text in Verbindung mit dem Schneckenmotiv an. Bereits zu den Schneckenpassagen aus „Meine grüne Wiese“ fertigte Grass zarte Tuschezeichnungen an. Die Unwirklichkeit der Handlung wird darin durch vertauschte Größenverhältnisse der dargestellten Objekte hervorgehoben (Abb. 126).

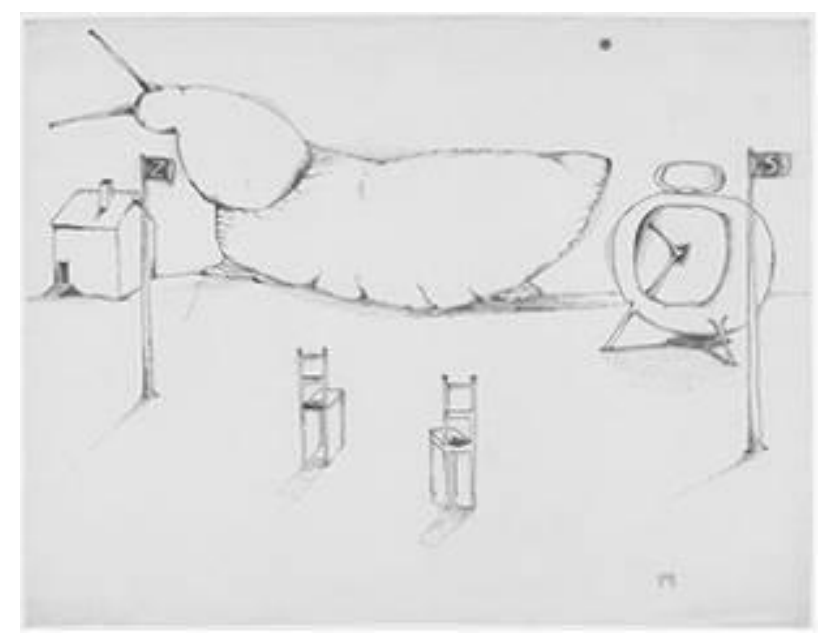

Abb. 126, Zeichnung zu „Meine grüne Wiese", 1955, Feder/Tusche, Akademie der Künste Berlin, Kunstsammlung, Inv.-Nr. HZ 2007

Im Tagebuch einer Schnecke und in den Zeichnungen, die parallel zum Manuskript entstanden sind, knüpfte Grass an diese Auseinandersetzung an: Das Mittel der surrealen Kombinatorik wird erneut verwendet und die Kontrastarmut der Bilder radikalisiert. Zudem werden zahlreiche weitere Bedeutungsfelder mit Hilfe der Gastropoden und ihrer biologischen Eigenschaften erschlossen: Die Schnecke ist Sinnbild der Persönlichkeit des sensiblen, mal beharrlich engagierten und mal nach Rückzugsmöglichkeiten suchenden Autor-Ichs. Sie repräsentiert seine Vorstellung von umsichtigem Handeln, das im politischen Slogan „Der Fortschritt ist eine Schnecke“ Zusammenfassung findet. Anders formuliert, repräsentiert sie den "Stillstand im Fortschritt" und damit den von Grass in seiner Dürer-Rede als notwendig rehabilitierten Zustand der Melancholie. Darüber hinaus verkörpert das Weichtier heilsame Sinn- und Zärtlichkeit und gleichzeitig, als Art, die sich selbst zu befruchten in der Lage ist, die Utopie einer sexuellen Selbstgenügsamkeit und Autonomie. ${ }^{502}$ Auffallend häufig wird das Tiermotiv in Bildbeschreibungen und sprachliche Bildentwürfe integriert, die ausdrücklich auf das grafische Medium Bezug nehmen, in dem sie Grass zeitgleich realisierte.

${ }^{501}$ Die Beschreibungen von surrealen Landschaften und Ereignissen sind durch Schwarz-weiß- und Komplementärkontraste geprägt (Kohlenberge vs. Milch/weißes Kleid, blutrot vs. wiesengrün) (I 562-568). ${ }^{502} \mathrm{Vgl}$. zur Ikonografie des Schneckenmotivs im Allgemeinen und in Bezug auf Sexualität: Werner (2015), S. 62-84. 
Für dieses intermedial entworfene, im Folgenden im Detail zu erläuternde Verfahren der Bedeutungsvermittlung konnte Grass auf ikonografische Traditionen zurückgreifen: Das Motiv der Schnecke ist ähnlich wie das der Schildkröte Bestandteil zahlreicher Embleme, die Beharrlichkeit, Vorsicht, Langsamkeit und Selbsterkenntnis veranschaulichen. Zudem stellt es ein Gegenbild zu Motiven dar, die traditionell zur bildhaften Vermittlung des Fortschritts verwendet wurden meist Darstellungen schneller Bewegung, sei es in Form von Rädern, Pfeilen ${ }^{503}$ oder, wie im Tagebuch selbst, in Pferdegestalt, womit Grass die Hegelsche Bezeichnung Napoleons als „Weltgeist zu Pferde" zitierte. ${ }^{504}$

Die Schnecke bildet ferner ein Gegenstück zu dem offensiv-kämpferischen, männlich konnotierten und lautstarken Tier, das Grass für die "Vorzüge der Windhühner" zeichnete, 1965 als Motiv für das Wahlkampf-Material der SPD wählte und 1969 weiterhin zu politischen Werbezwecken verwendete: dem Hahn. Grass ließ inn auf Plakaten und Plaketten Walt Whitman folgend das Lied der Demokratie krähen. Mit einem besonders prachtvollen Exemplar dieser Tierart wurde der Schriftsteller 1969 von Thomas Hoepker fotografiert (Abb. 127), zog drei Jahre später für ein von Maria Rama aufgenommenes Porträt-Foto jedoch bereits die Schnecke als Accessoire vor (Abb. 128). Im Tagebuch kommentiert der Erzähler:

Auf unseren Briefbögen steht: „Sozialdemokratische Wählerinitiative“. Daneben ein Hahnenkopf, den ich fünfundsechzig gezeichnet hatte und der immer noch Espede kräht; die Schnecke als Signum wäre am Fortschrittsglauben gescheitert: Schnecken bewundern Hähne. [...] (Thomas Höpker, der mit uns reiste, sah mich nicht mit der Schnecke, wollte mich plakativ mit dem lebenden Hahn fotografieren). (V 336, 438)
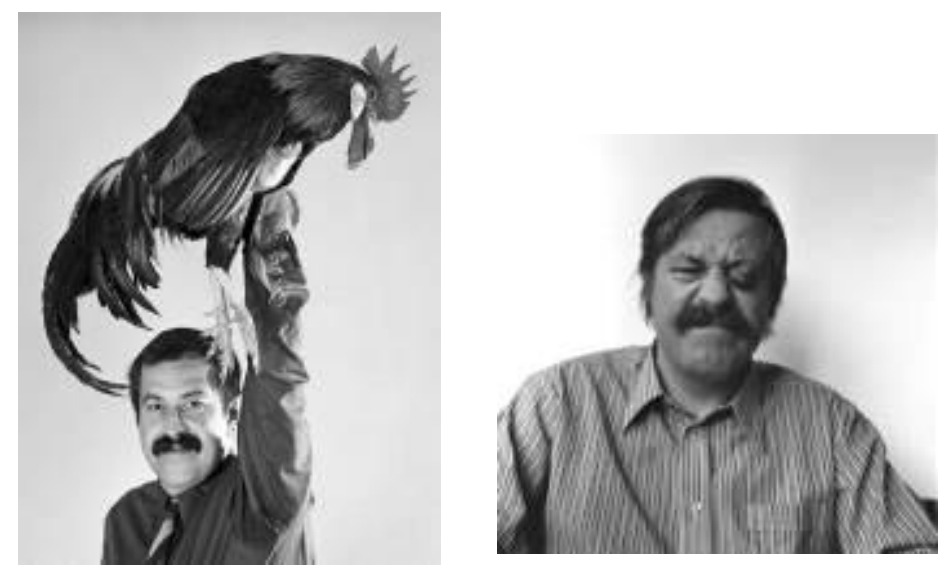

Abb. 127, Thomas Hoepker, Günter Grass mit Hahn, 1969, Fotografie

Abb. 128, Maria Rama, Günter Grass mit Schnecke, 1972, Fotografie, Akademie der Künste, Berlin, Sammlung Maria Rama, Nr. 273.1

Auf den nächsten Seiten wird das Schneckenmotiv in seinen verschiedenen Erscheinungsformen und Funktionen auf seine intermedialen Bezüge hin weitgehend in chronologischer Abfolge untersucht: als Strukturmodell der Prosaentwürfe, als in der Lyrik entwickelte Metapher sowie als im Erzähltext beschriebenes und als gezeichnetes Bild. Vor dem Hintergrund der Grass'schen Auseinandersetzung mit Anschauung und Anschaulichkeit, die der Schriftsteller im Tagebuch in den

\footnotetext{
${ }^{503}$ Vgl. Henkel/Schöne (1976), S. 616-622 und Wolff (2011), S. 346-352.

${ }^{504}$ Vgl. Neuhaus (2010), S. 142 und Stolz (1994), S. 301.
} 
Dienst eines aufklärerischen Schreibens stellt, wird der Schnecke ihr Ort zwischen den Medien zugewiesen.

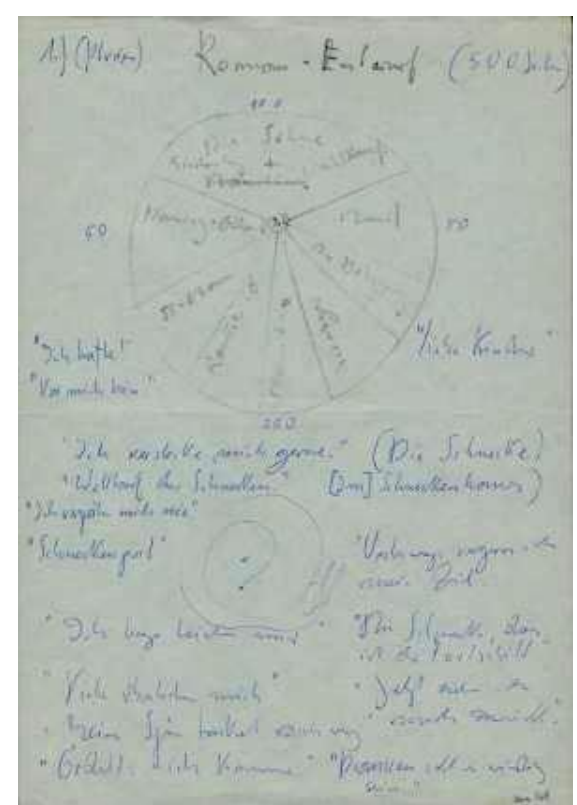

Abb. 129, Roman-Entwurf, 8.8.1969

Akademie der Künste, Berlin, Günter-Grass-Archiv, Nr. 169, Kugelschreiber/Bleistift 


\section{Die Schnecke als Modell}

Im Sommer 1969, wenige Monate vor der Wahl Willy Brandts zum Bundeskanzler und noch während Grass auf Wahlkampftournee unterwegs war, notierte er erste Ideen zu einem neuen Werk in seinem Arbeitstagebuch: Er plante das neue Schreibprojekt spätestens seit dem 3. Juni 1969 als eine Erzählung für seine Söhne. Sie sollte Kapitel über grundlegende Lebensthemen („Idealismus“, „Umgang mit Frauen“, „Niederlagen“, „Autorität“, „Trauer“, „Erziehung" und „Ehe“) enthalten, daneben die Belagerung Danzigs durch die Truppen Napoleons und den gegenwärtigen Wahlkampf behandeln und Beschreibungen seiner Kinder aufnehmen. ${ }^{505}$ Nur wenig später, am 8. August, entwarf der Schriftsteller einen Plan, in dem er die genannten allgemeinmenschlichen Aspekte vorwiegend durch historisch-politische Ereignisse und gesellschaftliche Diskurse ersetzte. Der auf einem A4-Blatt festgehaltene, während eines Urlaubes im bretonischen Plurien geschaffene Entwurf setzt sich aus schriftlichen und grafischen Elementen zusammen und ist über die beiden jeweils oben und unten dominierenden Zeichnungen horizontal in zwei Bereiche gegliedert (Abb. 129).

In der oberen Bildhälfte ist ein in acht Tortenstücke unterteilter Kreis erkennbar, in die die für das Buch geplanten Themen unter Berücksichtigung ihres vorgesehenen Umfangs eingetragen wurden. In dieser Planungsetappe treten die später tatsächlich verwirklichten Schwerpunkte der Handlung nun deutlich hervor: „Die Söhne, Kirchentag + Wahlkampf“, „Danzig-Gdansk“, „Mond“ (Mondlandung der Apollo 11), „SS-Mann“ (der Selbstmord des im Buch als ,Manfred Augst' geführten Apothekers auf dem evangelischen Kirchentag), „Ranicki-Geschichte“ (die leicht an Marcel Reich-Ranickis Biografie angelehnte Geschichte von Hermann Ott), "Mauritius" (die Vertreibung der Danziger Juden während des Zweiten Weltkrieges), "Kiesinger" (mutmaßlich eine Auseinandersetzung mit der nationalsozialistischen Vergangenheit des amtierenden Bundeskanzlers) und „Die Belagerung“. Das Thema der französischen Besetzung Danzigs zu Beginn des 19. Jahrhunderts sollte im Tagebuch ebenso wenig als eigenständiger Komplex ausgeführt werden wie das Thema „Kiesinger“. Stattdessen kam später die Auseinandersetzung mit Dürers Melencolia I hinzu und das Buch für die Söhne wurde zum Buch für die Kinder. Zunächst als Sammlung von Briefen des Vaters an den Nachwuchs geplant, wurde das Projekt nach und nach in die Form des Sudelbuchs überführt, in dem sich das Autor-Ich immer wieder direkt an die Kinder wendet. ${ }^{506}$

Im Mittelpunkt des Schemas ist ein kleiner Kreis zu sehen, in den das Wort "Ich" eingetragen wurde. Wie Rebecca Braun in ihrer Studie zur Konstruktion von Autorschaft in Grass' Werken herausarbeitete, wird hier die herausragende Rolle des Ich-Erzählers deutlich, der im Tagebuch als Günter Grass fest konturiert ist und die einzelnen Handlungsstränge als Ausgangspunkt miteinander verbindet. ${ }^{507}$

In der unteren Bildhälfte ist die Skizze einer nach rechts gewandten Schnecke erkennbar. Das Zentrum ihres spiralförmigen Gehäuses ist deutlich mit einem Punkt markiert. Rechts oberhalb der Zeichnung wurden die Titelvariationen „Die Schnecke oder Im Schneckenhaus“ vermerkt. Einzelne Textzeilen, die die Tierdarstellung umgeben, machen die Identifikation des darin Spre-

\footnotetext{
505 Vgl. Akademie der Künste, Berlin, Günter-Grass-Archiv, Nr. 1758, S. 23.

${ }^{506} \mathrm{Vgl}$. Akademie der Künste, Berlin, Günter-Grass-Archiv, Nr. 1758.

${ }^{507}$ Vgl. Braun (2008), S. 71.
} 
chenden mit der Beharrlichkeit, Langsamkeit und Verletzlichkeit der Schnecke deutlich: „Ich hafte vor mich hin", "Ich verstecke mich gern“, "meine Spur trocknet weg“, "Unterwegs vergesse ich mein Ziel“, „jetzt ziehe ich mich zurück“. Zudem enthält das Blatt auch die spätere, über die Charakterisierung des Individuums hinausgehende Kernmetapher des Tagebuchs: „Der Fortschritt ist eine Schnecke", die in der Prosa besonders auf politischem Feld ein bedächtiges, umsichtiges Handeln propagiert. Bei diesen im Roman-Entwurf niedergelegten Zeilen handelt es sich um Verse eines Gedichts, das später in das Buch aufgenommen wurde (V 325). Das handschriftliche Manuskript zu diesem lyrischen Text ist selbst nicht datiert, liegt jedoch dem Roman-Entwurf im Archiv direkt bei und scheint der verwendeten Tinte und dem Schreibduktus zufolge in einem Zug mit inm niedergelegt worden zu sein. ${ }^{508}$

Das Tortenschema und die Schneckenzeichnung sind auf dem Blatt in einer Achse untereinander platziert und weisen in der Rundform von Kreis und Schneckenhaus mit deutlich markiertem Zentrum und davon ausgehender, breiter werdender Segmentierung eine grundlegende Verwandtschaft auf. Über diese gemeinsame grafische Struktur und ebenso über die Betonung des Ich-Erzählers - oben als beschrifteter Nukleus und unten als Charakterisierung eines "Ich" durch die Verse und die Identifikation mit der Schnecke - sind die beiden Blatthälften miteinander verbunden.

Ihre Synthese zeigt eine in Berlin am 20. November 1969 entstandene Tuschezeichnung (Abb. 130). Zu sehen ist erneut ein Schneckenhaus in der Seitenansicht. ${ }^{509}$ Vor der Öffnung des Objekts rechts oben bezeichnet der Schriftzug: "Schema: Im Schneckenhaus" die Funktion der Zeichnung und ihren Gegenstand. Das dargestellte Gehäuse weist eine ungewöhnliche Musterung auf. Es trägt sowohl eine Bänderung längs seiner Windungen als auch eine Segmentierung quer zu innen. Vor dem Hintergrund des ersten bildlichen Textentwurfs betrachtet, scheint Grass hier die verschiedenen Handlungsstränge des Textes parallel zueinander gesetzt zu haben. In der Spiralform wird der immer weitere Kreise ziehende Verlauf der mehrgleisigen Erzählung visualisiert, den Zäsuren in Etappen unterteilen.

\footnotetext{
${ }^{508}$ Vgl. Akademie der Künste, Berlin, Günter-Grass-Archiv, Nr. 169.

${ }^{509}$ Abdruck in Grass (2014), S. 143.
} 


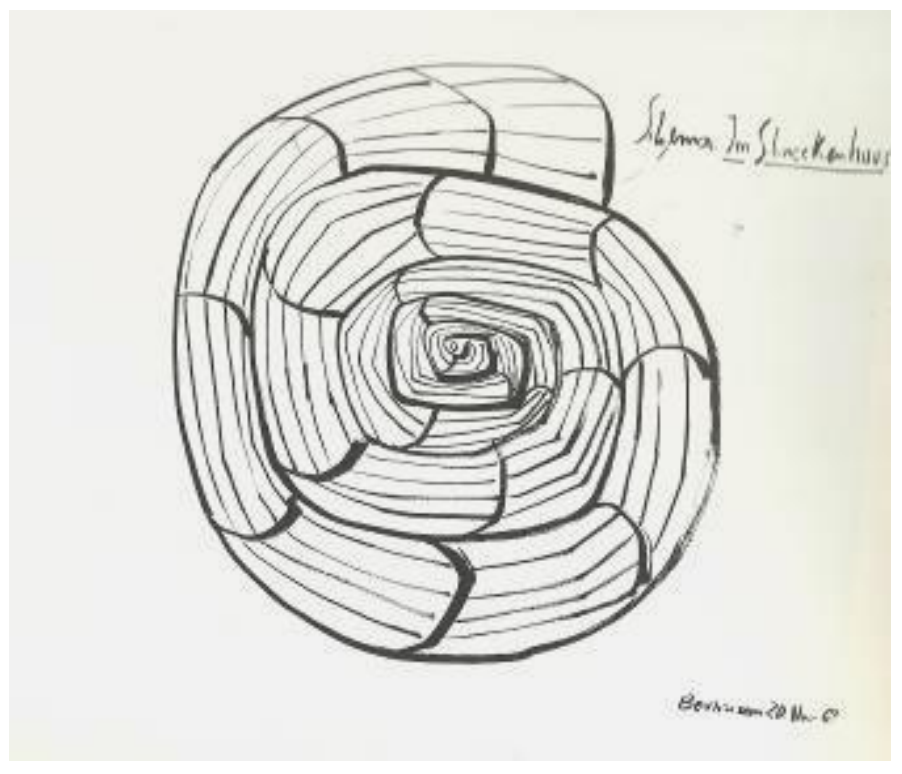

Abb. 130, „Schema: Im Schneckenhaus", Berlin, 20. Nov. 1969, Feder/Tusche

Rebecca Braun, die in ihrer Studie die verschiedenen Pläne zum Tagebuch verglichen hat, stellte abschließend fest, dass die Konzeption des Werkes als eines, das das Leben des Autors nicht nur in der autobiografischen Erzähler-Konstruktion berücksichtigt, sondern dessen Leben selbst zum Thema macht, erst wesentlich später von Grass entwickelt wurde. In einem Arbeitsplan vom Oktober 1969 heißt es zwar erstmals:

Am Tag nach der Wahl Willy Brandts zum Bundeskanzler, also nach dem ,Sieg' und im Zustand unausrottbarer Resignation, versuche ich ein Ich-Buch zu entwerfen, für das während des Wahlkampfes erste Stichworte zu Papier kamen. ${ }^{510}$

Die Notiz gibt jedoch noch keine näheren Auskünfte dazu, ob mit einem „Ich-Buch“ mehr als nur ein aus der Perspektive des Autor-Ichs erzähltes Werk gemeint ist. Erst seit dem 16. Juli 1970 taucht das "Ich" ausdrücklich als Schwerpunkt, und zwar auch unabhängig vom Thema des Wahlkampfes, neben den anderen Aspekten auf. ${ }^{511}$

Es sind Grass' Entwurfszeichnungen vom August und November 1969, die zusammen mit den Gedichtfragmenten deutlich machen, dass das Tagebuch schon in jenem Stadium autobiografische Züge tragen sollte. Die Schnecke ist gleichermaßen der Bildspender der Metapher, die das Textkorpus visualisiert, und die das lyrische Ich des Gedichtes zur Kennzeichnung seiner selbst und seiner politischen Auffassung verwendet. Erzähler und Werk fallen in der Repräsentation durch ein grafisches Bild zusammen.

Ein Vergleich zu dem Jahrzehnte später veröffentlichten Erinnerungsbuch Beim Häuten der Zwiebel (2006) zeigt eine auffällige Ähnlichkeit des Strukturmotivs des Schneckenhauses mit dem der Zwiebel, die Grass in einem frühen Entwurf seines autobiografischen Romans im Jahr 2003 skizzierte (Abb. 131). Auch hier bildet das „Ich“ den Mittelpunkt eines Kreises und verweist aus

\footnotetext{
510 Arbeitsplan vom 22. Oktober 1969, Dubrovnik, Akademie der Künste, Berlin, Günter-Grass-Archiv, Nr. 170, zitiert nach Braun (2008), S. 71.

${ }^{511} \mathrm{Vgl}$. Braun (2008), S. 70-75.
} 
dem Zentrum heraus auf viele einzelne Themen, deren grafische Begrenzungen sich strahlenförmig nach außen hin verbreiten und in leichter Beugung eine Rotation um das Kreiszentrum herum andeuten. Beide Bilder heben die wichtige Rolle des autobiografischen Erzählers für die Gesamtkonzeption der Bücher hervor. Beide Modelle vermitteln darüber hinaus durch die gewählte grafische Gesamtgestalt als Schneckenhaus/Zwiebel aber auch eine Identität von Buch und Erzähler. Letzterer ist nicht nur Ausgangspunkt für Handlungen, sondern die Handlungen sind Teil einer Rekonstruktion seiner selbst. ${ }^{512}$

Wie sehr und auf welche Weise der Schriftsteller sich die Schnecke als Wappentier zuordnete, machen ferner eine Reihe von Selbstbildnissen deutlich, die Grass 1972 geschaffen hat. ${ }^{513}$ Diese Bilder entstanden in Anlehnung an Porträt-Fotografien, die Grass' Hausfotografin Maria Rama im Monat der Veröffentlichung des Tagebuchs im Mai 1972 aufnahm. Sie zeigen inn in einem gestreiften Hemd, ein gebändertes Schneckenhaus wahlweise frei in die linke Augenhöhle geklemmt oder mit der linken Hand vor das linke Auge haltend (S. 211, Abb. 128). Die Schnecke wird auf diese Weise nicht nur zum Attribut des Schriftstellers, sondern auch als dessen Sehhilfe in Szene gesetzt. Auf der Grundlage dieser Aufnahmen schuf Grass Bleistiftzeichnungen und Radierungen (Abb. 132). Wie in der anfangs behandelten Umschlaggestaltung rückt auch hier das Sehen gemeinsam mit dem Schneckenmotiv in den Mittelpunkt. Der Schriftsteller betrachtet die Welt aus gewundener Schneckenperspektive. ${ }^{514}$ Das Tier wird zum Mittler zwischen dem kreativen Betrachter und seinen Objekten.

Im Motiv des gebänderten Schneckenhauses werden also die Anordnung des neuen Buches um und als das eigene Selbst, die Parallelführung verschiedener Handlungsstränge und die Schneckenperspektive als Perspektive des Autors zum Ausdruck gebracht - teilweise lange bevor diese Aspekte des Werkes von Grass schriftlich ausformuliert worden sind. Der Kreis mit strahlen- und spiralförmiger Binnenzeichnung lag der Genese des Textes vielmehr von Beginn an als noch auszugestaltendes Schema zugrunde. Das strukturgebende Motiv blieb in der Entstehungszeit des Prosatextes jedoch nicht unverändert. Die Kennzeichen, die es transportiert, bestimmen zwar deutlich das abgeschlossene Werk, werden aber um weitere ergänzt. Eine neue Metapher setzte das Schneckenhaus in Bewegung.

\footnotetext{
512 Vgl. ebd., S. 75.

${ }^{513} \mathrm{Vgl}$. das Motivverzeichnis der erhaltenen und/oder reproduzierten Zeichnungen zum Komplex der Schnecken in der vorliegenden Veröffentlichung.

${ }^{514} \mathrm{Vgl}$. Joch (1997), S. 20.
} 


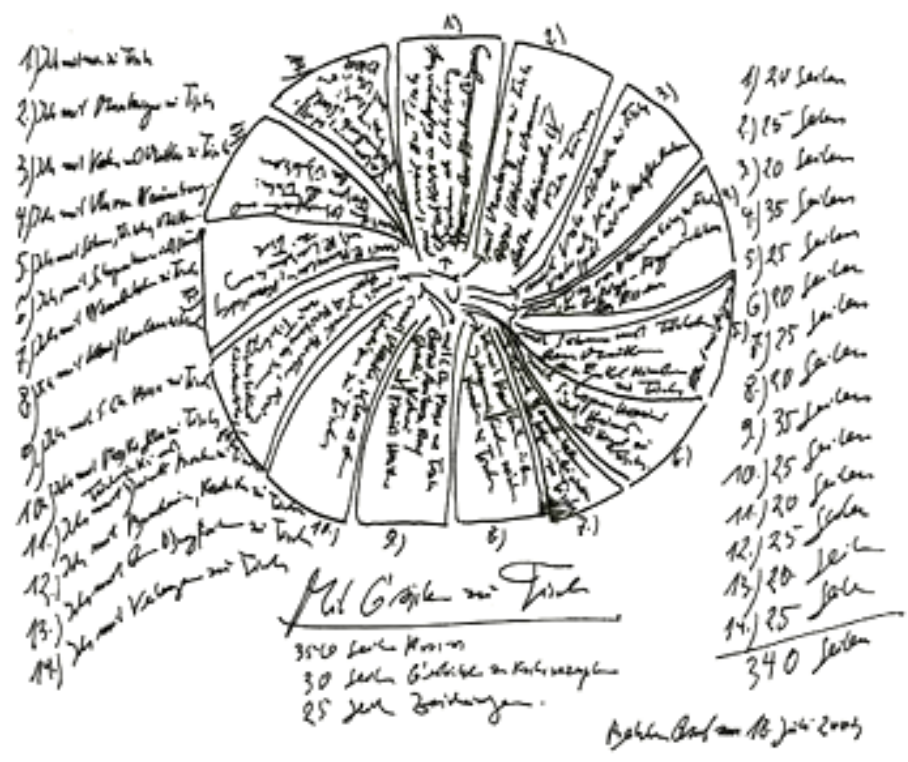

Abb. 131, Arbeitsplan zu Beim Häuten der Zwiebel, 26. Juli 2003, Feder/Tusche

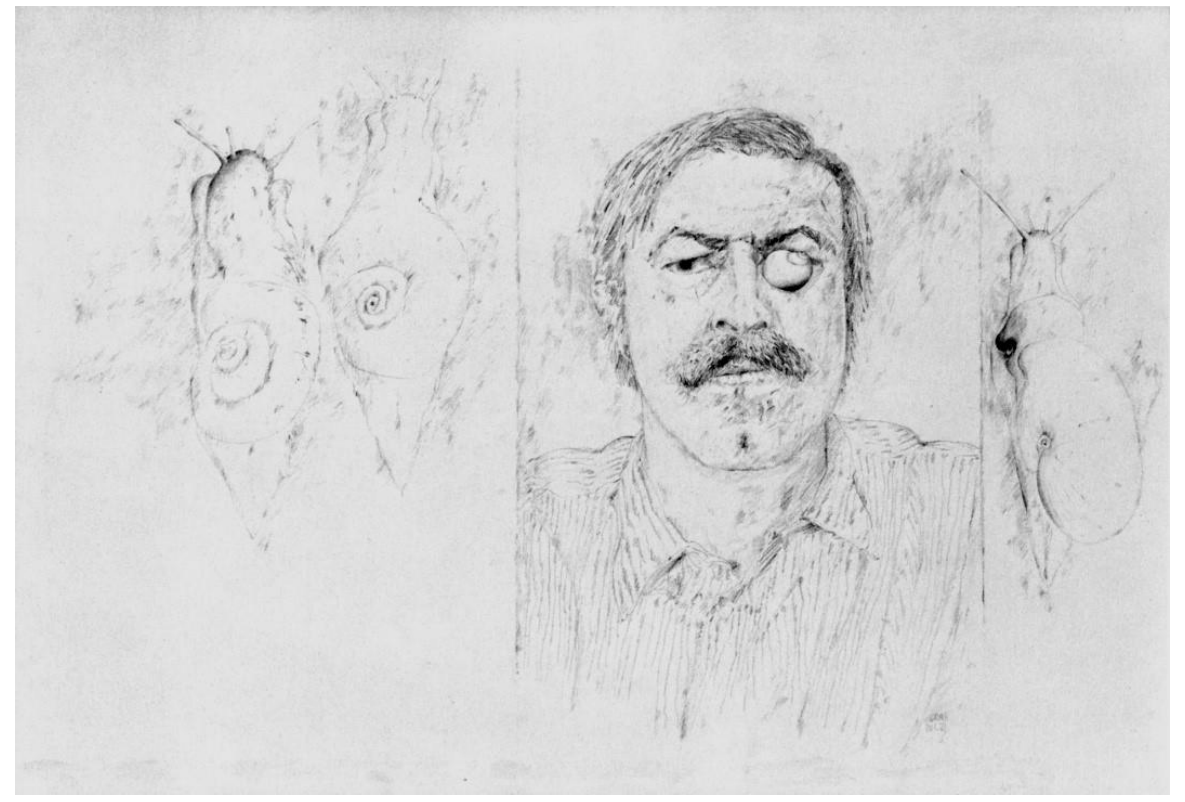

Abb. 132, Selbst mit Schnecken, 20.5.1972, Bleistift 
In einem dritten tabellarischen Entwurf vom 22. August 1971 trägt das vorangeschrittene Projekt bereits den abschließend verwendeten Titel (Abb. 133). Das Tier wird darin buchstäblich zum Verfasser eines Werkes, das einer bestimmten literarischen Gattung angehört, die chronologisch fortlaufende Einträge verspricht. Zu dem zentriert angeordneten, unterstrichenen Haupttitel enthält der Entwurf links oben einen Untertitel, der den Vorgang des Erzählens betont und mit der Bewegung der Schnecke verknüpft: „Die Gleitspur“. Nicht die Geborgenheit des Schneckenhauses, sondern der wegmarkierende Schleim der Schnecke wird hier zur Veranschaulichung des Erzählvorgangs genutzt. Die Spur kann an dieser Stelle als Sinnbild für die Erinnerung und für die Schrift im Allgemeinen sowie ebenso für Grass' Text im Besonderen verstanden werden, dessen Aufteilung und Inhalte der Entwurf festhält. ${ }^{515}$ Das abgeschlossene Tagebuch wird die Analogie von Schneckengang und Schreibvorgang in kurzen poetologischen Passagen aufnehmen (V 287, 398) und zudem durch die Konzeption der Schnecke als "Wappentier" des Autor-Ichs vermitteln (V 347). Grass' Umschlagbild wird wiederum die Handlungen des Buches durch die gegenläufige Bewegung zweier Gastropoden versinnbildlichen (S. 206, Abb. 124). Mit der Bezeichnung der Gleitspur kann jedoch nicht nur das Schreiben, sondern auch das Zeichnen assoziiert werden.

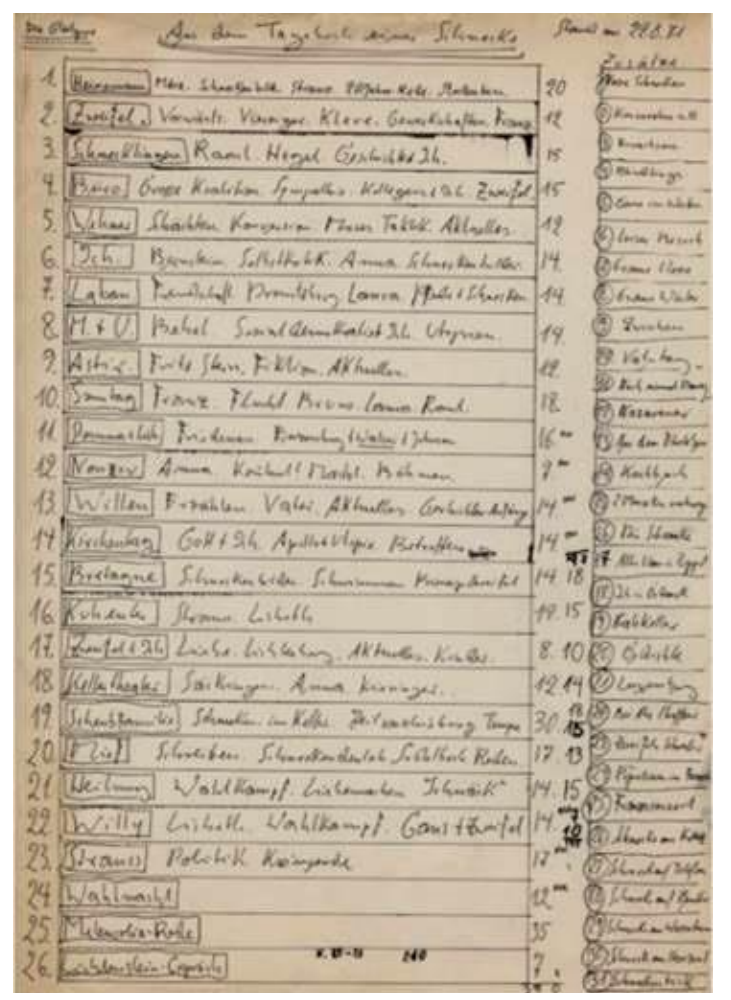

Abb. 133, Günter Grass, „Die Gleitspur“, 22.8.1971, Tinte, Akademie der Künste, Berlin, Günter-Grass-Archiv, Nr. 2081

\footnotetext{
515 Zur Spur als Metapher der Erinnerung vgl. Butzer (1998), S. 28-33; zur Spur als erkenntniskritisches Konzept in den Bild- und Kulturwissenschaften: Krämer/Kogge/Grube (2007) und Weigel (2015).
} 


\section{Geschriebene Bilder}

Den Tabelleneinträgen des "Gleitspur"-Entwurfs kann entnommen werden, dass das grafische Zeichen der Schnecke sich nicht nur in der Werkstruktur niederschlagen, sondern auch im Erzähltext thematisiert werden sollte. Grass sah für viele der Kapitel sogenannte "Schneckenbilder" vor. Er positionierte sie mit dieser Bezeichnung in der Tabelle und zwar in Gleichberechtigung vermittelnder Größe neben entscheidenden Handlungsschwerpunkten der betreffenden Abschnitte (Kapitel 1, 6 und 15). In den am rechten Rand des Blattes erkennbaren Kapitelzusätzen werden zudem einzelne Kompositionen konkret benannt: "Schnecke am Kreuz", „Schnecke auf Telefon“, "Schnecke auf Bunker", „Schnecke am Wasserturm" und "Schnecke am Horizont".

Der veröffentlichte Text gibt Aufschluss darüber, dass es sich bei diesen „Bildern“ um kurze Bildbeschreibungen handelt. Dank der Form des Sudelbuchs konnten sie ohne Überleitungen zwischen Versatzstücke der verschiedenen Handlungsstränge gestreut werden, wie beispielsweise das im achtzehnten Kapitel vorgestellte "Bild“, in dem das feinfühlige und bewegliche Tier dem von menschlicher Hand geschaffenen statischen Wehrbau gegenübergestellt wird:

Ich habe sie mit ihrer Kriechsohle auf den Bunker gesetzt. Verkantet und um sein Schußfeld gebracht überdauert er zwischen Dünen: nicht zu verkaufen, nicht zu sprengen. (Soll ich ihr, weil sie eine Nacktschnecke ist, den Atlantikwallbunker als Haus entwerfen und bis ins Detail zeichnen? Sehschlitze, Betonstrukturen, deutsche Wertarbeit?) (V 453)

Die Schnecke befühlt an dieser Stelle einen Bunker aus dem Zweiten Weltkrieg genauso wie der Schriftsteller Grass sich im übertragenen Sinne über Bauwerke und Objekte an die Vergangenheit herantastet - die Atlantikwall-Bunker hatten bereits in zwei Kapiteln der Blechtrommel und in dem Roman örtlich betäubt (1969) bei der literarischen Vergegenwärtigung des Zweiten Weltkrieges eine Rolle gespielt. ${ }^{516}$

Schilderungen wie diese ergeben zusammengenommen einen visuell vorstellbaren Kommentar zur Prosahandlung. Intermediale Bezüge werden dabei als solche markiert, indem in den kurzen Passagen entweder auf eine in optischem Modus beschriebene Imaginationsfähigkeit des Erzählers hingewiesen wird (V 286, 456, 489) oder unmittelbar auf das Medium der bildenden Kunst (V 390, 453, 464, 526). Ferner werden Kombinationen von Schnecken mit anderen Gegenständen als imaginierte oder tatsächliche Zusammenstellungen von Objekten geschildert, die Bildbeschreibungen sehr nahekommen, weil sie sich auf die Wiedergabe von statischen Objektanordnungen konzentrieren und isoliert zwischen verschiedene Handlungspassagen der Prosa gesetzt sind. (V 490, 513, 516, 556)

Die „Schneckenbilder" wirken durch ihre Knappheit zeichenhaft: Die Gegenstände einer Komposition werden darin nicht im Detail wiedergegeben oder durch atmosphärische Schilderungen vermittelt. Wie Christine Renz in ihrer detaillierten Textanalyse herausarbeitete, hemmen sie den Fluss der Handlung, ${ }^{517}$ gerade die ungewöhnlichen Objektkombinationen regen zudem zum Nach-

\footnotetext{
${ }^{516} \mathrm{VgI}$. Kapitel III.2. der vorliegenden Forschungsarbeit.

${ }^{517} \mathrm{Vgl}$. Renz (2000), S. 374.
} 
denken an. Es sind diese Eigenschaften, die Bezüge zwischen Grass' Bildbeschreibungen und der frühneuzeitlichen Emblematik herstellen. ${ }^{518}$

Die in der ersten Hälfte des 16. Jahrhunderts entwickelte Kunstform des Emblems bestand idealtypisch aus einem einzeiligen Motto („Lemma“), einem grafischen Bild („Icon“/„Pictura“) und einem Epigramm, das das allegorische Programm des Bildes in Versen erläuterte. Grass' „Schneckenbilder" wirken wie Beschreibungen - wohlgemerkt Beschreibungen und nicht Erläuterungen - der emblematischen Icones. Die von ihm beschriebenen Kompositionen bleiben zunächst unkommentiert, ihre Botschaft wird jedoch an anderer Stelle ausführlich im Prosatext erörtert. Diese somit gänzlich in die Literatur verschobene Variante des Emblems steht mit den frühen Formen der aus Wort und Bild zusammengesetzten Kunstgattung insofern im Einklang, als die rhetorischen Miniaturen trotz ihrer Bebilderung zunächst vorrangig als literarische Ausdrucksform wahrgenommen wurden. Die ersten beigefügten Grafiken waren in ihrer Ausführung von geringer Qualität, manchmal fehlten sie ganz. Die Embleme zielten darauf ab, Gegenstände vor allem mittels der Ekphrasis zum Sprechen zu bringen. Ihre Funktion lag in der moralischen bzw. religiösen Erbauung und Belehrung. In der auf den ersten Blick rätselhaft wirkenden Zusammenstellung von Motiven orientierten sich die Texte an Hieroglyphen, die im Tagebuch einer Schnecke ebenfalls erwähnt werden (V 475, 590)..$^{519}$

Auf die Assoziation der Grass'schen Schnecken-Schilderungen mit dieser humanistischen Kunst- und Literaturgattung verweist auch die im Text thematisierte Melencolia I. Indem der Erzähler sich mit diesem Bild und der allegorischen Sinngebung auseinandersetzt, legt er ebenfalls eine Verbindung zwischen seinen Ekphrasen und der Emblematik nahe - handelt es sich bei einem Emblem doch schließlich um eine Sonderform der Allegorie (V 377, 461). ${ }^{520}$ Spätere sprachlich dargelegte Bildideen im Treffen in Telgte (1979), einer im 17. Jahrhundert verorteten allegorischen Erzählung, bezeichnete Grass ausdrücklich als Embleme. ${ }^{521} \mathrm{Zu}$ dieser Prosa bilden die Schneckenkompositionen eine wichtige Vorstufe. Wie Alexander Weber in seiner Studie über das Verhältnis der Grass'schen Texte zur Literatur des Barocks erörterte, zeigen bereits die Motivkombinationen seiner frühen Gedichte und Zeichnungen eine Verwandtschaft mit der Emblematik, ohne dass zu dieser Zeit von einer bewussten Auseinandersetzung des Dichters und Grafikers mit ihnen ausgegangen werden kann. ${ }^{522}$ Um 1970 werden seine präferierten Kompositionsmuster aus der Beschäftigung mit der Emblematik heraus vielmehr neu akzentuiert.

Der anschauliche Charakter der geschriebenen Bilder tritt im Tagebuch umso deutlicher hervor, als der Erzähler sich darin nicht nur als Schriftsteller, sondern auch als bildender Künstler vorstellt, dessen aktuelles Sujet Gastropoden sind. Der enge Zusammenhang von Schneckenspur und gezeichneter Linie wird dabei ausformuliert:

\footnotetext{
${ }^{518}$ Vgl. ebd., S. 373. Renz bezeichnete Grass' Bildbeschreibungen aus dem Tagebuch zwar als Embleme, allerdings nur beiläufig, ohne auf die Tradition dieser Wort-Bild-Gattung einzugehen. Das Emblem wird in ihrem Beitrag vielmehr synonym mit dem Begriff des Zeichens verwendet.

${ }^{519} \mathrm{Vgl}$. Warncke (2005), S. 43-46.

$520 \mathrm{Vgl}$. ebd.

${ }^{521}$ dazu ausführlich: Weber (1995), S. 107-166.

522 vgl. Weber (1995), zum emblematischen Charakter der Bildkunst von Grass im Allgemeinen vgl. Joch (1997), S. 18 f.
} 
Ich zeichne, was übrig bleibt. Neuerdings zeichne ich Schneckengehäuse und Schnecken im Gegenverkehr. Die Fortschritte meiner Schnecken sind an rasch wegtrocknenden Spuren zu erkennen. Ein reicher, das heißt gebrochener, sich spleißender, streckenlang stotternder, hier verschweigender, dort dick verkündender Strich. Viele Striche. (V 356)

Die im Buch enthaltenen Bezüge zur bildenden Kunst im Allgemeinen und zur Emblematik im Besonderen werden durch die von Grass parallel zum Schreibvorgang geschaffenen Schneckenzeichnungen bestätigt.

\section{Gezeichnete Bilder}

Nach dem Anfertigen erster Schneckenskizzen in den Jahren 1969 und 1970 intensivierte Grass im Sommer 1971 seine bildkünstlerische Betätigung. Er wendete sich also in genau dem Zeitraum stärker der bildenden Kunst zu, in dem er auch den Entwurf der "Gleitspur" mit den darin enthaltenen "Schneckenbildern" entwickelte. Befördert wurde sein Interesse für die bildende Kunst in dieser Zeit durch die Liebesbeziehung zu Veronika Schröter, die als Architektin und Malerin tätig war. Den im realen Tagebuch des Künstlers festgehaltenen Erinnerungen ist zu entnehmen, dass er ihr seine Arbeiten zeigte und die Aussicht, die Zeichnungen mit ihr zu besprechen, ihn zusätzlich zu neuen Bildserien motivierte. ${ }^{523}$

Wie bereits in den beiden vorangehenden Kapiteln angemerkt, hatte Grass in den Sechzigerjahren von kubistischen und expressionistischen Gestaltungselementen Abstand genommen. Seine Arbeiten aus dieser Zeit weisen weiterhin Kompositionsschemata des Surrealismus auf, geben die einzelnen Objekte jedoch zunehmend naturgetreu wieder - eine Tendenz, die sich mit den Zeichnungen zum Schneckentagebuch weiter verstärkte. Zum einen könnte Grass' Beschäftigung mit der Kunst Albrecht Dürers sich in dieser Hinsicht auf sein eigenes Schaffen ausgewirkt haben. Über eine detaillierte Schilderung der Objekte hinaus kann jedoch weder hinsichtlich der Kompositionen noch der Linienführung eine Verwandtschaft zwischen den Arbeiten der beiden Künstler ausgemacht werden. ${ }^{524}$ Zum anderen könnte Grass von der zeitgenössischen Kunst inspiriert worden sein. Ende der Sechzigerjahre bestimmte der Fotorealismus das Ausstellungsgeschehen und der von Grass sehr geschätzte Horst Janssen erhielt den Grafikpreis der Venedig-Biennale von 1968. ${ }^{525}$ Grass' Radierungen, die häufig durch dichter oder weiter gestreute Punkte Volumen illusionieren, erinnern darin ferner an Tuschezeichnungen seines Freundes Ludwig Gabriel Schrieber, die zu Beginn der Vierzigerjahre entstanden sind. ${ }^{526}$

Eine Kontinuität zwischen den Zeichnungen des Gedichtbandes Ausgefragt (1967) und den mit Bleistift ausgeführten Schneckenbildern liegt hingegen in ihrer Kontrastarmut: Ein Großteil der Arbeiten ist betont blass gehalten. Die Verknüpfung der bildkünstlerischen Konzentration auf feine Grauwerte mit einer Botschaft im Text wird in den Schneckenzeichnungen und im Tagebuch

\footnotetext{
${ }^{523}$ Vgl. Akademie der Künste, Berlin, Günter-Grass-Archiv, Nr. 1758.

${ }^{524}$ Eine entgegengesetzte, aber nicht belegte Position vertritt Thompson (1990).

525 Grass hatte Janssen 1965 gebeten, Die Blechtrommel zu illustrieren. Wie sein kurzer Briefwechsel mit Janssens Frau Verena Janssen vermittelt, war der Grafiker in jener Zeit physisch nicht zu einem Projekt dieses Umfangs in der Lage. Vgl. dazu Akademie der Künste, Berlin, Günter-Grass-Archiv, Nr. 3365 und Nr. 7040.

${ }^{526}$ Vgl. Kat. Ausst. Berlin (2007), S. 8 f., S. 14, S. 17, S. 18, S. 20.
} 
ebenso deutlich wie zuvor in dem bebilderten Lyrikband. Erneut wird die Farbe Grau als Metapher der Skepsis verwendet. Im Tagebuch steht sie nicht nur mit der Kritik an metaphysischer und religiöser Spekulation in Verbindung, sondern auch mit dem Postulat der politischen Umsichtigkeit zwischen den Positionen der (schwarzen) CDU und der (roten) linken Studentenbewegung (V 305, 315, 356, 444 f.).

Von den zwischen 1969 und 1972 entstandenen Schneckenbildern in Bleistift, Filzstift und Kohle sind heute noch knapp fünfzig in Katalogen und Archiven zugänglich. 1972 begann Grass' Zusammenarbeit mit dem Berliner Drucker und Galeristen Anselm Dreher, der den Schriftsteller zum ersten Mal seit dessen Studium wieder an das Radieren heranführte. ${ }^{527}$ Fünfzehn der gezeichneten Schneckenmotive wurden 1972 in der Tiefdrucktechnik umgesetzt. ${ }^{528}$ Acht Motive wurden zusammen mit einem Gedicht in einer Mappe von Dreher vertrieben, als Grass eine Ausstellung seiner Arbeiten in Drehers Galerie André präsentierte. ${ }^{529}$

Grass' Zeichnungen zum Tagebuch zeigen drei Typen von Bildkompositionen: Schnecken mit einzelnen Gegenständen (im Folgenden als „emblematische Zeichnungen“ angeführt), Schnecken auf oder neben weiblichen Torsi sowie Schnecken in verschiedenen Landschaften. Im November 1971 unternahm der Schriftsteller eine Reise nach Israel, wo er für das Tagebuch recherchierte. ${ }^{530}$ In der Stadt Eilat entstanden Bleistiftzeichnungen, die jeweils eine Schnecke in der Kulisse des dortigen Umlands zeigen. Auf Reisen nach Griechenland und nach Polen und im Frühjahr 1972 zeichnete er ebenfalls Gastropoden, die er durch diese spezifischen Landschaften kriechen ließ. Entwürfe zum Umschlag des Tagebuchs schuf er im Winter 1971/1972. Kombinationen von Schnecken mit Pilz- und Fischmotiven leiteten nach Abschluss des Tagebuchs langsam zum nächsten Projekt, zum Butt, über. ${ }^{531}$

\footnotetext{
${ }^{527}$ Vgl. Grass (2014), S. 211, S. 227.

${ }^{528}$ Vgl. Ohsoling (2007), R 1-R 15.

${ }^{529} \mathrm{Vgl}$. Rolf Michaelis, „Schnecke im Auge“, Frankfurter Allgemeine Zeitung, 23.5.1972. Darin findet sich ein Hinweis auf die druckgrafische Sonderedition.

${ }^{530} \mathrm{Vgl}$. Grass (2014), S. 145

${ }^{531} \mathrm{Vgl}$. ebd.
} 


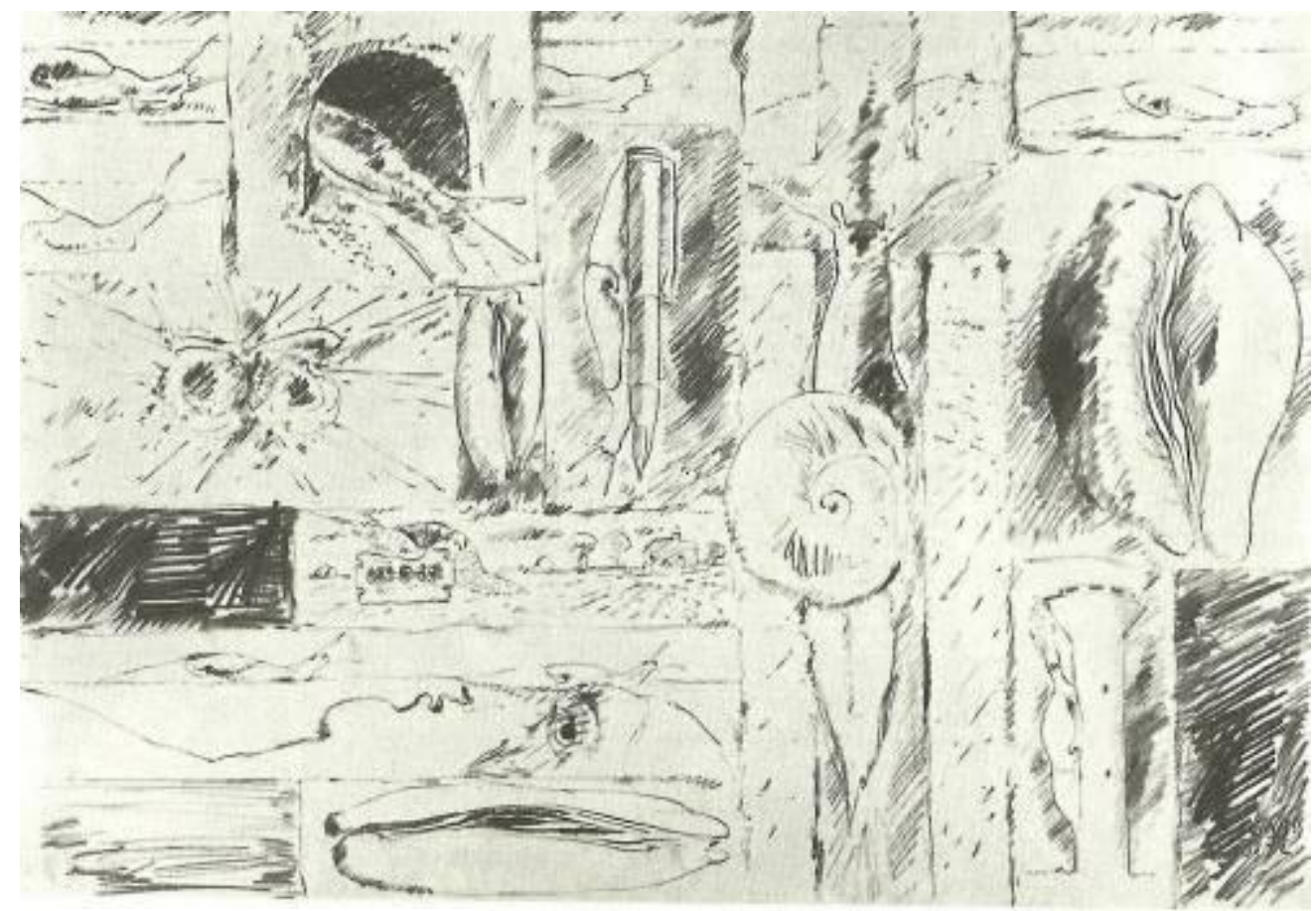

Abb. 134, Skizzenkomposition, 1972, Kohle

Abb. 135, Salvador Dalí, Gebirgssee, 1938, Öl auf Leinwand

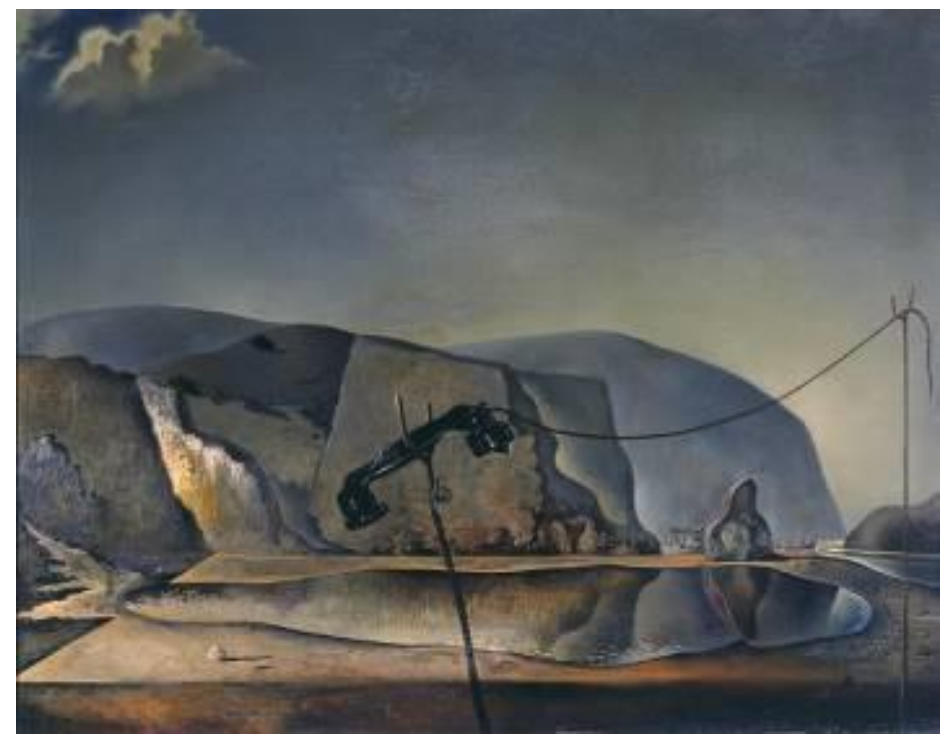

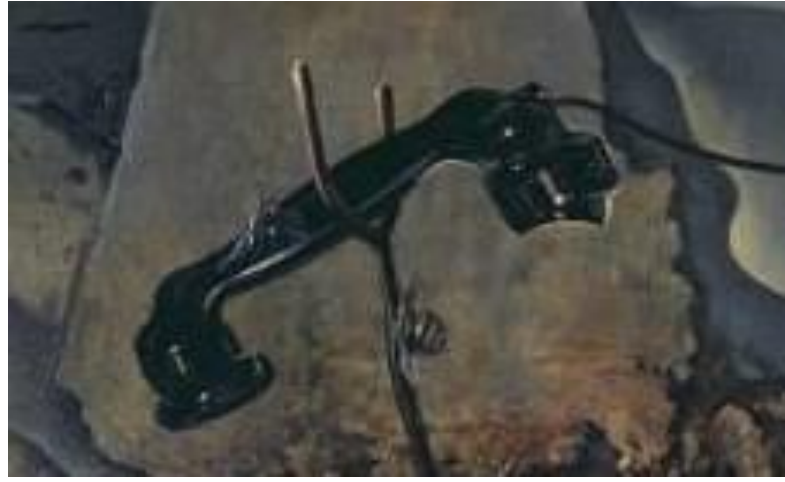

Abb. 136, Ausschnitt aus Abb. 135

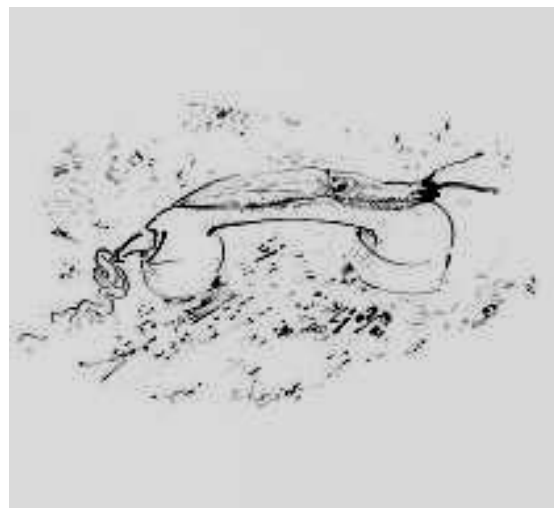

Abb. 137, Besetzt / Schnecke hört mit, 1971, Feder/Tusche 


\section{a) Emblematische Schnecken}

1972 zeichnete Grass eine zwischen Comic-Strip und Musterbuch angesiedelte Zusammenstellung von Miniatur-Schneckenbildern, die er durch Rahmenlinien deutlich voneinander trennte und deren Kompositionen er vorab einzeln in größeren Formaten umgesetzt hatte (Abb. 134). Das Blatt bietet einen Überblick über einige der im Folgenden als emblematische Zeichnungen zu bestimmenden Arbeiten.

In dem vorliegenden Sammelbild nimmt das Motiv einer Schnecke am Kreuz, leicht nach rechts aus dem Zentrum verschoben, von allen Kompositionen den größten Raum ein. Rechts davon ist eine Schnecke zu sehen, die an einem Wasserturm empor kriecht. Zur Linken der Kreuzdarstellung befinden sich die Schilderung eines über eine Rasierklinge gleitenden Weichtieres sowie die Darstellung eines Gastropoden auf einem Füllfederhalter und einer Schnecke, die sich auf Schienen aus einem Tunnel bewegt. Zudem ist unterhalb dieser Skizze eine Variante des Umschlagmotivs erkennbar - eine auf der Stirn eines Menschen sitzende Nacktschnecke.

Grass' Zeichnungen bilden die zusammengestellten Objekte meist ohne einen ausgestalteten Hintergrund ab und zeigen sie in einem engen Bildausschnitt. Die Skizzen ähneln darin den Zeichnungen, die der Schriftsteller zu seinen ersten drei Gedichtbänden geschaffen hatte. Ähnlich wie in den Bildern zum ersten Gedichtband Die Vorzüge der Windhühner (1956) werden die einzelnen Objekte losgelöst von jeglichem Kontext zu überraschenden Kombinationen zusammengefügt, wobei die Schnecke im Vergleich zu den mit ihr abgebildeten Dingen oder Lebewesen meist in starker Vergrößerung dargestellt wird. Die wirklichkeitsgetreue Abbildung der einzelnen Gegenstände fördert dabei eine stärkere Konzentration der Rezipienten auf die dargestellten Objekte als auf die Beschaffenheit ihrer Darstellung. Zum einen ergeben sich daraus Berührungspunkte mit bildkünstlerischen Arbeiten der Surrealisten wie den Werken Salvador Dalís, zu welchen eines der Schneckenbilder auch einen ikonografischen Bezug aufweist. Ein Vergleich dieser Zeichnung mit dem Titel Besetzt / Schnecke hört mit Dalís Gemälde Gebirgssee (Abb. 135, 136, 137) macht jedoch zum anderen deutlich, dass Grass' Arbeit nicht auf die perfekte Illusion einer Phantasie abzielt. Keine Traumlandschaft wird darin imaginiert; vielmehr werden die Betrachterinnen und Betrachter durch die Beschränkung auf wenige Objekte und durch die klare Konturierung des Dargestellten zum Nachdenken über die geschaffene Komposition angeregt. In diesen Eigenschaften erinnern die Grass'schen Schnecken-Stillleben an emblematische Icones und tatsächlich handelt es sich bei den meisten Zeichnungen um grafische Entsprechungen zu den oben behandelten Bildbeschreibungen aus dem Tagebuch.

Einige der Zeichnungen sind noch vor dem "Gleitspur"-Plan entstanden, ihr Großteil während Grass' Arbeit am Manuskript. Auch wenn eine zeitliche Abfolge zwischen geschriebenen und gezeichneten Icones nicht zu ermitteln ist, liegt ein Zusammenhang zwischen der Wiederaufnahme seiner Betätigung als Grafiker und dem Plan, literarische Embleme in das Tagebuch einzufügen, sehr nahe. Die Konzeption der sprachlich wiedergegebenen Objektkonstellationen ist eine bildnerische, eine grafisch-visuelle, und zudem als eine solche markiert. Mit Hilfe der entsprechenden Zeichnungen konnte Grass sie entweder vorbereitet oder nachträglich auf ihre visuelle Wirkung hin überprüft haben. 


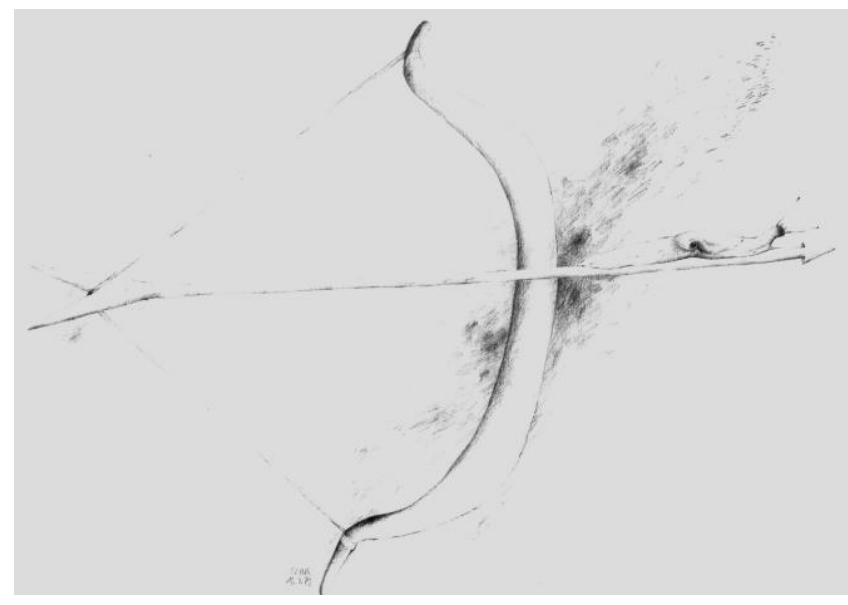

Abb. 138, Pfeilschnelle Schnecke, 12.3.1971, Bleistift

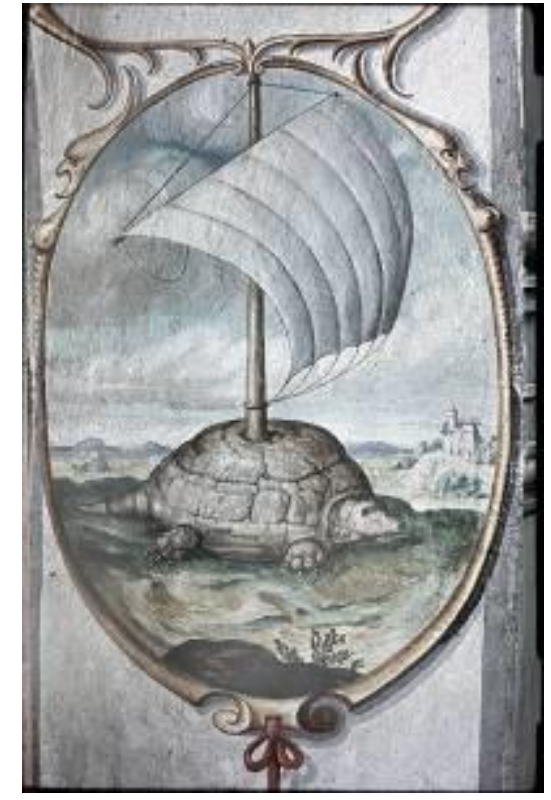

Abb. 139, Festina lente, 1613, Wandbild, Nürnberg, Altes Rathaus, zerstört 1944/1945, Aufnahme von Müller und Sohn $1943 / 1945$

Als besonders treffendes Beispiel für die Verwirklichung einer Bildidee in Literatur und Grafik mit einem Bezug auf die Emblematik bietet sich das Motiv der Schnecke auf einem Pfeil an (Abb. 138). Die Bleistiftzeichnung Pfeilschnelle Schnecke entstand am 12. März 1971, also fünf Monate vor dem "Gleitspur"-Plan. Sie zeigt eine Nacktschnecke, die auf dem Schaft eines in einen Bogen gespannten Pfeiles haftet. Die Eigenschaften der Schnelligkeit und Langsamkeit, die jeweils mit einem der Objekte assoziiert werden können, werden in der Zeichnung miteinander kombiniert. Die Grafik visualisiert das im Tagebuch als „Stillstand im Fortschritt“ auf den Punkt gebrachte Wechselspiel von Melancholie und Utopie, das im Prosatext mehrfach auf unterschiedliche Art erläutert wird:

Als habe der Fortschritt den Stillstand zum Echo. Als sei die Melancholie das Unterfutter der Utopie. Als hindere unverkäuflich den Läufer ein Klotz. Als begrüße am Endziel Schwermut den Sieger. Als leide die Welt unter Heuschnupfen und chronisch nicht nur Zweifel allein. (V 376)

Die folgende Beschreibung eines gezeichneten Icons in der Prosa fasst das Motiv im Gegensatz zu der vergleichbaren grafischen Komposition etwas weiter: Sie bezieht einen Schützen mit ein. Indem der Erzähler das Bild als Zeichnung beschreibt, stellt er einen Bezug zum Medium der Grafik her:

Ich zeichne euch, Kinder, einen Bogenschützen, der einen Pfeil einlegt, auf dessen Schaft eine Nacktschnecke haftet. (V 526)

Die Schnecke wird so zur Verkörperung der Melancholie als Stillstand im Fortschritt. Grass' DürerRede macht hinreichend deutlich, dass diese Drosselung der Geschwindigkeit nicht negativ verstanden werden soll. Der Schriftsteller kann sich mit dieser Haltung auf ganz bestimmte Embleme 
der Frühen Neuzeit berufen. Sowohl das gezeichnete als auch das beschriebene Bild der „pfeilschnellen Schnecke" erinnern an verschiedene Icones, die im 16. und 17. Jahrhundert das bedächtige Handeln als Tugend thematisierten. ${ }^{532}$ Das hier abgedruckte Wandbild zeigt ein weit verbreitetes Icon zum Lemma „Festina lente“, das zur Ausstattung des alten Nürnberger Rathauses gehörte. Das Gesamtprogramm wurde nach Entwürfen von Albrecht Dürer und Willibald Pirckheimer 1520 bis 1522 ausgeführt. 1613 wurde es um Embleme wie das hier abgedruckte ergänzt, die der Nürnberger Georg Volckamer mitunter Emblembüchern des ersten Drittels des 16. Jahrhunderts entnommen hatte. ${ }^{533}$ Nach der Zerstörung 1944/1945 ist das Bild nur noch in Abbildungen überliefert (Abb. 139). Es zeigt eine Schildkröte, in deren Panzer ein Segel eingelassen ist. Der Schubkraft des Windes, der das Segel aufbläht und das Tier antreibt, wird die Langsamkeit der Schildkröte entgegengesetzt. Das wenig später, 1617, in der Emblemata Politika von Peter Isselburg zur Darstellung veröffentlichte Epigramm weist das Icon als ein Lob auf das umsichtige Handeln aus. ${ }^{534}$

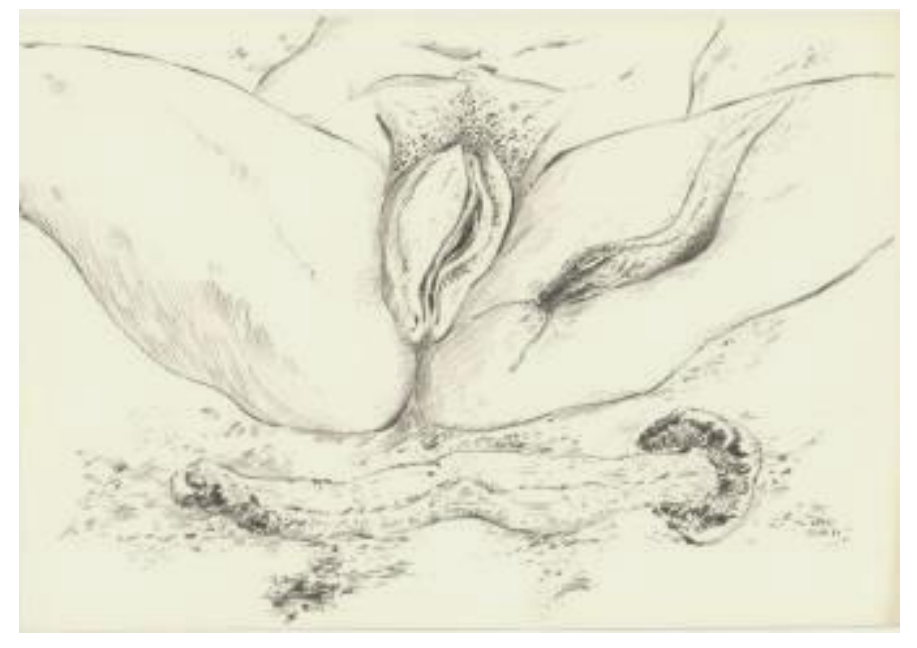

Abb. 140, Mit Pilz und Schnecke, 1971, Kohle

\footnotetext{
532 Vgl. Henkel/Schöne (1976), S. 612, S. 615, S. 618, S. 620, S. 785.

${ }^{533}$ Vgl. Mende (1979), S. 333-337 sowie S. 344 und Warncke (2005), S. 134-139.

${ }^{534}$ Vgl. das Epigramm zitiert nach Henkel/Schöne (1976), S. 615: „FESTINA LENTE Eile mit Weile Ein Schildkrot / obs schon langsam kreucht / Jedoch so sie sich nicht auffzeucht Auffm Weg / sondern emsig fortschreit / Kompts auch zum Ziel zur rechten Zeit. Wann was nur wol und glücklich geschicht. / Hat man's zeitlich gnug ausgericht."
} 
Grass' Bleistift- und Kohlezeichnungen von Schnecken, die über einen nackten weiblichen Körper kriechen, sind auf Oktober und Dezember 1971 sowie auf August und September 1972 datiert. ${ }^{535}$ Die Bilder zeigen stets eine Vulva im Zentrum. Meist sind innerhalb des gewählten Bildausschnitts noch die Ansätze der Oberschenkel, der Bauch und auf einem der Blätter auch die Brüste der Figur zu sehen. Die Schnecke wird der Nackten auf den Bauch oder auf einen der Oberschenkel gesetzt. Wie in dem hier abgedruckten Blatt wird diese Anordnung häufig mit einem langstieligen Pilz oder einer Rübe kombiniert (Abb. 140).

Die Zeichnungen betonen die formale Ähnlichkeit zwischen den Gastropoden und dem weiblichen Genital. Die vorliegende Zeichnung zeigt dies exemplarisch: Die leicht geschwollenen, wulstförmigen Schamlippen entsprechen in Länge und Breite der daneben platzierten Nacktschnecke. Hervorgehoben wird die formale Verwandtschaft dadurch, dass die Gestalt der Vulva der Sförmigen Körperhaltung des Weichtiers nachempfunden ist. Weitere brückenschlagende Aspekte zwischen der Erscheinung der Objekte wie Feuchtigkeit und Glätte, bleiben, da die Zeichnung lediglich die Form, nicht die Beschaffenheit der Körperoberfläche wiedergibt, der Phantasie von Betrachterinnen und Betrachtern überlassen. Die phallusförmigen Pilze, die im folgenden Kapitel noch eingehend untersucht werden, deuten auf eine bevorstehende oder bereits erfolgte sexuelle Handlung hin.

Grass' Zeichnungen bilden das visuelle Gegenstück zu der im Tagebuch beschriebenen, phantastisch anmutenden Schneckentherapie, mit deren Hilfe Hermann Ott seine Geliebte Lisbeth Stomma von ihrer reaktiven Depression heilt. Lisbeth ist schwermütig geworden, nachdem sie zu Beginn des Krieges ihren Geliebten und ihren Sohn verloren hat. Sie wird in jeder Beziehung und insbesondere in sexueller Hinsicht empfindungsarm. Dieser Zustand wird mit dem Zustand der Melancholie in Verbindung gebracht und die Figur der Lisbeth mit Dürers Darstellung der "Melencolia“. Sie werden etwa zusammengeführt, wenn auf eine Passage, die die Gefühllosigkeit der Danzigerin thematisiert, ein lyrischer Text folgt, der Dürers Melencolia buchstäblich Frigidität andichtet (V 475). Ferner wird darauf hingewiesen, dass Dürers Frau Agnes, die vermutlich für den Meisterstich Modell stand, ebenso xanthippische Züge getragen haben soll, wie sie Lisbeth nach ihrer Genesung zeigt (V 564).

Die Heilung vollzieht sich wie folgt: Ott bemerkt, dass das Auflegen einer Nacktschnecke von inm unbekannter Klassifizierung eine wohltuende Wirkung auf seine Geliebte hat. Wohl nicht zufällig auf eine Bildvorlage zurückgreifend (der Erzähler kommentiert sein Vorgehen mit einem Verweis auf Vorbilder in persischen Miniaturen, V 529), setzt er Lisbeth schließlich die Schnecke auf Hüfte und Venushügel, was zu einer extremen Reaktion führt, die er genau beobachtet und mit wissenschaftlicher Nüchternheit dokumentiert:

Die Normalisierung. Unter dem 6. November 1944 steht in Zweifels Schulheft: „Sogleich nach Beginn der Behandlung (Beckenpartie bis Schambein) steigerte sich L. St. in einen Erregungszustand, der nach etwa vier Minuten Dauer zum Orgasmus der Patientin führte. Nach zehnminütiger Pause (bei angesetzter Sogschnecke) kam es nach kurzer, doch von Beginn an starker Erregung abermals zum Orgasmus, wobei die Patientin zweimal den Vornamen des bei Kriegsbeginn gefallenen Roman

\footnotetext{
535 Kleinformatige Fotografien in der Akademie der Künste Berlin lichten zwei Zeichnungen vom Oktober 1971, eine Zeichnung vom Dezember 1971, zwei vom August 1972 und eine vom September 1972 ab (AdK, Berlin, Günter-Grass-Archiv / Sammlung Maria Rama, Nr. 583).
} 
Bruszinski (Vater ihres verstorbenen Sohnes Hannes) ausrief. Das Anschwellen der Schamlippen und reichlicher Ausfluß zeigte normal-geschlechtliches Verhalten an. Als sich die Sogschnecke über das Schambein zog, geriet die Patientin abermals in erregten Zustand: Zuckungen, rascher Atem, Aufgehen der Schamlippen, hechelndes Stöhnen. (Die Behandlung mußte ausgesetzt werden, weil das Atemloch der Sogschnecke Bläschen zu treiben begann.)“ - Zweifel hatte jetzt eine Frau. (V 542)

Sprachlich wird die ,Ähnlichkeit' von Schnecke und Vagina im Text nicht nur durch die Beschreibung von Feuchtigkeit ausscheidendem Tier und Genital, sondern auch explizit durch den dem Schweizerdeutschen entnommenen Kosenamen "S' Schnäggli“ hervorgehoben:

Wie Lisbeth als Frau normal wurde. (Mehrere Schweizer haben es mir bestätigt: „De Schnägg“ oder "'s Schnäggli“ oder „Du chlyne heerzige Schnägg“ sind nicht nur in Zürich-Nierendorf sondern auch in ländlichen Kantonen vulgäre und zärtliche Benennung der Vagina; bildlicher als Fötzchen oder Möse.) Ihr habt es gut. Laura wird ihr Schnäggli hüten, Franz und Raoul werden 's Schnäggli suchen, und Bruno wird viele Schnäggehüüsli bewohnen. (V 541 f.)

Die Formanalogie zwischen Scham und Schnecke wird jedoch erst in der Zeichnung offensichtlich. Mit der grafischen Umsetzung eines im Text nur angedeuteten visuellen Vergleichsaspekts greift Grass erneut auf Kennzeichen der Arbeitsteilung von Wort- und Bildkunst in seinem Schaffen zurück. Die Analogie unterstreicht die Bedeutung und Funktion der Schnecke in diesen Passagen des Tagebuchs, denn die zarte Berührung des Tieres, dessen Form und Oberfläche Ähnlichkeit mit der Gestalt der weiblichen Scham hat, ist in der Lage, Melancholie zu lindern. Die Schnecke erhält an dieser Stelle als Verkörperung der Zärtlichkeit eine weitere Rolle.

\section{c) Schnecken in der Landschaft}

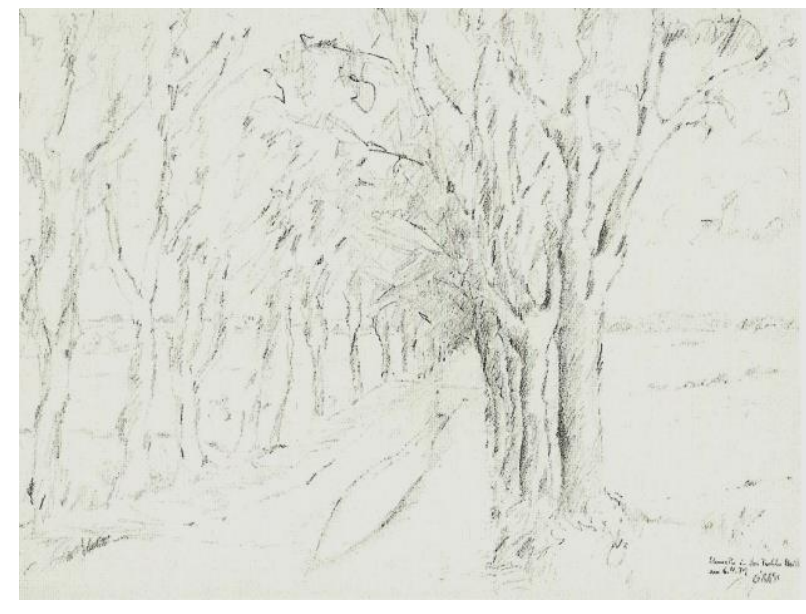

Abb. 141, Schnecke in der Tuchler Heide, 6.4.1972, Bleistift

Eine Reihe von Bleistift- und Kohlezeichnungen von Schnecken in bestimmten Landschaften schuf Grass auf seinen Reisen nach Israel im November 1971, nach Griechenland im März 1972 und nach Polen im April 1972. Blätter wie das als Schnecke in der Tuchler Heide betitelte vom 6. April 1972 zeigen jeweils eine im Verhältnis zu ihrer Umgebung stark vergrößerte Nacktschnecke (Abb. 141). Da auch diese Arbeiten äußerst kontrastarm sind, verschwinden die Tiere nahezu in den geschilderten Landschaften. In der Zeichnung wurde die Schnecke auf eine von Bäumen ge- 
säumte Allee gesetzt, die aus dem Bildvordergrund in den Hintergrund führt. Durch ihre Positionierung auf dem Landweg und ihre für die Zeichnung gewählte Körpergröße kann die Reisende mit einem Automobil assoziiert werden, wodurch gerade die Langsamkeit der Schnecke betont wird, die zum Kraftfahrzeug im Gegensatz steht.

Da der Grafiker Ort und Datum rechts vermerkt hat, scheinen sich in den Zeichnungen Schnecken- und Schriftstellerreisen zu überlagern: Die Schnecke ersetzt den prominenten Dichter, der sich zur selben Zeit am selben Ort befindet, im Bild und repräsentiert inn als ein Wesen, das langsam sein Umfeld erkundet. Die im „Gleitspur“-Entwurf angedeutete Gleichsetzung von Kriechund Schreibprozess wird in diesen Blättern zeichnerisch realisiert. Die Schneckenreisen entsprechen dabei dem Vorgang des Zeichnens nach der Natur, denn auch der bildende Künstler befühlt die Landschaft mit seinem Blick, um sie in der Zeichnung wiederzugeben.

Im Tagebuch wird die Darstellung des reisenden Schriftstellers und politischen Redners als Schnecke sprachlich umgesetzt. Dabei entwirft der Autor eine visuelle Vorstellung dieser Fantasie aus der Perspektive eines Kameramanns:

Wer filmt mich und zeigt einen Spielfilm lang, wie ich mich auf meinem Muskelfuß durchs Bergische Land seitlich dem Ennepetal, vorbei am Ruhrgebiet, von Unna über Kamen nach Bergkamen bewege? (V $347 \mathrm{f}$.)

Ein Teilmotiv, "die Schnecke am Horizont“, wie im Entwurf "Die Gleitspur“ notiert, imaginiert der Erzähler während des Urlaubsaufenthalts in der Bretagne („Wie sie über den Horizont kriecht, ihn langzieht: ohne Rauchfahne in Richtung Kanalinseln oder weiter." $V$ 455). Es findet sich grafisch sowohl im Umschlagmotiv, als auch in einer Bleistiftzeichnung wieder, die Grass während seines Aufenthaltes in Eilat schuf (Abb. 142). Beide, sowohl das sprachliche als auch das grafische Bild, setzen die distanzierte Perspektive, eine Vorstellung des Sehens aus der Entfernung voraus. Über die genau geschilderte Sichtweise des Erzählers wird die Passage als visuell vorstellbares Bild gekennzeichnet.

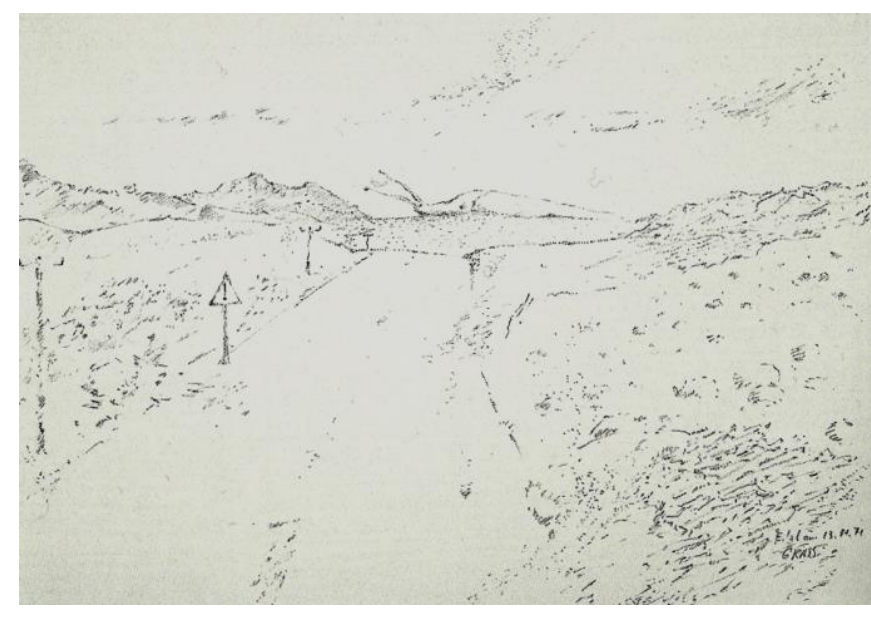

Abb. 142, Schnecke in Eilat, 13.11.71, Bleistift 


\section{Allegorie, Melancholie und Anschaulichkeit}

Für die konsequente Intensivierung des anschaulichen Schreibens im Tagebuch einer Schnecke sind bislang nur am Rande behandelte kunsthistorische und philosophische Einlassungen des Autors von großer Bedeutung: Grass' Auseinandersetzung mit Dürers Melencolia I (Abb. 143) und der Stilfigur der Allegorie sowie mit den Werken Arthur Schopenhauers. Beide Themenkomplexe gehen aus seinen Notizen und Vorbereitungsmaterialien hervor und werden im Prosatext ausdrücklich erörtert. Sie unterstützen die Wahrnehmung der bildhaften Gesamtstruktur des Buches und der darin eingestreuten Embleme. Zugleich erhält die bereits in Grass' programmatischen Gedichten aus Gleisdreieck formulierte Konzentration auf den Gegenstand um 1970 ein theoretisches Unterfutter.

Im März 1969 fragte der damalige Nürnberger Kulturdezernent Hermann Glaser bei Günter Grass an, ob dieser sich mit einem Vortrag an den Feierlichkeiten zum 500. Geburtstag Albrecht Dürers beteiligen wolle. Grass beschloss, über die Melencolia I zu sprechen (V 289 f., 579). Der Meisterstich begleitete ihn als Postkarte auf seiner Wahlkampftournee von März bis September 1969 und auf diversen anderen Reisen in den folgenden anderthalb Jahren. ${ }^{536}$

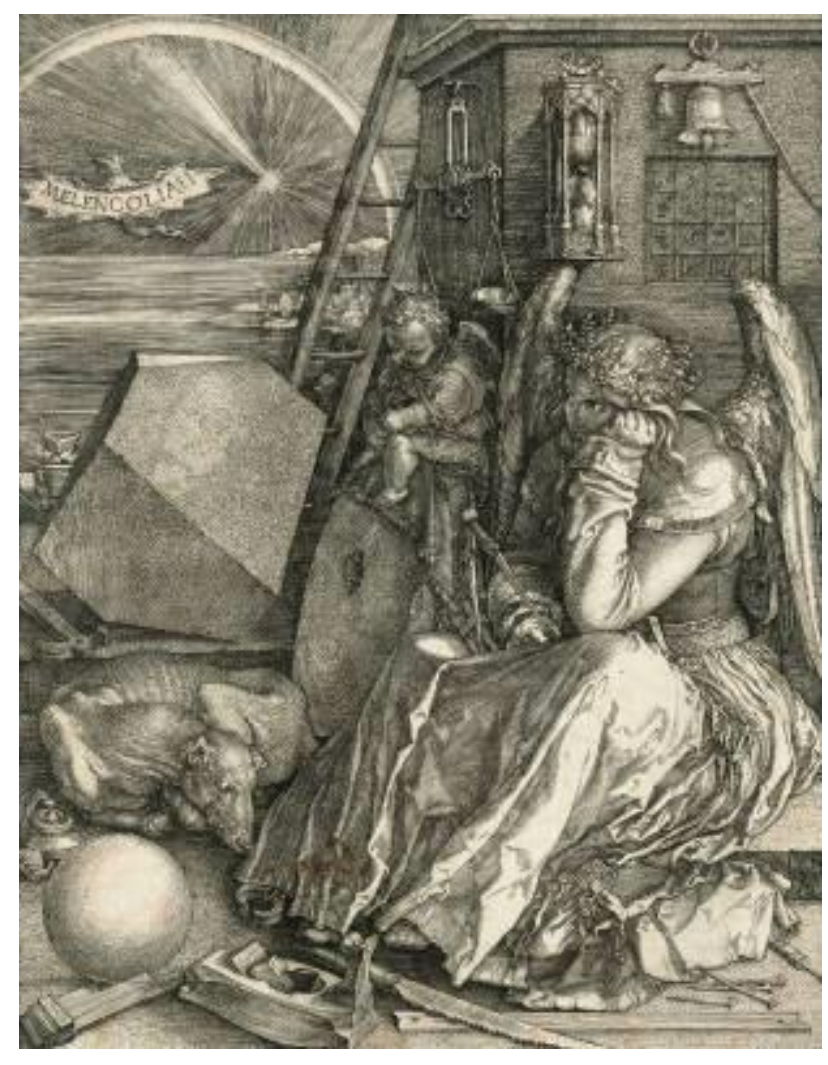

Abb. 143, Albrecht Dürer, Melencolia I, 1514, Kupferstich, Kupferstichkabinett, Staatliche Museen zu Berlin, Inv.-Nr.: 102-1893

\footnotetext{
${ }^{536}$ Die Karte befindet sich zusammen mit den anderen zwei Meisterstichen Dürers und dessen $H I$. Georg zu Pferd im Postkartenformat in der Akademie der Künste, Berlin, Günter-Grass-Archiv, Nr. 178.
} 
Kopien von Bibliotheks-Karteikarten, auf welchen verschiedene Titel der Dürer-Fachliteratur notiert sind, geben Auskunft über die mutmaßliche Lektüre des Schriftstellers. Die Literaturangabe zu Fritz Saxls und Erwin Panofskys Melancholie-Studie wurde von Grass mit drei Kreuzen besonders deutlich markiert. ${ }^{537}$

Grass nutzte die berühmte Publikation, wie es in einem 2009 aufgezeichneten Gespräch des Schriftstellers mit den Kunsthistorikern Peter-Klaus Schuster und Matthias Mende heißt, als „Lotse“ und „Trittleiter" zur Auseinandersetzung mit dem Meisterstich. ${ }^{538}$ Ein Abgleich seiner Rede mit den Befunden der Forschungsarbeit zeigt, dass der Schriftsteller den kunsthistorischen Beitrag rezipierte, um die Entstehung des Meisterstichs, die ikonografische Tradition, aus der er hervorging und die Kennzeichen seiner herausragenden Qualität im Vergleich zu zeitgleich entstandenen Werken referieren zu können (V 584-586, 589-592). Grass' Interpretation des Stichs setzt jedoch einen anderen Schwerpunkt als die Studie und zwar einen, der das Anknüpfen an eigene Melancholie-Erfahrungen ermöglicht. Während Panofsky und Saxl die Melencolia I als Ausdruck einer Resignation sehen, die den gebildeten Menschen der Frühen Neuzeit ereilt, weil er allem gewonnenen empirischen Wissen zum Trotz nicht über dieses hinaus in metaphysische Höhen vordringen kann, ${ }^{539}$ schilderte Grass sie als Ausdruck der Resignation darüber, dass Wissen auch in weltlichen Sphären nur geringe Wirkung zeigt, als "Stillstand im Fortschritt“:

Auflösung und Zerrissenheit, Krieg und Chaos ahnend, verzweifelten die Humanisten an der Machtlosigkeit ihres Wissens und an der Unwissenheit ihrer Macht. Ihrer Ohnmacht bewußt, nahmen sie Zuflucht in formal beherrschter Melancholie. Erst im folgenden Jahrhundert, solange der Dreißigjährige Krieg dauerte und nachwirkte, fand barocke Sprache zum Trauerspiel - Andreas Gryphius -, handelte barocke Lyrik vom Schmerz - Quirinus Kuhlmann -, wurde aus chaotischer Unordnung die Hoffnung zum Prinzip; ihr Ort hieß Jammertal, ihr Ziel: Erlösung.

Hier soll nicht gesagt werden, Dürer habe - über die Kupferplatte gebeugt - solch Ausmaß Elend und Verdunkelung voraussehen können, voraussagen wollen. Nur soviel: Ähnlich wie wir heute, sah

537 Es handelt sich um die Ausgabe: Erwin Panofsky und Fritz Saxl: Dürers Melencolia I. Eine quellen- u. typengeschichtliche Untersuchung, Leipzig 1923; markiert wurden ferner: Erwin Panofsky: Symbolism and Dürers Melencolia I., in: Morris Weitz (Hg.): Problems in Aesthetics. An Introductory Book of Readings, New York 1959, S. 360-379; Karl Giehlow: Dürers Stich Melencolia I und der maximilianische Humanistenkreis (Fortsetzung). In: Mitteilungen der Gesellschaft für vervielfältigende Kunst Wien 27 (1904), S. 57-78 sowie Heinrich Wölfflin: Zur Interpretation von Dürers Melencolia, in: Gedanken zur Kunstgeschichte. Gedrucktes und Ungedrucktes, Basel 1941, S. 96-105. Vgl. Akademie der Künste Berlin, Günter-Grass-Archiv, Nr. 178.

${ }^{538} \mathrm{Vgl}$. Das Gespräch wurde 2009 anlässlich des 500. Jubiläums des Albrecht-Dürer-Hauses in Nürnberg mit drei Kameraeinstellungen gefilmt und als dreigeteilte Bildschirmpräsentation im Albrecht-Dürer-Haus präsentiert: Schuster/Mende (2009).

539 Panofsky/Saxl (1923), S. 76: „So scheint denn, unbeschadet aller Zusammenhänge mit der Astrologie und der Medizin, mit Marsilio Ficino und den Planetenkinderbildern, doch auch die Empfindung derer gerechtfertigt, die in dem Kupferstich ,Melencolia I' etwas anderes sehen möchten, als ein, wenn auch noch so sehr veredeltes, Temperaments- oder Krankheitsbild: ein Selbstbekenntnis und einen Ausdruck faustischen ,Nichtwissenkönnens“", und Panofsky (1948), S. 168: „Melancholics, then, are gifted for geometry - for, Henry's own definition restricts the field of ,mathematics' to a science of ,situs et magnitudo' - because they think in terms of concrete mental images and not abstract philosophical concepts; conversely, people gifted for geometry are bound to be melancholic because the consciousness of a sphere beyond their reach makes them suffer from a feeling of spiritual confinement and insufficiency. This is precisely what Dürer's Melancholia seems to experience. Winged, yet cowering on the ground - wreathed, yet beclouded by shadows - equipped with the tools of art and science, yet brooding in idleness, she gives the impression of a creative being reduced to despair by an awareness of insurmountable barriers which separate her from a higher realm of thought." 
er die Grenzen seiner Zeit, sah er Neues ungeformt aufkommen, bedrückten ihn die Unzulänglichkeit und Ohnmacht des Denkens in Vorsorge. (V 595 f.)

Dürers Komposition des Stichs diente Grass als „Muster" für eine Darstellung von gegenwärtiger Schwermut, die er sowohl an sich selbst als auch in seinem Umfeld im Zuge seiner politischen Aktivität von 1969 erfahren hatte. Nach Vorbild des Meisterstichs entwickelte der Schriftsteller sprachliche Bilder, die aktuelle Formen der Resignation verkörpern. Bereits der Auftakt der Rede deutet diese Systematik an: Aufnahmen von der Landung der Apollo 11 auf dem Mond und der ersten Menschenschritte auf dem Himmelskörper werden mit Versatzstücken aus Dürers Melencolia I kombiniert:

Edwin Aldrin stellte die Waage, die Sanduhr, die Glocke auf, bettete das magische Zahlenquadrat und spießte den geöffneten Zirkel, der einen ordentlichen Schatten warf; Neil Armstrong zeichnete mit dem Finger im Handschuh groß und wie für ewig die Initialen des Nürnberger Meisters: zwischen gespreizten Beinen nahm das A im Mondstaub das D in Schutz. (V 578)

Diese Passage ist der Auftakt zu einer ganzen Reihe von Bildneuschöpfungen: Sprachlich skizziert wird zunächst die Melancholie der von ihrer Arbeit und sich selbst entfremdeten Arbeitnehmerin - einer am Fließband tätigen Fabrikarbeiterin, die sich dem Zusammensetzen von Plastikfiguren widmet, die Dürers Personifikation dreidimensional wiedergeben (V 580 f.). Dieser neuen Melencolia wird eine ebenso bedrückende Personifikation der Freizeit, eine „Touristica“, gegenübergestellt (V 581 f.). Daran schließt der Entwurf einer aus Kommunikationsunfähigkeit und Narzissmus gespeisten Wohlstands-Melancholie an, geschildert als eine sogenannte Grüne Witwe im Vorstadt-Bungalow (V 589). Es folgen die Vorstellung einer sozialistischen Schwermut, verkörpert durch Rosa Luxemburg, die von "Ausstellungsstücken der Revolution“ (V 593 f.) umgeben ist sowie einer von Geschichtslosigkeit geprägten „resignativen Utopie“, einer konsumfeindlichen Asketin im Leinenhemd, frei nach Herbert Marcuse (V 597 f.).

Diese als Collagen vorstellbaren Bilder einer gegenwärtigen Melancholie nehmen Dürers Melencolia I insofern zum Vorbild, als diese doch, wie bei Klibansky, Panofsky und SaxI nachzulesen ist, trotz der Menge der durch die Darstellung vermittelten Zusammenhänge „gleichwohl völlig konkret ist". ${ }^{540}$ Grass' Varianten folgen Dürers Komposition, verzichten jedoch auf Anleihen bei der traditionellen Melancholie-Ikonografie - so zum Beispiel seine sozialistische Melancholie, die als Arrangement um die Figur Rosa Luxemburgs angelegt ist:

Ich tausche den saturnischen Engel mit seinen Versatzstücken gegen eine vielzitierte Sozialistin aus. Anstelle des an sich irre gewordenen Zirkels hält sie Hammer und Sichel. Zu ihren Füßen sind die Ausstellungsstücke der Revolution versammelt: Lenins nach vorne weisender Finger, die Pickelhaubenmützen der Bolschewiki, in Modellgröße der Kreuzer Aurora, Trotzkis Kneifer, Karl Marx als Büste. Möge das Kommunistische Manifest - Titelblatt der Erstausgabe - für das Zahlenquadrat stehen. Möge anstelle des geometrischen Körpers ein Schema Hegelscher Dialektik Platz finden. Möge den unlustigen Hund der Weltgeist in Kleppergestalt verdrängen.

Auch die vielzitierte Sozialistin stützt den Kopf mit geballter Faust. Zwar blickt sie aus verschattetem Gesicht, aber wo sie hinblickt, öffnet sich nichts. Wohin hat sich ihr spontaner Sozialismus verflüchtigt? Unter altmodisch großem Hut ist sie von heute. Sie wurde vor hundert Jahren geboren. Das Dürerjahr und der Kupferstich Melencolia I regen an, ein Foto der Rosa Luxemburg zu montieren und nach drei vier Varianten ein weiteres Blatt, die „Melencolia V“, aufzulegen. (V 593 f.)

${ }^{540}$ Vgl. Klibansky/Panofski/Saxl (1992), S. 431 
Die von Grass in seiner Rede geleistete Übertragung der Melencolia I ins 20. Jahrhundert wird bereits im vorausgehenden Erzähltext eingeleitet. Der Erzähler des Tagebuchs streut einzelne Ideen und Assoziationen zum vorzubereitenden Vortrag in die Gegenwartshandlung ein und setzt sich gemeinsam mit seinen Kindern mit dem Stich auseinander. Dabei wird den Leserinnen und Lesern nicht nur das Kunstwerk vor Augen gestellt. Mit den Erläuterungen des Erzählers wird bereits der Weg zu den aktualisierten Melancholie-Darstellungen der Dürer-Rede gebahnt. Im Zusammenhang mit der Prosa des Tagebuchs erscheinen sie als Ergebnis der vorausgehenden Versuche, den Kupferstich für die Kinder sprachlich in ihre Alltagswelt zu übersetzen:

Ich zeige ihn [den Kupferstich, V. K.] Dir als Kunstpostkarte.

"Was issen mit der los? Sucht die ne Wohnung?"

Nicht angekündigt und vor die Tür gesetzt. Doch du hast recht. Man möchte Pechvogel sagen oder: bestellt und nicht abgeholt.

„Und was die für'n Kreuz hat. Und wie die dahockt."

Das läßt sich ausmessen: breitärschig knatscht sie über Verlust. Im Rheinland sagt man: „Das arme Tier haben." - So etwas wie schlechte Laune, oft auf Verstopfung, auf Blähungen, auf ausbleibenden Orgasmus zurückzuführen. Was das ist, erklär ich dir später. (Raoul kommt dazu und wirft einen Blick.) [...]. Ihr könntet meinen, dem armen Mädchen sei der Goldhamster weggelaufen oder es schaue (was der Kupferstich nicht zeigt) dem Fernsehprogramm zu: irgendein Quiz oder Kulturmagazin [...]. Heißt mal so, heißt mal so. Das Wort Weltschmerz läßt sich nicht übersetzen [...]. Zwar sage ich: Miesepetrig sauertöpfisch verschnupft - zwar deute ich: Sie bläst Trübsal, kaut Kummer, trägt schwer an sich; doch meine Befunde sind zu familiär, um diesem Waisenkind einen Namen zu geben. (V 400 f.)

Dürers Kupferstich bildet einen der Schnittpunkte zwischen der Handlung des Grass'schen Wahlkampfengagements und derjenigen um Hermann Ott. Auf seiner Flucht aus der Stadt Danzig nimmt Zweifel zwei Bilder mit, die er später in Stommas Keller auf der linken und rechten Seite eines Kellerfensters anbringen wird (V 400, 474, 533): Das eine ist ein „englischer, handkolorierter Stich einer gebänderten Schnirkelschnecke“, das andere eine Reproduktion der Dürer'schen Melencolia I als Postkarte. So ist die Melancholiedarstellung in beiden Handlungssträngen des Tagebuchs präsent.

Über die Figur Zweifels wird der enge Zusammenhang zwischen dem Zustand der Melancholie und der allegorischen Form, in der Dürer sie zum Ausdruck brachte, hergestellt. In Stommas Keller setzt Zweifel im Herbst 1944 ein Stillleben aus Gebrauchsgegenständen und Schnecken zusammen, das an entsprechende Gemälde des niederländischen Barocks erinnert und Melancholie veranschaulichen soll. Durch die Bezeichnung als Stilleben und die auf einen bestimmten Ausschnitt der wahrnehmbaren Wirklichkeit konzentrierte Beschreibung stellt Grass den Leserinnen und Lesern ein Bild vor Augen:

Auf dem Tisch hat er ein Stilleben aufgebaut: neben der Briefwaage aus Messing liegt die schönleise tickende Taschenuhr, deren Kette Umwege macht und auf das offene Rasiermesser hinweist, an das sich die Lupe (ohne Schnürsenkel) lehnt. Dazwischen, über die Uhrkette, auf dem Glasfuß der Waage und nahe dem offenen Rasiermesser bewegen sich oder zögern zwei Wegschnecken (ziegelrot torfbraun) zwei Weinbergschnecken (von denen eine später schadlos über das offene Rasiermesser gleitet) eine Gelbe Egelschnecke. Jetzt ruht die andere Weinbergschnecke mit ihrem Haus auf dem Glas überm Zifferblatt der schönleise tickenden Taschenuhr. Jetzt steigt die Egelschnecke am Messingständer der Briefwaage und wird sie zum Ausschlag bringen. Bezüge freihaus. Zweifel bezieht sich auf jenen Kupferstich (rechts vom Kellerfenster) und hat Spaß an seiner Melencolia. (V 532 f.) 
Die einzelnen Bestandteile der Anordnung spielen, wie schon die oben behandelten kurzen Icones-Beschreibungen, mit dem Gegensatz zwischen den Kennzeichen von Schnecken und solchen bestimmter Gegenstände und unterstreichen die Eigenschaften der Tiere positiv: Die Kombination von Uhr und Kriechtier hebt die Langsamkeit der Schnecke gegenüber der verstreichenden Zeit hervor, als könne erstere letztere aufheben - wieder wird ,Stillstand im Fortschritt' veranschaulicht. Die Kombination von Schnecke und Messer betont dagegen den Schutz, den der bedächtige Kriechgang vor Gefahren bietet. Zwischen den Gegensatzpaaren verdeutlicht die an der Waage hochkriechende Schnecke, dass auch etwas von scheinbar geringer Bedeutung Veränderungen herbeiführen und als sprichwörtliches „Zünglein an der Waage“ dienen kann. Der Erzähler-Kommentar „Bezüge freihaus“ schließt jedoch eine eindeutige Auslegung dieser Anordnung aus. Vielmehr scheint hier das Arrangement von bedeutsamen Objekten an sich die Melancholie zu versinnbildlichen. Diese Verbindung von barocker Allegorie und Melancholie geht offenkundig auf eine prominente Quelle zurück: Wie es zu Beginn des Buches heißt, hatte sich Zweifel mit dem Verhältnis von Allegorie und Melancholie auseinandergesetzt und dazu den Ursprung des deutschen Trauerspiels von Walter Benjamin studiert (V 375, 377). ${ }^{541}$

Bei Benjamin ist die barocke Allegorie Ausdruck einer sinnentleerten Welt, die dem Melancholiker unter den Augen in Bruchstücke zerfallen ist und die er erneut mit Bedeutung aufzuladen versucht. Die grundsätzliche Aussichtslosigkeit dieser Unternehmung finde sich in der allegorischen Form mitreflektiert, die nie eine Identität von Zeichen und Bezeichnetem suggeriere. Darin liege ihre große Qualität, die sie auch für die Auseinandersetzung mit der krisenbehafteten Moderne zum angemessenen rhetorischen Mittel mache. ${ }^{542}$ In Dürers Melencolia I sieht Benjamin die allegorischen „Bilder und Figuren“ des deutschen Trauerspiels vorweggenommen. ${ }^{543}$ Die vielfältige Verwendung von Allegorien im Prosatext des Tagebuchs einer Schnecke und in Grass' Rede zum Dürer-Jahr wird durch Benjamins „Rehabilitierung der Allegorie “544 theoretisch untermauert.

Die Figur Zweifels ermöglicht in ihrer Gelehrsamkeit zudem die Vermittlung des Diskurses um Begriff und Anschauung, die sich auf Ausführungen Schopenhauers stützt. ${ }^{545}$ Hermann Otts Begeisterung für den Danziger Philosophen wird in seiner Biografie verankert: In seiner Tätigkeit als Lehrer bringt er seinen Schülern Schopenhauers „skeptische Ansicht" nahe (V 308) und ist in seiner Freizeit als zweiter Sekretär der Schopenhauer-Gesellschaft tätig, „einer mehr lokalpatriotischen als wissenschaftlichen Versammlung älterer und aus Prinzip konservativer Herren“ (V 306, 308). Das Überleben in Stommas Keller wird ihm durch das Memorieren seines bisher gesammelten theoretischen und lebenspraktischen Wissens und das gedankliche Zwiegespräch mit dem „Pudelfreund“ erträglich. An der imaginären Unterredung mit Schopenhauer wird die Wertschätzung der beiden Diskutanten gegenüber Beobachtung und Anschauung hervorgehoben: „Sie legen

\footnotetext{
${ }^{541} \mathrm{Vgl}$. zum Zusammenhang zwischen allegorischem, bildhaftem Schreiben im Tagebuch und Walter Benjamins Überlegungen zur Vermittelbarkeit von Geschichte: Renz (2000), zur Allegorie und zum Bezug auf Benjamins Ursprung des deutschen Trauerspiels insbesondere S. 375.

${ }^{542} \mathrm{Vgl}$. Benjamin (1925), S. 336-366 und Drügh (2000), S. 281, S. 337, S. 343.

${ }^{543} \mathrm{Vgl}$. Benjamin (1925), S. 319, 335 und Drügh (2000), S. 328.

$544 \mathrm{Vgl}$. Hans-Georg Gadamer zitiert nach Drügh (2000), S. 281.

${ }^{545}$ Einen Überblick über Grass' Schopenhauer-Rezeption im gesamten literarischen Werk bietet Frizen (1987).
} 
sich Beobachtungen vor. Sie feiern Anschauung, bis es zur Erkenntnis, Teilerkenntnis kommt." (V 459). Der anschaulichen Erkenntnis steht das Denken in Ideen und Begriffen gegenüber, das im Tagebuch mit der Lehre Hegels verbunden wird (V 318, 326 f.). Die hohe Wertschätzung der Anschauung wird nicht nur mittels konkreter Einsprengsel zur Philosophie dargelegt, sondern spiegelt sich auch in Zweifels Unterrichtsfach Biologie und seinem Umgang mit Schnecken:

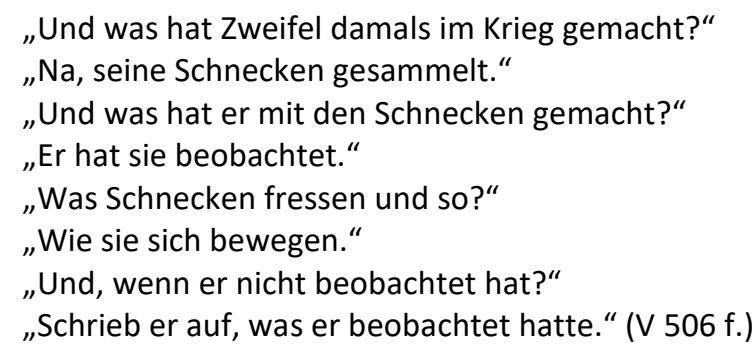

Schopenhauers gegen die Philosophie Hegels und gegen den deutschen Idealismus gerichtetes Plädoyer für die Anschauung ist dem siebten Kapitel des zweiten Bandes der Welt als Wille und Vorstellung zu entnehmen, der Passage „Vom Verhältnis der anschauenden zur abstrakten Erkenntnis." Anschauung wird dabei nicht nur mit Erkenntnis in Verbindung gebracht, sondern gilt darüber hinaus als Grundlage eines verinnerlichten, also nicht allein konventionell bestimmten, moralischen Handelns:

Die Anschauung ist nicht nur die Quelle aller Erkenntnis, sondern sie selbst ist die Erkenntnis ... [schlechthin], ist allein die unbedingt wahre, die echte, die ihres Namens vollkommen würdige Erkenntnis: denn sie allein erteilt eigentliche Einsicht, sie allein wird vom Menschen wirklich assimiliert, geht in sein Wesen über und kann mit vollem Grund sein heißen; während die Begriffe ihm bloß ankleben. Im vierten Buch sehn wir sogar die Tugend eigentlich von der anschauenden Erkenntnis ausgehn: denn nur die Handlungen, welche unmittelbar durch diese hervorgerufen werden, mithin aus reinem Antriebe unserer eigenen Natur geschehn, sind eigentlich Symptome unseres wahren und unveränderlichen Charakters; nicht so die, welche aus der Reflexion und ihren Dogmen hervorgegangen, dem Charakter oft abgezwungen sind und daher keinen unveränderlichen Grund und Boden in uns haben. ${ }^{546}$

Sowohl Günter Grass als Referent des Dürer-Jubiläums als auch der Erzähler des Tagebuchs teilen Schopenhauers und Zweifels Wertschätzung der Anschauung. In seiner Rede betont Grass, dass seine Ausführungen zur Melancholie sich vorrangig aus der Praxis, aus den Erfahrungen des Wahlkampfs von 1969 speisen und erst nachträglich durch die Lektüre einschlägiger philosophischer, kunst- und kulturwissenschaftlicher Studien ergänzt worden seien. Die in der betreffenden Passage enthaltenen Sätze zum Begriff der Anschauung hatte Grass erst in einer der späteren Fassungen des Manuskripts eingefügt - sie wurden also sehr bewusst dort platziert: ${ }^{547}$

Vernarrt in Gegenwart und täglich von Stimmungen demi-politischer Trübung umspült, fiel es mir schwer, jene Distanz zu gewinnen, die den wissenschaftlichen Blick kühl und das Thema trocken zu halten hat. Weil ich, verehrte Vertreter der Wissenschaft, so eng umstellt war von den Ausrufern einander überhüpfender Utopien und täglich, ob in fränkische oder emsländische Verhältnisse gebracht, der Melancholie ins Stopfgarn geriet, fand sich wenig Zeit, bei Aristoteles und Ficino, bei

\footnotetext{
${ }^{546}$ Vgl. Schopenhauer (1873/1996), S. 103.

547 Vgl. Akademie der Künste Berlin, Günter-Grass-Archiv, Nr. 178, undatiertes Manuskript, masch. m. hs. Korrekturen, S. 30.
} 
Burton und Shakespeare, bei Kierkegaard und Schopenhauer, bei Benjamin und Marcuse nachzuschlagen. Weder Panofsky noch Saxl schoben mir Spickzettel zu. Erst später verglich ich bei Wolf Lepenies und Arnold Gehlen, wie sich linke Melancholie zur rechten verhält. Erst später konnte ich eigene Anschauung durch Lektüre bestätigen, in Frage stellen, erweitern. Meine Anschauung sagt: Dort, wo sie ausbricht stattfindet andauert, ist sich Melancholie ihrer selbst nicht bewußt [...]. (V 583) [Hervorhebung der neu in das Manuskript eingefügten Passage: V. K.]

Der Zugang zum Thema der Melancholie über die sinnliche Wahrnehmung wird in der Rede am Beispiel einer in Stockholm beobachteten und unmittelbar literarisch wie bildkünstlerisch mit Bezug auf Dürers Melencolia I umgesetzten Szene erläutert:

\begin{abstract}
Ich notierte, was ich sah, was mir überdies einfiel und was sich, unabhängig von enger Fotooptik, als Zusammenhang und Widerspruch begreifen ließ: [...]. Ich schrieb auf und skizzierte: Wie Karl der Zwölfte an überlängtem Arm mit der Hand nach Osten weist. Die nicht beeindruckten Möwen. Entrückten Verkehr, sein Geräusch. Den sozial kreisenden Joint. Gesten der verspielten und der abflauenden Liebe im Licht unter Bäumen. [...] Ich sah: In einer Luftblase, entrückt, Macht und Ohnmacht. Die Erwartung eines gegenstandslosen Messias. Mao-Büchlein und ältere Breviere. Dürers komplexe Versammlung bei schönem Wetter. (V 599 f.)
\end{abstract}

Der Erzähler des Tagebuchs tauscht sich während seines Urlaubsaufenthalts in Plurien in Gedanken mit seinem Protagonisten Zweifel über Dürers Melencolia I aus. Zu ihren Diskussionsthemen zählt auch die „allegorische Sinngebung“:

Zweifel kommt auf. In vollen Aschenbechern alles bewiesen. Jeder Topf fand sein Deckelchen. Beim Vornamen gerufen, rief das Geheimnis: Hier! Wir plauderten (bei bretonischem Cidre) und stritten (bei Ebbe am Strand) über die Zange unterm Rocksaum, über das magische Zahlenquadrat und den Zirkel, allgemein über allegorische Sinngebung. Wir zitieren Benjamin und Proust, den konservativen Gehlen und dessen linken Schüler Lepenies, Zweifel (mit Vorliebe) seinen Pudelfreund, ich (mit Vorliebe) den buckligen Meister der Pfennigwahrheiten. (V 461)

Bei seinen Spaziergängen mit dem imaginären Freund Zweifel umschreibt der Erzähler viele der oben behandelten emblematischen Schneckenbilder - Anschauung wird nicht nur zum Gesprächsgegenstand, sondern findet auch unmittelbar Anwendung. Die Bleistiftzeichnung Schnecke am Wasserturm (Abb. 149), entstanden am 15. August 1971, steht mit der folgenden Bemerkung in Verbindung:

Den Wasserturm von Plurien, wie er bleich gegen den Himmel steht, seitlich (der Anschauung wegen) von meiner Schnecke besteigen lassen. (V 456)

Wie eine Erweiterung des Sehsinns tastet die Schnecke in der Vorstellung des Erzählers das phallisch-vertikale Wasserreservoir ab. Die Schnecke wird zur Erweiterung der Anschauung ins Taktile. In der Zeichnung werden Tier und Gebäude einander hinsichtlich ihrer Größe angenähert, so dass ein surreales Bild entsteht. 


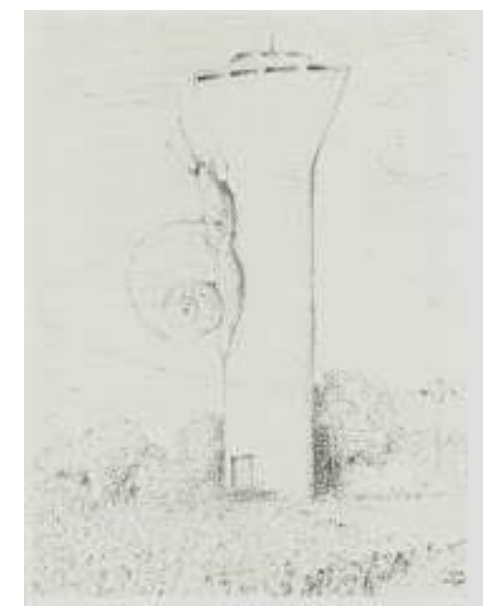

Abb. 144, Schnecke am Wasserturm, 15.8.1971, Bleistift

Die Betonung der Anschauung gegenüber dem begrifflichen Denken als Weg zur Erkenntnis fügt sich in eine generelle Kritik des Erzählers an der linkshegelianischen Welt- und Geschichtsbetrachtung. Das Gegensatzpaar Schopenhauer und Hegel wird auf der Gegenwartsebene thematisiert, um der sich auf Hegel stützenden Ideologie der linken Studentenbewegung mit Schopenhauers Skepsis zuzusetzen. Oder: Nur das anschauliche Denken ermöglicht Grass zufolge einen aufgeklärten Umgang mit Geschichte und Gegenwart. ${ }^{548}$

\section{Anschaulichkeit und Aufklärung}

Die große Bedeutung, die im Tagebuch dem Sehen und der Anschaulichkeit im weitesten Sinne zukommt, konnte an verschiedenen Elementen des Tagebuchs aufgezeigt werden: Sie wird grafisch in der Umschlaggestaltung hervorgehoben, die Auge und Autor zueinander in Beziehung setzt; sie zeigt sich an einer Gesamtstruktur des Buches, die aus grafischen Schnecken-Schemata entwickelt wurde, und sie wird an emblematischen, gezeichneten und beschriebenen Schneckenbildern manifest sowie durch die Diskurse über die allegorische Sinngebung und Schopenhauers "anschauliche Erkenntnis" untermauert. Diese Aspekte werden in Grass' Sudelbuch miteinander verzahnt und in seinen „Variationen“ zu Dürers Melencolia I verdichtet.

Nun ist das Tagebuch einer Schnecke ein Werk mit didaktischem Anliegen. Der Autor-Erzähler macht deutlich, dass er sich mit seinem politischen Engagement in den Dienst und in die Tradition der Aufklärung stellt (V 596). Diesem Impetus folgt auch die Anrede des Buches an die Kinder. ${ }^{549}$ Zwar ist das Werk in seiner gedruckten Fassung nicht mehr durchgehend explizit an den Nachwuchs gerichtet. Dennoch gilt hauptsächlich inm die Erzählung und es ist ein deutlich erkennbares Anliegen des Vaters, seine Lebenserfahrungen an die Kinder weiterzugeben, innen von seiner künstlerischen Tätigkeit und seinem politischen Engagement zu erzählen und ihnen - vor allem anderen - das Gedenken der Schoah als grundlegende Motivation seines Einsatzes zu vermitteln.

Der Erzähler reflektiert die Problematik dieser Vermittlungsarbeit mit. Angesprochen wird sein Werben um die Aufmerksamkeit der Kinder und sein Bemühen um bildhaftes Erzählen. Als Nega-

\footnotetext{
${ }^{548}$ Vgl. Frizen (1987), S. 157; Grass/Zimmermann (1999), S. 112.

${ }^{549} \mathrm{Vgl}$. Stolz (1994), S. 310.
} 
tivfolie dienen dabei andere Informationsmedien: das Fernsehen und die Zeitung. Der Vater tritt mit seinen Erzählungen gegen flimmernde Unterhaltungsbilder an:

Sobald ich etwas (das nur Bild ist) zu erklären versuche, hört ihr viermal verschieden zu oder weg oder anderes. Ich versuche, einfach zu sprechen (bildhaft) möglichst für jeden und für Laura besonders.[...] Plötzlich, mitten im immer stärker schlingernden Satz, ist es Zeit für Bonanza, Flipper, Sandmännchen-Ost...

„Dürfen wir?“

„Fängt gleich an.“

"Guck doch mit."

„Nachher darfste auch wieder über Biafra und so.“ (V 383 f.)

Der buchstäblich platten Zeitung stellt der Erzähler das plastische Formen in Ton gegenüber, aus dem heraus das biblisch-märchenhafte Bild einer Schneckenarche für die Flucht der Danziger Juden über das Meer entworfen wird.

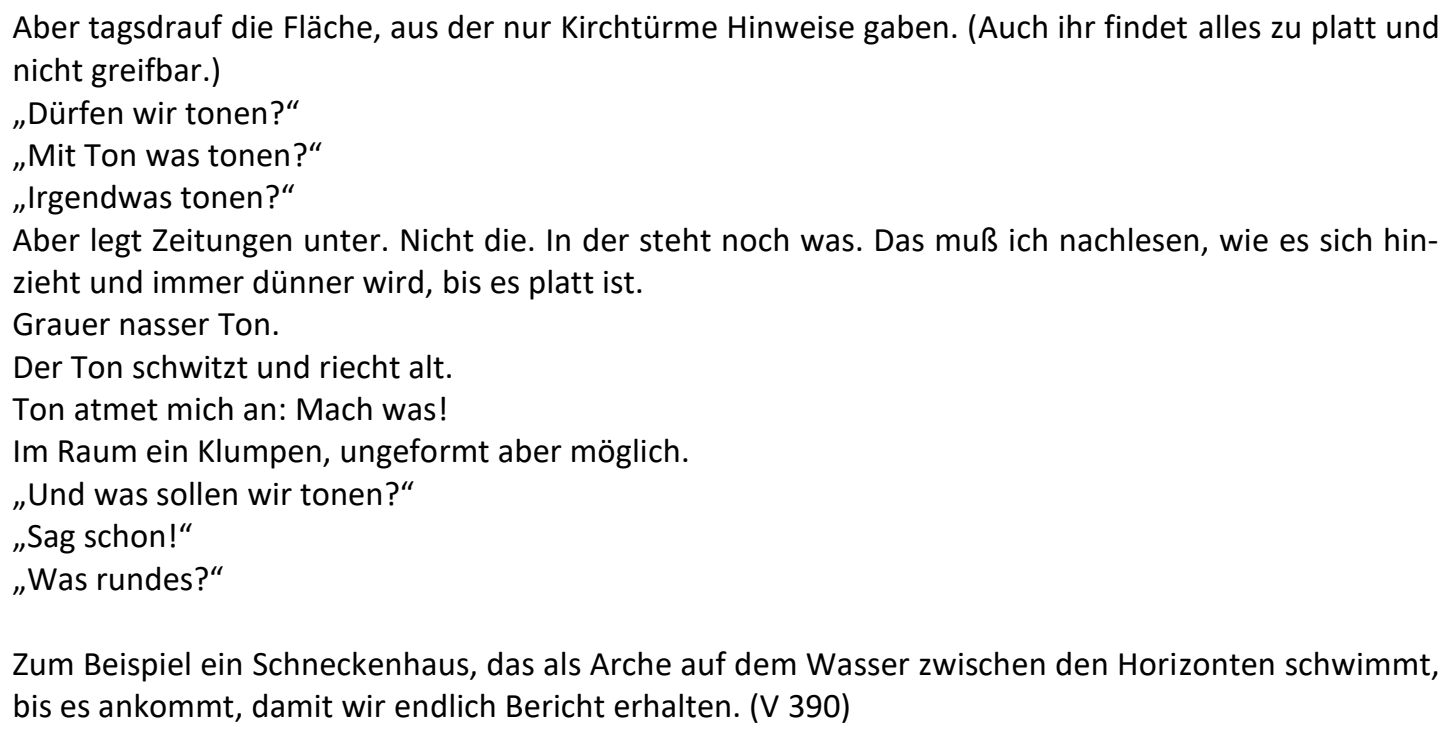

Zum Beispiel ein Schneckenhaus, das als Arche auf dem Wasser zwischen den Horizonten schwimmt, bis es ankommt, damit wir endlich Bericht erhalten. (V 390)

Die oben behandelten und auf visuelle Vorstellbarkeit abzielenden Schachzüge des Erzählers werden durch weitere Formen des weniger anschaulichen als eindringlichen Erzählens ergänzt: mit Bezug auf Äsops Fabeldichtungen durch Schneckenfabeln (V 408), durch Zweifels belehrendes Kellertheater und nicht zuletzt durch die Erfindung der Figur Hermann Ott selbst, der den Kindern - die sich bereits von dem Tagebuch der Anne Frank berührt gezeigt haben (V399) - die Geschichte der Danziger Juden als Identifikationsfigur nahe bringen soll und zugleich eine Personifikation der Skepsis darstellt.

Das anschauliche Schreiben trägt wesentlich zur didaktischen Vermittlung der Inhalte des Tagebuchs bei. Wie die ersten Kapitel der vorliegenden Untersuchung gezeigt haben, ist ein aufklärerischer Anspruch in Grass' Werk nicht erst in den Siebzigerjahren erkennbar. Seine auf die sinnliche Überprüfung der Wirklichkeit setzende Poetologie entwickelte er im Wechselspiel mit der bildenden Kunst in der ersten Hälfte der Fünfzigerjahre. In Aus dem Tagebuch einer Schnecke zeigt sich dieser grundsätzlich schon aufklärerische Zug seiner Literatur jedoch noch stärker in 
einer Kombination aus Aufklärungsdenken und Empirismus. ${ }^{550}$ Durch Schopenhauer wird dieses Programm unterfüttert, durch Benjamin die Bestätigung der Allegorie als zeitgemäße Kunstform gestützt und mit dem Motiv der Schnecke in verschiedenen Varianten vorgeführt. Wie schon in den Fünfzigerjahren geht die Betonung des Anschaulichen mit einer intensiven bildkünstlerischen Betätigung einher. Beide künstlerischen Ausdrucksformen rücken über den in Texten und Zeichnungen gleichermaßen deutlichen Bezug auf die Icones der Emblematik und ihre gemeinsame Wurzel im Zeichen näher zusammen als je zuvor. Die Schnecke stellt kein beliebiges Sujet dieser bildgebenden Methoden des Tagebuchs dar, sondern versinnbildlicht durch ihre besonderen Eigenschaften die Verlängerung des Sehens in das Fühlen. ${ }^{551}$

550 Vgl. Grass/Zimmermann (1999), S. 122; hier erklärt Grass in Bezug auf das Aufklärungsdenken im Tagebuch: „Ich möchte das Aufklärungsdenken auch erweitern. Ich möchte nicht von der Vernunft weggehen, sie aber von den Fesseln der Vernunft befreien, um wieder Phantasie, Lebensnähe, Anschauung hineinzubringen. Das war mein Versuch: die Aufklärung der Vernunft mit den Mitteln der Aufklärung."

551 Vgl. Renz (2000). 


\section{Pilze: Ausloten des Irrationalen}

Bereits in den Akt-Stillleben, die Grass anfertigte, während er die Arbeit an Aus dem Tagebuch einer Schnecke beendete, treten Pilze zusammen mit Schnecken in Erscheinung. In den Darstellungen repräsentieren verschiedene Naturobjekte Geschlechtlichkeit und Fortpflanzung. Die Kompositionen bilden einen Übergang zwischen den Zeichnungen, die von 1969 bis 1972 zum Tagebuch entstanden sind und folgenden Arbeiten, die die Themen des 1977 veröffentlichten Butt umkreisen. ${ }^{552}$ In diesen zwischen 1973 und 1977 geschaffenen Werken kommt Pilzen eine wichtige und vielfältige Rolle zu. ${ }^{553}$ Auf Grass' Plädoyer für das vernünftige, besonnene Handeln im Tagebuch folgt im Butt eine Auseinandersetzung mit irrationalen Aspekten des menschlichen Denkens und Verhaltens, die literarisch und bildnerisch in Darstellungen des Pilzmotivs vollzogen wird.

1972 bezog Grass gemeinsam mit seiner neuen Partnerin Veronika Schröter ein Haus in Wewelsfleth an der Westküste Schleswig-Holsteins. Die abgeschieden in der Wilstermarsch gelegene Wohnstätte bot inm Motive aus der Tier- und Pflanzenwelt für sinnbildliche Darstellungen in Wort und Bild, in welchen der Naturbeobachtung eine große Bedeutung zukommt. Dabei beschäftigte er sich in seinen Schilderungen von Pilzen mit Empfindungen und Verhältnissen, die die fühlenden Akteure zeitweise in einen Zustand der Blindheit versetzen: Ausgehend von der Form verschiedener Pilzsorten stellte Grass Bezüge zur männlichen und weiblichen Sexualität her und bettete sie in eine umfassende Auseinandersetzung mit dem Thema der Liebesbeziehung ein. Der Schriftsteller nutzte den Topos des Feuchtgebiets, auf welchen in der Literatur und Kunst gemeinhin gerne zur Schilderung von körperlicher Liebe zurückgegriffen wird. Besonders Pilze bieten sich dazu seit der Antike aufgrund ihrer schnellen Fortpflanzung und ihrer phallischen Form an. ${ }^{554}$

Pilze dienten Grass bereits in der Blechtrommel zu einer Konkretisierung der Liebe und ihrer Abgründe in sinnlich erfahrbaren Gegenständen: Der sechzehnjährige Oskar Matzerath meint zwischen den Beinen seiner Geliebten Maria Moos zu riechen und Pfifferlinge zu schmecken. Grass vermittelt in seinem Debütroman die sexuelle Erfahrung des Protagonisten, indem er sowohl das Begehren als auch die Vergänglichkeitsempfindung des Liebenden an bestimmte Gerüche und Geschmäcke koppelte. Die folgende lyrische und grafische Verwendung des Pilzmotivs im Gedichtband Ausgefragt (1967) als Zeichen für die nukleare Verseuchung, blieb ein weitgehend nachhallloses Intermezzo. In den Siebzigerjahren wurde der Einzeller wieder in geschlechtliche Zusammenhänge eingebunden. ${ }^{555}$

1973 veröffentlichte Grass ein Buch, das das Gedicht „Mariazuehren“, Fotografien von Maria Rama und einen Querschnitt durch sein bis dato geschaffenes bildkünstlerisches Werk enthält,

\footnotetext{
552 Grass (2014), S. 165: „Gedichte und Zeichnungen kreisten das Thema ein, setzen Pfähle in noch unvermessenes Land. Kurze Prosa zum Ausprobieren. Kochrezepte, Anleitungen zum Aaleschlachten, der Umgang mit neuer Landschaft, die so neu nicht war: die Wilstermarsch bei Wewelsfleth [...].“

${ }^{553}$ Die erste Zusammenstellung grafischer Pilzmotive bot: Hille-Sandvoss (1987), S. 162-185, aktualisiert im Motivverzeichnis der vorliegenden Publikation.

${ }^{554} \mathrm{Vgl}$. Leonhard (2013), S. $26 \mathrm{f}$.

555 Vgl. Hille-Sandvoss (1987), S. 162 f. Der Pilz kommt im Gedichtband aufgrund seiner dem Atompilz ähnlichen Form und seiner Eigenschaft, radioaktive Strahlung zu speichern, zum Einsatz. Diese Verwendung des Motivs wird erst in Grass' letztem Buch Vonne Endlichkait (2015) erneut aufgegriffen.
} 
zudem Montagen seiner Bilder mit handschriftlich niedergelegten Versen aus dem Gedicht und mit Maria Ramas Fotos. ${ }^{556}$ Ein Jahr später publizierte er ein Portfolio mit sieben originalen Radierungen und sieben Gedichten unter dem Titel Liebe geprüft. ${ }^{557}$ In beiden Veröffentlichungen verweisen Pilze durch ihren an das männliche Glied erinnernden Stiel auf Männlichkeit und versinnbildlichen einen andauernden und die Menschheit erhaltenden Fortpflanzungsdrang. In den Gedichten und im Butt (1977) wird das Motiv ferner in den ökonomischen und gesellschaftspolitischen Zusammenhang von Überbevölkerung und Hunger eingebettet. Vor dem Hintergrund der feministischen Debatten dieser Jahre, die auch in der Beziehung von Grass und Veronika Schröter im Privaten geführt wurden, dienen viele der Motivrealisierungen darüber hinaus dazu, den Wandel von Rollenverständnissen zu sondieren. ${ }^{558}$ Indem Grass die phallische Form von Pilzstielen und die vaginale Form bestimmter Pilzhüte besonders herausarbeitete, gestaltete er die Pilze als Zwitterwesen, die gleichermaßen männliche und weibliche Elemente enthalten. Die Vorgänge des Zeugens und Gebärens wurden auf diese Weise in einem Motiv zusammengeführt.

In Mit Sophie in die Pilze gegangen (1976/1987) $)^{559}$, das als Künstlerbuch und als Gedichtband veröffentlicht wurde, und im sechsten Kapitel des Butt nutzte Grass die Tätigkeit des Pilzesammelns, um allegorisch den Beginn und den Zerfall von Liebesbeziehungen zu charakterisieren: Das Verlorengehen und Wiederfinden der Pilzesammlerinnen und -sammler im Wald wie auch das Prüfen und Vergleichen der getätigten Funde veranschaulichen das Auseinanderdriften und sich Annähern der Liebenden sowie das Begutachten ihres Verhältnisses. Der Vorgang wird als ein irrationaler dargestellt, der sich eher über den Tast- als über den Sehsinn vermittelt. Im Roman wird folgerichtig auf die drohende Gefahr der Fehleinschätzung, Verwechselung und der Idealisierung des geliebten Gegenübers verwiesen. Die Wirkung des Pilzverzehrs - von wohltuender Sättigung über den Rausch bis hin zur tödlichen Vergiftung - spiegelt die Bandbreite der Emotionen, die diese Vorgänge auslösen können.

In das sechste, zeitlich um 1800 verortete Kapitel des Butt gebettet, erfährt das Motiv des Pilzes nicht nur eine Aufladung mit der Bedeutung der Idee der Liebe, sondern wird schließlich an die Idee an sich geknüpft, die sowohl im Zusammenhang mit den Vorstellungen der Romantiker als auch mit denjenigen der Verfechter der Französischen Revolution thematisiert wird. Bei seiner Auseinandersetzung mit Gefühl, Trieb, blindem Idealismus und Romantik verwendete Grass erneut fantastische Motivkombinationen und hob in Wort und Bild das Nicht-Sehen der Beteiligten als wesentliches Charakteristikum hervor. Die frühe Prägung des bildenden Künstlers durch den Surrealismus zeigt damit auch in seinen Arbeiten der Siebzigerjahre Wirkung. Die folgende Untersuchung der Grass'schen Pilzdarstellungen in verschiedenen Medien und Veröffentlichungen widmet sich gemäß der zeitlichen Abfolge ihrer Entstehung zunächst dem Kooperationsprojekt mit der Fotografin Maria Rama, Mariazuehren.

\footnotetext{
556 Grass (1973).

557 Liebe geprüft, Sieben Radierungen und Gedichte, Bremen: Schünemann Verlag 1974. Die Bilder und Texte gingen 1983 zusammen mit anderen Grafiken und Gedichten in den Gedichtband Ach Butt, dein Märchen geht böse aus ein: Grass (1983).

558 Vgl. Neuhaus (2012), S. 285.

559 Vgl. Günter Grass: Mit Sophie in die Pilze gegangen, Lithografien und Radierungen, Mailand: Giorgio Upiglio 1976 und Grass (1987).
} 


\section{Mariazuehren (1973) - lustvolle Anbetung des Sichtbaren}

Grass lernte Maria Rama (1911-1997) bereits während seines Kunststudiums in Berlin kennen. Sie führte gemeinsam mit ihrem Mann, dem Fotografen Hans Rama, ein Fotoatelier am Kurfürstendamm, das auf Porträts von Künstlerinnen und Künstlern verschiedener Disziplinen spezialisiert war. Ihre Freundschaft begann, als Hans Rama in den Fünfzigerjahren Aufnahmen von Grass' erster Ehefrau, der Tänzerin Anna Grass machte. 1967 starb der Fotograf und Grass hatte ihm zuvor versprochen, sich um dessen Frau zu kümmern. Maria Rama und Grass waren lebenslang eng befreundet. Sie verwaltete sein bildkünstlerisches Werk und wurde als Fotografin zu einer Chronistin des Grass'schen Familienlebens, wovon ihr heute in der Akademie der Künste verwahrter Nachlass genauso zeugt wie Grass' Mariazuehren und das zweite autobiografische Buch des Schriftstellers, Die Box (2008). ${ }^{560}$ Den darin literarisierten Erinnerungen des Dichters zufolge hatte Maria Rama zudem bereits seit den Sechzigerjahren Gegenstände für ihn fotografiert, die er später in seine Motivwelt integrierte. ${ }^{561}$ Fotos dieser Art - im Archiv unter der Rubrik "Material" geführt - sind jedoch nur aus den Siebzigerjahren mit Verweis auf das hier behandelte Buchprojekt erhalten.

Das achtundachtzig Seiten zählende Buch Mariazuehren enthält auf den ersten Seiten ein Gedicht, das denselben Titel trägt wie die gesamte Veröffentlichung. Es ist in Grass' fünfundvierzigstem Lebensjahr entstanden und wurde im Buch auf Deutsch, Französisch und Englisch abgedruckt. ${ }^{562}$ Auf den Text folgen Arrangements von Fotos, die verschiedene Fundsachen zeigen, zudem Puppen und Tiere sowie Grass am heimischen Schreibtisch, in der Druckwerkstatt, beim Spaziergang am Elbstrand und mit seiner Familie. Darüber hinaus nimmt das Buch Fotografien seiner Zeichnungen und Radierungen wie auch einzelne, handschriftlich niedergelegte Strophen bzw. Strophenteile des Gedichts in abgewandelter Reihenfolge auf. Das Layout stellte P.J. Wilhelm zusammen, dessen Name im Schmutztitel des Buches in gleicher Größe platziert wurde wie Maria Ramas und dessen Rolle bei der abschließenden Gestaltung des Bandes daher nicht zu überschätzen ist. Für die Montagen wurden einzelne Abbildungen in geringen Abständen nebeneinandergesetzt, Zeichnungen von dem Künstler unmittelbar auf die Fotografien aufgetragen, Ablichtungen von Zeichnungen und von Objekten übereinander geblendet oder Grafiken fotografiert, auf die zuvor einzelne Gegenstände gelegt oder gestellt worden waren. Die fotografischen Vorlagen für diese Bildseiten sind zwischen 1971 und 1973 entstanden. Über die verwendeten

\footnotetext{
560 Vgl. Sprenger (2013).

561 Vgl. Grass (2008), S. 15 f: „Als Mariechen nun aber ganz allein lebte in dem großen Atelier, wußte sie nicht, was machen mit sich. Erst als Vater sie beredet hat - sowas kann er -, fing sie an, mit der Leica, dann mit der Hasselblad, dann aber mit der Box, fast nur mit der Box, für Vater besondere Sachen und gefundenes Zeug zu knipsen, na, Muscheln, die er von Reisen mitbrachte, kaputte Puppen, krumme Nägel, ne unverputzte Mauer, Schneckenhäuser, Spinnen im Netz, plattgefahrene Frösche, sogar tote Tauben, die Jorsch gefunden hatte [...]. Aber angefangen, alles zu knipsen, was für ihn wichtig gewesen ist, hat sie schon in der Karlsbader... Stimmt! Ging los mit der Knipserei, als Vater mit seinem Buch, das er damals in der Mache hatte und das von Hunden und Vogelscheuchen handelte, aber noch lange nicht fertig war, mit dem er dann aber richtig Knete gemacht hat, so daß er für uns das Friedenauer Klinkerhaus kaufen konnte..."

562 Zwei undatierte, maschinengetippte Manuskriptfassungen mit handschriftlichen Korrekturen befinden sich in der Akademie der Künste, Berlin, Günter-Grass-Archiv, Nr. 622 und Nr. 1039. Zwei handschriftliche Fassungen sind in Sechs Jahrzehnte abgedruckt, eine von ihnen ist auf den 25.5.1973 datiert, vgl. Grass (2014), S. 194 f.
} 
Fotografien hinaus hatte Rama zahlreiche weitere Objektaufnahmen geschaffen, die sich heute in der Berliner Akademie der Künste befinden. ${ }^{563}$

Die dreiundzwanzig im Band präsentierten Zeichnungen und Radierungen wurden zwischen 1955 und 1973 gefertigt, wie eine Auflistung aller Arbeiten im Anhang der Veröffentlichung zeigt. Das Buch bot damit zum ersten Mal einen Überblick über Grass' grafisches Schaffen. Entsprechend enthält es, im Gegensatz zu seinen illustrierten Gedichtbänden, hinsichtlich der abgelichteten Zeichnungen und Radierungen kein in sich geschlossenes Konzept. Ein innerer Zusammenhang der Veröffentlichung erschließt sich vielmehr aus der Verbindung zwischen dem vorangestellten lyrischen Text und den Medienmontagen. Das Gedicht kündigt an, was die folgenden Bilder zeigen: eine Verbeugung vor der Natur und ihren sinnlich erfahrbaren Objekten, die gleichermaßen in Wort, grafischem Bild und Fotografie zum Ausdruck kommt und das Resümee einer auf der unmittelbaren Anschauung basierenden und sich von einzelnen Motiven aus entwickelnden intermedialen Ästhetik. Ein religiöser Aspekt dieser Huldigung tritt darin durch den Namen Maria in Erscheinung, der nicht nur auf die befreundete Fotografin verweist, sondern auch auf die christliche Mutter Gottes. Wie schon in Grass' frühen Werken werden in „Mariazuehren“ Liebe, Religion und Kunst parallelgeführt und damit teils die Kunst zur Religion erhoben, teils religiöse Vorstellungen persifliert.

Das Gedicht wird durch die direkte Ansprache der Fotografin strukturiert. Wiederholt fordert das lyrische Ich sie zum Hinsehen und Fotografieren auf („Schau, die Kartoffel [...]“, „Schau, wie das laufende halbe Schwein [...]“" „Maria, knips mal die Spuren“ etc.) und hebt im Wechsel dazu zur Beschreibung von technischen Hilfsmitteln und ihrer Funktionen an („Dein Lichtmesser schlägt aus [...]", "Deine wechselnden Blenden [...]", „Dein Auslöser [...]") - es ist dieser Rhythmus aus verschiedenen Strophenanfängen, der die im Folgenden jeweils schlaglichtartig geschilderten Natureindrücke miteinander verbindet.

In erweiterter Form wird die Arbeitsteilung zwischen dem Sprechenden und der Fotografin in der siebten Strophe dargestellt: In diesem Porträt-Fragment zu „Maria“ wird entdeckt, dass es das lyrische Ich ist, das auf interessante Objekte hinweist, die Fotografin diese ablichtet und das lyrische Ich sie zeichnet. Die letzten drei Verse bringen diese Reihenfolge der künstlerischen Tätigkeiten zum Ausdruck und entsprechen Grass' fiktionalisierter Beschreibung seiner Zusammenarbeit mit Maria Rama in der Box. Zugleich wird in diesen Versen eine unprätentiöse Kunstauffassung formuliert: Sowohl der Grafik als auch der Fotografie kommt den Zeilen zufolge zunächst eine rein abbildende Funktion zu. Die kreative Leistung des Künstlers oder der Künstlerin liegt demnach vor allem in der Auswahl der Objekte und ihrer Übertragung ins Bild:

Ein masurisches Handchenvoll, aber säuft und frißt

in sich rein, was ich tische: den Steinbutt (in Dill),

nachdem er belichtet, mit raschem Pinsel getuscht

\footnotetext{
${ }^{563}$ Vgl. Akademie der Künste, Berlin, Günter-Grass-Archiv / Sammlung Maria Rama, Fotos/Material (2.4). Bei diesen Bildern handelt es sich um eine Werkgruppe von insgesamt 523 Ablichtungen, die 36 Motive behandeln. Die Fotos konzentrieren sich auf die Erfassung der Objekte. Sie zeigen die Gegenstände vergrößert, meist vor einem neutralen Hintergrund in Schwarzweiß. Grass hatte die Ablichtungen wohl als Montagematerial und Gedächtnisstütze, jedoch, soweit ersichtlich ist, nicht als direkte Vorlage für seine Zeichnungen genutzt.
} 
und mystifiziert... (Das ist Anschauung, Ausbeutung;

von Kunst quasselt nur das Gewerbe.)

In „Mariazuehren“ werden nicht nur Zeichnungen des lyrischen Ich zu Marias Fotografien in Beziehung gesetzt. Der Text evoziert Marias Fotografien darüber hinaus mit sprachlichen Mitteln. ${ }^{564}$ Er setzt sich selbst zur Fotografie in Beziehung, indem er Beschreibungen als Fotografien bezeichnet und mit sprachlichen Imitationen des technischen Vorgangs des Fotografierens einleitet:

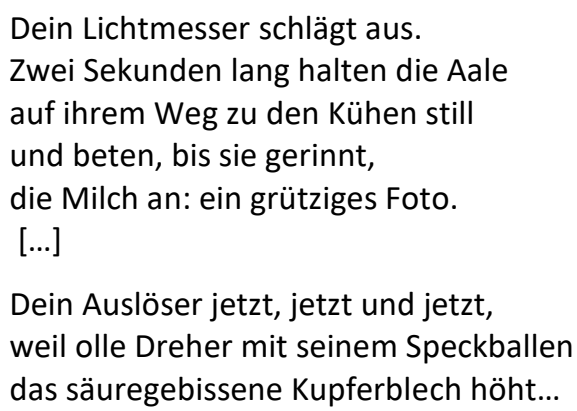

Bei den Objekten, auf die Maria aufmerksam gemacht wird, handelt es sich um „plappernde Fundsachen" und insbesondere um Gegenstände, die über die Existenz des lyrischen Ich qua Abdruck sichtbar Rechenschaft ablegen: Äpfel, die Spuren seiner Zähne zeigen, Zigarettenstummel, die die sie ausdrückende Hand noch erahnen lassen: und vor allem das "Vera Ikon", das Schweißtuch der Veronika, das mit dem so implizierten weiblichen Vornamen auf Grass' damalige Partnerin und somit auf ihn selbst zurückverweist. Diese Spuren können als gegenständliche Charakterisierung des Wesens der Fotografie gedeutet werden, wie sie durch Formulierungen von Charles Sanders Peirce in Elements of Logic bekannt und in der Fotografie-Theorie wirkmächtig wurde. Peirce definierte das Foto darin als Abdruck des Lichts, das von einem Gegenstand auf behandeltes Papier projiziert wird, als indexikalisches Zeichen. ${ }^{565}$ Die beschriebenen Existenzbeweise des lyrischen Ich stehen damit durch die Art ihrer Entstehung strukturell zu fotografischen Aufnahmen in Beziehung. ${ }^{566}$

Mit der dritten Strophe des Gedichts mischte Grass seine literarischen und bildkünstlerischen Motive unter die exponierten Gegenstände. Es handelt sich um Motive, die zu diesem Zeitpunkt bereits aus seinem Werk bekannt waren oder zukünftig darin in Erscheinung treten würden: Hühner, Nonnen, Vögel, Scheuchen, Schnecken, Pilze und der Butt. Wie bereits im einleitenden Teil dieser Arbeit erwähnt, werden sie im Gedicht nicht als reale Objekte angeführt, sondern explizit als Zeichen benannt, womit ein Begriff gewählt wird, der sowohl in der bildenden Kunst als auch in der Literatur Verwendung findet. Welche Art von Zeichen hier gemeint ist, bleibt offen. Für ein schreibendes und zeichnendes lyrisches Ich, das Kunst als Anschauung feiert, hat es im Gedicht genauso als ein symbolisch Bezeichnendes wie als abbildendes „Ikon“ Gültigkeit. Wie aus den letzten Versen der Strophe deutlich wird, soll das Zeichen als eine ikonische Darstellung verstanden werden, die außer der Ähnlichkeit mit einem Gegenstand noch weitere Informationen vermittelt. Dies wird anhand der lyrischen Manifestation des Pilzmotivs besonders deutlich. In

\footnotetext{
${ }^{564}$ Vgl. Stolz (1994), S. 134 f.

${ }^{565}$ Vgl. Peirce (1932), S. 184.

${ }^{566}$ Vgl. Stolz (1994), S. 134 f.
} 
den letzten Zeilen der Strophe werden Einzeller metaphorisch zum männlichen Geschlecht in Beziehung gesetzt:

Ich setze ein Zeichen und lösche es mit dem nächsten.

Die Hühner, die Nonnen, die Vögel, die Scheuchen...

Und als ich heimkam, zerredet ganz und hartgesotten,

ging ich zu, kamen mir Pilze entgegen,

Schirmlinge und Boviste, entwurzelte Pimmel,

die himmelwärts zeugen.

Diese lyrische Charakterisierung einer Motivwelt entspricht der von Grass im selben Jahr für das Magazin der ZEIT formulierten Ästhetik. ${ }^{567}$ Wie in Kapitel III.3. dieser Arbeit angemerkt, wurde sie bereits in den Hundejahren als Kunstauffassung des Vogelscheuchenbauers Eddi Amsel angelegt. Zehn Jahre nach der Romanveröffentlichung verdeutlicht Grass' kurzer Text zu seiner bildenden Kunst, dass seine Betrachtung des Gegenstands darauf abzielt, Strukturen zu entdecken, die über sich selbst hinausweisen:

Alle Gegenstände der Natur, auch die ausgestopften, sind mir Modell. [...] auch schaue ich mir die Gegenstände der Natur immer wieder neu an, bis ich mir ihrer organischen und bildhaften Bezüglichkeit bewußt bin. (XI 864)

Die in "Mariazuehren“ verdichtete Ästhetik ist zudem durch einen zweiten Aspekt gekennzeichnet: Die spannungsreiche Kombination von Objekten, die in den Versen „Fremd stehen sich gegenüber, / warten auf Zufall, bilden Legende“ zum Ausdruck gebracht wird. Grass hebt damit die Methode der Kombinatorik hervor, die seit Mitte der Fünfzigerjahre für seine Bilder und Texte entscheidend war.

Als eine poetologische und kunsttheoretische Selbstreflexion charakterisieren biografische Angaben das Gedicht: Die Erwähnung bereits aus anderen Grass-Werken bekannter Motive, die Angabe des Alters des realen Günter Grass („Jetzt bin ich fünfundvierzig und noch immer erstaunt. ") und der Verweis auf Veronika Schröter. Wäre damit nicht genug, bilden die Fotografien, die Grass gemeinsam mit seiner Familie zeigen, den biografischen Rahmen des Werkes - die im Tagebuch einer Schnecke entwickelte Konstruktion eines Autor-Erzählers wird in Mariazuehren also in Wort und Bild fortgeführt.

Auf welche Art sich die im Gedicht formulierte Kunstauffassung in den im Buch abgedruckten Bildwerken wiederfindet, ist am Beispiel von sechs Pilzdarstellungen besonders gut nachvollziehbar. Wie Elemente einer Serie folgen sie in der Veröffentlichung unmittelbar aufeinander. Die Arbeiten lassen sich in unterschiedlichem Unmittelbarkeitsgrad zu den letzten Versen der oben bereits zitierten dritten Strophe des Gedichts in Beziehung setzen, wobei nur eines von ihnen mit handschriftlichen Ausführungen ebendieser Zeilen kombiniert wird. In dieser Textpassage berichtet das lyrische Ich von einer Heimkehr, bei der es in seinem privaten Schutzraum mit Pilzen konfrontiert wird, die an erigierte männliche Genitalien erinnern. Die anthropomorphisierten Glieder haben sich selbständig gemacht und mobilisiert. Da der "Stiel“ dem mütterlichen Erdboden entrissen ist und die männliche Erregung ziellos ins Leere zu laufen droht, sind die entwurzelten Ein-

${ }^{567} \mathrm{VgI.} \mathrm{ZEIT-Magazin,} \mathrm{12.10.1973,} \mathrm{S.} \mathrm{16.} \mathrm{(XI} 864$ f.) 
zeller hier Teil einer beängstigenden Szenerie - die versinnbildlichte Männlichkeit erscheint in Verbindung mit dem blasphemisch „himmelwärts" zeugenden Pilz als eine unglücklich auf den Kopf gestellte. An drei Bildern aus Mariazuehren sollen die Art, in welcher das Pilzmotiv mit über sich selbst hinausweisender Bedeutung versehen wird und das Zusammenwirken verschiedener Medien in der Publikation untersucht werden.

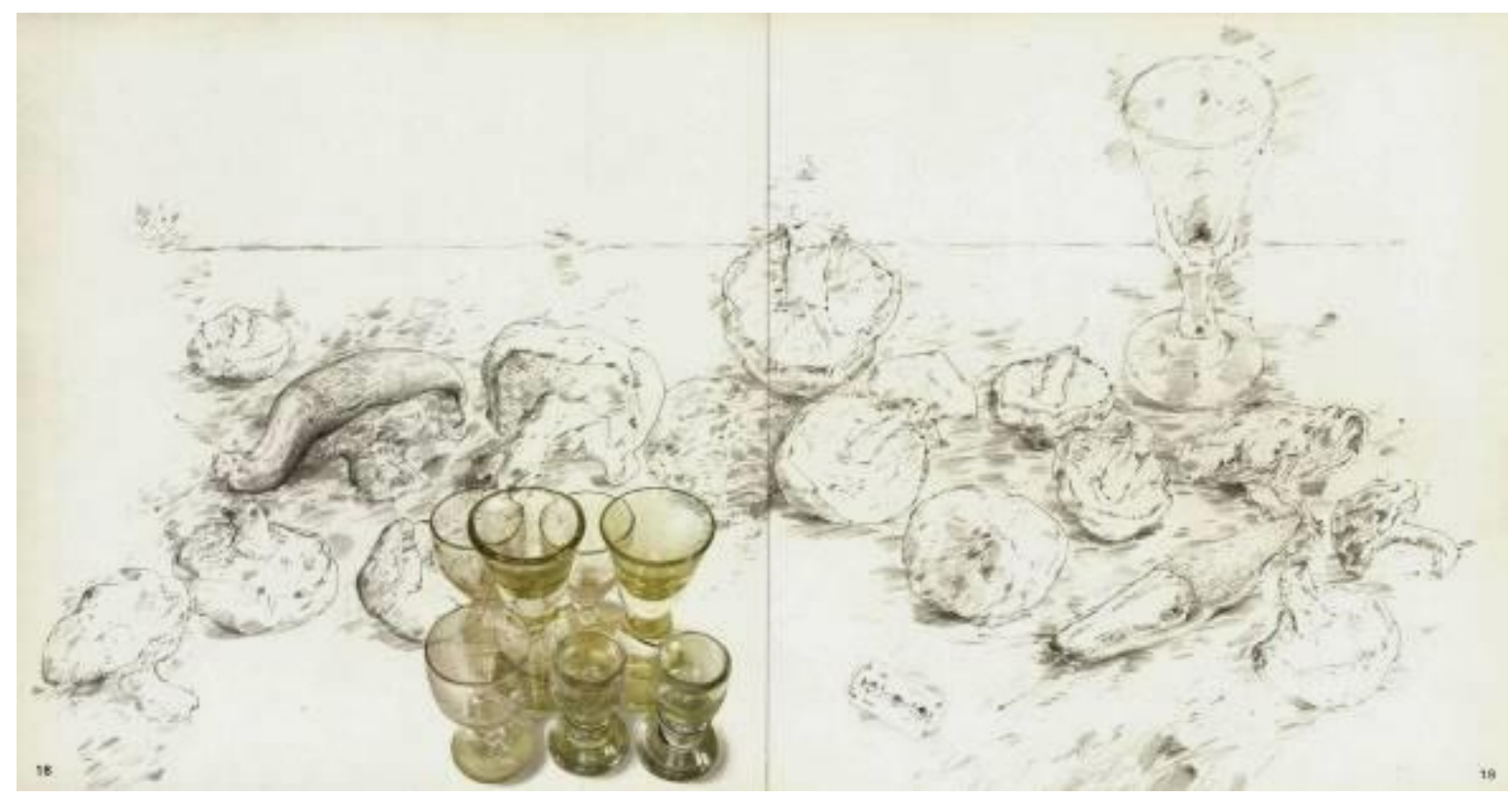

Abb. 145, Mariazuehren, München 1973, S. 18 f. (Pilze, Glas mit Schnecken und Klinge, 1972, Bleistift)

Bei der ersten Komposition handelt es sich um eine Fotografie von einer Bleistiftzeichnung, die mit einer Aufnahme von Weingläsern überblendet wurde (Abb. 145). Es scheint deshalb auf den ersten Blick so, als stünden sieben Gläser auf dem Blatt. Die Zeichnung ist auf das Jahr 1972 datiert und trägt den Titel Pilze, Glas mit Schnecken und Klinge. Dem Gedicht gemäß zeigt die Arbeit zahlreiche auf ihrem Hut aufliegende, mit ihren Stielen nach oben weisende Pilze. Die Einzeller sind über eine nicht näher definierte Fläche gestreut. Neben einem in der Mitte oben platzierten und so besonders exponierten Exemplar ist ein Weinglas zu sehen, das mit seinem kurzen Stiel den fotografierten Gläsern ähnelt. Unterhalb des gezeichneten Glases ist eine Nacktschnecke dargestellt, die auf eine Rasierklinge zu kriecht, während eine zweite, links im Bild, einer Pilzkrempe aufsitzt.

An der Konfrontation von Pilzen mit Gläsern ist zu beobachten, wie der Zeichner die „Bezüglichkeiten" der Pilzform auslotete: Die Gläser ähneln den Einzellern hinsichtlich des grundlegenden Aufbaus ihrer Gestalt. Im Gegensatz zu ihnen stehen sie jedoch weiterhin auf ihren Stielen. Ihre Gefäße sind konkav geformt und nicht wie die hier gezeichneten Pilzhüte konvex. Konnotiert der vertikal nach oben gerichtete Pilzstiel männlich, so das offene Gefäß weiblich. Der entwurzelte Pilz wird zum Sinnbild der verunsicherten Männlichkeit, dem dasjenige einer stabilen Weiblichkeit gegenübersteht.

Die unmittelbare Konfrontation des fotografierten Gegenstandes mit demselben Gezeichneten greift die Kooperation zwischen Fotografie und Grafik auf, die im Gedicht „Mariazuehren“ ge- 
schildert wird und zieht die aufeinanderfolgenden Arbeitsetappen zu einem Bild zusammen. Kombiniert werden eine scheinbar objektive technische Wiedergabe des Gegenstandes und eine subjektive Schilderung, die durch die individuelle Linienführung des Künstlers geprägt ist. Der Zeichnung zur Seite gestellt, belegt der fotografierte Gegenstand die Abbildungstreue des gezeichneten und dessen unmittelbare Bezugnahme auf ein wirklich gegebenes Objekt.
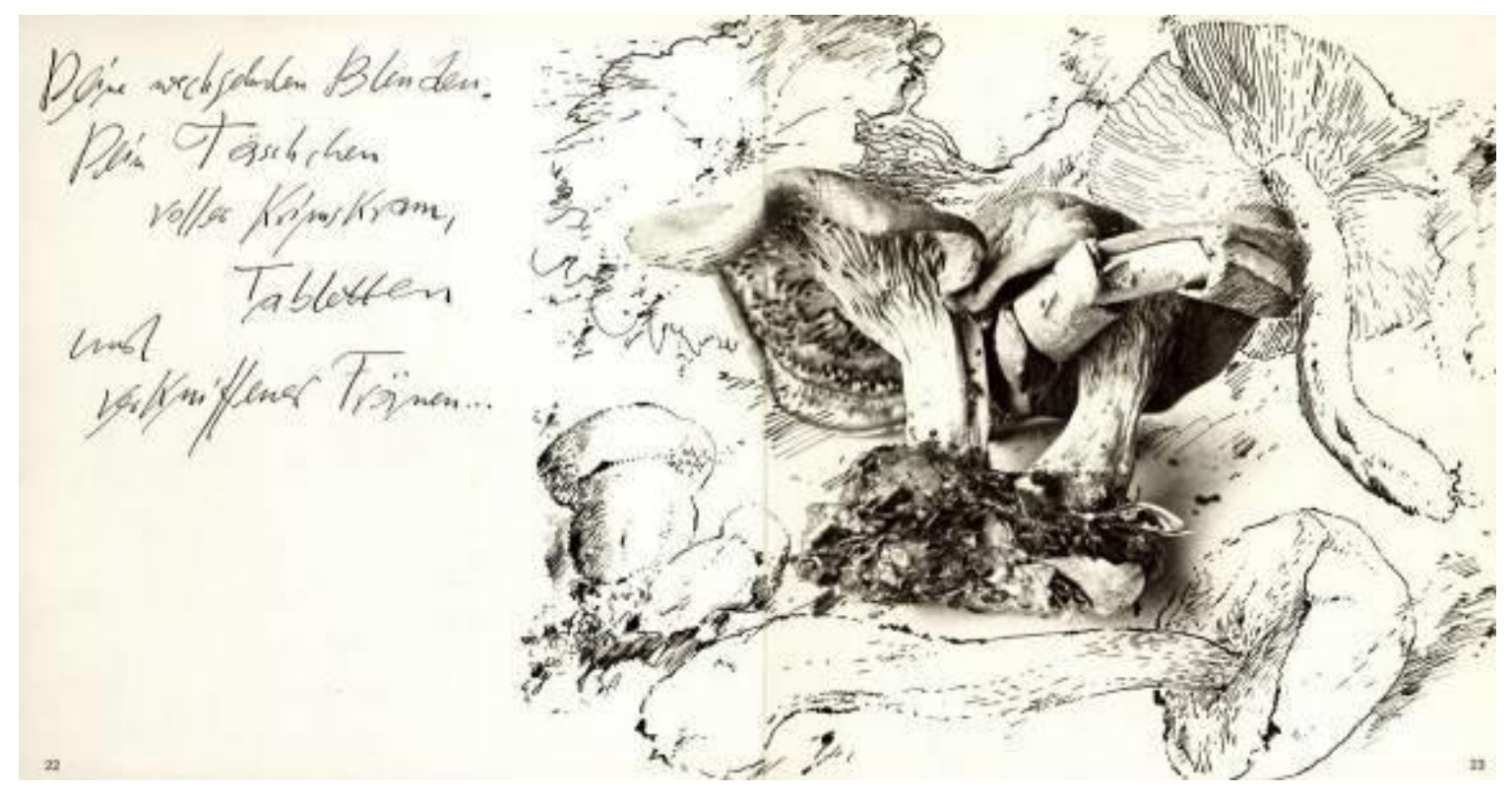

Abb. 146, Mariazuehren, München 1973, S. 22 f. (Pilze, 1973, Feder/Tusche und Foto)

Eine andere Arbeit aus dem Motivbereich der Pilze ist besonders bemerkenswert, weil sie Fotografie und Zeichnung noch enger miteinander verbindet und zudem handschriftlichen Text in die Doppelseite integriert (Abb. 146): Es handelt sich um ein Schwarzweiß-Foto, auf dem zwei liegende Pilze zu sehen sind, an deren Stielen Erde haftet - eine andere Erscheinungsform der Entwurzelung, die die Herkunft des Einzellers also noch mit andeutet. In das Foto hinein zeichnete Grass mit Feder und Tusche weitere Pilze, so dass die fotografierten Objekte von fünf gezeichneten eingefasst werden. Am linken Bildrand wurde die fünfte Strophe des Gedichts gleichmäßig und gut lesbar neben dem Foto platziert, ohne dass das Foto mit seinem hellen Bildhintergrund von der weißen Buchseite sichtbar abgegrenzt wäre. Da alle Medienerzeugnisse über Graustufen in Erscheinung treten und die Zeichnung das plastischere Fotomotiv teilweise überlagert, rücken die einzelnen Bildelemente in der Wahrnehmung von Betrachterinnen und Betrachtern zusammen. ${ }^{568}$

Handschrift und Zeichnung des Bildes sind über die verwendete Technik - Feder und Tusche miteinander verbunden und verdeutlichen, dass es sich bei dem Dichter und dem Grafiker um dieselbe Person handelt. Trotz dieser Annäherungen entsteht auch ein Spannungsverhältnis zwischen Schrift und Bild, da beide auf eine andere Art rezipiert, nämlich einerseits als Symbole erkannt und andererseits zugleich als ikonische Zeichen betrachtet werden müssen. Zwischen der fünften Strophe von „Mariazuehren“, die dem Bild anbei gestellt wurde, und dem grafischen Zei-

${ }^{568}$ Vgl. Hille-Sandvoss (1987), S. 165 f. 
chen des entwurzelten Pilzes besteht nur ein vager inhaltlicher Zusammenhang. Es handelt sich um einige der wenigen Verse, die die sinnlich ,angebetete' Maria Rama als Person charakterisieren. Die geschlechtliche Assoziationen hervorbringenden Pilze werden also mit einer fragmentarischen Charakterisierung der geliebten Freundin kombiniert.
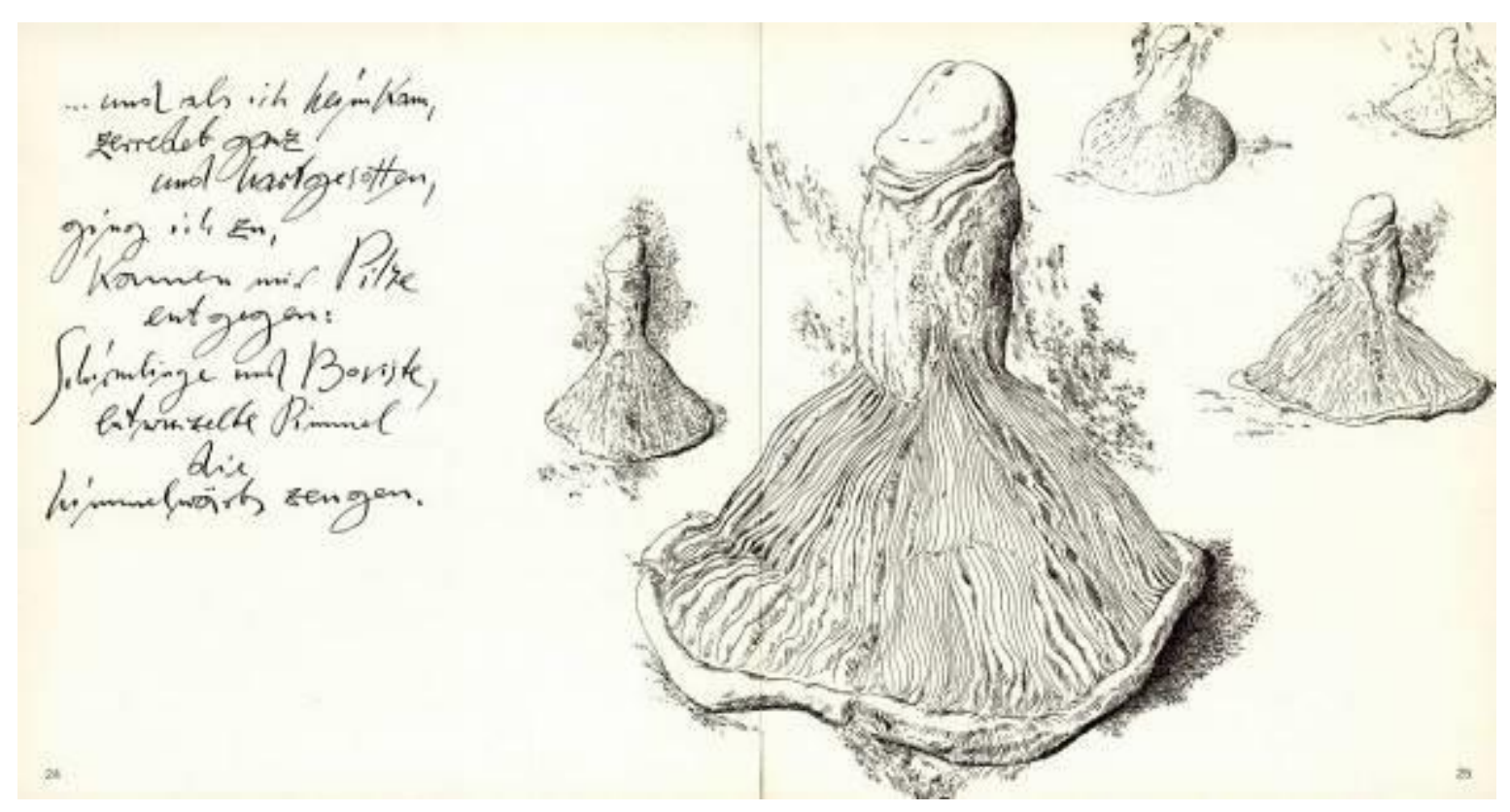

Abb. 147, Mariazuehren, München 1973, S. 24 f. (Pimmelpilze, 1973, Radierung)

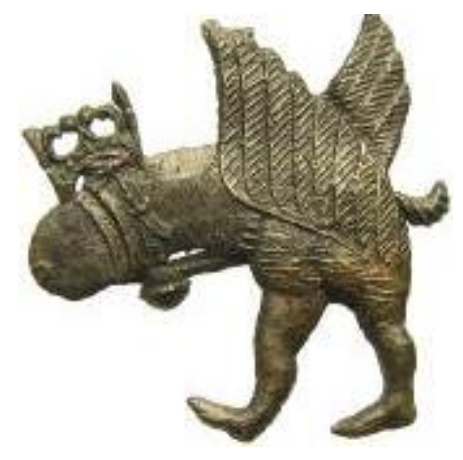

Abb. 148, Bekrönter Phallus mit Flügeln und Glöckchen, 1375-1425, Blei-Zinn-Legierung, Family Van Beuningen Collection, Langbroek, Niederlande, Inv.-Nr. 1856

In der folgenden Abbildung stehen Text und Bild dagegen in enger Verbindung (Abb. 147). Die einschlägig pilzbezogenen Verse aus „Mariazuehren“ werden mit der Radierung „Pimmelpilze“ kombiniert. Auch auf dieser Doppelseite erscheint der handschriftliche Text auf der linken Bildseite. Die Grafik zeigt fünf Gebilde, die sich aus Pilzhüten und erigierten Penissen zusammensetzen. Die Glieder, die aus Pilzhüten hervorgehen, welche mit ihrer Unterseite nach oben gerichtet sind, wurden ebenso wie die Lamellen der Einzeller sehr detailliert in Form und Oberfläche wiedergegeben, als gelte es, die surrealen Objekte in ihren einzelnen Bestandteilen besonders wirklichkeitsnah abzubilden. Je höher die Einzeller auf dem Blatt angesiedelt sind, desto kleiner werden sie geschildert, sodass die Illusion von Tiefenraum erzeugt wird. 
Das Bild zeigt eine grafische Entsprechung zur bestimmenden Metapher der Verse: Beschränkt sich die oben behandelte Bleistiftzeichnung auf eine Darstellung von Einzellern, die lediglich Assoziationen zu einem anderen Gegenstand auslöst, so wird die lyrische Koppelung "ging ich zu, kamen mir Pilze entgegen / [...] entwurzelte Pimmel, / die himmelwärts zeugen“ in der Radierung unmittelbar durch das Verschmelzen der beiden Bildelemente visualisiert, die auch der Titel der Grafik, Pimmelpilz zum Ausdruck bringt. Das selbständige „Entgegenkommen“ der Pilze wird in der Grafik durch die zu den Betrachtenden hin immer größer werdenden Figuren vermittelt. In der Betonung der von jeher, bereits in der antiken Literatur, erörterten und gefürchteten Eigenmächtigkeit des männlichen Gliedes zeigt der Grass'sche Pimmelpilz Ähnlichkeit mit genitalen Monstren der mittelalterlichen Kunst. Darstellungen von Penissen wurden in der Kunst des 14. Jahrhunderts mit solchen von Tierkörpern verschmolzen und so die befremdliche Selbständigkeit des Gliedes in Szene gesetzt (Abb. 148) ${ }^{569}$ Gleichwohl Grass' Figuren weniger mobil zu sein scheinen, zeigen seine Zeichnungen das Genital doch als unabhängiges, vom Körper getrenntes Subjekt, das mit einem Organismus verschmolzen ist, der als unkontrolliert fortpflanzungsfreudiger bekannt ist.

Das Gedicht „Mariazuehren“ kündigt die Bilder des Bandes als Ergebnisse einer außerordentlichen Bewunderung der Natur und ihrer Gegenstände an. Diese manifestiert sich auch im Pilzmotiv, das sowohl das männliche Begehren und den Fortpflanzungsdrang veranschaulicht als auch eine diffuse Verunsicherung des männlichen Geschlechts und eine Umkehrung seines bisherigen Selbstverständnisses zum Ausdruck bringt. In den Grafiken und Fotomontagen, die Einzeller zeigen, wird zugleich die Suche des Grafikers und Lyrikers nach verschiedenen von dem Pilz ausgehenden Bezügen erkennbar. Sie bereitet die späteren Darstellungen des Einzellers als zwitterhaftes Zeichen vor, das mit Männlichkeit wie mit Weiblichkeit assoziiert werden kann.

Vermittelt über das Medium der Fotografie hebt das Buchprojekt die Wiedergabe des sichtbaren Gegenstands als gemeinsamen Nenner der Dichtung und Grafik von Günter Grass hervor. Die literarischen und die bildkünstlerischen Darstellungen betonen dabei die von innen angestrebte Wirklichkeitstreue und die Subjektivität des Künstlerblicks gleichermaßen.

\section{Liebe geprüft - Betrachtungen des Unsichtbaren}

Die in Mariazuehren akzentuierte Anschauung wird auch im Mappenwerk Liebe geprüft betont, und zwar als präzises Analyseinstrument des Dichters und Künstlers, das zur Erfassung eines besonders schwer zu handhabenden Themas eingesetzt wird: Das Portfolio, bestehend aus sieben Ätzradierungen und sieben Gedichten, widmet sich dem Titel gemäß der Liebe. Erneut stellt Grass einzelne Objekte in den Mittelpunkt der Arbeiten, wobei der Pilz einen der Texte und eine Radierung bestimmt.

Jede Druckgrafik ist lose in einen einfach gefalteten weißen Papierbogen eingelegt, auf dessen Vorderseite das dazugehörende Gedicht abgedruckt ist. Text und Bild können daher nach Belieben nacheinander oder nebeneinander betrachtet werden. Die Reihenfolge der Gedichte ist zwar

\footnotetext{
${ }^{569}$ Vgl. Simons (2011), S. 79-81: Erörterungen zur Unabhängigkeit des männlichen Geschlechtsorgans fin-
} den sich bereits bei Platon und Aristoteles. 
durch die Sortierung in der dazugehörenden Kassette vorgegeben, aber nicht durch eine Nummerierung fixiert.

Allen grafischen Objektdarstellungen gemein sind ihre durch die Technik der Ätzradierung begünstigte Detailliertheit und ein besonders eng gesetzter Bildausschnitt. Für zwei der Radierungen wurde eine ovale bzw. runde Druckfläche gewählt, die zum einen den Eindruck erweckt, als werde die Begrenzung eines Sichtfeldes angedeutet und zum anderen an die Formate der emblematischen Icones denken lässt. Ebenso wie in den emblematischen Zeichnungen zum Tagebuch werden auch in den Radierungen zu Liebe geprüft einzelne naturgetreu geschilderte Objekte zu spannungsreichen und surrealen Konstellationen zusammengeführt. Rückbezüge auf bestimmte traditionelle Motive der Emblematik sind bei diesen Bildern jedoch nicht erkennbar. Stattdessen erinnert Grass' Gestaltung dieser Serie an die stilllebenartigen Objektkombinationen Bruno Gollers. Für die Radierung Ohr im Wind von 1974 (Abb. 149) wählte Grass dasselbe Motiv wie der Düsseldorfer Maler für sein Ölbild Das Ohr von 1956 (Abb. 150). In beiden Arbeiten ist das Hauptobjekt von einer Rahmenlinie umschlossen, die seinen Umrissen entspricht. Die Formäquivalenz und der enge Bildausschnitt lenken die Aufmerksamkeit von Betrachterinnen und Betrachtern verstärkt auf den dargestellten Gegenstand.

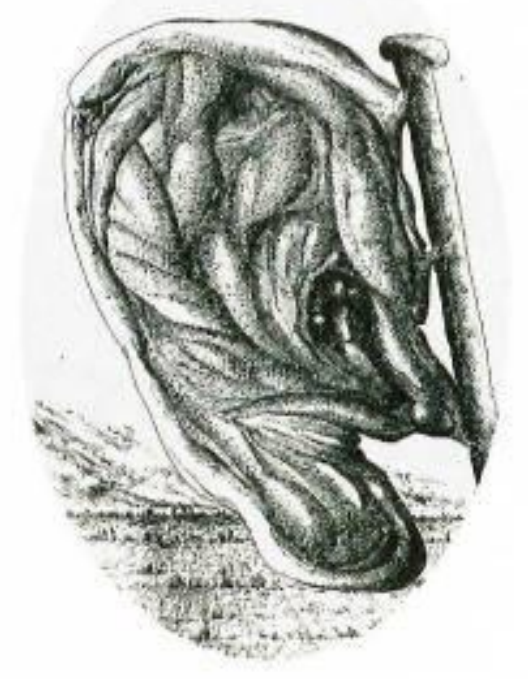

Abb. 149, Liebe geprüft, 1974, Ohr im Wind, 1974, Ätzradierung auf ausgesägtem Kupfer

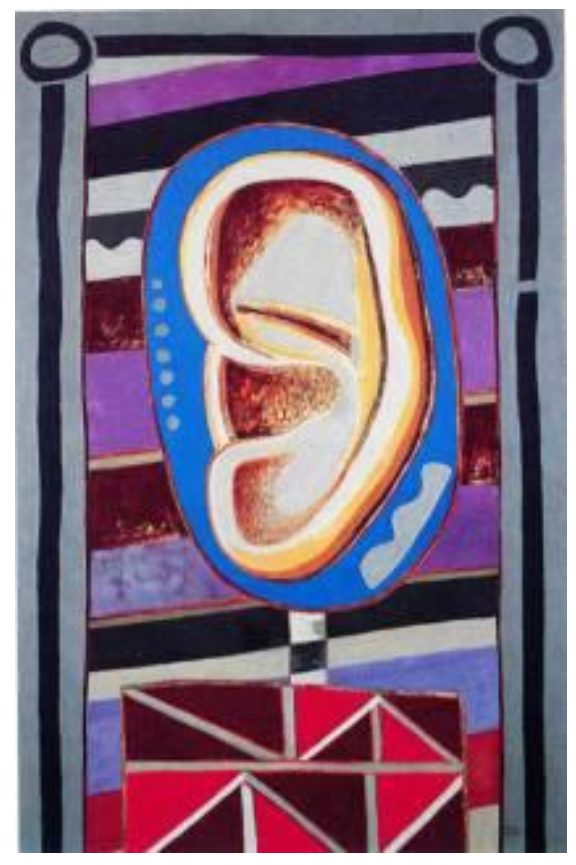

Abb. 150, Bruno Goller, Das Ohr, 1956, Öl auf Leinwand

Das Gedicht "Dein Ohr", beschäftigt sich mit der Kommunikation zwischen zwei Personen, und den mit ihr verbundenen und insbesondere an sich selbst gestellten Erwartungen des lyrischen Ich. Das Sprechen einer Person und das Zuhören ihres Gegenübers wird in seiner ganzen Unzulänglichkeit, im Text genauso wie in der Grafik, als ein Ohr anschaulich gemacht, das wie eine 
Fahne im Wind weht: „In den Wind gehißt, / flattert Dein Ohr, / hört sich flattern. / Beim Fädeln spleißen die Wörter danebengesagt." Weder ist der oder die Sprechende in der Lage, Gedanken so zu formulieren, dass die Botschaft den Adressaten vollständig erreicht, noch der oder die Zuhörende fähig, das Gesprochene komplett aufzunehmen. Im grafischen Bild vereint das an einem Fahnenmast hängende Ohr beide Elemente der Metapher.

Das die Mappe betitelnde Gedicht Liebe geprüft nutzt das Motiv des angebissenen Apfels, das auch in Mariazuehren enthalten ist, um die Auseinandersetzung zweier Liebender miteinander zu erörtern. Der Text behandelt das Thema anhand eines Vergleichs der Zahnabdrücke der Liebenden in angebissenen Äpfeln. Die visuelle Wahrnehmbarkeit der Unterschiede zwischen ihnen wird durch die religiöse Symbolik des Apfels zugleich als Wahrnehmbarkeit verschiedener Formen der Schuld deutbar und thematisiert zugleich die Erkenntnis. Der Vorgang des Zubeißens und des Vergleichens wird durch den performativen Charakter der Verse und den im Gedicht mittig gesetzten Imperativ „Schau“ vermittelt:

LIEBE GEPRÜFT

Dein Apfel - mein Apfel.

Jetzt beißen wir gleichzeitig zu:

schau, wie auf ewig verschieden.

Jetzt legen wir Apfel auf Apfel

Biß gegen Biß.

Die zum Gedicht gehörende Radierung macht die Allegorie durch die Schilderung zweier Äpfel mit Bissspuren, um die jeweils ein Halbkreis gezogen ist, sichtbar und ermöglicht es, der Aufforderung des lyrischen Ich unmittelbar Folge zu leisten (Abb. 151). Die Verschiedenheit der Liebenden wird im Bild nicht nur durch die detaillierte Darstellung der beiden angebissenen Äpfel zum Ausdruck gebracht, sondern auch, indem der um den rechten Apfel gezogene Halbkreis den Verlauf des von dem Gegenstand geworfenen Schattens abrupt begrenzt.

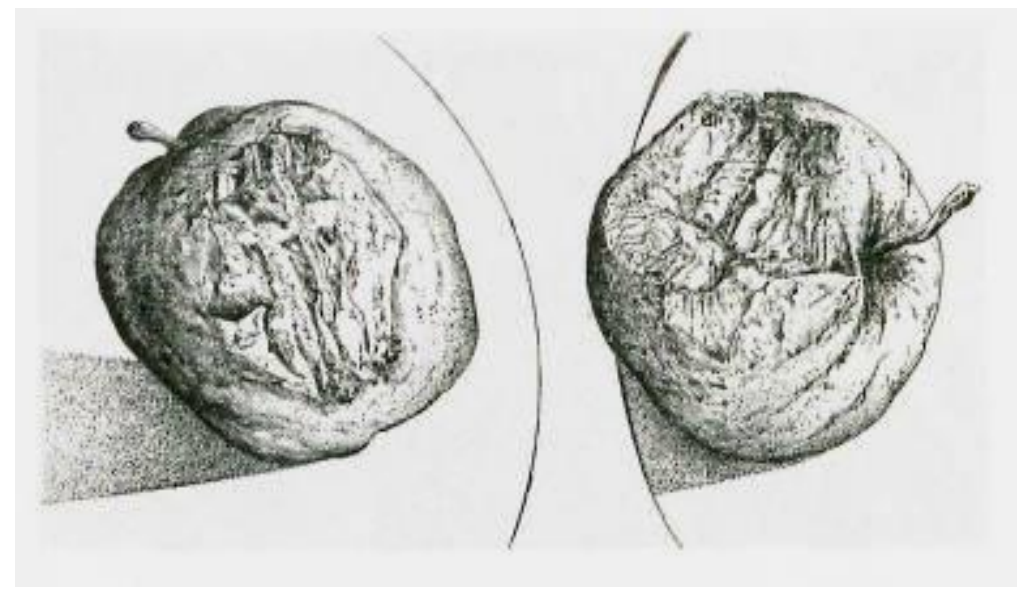

Abb. 151, Liebe geprüft, 1974, Liebe geprüft, 1974, Ätzradierung

Explizit zum Thema erhoben wird die wichtige Rolle des Sehens in der Grafik Mit Brille neuerdings (Abb. 152) und in dem Gedicht "Doch aber". Die Radierung zeigt eine runde Brille, die in das Bild hinein gerichtet ist. Durch ihre Gläser hindurch kann man erkennen, dass zwei gerade Linien vergrößert als komplexe chaotische Struktur erscheinen. Das dazugehörende Gedicht „Doch aber", 
beschreibt die veränderte visuelle Wahrnehmung des lyrischen Ich nach dem Erwerb einer Brille. Der mit voranschreitendem Alter veränderte Blick auf die Geliebte sowie auf das eigene Selbst wird durch die Beschreibung des gewandelten Sehens von Körperoberflächen vermittelt:

DOCH ABER

Mit Brille neuerdings

mehr Pickel freundlicher sehen.

Im Ausschnitt befangen,

fältchengetreu (begabter für Liebe)

doch ohne Einsicht in jenen Zusammenhang,

den das Gebirge als Horizont diktiert.

Aber die eigenen brüchigen Nähte

sind mir jetzt näher.

Neu und entsetzt

sehe ich meinen Abfall

und wie die Linien wackeln.

Der geschärfte Blick bietet Detailansichten, aber keinen Überblick über das große Ganze. Es ist die am „Ausschnitt“ orientierte Betrachtung der Wirklichkeit, die dem Lyriker jedoch erlaubt, sich ein Bild von abstrakten Begriffen und Emotionen zu machen.
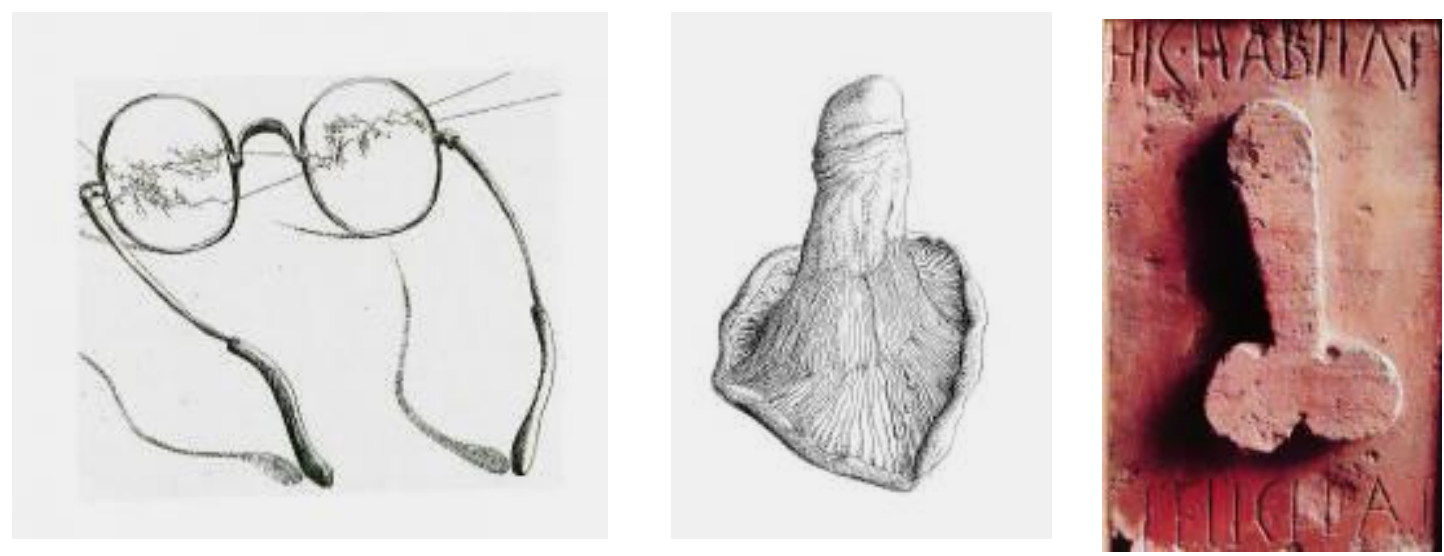

Abb. 152, Liebe geprüft, 1974, Mit Brille neuerdings, 1974, Ätzradierung auf Kupfer Abb. 153, Liebe geprüft, 1974, Fruchtbarer Pilz, 1974, Ätzradierung auf ausgesägtem Kupfer Abb. 154, Relief mit Phallus und Inschrift „hic habitat felicitas“, vor 79. n. Chr., Stein, gefunden in Pompeji

Das Pilzmotiv dient in der Mappe dazu, dem Fortpflanzungstrieb nachzugehen, der hier in einen größeren Zusammenhang eingebettet wird. Die Ätzradierung mit Kaltnadel unter dem Titel Fruchtbarer Pilz zeigt wie in Mariazuehren einen Einzeller, dessen Stiel wie ein erigierter Penis geformt ist (Abb. 153). Der Einzeller-Phallus ist nun vereinzelt im Zentrum der ansonsten ungestalteten Bildfläche zu sehen, sodass das Objekt an Darstellungen des Phallusmotivs als Fruchtbarkeits- und Glückssymbol erinnert, die in der Antike verbreitet waren (Abb. 154). ${ }^{570}$ Die Assozia- 
tion mit einem isolierten Kultgegenstand wird in der Grafik dadurch verstärkt, dass die Umrisslinien der Objektzeichnung zugleich auch die Ränder der Druckplatte sind. Der besondere Pilz allein befindet sich durch die Vertiefung der Druckfläche auf einer anderen Höhe als der Rest der weißen Büttenpapierseite.

Die Radierung ist in der Mappe dem Gedicht „Fortgezeugt“ zugeordnet. Dieser Text kleidet sowohl den "Gedanken" einer menschenlosen Welt als auch den des Fortbestandes der Menschheit in jeweils ein Sinnbild. Ist der leergefegte Planet als eine glatt „ins Abseits“ rollende Kugel vorstellbar, verkörpert der nach oben weisende Pilz den männlichen Part der Fortpflanzung. Sein weibliches Gegenstück wird durch das lyrische Ich direkt angesprochen - es wird als "offenes" Du adressiert, eine potenziell zur Kastration fähige Bedrohung:

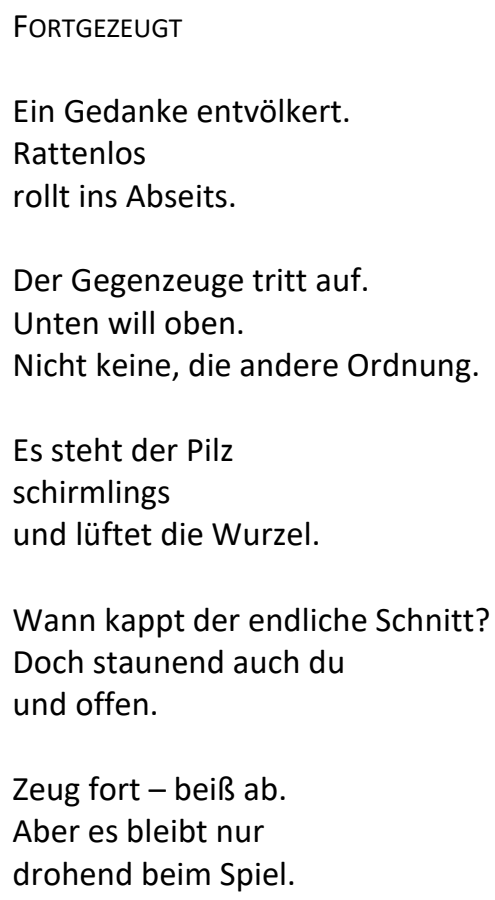

Im Gegensatz zum Gedicht "Mariazuehren“ wird die Assoziation des Pilzstiels mit einem Penis in „Fortgezeugt“ nicht explizit als Metapher realisiert. Stattdessen führt die Grafik diesen metaphorischen Gedankensprung aus, indem sie inn in einem surrealen Bild sichtbar macht. Dem buchstäblich globalen Zusammenhang, den das Gedicht erschließt, entspricht in der Grafik die exemplarische Singularität des Objekts. Im dritten Kapitel des Butt stellt Grass das Thema der Fortpflanzung in den Kontext der Überbevölkerung: Im Zuge einer Reise nach Indien beginnt der Autor-Erzähler Zweifel an der fortgesetzten Vermehrung der Menschheit zu hegen. Das Elend der Bevölkerung und insbesondere ihr Mangel an Nahrung fallen dem Schriftsteller, der sich gleichzeitig intensiv mit der Kulturgeschichte des Essens und Kochens beschäftigt, besonders ins Auge.

Während in diesen beiden Arbeiten noch das männliche Element des Zeugens im Vordergrund steht, zeigen andere Bilder die Zusammenführung beider Geschlechter im Motiv des Pilzes. Bereits mit der Ätzradierung Große Pilze von 1972 (Abb. 155) wird deutlich, dass Grass nicht nur das Phallische des Pilzstieles zur Darstellung reizte. Die Grafik zeigt detailliert einen Pilz mit trichterförmigem Hut, dem ein Einzeller mit einem phallisch geformten Stiel zur Seite gestellt ist. In der 
unteren Hälfte des Bildes wurden ein langstieliger Pilz und eine weibliche Scham nebeneinandergesetzt, sodass den Betrachtenden die geschlechtliche Assoziation, die von den Einzellern in der oberen Bildhälfte ausgeht, visuell in der unteren Bildhälfte mit angeboten wird. Als grafisches Leitmotiv wird der zwittrige Pilz im Künstlerbuch Mit Sophie in die Pilze gegangen in verschiedenen Varianten zum Einsatz kommen.

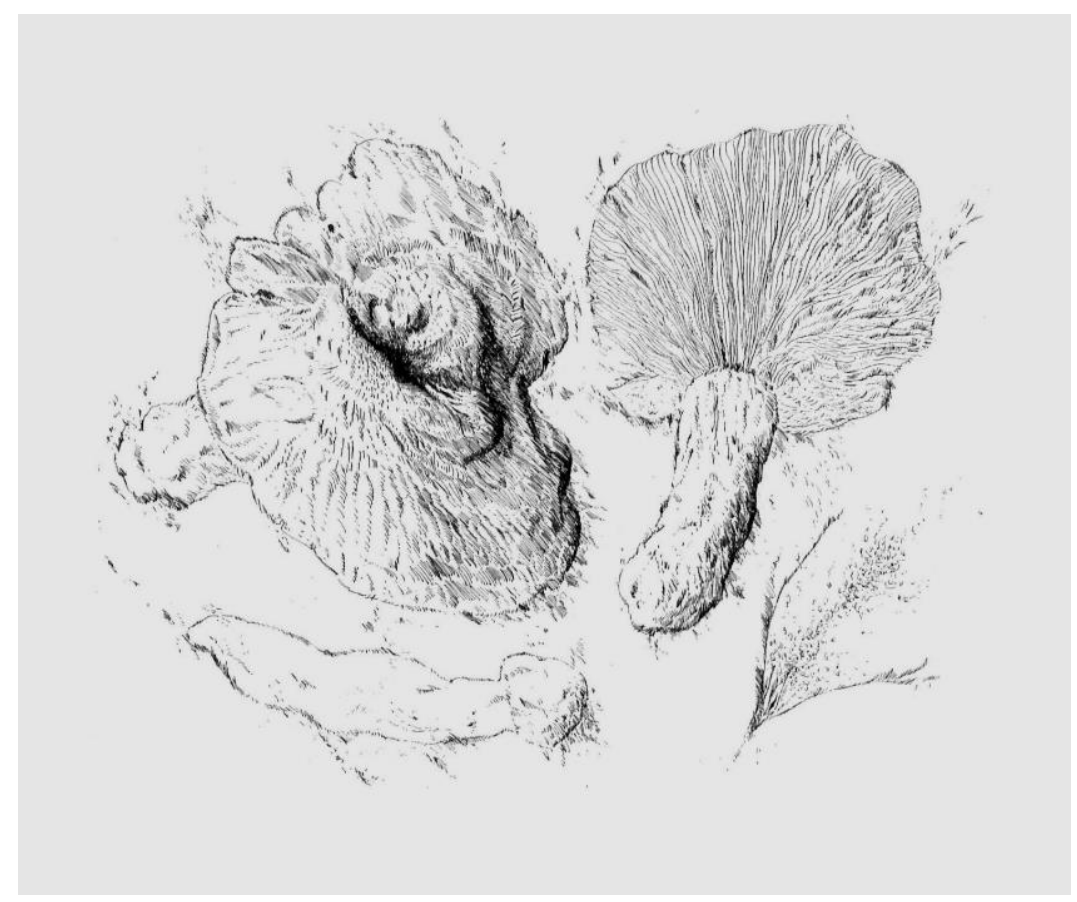

Abb. 155, Große Pilze, 1972, Ätzradierung auf Kupfer

\section{Mit Sophie in die Pilze gegangen: Rollenspiele}

Der 1987 veröffentlichte Gedichtband wurde bereits 1976 als großformatiges Künstlerbuch herausgegeben. ${ }^{571}$ Enthalten sind in beiden Publikationsformen neun Gedichte und neunzehn Lithografien in identischer Abfolge. Die Seitenzählungen weichen allerdings voneinander ab, und die hier verwendeten Abbildungen und Seitenzahlen sind der Buchausgabe von 1986 entnommen. Bis auf eine Ausnahme werden die Texte mit mehreren, mit jeweils bis zu vier Lithografien kombiniert und das bereits im Titel präsente Motiv des Pilzes in nahezu jedes Bild integriert. Ebenso wie die einheitliche stilistische Gestaltung der Grafiken trägt diese Motivkontinuität zu einer geschlossenen Gesamterscheinung der Bücher bei. Die Gedichte nehmen verschiedene Themen des Butt vorweg und viele von ihnen wurden in den Roman aufgenommen. ${ }^{572}$ Damit erschließen sie ein weites Feld: Neben dem Verhältnis der Geschlechter beschäftigen sie sich mit der Verknüpfung von individueller Biografie und Kulturgeschichte von der Steinzeit bis in die Siebzigerjahre. Den Butt bestimmt wie schon Aus dem Tagebuch einer Schnecke ein Autor-Erzähler. Dieser schlüpft im Roman von 1977 jedoch in verschiedene Rollen in verschiedenen Jahrhunderten. Er berichtet, wie

\footnotetext{
571 Die Papierbögen haben darin die Maße von 50 x $71 \mathrm{~cm}$. Vgl. Ohsoling (2007a), S. 12

572 Vgl. Mayer(-Iswandy) (1988), S. 89.
} 
er in all seinen Daseinsformen durch die gesamte Menschheitsgeschichte hindurch von einem sprechenden Fisch darin beraten wurde, sich den Frauen gegenüber durchzusetzen. Wie im folgenden Teilkapitel näher erörtert werden wird, basiert Grass' Roman damit auf einer Umkehrung des Grimm'schen Märchens Von dem Fischer un syner Fru. Dem reichen Themenspektrum des Romans und der Gedichte aus Mit Sophie in die Pilze gegangen entgegen, akzentuieren die in den Lithografien zur Gedichtsammlung dargestellten Pilze durch ihre besondere Form immer wieder den Aspekt des Mann-Frau-Verhältnisses und nehmen auf diese Art Einfluss auf die Textlektüre.

Die bereits in einer frühen Radierung von 1972 angedeutete Verbindung von weiblichen und männlichen Geschlechtsformen bei der Darstellung von Einzellern wird in den Lithografien aus Mit Sophie in die Pilze gegangen aufgegriffen und in verschiedenen Kombinationen mit anderen Objekten zusammengeführt. ${ }^{573}$ Wie schon der Titel des Gedichtsammlung offenbart, werden darin nicht nur die Einzeller selbst zum Motiv, sondern ebenso der Vorgang des Suchens und Sammelns von Pilzen. Entsprechend zeichnen sich die Grafiken zum Gedichtband und Künstlerbuch durch ihren narrativen Charakter aus. Zum ersten Mal fungieren handschriftliche Versionen der Gedichte in Grass' Werk zudem als ein eigenständiges gestalterisches Element einer grafischen Serie. Zwar hatte er in Mariazuehren bereits Schrift und Bild zusammengeführt, beide Ausdrucksformen darin jedoch nur auf Abstand nebeneinandergesetzt. Die Lithografien von Mit Sophie in die Pilze gegangen weisen dagegen eine freie Verzahnung der Elemente auf dem Papier auf. Grass muss hier mit Umdruckpapier gearbeitet haben, denn dem Schriftbild zu Folge war er nicht dazu gezwungen, den Text spiegelverkehrt aufzutragen.

Gleich zu Beginn wird das Motiv des Pilzes als erotisch konnotiertes Sinnbild im Zusammenhang mit dem Titel und dem Gedicht „Zum Fürchten“ vorgestellt. Auf den Schmutztitel und - im Fall der Veröffentlichung für den Buchhandel: auf das Inhaltsverzeichnis - folgt eine Lithografie, die im unteren Bilddrittel den Schriftzug „Mit Sophie in die Pilze gegangen“ mit der grafischen Darstellung eines Pilzes koppelt, dessen Stiel wie ein männliches Glied geformt ist. Die Platzierung der Zeichnung auf der Seite entspricht der Position der natürlichen Gedeihenszone der Einzeller im Unterholz (Abb. 156).

Die schwarze Handschrift überlagert den liegenden, mit dem Stiel auf die Betrachtenden weisenden Pilz an dessen Hut. Die Teilform des Hutes ist so dicht schraffiert, dass keinerlei Volumen suggeriert wird. Das Wort „Pilze“ setzt sich hell vor der dunklen Fläche ab und wurde im Unterschied zu den verbleibenden Worten nicht einfach niedergeschrieben, sondern in die Schraffur hinein gekratzt. Der Schriftzug „Pilze“, der in Umrissen gezeichnete Einzeller und das in der Figur auszumachende männliche Glied sind gleichzeitig erkennbar. Ikonisch und symbolisch werden dem Objekt damit jeweils verschiedene Bedeutungen zugeschrieben und auf dem Blatt zusammengeführt. Die Leserinnen und Leser der Überschrift "Mit Sophie in die Pilze gegangen“ wissen nicht, wer die darin angesprochene "Sophie“ ist, können aber aus der Darstellung ersehen, dass das In-die-Pilze-Gehen mit ihr einen erotischen Hintersinn haben muss und der Pilz als ein Zeichen für männliche Geschlechtlichkeit aufzufassen ist. Der Name Sophie kann hier stellvertretend für die weibliche Akteurin der geschlechtlichen Vereinigung, wie er von Grass bereits in seinem ersten Gedichtband verwendet wurde, gedeutet ${ }^{574}$ und zugleich in ihrer wörtlichen Bedeutung als „Weisheit" verstanden werden. In diesem Sinne scheint die Grafik darauf vorzubereiten, dass ein

\footnotetext{
573 Vgl. Ohsoling (2007), R 16: Günter Grass, Große Pilze, Ätzradierung, 1972.

${ }^{574}$ Vgl. Stolz (1994), S. 144.
} 
kluger Umgang mit der geschlechtlichen Liebe ein entscheidendes Thema der folgenden Gedichte und Bilder sein wird.
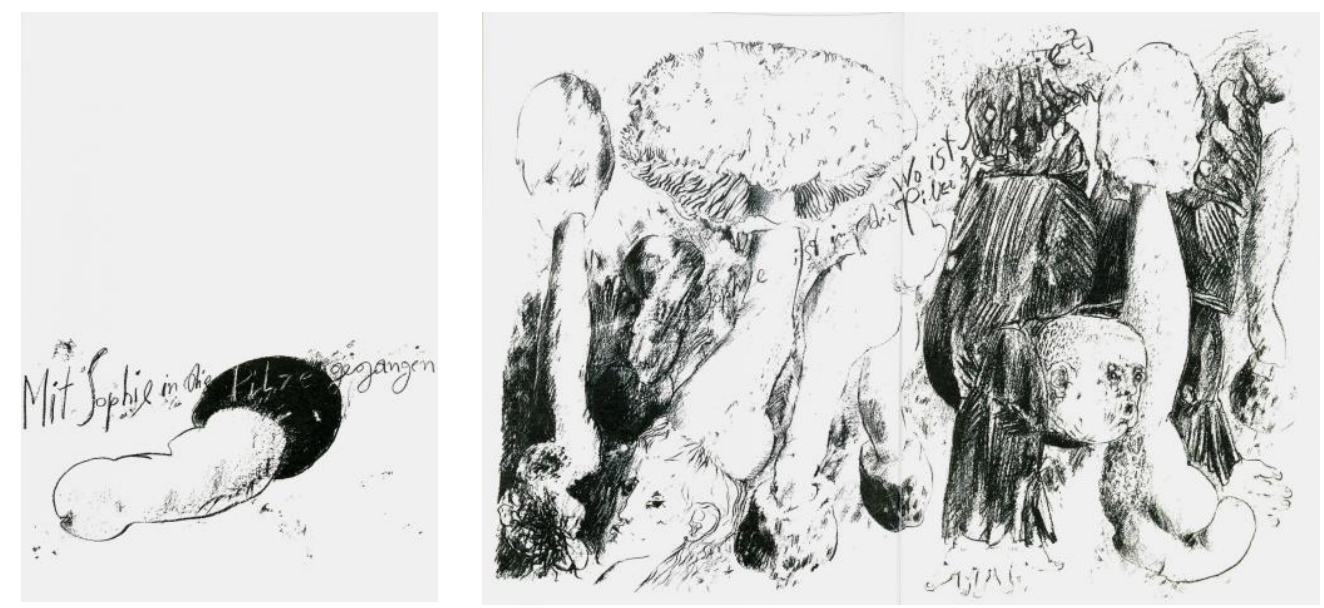

Abb. 156, Abb. 157, Mit Sophie in die Pilze gegangen, Göttingen 1987, S. 7, S. 8 f.

Auf die besprochene Lithografie folgt eine zweite, die sich über eine Doppelseite erstreckt (Abb. 157). Sie zeigt - wie schon Grass' frühe Vogel- und Vogelscheuchen-Darstellungen nebeneinander gereihte Objekte: verschiedene Pilze, eine Frau, die einen Einzeller auf dem Kopf trägt, und einen Mann, der einen Kopfstand vollführt. Die Pilze entsprechen in ihrer Größe den menschlichen Figuren, sodass der umgangssprachliche Gang in die Pilze darin in seiner buchstäblichen Bedeutung geschildert wird. Von links nach rechts betrachtet, ergibt sich im Detail folgendes surreale Bild: Auf eine Morchel mit schwarzer, an Schamhaar erinnernder Wurzel folgt ein Parasol mit weit ausladender Krempe, der von einer schmalgesichtigen Frau wie eine Krone auf dem Kopf getragen wird. Ihre Gestalt ist im Vergleich zu allen anderen Objekten nach unten versetzt und deshalb lediglich bis zum Halsansatz sichtbar. Rechts daneben sind zwei an der Wurzel zusammengewachsene, mit ihren Hüten nach unten gerichtete Pilze zu sehen, daneben eine säuglingshaft glatzköpfige männliche Figur mit grobumrissenem Körper, die auf ihren Händen steht und die Lippen zum Pfeifen spitzt. Ängstlich - denn warum sonst im Dickicht pfeifen - wechselt der Mann hier seine Perspektive und betrachtet die mannshohen phallischen Pilze von unten. Seine Furchtsamkeit steht in Kontrast zur selbstsicheren Kühle der von ihm abgewendeten Frauenfigur, die im dunkel-verfilzten Unterholz gesucht wird.

Erst auf diese beiden Bilder, die die geschlechtliche und bedrohliche Dimension des Pilzesammelns zum Ausdruck bringen, folgt das erste Gedicht „Zum Fürchten“. Es beschreibt in den ersten beiden Strophen die Angst eines sich im Wald verirrenden lyrischen Ich vor irrationalen und unkontrolliert voranschreitenden Vorgängen:

ZUM FÜRCHTEN

Im Wald laut rufen.

Die Pilze und Märchen

holen uns ein. 
Jede Knolle treibt jüngeren Schrecken.

Noch unter eigenem Hut,

doch die Angsttrichter rings

sind schon gestrichen voll.

Das Motiv des anthropomorphisierten Pilzes wird in der dritten Strophe des Gedichts, also in dessen Zentrum, mit dem Geschlechtstrieb verbunden und erhält mit dem Ausdruck des „zerstörten Bettes", das gleichermaßen Wurzel- und Menschenbett meinen kann, einen negativen Beigeschmack:

Immer war schon wer da.

Zerstörtes Bett - bin ich es gewesen?

Nichts ließ mein Vorgänger stehen.

Diese Konnotation steigernd werden Pilze im Folgenden als tödliche Gefahr kenntlich gemacht:

Wir unterscheiden: schmackhafte

ungenießbare giftige Pilze.

Viele Pilzkenner sterben früh

und hinterlassen gesammelte Notizen.

Reizker, Morchel, Totentrompete.

Aller Allgemeingültigkeit zum Trotz, die durch die Andeutungen der stetigen Wiederholung erzeugt wird, erhält der geschlechtliche und tödliche Genuss auch eine präzise zeitliche Verortung. Zugleich wird das Suchen der Pilze an jener Stelle als eine blinde Suche gekennzeichnet:

Mit Sophie gingen wir in die Pilze.

Das war, als Napoleon nach Rußland zog.

Ich verlor meine Brille

und nahm den Daumen;

sie fand und fand.

Das Gedicht vermittelt den Gang in die Pilze damit als einen beängstigenden, buchstäblich düsteren und sogar todbringenden Prozess, der als eine Allegorie des Irrationalen im Allgemeinen und der geschlechtlichen Liebe im Besonderen gedeutet werden kann. Mit der zeitlichen Festlegung der ,Handlung' auf das Jahr von Napoleons Russlandfeldzug und mit der Erwähnung der Märchen in der ersten Strophe wird sie zugleich in der kulturhistorischen Epoche der Romantik verortet und das Gedicht mit einer Strömung in Verbindung gebracht, die in einer Gegenbewegung zur Aufklärung das Unterbewusste thematisierte und rehabilitierte. Die grafischen Pilzdarstellungen machen einen erotischen Subtext sichtbar, indem sie den Pilz in der ersten Grafik als Phallussymbol visualisieren und in der zweiten durch verzerrte Größenmaßstäbe hervorheben. Die figurenreiche zweite Lithografie bringt zudem die Botschaft einer Umkehrung der Geschlechterrollen zum Ausdruck, die die Verse lediglich andeuten. Ein Rückblick auf die frühen Kapitelentwürfe zu Aus dem Tagebuch einer Schnecke erlaubt den Schluss, dass das Gedicht bereits 1969 zum Thema 
der Belagerung Danzigs durch Napoleon geschrieben worden sein könnte, das Grass zunächst zu einem der Schwerpunkte seines Schneckenbuches machen wollte. ${ }^{575}$

In der letzten Grafik zu diesem Text werden Zeugen und Gebären im Pilzmotiv zusammengezogen. (Abb. 158) Während eine weibliche Figur links einen phallischen Pilz auf dem Kopf trägt, gleitet eine männliche glatzköpfige Figur rechts aus dem trichterförmigen, konkaven Hut eines solchen, als würde sie soeben geboren. Beide Pilze enthalten mit der Trichterform ihrer Hüte weiblich und mit dem Stiel männlich konnotierte Elemente. Da sowohl der Frau als auch dem Mann in der Darstellung ein zwittriger Pilz beigefügt wird, werden beiden Geschlechtern auch Anteile des jeweils anderen zugeschrieben. Im unteren Bildviertel wird handschriftlich die letzte Strophe des Gedichtes angeführt, die das In-die- Pilze-Gehen des Iyrischen Ich mit Sophie thematisiert, also die Passage, aus der die erotisierte Arbeitsteilung von Mann und Frau beim Gang in die Pilze am stärksten hervorgeht: „Ich verlor meine Brille und nahm den Daumen sie fand und fand."

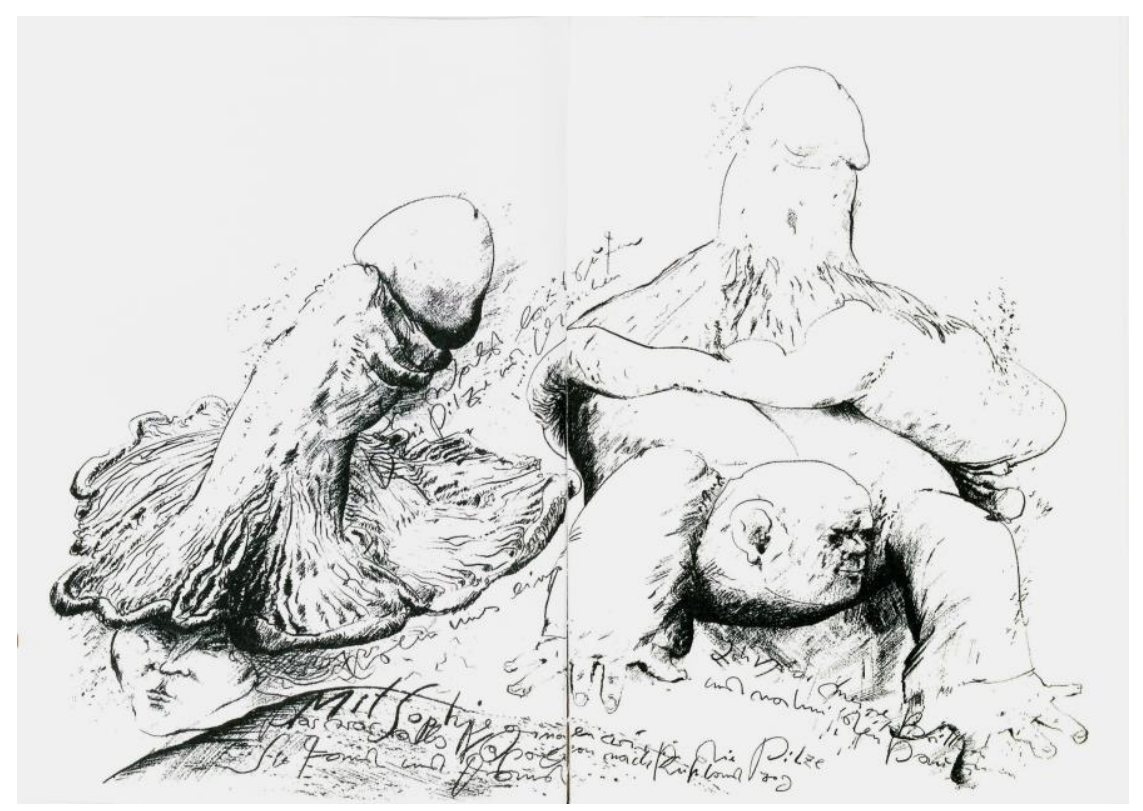

Abb. 158, Mit Sophie in die Pilze gegangen, Göttingen 1987, S. 12 f.

Die auf den ersten Seiten der Veröffentlichungen präsenten Pilze sind in ähnlich verweiskräftiger Form auch in den folgenden Lithografien enthalten, jedoch ohne zugleich ausdrücklich auf die dazugehörenden Texte Bezug zu nehmen: Zu dem Gedicht „Arbeit geteilt“, in dem das lyrische Ich klischeehafte Vorstellungen der Rollen von Männern und Frauen aneinander reiht und dabei seine eigene Konfusion offenbart, gestaltete Grass eine Grafik, in der der handschriftliche Text wie aus Megaphonen aus trichterförmigen Pilzhüten strömt (Abb. 159). Auch diese Pilze weisen erneut sowohl weiblich als auch männlich konnotierte Teilformen auf. Aus jedem der vier Pilze heraus

\footnotetext{
575 Vgl. Mayer (1982), S. 20. Die Forscherin führt eine andere Spur zu diesem Schluss, nämlich die Erwähnung der früh sterbenden Pilzkenner, die "gesammelte Notizen“ hinterlassen. Diese bringt sie schlüssig mit der Figur des Selbstmörders Augst aus dem Tagebuch in Verbindung, zu dessen wenigen Leidenschaften das Pilzesammeln zählt.
} 
setzt der Text neu an, sodass er als simultan gesprochene Sprache vorstellbar wird. Die Schrift ist dabei nur zum Teil lesbar. Als ikonisches Linienknäuel geht sie in eine Masse gezeichneter Zigarettenstummel und abgenutzter Streichhölzer über, die den Trichtern zudem entfallen.

In der Grafik zum Gedicht „Was Vater sah“ ist es dagegen ein Säugling, den ein trichterförmiger Pilz hervorbringt (Abb. 160). Die Assoziation des besonderen Pilzhutes mit einer Vagina wird durch diese Darstellung aufs Deutlichste bestätigt - im Gedicht wird die Geburt der Tochter Helene beschrieben.

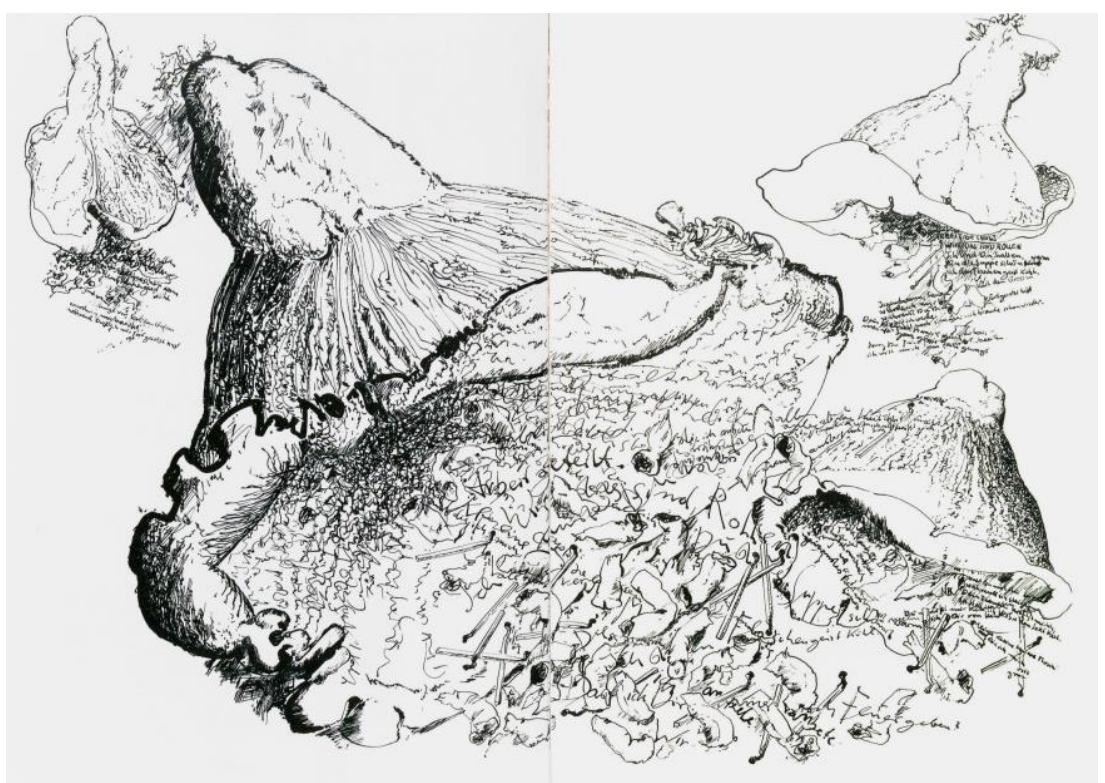

Abb. 159, Mit Sophie in die Pilze gegangen, Göttingen 1987, S. 20 f.

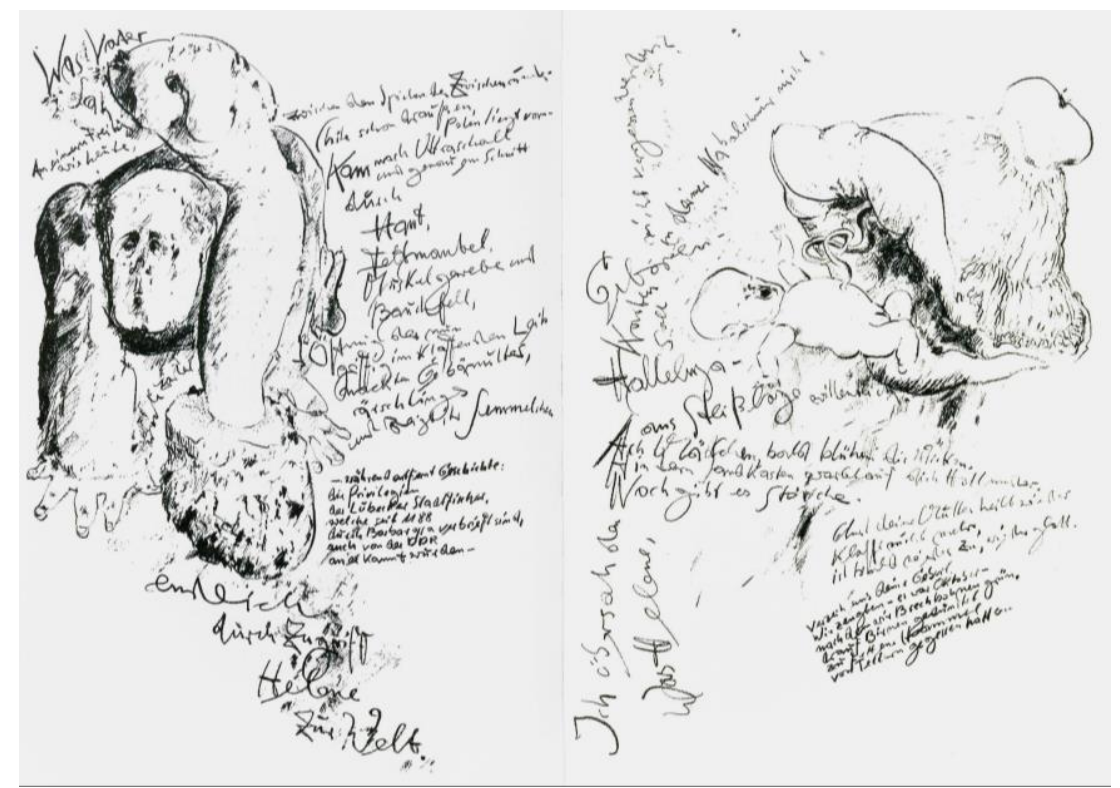

Abb. 160, Mit Sophie in die Pilze gegangen, Göttingen 1987, S. 24 f. 
Wenn Grass hier erstmals handschriftliche Fassungen seiner Gedichte gestaltend in die lithografierte Bildserie integriert, ist daran nicht allein die stärkere Synthese von Wort und Bild und die deutlichere Unabhängigkeit der so ergänzten Grafik von der gedruckten Textfassung erwähnenswert. Die Handschrift wird teilweise - wie in dem Bild zu „Arbeit geteilt“ - ikonisch eingesetzt, ist also einerseits lesbar und fügt sich andererseits zu figürlichen Formen. Sie variiert im Gegensatz zu der gleichmäßigen Schrift in Mariazuehren in ihrem Duktus und unterstreicht mit ihrer jeweiligen Erscheinungsform den Inhalt des Geschriebenen. In der Lithografie zu "Was Vater sah" werden beispielsweise die historischen und biografischen Fakten, die der Text enthält, nämlich die Anerkennung der Privilegien der Lübecker Stadtfischer durch die DDR zum einen und die Zeugung der Tochter im Oktober zum anderen, besonders nüchtern in kleinen und gleichmäßig gesetzten Buchstaben niedergelegt.

Der mit der Hand verfasste Text bindet das Gedicht durch die visualisierte körperliche Geste des Schreibens stärker an den realen Dichter zurück. ${ }^{576}$ Diese Rückkoppelung und Subjektivierung der Texte unterstützt das autobiografische Element der Gedichtsammlung, die mit Fakten aus Grass' Leben durchsetzt ist. In den Grafiken zu den Gedichten „Federnblasen“ und „Gestillt" wird dieser Eindruck auch auf einer anderen Ebene hergestellt, da beide Bilder Selbstporträts des Künstlers enthalten.

Die Lithografie zu „Helene Migräne“ thematisiert schließlich einen letzten wichtigen, im Butt noch stärker an Bedeutung gewinnenden Aspekt des In-die-Pilze-Gehens (Abb. 161): Das Bild zeigt eine Frau und einen Mann inmitten vieler kleiner Pilze. Die Frau trägt, wie bereits aus anderen Grafiken bekannt, einen phallischen, trichterförmigen Pilz auf dem Kopf. Der Umriss ihres Rumpfes ist mit dem Text des entsprechenden Gedichts dicht gefüllt. Aufgebracht scheint sie auf den Mann neben ihr einzureden, von dem nur das Gesicht - im Vergleich zur Frauengestalt um ein Vielfaches vergrößert - erkennbar ist. Dieses zum Betrachter gewendete Antlitz wird von einem phallischen Pilz teilweise verdeckt. Nur mit Mühe kann der Mann unter dem Pilzhut hervorlugen. Dem nach oben gerichteten Einzeller ist eine Brille aufgesetzt, die durch diese Zusammenstellung ihrer Funktion enthoben ist. Das In-die-Pilze-Gehen ist demnach offenkundig keine Tätigkeit, bei der es auf den Sehsinn besonders ankommt - das Sehen wird dabei vielmehr verstellt. Die Metapher des „Pimmelpilzes“ wird in Mit Sophie in die Pilze gegangen zu einer allegorischen Szenerie erweitert, die wiederum eine Grundlage für ein Kapitel des 1977 veröffentlichten Butt bildet.

\footnotetext{
${ }^{576} \mathrm{Vgl}$. zu den Wahrnehmungsmodi grafischer Linien als Phänomene zwischen ikonischer und symbolischer Form: Schwerzmann (2012).
} 


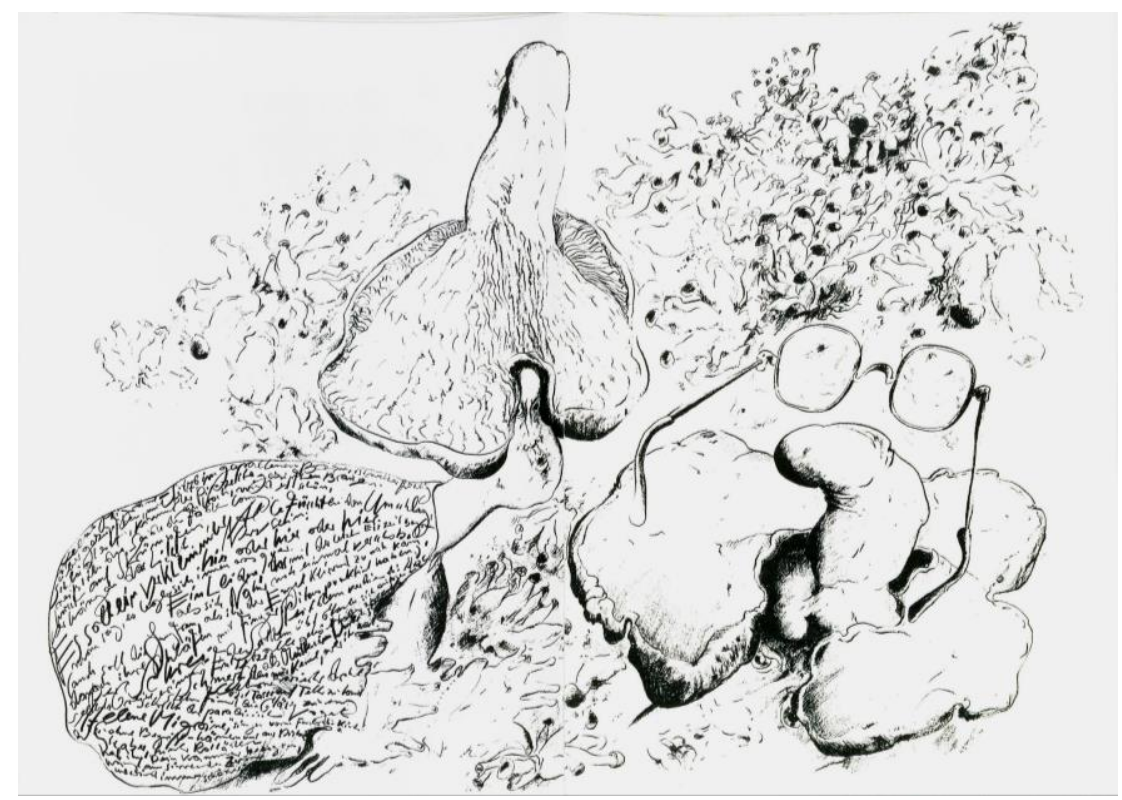

Abb. 161, Mit Sophie in die Pilze gegangen, Göttingen 1987, S. 28 f.

\section{Der Pilz im Butt - Bedeutungen auch über das Geschlechtliche hinaus}

Das Motiv des Pilzes und des In-die-Pilze-Gehens durchwirken das sechste Kapitel des Butt. Vergangenheit und Gegenwart verwebend, ist dieser Abschnitt der Literatur- und Kunstepoche der Romantik, den Idealen der Französischen Revolution sowie dem jederzeit stattfindenden Suchen, Finden und Verlieren der Liebe gewidmet.

Der Gang in die Pilze und der Pilz werden zu Beginn des Kapitels in einem Gedicht thematisiert und hinsichtlich der von innen ausgehenden Assoziationen erweitert. Wie bereits in dem Gedicht „Zum Fürchten“ wird der erotisierte Vorgang des Pilzesammelns in den Versen von "Sophie" als ein beängstigender und vernunftloser beschrieben, der die Suchenden mit Blindheit schlägt. Darüber hinaus werden Pilze in diesem Text explizit als dankbare Bildspender für Gleichnisse hervorgehoben und es wird angedeutet, dass gerade ihre zum Verwechseln ähnlichen, aber trotzdem verschiedenen Sorten sie als Motiv zur Veranschaulichung verschiedener Inhalte verwendbar machen:

SOPHIE

Wir suchen

und meinen zu finden;

aber anders heißt er

und ist auch anders verwandt.

Einmal fanden wir einen,

den gab es nicht.

Meine Brille beschlug,

ein Häher schrie,

wir liefen davon.

In den Wäldern um Saskoschin

sollen sie sich verglichen haben. 
Weil immer noch kenntlich,

wurden die Pfifferlinge verlacht.

Pilze bedeuten.

Nicht nur die eßbaren

stehen auf einem Bein

für Gleichnisse stramm.

[...] (VI 437 f.)

Im sechsten Kapitel des Romans fungiert der Gang in die Pilze zunächst als versöhnendes Element zwischen den Geschlechtern, und zwar mit Bezug auf eine Debatte, die das Märchen auslöst, das die Struktur des Buches grundlegend bestimmt. Die plattdeutsche Erzählung Von dem Fischer un syner Fru ist in ihrer Umkehrung als Allegorie der männlichen Hybris das Handlungsmuster für die im Butt niedergelegte Geschlechtergeschichte. Grass siedelt die Geschichte der Textüberlieferung im Unterkapitel „Die andere Wahrheit“ im Jahr 1807 an. An sie knüpft er eine Auseinandersetzung der Romanfiguren mit dem Verhältnis zwischen Männern und Frauen. ${ }^{577}$

Die Handlung der Passage beginnt mit einer fingierten Zusammenkunft Jacob und Wilhelm Grimms, Clemens Brentanos, Achim und Bettina von Arnims und des Malers Philipp Otto Runge im Olivaer Wald bei Danzig. Abseits aller nachrevolutionärer Wirren, untergebracht in einem bescheidenen Försterhaus, in dessen Dachkammern „die Freunde ihr Glück verträumten und ihren Kummer verschliefen" (VI 440), wollen sie über die geplante Fortsetzung der Hausmärchensammlung Des Knaben Wunderhorn beraten. Dabei stellt Runge zwei Fassungen eines Märchens vor, die inm von einer Marktfrau auf Hiddensee erzählt worden sind und die beide gleichermaßen Gültigkeit haben sollen: Die eine real überlieferte Version handelt von der Fischersfrau Ilsebill, die sich und ihren Mann durch ihre immer maßloseren Wünsche um die Möglichkeit bringt, zu Glück und Wohlstand zu gelangen. Als ihr Mann einen sprechenden Butt fängt, der ihm für seine Freilassung Wünsche zu erfüllen bereit ist, trägt Ilsebill ihrem Mann auf, zu fordern, sie möge König, Kaiser, Papst und schließlich sogar wie Gott werden. Die Fischersfrau erlebt auf diese Weise zunächst verschiedene Grade des Wohlstands und der Macht. Die Verwirklichung ihres letzten, verstiegensten Wunsches versetzt das Ehepaar jedoch in ihre Ausgangslage, in ihr ärmliches Leben in einem „Pißpott“ zurück. In der anderen Märchenfassung sind Handlungen und Akteure vertauscht: Es ist der Fischer, den Geld- und Machtgier auszeichnen:

Brücken über den breitesten Fluß, Häuser und Türme, die bis in die Wolken reichen, schnelle Wagen, weder von Ochs noch Pferd gezogen, Schiffe, die unter Wasser schwimmen, will er bauen, begehen, bewohnen, ans Ziel fahren. Die Welt beherrschen will er, die Natur bezwingen und von der Erde weg sich über sie erheben. [...] Und wie zum Schluß der Mann, obgleich ihm seine Frau Ilsebill immer wieder Zufriedenheit anrät [...] hoch zu den Sternen reisen möchte [...] fällt all die Pracht, Türme, Brücken und Flugapparate, in sich zusammen [...]. (VI 443)

Über die Entscheidung, welche der Varianten gedruckt werden soll und damit die Einschätzung der Nachwelt von Mann und Frau beeinflussen könnte, geraten die Anwesenden in Streit. Ilsebill und der Fischer werden von ihnen als Repräsentanten ihres Geschlechts diskutiert. Während Bettina Brentano und Wilhelm Grimm den Ruf der gesellschaftlich ohnehin benachteiligten Frau-

${ }^{577}$ Vgl. Øhrgaard (1983), S. 136. 
en wahren möchten, verwenden sich Clemens Brentano und Jacob Grimm für die Sache der Männer und unterstützen die erste Märchenfassung, weil mit der zweiten Version alle männlichmenschlichen Errungenschaften in Frage gestellt würden. Ihre Auseinandersetzung schlichtet ein Gang in die Pilze, bei dem die noch unverheirateten Bettina und Achim einander näherkommen und durch den Genuss von Fliegenpilz-Stückchen in Verzückung geraten:

Indessen hatten sich Arnim und Bettina [...] wie zufällig gefunden. Sie zeigten sich, was sie in ihre Körbe gesammelt hatten [...] die verspielte Bettina [...] bat um Nachsicht für die gesammelten Fliegenpilze: Die seien wie Märchen schön. Von denen gehe ein Zauber aus. Sie wisse, daß der Fliegenpilz, selbst wenn man nur wenig von ihm speise, Träume mache, die Zeit aufhebe, das Ich erlöse und alles, so grob es gegeneinander stehe, miteinander versöhne. (VI 446 f.)

Runge, der nicht am versöhnenden Spaziergang teilnimmt, verbrennt wenig später eigenmächtig die männerkritische Niederschrift. Dies kann nur deshalb ohne größeren Protest gelingen, weil die anderen Freunde zunächst davon hingerissen sind, „wie der volle Mond über den Teich, auf dem Schwäne schliefen, und über die Rehwiese, auf der Rehe ästen, sein Licht goß“ (VI 449).

Dem Gang in die Pilze kommt in dieser Episode allegorisch die Rolle des Schlichtens zwischen Männern und Frauen, zwischen der einen und der anderen "Wahrheit" zu. Die Bedeutung, die dem Prozess beigemessen wird, entspricht der Synthese aus männlichen und weiblichen Elementen des Pilzes in Grass' Grafik. Die rauschhafte Wirkung des Fliegenpilzes beflügelt den Versöhnungs-Effekt in dieser Episode des Butt. Die von Bettina geäußerte Sehnsucht danach, das Ich aus seinen Schranken zu befreien, repräsentiert ein zentrales Anliegen der Romantiker: Als Gegenreaktion gegen die Vernunftgläubigkeit der Aufklärung entdecken sie das Unterbewusste in seiner ganzen Ambivalenz als wesentlichen Teil der menschlichen Existenz. ${ }^{578}$

Diese Auffassung wird im Butt weitgehend affirmativ vermittelt und bildet einen der vielen Anknüpfungspunkte, die der Roman zur romantischen Literatur enthält. Neben der Ergänzung einer realitätsnahen Handlung um andere, innere Wirklichkeiten liegen weitere Bezugnahmen auf der Hand: Die Fabel des Butt rekurriert auf das Märchen Von dem Fischer un syner Fru, indem es eine fulminante, die ganze Menschheitsgeschichte ausschreitende Gegenfassung zu ihr bildet. Grass' Roman sollte ursprünglich die Gattungsbezeichnung „Märchen“ tragen, worauf nur aufgrund einer pessimistischen Einschätzung der öffentlichen Rezeption dieses Begriffs verzichtet wurde. ${ }^{579}$ Mit der Verknüpfung von Lyrik und Prosa sowie der Betonung der mündlichen Überlieferung im Butt folgt Grass Schlegels Entwurf einer „progressiven Universalpoesie“ aus dem 116. AthenäumsFragment.

Dennoch wird die Kunstepoche von ihm auch kritisch behandelt: Die Weltflucht der porträtierten Romantiker wird genauso ironisch geschildert, wie ihre ausnehmende Empfindsamkeit und ihr angesichts der idyllisch mondbeschienenen Landschaft ausbrechender Ästhetizismus. Die Absicht, die die Freunde dem Roman gemäß mit ihrer Märchensammlung verfolgen, steht Grass' Ästhetik diametral entgegen:

Im Vorjahr hatten von Arnim und Brentano einen Sammelband voller kostbarer Stücke, Des Knaben Wunderhorn, herausgegeben; und weil das allgemeine Kriegselend die Bedürfnisse nach schönen

\footnotetext{
${ }^{578}$ Vgl. Brady (1990), S. 220.

${ }^{579}$ Vgl. Neuhaus (2010), S. 158.
} 
Worten steigerte und Angst die Zuflucht im Märchen suchte, wollte man in Ruhe, entrückt dem städtischen Getriebe und frei vom politischen Alltagsgezänk, aus der noch ungeordneten Fülle seltsamer Schätze einen zweiten und dritten Band zusammenstellen, damit dem Volk, nach so viel kühler Aufklärung und klassischer Strenge, endlich Trost zuteil werde: und sei es durch die Gnade des Vergessens. (VI 438 f.)

Die hier erwähnte Nachkriegszeit, die schönen Worte und das Vergessen lassen sogar darauf schließen, dass in Grass' Darstellung der Kultur und der politischen Ideale um 1800 auch eine Parallele zur westdeutschen Nachkriegskultur gezogen wird, der der Schriftsteller Verdrängung und Weltflucht vorgeworfen hatte. ${ }^{580}$ Die Wirkung des Irrationalen, des Rausches, auch des Fliegenpilzrausches, wird im Butt nicht allein positiv geschildert: Die Problematik der blinden Liebe wird zusammen mit der Gefahr des blinden Vertrauens auf eine politische Ideologie im nächsten Unterkapitel des "Sechsten Monats“ thematisiert.

Die Episode unter dem Titel „In die Pilze gegangen“ bestimmt die Geschichte der Köchin, die den Romantikern den Ertrag ihrer Pilzsuche am Herd des Försterhauses zubereitet: Sophie Rotzoll. Erzählt wird von ihrer Liebe zu dem Revolutionär Fritz Bartholdy, der schon in jungen Jahren, nach der Aushebung des von ihm gegründeten Jakobinervereins, inhaftiert wird. Ein zunächst nicht klar konturierter zeitgenössischer Erzähler berichtet von der Politisierung der vierzehnjährigen Sophie durch den siebzehnjährigen Fritz und seine Freunde Gottlieb und Max. Nicht ohne Grund zeichnen sich die jungen Idealisten alle drei durch gleichförmige Pilzfrisuren aus, die an die Beatles zu Beginn der Sechzigerjahre erinnern. Wie zuvor die Romantiker werden die Jungen als Wirklichkeitsflüchtige porträtiert, die bei der Suche nach Pilzen ihrer Vorstellung von „Freiheit durch Gewalt" nachträumen, während diese Idee anderswo wirkliche und tödliche Folgen hat:

Sieben Jahre lang gingen wir, während hinter den Wäldern die Revolution stattfand und die Guillotine als humaner Fortschritt gefeiert wurde, in die Pilze und hatten eine schöne Idee. (VI 452)

Für Sophie ist ihr Geliebter, als welcher sich der Erzähler bald zu erkennen gibt, die Personifikation des revolutionären Freiheitsgedankens, und beide sehen bald in Napoleon, dessen kurzer Körper und ausladender Hut im Umriss an einen Pilz erinnert, eine neue Verkörperung ihrer Ideale:

weil wir so lange und immer wieder in die Pilze gegangen waren, hatte sich uns die Idee erhalten. Die war schön wie ein einzeln stehender Steinpilz. Und als Sophie vom siegreichen General Bonaparte aus der jüngsten Zeitung laut vorlas, sagte Fritz: „Vielleicht ist dieser Napoleon jetzt die Idee.“ (VI 451)

In die Gefangenschaft sendet Sophie ihrem Geliebten zur Aufmunterung politische Liedtexte, in welchen sie Pilze untermischt: „Im Traum ich einen Steinpilz seh: / Die Freiheit kömmt. La Liberté!“ (VI 457). Jahrzehntelang hält sie an ihrer Liebe zu Fritz und den gemeinsam mit ihm vertretenen politischen Idealen fest. Als Köchin des napoleonischen Generals Rapp, der um ihre Gunst buhlt, bemüht sie sich, seine Freilassung zu erwirken. Erst nach Jahren wird ihr bewusst, dass Rapp nur bereit ist, ihr zu helfen, wenn sie sich ihm hingibt. Sie beschließt daraufhin, sich an inm zu rächen und den Gouverneur mit einem Pilzgericht zu vergiften - ein Plan, der missglückt, weil Rapp gewarnt wird.

${ }^{580} \mathrm{Vgl}$. Kapitel II.3. der vorliegenden Untersuchung. 
Nachdem Fritz nach achtunddreißig Jahren endlich entlassen wird, geht das Paar gemeinsam in die Pilze und berauscht sich, ebenso wie lange zuvor Bettine und Achim, an der Wirkung des Fliegenpilzes. Sophie versucht, in dem gebrochenen Alten den bewunderten Mut und Freiheitsdrang ihrer Jugendliebe wiederzufinden. Ihre Suche wird durch die berauschende Wirkung des giftigen Einzellers unterstützt und ihre Vorstellung von Freiheit erneut mit dem Steinpilz gleichgesetzt. Der Erzähler, der im Laufe des Kapitels die Rolle von Fritz annimmt, beschreibt es so:

Sie suchte etwas in mir, was ich gewesen sein soll, als wir jung in die Pilze gegangen sind und Verlorengehen gespielt haben. Sophie glaubte noch immer. Für sie war der Steinpilz noch immer Idee. Dabei half ihr, wenn sie Freiheit erinnern, Freiheit erleben wollte, der sonst nichtsnutze Fliegenpilz [...]. (VI 456)

Mit der Suche der als kurzsichtig beschriebenen Sophie nach dem Ideal der Freiheit wird „Im sechsten Monat" eine andere Suche parallel geführt: diejenige Ilsebills, der Partnerin des AutorErzählers der Siebzigerjahre, nach der großen Liebe, die schließlich in Hass umschlagen soll. Schon aus der Rückschau der bereits gescheiterten Beziehung heraus suggerieren die Ausführungen des gegenwärtigen Erzählers, es seien die zu anspruchsvollen, an einem Ideal, nicht an der Realität orientierten Vorstellungen seiner Partnerin gewesen, die das Gelingen der Beziehung erschwert hätten:

Sie meint, es sei jeder Pilz, den sie findet, der erste und letzte. Nie habe es vorher vergleichbare ge-
geben. Nie wieder werde auf solchem Stiel, so geil behütet und einzeln auf Moosgrund ein Steinpilz
stehen und - während die Hand noch zögert - irgend jemanden glücklich, unvergleichbar glücklich
machen. (VI 452)
Unsere Liebe [...] ist nicht mehr, Ilsebill. Oder sie will nur noch unter Bedingungen möglich, womög-
lich sein. Oder sie ist noch - aber woanders. Oder sie war nie und ist deshalb noch denkbar. Oder wir
gehen mal wieder, wie ich mit Sophie ging, tief in die Pilze, um sie zu suchen. (Doch wenn ein Stein-
pilz einzeln ohne Vergleich stand und von dir oder dir gefunden wurde, war nie ich gemeint.) (VI 461)

Der Steinpilz wird im Butt zum Sinnbild der Freiheit, der Liebe und des Hasses. Das Motiv wird damit weitgehend aus den zuvor über Formanalogien hergestellten Assoziationen mit dem weiblichen und dem männlichen Geschlecht gelöst. Gerade die Aufhebung dieser Bindung steht jedoch schlüssig mit dem Vorgang der Pilzsuche in Zusammenhang. Während Sophie ihrem Freiheitsideal nur blind und berauscht folgen kann, werden Ilsebills mutmaßlich falsche Vorstellungen von ihrem Geliebten, als Verwechslung des tatsächlichen Mannes mit ihren Idealvorstellungen von inm charakterisiert. Diese Selbsttäuschung wird nicht per se llsebill zugeschrieben, sondern der Liebe an sich. In dem Gedicht „Auf der Suche nach ähnlichen Pilzen“, das ebenfalls in den Prosatext eingefügt wurde, steht der Vorgang des schwierigen Unterscheidens der so ähnlichen Pilze bei „diffusem Licht“ im übertragenen Sinne für eine von Sehnsüchten geleitete Suche nach dem genau richtigen Partner:

AUf DER SUCHE NACH ÄHNLICHEN PILZEN

Ein Wurf Boviste, glücklich gefunden, daneben.

Als ich recht bekam, 
gab ich den Rest, alles,

verloren.

Dieser Hut paßt

einen Kopf kürzer

auf Maß.

Nimm es diffus;

auch das Licht

schummelt sich durch.

Zwar sind es Boviste,

doch falsche,

genau. (VI 465 f.)

Sophies Glaube an die Freiheit und Ilsebills Erwartungen an das Liebesglück haben Irrationalität und Starrsinn gemeinsam. Die Einschätzungen beider Pilzsammlerinnen vermitteln die bereits aus Grass' frühen Werken bekannte Warnung vor jeglichem Idealismus, dem die genaue Betrachtung der Wirklichkeit und ihrer Gegenstände entgegenwirken kann. Die hier geschilderten Zusammenhänge werden im Butt über die Beschreibung des Pilzesammelns im dunklen Dickicht des Waldes anschaulich gemacht. Als Metapher bleibt der Einzeller dem Roman innerhalb der Allegorie erhalten. Intermediale Bezüge weisen in der Prosa darauf hin, dass die Sinnbilder auch als grafische Darstellungen imaginiert werden sollen.

Das sechste Kapitel des Butt enthält solche Referenzen in zwei Passagen. Zum einen wird Sophie von ihrem Fritz gezeichnet und diese Zeichnung selbst im Text beschrieben. Das Porträt Sophies zeigt die Köchin mit einem phallischen Pilzhut auf dem Kopf und greift damit das Motiv auf, das bereits aus Mit Sophie in die Pilze gegangen, aus zwei Lithografien zu dem Gedicht „Zum Fürchten“, bekannt ist (S. 258, Abb. 158; S. 261, Abb. 161):

Sophie trug einen trichterförmigen Mehlpilz als Hut, dessen handlicher Stiel himmelwärts zeugte und dem Pimmel meines Vaters glich, als er mit offener Hose treppauf zu meiner Mutter stieg, um mich, seinen Sohn Fritz, zu zeugen. (VI 453)

Neben den oben bereits erörterten Assoziationen, die mit dem zwitterhaften Einzeller in Verbindung gebracht werden können - die Visualisierung von männlichen und weiblichen Anteilen des Menschen sowie der unendliche Fortgang der Fortpflanzung - wird im Text eine weitere Verständnisebene aufgespannt. Die Prosa führt die Bedeutung dieses besonderen Attributs im Zusammenhang mit Sophies Biografie weiter aus. Gerade die mit einem phallischen Pilz vorgestellte Köchin ist Jungfrau geblieben und liebt gezwungenermaßen ihr Leben lang ausschließlich geistigideell:

Viel später, als mir llsebill unterm Mehlpilz stillsaß und ich mit weichem Blei ein Bild zeichnete, aus dem Sophie ernst schaute, sah sie nicht mehr aus wie ein Kind. Schon wusste sie alles. Keine Neugierde mehr. Deshalb hat sie auch nie dem Gouverneur Rapp, so herrisch der wollte, erlaubt, mit seiner Stinkmorchel bei ihr Grund zu suchen. Sophie blieb zu. (VI 453)

Ähnlich wie schon im Fall der Nonnenzeichnungen von Günter Grass, die Mitte der Fünfzigerjahre entstanden sind, wird auch mit Sophie eine sexuell enthaltsame Frau mit einer phallisch konno- 
tierten Kopfbedeckung dargestellt. Die Bildbeschreibung fasst diese Botschaft verdichtet und als Zeichnung benannt zusammen, erinnert Kennerinnen und Kenner der Grass'schen Bildwerke aber auch an die für Mit Sophie in die Pilze gegangen entstandenen Lithografien.

Im anderen Fall entwirft Grass eine Bildbeschreibung zu einem fiktiven Bild, das im Aufbau einem kanonisierten Meisterwerk der Kunstgeschichte folgt. Grass verfährt an dieser Stelle wie in seinem Vortrag zu Dürers Melencolia I, wenn er Eugène Delacroix' Gemälde Die Freiheit führt das Volk von 1830 (Abb. 162) nach eigenen Vorstellungen transformiert. Die Position der Personifikation der Freiheit auf den Barrikaden nimmt in seiner Ekphrasis eines Posters, das gemäß der Romanhandlung Feministinnen in den Siebzigerjahren herstellen lassen, Sophie Rotzoll ein, während die gefallenen und teils entkleideten Kämpfer durch entwurzelte Pilze ersetzt werden:

Nach ihrem vermuteten oder vom Butt mit Stichworten skizziertem Aussehen wurde (nicht unähnlich der Beisitzerin Dubertin) ein mehrfarbiges Poster angefertigt und in den feministischen Devotionalienhandel gebracht. Drauf sah man Sophie in hafenstädtischer Marktmädchentracht auf einer Barrikade stehen und den Butt linkshändig bei der Schwanzflosse fassen, während sie rechts ein Küchenmesser im Griff hatte. Ihr finsteres Schmalgesicht. Die torfbraunen Haare mit Tricoloreband hochgebunden. Das Mündchen geschwungen offen, als singe sie Revolutionäres. Und vor der Barrikade entwurzelte Pilze, eindeutig anspielend, als habe ein entmannendes Massaker stattgefunden. (VI 505)

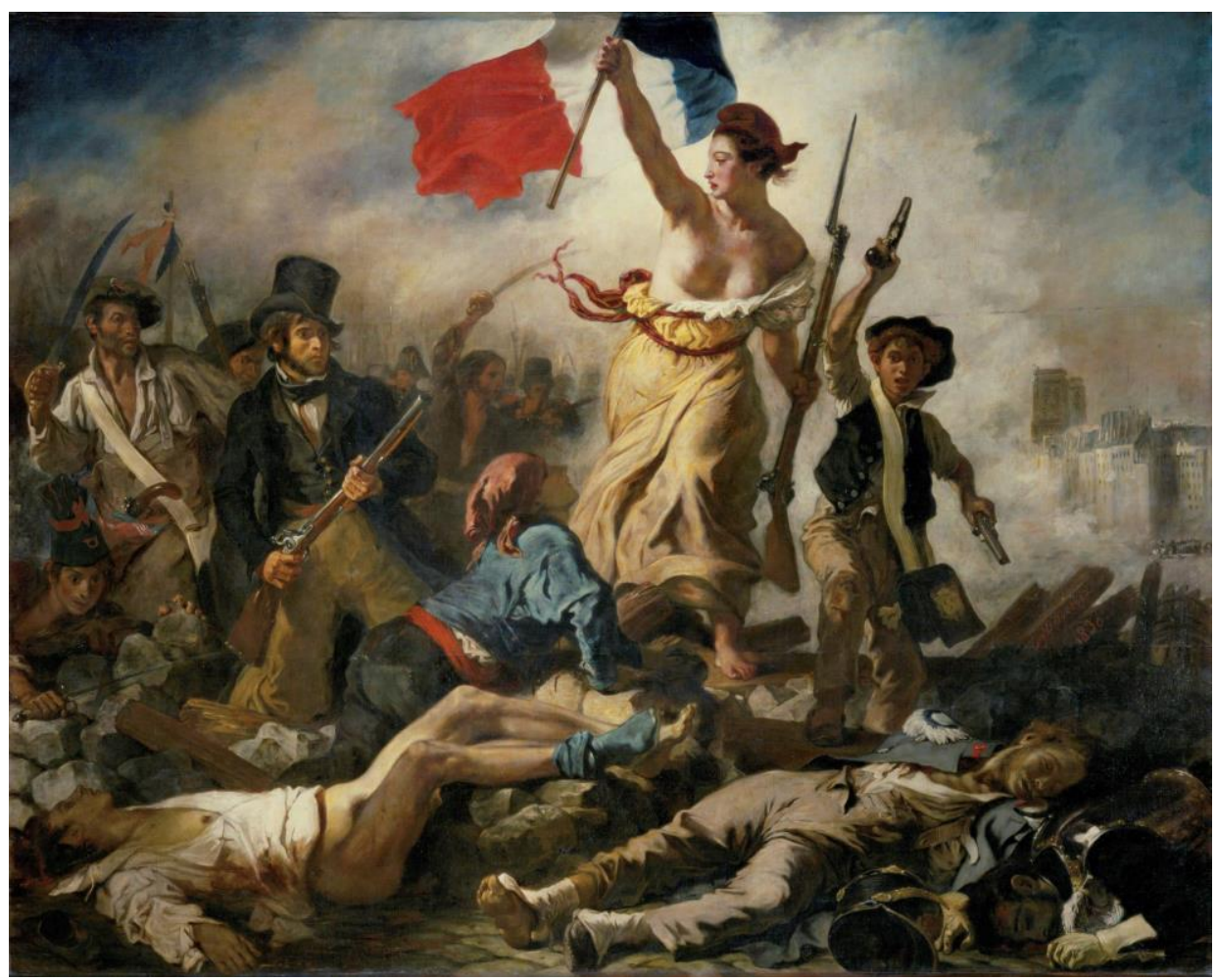

Abb. 162, Eugène Delacroix, Die Freiheit führt das Volk, 1830, Öl auf Leinwand 
Die Rolle Sophies als pilzliebender und zugleich -mordender Freiheitskämpferin wird in diesem geschriebenen Bild zusammengefasst. Seine Eindrücklichkeit wird für Leserinnen und Leser durch die bekannte Bildkomposition Delacroix' verstärkt. Zudem reizt das Bild - da die heroisch fahnenschwenkende Libertas durch eine Köchin ersetzt wird, die einen zappelnden Plattfisch schwingt zum antiideologischen Lachen. Das Pilzmotiv hat in dieser bildhaften Passage des Butt seinen vorerst letzten, Männlichkeit auf bekannte Weise repräsentierenden Auftritt.

Grass' lyrische und grafische Arbeiten aus der Entstehungszeit des Butt gehen mit einer intensiven Auseinandersetzung des Dichters und Künstlers mit seinen eigenen künstlerischen Mitteln einher, die in Mariazuehren in Wort und Bild zum Ausdruck gebracht werden. Die in dem Band umrissenen Gestaltungsprinzipien - das naturgetreue Wiedergeben des Objektes, das Betonen seiner Bezüglichkeiten und die weitere Assoziationen generierende Konfrontation von Gegenständen aus disparaten Zusammenhängen - werden in dieser Publikation und ebenso ein Jahr später im Portfolio Liebe geprüft zur Anwendung gebracht. Das Pilzmotiv tritt in beiden Veröffentlichungen als hybrides Gebilde aus Pilz und Penis in Erscheinung und lässt beide Bildspender einer Metapher miteinander verschmelzen. Aufgegriffen wird damit eine aus dem Surrealismus und aus Grass' bildkünstlerischem Frühwerk bekannte Methode.

1976 wird das Motiv grafisch zu einem Zwitter aus weiblichen und männlichen Geschlechtsmerkmalen weiterentwickelt. Der Fokus der Bilder und Gedichte verschiebt sich zum Vorgang des Pilzesammelns hin, das allegorisch irrationale Vorgänge, vor allem die Annäherung zwischen Männern und Frauen, vermittelt. Ausgehend von den Lithografien und Texten aus Mit Sophie in die Pilze gegangen vertiefte Grass das Thema in der Auseinandersetzung mit der Romantik sowie der französischen Revolution und ihren Nachwirkungen im Butt weiter. Das eigene, früh durch den Surrealismus geprägte Interesse an psychologischen, schwer fassbaren Prozessen wird über die Beschäftigung mit der Romantik wieder aufgegriffen. Grass' Auseinandersetzung mit der Kunstepoche folgt konsequent chronologisch auf diejenige mit der Aufklärung im Tagebuch einer schnecke. 


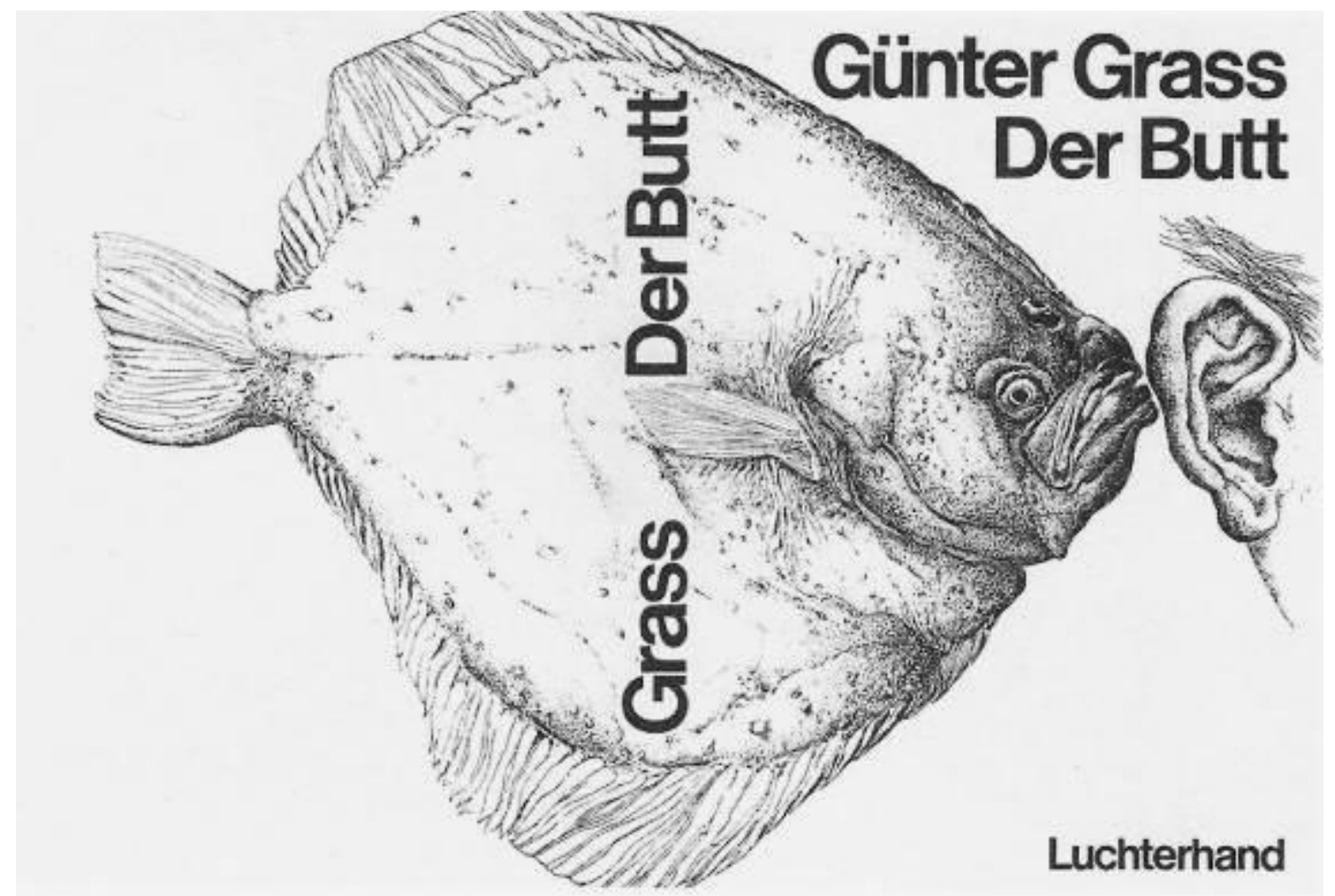

Abb. 163, Der Butt, Darmstadt 1977, Umschlag 


\section{Fische: Schreiben und Zeichnen jederzeit}

Wie alle Buchumschläge zu den Veröffentlichungen von Günter Grass gibt auch derjenige zur Erstausgabe des Butt (1977) in komprimierter Form zu verstehen, welche Motive und Strukturen das dahinterliegende Werk bestimmen (Abb. 163). Er zeigt einen Butt im Profil, dessen Maul auf ein menschliches Ohr gerichtet ist. Über den beiden Elementen sind der Name des Schriftstellers und der Titel des Buches angeführt. Der Plattfisch ist hier nicht nur titelgebend und bildbestimmend. Es handelt sich um das erste Tiermotiv im Werk von Günter Grass, das - der sprichwörtlichen Stummheit der Fische zum Trotz - spricht und eine zentrale Romanfigur verkörpert. Der menschlich anmutende Butt tritt im Erzählwerk, wie auf dem Buchumschlag angekündigt, als Dialogpartner eines Autor-Erzählers in Erscheinung.

Butte stellte Grass bereits Mitte der Fünfzigerjahre in seinen Zeichnungen und Plastiken dar. Das Interesse des Künstlers an der Fischform im Allgemeinen zeigte sich wenig später in narrativen Strukturen der Blechtrommel und in vergleichbarer Weise im Butt. In der Entstehungszeit des Butt, zwischen 1972 und 1977, arbeitete er zudem intensiv an Zeichnungen und Radierungen, in welchen er Themen des entstehenden Buches behandelte und das Fischmotiv in verschiedenen Varianten zur Darstellung brachte. ${ }^{581}$

Im Gegensatz zu den zuvor untersuchten Motivkomplexen stehen die Bilder von Fischen aus den ersten beiden Jahren der Arbeit am Roman nur mit wenigen der gleichzeitig verfassten und später veröffentlichten Gedichte in engem Zusammenhang. ${ }^{582}$ Die in das Buch integrierten lyrischen Texte, von welchen zahlreiche vor Erscheinen des Butt im Portfolio Liebe geprüft (1974) und im Künstlerbuch Mit Sophie in die Pilze gegangen (1976) publiziert worden sind, hatte Grass 1983 noch einmal in dem Gedichtband Ach Butt, dein Märchen geht böse aus veröffentlicht. ${ }^{583}$ Das Buch enthält neben den sieben Radierungen aus Liebe geprüft die Radierfolge Als vom Butt nur die Gräte geblieben war (1977) sowie weitere Druckgrafiken, die zu den Gedichten in einem relativ vagen Verhältnis stehen. Text und Bild folgen hier keinem erkennbaren Gesamtkonzept. Umso enger ist die Verbindung der Bilder mit dem Prosatext - mit der Figur des Butts, die erst 1974 in die Konzeption des Erzählwerks Eingang fand, vielen von Fischmotiven geprägten Passagen und der Struktur des Romans.

Der Butt ist in neun als Monate bezeichnete Kapitel gegliedert. Die Biografien von elf Köchinnen von der Jungsteinzeit bis in die Siebzigerjahre des vergangenen Jahrhunderts werden darin weitgehend chronologisch erzählt. Bei dem Erzähler handelt es sich, wie schon im Tagebuch einer Schnecke, um einen Autor-Erzähler, der im Butt jedoch Rollen verschiedener männlicher Figuren, Geschlechtspartner der porträtierten Frauen, annimmt. ${ }^{584}$ Das Verhältnis zwischen den Liebenden wird stets als Machtkampf der Geschlechter vermittelt, denn bis in die Gegenwart hinein wird der Autor-Erzähler in seinen verschiedenen Rollen von dem immergleichen sprechenden Plattfisch

\footnotetext{
${ }^{581}$ Einen Überblick über grafische Realisierungen des Fischmotivs bietet: Hille-Sandvoss (1987), S. 186-233; eine aktualisierte Übersicht aller erhaltenen bzw. abgedruckten Werke zu diesem Komplex befindet sich im Motivverzeichnis der vorliegenden Publikation.

582 Zu weiteren und engeren Bezügen zwischen Lyrik und Prosa sowie zur Funktion der in den Text eingefügten Gedichte vgl. Mayer(-Iswandy) (1988), S. 87-89.

583 Grass (1983).

${ }^{584} \mathrm{Vgl}$. Braun (2008), S. 96-109.
} 
darin beraten, wie er seine jeweilige geliebte Frau am besten übervorteilen kann. Wie im vorausgehenden Kapitel bereits erörtert wurde, geht diese Struktur auf eine Umkehrung des Märchens Von dem Fischer un syner Fru zurück. Der Text aus der Märchensammlung der Brüder Grimm, dessen Veröffentlichungsgeschichte im sechsten Kapitel des Romans thematisiert wird, stellt die Fischersfrau Ilsebill als maßlos gierige und schließlich an ihrer eigenen Hybris scheiternde Tyrannin dar. Der Butt bildet dazu eine Gegendarstellung, in der dem Mann zwar keine Wünsche erfüllt werden, in welcher er jedoch von dem manipulativen Fisch zu Machtstreben und Fortschrittsgläubigkeit angelernt wird. Das Tier repräsentiert dabei, wie Volker Neuhaus ausführt:

alle menschlichen Versuche, der Geschichte und ihrer Entwicklung einen Sinn zu geben, sei es der Glaube an einen lenkenden Gott vom bronzezeitlichen Buttidol, „den buttigen Gott" über Zeus bis zum Gott der Bibel und zum „Liebgottchen“, „Liebbuttchen“ der Amanda Woyke: sei es der Glaube an einen steten technologischen und gesellschaftlichen Fortschritt, an ein evolutionäres Prinzip; sei es Hegels Weltgeist, der "Staat als Idee“, Marx, Blochs „Prinzip Hoffnung“; sei es die „ideologisch saubere Überichstütze“, wie es im linken, gestützt auf Herbert Marcuse Marx mit Freud verschmelzenden Feministinnenjargon heißt. ${ }^{585}$

Da sich das männliche Geschlecht durch Gewalt gegen Mensch und Natur, vor allem aber durch fortschreitende Resignation der Beratung zunehmend als unwürdig erweist, beschließt der Butt in den feministisch geprägten Siebzigerjahren, zu den Frauen überzulaufen; auf dem „Machtwechsel der Geschlechter" beruhe schließlich sein Prinzip (VI 52). Statt sein Angebot unmittelbar anzunehmen, laden die drei Finderinnen inn jedoch vor ein feministisches Tribunal, bald als „Feminal“ bezeichnet, um seine Schuld an der jahrhundertelangen Unterdrückung der Frau herauszuarbeiten. Nach seiner Verurteilung zwingt man ihn, zwecks Buße einem Buttessen beizuwohnen. Um Sühne üben zu können und fortan den Frauen zu helfen, wird er abschließend in der Ostsee ausgesetzt. $^{586}$

Die Biografien der verschiedenen Köchinnen von der Steinzeit bis in die Gegenwart sind Gegenstand des „Feminals“. Das Einwirken des Butts auf ihre Partner, und damit auch auf ihr eigenes Schicksal, wird im Prozess verhandelt. Da die Beschaffung und Zubereitung sowie das Vertilgen von Nahrung bei der Schilderung der Lebensläufe von Köchinnen eine große Rolle spielt, ist der Roman zugleich eine mit Rezepten versetzte Ernährungsgeschichte. Dem „Feminal“ darf der Erzähler als Beobachter beiwohnen und ergänzt die Verteidigungsreden des Fisches für die Leserinnen und Leser durch eigene Berichte, die sich schlüssig aus seiner Zeitzeugenschaft ergeben. Da er nicht nur Schriftsteller, sondern zu jeder Zeit auch bildender Künstler gewesen ist, enthalten seine Ausführungen nicht nur Gedanken zur Literatur, sondern auch Passagen zu bildkünstlerischen Ausdrucksformen. Präsentiert werden seine Erinnerungen und Beobachtungen insgesamt, wie schon in anderen Werken des realen Autors, im Rahmen der Erzählfiktion als Beiträge zu einem Buchprojekt: Der gegenwärtige Autor-Erzähler hat es sich zur Aufgabe gemacht, die Jahrhunderte umfassende Geschichte seiner Liebesverhältnisse von der Steinzeit bis in die Gegenwart zu erzählen - mitunter, um sich mit seiner Mitschuld an der jahrhundertelangen Unterdrückung der Frauen auseinanderzusetzen. Seine Darstellung richtet sich unmittelbar an seine gegenwärti-

\footnotetext{
${ }^{585}$ Vgl. Neuhaus (2010), S. 161.

586 Überblicksdarstellung bieten: Moser (2000) und Neuhaus (2010).
} 
ge Partnerin, Ilsebill genannt. Das Buch, das sich aus dieser Narration zusammensetzen soll, schreibt er in den neun Monaten, in denen Ilsebill ihr gemeinsames Kind austrägt. Die in der Gegenwart angesiedelte Handlung des Romans beginnt entsprechend mit der Zeugung des Kindes im Oktober 1973 und endet kurz nach der Geburt der Tochter Helene im Sommer 1974; zudem enthält sie jedoch zeitliche Vor- und Rücksprünge.

Während die im Butt erzählte Individual- und Kulturgeschichte weitgehend chronologisch und damit linear verläuft, sorgen andere Elemente dafür, dass die im Roman präsentierte Geschichtsauffassung als eine zyklische verstanden werden kann: ${ }^{587}$ Der in jeder Epoche zum Ratschlag ansetzende Märchenfisch, der im Kern immer gleichbleibende Mythos der Hybris und der in seinem Inneren stets unveränderte Erzähler tragen wesentlich zu diesem Eindruck bei. Ferner haben die verschiedenen Köchinnen, die alle in verschiedenen Epochen mit dem Autor-Erzähler liiert waren, charakterlich und äußerlich Ähnlichkeit mit je einer Teilnehmerin des „Feminals“, mit welchen der Erzähler in jüngerer Vergangenheit Beziehungen und Affären unterhielt, und darüber hinaus mit seiner aktuellen Partnerin Ilsebill. Schließlich werden auch zwischen verschiedenen, aber strukturell gleichförmigen historischen Ereignissen Parallelen gezogen.

Dass Grass' Beschäftigung mit Claude Lévi-Strauss' strukturalistischer Mythenanalyse in den Roman eingeflossen ist, wurde in der Forschungsliteratur bereits herausgearbeitet. ${ }^{588}$ Den Titel der kulturwissenschaftlichen Veröffentlichung Das Rohe und das Gekochte (1964) hat Grass an verschiedenen Stellen in seinem Roman zitiert (VI 9, 15, 16, 66, 67-69, 373, 567, 588). Im ersten Kapitel brachte er den von Lévi-Strauss analysierten Mythos über die Herkunft des Feuers ein, der bei den Indianern des Amazonasgebietes in unterschiedlichen Varianten zirkulierte. Mit großer Wahrscheinlichkeit wurde Grass auch von Lévi-Strauss' Unterteilung des Nutzens von Feuer in einen konstruktiven (Kochen, Gemeinschaft) und einen destruktiven Nutzen (Schmieden von Waffen) angeregt - diese Kategorisierung könnte Einfluss genommen haben auf den im Butt entworfenen Gegensatz zwischen einer von Aggression und Gewalt geprägten kulturellen Entwicklung des Mannes und der konstanten Rolle der Frau als der eigentlichen Ernährerin. ${ }^{589}$ Vor allem jedoch ist anzunehmen, dass Lévi-Strauss' grundsätzliche Forschungsmethode, das Aufzeigen von Strukturen des menschlichen Verhaltens im Mythos, Grass dazu ermuntert hat, seine Geschlechtergeschichte ganzheitlich der Struktur des Märchens unterzuordnen und darin einzelne Mythen einzuflechten. Die beiden literarischen Gattungen sind miteinander verwandt und sorgen für eine anschauliche Verdichtung der geschilderten Vorgänge, worin sie, wie Ingeborg Hoesterey erkannte, visuellen Bildern nahe stehen. ${ }^{590}$ Grass selbst hatte 1981 in seiner Rede "Literatur und Mythos" in Bezug auf Camus' Darstellung des Sisyphos-Mythos' festgestellt, dass das „Bild vom heitereren Steinewälzer [...] die menschliche Existenz komplexer und obendrein sinnlicher" nachweise, „als es der Informationswust unserer Tage, oder gar die soziologische Überproduktion“ vermöge. (XII 22)

Wie im Folgenden gezeigt werden wird, sind es im Butt auch die sprachlich durch intermediale Bezüge realisierten Bilder, die die Existenz wiederkehrender Ereignisse und Zustände verdeutli-

\footnotetext{
${ }^{587}$ Vgl. O’Neill (1982), Stallbaum (1989), S. 147-152 und Crick (1990).

${ }^{588} \mathrm{Vgl}$. Hoesterey (1988), Abbott (1983) und Diller (1983).

${ }^{589} \mathrm{Vgl}$. Abbott (1983).

${ }^{590} \mathrm{Vgl}$. Hoesterey (1988) und Diller (1983).
} 
chen und damit gleichzeitig ein entscheidendes Charakteristikum der Grafiken und Plastiken von Günter Grass im Allgemeinen offenbaren. Beschreibungen von steinzeitlichen und barocken Kunstwerken, die im Roman als Erzeugnisse des Autor-Erzählers eingehend behandelt werden, weisen darüber hinaus auf bestimmte Aspekte der Grass'schen Ästhetik zurück.

Neben Bezügen zur bildenden Kunst enthält der Roman auch solche zum Medium des Films, wodurch der anschauliche Charakter des Prosatextes verstärkt wird. Sie treten gehäuft in dem Kapitel „Vatertag" auf, das Grass bereits 1961 als Filmprojekt entworfen hat. Zum Kapitel ist nachträglich, 1981/1982, eine 22-teilige Folge von Lithografien entstanden, die das Romangeschehen entgegen ihrer Betitelung als „Zyklus Vatertag“ weniger narrativ visualisiert, als vielmehr einzelne Aspekte der Erzählung in universellen Zeichen zusammenfasst. Für Grass' Bildkunst wichtige und über Jahrzehnte hinweg entwickelte Methoden der visuellen Sinngebung können an diesen Bildern besonders klar herausgearbeitet werden. Das liegt daran, dass Grass seine Grafiken in diesem Fall nicht parallel zu Gedichten schuf, die anschließend in Prosa aufgehen sollten, sondern umgekehrt - wie erstmals in seinen Federzeichnungen zu Bachmanns Ein Ort für Zufälle (1965) einen Prosatext nachträglich zu Bildern verdichtete. Obgleich der Zyklus mit den Jahren seiner Entstehung 1981/1982 aus dem zeitlichen Rahmen dieser Untersuchung fällt, wird er aufgrund seiner engen Beziehung zum Roman darin einbezogen.

\section{Grundlagen: Frühe Fische in Grass' bildender Kunst und Literatur (1955-1959)}

Der Butt gehört zu den Tieren, die Grass schon 1955 als Grafiker und als Bildhauer interessierten. Neben Kohlezeichnungen, in welchen das Knochengerüst des Plattfisches aus vegetabil anmutenden Schraffuren zusammengesetzt ist und seine äußere Hülle nahezu transparent erscheint (vgl. S. 72, Abb. 46), schuf Grass eine Bronzeplastik, in der das Skelett des Fisches und die Umrisse seines Körpers modelliert, die dem Fleisch vorbehaltenen Zwischenräume jedoch weitgehend ausgespart wurden (vgl. S. 68, Abb. 43). Beide Arbeiten spielen mit dem Gegensatz zwischen äußerer Kontur und innerem Aufbau des Butt-Körpers, indem sie sie simultan sichtbar machen. Noch besser als die Figur des Vogels eignet sich der Butt für eine grafische Darstellung, da vor allem seine fast zweidimensionale Profilansicht, mit beiden Augen auf einer Körperseite, Anreize für die Gestaltung bietet. Auch Grass' Fischplastik nähert sich daher bereits durch ihren Gegenstand an das Medium der Grafik an. Im Gegensatz zum Vogelmotiv sind zum Motiv des Butts keine frühen Texte erhalten. Das Zusammenspiel von unversehrtem und skelettiertem Fischkörper sollte erst in seinen Romanen sinnbildlich eingesetzt werden. Einige der im Butt mit dem Plattfisch hervortretenden Konnotationen und Symboliken wie auch die narrative Funktion des Motivs wurden bereits in der Blechtrommel entwickelt. Darin spielten zwar noch keine Butte die Hauptrolle, dafür aber verschiedene andere Fische - wie im Folgenden ausgeführt werden soll, bereitete Grass' Umgang mit diesen Motiven in den Fünfzigerjahren die Verwendung des Buttmotivs in den Siebzigerjahren vor.

Die zwei Passagen des Debütromans, in welchen das Essen von Fisch beschrieben wird, befassen sich mit Liebe und Tod wie auch mit der kreisförmigen Struktur, in die diese beiden existenziellen Zustände eingebunden sind. Bei der ersten Passage handelt es sich um die aufeinander folgenden Kapitel „Karfreitagskost" und „Die Verjüngung zum Fußende“, die sich mit Agnes 
Matzeraths Kenntnisnahme ihrer Schwangerschaft und der daraufhin von ihr selbst herbeigeführten, tödlichen Fischvergiftung beschäftigen. Diese Vorgänge werden mit einem Familienausflug in den Danziger Stadtteil Brösen, einen Ausflug an den Strand, eingeleitet. Während eines Spaziergangs beobachtet die Familie, wie Aale mit Hilfe eines abgeschlagenen Pferdekopfes gefangen werden. Agnes übergibt sich bei dem Anblick der sich aus dem Schädel des Gauls windenden Fische. Die über ihre besondere Form sowohl geschlechtlich (Phallus) als auch religiös (Schlangen, Sündenfall) konnotierten Aale erhalten über drei kurze Aal-Anekdoten ihre Bedeutung für den weiteren Handlungsverlauf: Der Fischer berichtet erstens, die Fische würden sich von Leichen ernähren; zweitens könnten Aale ausgetrocknet werden, indem man sie lebendig in einen Eimer voll Salz werfe, weil sie sich ihrer Natur nach zwangsläufig immer weiter darin bewegten, und sie könnten drittens Frauen als (gefährliches) Instrument zur Selbstbefriedigung dienen. Die Verzahnung von geschlechtlicher Liebe und Tod wird mittels der Beschreibung der Fische und einiger ihrer Eigenschaften angedeutet, kurz bevor die Lesenden erfahren, dass Agnes von ihrem Geliebten Jan Bronski schwanger ist. ${ }^{591}$ Nach dem Spaziergang wird sie sich durch manischen Fischverzehr aus dem Dreiecksverhältnis mit Matzerath und Bronski und damit aus der fortwährenden Abfolge von Ehebruch und Ohrenbeichte befreien, die der Roman ebenfalls behandelt. ${ }^{52} \mathrm{Da}$ Agnes gerade den zur christlichen Fastenmahlzeit bestimmten und symbolisch auf Christus verweisenden Fisch in Massen vertilgt, um sich das Leben zu nehmen, wird deutlich, dass die Protagonistin auf die katholische Form der Errettung nicht mehr setzen mag. Der Fischverzehr, der Agnes den desaströsen Karfreitagsspaziergang immer wieder aufs Neue in Erinnerung bringt, soll gleichzeitig dessen Wiederholung verhindern:

Kinder und Erwachsene sammelten sich auf der Straße, man fuhr sie fort, und es sollte sich herausstellen, daß Mama weder die Mole noch den Pferdekopf vergessen hatte, daß sie die Erinnerung an den Gaul - ob der nun Fritz oder Hans geheißen hatte - mit sich nahm. Ihre Organe erinnerten sich schmerzhaft überdeutlich an den Karfreitagsspaziergang und ließen, aus Angst vor einer Wiederholung des Spaziergangs, meine Mama, die mit ihren Organen einer Meinung war, sterben. (III 206 f.)

Die zweite Passage ist das bereits im Zusammenhang mit dem Nonnenmotiv behandelte Kapitel „Am Atlantikwall oder es können die Bunker ihren Beton nicht loswerden“. ${ }^{593}$ Es handelt sich dabei um eine Reprise der ähnlich aufgebauten Szene aus dem Kapitel „Beton besichtigen - oder mystisch barbarisch gelangweilt", die am selben Ort in der Kriegszeit angesiedelt ist. Erzählt wird, wie Oskar und sein Künstlerfreund Lankes in die Normandie fahren und dort den Bunker aufsuchen, an dem Lankes während des Krieges als Obergefreiter stationiert war und eine Gruppe Nonnen erschoss. Die beiden lassen sich auf dem Bunkerdach nieder, wo sie - es ist Freitag einen Kabeljau zum Mittagessen braten. Lankes kann sich zunächst nicht entscheiden, ob er das Kopf- oder Schwanzstück für sich auswählen soll. Seinen Begleiter beratend, erinnert Oskar an seine Mutter Agnes:

\footnotetext{
${ }^{591}$ Vgl. Neuhaus (2010), S. 73 f.

592 Vgl. Steuer (2013).

${ }^{593}$ Vgl. Kapitel III.2. dieser Veröffentlichung.
} 
„Als Freund würde ich sagen: Nimm den Schwanz. Als Koch kann ich dir nur den Kopf empfehlen. Meine Mama jedoch, die eine große Fischesserin war, würde jetzt sagen: Herr Lankes, nehmen sie den Schwanz, da wissen Sie, was sie haben. [...]“ (III 716)

Am Strand erscheint kurz darauf die Novizin Agneta. Sie wird von Lankes verführt, nimmt anschließend kurz am Mittagessen teil und verhält sich dabei ",, als kaute sie mit dem Fisch etwas wieder, was sie vor dem Fisch genossen hatte“. Wie Oskars Mutter Agnes scheint auch Agneta durch den Verzehr des Fisches an den Bruch eines Gelübdes erinnert zu werden und zieht daraus einen ähnlichen Schluss, indem sie sich im Meer ertränkt. Die Handlung des Romans wird über die Wiederaufnahme des Fisch- bzw. Karfreitagsmotivs als ringförmige markiert, als Nietsche'sche „ewige Wiederkunft des Gleichen“.594 Gleichzeitig betonen Hinweise auf das während des Mittagessens fortlaufend abnehmende Fischfleisch und die zugleich immer deutlicher hervortretenden Gräten des Fisches den linearen Verlauf des Handlungsstrangs, der mit Agnetas Tod endet (III 714, 715, 716, 717, 724, 725, 726). Die bildkünstlerisch von Grass zu einer Gestalt zusammengezogene, ganze und zugleich skelettierte Form des Fisches markiert im Roman den Anfangs- und Endpunkt dieses Handlungsstrangs. Sowohl auf die Erscheinung des vollständigen Fisches als auch auf seine nicht verwertbaren Überreste wird im Text explizit hingewiesen. Während der unverzehrte Fisch von Lankes in einem Aquarell festgehalten wird (III 714), richtet sich Oskars Augenmerk gegen Ende der Passage auf die Gräte des Kabeljaus:

Ich blickte hinter mich und sah Lankes ausgestreckt qualmen. Die blanke Gräte des Kabeljaus flimmerte weiß und den Tisch beherrschend in der Sonne. (III 726), [Hervorhebungen V. K.]

Der Verzehr von Fisch sollte bei der Veranschaulichung von nur scheinbar widersprüchlichen, gleichermaßen linearen und zyklischen Vorgängen im Butt erneut eine Rolle spielen.

\section{Über Gräten und Erzählstruktur}

Bei der Planung des Romans stand zunächst die Idee eines „erzählenden Kochbuchs“ im Vordergrund. Der Erzähler des Tagebuchs einer Schnecke kündigt es bereits 1972 an:

Bevor ich mal alt bin und womöglich weise werde, will ich ein erzählendes Kochbuch schreiben: über 99 Gerichte, über Gäste und Menschen als Tiere, die kochen können, über den Vorgang Essen, über Abfälle... (V 465)

Bei den ersten datierten Notizen zum Butt handelt es sich entsprechend um Kochrezepte und historische Daten zur Verbreitung einzelner Gemüsesorten. ${ }^{595}$ Wie Werner Frizen in seiner Untersuchung der Romangenese darlegt, bildeten bis Januar 1974 neben Rezepten Erzählungen über Köchinnen, historische Episoden und Figuren, Gedichte sowie um Veronika Schröter kreisende Beziehungsgeschichten das Materialreservoir für den mehrgleisig entstehenden Roman. ${ }^{596}$ Veronika Schröters Schwangerschaft setzte wenige Monate nach der Empfängnis im Dezember

\footnotetext{
${ }^{594}$ Vgl. Arker (1989), S. 340-365 und Stallbaum (1989), S. 147-152.

${ }^{595}$ Akademie der Künste, Berlin, Günter-Grass-Archiv, Nr. 344, darin u. a.: „Die ersten zwanzig Rezepte für das Kochbuch am 7. und 8. Mai 72“, „Rezepte für Kochbuch am 9/10. 5.72“.

${ }^{596}$ Vgl. Frizen (2018), S. 304-319.
} 
1973 den Impuls, diese Sammlung in Monate, schließlich in neun Monate einer Schwangerschaft zu gliedern. ${ }^{597}$ Kurz darauf, im Frühjahr 1974, füllten vor allem die Köchinnen und ihre Geschichten aus verschiedenen Epochen diese Kapitel und wurden von einem durch die Zeit wandernden Autor-Erzähler begleitet. ${ }^{598}$ Eines der Kapitel - im abgeschlossenen Roman der "Sechste Monat", der sich mit der Köchin Sophie Rotzoll beschäftigt - ist vermutlich vor allen anderen Biografien entworfen worden. Der historische Kontext, in dem ihre Geschichte angesiedelt ist, die Belagerung Danzigs durch Napoleon, war zunächst als ein Schwerpunkt für Aus dem Tagebuch einer Schnecke in Erwägung gezogen worden. ${ }^{599}$ Die Ebene der Gegenwart ist im Frühjahr 1974 maßgeblich durch Episoden vertreten, die mit der Beziehung des Autor-Erzählers zu Veronika Schröter in Zusammenhang stehen. Zu Beginn des Jahres 1974 gerät schließlich der Butt, eingebettet in das Grimm'sche Märchen, mit ins Bild und zugleich die Idee, es dem Erzählwerk in einer neuen Variante einzuverleiben, auch wenn die zunächst von Februar bis April 1974 entstehende Version nicht annährend mit der später entwickelten Fassung zusammenfällt. ${ }^{600}$

Auf welche Weise und in welcher Funktion der Schriftsteller den Plattfisch in das Romankonzept einbrachte, zeigen wiederum seine Aufzeichnungen. In einem Arbeitsplan vom 30.12.1974 führte Grass eine Liste nummerierter Frauenbiografien unter einer Liste nummerierter Themen, die vor allem den Butt betreffen und seine Kommentare zu Lebensgeschichten einzelner Köchinnen andeuten. ${ }^{601} \mathrm{Im}$ Roman wurden diese beiden Auflistungen miteinander verzahnt. Entsprechend stellten die Figur des Butts und das von Grass neu entworfene Märchen eine dialogische Struktur innerhalb des schon vorhandenen Romanaufbaus her, der aus den Lebensgeschichten der Köchinnen besteht.

Diese Binnenstruktur sollte im Folgenden die Brücke zur zeitgenössischen Romanhandlung schlagen. Mit dem feministischen Prozess, dessen Gegenstand das jahrhundertelange Wirken des Plattfisches ist, konnte Grass die Frauenbiografien nicht nur von dem Butt und dem Erzähler, sondern auch von verschiedenen in der Gegenwart der Siebzigerjahre lebenden Frauen kommentieren lassen. Darüber hinaus treibt das „Feminal“ die gesamte Narration als übergeordneter, zielgerichteter Vorgang auf der Gegenwartsebene an. Diese Entwicklung wird in bereits bekannter Form versinnbildlicht: Im Laufe der Verhandlung wird der Butt zusehends transparent und sein Skelett sichtbar (VI 571, 651, 657, 667, 676). Zur Strafe für seinen Beitrag zu den von Gewalt und Tod geprägten Frauengeschichten muss das Tier zudem dabei zusehen, wie seine stummen Artgenossen bei einem feierlichen Mahl von den Verhandlungsteilnehmerinnen und dem anwesenden Erzähler verspeist werden. Allein die Fischgräten bleiben übrig und werden dem Butt demonstrativ als Memento Mori entgegengehalten:

Da nahmen Griselde Dubertin und Ruth Simoneit, die Huntscha und die Paasch, aber auch Elisabeth Güllen und Beate Hagedorn, die bisher geschwiegen, verbissen geschwiegen hatten, je eine Hauptgräte, und andere Frauen nahmen die restlichen Gräten, Köpfe und Schwanzflossen und zeigten sie

\footnotetext{
597 Vgl. ebd., S. 302.

598 Vgl. ebd., S. 318-321.

${ }^{599} \mathrm{Vgl}$. S. 213 und S. 257 f. der vorliegenden Untersuchung.

600 Vgl. Frizen (2018), S. $307 \mathrm{f}$.

${ }^{601}$ Akademie der Künste, Berlin, Günter-Grass-Archiv, Nr. 323: Arbeitsplan, Plan für 1975 am 30.12.1974, vgl. zum Dialog des Erzählers mit dem Butt das Dokument Nr. 343: „Der Butt + Ich“.
} 
dem Butt, auf daß er sehen mußte. Und einige Frauen riefen: „Sterblich bist du!“ Andere behaupteten: „Eigentlich bist du tot!“ (VI 671)

Ähnlich wie in der Blechtrommel wird somit der Verlauf einer Handlung durch den Verzehr von Fischfleisch und das Sichtbarmachen von Fischgräten verdeutlicht. Versinnbildlicht wird im Butt dabei ferner die detaillierte Beschäftigung mit männlich dominierter Geschichte, also buchstäblich deren Analyse (= gr. Auflösung).

Die visuelle Konzeption dieser Allegorie wird nachträglich durch eine Folge von Radierungen mit dem Titel Als vom Butt nur die Gräte geblieben war (1977) bestätigt. Sie setzt die Verwertung des Fisches grafisch ins Bild. ${ }^{602}$ Gemeinsam legen die Bildwerke zum Butt aus den Fünfziger- und späten Siebzigerjahren nahe, dass der literarischen Veranschaulichung des „Feminals“ ein bildnerischer Einfall vorausgegangen ist.

Die Radierfolge zeigt zunächst einen seitlich gebetteten Butt (Abb. 164, Abb. 165), dann dessen Zwiegespräch mit einem Menschen, das bereits als Umschlagmotiv kurz vorgestellt wurde (Abb. 166), die Enthauptung des Fisches (Abb. 167), sein nahezu freigelegtes Skelett (Abb. 168, Abb. 169) und schließlich einen gänzlich blanken, im Ausschnitt detailliert eingefangenen Teil seines Skelettes zusammen mit einer runden Brille und dem Schriftzug „Als vom Butt nur die Gräte geblieben war / Als das Märchen zu Ende war" (Abb. 170). Abgebildet sind in der letzten Grafik damit Überreste des Fisches und des Menschen, die als Vanitasmotiv interpretiert werden können, zumal die spitzen Gräten das Bild gefährlich abgespreizt durchziehen. Die Brille verweist zugleich auf den Brille-tragenden Dichter und Künstler, bei Berücksichtigung der Romanhandlung ebenfalls auf den Autor-Erzähler (VI 116) und die bebrillten Köchinnen (VI 565-567). In jedem Fall richtet die Sehhilfe die Aufmerksamkeit von Betrachterinnen und Betrachtern zusätzlich auf die Fischgräte und fordert zum genauen Hinschauen auf. Die Radierung trägt den Titel: Als das Märchen zu Ende war und scheint damit den fünf Jahre später veröffentlichten Gedichtband Ach Butt, dein Märchen geht böse aus anzukündigen, für den Grass ebendiese Grafik zur Umschlaggestaltung wählte. Die schon in der Blechtrommel mit Fischgräten in Verbindung gebrachte negative Konnotation wird also auch in dieser Zusammenstellung von Text und Bild umgesetzt.

${ }^{602}$ Vgl. Joch (1997), S. 27. 


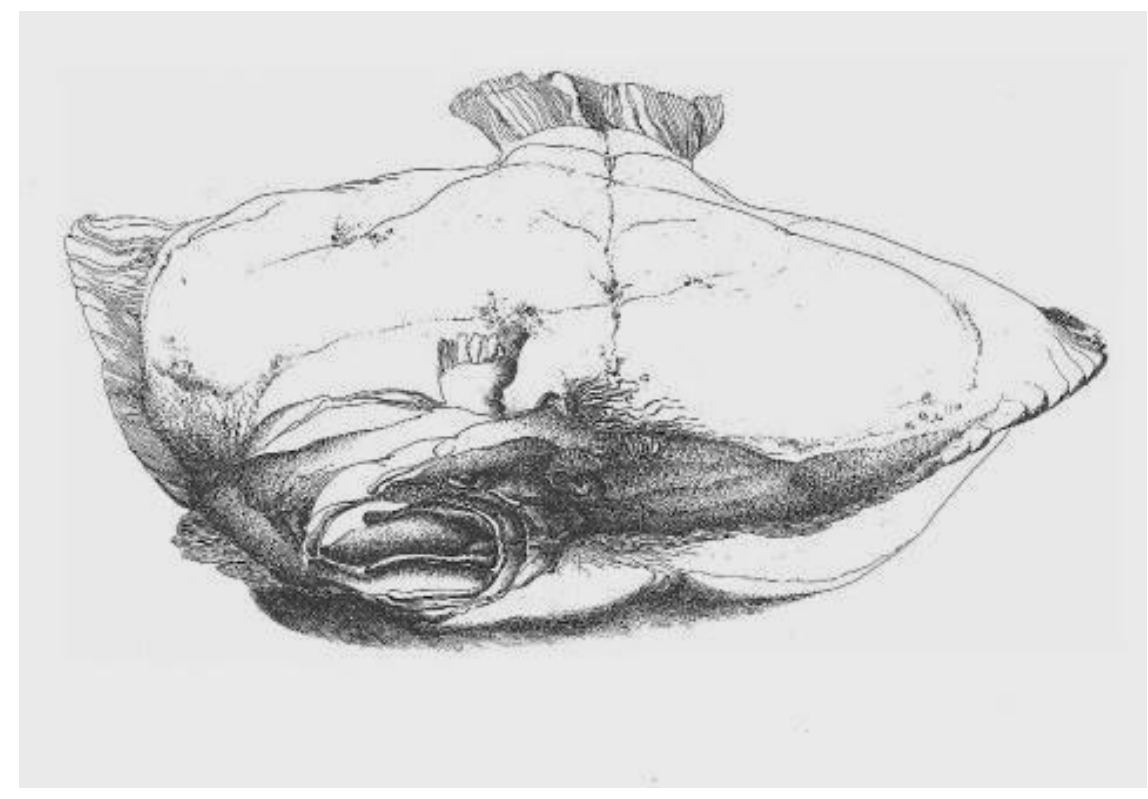

Abb. 164, Als vom Butt nur die Gräte geblieben war, 1977, Blatt I, Butt in Sand gebettet, 1977, Ätzradierung auf Kupfer

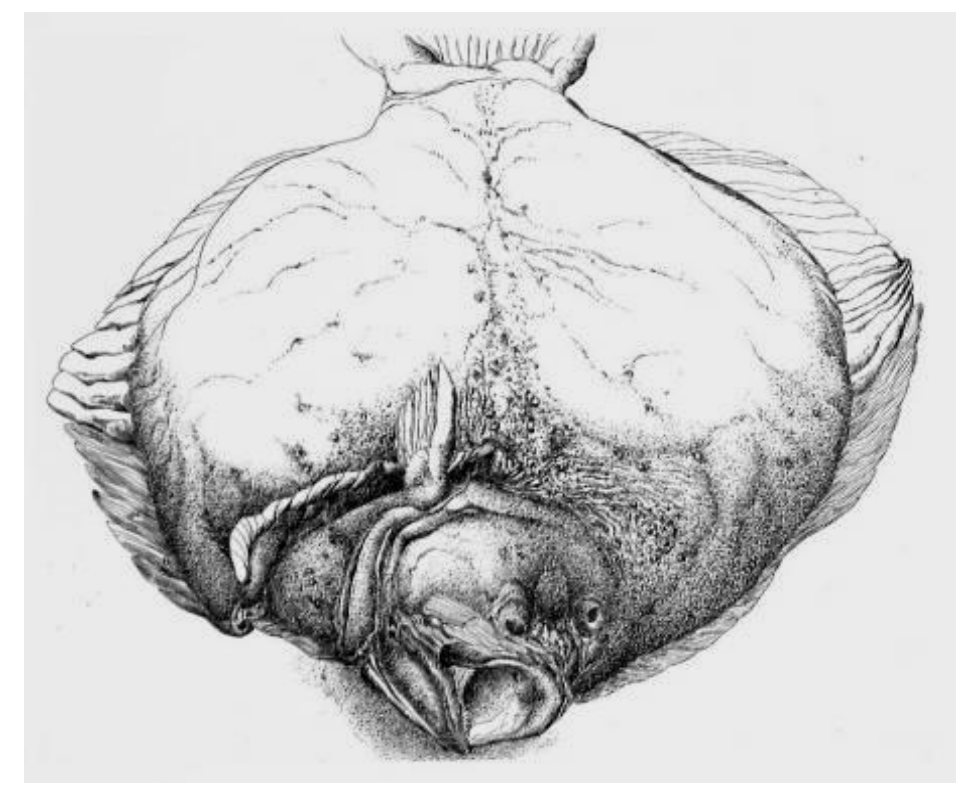

Abb. 165, Als vom Butt nur die Gräte geblieben war, 1977, Blatt II, Butt II, 1977, Ätzradierung auf Kupfer 


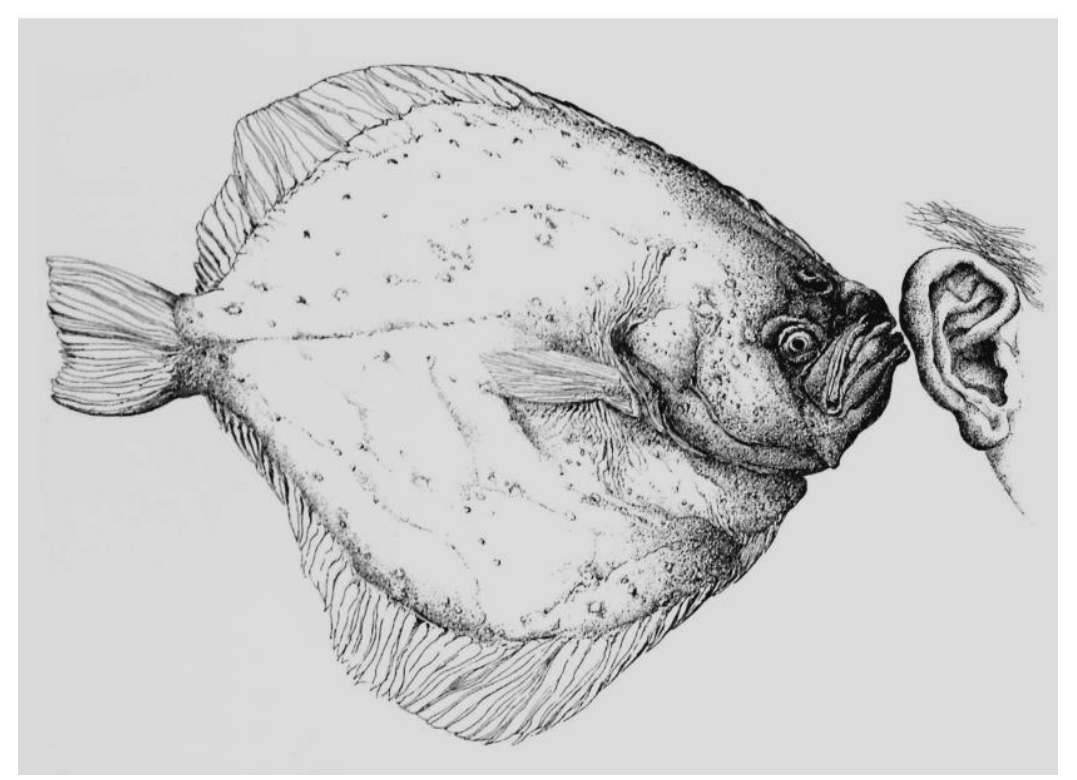

Abb. 166, Als vom Butt nur die Gräte geblieben war, 1977, Blatt III, Der Butt, 1977, Ätzradierung auf Kupfer

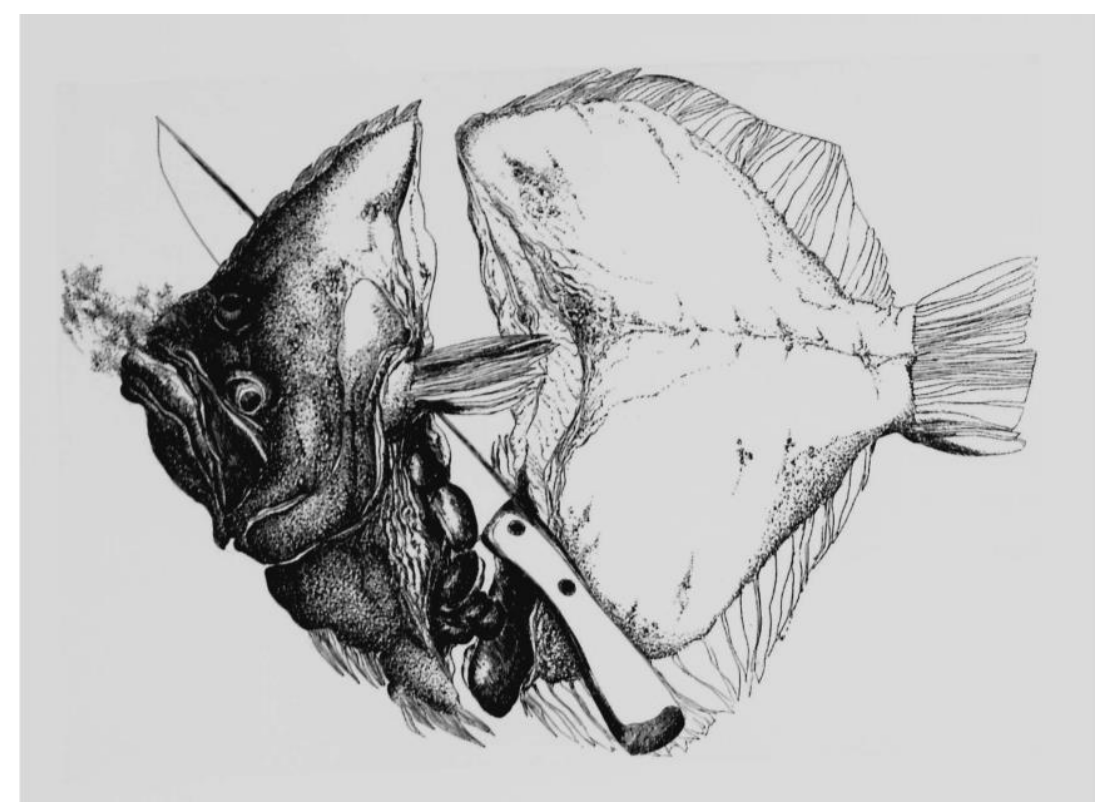

Abb. 167, Als vom Butt nur die Gräte geblieben war, 1977, Blatt IV, Butt mit Messer, 1977, Ätzradierung auf Kupfer 


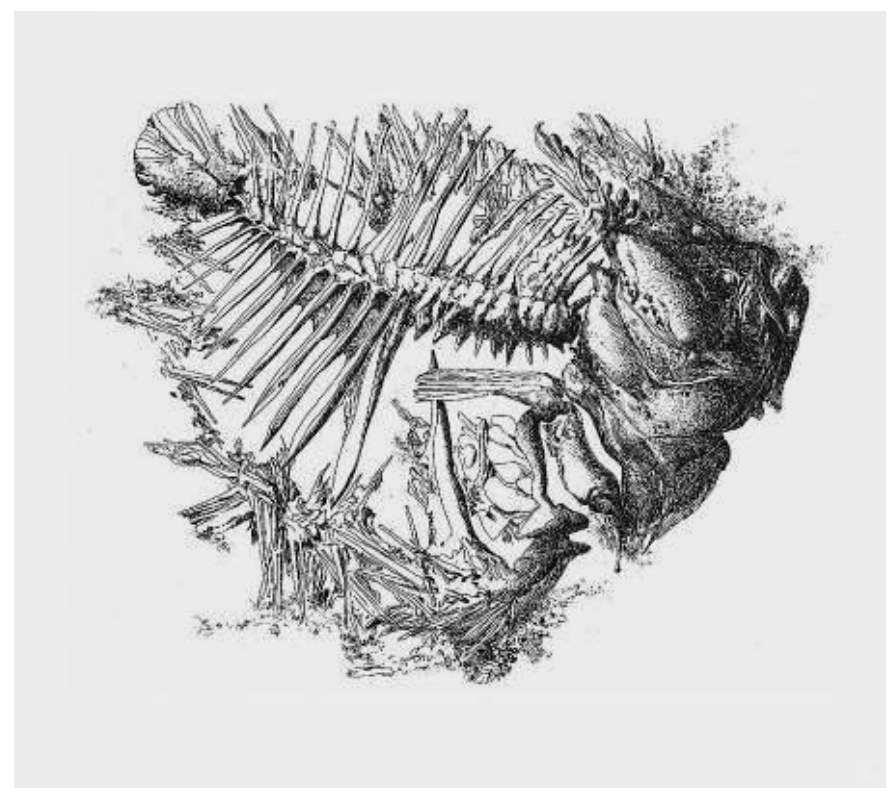

Abb. 168, Als vom Butt nur die Gräte geblieben war, 1977, Blatt V, Als vom Butt nur die Gräte geblieben war, 1977, Ätzradierung auf Kupfer

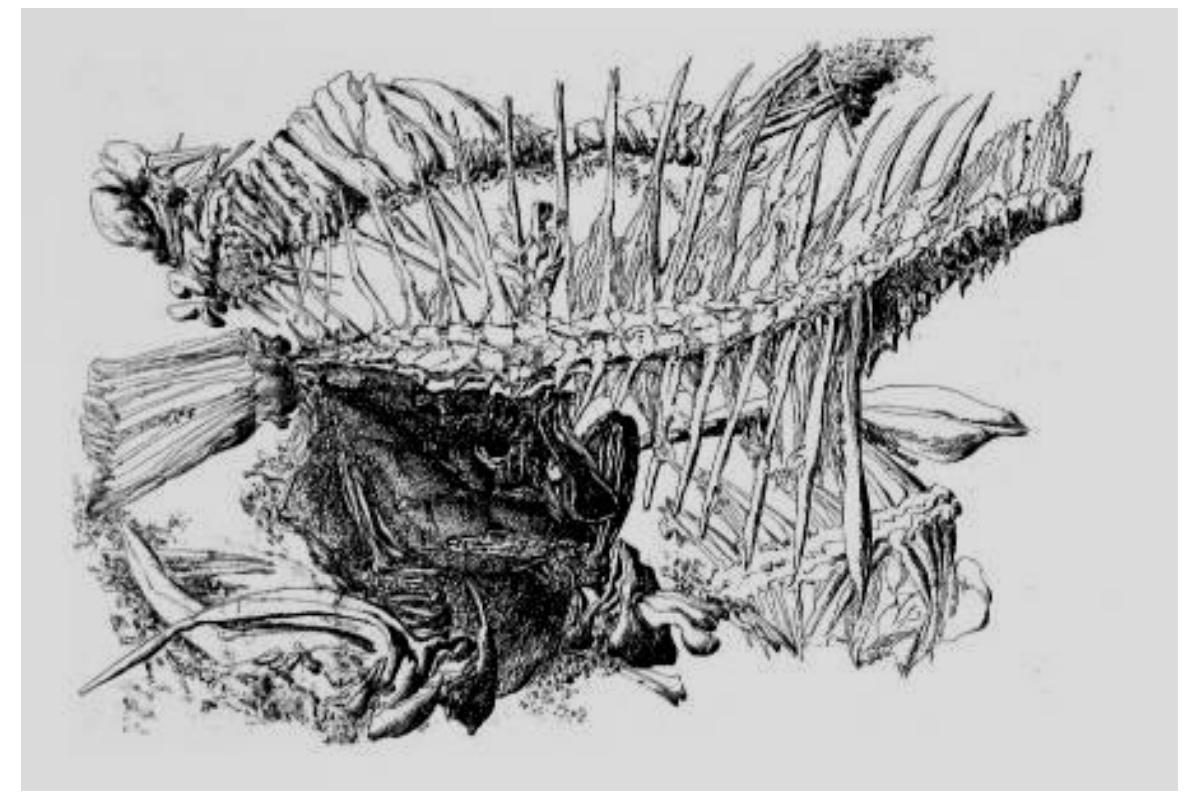

Abb. 169, Als vom Butt nur die Gräte geblieben war, 1977, Blatt VI, Kopf und Gräte, 1977, Ätzradierung auf Kupfer 


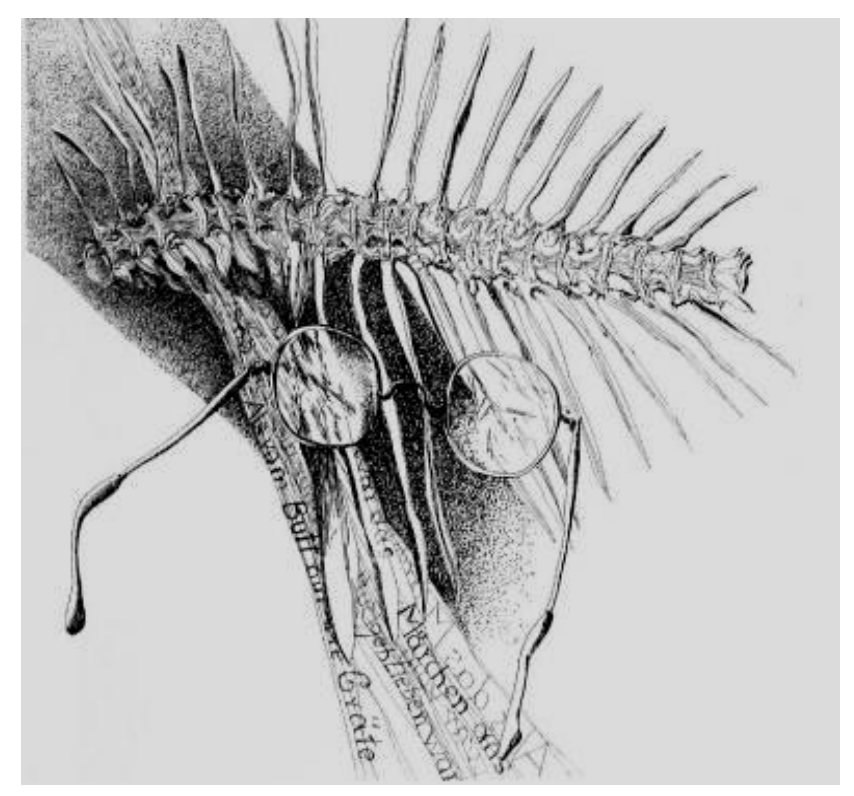

Abb. 170, Als vom Butt nur die Gräte geblieben war, 1977, Blatt VII, Als das Märchen zu Ende war, 1977, Ätzradierung auf Kupfer

Wie schon in der Blechtrommel wird der Fischverzehr auch im Butt mit dem Vorgang der Erinnerung verknüpft. In dem Gedicht „Bei Kochfisch Agnes erinnert“, das im vierten Kapitel des Romans platziert ist, wird die Zubereitung eines Kabeljaus für zwei Gäste beschrieben. Im Zuge dieses Vorgangs wird an eine Agnes erinnert. Sowohl der Name als auch die zubereitete Fischart gemahnen an die beiden oben behandelten Passagen der Blechtrommel, in welchen das Fischessen zum Erinnern in Beziehung gesetzt worden war:

\section{BEI KOCHFISCH AGNES ERINNERT}

Auf den Kabeljau heute,

den ich in Weißwein und Gedanken an Dorsch, als er noch billig - Pomuchel! Pomuchel!-, auf schwacher Hitze gekocht habe, legte ich, als sein Auge schon milchig und Fischaugen weiß dem fiebrigen Opitz übers leere Papier rollten, grüne Gurken, in Streifen geschnitten, dann, von der Hitze genommen, Dill in den Sud.

Über Kochfisch streute ich Krabbenschwänze, die unsere Gäste - zwei Herren, die sich nicht kannten -, während der Kabeljau garte, gesprächig und um die Zukunft besorgt, mit Fingern gepult hatten.

Ach Köchin, du schaust mir zu, wenn ich mit flachem Löffel dem zarten Fleisch helfe: willig gibt es die Gräte auf und will erinnert, Agnes, erinnert werden.

Nun kannten die Gäste sich besser. 
Ich sagte, Opitz, in unserem Alter, starb an der Pest.

Wir sprachen über Künste und Preise.

Politisch regte nichts auf.

Suppe von sauren Kirschen danach.

Mitgezählt wurden frühere Kerne:

als wir noch Edelmann Bettelmann Bauer Pastor... (VI 341 f.)

Im vierten Kapitel des Butt steht das Gedicht vor allem mit einer anderen Agnes, mit der Küchenmagd Agnes Kurbiella in Verbindung, die ebenso wie Agnes Matzerath in einem Dreiecksverhältnis Platz genommen hat. ${ }^{603}$ Dieser Teil des Romans, der weiter unten ausführlicher behandelt werden wird, ist im 17. Jahrhundert angesiedelt und erzählt ihre Geschichte.

\section{Grass' bildende Kunst nach 1972 und ihr Verhältnis zum Butt}

Beherrschendes Element der nach 1972 entstandenen Tusche-, Bleistiftzeichnungen und Radierungen, die Fische behandeln, sind zunächst Aale. Die phallisch geformten Tiere schlängeln sich zwischen Kuheutern, die in Grass' Darstellungen an Brüste erinnern (Abb. 171), sie gleiten über unbekleidete weibliche Puppen oder winden sich zwischen Frauenschenkeln (Abb. 172, Abb. 173). Zum einen wird der Hinweis auf weibliche Selbstbefriedigung mit Hilfe des Aals aus der Blechtrommel in diesen Bildern umgesetzt, zum anderen die Beschreibung einer von Eddi Amsel in den Hundejahren angeblich beobachteten Szene auf einer Weide. Die mit der Erscheinung verbundenen erotischen Konnotationen gehen auch aus der literarischen Darstellung deutlich hervor:

Warm liegen Kühe auf schwarzweißer Seite. Euter preisen sich an: fahl gelblich morgendlich prall: neun Kühe, sechsunddreißig Zitzen, achtzehn Aale. Die finden hin und saugen sich fest, verlängern braunschwarz rosagefleckte Zitzen: Sückeln Labbern Nuckeln Durst. Anfangs zittern die Aale. Lust wer wem? Dann lassen die Kühe nacheinander die Köpfe übergewichtig in den Klee fallen. Milch fließt. Aale schwellen. (IV 209)

In beiden Medien hat die Repräsentation von männlich-weiblicher Geschlechtlichkeit durch Tierkörper einen distanzierenden und verallgemeinernden Effekt. Sie verschafft dem Dargestellten eine überzeitliche Wirkung und erzeugt durch die irritierende Zusammenstellung der Geschöpfe und ihrer gegensätzlichen Qualitäten (Wärme, Behaarung, Trockenheit vs. Kälte, Glätte, Feuchtigkeit) einen starken sinnlichen Eindruck. Eine sexuelle Annäherung ist durch die Formanalogie von Kuheutern und Brüsten sowie Aalen und männlichen Gliedern angedeutet. Die Verbindung von Lust, Verführung, Sünde und Tod wird erneut durch die Ähnlichkeit der Aale mit Schlangen vermittelt. Im Butt wird die Komposition literarisch noch einmal aufgegriffen, und zwar als ein „Bild“ von ewiger Aussagekraft:

Wir kaufen teuer aus fremdem Wasser: Tiefgefroren tauen die Aale aus Schottland hier wieder auf und beleben sich wunderbar. Ich weiß Geschichten, Ilsebill: mit Ästen gegabelt, peitschten sie meinen Rücken. Sie hingen in jedes Bild. Sie glitten, wie ich, den Kühen unter das Euter. Sie sind so alt wie der Butt. (VI 285)

${ }^{603} \mathrm{VgI}$. O’Neill (1982), S. 8. 
Fische anderer Art werden in Grafiken aus den Siebzigerjahren mit Objekten wie Gläsern und Pilzen zusammengestellt. Die Radierung Wewelsflether Blatt (Abb. 174) kombiniert einen Fisch mit zwei Pfifferlingen und einem kurzstieligen Weinglas. Ähnlich wie in der oben behandelten Bleistiftzeichnung Pilze, Glas mit Schnecken und Klinge aus Mariazuehren wurde hier ein Stilleben kreiert, das Motive der weiblichen und männlichen Geschlechtlichkeit miteinander verbindet. Hinsichtlich seines Inventars ist das vorliegende Blatt mit niederländischen und flämischen Stilleben des 16. und 17. Jahrhunderts vergleichbar, die gedeckte Tische zeigen, sogenannte Banketjes. ${ }^{604}$ Im Unterschied zu Gemälden wie Pieter Claeszs Hering mit einem Glas Bier und einem Brötchen (1636) (Abb. 175) weist Grass' Radierung jedoch keinen ausgestalteten, geschweige denn naturalistisch wiedergegebenen Bildraum auf. Auch widmete sich der Grafiker den visuellen Qualitäten der Objekte nicht mit derselben Intensität. Sie wurden zudem ohne Überschneidungen, in Abständen zueinander arrangiert, was für Betrachterinnen und Betrachter den Impuls verstärkt, nach Verweisen auf andere Bedeutungsebenen des Dargestellten zu suchen.

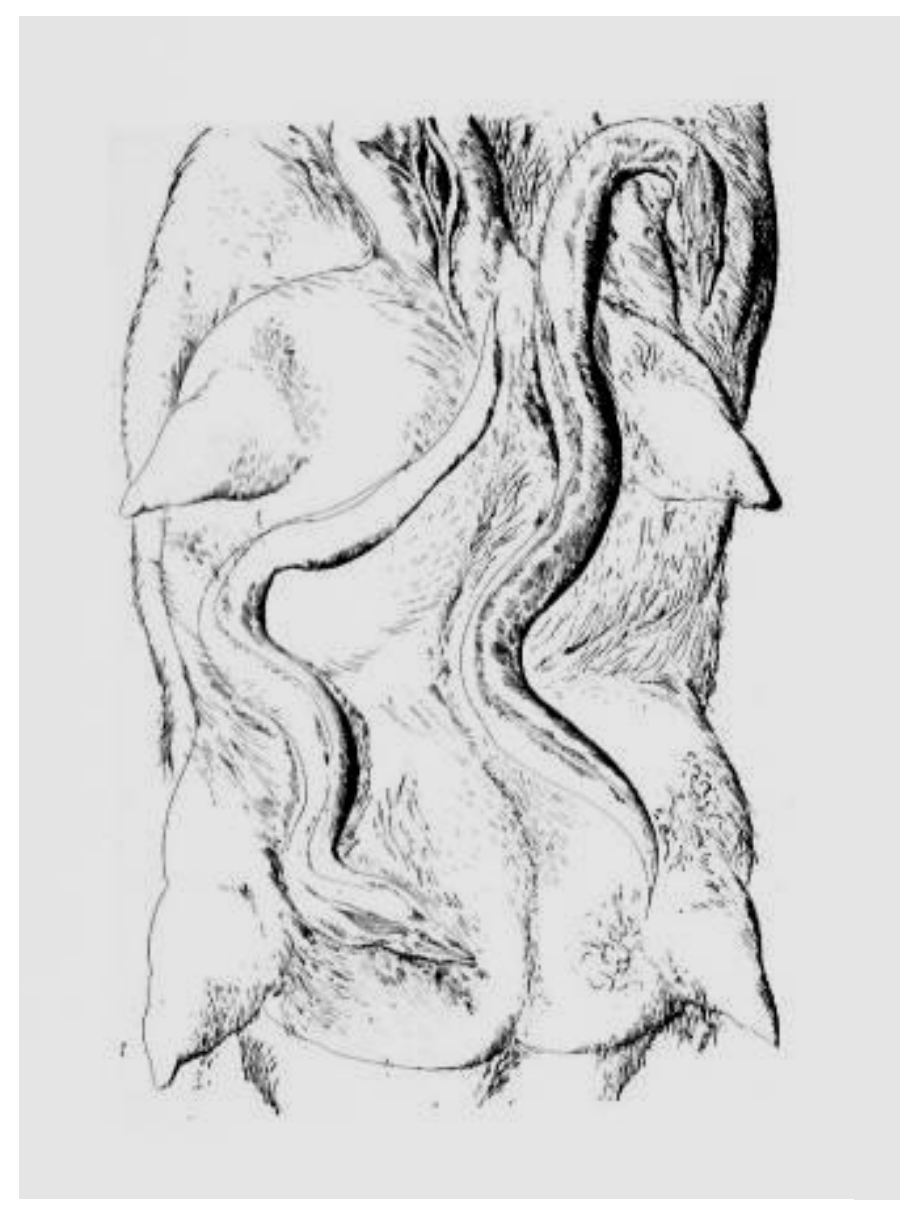

Abb. 171, Aale mit Euter, 1972, Ätzradierung auf Kupfer

${ }^{604}$ Vgl. Brakensiek (2002), Chong/Kloek (1999) und die Fischstillleben von Abraham van Beyeren in: Bergström (1983). 


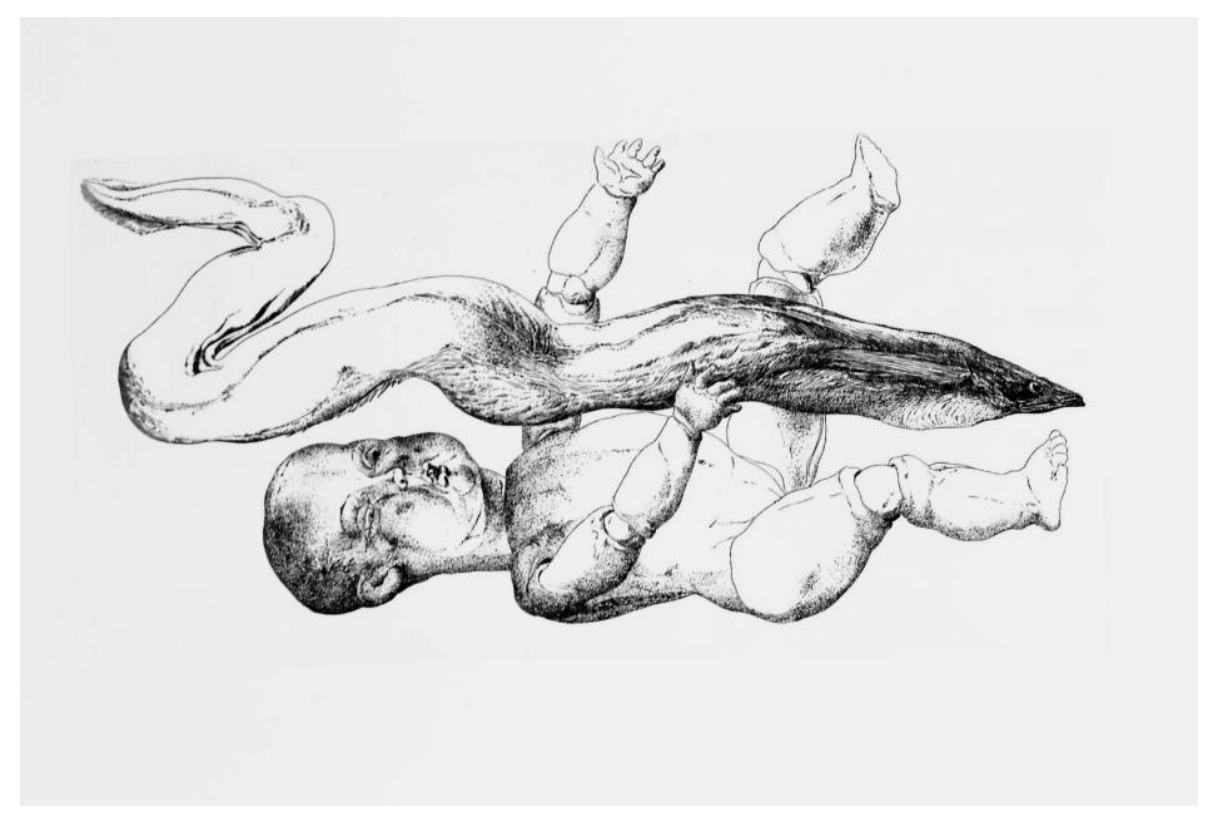

Abb. 172, Puppe und Aal, 1973, Ätzradierung auf Kupfer

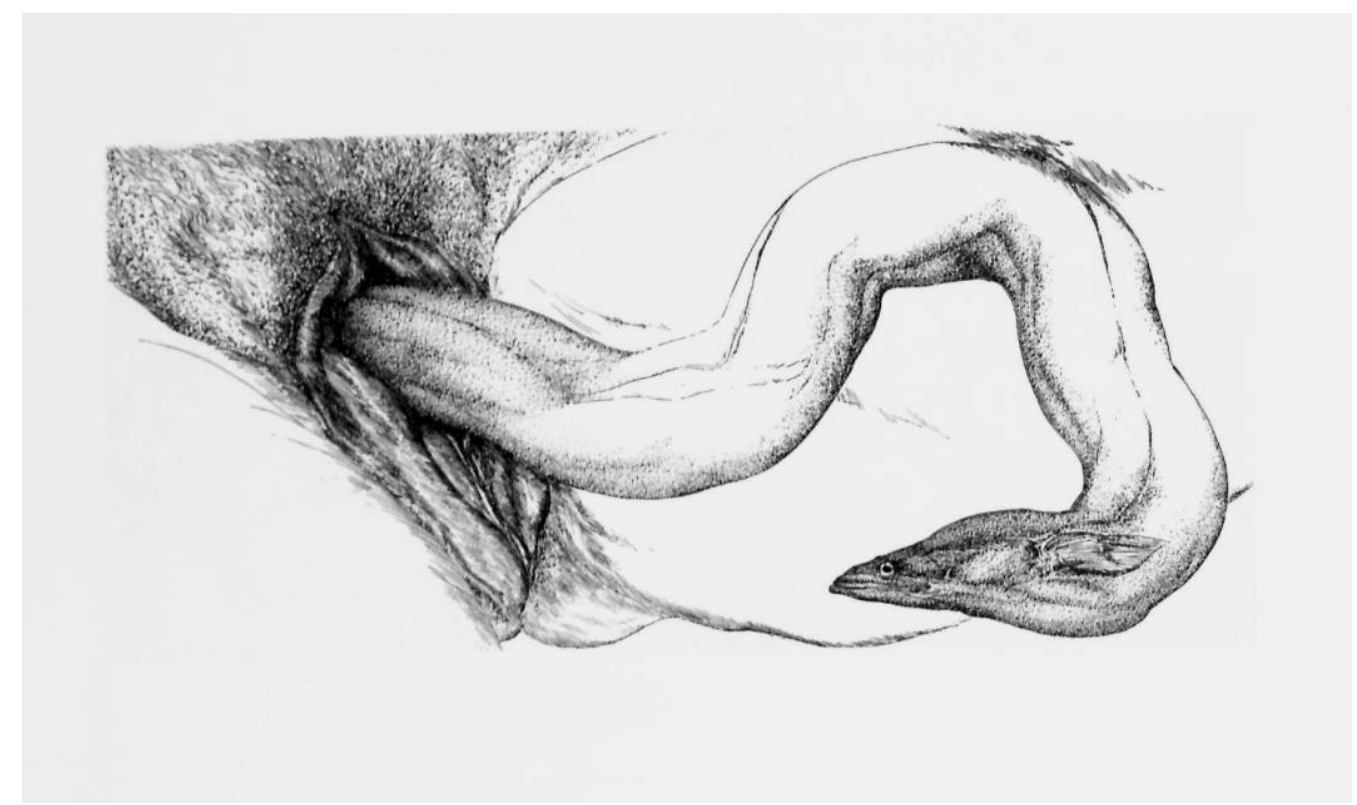

Abb. 173, Kein Traum, 1973, Ätzradierung auf Kupfer 


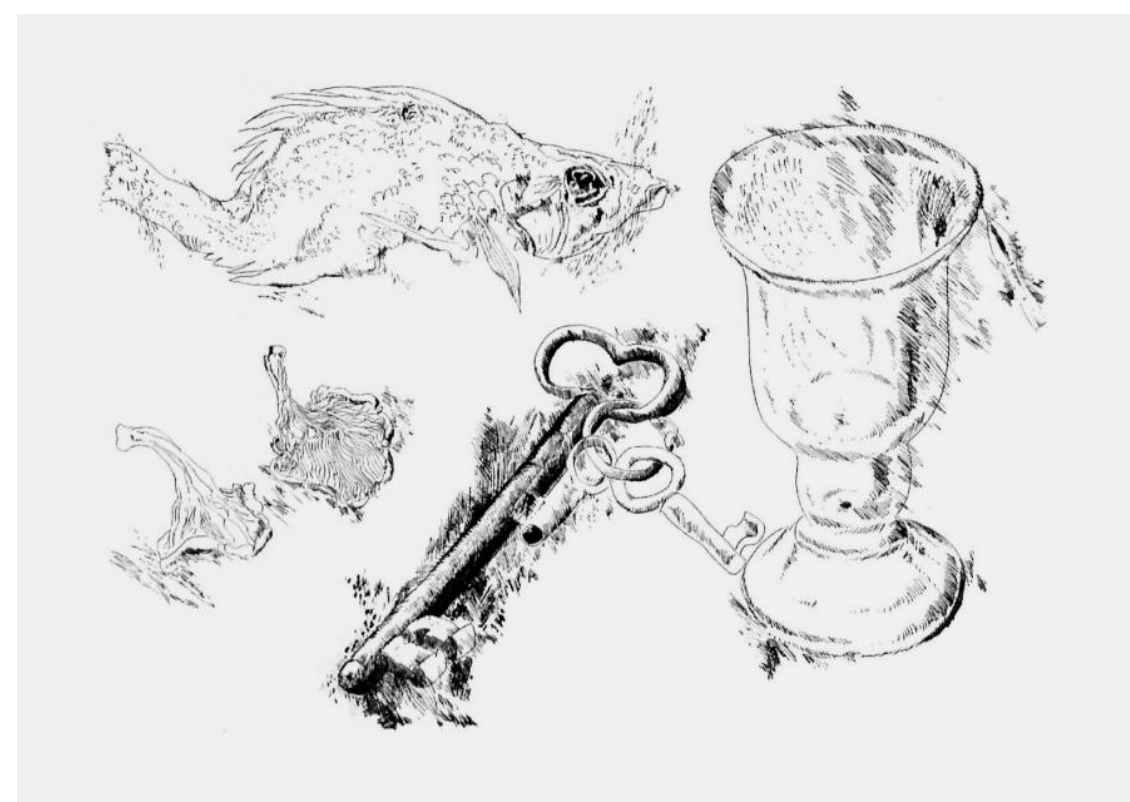

Abb. 174, Wewelsflether Blatt, 1972, Ätzradierung auf Kupfer

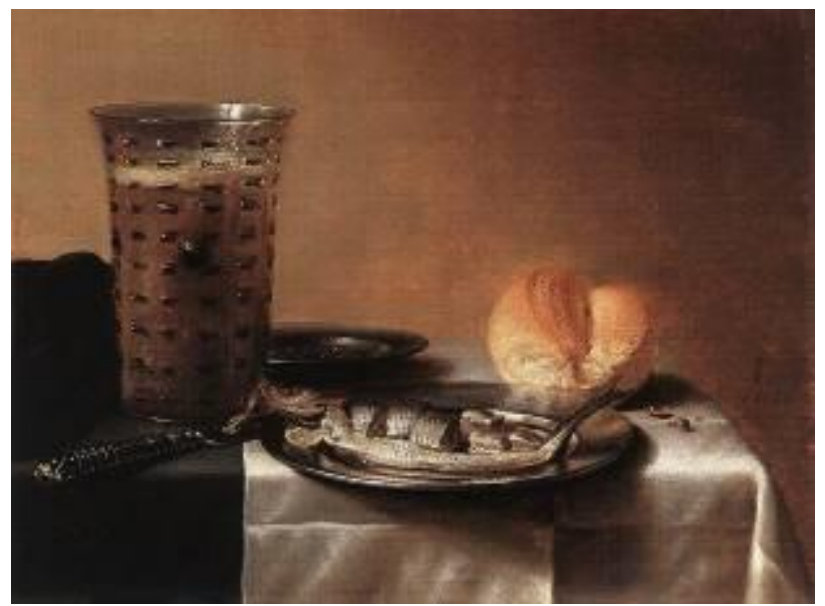

Abb. 175, Pieter Claesz, Hering mit einem Glas Bier und einem Brötchen, 1636, Öl auf Holz

Eine besonders große Gruppe von grafischen Fischmotiven aus der Vorbereitungsphase des Butt bilden auf Stangen gespießte Fischköpfe verschiedener Gattungen. Stets werden sie detailliert im Bildvordergrund präsentiert, wo die Köpfe nahezu die gesamte Bildfläche füllen. 1973, also etwa ein Jahr bevor der Butt im Rahmen des Märchens Von dem Fischer un syner Fru in die Konzeption des Romans eindrang, wird erstmals ein Buttkopf in einer Radierung dargestellt (Abb. 176). ${ }^{605}$

Genau abgebildet werden die von Furchen durchzogene und von Runzeln geraute, an eine Landschaft erinnernde Haut des Fisches, die ihn ,steinalt' wirken lässt, sowie beide aus dem Bild heraus gerichtete Augen des Tieres und seine nach unten herabhängenden Lefzen, die grundsätzlich missmutig anmuten. Wie weiter unten erörtert werden wird, muss gerade die für eine detail-

${ }^{605}$ Vgl. Mayer (1982) sowie Günter Grass in seinem kurzen Text für das Kunstmagazin Art vom April 1979: „Lange bevor ich siebenhundert Seiten lang das Märchen vom Butt als Roman schrieb, habe ich den großen Plattfisch mit dem Pinsel, mit der Rohrfeder, mit spröder Kohle und mit weichem Blei gezeichnet." (XI 1048) 
freudige Wiedergabe so notwendige intensive Betrachtung des Fisches für die literarische Gestaltung der Romanfigur bedeutsam geworden sein.

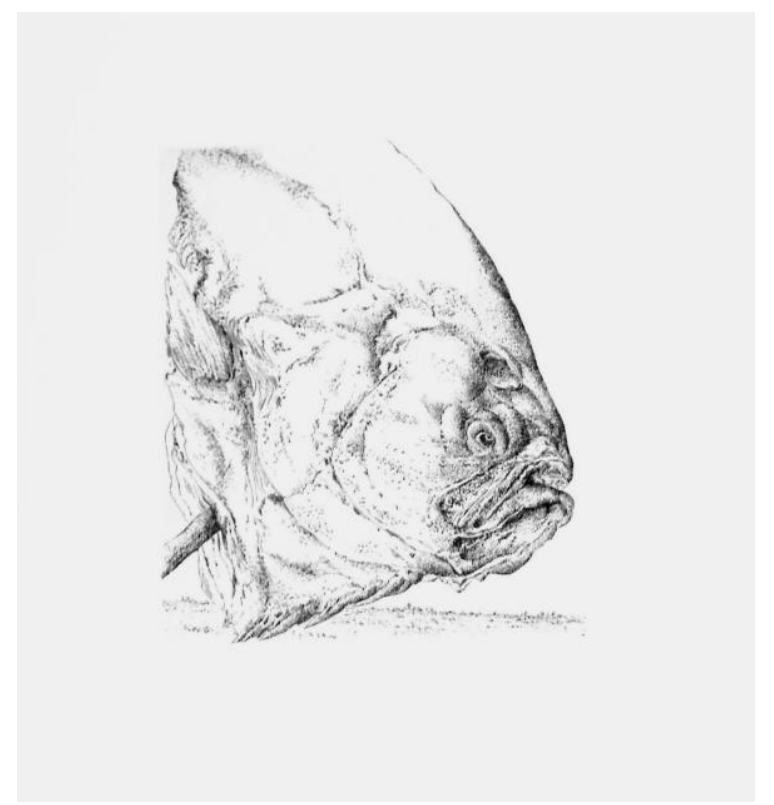

Abb. 176, Butt I, 1973, Ätzradierung auf Kupfer

Dem Aufspießen von Fischköpfen kommt im Butt eine besondere Rolle zu, die die Komposition der Grafik nachträglich erklärt: Den frühmittelalterlichen Bewohnern des Weichselufers wird der heidnische Brauch zugeschrieben, ihren Fischgott „Ryb“, der die Gestalt des Butts hat, an Ostern durch verschiedene an Stangen in die Höhe gehaltene Fischköpfe zu ehren:

\begin{abstract}
„Buttke, Buttguttke!“ riefen die Hakelwerkkinder. Sie waren mit altem Netzwerk und mit morschen Korbreusen behängt. Auch als man uns, nach Mestwinas Tod, christlich gemacht hatte, haben wir nicht aufgehört, gutheidnisch zu sein. Auf Ostern, warum nicht auf Ostern? - zeigten wir, nachdem wir uns am Radauneufer mit Weidenzweigen gepeitscht hatten, in frommer Prozession den Fischen die Flüsse, die See. [...] Später zum Abend wurde das Weidengeäst mit den Köpfen drauf in den Knüppeldamm, der zur Fischerinsel führte, wie ein Zaun gepflanzt. Schreiend liefen die Hakelwerkkinder davon. Schon kamen die Möwen in steilem Anflug. Bis zum Damm waren sie schrill der Prozession gefolgt, doch in Abstand geblieben. Jetzt stießen sie zu und nahmen zuerst die Augen. (VI 108)
\end{abstract}

Mit der Darstellung der aufgespießten Fischköpfe ist darüber hinaus eine Nähe zu Eddi Amsels Vogelscheuchen aus den Hundejahren gegeben, die auf Ästen oder Stangen in die flache Landschaft nahe der Weichselmündung gestellt wurden. Schon zu Beginn der Arbeit an den Hundejahren hatte Grass im Jahr 1961 Karikaturen gezeichnet, die einzelne, auf Pfähle gespießte Objekte zeigen - es handelt sich um Vogelscheuchen, die Otto von Bismarck und Walter Ulbricht repräsentieren. Die Ulbricht-Scheuche verbindet das Haupt des Politikers mit einem Fischskelett. Unter ihr legt ein Vogel den Kopf in den Nacken, um das Gebilde mit offenstehendem Schnabel zu betrachten. Durch das Skelett wird der für den Mauerbau verantwortliche Ulbricht als Person charakterisiert, die Unheil verursacht, und zugleich niemanden, zumindest keinen Vogel, mehr schrecken kann (Abb. 177). In einer Federzeichnung zu Ingeborg Bachmanns Ein Ort für Zufälle hatte Grass 
das Fischskelett ebenfalls als politisches Warnmotiv verwendet (Abb. 178). Wie bedrohliche Wegweiser setzte er in der Komposition zwei Fischgräte auf die Berliner Mauer, die jeweils in die andere Stadthälfte zeigen und für beide Seiten des geteilten Landes Elend ankündigen.

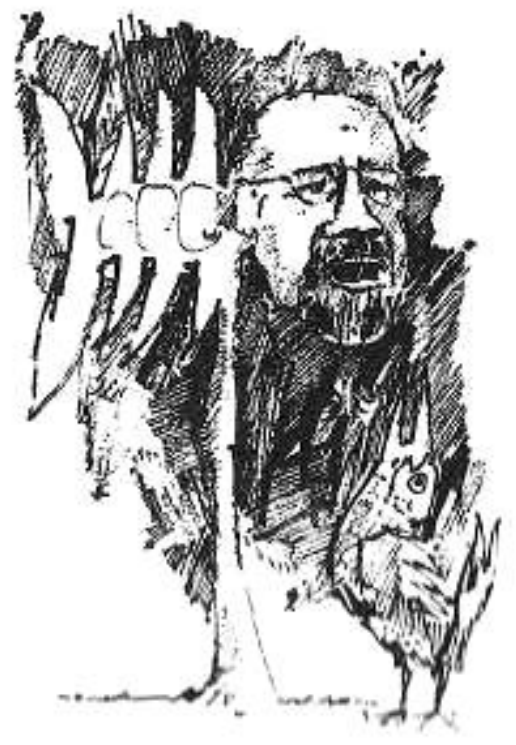

Abb. 177, Ulbricht-Karikatur zum Komplex „Vogelscheuchen“, 1961, Feder/Tusche

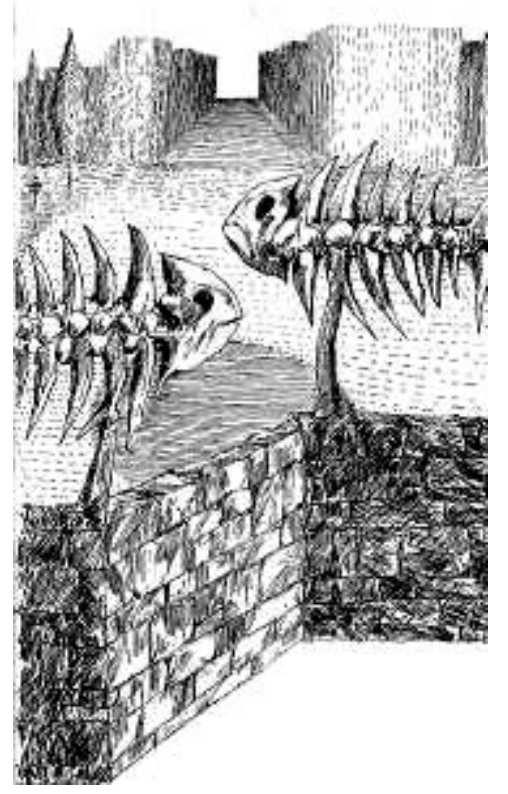

Abb. 178, Ingeborg Bachmann, Ein Ort für Zufälle, mit 13 Zeichnungen von Günter Grass, Berlin 1965,

S. 67

Weitere Zeichnungen und Radierungen des Schriftstellers aus den Siebzigerjahren kombinieren Fische mit Fußabdrücken und auf Stangen gespießte Fischköpfe mit Schuhen. Der Fisch und die menschliche Gestalt bzw. Formen und Gegenstände, die diese repräsentieren, werden auf diese Art miteinander verglichen. Sie werden auf Ähnlichkeiten und Unterschiede hin ausgelotet: Die Grafik Schuh und Steinbeißer (Abb. 179), eine von vier Radierungen aus der Serie Boots, ${ }^{606}$ zeigt einen auf einer Stange parallel zur Bildfläche gehaltenen Fischkopf und daneben einen mit der Spitze auf den Betrachter weisenden Schnürschuh. Einerseits verhält sich der Schuh zum Fischkopf als Gegensatz: Er ist ein Gebrauchsgegenstand und hat seinen Platz am Fuß des Menschen. Andererseits haben beide eine faltige Oberfläche und bei beiden handelt es sich um totes tierisches Material. In der Radierung Fußlange Scholle (Abb. 180) ordnete Grass den Fisch neben einen Fußabdruck. Das Bild vermittelt damit eine Ähnlichkeit zwischen dem sich mit seinem ganzen Körper fortbewegenden Tier und dem gleichgroßen menschlichen Fuß.

Kombinationen von Fischköpfen mit Frauenporträts verfolgen noch deutlicher die Absicht, verschiedene Bildelemente auf Verwandtschaften und Gegensätze hin abzutasten, nämlich die querstehenden Augen des Butts mit dem menschlichen Dreiviertelprofil in Beziehung zu setzen. In

${ }^{606}$ Die vierteilige Serie erschien 1973 bei: Observer Art - Patrick Seale Gallery, London. 
mehrfach variierten Darstellungen eines Kusses von Fisch und Frau (Abb. 181) wird eine formale Annäherung der beiden Beteiligten umgesetzt.
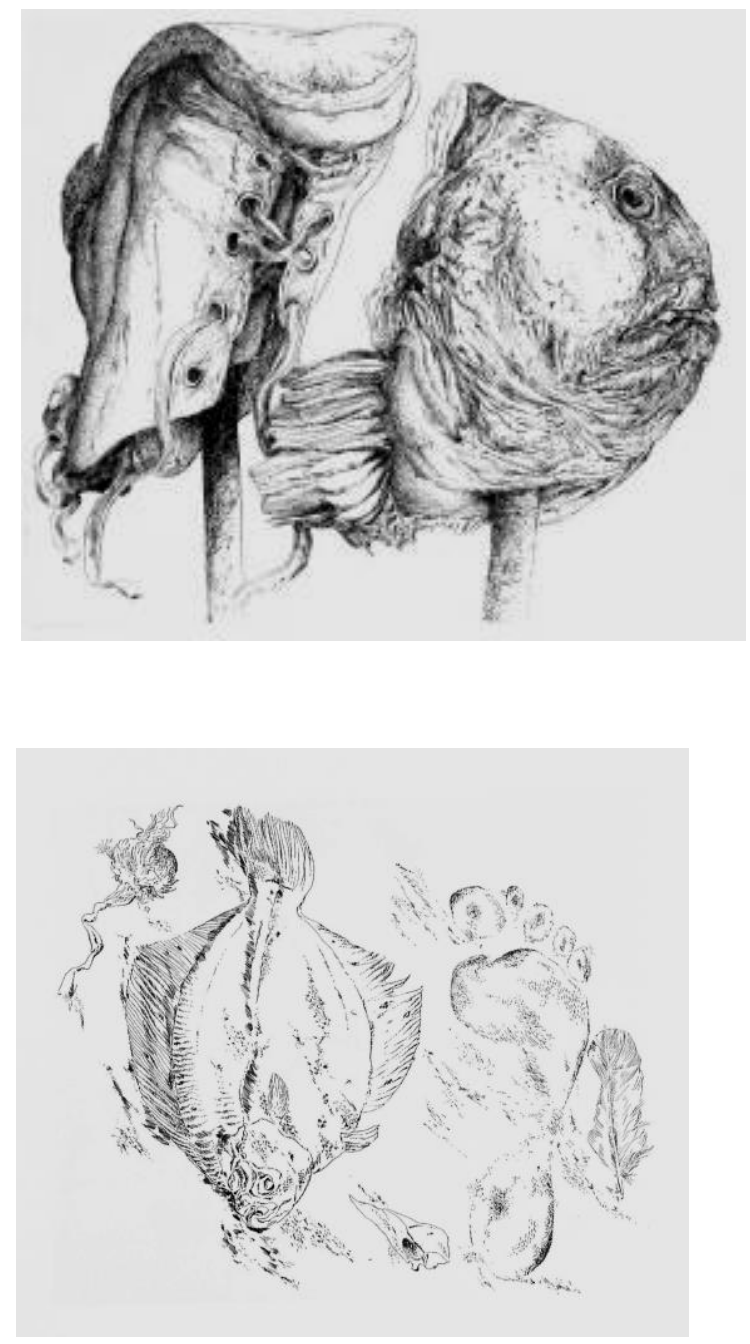

Abb. 180, Fußlange Scholle, 1972, Ätzradierung auf Kupfer
Abb. 179, Schuh und Steinbeißer, 1972 Ätzradierung auf Kupfer

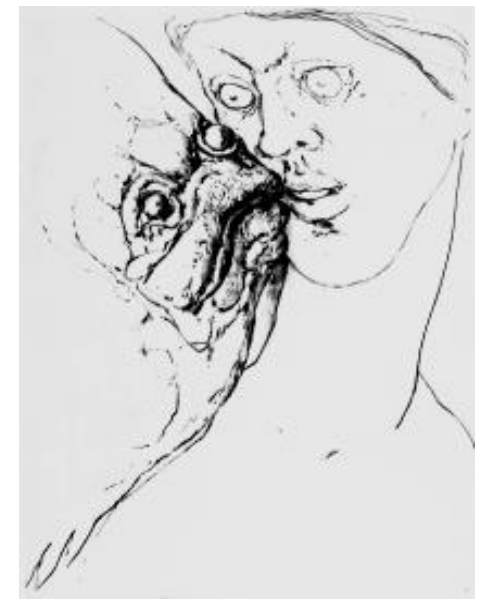

Abb. 181, Kuß II, 1975, Kaltnadelradierung auf Kupfer

Die Darstellungen lassen sich auf eine im Roman geschilderte Vereinigung der Köchin Dorothea mit dem Butt beziehen. Jede Zusammenkunft mit dem Fisch verändert die Gläubige, die „nicht ihn, sondern in seiner Gestalt ihren Liepjesu" zu küssen meint. Im Text ist die Begegnung als Konfrontation auf Augenhöhe beschrieben - dem entspricht die Gegenüberstellung von Frau und Fisch im Bild:

Der Butt sagte nichts, bot Dorothea sein schiefes Maul. Sie hatte vom Küstenwind gesprungene Lippen. Mit ihren langen asketischen Fingern hielt sie seine weiße Blindseite und seine gesteinte Draufsicht. Beide küßten sich lange. Ein Saugkuß. Sie küßten sich, ohne die Augen zu schließen. [...] Nach dem Kuß war sie verändert. Ihr Mund hatte sich, wenn auch kaum merklich, verzogen. Nicht von ihrem süßen Jesus war sie geküßt worden. Mit leicht schiefem Mund wollte sie sogleich vom Butt wissen, wie viele andere Frauen er vor ihr geküßt habe. Und ob den anderen Frauen sein Kuß 
von gleichem Geschmack gewesen sei. Und was ihm ein queres Maul mache. Und wie sie das alles ihrem Liepjesu erklären solle. (VI 171)

Wie ihre Fragen zeigen, verliebt sich Dorothea wider Willen auf recht irdische Art in den Butt. In der physiognomischen Veränderung werden die durch das Zusammensein mit dem Fisch ausgeIösten Gefühle anschaulich gemacht. Die Bildhaftigkeit des Vorgangs wird im Text als solche markiert, indem der Erzähler nach dem Bericht über weitere Veränderungen in Dorotheas Gesicht darauf hinweist, dass er eine ähnlich fischartige Gesichtsform an seiner gegenwärtigen Ilsebill erkennt und aufzeichnen will:

Dennoch kam sie abermals verändert zurück: Jetzt standen ihr auch die Augen leicht quer und verkantet zum schiefen Mund. Fischäugig kam sie zurück, wie ich sie zeichnen werde, wenn mir Ilsebill stillsitzt. (VI 174)

In einem Artikel vom April 1979 hatte Grass darauf hingewiesen, dass die Konfrontation von verschiedenen Bildelementen ein wichtiges Anliegen seiner Grafiken sei - mittels der Zeichnung ergäbe sich die Möglichkeit, Bezüge zwischen grundverschiedenen Gegenständen aufzudecken:

Mit gleichmütiger Linie hebt sie [die Zeichnung, V. K.] Fremdheiten auf, sie bettet Gegensätzliches unter einer Schraffur, sie widerlegt - wie das Gedicht - die Gewohnheit, sie macht das Niegehörte sichtbar. Die Konfrontation des Gegenständlichen ist mein Thema. Auf Stangen gespießt sind sich der Fischkopf und der alte Schuh feindselig verwandt. Das Märchenmotiv: Ilsebill küßt den Fisch - führt grafisch zur Anverwandlung der Physiognomien. (XI 1048)

Diese Zielsetzung des Grafikers bildet sich nicht erst in den Siebzigerjahren heraus, wird allerdings erst dann schriftlich durch den Künstler reflektiert. Auch die Motivverbindung von Frauen und Tieren ist nicht neu. Sie erinnert insbesondere an einige der in Kapitel III.1. vorgestellten Zeichnungen von Grass aus den Fünfzigerjahren, in welchen er auf der Grundlage des Mythos „Leda und der Schwan" Frauen- und Vogelkörper miteinander verband. ${ }^{607}$ In den Siebzigerjahren beschäftigte inn die Kombination von Mensch und Tier weiterhin. Nach der Veröffentlichung des Butt hatte Grass nicht nur Küsse, sondern eine auf den ganzen Körper bezogene Vereinigung von Frau und Fisch grafisch dargestellt (Abb. 182).

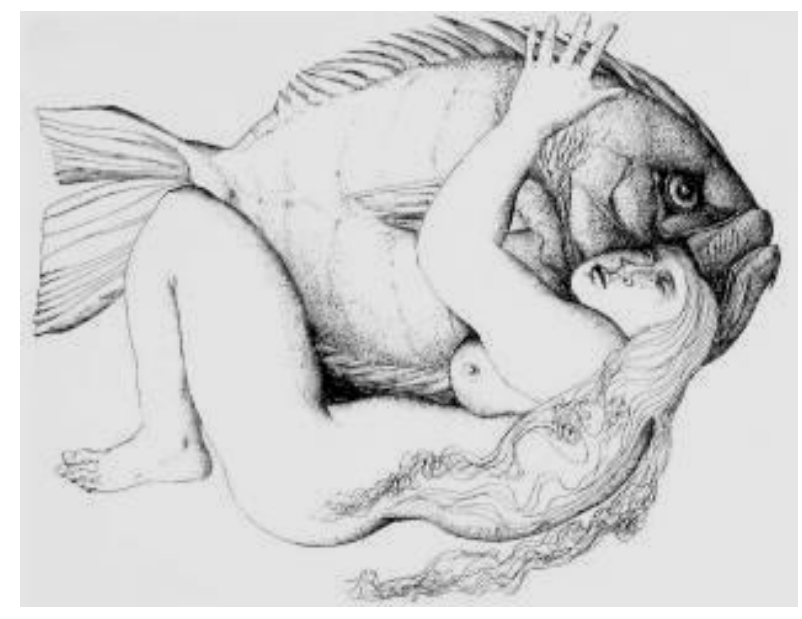

Abb. 182, Paar, 1979, Ätzradierung auf Kupfer

${ }^{607}$ Vgl. S. 112 f. der vorliegenden Untersuchung. 


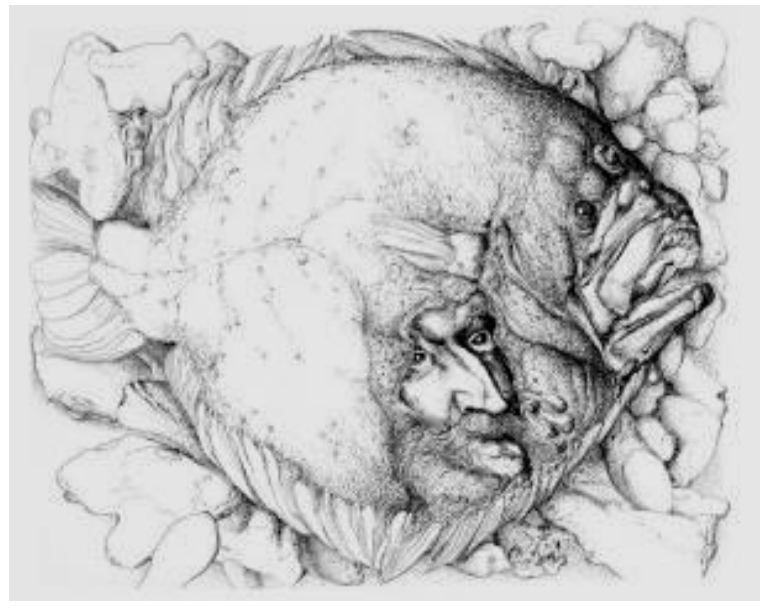

Abb. 183, Mann im Butt, 1978, Ätzradierung auf Kupfer

In der Radierung aus dem Jahr 1979 ist der Butt auf Menschenmaß vergrößert. Eine mit geöffnetem langen Haar dargestellte Nackte schmiegt sich an seine Unterseite, so dass ihr linkes Bein, ihre linke Brust, ihr linker Arm und ihr Gesicht der zu den Betrachterinnen und Betrachtern gewandten Seite des Fisches eng anliegen. Der äußere Umriss ihres Rückens vollzieht die Kontur des Butts nach und lässt Frau und Fisch auf diese Art miteinander verschmelzen. Auf den Zusammenhang mit dem Leda-Mythos deutet auch der Romankontext insofern hin, als dass Dorothea zunächst meint, sich mit einem Gott, nicht mit einem Tier, zu vereinigen.

Eine andere Form der speziesübergreifenden Annäherung zeigen Grass' Selbstporträts mit dem Plattfisch. Ein Jahr nach der Veröffentlichung des Butt hatte Grass eine Radierung geschaffen, in der das Abbild seines Gesichts aus einer Seite des Fisches hervordringt und so die Nähe zwischen dem Autor-Erzähler und dem ihn beratenden Tier zum Ausdruck bringt (Abb. 183). Ähnlich wie in den Frauendarstellungen mit Butt wird die Beziehung der Dargestellten zudem über die vergleichbare Ausrichtung der Augenpartie, über das menschliche Dreiviertelprofil hergestellt.

Bereits im Portfolio Liebe geprüft (1974) zeigt die Radierung Szenisches Madrigal eine Annährung von Künstlerselbstbildnis und Fischkopf. Dargestellt ist das Haupt des Tieres von der Seite, mit einem weit aufgerissenen Auge und die Augenpartie eines anhand seiner Augenform als Günter Grass identifizierbaren Mannes. Mann und Fisch wurden in der Art neben- und untereinander gesetzt, dass sich das Fischauge wie ein drittes Menschenauge mittig über den Augenbrauen des Mannes befindet und sein Sehen in starrer, distanzierter Form zu ergänzen scheint (Abb. 184). Das Doppelportrait erinnert in dieser Hinsicht an dasjenige zum Tagebuch einer Schnecke (S. 217, Abb. 132), in dem Grass ein zentrales Tiermotiv als Sehhilfe inszeniert. 


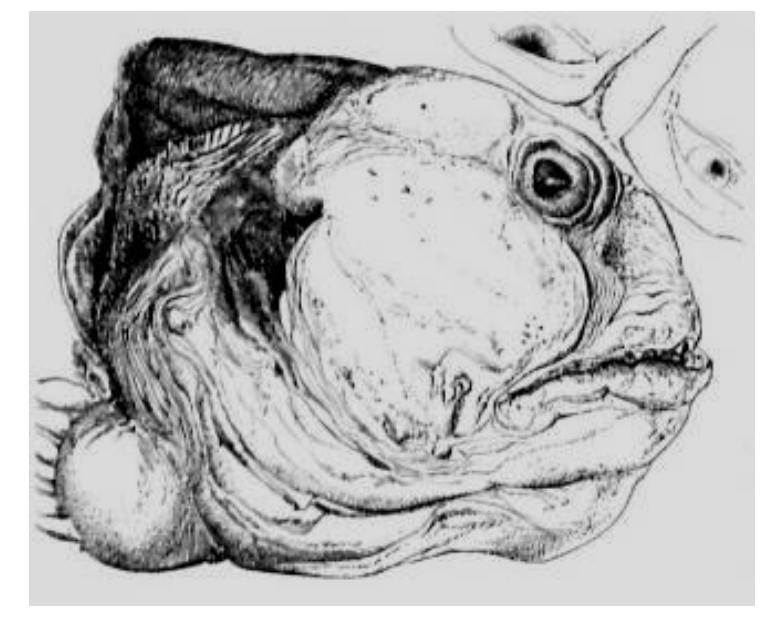

Abb. 184, Szenisches Madrigal, 1974,

Ätzradierung auf Kupfer

Im Unterschied zu den emblematischen Zeichnungen zum Tagebuch konstituiert sich die Assoziationskraft vieler Porträts und Stillleben zum Butt wieder stärker über Formanalogien. In manchen Fällen wirken die Konfrontationen spielerisch, noch auf kein bestimmbares Ergebnis hinauslaufend. In anderen wie den Frauenporträts und den Selbstbildnissen mit Fischen werden Formkorrespondenzen gefunden, deren Bedeutung später durch den Roman näher umrissen wird. In der Inkubationszeit des Butt arbeiteten bildkünstlerische Werke des Schriftstellers auf diese Art epischen Entsprechungen zu. Die Absicht, innere Vorgänge durch die physiognomische Gestaltung von Figuren auszudrücken, sollte auch in der literarischen Beschreibung der Butt-Gestalt ein Echo finden.

\section{Der Plattfisch als literarisches Sinnbild}

Ebenso wie die Schnecken im Tagebuch als „beispielhafte, fabelhafte, prinzipielle und solche, die wirklich vorkommen" behandelt werden, ist auch Grass' Darstellung des Plattfisches im Butt facettenreich. Im Gegensatz zum Protagonisten des Grimm'schen Märchens ist das Tier im Roman eine detailliert ausgestaltete Figur. ${ }^{608}$ Nicht nur kommen sein Wesen und seine Auffassungen durch lange Gesprächsbeiträge und Monologe zum Ausdruck, werden seine Rollen in Märchen, Mythen und heidnischen Bräuchen angedeutet, seine ideologischen Positionen zusammengefasst und Möglichkeiten seiner kulinarischen Zubereitung benannt, sondern auch seine äußere Erscheinung beschrieben. Obwohl es sich bei dem Butt um einen unsterblichen Märchenfisch handelt, der allein dadurch, dass seine Auftritte im Prosatext meist von einem bestimmten Artikel begleitet werden, als Repräsentant seiner Gattung vorgestellt wird, erfährt seine Gestalt eine detaillierte Beschreibung:

Wie im Märchen vom Fischer und seiner Frau Ilsebill nur immer, ohne genaue Angabe, vom Butt die Rede ist - „Dar sed de Butt to em... Dar kam de Butt answemmen un sed..." -, so spreche auch ich vom Butt, als gäbe es nur den einen allwissenden, der mich, wann immer ich zeitweilte, beraten, belehrt, indoktriniert, zum Mannestum erzogen und kategorisch unterwiesen hat [...]. Dabei gibt es den

${ }^{608}$ Vgl. Runge (1987) und Rölleke (2008): Der Butt wird im Märchen nicht näher beschrieben. Der Beitrag des Plattfisches zum Gespräch mit dem Fischer besteht in dem knappen Gewähren der Wünsche Ilsebills, also Variationen von: „Geh nur nach Hause, sagte der Plattfisch, sie hat sie [eine Hütte] schon“. 
Glattbutt, den Heilbutt, den Goldbutt, den Strufbutt. Meiner war und ist ein sogenannter Steinbutt, der dem Glattbutt zwar ähnelt, doch buckeln kieselsteingroße Verknöcherungen seine Haut.

Der Steinbutt ist im Mittelmeer, in der nördlichen See bis zur norwegischen Küste und in der Ostsee, meinem baltischen Meer, verbreitet. Wie bei allen Plattfischen ist seine Augenachse im Verhältnis zum Schiefmaul schräg verkantet, was ihm den neunmalklugen und zugleich tückischen, ich sage, zwischensichtigen Blick gibt: Er schielt zeitraffend [...]. Wie mit Distanz zu sich, also schiefäugig ironisch, konnte er seinen Wohlgeschmack preisen [...]. (VI $41 \mathrm{f}$.

Die letzten Sätze des zitierten Textes verdeutlichen, dass einzelne Eigenschaften der ButtPhysiognomie als bedeutungstragend verstanden werden sollen. Das schiefe Maul und die schrägstehenden Augen auf einer Körperseite werden im Text als Ausdruck seiner Neigung zur Ironie und seiner Fähigkeit, Ereignisse verschiedener Zeiten zusammenzusehen entdeckt. Der Schriftsteller, der den Butt vorab als Grafiker detailliert porträtierte, macht Eigenschaften seiner Romanfigur sprachlich an ihrer visuell wahrnehmbaren Gestalt fest und damit anschaulich.

Diese sinnbildliche Auslegung der Tiergestalt wurde von Grass in einer früheren Textfassung noch ausführlicher vorgenommen. Der Duktus des betreffenden Entwurfs erinnert an den Dialog des Autor-Erzählers mit seinen Kindern in Aus dem Tagebuch einer Schnecke und lässt das Bemühen erkennen, die Auswahl des Butts als bedeutender Figur des Romans auch unabhängig von der bekannten Märchenvorlage zu begründen. ${ }^{609}$ Die Charakterisierung des Fisches in dieser Fassung thematisiert zudem das Verhältnis zwischen dem Tier und den Menschen, mit welchen es kommuniziert, als ein spiegelbildliches und greift damit im übertragenen Sinne die Gegenüberstellungen aus den oben behandelten Grafiken auf:

Von allen Fischen spricht nur der Butt. Warum der Butt und nicht der Dorsch oder silbrige Lachs? Weil der Butt ein schiefes, zu den Augen verkantetes Maul hat. Warum hat der Butt ein Schiefmaul? Weil er schwierige Wörter, wie „infolgedessen“ oder „das Neolithikum“ mit seinem Maul formen muß. Welche Sprache spricht denn der Butt? Die Sprache des Fragenden: jede Art Küstenplatt, Mönchslatein, Kanzleideutsch. Er spricht soziologisch, den Jargon der Eigentlichkeit, in technokratischen Kürzeln, und neuerdings hegelt er wieder. Kann der Butt singen oder pfeifen? Das nicht. Doch offenbar belesen, zitiert er gerne: die Kirchenväter, Vorsokratiker, aber auch Epikur und Montaigne, die Weimarer Klassik, Marxengels und was zeitweilig modern ist. Wer oder was spricht aus ihm? Was man will, wer gemeint ist: platterdings Gott, das fischgewordene Prinzip, ein verwunschener Märchenprinz, der absolute Widerspruch, ein aufgeklärter Teufel, die Dialektik der Natur.

Welcher Art ist der Butt? Kein Glatt- oder Heilbutt, ein Steinbutt. Denn was wir Steine nennen knorpelige Verhärtungen unter der dunklen, vielfältig gerunzelten oder straff glänzenden Oberhaut sind Fragen, die ihre Antwort bei sich hielten. ${ }^{610}$

Die zitierte Textstelle ist im Manuskript Teil des ersten Kapitels des Butt, und zwar des Unterkapitels „Wozu ein gußeiserner Löffel gut ist“. Es handelt davon, wie der Liebhaber der mittelalterlichen Köchin Mestwina, Bischof Adalbert von Prag, das pomorsche Volk zu bekehren und von heidnischen Ritualen abzubringen versucht. Religion wird hier am Beispiel ihrer jeweiligen Bildbzw. Objektverehrung dargestellt. Parallel zur steinzeitlichen dreibrüstigen Urmutter Aua huldigt das Weichselvolk zunächst, wie oben bereits erwähnt, dem Fischgott „Ryb“, indem es Fischköpfe

\footnotetext{
${ }^{609}$ In der dritten Fassung wurde die Passage mit Zeilenumbrüchen versehen und damit als Gedicht gesetzt. Aus der vierten Fassung wurde sie schließlich ganz gestrichen und in veränderter Form in ein anderes Kapitel übertragen.

${ }^{610}$ Vgl. Akademie der Künste, Berlin, Günter-Grass-Archiv, Nr. 219, S. 3 f., Typoskript mit hs. Korrekturen.
} 
auf Ästen gespießt durch die Landschaft trägt und so über Meer und Fluss schauen lässt. Diese Prozessionen werden bald mit der Verehrung von christlichen Heiligen vermischt wie derjenigen der Heiligen Barbara, deren Bildnis am Übergang zum Mittelalter vor den Fischköpfen hergetragen wird (VI 108). Die dreibrüstige Gestalt Auas geht ferner nahtlos in erste Mariendarstellungen über (VI 110).

In der früheren Variante des Kapitels folgt der Beschreibung des Plattfisches dessen eigene Erörterung zur christlichen Religion und ihren Bildnissen. Der Butt befürwortet den kulturellen Wandel vom heidnischen Auakult zu einem "männlich herrschenden Gott" und empfiehlt dem zeitweiligen Autor-Erzähler möglichst sinnliche Gottesbilder zu fertigen, um das Volk für das Christentum zu gewinnen:

\begin{abstract}
Da sagte der Butt: ,Das ist gut so, [...] mein Sohn. Ihr braucht einen männlich herrschen[den?] Gott. Ja, nicht nur simpel einen einzigen, sondern jenen aus Vater, Sohn und Heiligem Geist fusionierten, dreieinigen Gott, wie ihn der böhmische Adalbert nicht ohne Geschick an den Mann bringt. Noch zögern eure Frauen, weil ihnen Gottvater zu streng und der Heilige Geiste [sic] zu abstrakt ist. Es gilt, die Intimbeziehung zwischen dem Gottessohn Jesus und der irdischen Gottesmutter Maria sinnlicher darzustellen. Auch sollte man unterschwellig - wenn es der Adalbert offiziell nicht tun will oder kann - die drei Brüste eurer urzeitlichen Aua als dreieinige Brüste im Sinne des dreieinigen Gottes interpretieren. ${ }^{611}$
\end{abstract}

Die besondere Qualität sakraler Bildnisse wird an dieser Stelle dadurch gekennzeichnet, dass sie durch sinnliche Gegenständlichkeit abstrakte Prinzipien veranschaulichen. Grass' schon zu Beginn seines Schaffens in ihren Grundzügen vorhandene Ästhetik wird hier zu der Funktionsweise sakraler Kunst in Beziehung gesetzt. Die Sinnlichkeit der religiösen und insbesondere katholischen Bildwelt und Liturgie hat den Schriftsteller aller Kirchenkritik zum Trotz zeitlebens fasziniert ${ }^{612}$ und diese Faszination bereits in die Blechtrommel und Katz und Maus unübersehbar Eingang gefunden. Besonders die Novelle Katz und Maus ist für diesen Zusammenhang von herausragender Aussagekraft: Der Protagonist Mahlke bezeichnet sich selbst zwar als ungläubig, ist jedoch der Jungfrau Maria so irdisch zugewandt, dass er sie durch ein reales sexuelles Abenteuer zu beleidigen fürchtet. Repräsentiert wird die Mutter Gottes durch Bilder: Durch ein Medaillon, das die Schwarze Madonna von Częstochowa zeigt, und durch eine Reproduktion der Sixtinischen Madonna Raffaels. (IV 21 f.) Dabei wird in Katz und Maus, ebenso wie im Butt deutlich, dass von Bildern wie diesen eine gefährliche, da instrumentalisierbare Wirkung ausgeht. Im weitesten Sinne verfolgt die anschauliche Charakterisierung des Butts dennoch denselben Zweck wie ein Gottesbild: Die sinnbildliche Beschreibung des Plattfisches macht unsichtbare Eigenschaften der Figur sichtbar, das verdeutlicht die Abfolge der oben zitierten Passagen. Eine Voraussetzung für diese Beschreibung schuf die genaue Betrachtung des Fisches durch den bildenden Künstler.

\footnotetext{
${ }^{611}$ Vgl. ebd., S. 4 f.

${ }^{612}$ Vgl. Neuhaus (1988), insbesondere S. 108.
} 


\title{
Bildende Kunst im Butt
}

Die allegorischen Darstellungen des Prozessverlaufs und der Figur des Butts sind im Roman in eine Reihe verschiedener intermedialer Bezüge gebettet. Eine Betonung des anschaulichen Erzählens wird im Butt wie schon in der Blechtrommel, den Hundejahren und dem Tagebuch einer Schnecke grundlegend dadurch gewährleistet, dass bildende Kunst auf der Handlungsebene des Buches wiederholt eine wichtige Rolle spielt. Der mühelos durch die Zeit wandernde Autor-Erzähler tritt in seiner zeitgenössischen Gestalt und in seinen vielen weiteren Rollen in anderen Epochen als bildender Künstler auf. Folgerichtig finden auch seine Werke und deren jeweilige kulturelle Funktion - kommentiert durch den rundum gebildeten Butt - in den Text. Von herausragender Bedeutung sind dabei die Epoche der Steinzeit bzw. des frühen Mittelalters, des Barock sowie der Gegenwart. An ihnen wird nicht nur der jeweilige kulturelle Entwicklungsstand des Weichseldeltas demonstriert, sondern in hohem Maße auch die Ästhetik des Autor-Erzählers, in der markante Kennzeichen der Werke von Günter Grass wiederzuerkennen sind. Ebenso wie die Figur des Plattfisches im Roman eine unveränderliche ist, den Mythos der Hybris immer wieder aufs Neue anstößt und deshalb das im Roman angelegte zyklische Geschichtsbild bestätigt, dienen Beschreibungen von Kunstwerken mitunter dazu, existenzielle, zeitlose Phänomene, die der Erzähler über Jahrhunderte hinweg beobachtet, als Wiederholungen zu kennzeichnen.

Der in der Jungsteinzeit lebende Erzähler charakterisiert seine kreative Tätigkeit, wie schon das lyrische Ich im Gedicht "Mariazuehren“, als „Zeichen setzen“ und deutet damit den gemeinsamen Ursprung von Sprache und Bildkunst an. ${ }^{613}$ Es handelt sich um Zeichnungen von im Alltag beobachteten Tieren, Menschen und Vorgängen. Ihre Abbilder entstehen, während gleichzeitig Begriffe für sie gefunden werden:

\begin{abstract}
Aal und Reuse wurden als Wortpaar Begriff und durch mich, der ich zwanghaft überall Zeichen setzen mußte, ins Bild gebracht. Bevor ich, nach dem Auslegen der Reusen, den Strand verließ, zeichnete ich mit scharfem Muschelrand in den nassen Sand: zum Beispiel sich windende Aale hinter kunstvollem Flechtwerk. Und wäre unsere Gegend nicht flach und sumpfig, sondern gebirgig zur Höhlenbildung fähig gewesen, hätte ich sicher den Aal in der Reuse als Höhlenzeichnung hinterlassen. „Neolithische Felsenritzbilder nordosteuropäischer Fischerkulturen, verwandt den südskandinavischen Maglemosezeichnungen auf Knochen und Bernstein“, würde der Butt in seiner heutigen Zeitweil sagen; er hielt ja von Anfang an auf Kultur. (VI 31)
\end{abstract}

Auf diesen Zusammenhang von Wort und Bild in der Vorzeit der menschlichen Kulturentwicklung sollte Grass 1979 in dem Aufsatz „Bin ich nun Schreiber oder Zeichner?“ hinweisen. Der gemeinsame Nenner der beiden Kulturtechniken liege in der grafischen Linie und in der Bildhaftigkeit der Idee:

Nicht nur, weil Schrift und zeichnerische Linie gleichermaßen grafisch sind, sondern auch aus Gründen der Bildhaftigkeit stehen Zeichnen und Schreiben zueinander in Wechselbeziehung: In Praxis überschreitet die zeichenhafte Vorstellung die Grenzen künstlerischer Gattungsbestimmung, so irritierend verschieden jeweils das Handwerk und seine Materialien sind. Vielleicht sind es die Ursprünge der Kunst, von der Bildersprache zu Bilderschrift, die daran erinnern, daß unsere klassische Einteilung und Abgrenzung der Künste jüngeren Datums und einzig von akademischem Zwang geleitet ist. (XI 1047)

\footnotetext{
${ }^{613}$ Vgl. S. 243 f. der vorliegenden Forschungsarbeit.
} 
Der steinzeitliche Künstler legt auf die Haltbarkeit seiner in Sand gezeichneten Arbeiten keinen Wert. Unabhängig von ihrem Fortbestehen haben seine Motive überzeitliche Gültigkeit (IV 285). Es ist der Plattfisch, der den ahnungslosen Kunstschaffenden vorausschauend als jemanden schätzt, der Gegenwart konservieren und deshalb Geschichte machen kann (VI 34). Als „schwimmende Zeitung" versorgt der Butt ihn mit Neuigkeiten aus sich zeitgleich anderenorts entwickelnden Kulturen, manipuliert inn und will sein Talent der eigenen Zielsetzung, der Beförderung der Männersache, dienstbar machen. Durch sein künstlerisches Geschick wird der Erzähler für den Butt als Werkzeug relevant:

Einzig meine bildnerische Begabung, der zwanghafte Drang, Zeichen, Ornamente, Figuren in den Sand zu ritzen, habe ihm Hoffnung gemacht, ich könne, auf seinen Rat hin, Voraussetzungen schaffen für die schrittweise, er sagte, „evolutionäre“ Ablösung der Weiberherrschaft. (VI 51)

Es ist der Butt, der seinen Zögling geradezu teuflisch aus der paradiesischen Unwissenheit reißt. Er erklärt ihm, dass seine Kunst politisch relevant ist, dass er die Vormacht der Frauen bestätigt, indem er Bilder nach ihrer Gestalt anfertigt (VI 32). Dann überredet er ihn dazu, phallische Tongebilden herzustellen, um Aua dazu zu bringen, mit einem Elchbullen zu schlafen und so ein mythisches Mischwesen hervorzubringen. Nach Vorbild des antiken Minotaurus-Stoffes sollen der Zeugungsmythos des Mannes begründet und die "Zuchtlosigkeit des Mutterrechts“ belegt werden, um einen Herrschaftswechsel zwischen den Geschlechtern herbeizuführen:

Das Zeusprinzip, der männliche Samen, die reine Idee setze sich durch. Denn das stierköpfige Monstrum beweise geradezu bilderbuchhaft die Zuchtlosigkeit des Mutterrechts. Das könne man auch auf ostischem Nährboden demonstrieren. (VI 121)

Der Einfluss des Butts auf die Kunst und ihre Rezeption hat jedoch Grenzen: Aua ahnt die böse Absicht, zeigt am Bullen kein Interesse und rächt sich am jungen Bildhauer. Auch der Versuch des Butts, den Plan wenigstes in der Kunst, durch in Ton geformte Elchmänner als gelungen zu überliefern, misslingt kläglich: Die Nachwelt missversteht die durch den Künstler geschaffenen „neun handlangen Männchen unter Elchköpfen mit Schaufelgeweih", denen das Geweih im Laufe der Jahrtausende abhandengekommen ist:

Man sprach von neolithischen Schweinskerlen. In den Heftchen zur „Westpreußischen Heimatkunde" wurde erstaunlich frühe Hausschweinhaltung im Sumpfland der Weichselmündung vermutet. (VI 124)

An der Schwelle von heidnischem Kult und christlicher Religion macht der Bildhauer deutlich, dass er selbst, aller möglichen gesellschaftlichen Vereinnahmung zum Trotz, nur an seiner mimetisch abbildenden Arbeit, nicht an ihrer gesellschaftlichen Wirkung interessiert ist. Der BildhauerErzähler schlüpft gleichzeitig in die Rolle des christlichen Missionars Adalbert und in die des heidnischen Schäferkünstlers, ohne an diesem Widerspruch zu leiden. Die Kultbilder der dreibrüstigen Aua, die der reale Günter Grass nachträglich in Zeichnungen, Radierungen und Plastiken umsetz- 
te, ${ }^{614}$ lässt der fiktive Künstler in die oben bereits erwähnten Darstellungen der christlichen Gottesmutter übergehen:

Doch wir Pomorschen blieben heidnisch, auch wenn ich, in meiner Zeitweil als Schäfer, aus Lindenholz griffige Marienfigürchen schnitzte, die unterm Faltenwurf allerdings dreibrüstig waren. (Du kannst mir glauben, Ilsebill, auch als Missionar einerseits bin ich als Schäfer andererseits Künstler geblieben.) (VI 105 f.)

Nicht nur in der Zeichenhaftigkeit, nicht nur im Anspruch des mimetischen Abbildens und des Konkretisierens von Begriffen in der Bildkunst liegen Ähnlichkeiten zwischen den Werken des fiktiven und des realen Künstlers. Auch hinsichtlich des Motivrepertoires und dessen Zeitlosigkeit sind Grass' Bildwerke mit solchen des fiktiven Steinzeitkünstlers verwandt, und zwar weit über Grass' unmittelbar mit dem Butt verknüpfbare Arbeiten hinaus, die zwischen 1972 und 1977 entstanden sind. Für seine Bildkunst wählte er schließlich sehr häufig, wie die Künstlerinnen und Künstler der Steinzeit tatsächlich, ${ }^{615}$ einzelne Gegenstände der Natur, Tiere und Pflanzen, Fruchtbarkeits- und Geschlechtssymbole sowie aus verschiedenen Spezies zusammengesetzte Metamorphosen.

Es verwundert also nicht, dass Grass selbst in der kurzen ästhetischen Selbstauskunft „Bilder können die Welt nicht verbessern“ von 1973 informiert, er habe Vorbilder "von der frühen Höhlenmalerei bis zum späten Picasso“. Auch der hier vollzogene zeitliche Spagat kann im Grunde nicht irritieren, hat Picasso doch wie viele andere Künstlerinnen und Künstler der Klassischen Moderne in seinen Werken auf primitive Kunst Bezug genommen. Auch Grass' früherer Mentor und Freund Ludwig Gabriel Schrieber, mit dessen bildkünstlerischen Arbeiten der Schriftsteller sehr gut vertraut war, zählte etruskische Skulpturen zu seinen Vorbildern. ${ }^{616}$ Während Grass den Butt schrieb, müssen der ältere Bildhauer und dessen Schaffen für ihn sehr präsent gewesen sein, denn Schrieber starb 1975 und wurde als Nebenfigur im Roman verewigt. Ebenso wie der AutorErzähler, nimmt „Lud“ in verschiedenen Jahrhunderten verschiedene Rollen an und tritt dabei als bildender Künstler auf (VI 82 f., 111, 127, 629-634).

Während die Ausführungen zur Kunst der Steinzeit im Butt Grass' eigene Präferenz für Naturgegenstände und für die zeichenhafte Darstellung komplexer Zusammenhänge bestätigen, beleuchten Erörterungen zur Literatur und Kunst des Barock die von Grass immer wieder verwendeten Stilfiguren der Veranschaulichung: die Allegorie und die Metapher. Besonders interessant ist in dieser Hinsicht die Figurenkonstellation des vierten Romankapitels, die als eine Allegorie der Allegorie verstanden werden kann:

Der Erzähler behauptet, im 17. Jahrhundert zuerst der Dichter Martin Opitz und kurz darauf der Danziger Historienmaler Anton Möller gewesen zu sein. Beide werden von der Küchenmagd Agnes Kurbiella mit Nahrung und Liebe versorgt. Wie in den Ausführungen zum Gedicht „Bei Kochfisch Agnes erinnert" angedeutet, bildet somit erneut eine Frau namens Agnes den Mittelpunkt eines erotischen Dreiecksverhältnisses. Der Butt vermittelt den schon gealterten und in ihrer Schaffenskraft erlahmten Männern die Küchenmagd als Muse. Gleichwohl auch dieser Ver-

\footnotetext{
${ }^{614}$ Vgl. Ohsoling (2007), R 84, Grass (2002a), S. 70-72, S. 155 und Dreher (1982), S. 104 f., Abb. 67 f.

${ }^{615} \mathrm{Vgl}$. Filip (1985), S. 73-121.

${ }^{616} \mathrm{Vgl}$. Domscheit (1985), S. 15.
} 
such seiner Einflussnahme erfolglos bleibt, zeigen der Maler und der Dichter gleichermaßen an Agnes Interesse, weil sie zu allegorischen Deutungen verführt:

Was wir an Agnes mochten, war ihre allegorische Leere. Man konnte in sie hineinlegen, was man wollte, immer ließ sie Bedeutung zu. (Sie sah nicht deutlich aus; sie konnte ungefähr aussehen wie.) (VI 351)

Betrachtet man die Figuren als Stellvertreter innerhalb einer Auseinandersetzung über das Verhältnis der Künste zueinander, bildet Agnes, als Allegorie, das verbindende Element zwischen Opitz, der Literatur, und Möller, der bildenden Kunst. Indem der Autor-Erzähler beide letztgenannten Pole dieses Dreiecks einnimmt, kennzeichnet er die hier geschilderte Ästhetik als seine eigene. Das Verhältnis zwischen seinen beiden Verkörperungen ist dabei kein konfliktfreies, sondern deutet auf eine Polarisierung in Theorie und Praxis hin:

Die Küchenmagd Agnes und wir, sagte der Butt, gaben ein klassisches Dreieck ab: jeder Winkel besetzt. Es kann also sein - oder ist so -, daß ich als Anton Möller die schwangere, von mir geschwängerte Agnes gemalt habe, obwohl ich (wenig später) jener Opitz gewesen bin, der vergeblich versucht hat, dieselbe Agnes - kurz vor meinem üblen Verrecken - in barocke Sprache zu setzen. [...] Der Maler, der Dichter. Die beiden mochten sich nicht. Dem Opitz war der Möller zu derb; Möller sah Opitz als dünnbeinige Theorie. Agnes jedoch mußte einen Speisezettel für beide bedenken und den leicht zu verschreckenden Magen des Opitz und die geschwollene Leber des Säufers schonen. Ich wollte ja Maler und Dichter zugleich sein: leichthin mit Rötelkreide und tüftelnd Versfüße zählend. (VI 350)

Die deutlich hervorgehobene Kennzeichnung des Autor-Erzählers als Schriftsteller und bildender Künstler rekurriert auch in diesem Romankapitel auf die Mehrfachbegabung des realen Günter Grass und lässt Rückschlüsse auf dessen eigene intermediale Ästhetik zu. Grass' Vorliebe für die Allegorie als Stilfigur, die er im Tagebuch einer Schnecke ausführlich behandelt hat, findet schon mit der Anlehnung des Konzeptes des Fisch-Romans an das Märchen Von dem Fischer un syner Fru erneut Anwendung. Sie wird in diesem barocken Kapitel des Butt nur mehr auf den Aspekt der Verbindung von Literatur und bildender Kunst hin ausgelotet. Die Erörterungen fügen sich dabei schlüssig in die Romanfiktion, weil letztere in der Epoche angesiedelt ist, in der das Streben nach einer bildhaften Literatur seinen Höhepunkt erreichte. Berühmte Formeln von Simonides und Horaz, die die enge Verwandtschaft der Künste behaupteten, wurden zum stilbildenden Prinzip erhoben und Emblem-Sammlungen des 15. und 16. Jahrhunderts in abgewandelter Form als Motti vorangesetzt: Die Dichter sollten den Lesern Bilder vor Augen stellen und die Maler in ihren Bildern komplexe Inhalte sprechen lassen. Sowohl Literatur als auch bildende Kunst zielten schließlich gleichermaßen auf die Nachahmung der Natur ab. ${ }^{617}$

Allegorien, Metaphern und Embleme ermöglichten Annäherungen zwischen den künstlerischen Ausdrucksformen und wurden von Grass auch in diesem Sinne genutzt und betont. Das 17. Jahrhundert sollte deshalb nicht als einzige Wurzel für die von Beginn seines Schaffens an präsente Verwendung dieser Figuren betrachtet werden. Die barocke Poetik wurde seit der Arbeit an Aus dem Tagebuch einer Schnecke jedoch zu einer wichtigen Quelle der Reflexion und Bestäti-

${ }^{617}$ Vgl. Schöne (1964), S. $199 \mathrm{f}$. 
gung seiner ästhetischen Vorlieben - das zeigen das Tagebuch ebenso wie der Butt und 1979 die im 17. Jahrhundert angesiedelte Erzählung Das Treffen in Telgte. ${ }^{618}$

Sowohl Möller als auch Opitz figurieren nicht nur als Repräsentanten von Kunst und Literatur, also als Eckpunkte eines allegorischen Dreiecks im Roman, sondern werden auch durch Beschreibungen ihrer Werke als Künstler bzw. Dichter vorgestellt, die gleichermaßen mit bildhaften Vorstellungen hantieren. Anton Möller arbeitete nachgewiesenermaßen seit 1587 in Danzig und galt als einer der populärsten Historienmaler seiner Zeit. ${ }^{619}$ Sein Leben und Werk interessierte Grass bereits in den Sechzigerjahren, als er eine Passage zu Möller in den Roman örtlich betäubt integrierte. Wie bereits in Kapitel IV. erörtert, wird darin die Geschichte eines Dreiecksverhältnisses zwischen Möller, seiner Verlobten und einem Aktmodell als Gleichnis für persönliche und ästhetische Kompromisse erzählt (V 272-274). Unter Möllers Gemälden ist es im Butt zunächst Der Zinsgroschen (1601/1602), den der Erzähler thematisiert. Eine Beschreibung des manieristischen Gemäldes, das eine detaillierte Ansicht des Langen Marktes in Danzig zeigt und den Architekten während des Wiederaufbaus der Stadt nach 1945 als Quelle diente, wird im Roman mitunter dazu genutzt, eine erste Überleitung zwischen der Gegenwartshandlung und der Geschichte von Agnes Kurbiella zu schaffen (VI 143). Die Beschreibung des Bildes wird über die Erwähnung eines anderen Mediums eingeleitet, nämlich als Gegenstand einer Filmdokumentation vorgestellt (VI 141). Der Autor-Erzähler nimmt an diesen Dreharbeiten genauso teil, wie der reale Günter Grass 1975 in dem Dokumentarfilm Teure Geschichte über den Wiederaufbau von Danzig/Gdańsk mitwirkte, den er für den NDR konzipiert hatte. ${ }^{620}$

Einen Überblick über das Gesamtwerk Anton Möllers leistet im Butt der Diavortrag eines Kunsthistorikers vor dem „Feminal“ (VI 320 f.). Das von dem Autor-Erzähler dann am ausführlichsten besprochene Bildnis ist jedoch kein tatsächlich von Möller erhaltenes oder in seiner Existenz überliefertes Gemälde, sondern eine von Grass erfundene allegorische Darstellung. Möllers Arbeitsweise wird an einem angeblich sofort nach Fertigstellung zerstörten Bild demonstriert, das den Künstler als glücklichen und traurigen Vater zeigt. Durch die Ekphrasis des fiktiven Bildes vollzieht Grass keine malerische Allegorie nach, sondern schafft selbständig mittels intermedialer Bezüge eine bildkünstlerische Allegorie der Vaterschaft in seinem Prosatext:

Nach vielen eher braven Rötelzeichnungen malte Möller kurz vor ihrer [Agnes', V. K.] Niederkunft, als wolle er seine bevorstehende Vaterschaft bestätigen, sein Selbstporträt mit farbiger Kreide auf den gewölbten Leib seiner Küchenmagd: ein bewegtes Bild, denn sobald das Ungeborene seine Lage veränderte oder die Glieder erprobte, beulte es das straffe Bildnis des mutmaßlichen Vaters. Er sah bäuerlich drein mit Lachaugen, vielen Plusterbäckchen und rötlichem Bart um den Mund. Danach malte Möller die hochschwangere Agnes, wie sie seine gesunde Physiognomie vor sich hertrug, lebensecht mit Ölfarbe auf Leinwand, ließ aber auf der rechten Bildseite Platz. Gleich nach der Geburt - das Mädchen wurde kein Jahr alt - kreidete er sich zuerst auf den eingefallenen Leib der jungen Mutter, dann setzte er Agnes mit seinem leberkranken Ausdruck auf die noch leere Bildfläche neben den hoffenden Leib (drauf sein Spaßvogelgesicht) in Öl: der pausbäckige und der grämliche Vater.

Doppelt sah sich der Maler Möller. Ihm wurde alles zur Allegorie. Schade, daß das gelungene, bei aller Manieriertheit ansprechende Bild nicht überkommen ist; denn nach dem Tod der kleinen

\footnotetext{
${ }^{618} \mathrm{Vgl}$. Weber (1995), S. $74 \mathrm{f}$.

${ }^{619} \mathrm{Vgl}$. Gmelin (1996).

${ }^{620}$ Vgl. Krason (2010).
} 
Jadwiga soll Möller die Leinwand zerkratzt, durchstoßen, geschlitzt und - sich betreffend - doppelt ermordet haben. (VI 344 f.)

Im Gegensatz zum Werk Möllers wird das Schaffen des Barockdichters Martin Opitz im Butt zunächst nicht für seine Bildmächtigkeit gelobt. Im Gegenteil, es heißt: „Zu klug und zu sehr der ordnenden Vernunft verpflichtet sei er gewesen, um sich kühne, verstiegene und in ihrer Schönheit dumme Metaphern zu leisten“ (VI 322). Seine Übersetzung der 1638 erschienenen Arcadia (1590) von Philip Sidney wird jedoch aufgrund ihrer treffenden Metaphern und Sinnbilder gleich an zwei Stellen des Romans hervorgehoben. Eine in der Übersetzung beschriebene Schlacht hatte dem von Grass geschätzten Grimmelshausen für seine berühmte Schilderung der Schlacht bei Wittstock an der Dosse als Vorbild gedient: ${ }^{621}$

Womöglich habe der junge Grimmelshausen als Augenzeuge von einem Baum herab die Schlachtenszene mit den gedruckten Metaphern verglichen und als tatsächlich erkannt, weil sich die Wirklichkeit, wie ihr von der Literatur vorgeschrieben war, in schrecklicher Anschaulichkeit verhielt; was wieder einmal beweise, daß alles Geschehen schon vorgedruckt sei. (VI 322)

Nicht allein die Wirklichkeitsnähe der Schlachtenschilderung in der Arcadia wird angepriesen, sondern auch deren überzeitliche Gültigkeit - sie charakterisiert nicht nur eine bestimmte, sondern zugleich alle vergangenen und zukünftigen Kriegshandlungen mit. ${ }^{622}$ Auch im „Vatertags"-Kapitel wird Opitz' Übersetzung erwähnt und dabei explizit darauf hingewiesen, dass seine Darstellung eine bildhafte ist. Eine der Protagonistinnen des Kapitels, Susanne alias „Mäxchen“, versetzt sich in die Rolle Grimmelshausens, wenn sie berichtet:

„Im ersten Schreck, und weil im Getümmel kein Aufpassen war, rettete ich mich auf einen Baum“, sagte das kauende Mäxchen, „und las Zeile nach Zeile in einem Buch, das ich dem Profoß geklaut hatte. Und in dem Buch stand genau geschrieben, was auf dem Schlachtfeld geschah: in Bildern und Worten. (VI 592)

Das an Opitz' Übersetzung gelobte Aufzeigen allgemeingültiger Formulierungen für Geschehnisse in „Bildern und Worten“ wird auch von Grass im Butt praktiziert, indem er einzelne metaphorisch oder allegorisch auslegbare Gegenstände und Ereignisse beschreibt und diese auf Vorgänge aus anderen Epochen überträgt. Auch dabei kommen intermediale Bezüge, Hinweise auf Porträtzeichnungen, Situationsskizzen oder Stillleben des Autor-Erzählers, zur Anwendung: Sei es der gegen den eigenen Zustand aufbegehrende Sprung Ilsebills, die der Erzähler gerne „als eine springende Melencolia (frei nach Dürer) in Kupfer stechen" würde und mit dem Sprung minoischer Mädchen und der mittelalterlichen Dorothea vergleicht (VI 424 f.), sei es der Nagel, dem in verschiedenen Epochen Verschiedenes anhing (VI 532) und den der gegenwärtige Künstler ebenso

\footnotetext{
${ }^{621} \mathrm{Vgl}$. Haberkamm (1985).

${ }^{622}$ Vgl. Weber (1995), S. 91-94. Die am Vatertag beteiligten Lesbierinnen werden zugleich als Teilnehmerinnen der Schlacht an der Dosse präsentiert, was die Wiederholungsstruktur von Typen und Ereignissen unterstreicht.
} 
wie Günter Grass „mit weichem Blei oder englischer Stahlfeder“ zeichnet, ${ }^{623}$ oder seien es „viele Stillleben mit Brille[n]“, die jeweils anderen Köchinnen gehörten (VI 565).

Zusammenstellungen von Gegenständen wie die letztgenannten, die assoziativ und über die Kontextualisierung durch das literarische Werk ihre Bedeutung entfalten, sind ein wesentliches Element der bildenden Kunst von Günter Grass. Die Konzentration auf funktionale Gegenstände, Pflanzen und Tieren, die nur selten oder nur ansatzweise in einem definierten Bildraum angeordnet sind, betont die Zeitlosigkeit dieser Darstellungen.

\section{Vatertag}

Das Kapitel „Vatertag“ wurde vor allen anderen Teilen des Butt entworfen, und zwar für ein Medium, dass mit visuellen Bildern arbeitet. Bereits 1961 hatte Grass den Stoff zuerst als Erzählung, dann als Exposé für einen Film skizziert. Mit der Suche nach möglichen Schauplätzen wurde bereits die Realisierung des Projekts in Angriff genommen, dann jedoch nicht weiterverfolgt. Auch der anschließend im Arbeitstagebuch der Jahre 1959 bis 1967 festgehaltene und noch 1973 nicht aus der Hand gelegte Plan, den „Vatertag" als eigenständigen Roman zu gestalten, wurde nicht umgesetzt. ${ }^{624}$

An die filmische Etappe der Entstehungsgeschichte erinnern zunächst die Handlungszeit 1962, die mit den Entwürfen des Filmprojekts zusammenfällt, sowie der handlungsorientierte Aufbau des Kapitels, dem Werner Frizen eine Nähe zur griechischen Tragödie attestiert: ${ }^{625}$ Vier wie Männer gekleidete und als Lesben bezeichnete Frauen wollen ihre Männlichkeit unter Beweis stellen und am Berliner Grunewaldsee Vatertag feiern. Eine von innen, Billy (Sibylle), wird zunehmend von der Gruppe angefeindet, weil sie im Gegensatz zu den anderen drei Frauen als typisch weiblich geltende Verhaltensweisen zeigt. Während eines Mittagsschlafs träumen sich die Frauen in verschiedene Filmrollen. Während einer späteren, nachmittäglichen Ruhezeit ereilt die drei männlich agierenden Frauen der Traum, ein Kind zeugen zu wollen. Aufgewacht, vergewaltigen sie die noch schlafende Billy mit einem Plastikglied. Das entsetzte Opfer wird sich seiner Situation und gleichzeitig seines Frau-Seins bewusst und verlässt die Gruppe. Auf dem Heimweg wird Billy von Motorradfahrern, die sich vorab durch das männliche Gebaren der vier Frauen provoziert gefühlt haben, überfallen, vergewaltigt und ermordet.

\footnotetext{
${ }^{623}$ Entsprechende Bleistiftzeichnungen von Günter Grass aus dem Jahr 1977 sind abgedruckt in: Dreher (1982), S. 117-119.

624 Vgl. Frizen (2015), S. 178-181 sowie: Akademie der Künste, Berlin, Günter-Grass-Archiv, Nr. 1757, Arbeitstagebuch vom 3.6.1959-31.121967, hs.; darin Notizen zum „Vatertag“-Projekt: S. 62-65, S. 80 (Ankündigung als Film), S. 82-93, S. 99-101, S. 165. Das große Potenzial, das Grass der Idee zusprach verdeutlichen die Kommentare auf S. 101 und S. 165, Transkription: V. K.: „Nochmals: Der Film sollte keine Gelegenheitsarbeit werden, sondern mit seinem Gewicht alle Nachgeburten der Hundejahre verdrängen. Von Anfang an zum lesbaren Buch hinarbeiten. Vielleicht mit Klebearbeit in einem [Querformat?] [Abschluss mit Skizze]“ (S. 101, 28.9.63); „Vatertag ist die tragfähigste Romanform. Absolutes Erzählen. / - / Habe eine ,Vatertag-Mappe' angelegt. Will während Theaterproben das Material ausbreiten, damit ich in Amerika beginnen kann. Knapper bis hymnischer Stil. Umfang: schätze 500 Seiten. Termin: (Eine Legislaturperiode). Soll im Herbst 1969 erscheinen." (S. 165, Berlin, 20.10.65).
}

${ }^{625} \mathrm{Vgl}$. Frizen (2015). 
Die vormalige Konzeption des Stoffes als Film wird in die Sprache des Kapitels überführt. In einer Passage wird das ganze Vatertags-Panorama am Grunewaldsee geschildert, indem der Erzähler filmische Mittel sprachlich imitiert:

\begin{abstract}
Und auch Billy (meine Sibylle) hielt sich für berufen, wenn nicht zur Darstellung anderer Rollen, dann doch zur Selbstdarstellung. Oft nach dem Essen, also auch, als überall Vatertag gefeiert und die innen noch roten, erst zum Schluß gesalzenen Steaks und die saftigen Hammelnieren vernichtet waren [...] hat Billy gesagt: „Mein Leben ist ein einziger Film.“ Weshalb jetzt jener Vatertagsausflug zum Grunewaldsee, den zwischen hunderttausend Männern Billy und Fränki, Siggi und das Mäxchen bis zum entsetzlichen Ende mitgefeiert haben, aus wechselnden Perspektiven erinnert werden soll: bäuchlings im zertretenen Gras, von besteigbaren Grunewaldkiefern herab, aus Büschen, vom glatten See aus, wie sie ein Grüppchen am Ufer zwischen anderen Grüppchen sind. Und auch bei den restlichen neunzigtausend und mehr Männern in Spandau, Britz und im Tegeler Forst, an Biertischen und rund um die anderen Seen, sollen Kameramänner dabei sein und draufhalten. Überall getarnte Mikrofone, damit kein Gequatsche verloren geht. Jetzt! Jetzt! Während der Mittagspause... Nach sattem Rülpsen werden ewige Worte gesagt. (Das wollen wir festhalten und später zusammenschneiden.) Ein Bankangestellter, Mitte Vierzig, verkündet am Griebnitzsee überm gewesenen Schnitzel: „Aber so ist das Leben." (VI 596)
\end{abstract}

Der kollektive Mittagstraum der Heldinnen wird als „klassischer Western“ bezeichnet, während Billy in Frauenrollen verschiedener Filmgenres imaginiert wird (VI 597-600). Die Darstellung der Ereignisse als Film macht das Erzählte nicht allein anschaulich, sondern erzeugt ebenso den Eindruck von Authentizität der geschilderten Vorgänge wie eine objektivierende Distanz zu ihnen.

Die Lithografien, die Grass fünf Jahre nach dem Butt unter dem Titel Vatertag veröffentlichte, folgen dieser Filmästhetik nicht. ${ }^{626}$ Die Grafiken sind im Gegenteil gerade deshalb besonders interessant, weil sie sich zum einen, wie an ihren Titeln und ihrer Reihenfolge erkennbar ist, am Handlungsverlauf des Textes orientieren, zum anderen aber kaum narrative Strukturen aufweisen. Auf den Blättern werden einzelne Figuren und Objekte dargestellt, die im Kapitel eine Rolle spielen und nach Art der für Grass' Schaffen typischen Porträts, Tierbilder und Stillleben zusammengeführt. Da diese Bilder keine lyrischen Metaphern visualisieren, die anschließend episch erweitert worden wären, sondern nachträglich zu schon vorliegender Prosa geschaffen wurden und zudem handschriftliche Textpassagen enthalten, sind sie stärker mit bestimmten Zusammenhängen verbunden als viele andere Arbeiten des Grafikers.

In den folgenden Beispielen kommen zahlreiche der bislang behandelten Bildtypen aus dem bildkünstlerischen Schaffen von Grass zusammen. Sie machen deutlich, wie der Künstler seine Figuren durch Attribute charakterisierte, wie er Objekte sogar zu deren Repräsentanten werden ließ, wie er Gegenstände als Handlungsträger inszenierte, Metaphern durch das grafische Veranschaulichen ihrer Bildspender einer Prüfung unterzog, Schrift ikonisch einsetzte, Tierdarstellungen nutzte, um Perspektivenwechsel innerhalb der Erzählung bildhaft darzustellen und Fischgräten als Sinnbild eines tragischen Märchenschlusses verwendete.

Die Grafik Alle vier (Abb. 185) zeigt vier auf stockartigen Beinen stehende Figuren mit herzförmigen Torsi und stabförmigen Armen, deren Abschlüsse Kugeln bilden. Melonen-Hüte auf ihren Köpfen weisen sie als Männer aus. Wie schon in der frühen Vorbereitungsphase des Vogelscheuchen-Balletts von 1957 erinnern auch diese Gestalten an Figuren des Triadischen Balletts von

${ }^{626}$ Der Zyklus Vatertag wurde 1982 in der Edition Monika Beck, Hamburg, veröffentlicht. 
Oskar Schlemmer, das Grass zeitweilig sehr interessierte, weil es menschliche Eigenschaften durch abstrakte Formen und Bewegungen zum Ausdruck brachte. Die Körperhaltung der Dargestellten ist durch expressive Gesten, jeweils ein Heben oder Kreuzen der Arme, geprägt. Die vier lesbischen Protagonistinnen des "Vatertags" werden in diesem Bild als uniforme Wesen dargestellt, deren geschlechtliche Identität und Selbstverständnis lediglich durch ihre Hüte vermittelt wird. Auf die frühe filmische Entwicklungsetappe des „Vatertags“-Kapitels, die mit der Fertigstellung der Hundejahre zusammenfällt, wird durch das Zitat der vormaligen Stilexperimente hingewiesen.

In der Lithografie Mit Pilzhüten (Abb. 186) werden die vier Protagonistinnen durch die Kombination mit Gegenständen aus einem ganz anderen Zusammenhang als „männlich“ gekennzeichnet. Präsentiert werden vier Frauenköpfe mit leicht antikisierten Gesichtszügen, die phallisch geformte Pilze an Stelle von Männerhüten auf dem Kopf tragen. Die unter den Figuren platzierte Handschrift gibt die Passage des Romans wieder, in welcher die verschiedenen, typisch männlichen Kopfbedeckungen der Heldinnen benannt werden:

Billy trug einen Zylinderhut. Fränki saß mit Melone / Siggi hatte sich / ihre Schlägermütze verpaßt. / Dem Mäxchen hing ein / zu großer, um jede Fasson / gebrachter Filz / um die Ohren...

Die phallische Form der Hüte im Bild unterstreicht und verallgemeinert die Funktion der Kopfbedeckungen im Text, die in dieselbe Richtung weist, dort aber etwas weniger plakativ ausgeführt ist. ${ }^{627}$

Noch weiter wird die Charakterisierung von Menschen durch Gegenstände in einem der drei Bilder getrieben, die Grass als Zusammendruck mit dem Titel Siggi und Fränki anfertigen ließ (Abb. 187). Die Darstellung links unten präsentiert vier Tabakpfeifen parallel nebeneinander auf einer geraden Fläche. Der die obere Bildhälfte füllende Text bringt die männlich konnotierten Objekte mit den vier Protagonistinnen des Kapitels in Verbindung. Sie werden zu ihren Stellvertretern:

Billy, Fränki, Siggi, / das Mäxchen / liegen jeder für sich... / Die Gedanken, denen die Vier mittäglich / nachhängen, sind Gedanken, die / in einem klassischen Western zum Konflikt / zwischen Helden führen...

Die rechts von diesem Bild abgedruckte Darstellung zeigt hingegen ein Objekt, das für die Handlung des Kapitels wesentlich ist: Einen künstlichen, mit einer Schnur zu befestigenden Penis, also den Gegenstand, mit dem Billy von ihren Freundinnen vergewaltigt wird. Als Handlungsträger wird er erst bei Kenntnis des Textes deutlich; eine vorausgegangene Verwendung des Objekts lässt im Bild die Kräuselung der Schnur erahnen, die den Eindruck von Abnutzung erweckt.

Die unmittelbare grafische Umsetzung einer Metapher präsentiert eine Lithografie mit dem Titel Sind doch die Frauen wie schon Goethe sagte. ${ }^{628}$ Es handelt sich um eines von drei zusammengedruckten Bildern (Abb. 188). Der Titel des Blattes weist darauf hin, dass darin auf eine Passage angespielt wird, in der von den Protagonistinnen brüskierte Männer ihrer Empörung Luft machen und ihre Haltung gegenüber Frauen im Allgemeinen zum Ausdruck bringen. Einem

\footnotetext{
${ }^{627}$ Vgl. Joch (1997), S. 31.

${ }^{628}$ Vgl. ebd., S. 30.
} 
Goethe-Zitat folgend, gestehen sie diesen zu, sie seien wie silberne Gefäße, in die Männer goldene Äpfel legten (IV 606). ${ }^{629}$ Diese Metapher wird von Grass in einem Bild umgesetzt, das drei mit gemusterten Anzügen bekleidete Männer an einem runden Tisch zeigt, über den ein vierter Mann eine wie zum Gegenstand erstarrte, nackte Frau schiebt. Ebenso wie Grass in vielen seiner Bilder eigenen Stilfiguren überprüfte, indem er ihre Bildspender visualisierte, fügte er auch hier beide Aspekte der Metapher zusammen; in diesem Fall verdeutlicht die grafische Darstellung die Absurdität des Sprachbildes und die dahinterstehende Misogynie. ${ }^{630}$

In der Grafik Streit (Abb. 189) setzte Grass Schrift und Bild so miteinander in Verbindung, dass die Texte den dargestellten, sich prügelnden Frauen als Dialogfetzen zugeordnet werden können und damit auf die filmisch-dramatische Ursprungsgattung des Textes rekurrieren. Diese an einen Comic erinnernde Verwendung der Schrift ist eine Erweiterung des Umgangs mit Wort und Bild in Mit Sophie in die Pilze gegangen.

Mit Darstellungen von Krähen auf dem Blatt Die Krähen folgten griff Grass das Motiv der Vögel als emotionslos-distanzierte Beobachter tragischer Ereignisse aus den Hundejahren wieder auf (Abb. 190). Eine Verwandtschaft zu Vogeldarstellungen um 1955 wird auch bei dieser Grafik dadurch erkennbar, dass die Tiere in ähnlicher Körperhaltung - mit anliegenden Flügeln und nach oben gestrecktem Schnabel - gezeigt werden (vgl. S. 111, Abb. 68 f.).

Billys Tod schließlich, wird auf dem Blatt War das noch ein Mensch (Abb. 191) durch die Kombination eines zerschlagenen Frauengesichts mit den Gräten eines Butts zum Ausdruck gebracht. Auch hier verdeutlicht das nackte Fischskelett das Ende einer Geschichte und als Vanitasmotiv zugleich ihren tödlichen Abschluss.

Wie demonstriert werden konnte, dient die Beschreibung des Fischverzehrs bereits in der Blechtrommel zur Veranschaulichung eines Handlungsverlaufs mit unglücklichem Ausgang, den das Fischskelett als Zeichen der Vergänglichkeit markiert. Ein Ursprung dieser allegorischen Schilderung liegt in den frühen Bildwerken, die Grass in seiner Studienzeit anfertigte. Im Anschluss an die Verwendung des Fischmotivs in der Blechtrommel und im Butt visualisierte Grass das Skelett des Fisches in einer Reihe von Radierungen und Lithografien wie im Vatertag-Zyklus von 1982.

Die in der Konzeptionsphase des Butt entstandenen grafischen Darstellungen von Fischen widmen sich dem Thema der weiblichen und männlichen Geschlechtlichkeit, vor allem aber zeigen sie Tiere in Konfrontation mit Menschen und Objekten. Ähnlichkeiten und Gegensätze zwischen ihnen wurden zeichnend ausgelotet, um bestimmte menschliche Eigenschaften besonders hervorzuheben. Im Roman werden die Ergebnisse dieser Formuntersuchungen sprachlich realisiert, indem innere Vorgänge und Charaktermerkmale von Figuren über Beschreibungen ihres Äußeren und Anverwandlungen von Mensch- und Tierkörpern festgehalten werden. Die Physiognomie des Butts eignete sich besonders für einen unsterblichen, weil stets uralt aussehenden Protagonisten. Die Berufung auf das sich immer wieder ereignende Märchen und den Mythos

\footnotetext{
${ }^{629}$ Vgl. Eckermann (1981), Kap. 59.

${ }^{630} \mathrm{Vgl}$. Günter Grass in seinem Text für das Kunstmagazin art, April 1979: „Mehr als die eindeutige Linie ist der Vers durch das Geschwätz beliebiger Deutungen gefährdet. Erst ins grafische Bild übersetzt beweist die Wortmetapher, ob sie Bestand hat." (XI 1048).
} 
komplettiert das kreisförmige Geschichtsbild, das das Buch propagiert und verbindet seine zahlreichen Handlungsstränge.

Allegorische Gestaltungselemente sind Teil der anschaulichen Ästhetik des Butt. Die visuelle Vorstellbarkeit des Beschriebenen wird immer wieder durch die Auseinandersetzung mit bildender Kunst bekräftigt. Thematisiert wird dabei die Nähe der Kunst zur Sprache, ihre Funktion des sinnlichen Abbildens und Veranschaulichens abstrakter Inhalte und Begriffe in Form von Zeichen, Allegorien und Metaphern sowie die ihr gegebene Möglichkeit, überzeitliche und aussagekräftige Details des Weltgeschehens herauszugreifen und komprimiert darzustellen. Die im Roman hervorgehobenen Charakteristika der bildenden Kunst kennzeichnen auch Günter Grass' bildkünstlerische Arbeiten. Aus dem in innen erkennbaren Anspruch der Universalität erklärt sich Grass' Wiederaufgreifen und Variieren bestimmter Motive wie der Aale oder des Butts von den Fünfziger- bis in die Siebzigerjahre und darüber hinaus: Es handelt sich um Motive, die existenziell Menschliches zeitunabhängig zum Ausdruck bringen und deshalb kein Verfallsdatum aufweisen.

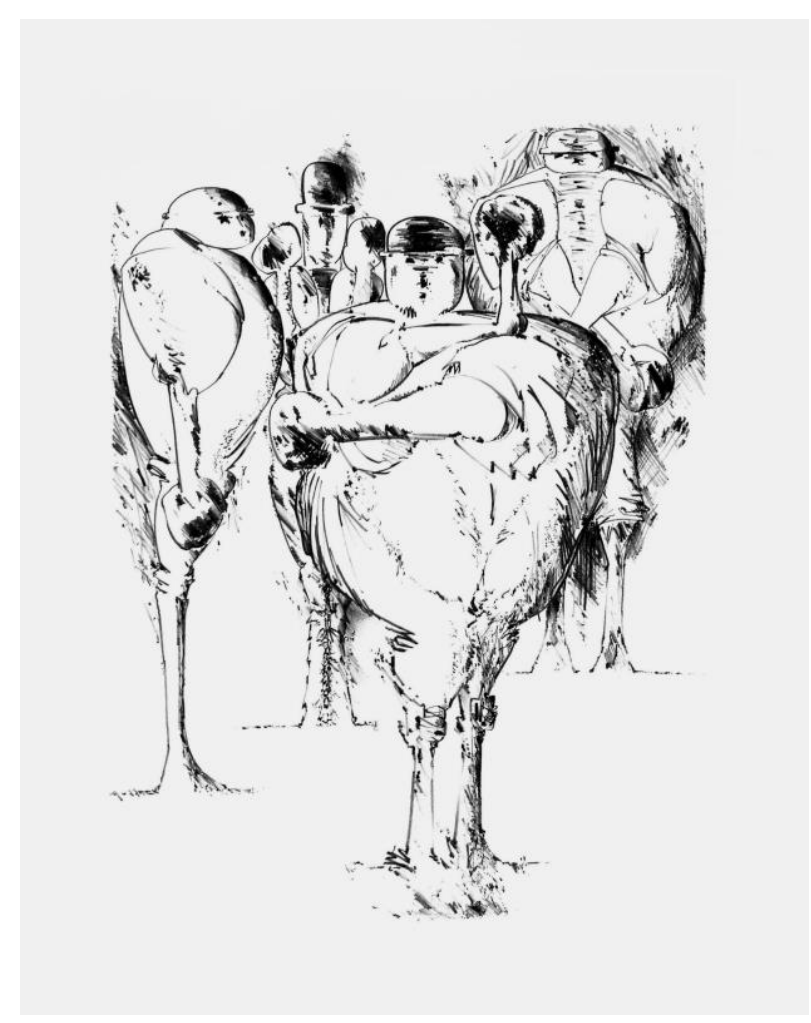

Abb. 185, Vatertag, 1982, Blatt II/XXII, Alle vier, 1982, Lithografie 


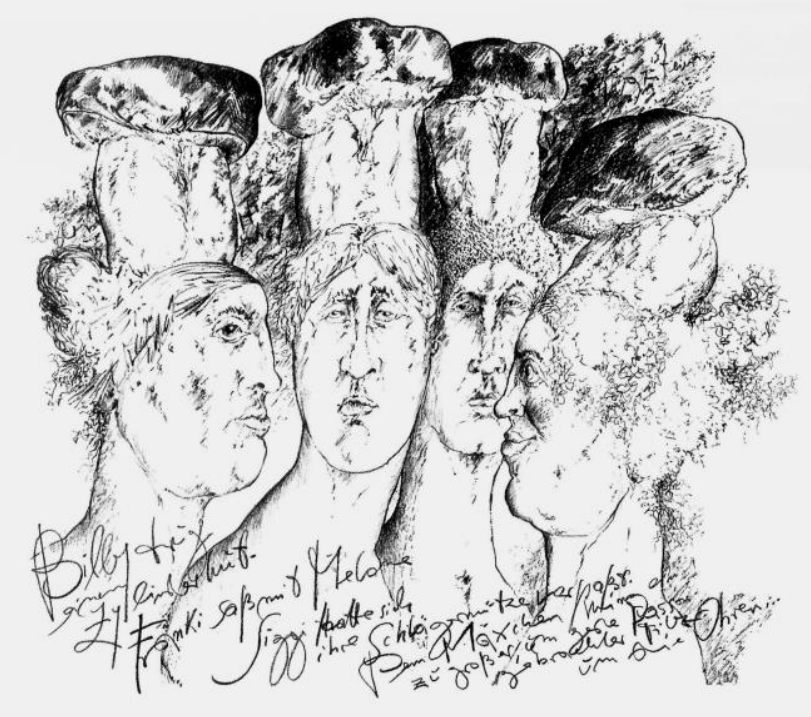

Abb. 186, Vatertag, 1982, Blatt III/XXII, Mit Pilzhüten, 1982, Lithografie
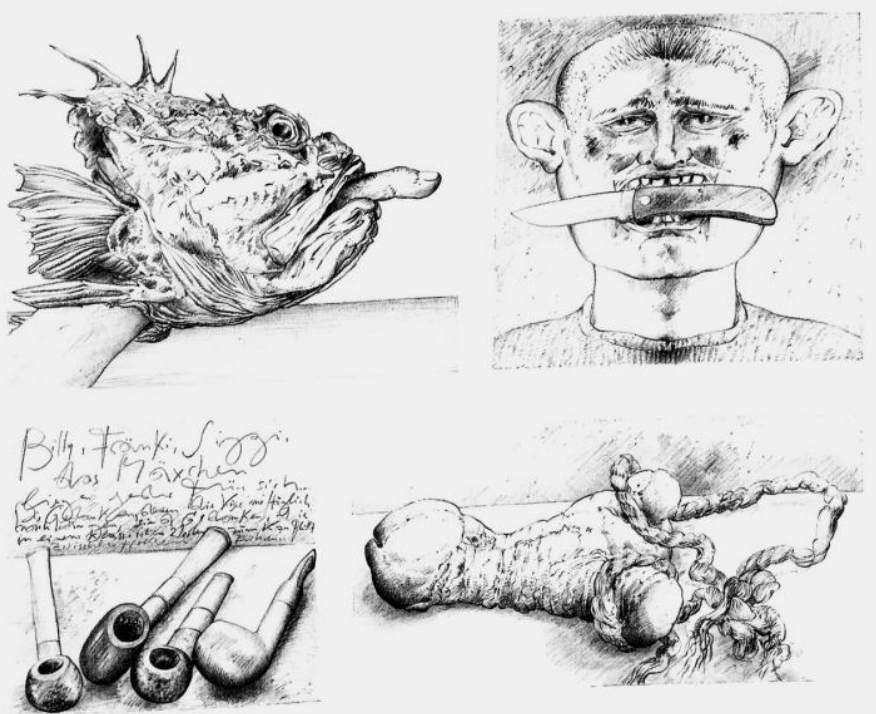

Abb. 187, Vatertag, 1982, Blatt XII/XXII, Siggi und Fränki, 1982, Lithografie 


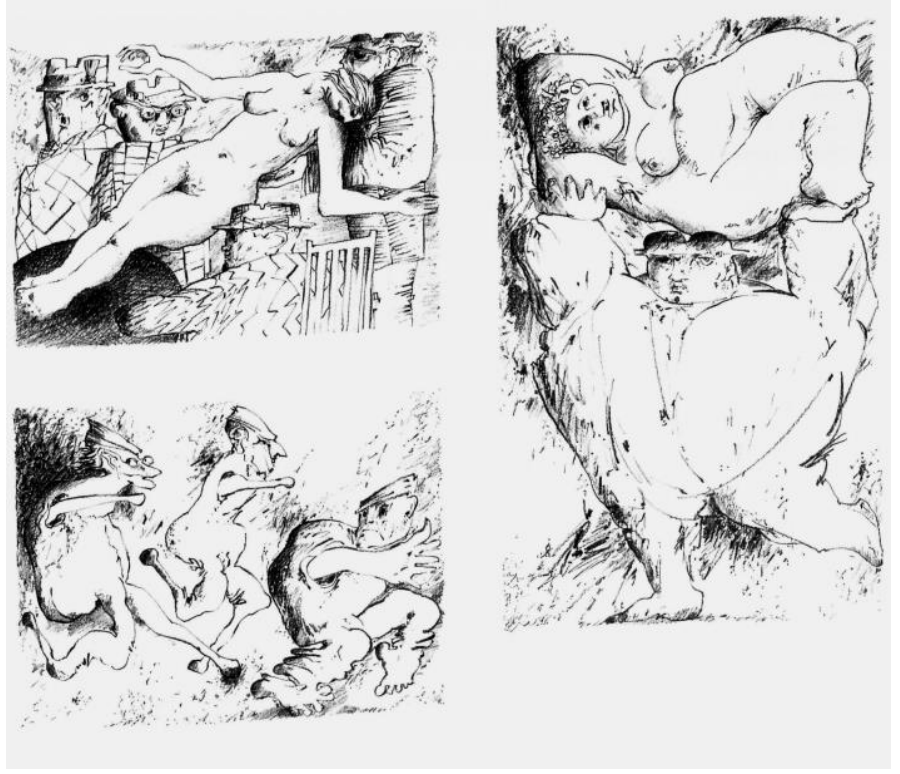

Abb. 188, Vatertag, 1982, Blatt XIV/XXII, Sind doch die Frauen wie schon Goethe sagte, 1982, Lithografie

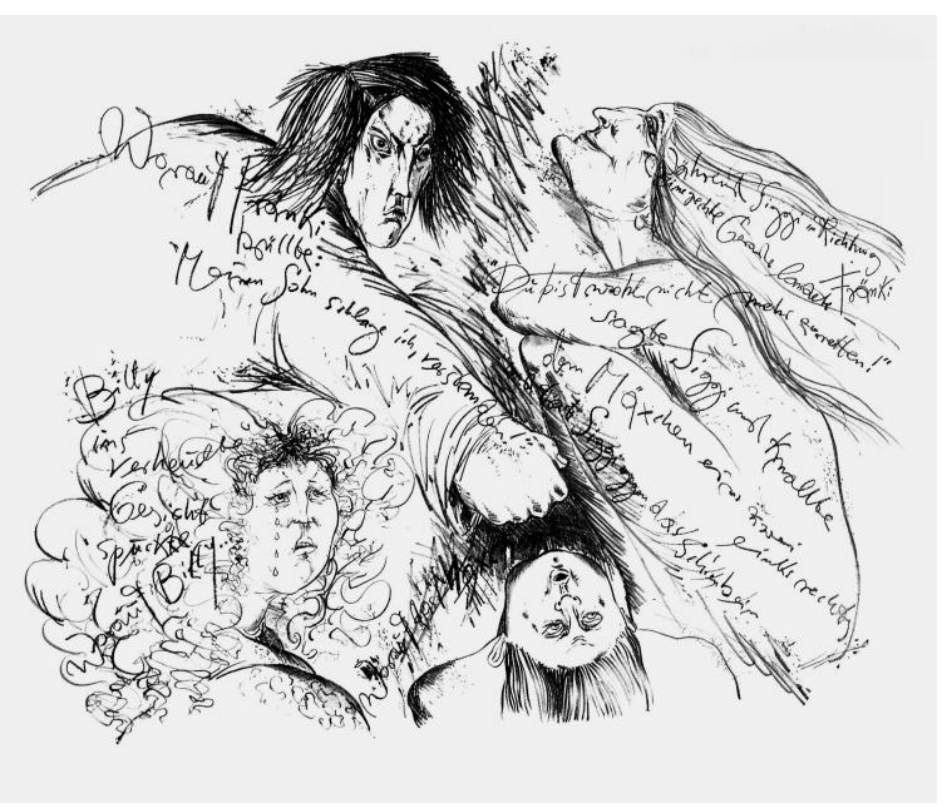

Abb. 189, Vatertag, 1982, Blatt XV/XXII, Streit, 1981, Lithografie 

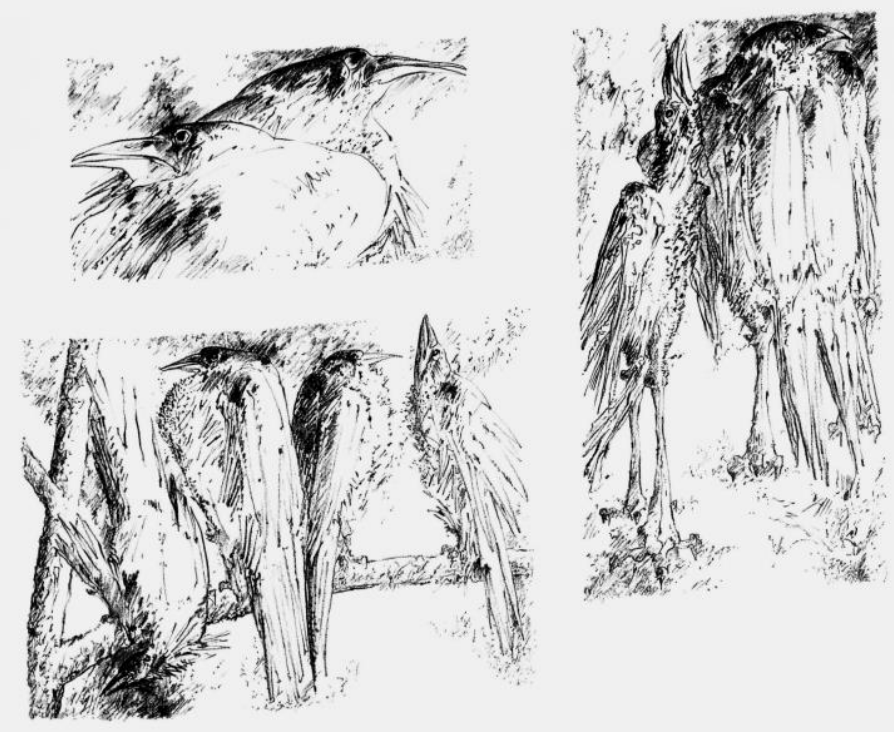

Abb. 190, Vatertag, 1982, Blatt XVI/XXII, Die Krähen folgten, 1981, Lithografie

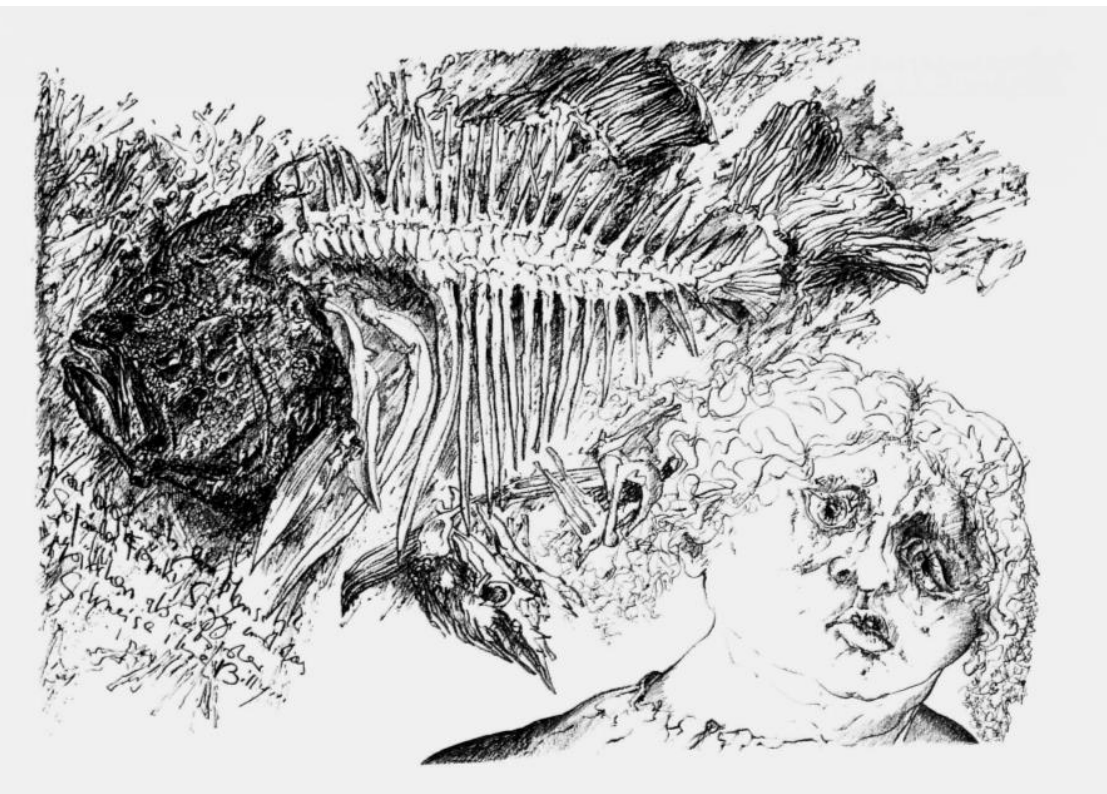

Abb. 191, Vatertag, 1982, Blatt XX/XXII, War das noch ein Mensch, 1981, Lithografie 


\section{ABSCHLUSS MIT AUSBLICK}

Die Zusammenhänge von Literatur und bildender Kunst in Günter Grass' Schaffen, das sollte in der vorliegenden Untersuchung im Umkreis der ,Danziger Trilogie', des Tagebuchs einer Schnecke und des Butt deutlich geworden sein, lassen sich nicht in wenigen Sätzen charakterisieren, geschweige denn auf einen einzigen Punkt bringen. Sie weisen sowohl Konstanten auf, die sich bereits während seines Kunststudiums ausgebildet haben, als auch Entwicklungen, die in den späteren Werken des Schriftstellers und Künstlers weiterverfolgt werden können.

Bereits Grass' in Düsseldorf entstandene Arbeiten zeigen sein immer klarer hervortretendes Interesse an der Struktur menschlicher Körper und ihrer Umgebung. Dabei griff er zusehends auf kubistische Stilelemente zurück und zerlegte das Dargestellte in Teilflächen und Teilformen. In vielen seiner Zeichnungen verselbständigen sich einzelne Elemente der präsentierten Gegenstände zu eigenständigen Objekten und es entstehen Werke, die teils an bekannte surrealistische Arbeiten, teils an solche der Art Brut oder der Neuen Sachlichkeit erinnern. In Berlin gestaltete Grass als Schüler von Karl Hartung vor allem auf die Grundform der dargestellten Gegenstände konzentrierte, stereometrisch abstrahierende Tierplastiken. Auch seine Zeichnungen fokussieren die grundsätzliche Beschaffenheit von Tierkörpern. In demselben Zeitraum gestaltete er Metamorphosen zwischen Tier und Mensch, die als widerspruchsreiche Verbindungen zweier Gegenstände Berührungspunkte mit den kühnen Metaphern seiner zwischen 1952 und 1954 entstandenen Gedichte aufweisen. Eine der wichtigsten Anregungen zu dieser Kompositionsmethode war die Kombinatorik des Surrealismus und insbesondere die Bildwelt Salvador Dalís, zu welcher sich auch in späteren Arbeiten des Schriftstellers und Künstlers immer wieder Parallelen finden lassen. Seine Figuren erinnern in ihrer universalen Gestaltung hingegen bis in die Sechzigerjahre hinein oftmals an neoklassische Werke Pablo Picassos.

In den lyrischen Texten und Zeichnungen zu den Vorzügen der Windhühner (1956) realisierte Grass erstmals durchgängig dieselben Motive in Wort und Bild. Einzelne alltägliche Objekte, deren Schilderungen im Gedicht als Bildspender einer Metapher oder einer Allegorie Verwendung finden, gab der Grafiker besonders in den frühen zeichnerischen Entwürfen zur Publikation nahezu unverfremdet wieder und fügte sie zu einer Bildsprache zusammen. In einigen Zeichnungen kombinierte er figürliche Elemente mit Schriftzeichen und richtungsweisenden Symbolen, die den Zeichencharakter der Objektdarstellungen betonen und sich selbst umgekehrt auch als ikonische Zeichen vermitteln - das verwandtschaftliche Verhältnis zwischen Bild und Schrift wird auf diese Weise unterstrichen.

Wie bereits Heinrich Detering bemerkte, rückten Lettern und Ziffern in Grass' späteren Arbeiten noch weiter ins Zentrum: ${ }^{631}$ Federzeichnungen einzelner mit handschriftlichen Gedichtzeilen und Landschaftsandeutungen umfangener Zahlen sind jedem der dreizehn Sonette des Gedichtbandes Novemberland (1993) beigefügt, auf dessen Umschlag eine entsprechende Darstellung der Ziffer „13“ zu sehen ist (Abb. 192); im Titelbild zu Mein Jahrhundert (1999) werden die Jahreszahlen, die die Erzählungen zu jedem Jahr des vergangenen Jahrhunderts bestimmen, zu einer schwarz-rot-goldenen Ziffernhalde angehäuft (Abb. 193); eine aquarellierte Buchstabenreihe

${ }^{631}$ Vgl. Detering (2016). 
schmückt den Umschlag zum autobiografischen Buch Grimms Wörter (2010), in welchem zudem jedes Kapitel von einer Aquarelldarstellung eines einzelnen Buchstabens eingeleitet wird, welche auf diese Weise sowohl als Synthese von Sprache und Bild als auch als Material des Schriftstellers in Erscheinung tritt (Abb. 194). Das von Grass entworfene Denkmal der Göttinger Sieben aus dem Jahr 2011 verbindet Buchstabe und Zahl schließlich als Repräsentanten von Literatur und Geschichte (Abb. 195).

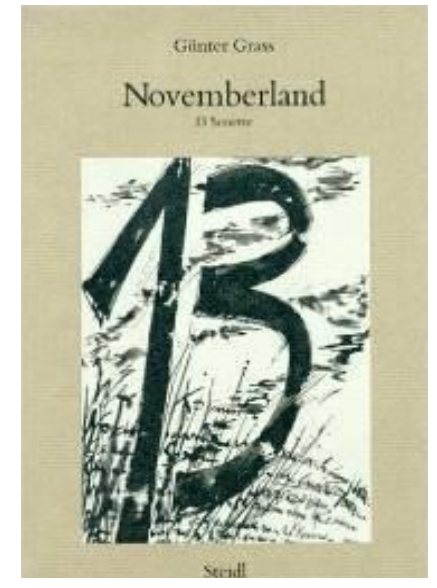

Abb. 192, Novemberland, Göttingen 1993, Umschlag, Titelbild

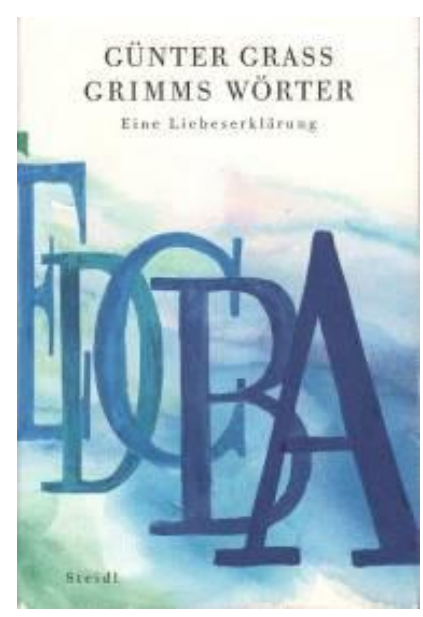

Abb. 194, Grimms Wörter, Göttingen 2010, Umschlag, Titelbild

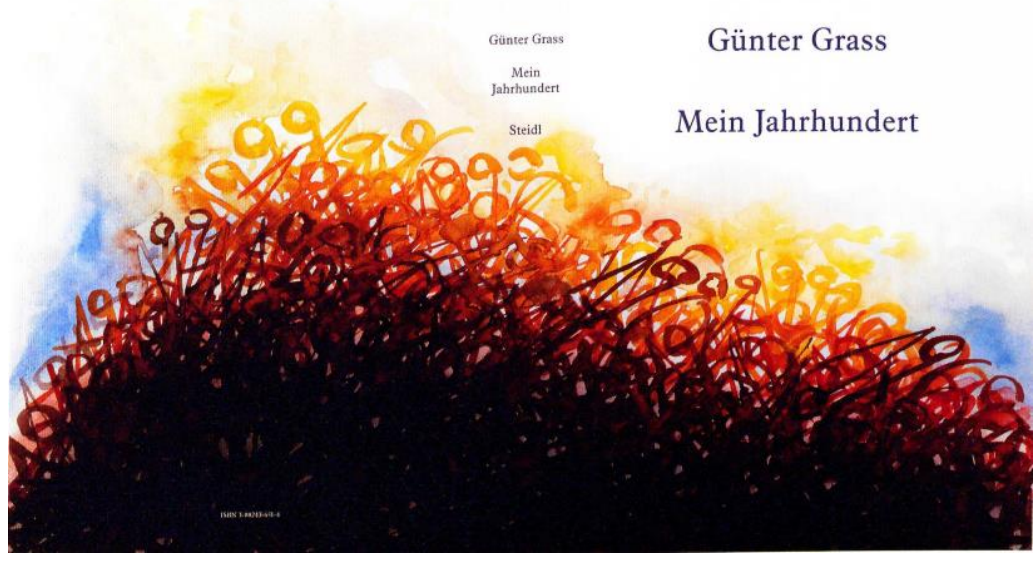

Abb. 193, Mein Jahrhundert, Göttingen 1999, Umschlag

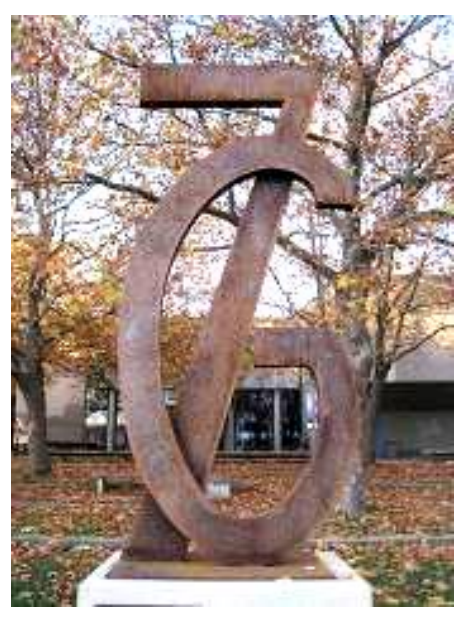

Abb. 195, Denkmal der Göttinger Sieben, Göttingen, 2011, Stahl 
Zahlreiche der in der vorliegenden Studie behandelten Grafiken von Günter Grass verdeutlichen über die Kombinationen von Gegenständen, die verschiedenen Kontexten entnommen sind, aber äußerliche Ähnlichkeiten aufweisen, einen überraschenden inneren Zusammenhang zwischen diesen Objekten. Die Motivkompositionen lösen auf Lebenserfahrung und Allgemeinwissen beruhende Assoziationen aus, können von Fall zu Fall aber auch mit Bedeutungen aus der Literatur-, Kunst- und Kulturgeschichte in Verbindung gebracht werden. Grass' bebilderte Gedichtbände geben ihren Betrachterinnen und Betrachtern zu verstehen, dass auch den sprachlich realisierten Motiven ein bildnerischer Einfall zugrunde liegt, der - ob tatsächlich vorab bildkünstlerisch ausgeführt oder nicht - durch die Betätigung des Dichters als bildender Künstler maßgeblich befördert wurde.

Das Aufzeigen von Formanalogien zur Veranschaulichung eines komplexen Inhalts spielt nicht nur in den Vorzügen der Windhühner eine Rolle, sondern ebenso in Grass' Nonnendarstellungen, den Zeichnungen zu Bachmanns Ein Ort für Zufälle, den Akten mit Schnecken und Pilzen sowie den Gegenüberstellungen von Menschen und Fischen zum Butt. Es bildet damit eine entscheidende Konstante der in dieser Arbeit betrachteten Werke. In Zeichnungen nachvollzogene Ähnlichkeiten der äußeren Erscheinung verschiedener Objekte führten den Grafiker zudem von einem Motivkomplex zum nächsten, etwa von Vögeln zu Nonnen.

Es verwundert nicht, dass Grass, der das Tierbild als Student in Berlin zu seinem bevorzugten Sujet gewählt hatte, auch in seinen Texten und zu ihnen entstandenen Bildwerken Tiermotive realisierte. Vom Tagebuch einer Schnecke über den Butt bis hin zur Rättin prägten sie seine Literatur in immer stärkerem Maße und wurden in beiden letztgenannten Büchern als sprechende Prosafiguren gestaltet. Wie den Beschreibungen dieser besonderen Tiere in den Texten entnommen werden kann, leitete der Schriftsteller allegorische Bedeutungen mitunter aus der äußeren Erscheinung der Tiere ab, welche er als Grafiker und Bildhauer genau studiert hatte. Indem Zusammenstellungen von Tier- und Pflanzenmotiven abstrakte Begriffe zum Ausdruck bringen, gewinnen die Darstellungen an Zeitlosigkeit und Allgemeingültigkeit, ohne gleichzeitig ihren Wirklichkeitsbezug einzubüßen.

Meist stehen Grass' grafische Arbeiten seinen Gedichten nahe, in denen Metaphern und Allegorien konzentriert auftreten. Da er seine Themen zuerst lyrisch und dann dramatisch und episch gestaltete, sind seine bildkünstlerischen Arbeiten häufig am Anfang seiner Großprojekte angesiedelt. Die gezeichneten Entwürfe zum Tagebuch einer Schnecke zeigen, dass die Grafiken des Schriftstellers auch als Strukturmodell für ein Prosakorpus fungieren konnten. Das sollte auch später, im Zuge der Arbeit an Beim Häuten der Zwiebel (2006) der Fall sein (vgl. S. 217, Abb. 131), während andere Entwürfe wie Grass' Arbeitspläne zur Rättin (1986) erst nach Abschluss eines Romanmanuskriptes um ihrer selbst willen grafisch ausgestaltet wurden (Abb. 196). Eine intensive Auseinandersetzung mit allen von Grass gezeichneten Plänen steht noch aus und sollte in einer separaten Untersuchung Platz finden. 


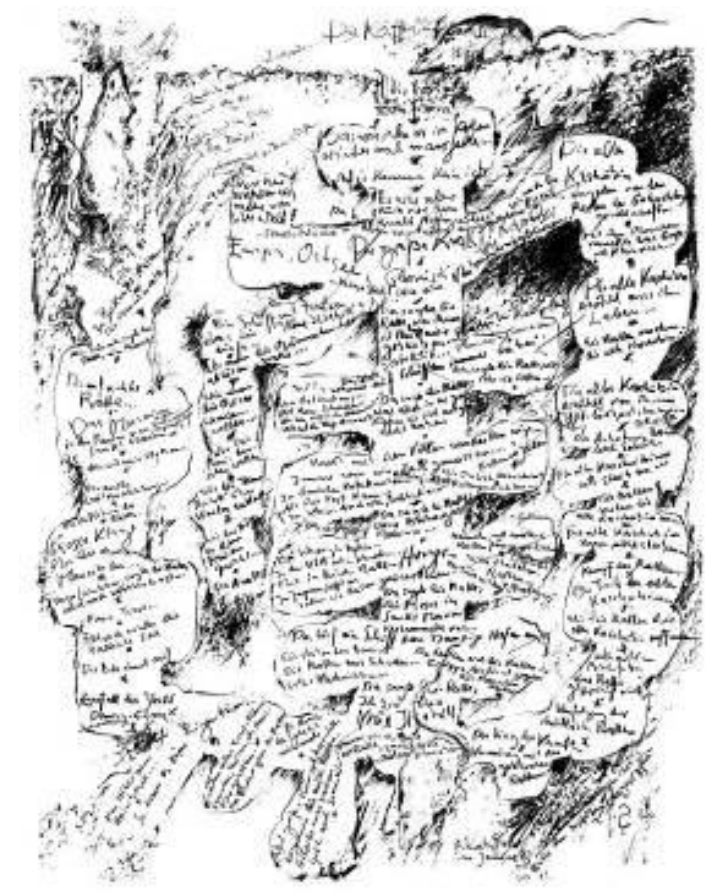

Abb. 196, Die Rättin - Plan II, Wewelsfleth, 1983, Lithografie

In Umkehrung zu den Arbeitsplänen komprimieren Grass' Buchumschläge und Zeichnungen zu fremden und eigenen Erzählwerken die Inhalte seiner Prosa zu zeichenhaften Darstellungen. Manchmal stehen sie mit einer bestimmten Stilfigur in Verbindung, die im Prosatext enthalten ist und als zusammenfassendes Motto einer Veröffentlichung gelten kann wie unter den hier behandelten Arbeiten zum Beispiel die tanzende Nonne zum Ballerina-Essay. In späteren Arbeiten wird diese Art der Buchgestaltung ebenfalls genutzt, besonders eindrucksvoll im Fall des Umschlages zu der Erzählung Das Treffen im Telgte (1979): Die für die Gestaltung des Buches verwendete Radierung versinnbildlicht durch die Darstellung einer Schreiberhand, die aus einer Geröllmasse ragt, die Situation von Schriftstellerinnen und Schriftstellern in der Nachkriegszeit (Abb. 197) sowohl die Lage der Dichter nach Ende des Dreißigjährigen Krieges, die im Buch explizit thematisiert wird, als auch die Lage der nach Ende des Zweiten Weltkrieges Schreibenden, mit der es sich implizit beschäftigt.

Innerhalb des in der vorliegenden Studie behandelten Schaffenszeitraums hatte Grass noch keine Bildwerke in seine eigenen Prosapublikation integriert. Der Zyklus Vatertag aus dem Jahr 1982 ist ein erster Ansatz zu dieser Kombination. Bei der Niederschrift des Romans Die Rättin (1986) zeichnete Grass Figuren und Szenen in das handschriftlich in einem Blindband festgehaltene Manuskript und führte diese Arbeitsweise bei der Arbeit an den folgenden Prosaprojekten fort. Bilder finden auch in folgende Prosaveröffentlichungen Eingang: In das indische Tagebuch Zunge zeigen (1988), in Mein Jahrhundert (Erzählungen, 1999) sowie in Form von Variationen eines einzelnen Motives in die Erzählung Unkenrufe (1992) und in die sogenannte Erinnerungstrilogie (2006-2010). Die Jubiläumsveröffentlichung der Hundejahre (2013) nimmt schließlich 136 detaillierte Radierungen auf. Eine Untersuchung der Manuskriptzeichnungen zur Prosa und ihres Verhältnisses zu den Aquarellen und Grafiken der Buchfassungen sowie separat entstandenen Bildern 
steht noch aus und ist gerade aufgrund der auf den ersten Blick erkennbaren Unterschiede zwischen den jeweiligen Text-Bild-Bezügen vielversprechend.

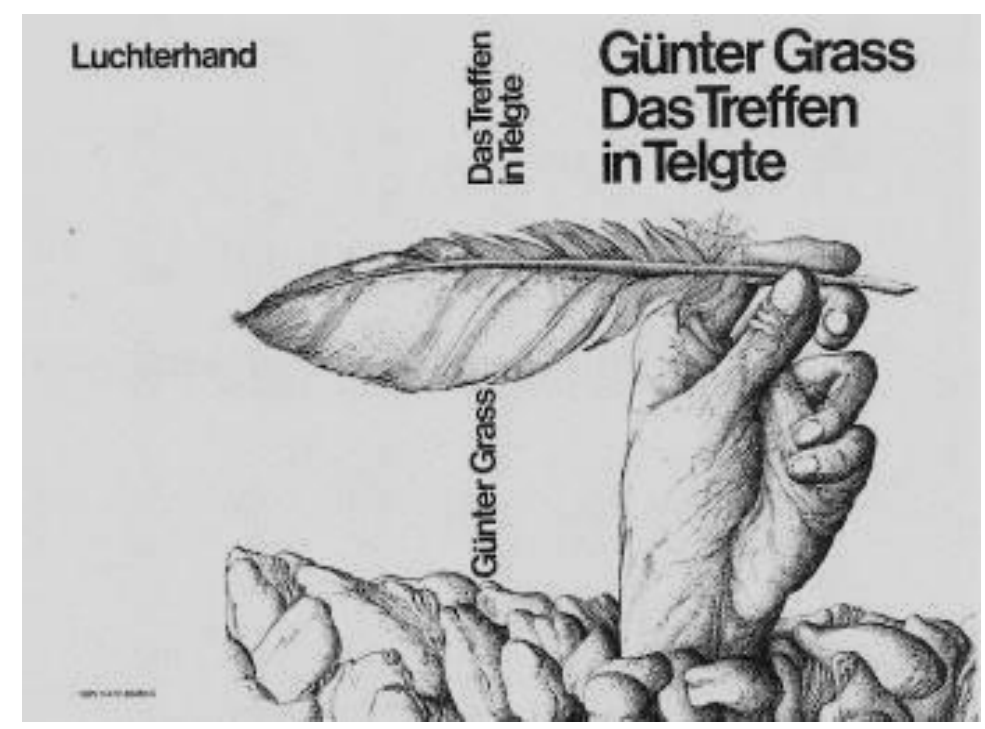

Abb. 197, Das Treffen in Telgte, Darmstadt 1979, Umschlag

Sei es in Kombination mit Lyrik oder Prosa - indem Grass seinen Texten in der Buchgestaltung Grafiken gegenüberstellte, hob er den visuellen Ursprung seiner sprachlichen Bilder hervor. Grass' Literatur enthält zudem Appelle an das genaue Hinsehen, die zusätzlich eine Brücke zwischen den literarischen und bildkünstlerischen Schilderungen der Wirklichkeit schlagen. Bereits in den Gedichten zu den Vorzügen der Windhühner wird die visuelle Wahrnehmung der Wirklichkeit betont, da die Schilderungen des lyrischen Ich oft ohne rationale Bezüge und Einordnungen auskommen.

In den hier untersuchten Prosawerken bettete Grass seine Motive zusammen mit Hinweisen auf ihre bereits erfolgte oder erst angedachte Darstellung in der bildenden Kunst ein. Eine Legitimation innerhalb der Erzählfiktion erhalten diese Verweise an erster Stelle dadurch, dass die betreffenden Erzähler als bildende Künstler vorgestellt werden oder zumindest Studiensemester im Fach Kunstgeschichte vorweisen können. Die Texte enthalten Ekphrasen realer bildnerischer Arbeiten von Günter Grass, erfundener und an die eigene Ästhetik angelehnter Kunstprodukte sowie Beschreibungen bekannter Werke der Kunstgeschichte, die der Autor durch freie Variationen und Aktualisierungen zu eigenen sprachlich geschaffenen Kunstwerken umgestaltete. Bildbeschreibungen fungieren in Grass' Prosa als Verdichtungen von Inhalten, die sich aus dem Erzählfluss herausheben. Diese Darstellungsweise suggeriert den Leserinnen und Lesern, die Schilderungen seien als visuelle Bilder wahrzunehmen. Ebenso wie lyrische und dramatische Passagen in Grass' Erzähltexten oft direkt eingefügt und nicht episch adaptiert werden, bleiben tatsächliche oder erfundene Kunstwerke in seinen Erzählungen und Romanen, gleichwohl literarisch umgesetzt, als Bilder vorstellbar. Ihre Eigenschaft, visuell erfahrbare Elemente miteinander zu verknüpfen, bleibt auch in der Prosa erhalten, komprimiert Handlungen und Inhalte und fordert, den Lesefluss verlangsamend, zum Nachdenken auf.

Diese Bezüge zur bildenden Kunst setzt Grass in seinen Essays und Erzählwerken bis 1977 auch ein, um Kennzeichen seiner Poetologie allegorisch darzustellen. Ferner dient die Auseinanderset- 
zung des Schriftstellers mit der Kunst Schlemmers und Kramers, mit der Fotografie, mit der Kunst der Steinzeit, der frühen Neuzeit und den Ideen der Romantik dazu, einzelne Aspekte seiner Bildkunst zu betonen und schärfer zu umreißen. Diese Akzentuierungen sind auch in den zeitgleich entstandenen grafischen Arbeiten erkennbar - in den abstrahiert und mechanisiert dargestellten Vogelscheuchen, in dem den Naturbezug der Zeichnungen besonders betonenden Fotobildband von 1973, in den an Emblemen orientierten Schnecken-Zeichnungen, in den surrealen Pilzdarstellungen und in den sexuell konnotierten Fisch-Kompositionen.

In seiner Prosa legte Grass solche umfangreichen Verweissysteme zur bildenden Kunst nach der Veröffentlichung des Butt nicht mehr in derselben Dichte an. Auf den Roman folgen keine Erzählwerke mehr, in welchen bildende Künstler durchgehend eine so herausragende und auf das eigene bildkünstlerische Schaffen bezogene Rolle spielen, wie in den Hundejahren, dem Tagebuch einer Schnecke und dem Butt. Eine Ausnahme bildet, und das ist naheliegend, das autobiografische Buch Beim Häuten der Zwiebel, in welchem Grass' Lehrjahre und damit sein Interesse für die bildende Kunst und seine Ausbildung zum Bildhauer und Grafiker viel Raum einnehmen. ${ }^{632}$ Intermedialität bleibt jedoch auch für die späteren Veröffentlichungen des Autors kennzeichnend. Immer werden die im Umfeld eines literarischen Werkes geschaffenen bildkünstlerischen Arbeiten auch durch entsprechende Verweise in den Text eingebunden und stets wird seine Prosa zu Werken der Kunstgeschichte in Beziehung gesetzt. Das sei an den beiden epischen Großprojekten demonstriert, die Grass nach dem Butt schuf: Die Rättin und Ein weites Feld.

In der Rättin thematisierte der Schriftsteller die Biografie des Kunstfälschers Lothar Malskat und damit den Zeitgeist der Nachkriegszeit, der "falschen Fuffziger“. Nachträglich grafisch umgesetzte Bildkompositionen, die Ratten zum Gegenstand haben, tauchen, wenn auch nicht als Bilder markiert, in einzelnen Passagen als Beschreibungen auf, die dem Autor-Erzähler auf einem Bildschirm präsentiert werden.

Zu Ein weites Feld hatte Grass vorab vor allem Zeichnungen und Lithografien des Protagonisten-Paars Fonty und Hofthaler geschaffen und die Beschreibungen dieser Figuren im Text als Schattenrisse und „Bilder" eingeführt. Sowohl gezeichnete als auch beschriebene Bilder werden ferner mit den „Neuruppiner Bilderbögen“ in Verbindung gebracht. ${ }^{633}$ Darüber hinaus behandelt Grass im Erzählwerk die von Malern wie Max Liebermann geschaffenen Porträts Fontanes, um den Lesenden die Figur „Fonty“ vor Augen zu stellen (VIII 44-68).

Grass' Ästhetik wird von einem an den Begriff der Gegenständlichkeit gebundenen und mit den Jahrzehnten schriftlich weiterentwickelten Programm hinterfangen. Bereits sein Lehrer Otto Pankok propagierte ein Kunstverständnis, welchem zufolge nur die figurative Kunst einen humanistischen Grundzug haben könne. Eine moralische und politische Durchdringung von Ästhetik hatte Grass dann verstärkt während des Berliner Kunststreits von 1955 erfahren. Nicht unmittelbar, aber nach und nach, wurde die Gegenständlichkeit für Grass in der zweiten Hälfte der Fünfzigerjahre zu einer Bedingung für eine Kunst, die sich mit der Realität und insbesondere mit der Kriegsschuld auseinandersetzen konnte. Bereits seine Zeichnungen zu den Vorzügen der Windhühner gaben diese Richtung vor: Indem der Dichter abstrakte Begriffe und Ideen mittels alltägli-

\footnotetext{
${ }^{632}$ Vgl. Krason (2013).

${ }^{633} \mathrm{Vgl}$. Schirrmacher (2015).
} 
cher, aber widerspruchsreicher Szenarien in Wort und Bild zur Darstellung brachte, verdeutlichte er seine antimetaphysische und antiideologische Grundhaltung. In der zeitgenössischen Gesellschaft präsente Gedankenkonstrukte wurden auf diese Weise entlarvt und der dazu notwendige bildnerische Denkprozess des Grafikers und Dichters durch die bildkünstlerische Buchgestaltung für die Rezipientinnen und Rezipienten transparent und überprüfbar.

Während der Jahre seines intensiven politischen Engagements setzte Grass diese Methode nur in geringerem Maße ein: Seine Literatur der späten Sechzigerjahre behandelt ihre Themen in dialektischer Form und enthält seltener Metaphern und Bezüge zur bildenden Kunst. Das bildkünstlerische Schaffen stellte Grass aus Zeitmangel gleichzeitig nahezu ein - eine Koinzidenz, aus der hervorgeht, wie unabdingbar seine Arbeitsweise und die Form des aus ihr hervorgehenden literarischen Kunstwerks miteinander verknüpft waren. Diese Zäsur in Wort und Bild ging mit einer starken Betonung des rationalen Denkens und der Aufklärung in Grass' politischen Reden und ebenso in seiner Lyrik und Prosa einher. Bereits mit dem Tagebuch einer Schnecke wurde diese Reduktion jedoch in beiden Medien aufgehoben: Grass erweiterte seinen Vernunftbegriff durch eine bewusste philosophische Auseinandersetzung mit der Anschauung und brachte seine Erkenntnisse erneut durch häufige Bezugnahmen auf die bildende Kunst in seiner Prosa zum Ausdruck. Im Butt setzte er sich schließlich mit dem Irrationalen auseinander, fügte Märchen und Mythen in seinen Text ein und stütze sich dabei sowohl auf die Forschung Claude Lévi-Strauss' als auch auf die ästhetischen Schriften von Albert Camus. Diese Rückkehr zum bildnerischen Denken demonstrieren auch die von Grass gezeichneten Embleme, die als kurze Ekphrasen literarische Entsprechungen im Tagebuch erhielten. Sieben Jahre später wurde die barocke Dichtkunst und in Verbindung mit ihr auch die Emblematik im Treffen in Telgte (1979) zum Thema.

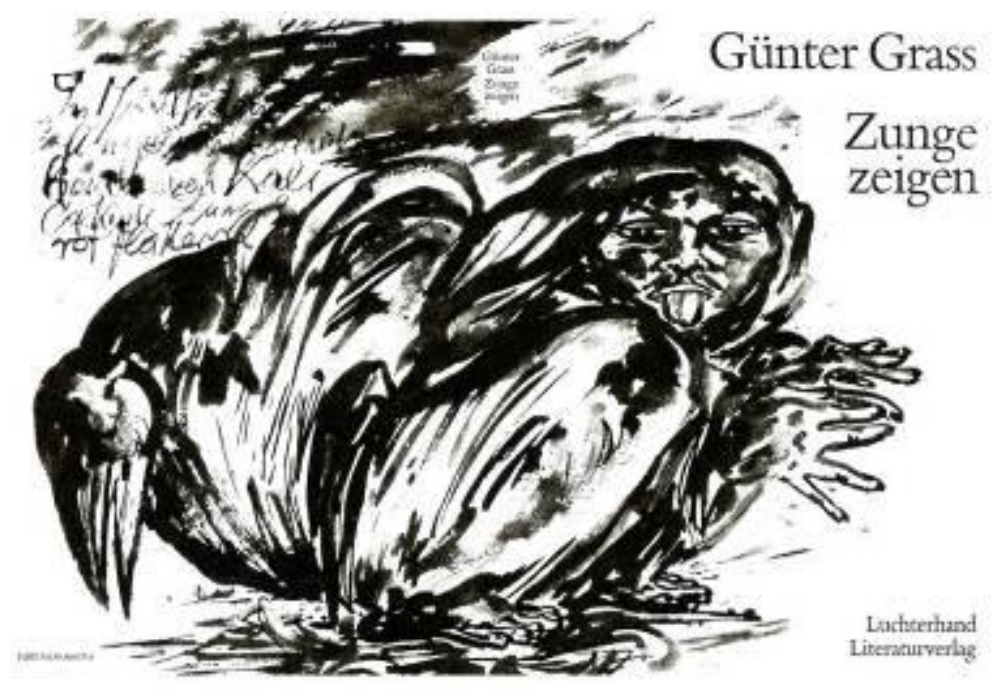

Abb. 198, Zunge zeigen, Darmstadt 1988, Umschlag 


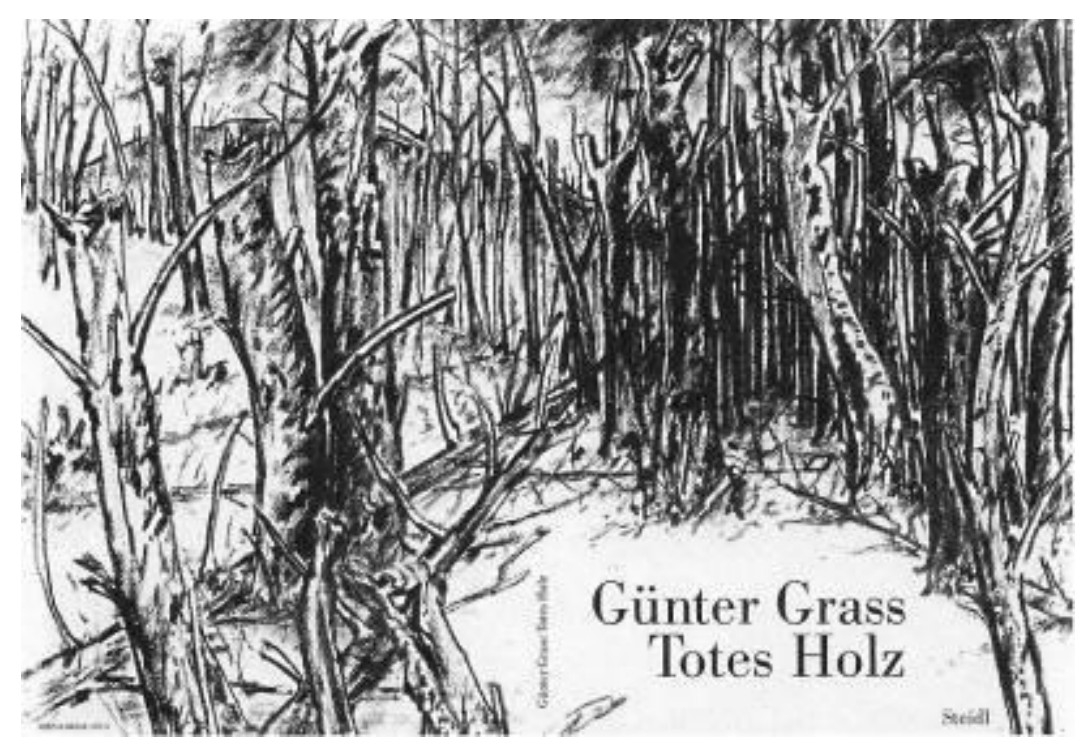

Abb. 199, Totes Holz, Göttingen 1990, Umschlag

Dem gezeichneten Bild als einem Mittel der Aufklärung kommt in den auf die Rättin folgenden Veröffentlichungen Zunge zeigen (1988) und Totes Holz (1990) eine entscheidende Rolle zu (Abb. 198, Abb. 199). ${ }^{634}$ Die darin erhobene Anklage gegen das Waldsterben und gegen Hunger und Armut in Indien wird mit Hilfe der Lithografien, Kohle- und Federzeichnungen ins Bild gesetzt, die die Bände in Reproduktionen enthalten. Zum ersten und einzigen Mal stellt Grass seine Arbeiten und das genaue Hinsehen ähnlich wie sein Düsseldorfer Lehrer Otto Pankok in den Dienst von konkretem gesellschaftlichem Engagement. Wohl nicht von ungefähr formulierte Grass seine vehemente Kritik an der nonfigurativen Kunst der Nachkriegszeit als einer verantwortungslos verdrängenden in den Achtzigerjahren. Der Grafiker sieht sich nun in der Rolle des „Augenzeugen“, der sich mit dem Aufgezeichneten gegen herkömmliche zeitgenössische Mittel der Aufklärung wendet. So heißt es in seinem "Nachruf" zu Totes Holz:

Es war wie Leichenfleddern. Hinsehen und festhalten. Oft fotografiert und farbig oder schwarzweiß zur Ansicht gebracht, blieb dennoch unglaubhaft, was Statistiken und amtliche Waldzustandsberichte bebildern sollten. Fotos kann jeder machen. Wer traut schon Fotos! [...] Hinsehen, wieder die Skizzen befragen. Nur nicht abstrakt werden. Dinglich bleiben. Du bist Augenzeuge. Sonst ist hier niemand.

Wie bereits Katja Standfuss in ihrer Untersuchung dargelegt hat, handelt es sich im Unterschied $z u$ den in dieser Arbeit behandelten Kunstwerken bei einem großen Teil der Darstellungen um komplett ausgestaltete Bildszenen in einem illusionierten Bildraum. Auch wenn einzelnen Objekten und Figuren dennoch eine entscheidende, bedeutungstragende Funktion zukommt, werden sie in Landschaften und Räume integriert, die der Grafiker aus vor Ort entstandenen Skizzen übertragen hat. So zeigt eine reproduzierte Tuschezeichnung aus Zunge zeigen eine Landschaft und eine Figur, wie sie Grass mehrfach aufgezeichnet und in seinem Skizzenbuch (1989) veröffentlicht hat (Abb. 200). Abgeschlagene Köpfe an Stelle von Kokosnüssen und die Geste des Zunge-Zeigens,

${ }^{634}$ Vgl. Platen (2001) und Standfuss (2008), S. 87-160. 
die die im Hintergrund hockende Frau ausführt, verweisen jedoch darauf, dass es sich nicht um eine spontane Beobachtung, sondern um eine Allegorie der Scham handelt. Die Verbindung zum Text wird über handschriftlich ins Bild eingefügte Zeilen geleistet. ${ }^{635}$

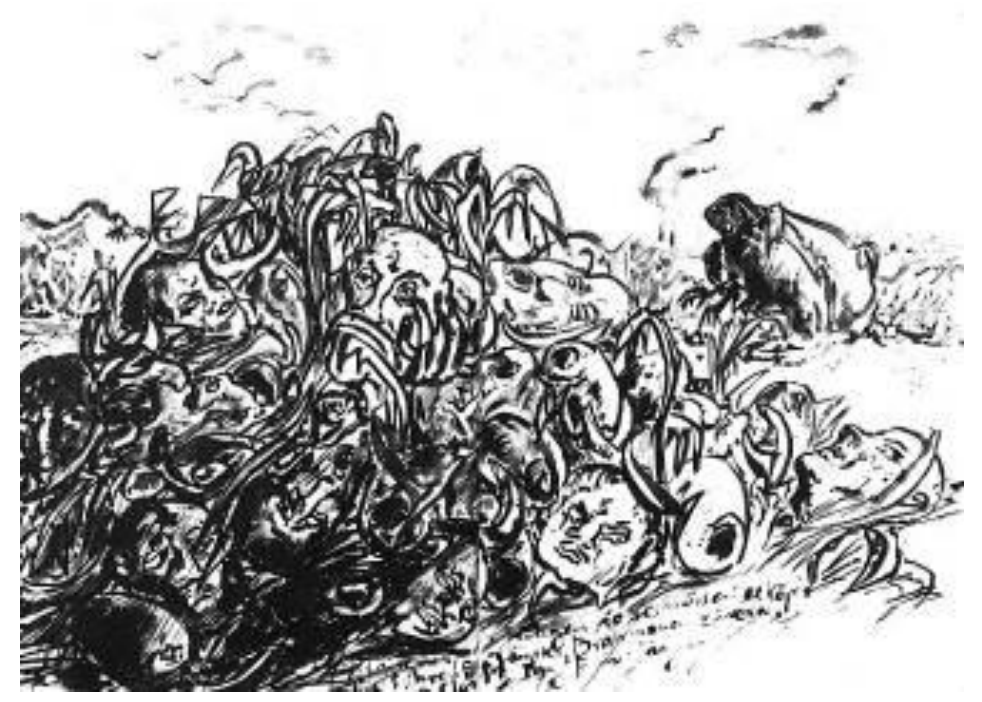

Abb. 200, Zunge zeigen, Darmstadt 1989, S. 8 f.

Eine stärker auf vorgefundenen Eindrücken als auf konstruierten Objektzusammenstellungen fußende bildkünstlerische Ästhetik ist auch in dem 1997 publizierten Gedichtband Fundsachen für Nichtleser erkennbar: Gegenstände werden erneut zum Ausgangspunkt für Allegorien, auch für Anekdoten oder Erinnerungen, doch können diese nur in Einzelfällen aus den Bildern allein erschlossen werden. Die Bedeutung, die die Objekte transportieren, wurden ins Bild gesetzt, indem Grass die Texte handschriftlich in die figürliche Darstellung einschrieb und teilweise die Schrift als ein Objekt unter anderen in den illusionierten Bildraum integrierte. Die Zusammenführung von Schrift und Bild sollte Grass in vielen Lithografien wie denjenigen aus dem Portfolio Küchenzettel (2001), aus den Gedichtbänden Letzte Tänze (2003) und Dummer August (2007) sowie in den Aquarellen aus dem Umfeld von Mein Jahrhundert (1999) weiterverwenden. Erst in den späten Radierungen zu den Hundejahren (2013) und den Bleistiftzeichnungen zu Vonne Endlichkeit (2015) hatte der Künstler wieder auf die Zugabe von handschriftlichem Text verzichtet.

Aufgrund ihrer universellen Aussagekraft verwundert es nicht, dass viele der von Grass bereits im Umfeld der ,Danziger Trilogie' gestalteten Motive bis zu seinem Tod auch in der bildenden Kunst immer wieder von ihm aufgegriffen wurden. Vögel, Pilze, Fische und weitere Tiere und Objekte seines Motivschatzes fanden durch alle literarischen und künstlerischen Gattungen hinweg Verwendung. Vor allem die genannten Naturobjekte, Alltagsgegenstände und Tiere wurden weiterbehandelt, seltener die Figuren der Nonnen und Vogelscheuchen, die in ihrer Bedeutung stärker gesellschaftlich und zeitlich gebunden waren. Die dargestellten Objekte wurden stets neu kontextualisiert, auch wenn bestimmte Konnotationen immer besonders deutlich mit ihnen in

${ }^{635}$ Vgl. Standfuss (2008), S. 113-142. 
Verbindung gebracht werden können. Der Pilz zum Beispiel wird in den meisten Darstellungen des Künstlers zu Geschlechtlichkeit, Erotik und Fortpflanzung in Beziehung gesetzt.

Das Festhalten an einem früh entwickelten Motivschatz wurde in Grass' bildkünstlerischem Werk zusätzlich durch den Wechsel von einer künstlerischen Technik zur anderen beflügelt. Die Beschäftigung mit der Lithografie und Radierung verführte inn ab 1972 offenkundig zur Neugestaltung von vertrauten, zuvor als Bleistift- oder Federzeichnung ausgeführten Motiven: der Schnecken, der Aale und der Köche.

Im Zuge der Vorbereitungen der Rättin (1986) wiederholte sich dieser Vorgang. Grass arbeitete zum ersten Mal seit dem Ende seines Studiums wieder plastisch. In dieser Phase entstanden Tonreliefs, die den Butt, die Schnecken, die Pilze, die Aale, Heuschrecken und aus Vögeln und Frauenfiguren zusammengesetzte Wesen zeigen (Abb. 201). Die Kompositionen wurden dabei oftmals genau aus Zeichnungen und Grafiken übertragen, die Grass Anfang der Siebzigerjahre geschaffen hatte, wie ein Vergleich von Kussdarstellungen in einer Radierung und einer Plastik zeigt (Abb. 202, Abb. 203). Der Künstler näherte sich dem dreidimensionalen Kunstwerk stufenweise vom zweidimensionalen Kunstwerk aus. Die ersten Manuskriptseiten zum Roman entstanden als plastische Inschriften in Tontafeln, die gewellt oder an Ecken eingerollt ein Eigenleben als Gegenstand erhalten (Abb. 204). Grass' dreidimensionale Plastiken, die für die Fotos des entsprechenden Werkverzeichnisses auf Naturmaterial, in Sand, auf Stein oder Holz gebettet wurden, zeigen bei einem Maßstab von eins zu eins zu ihrem Vorbild einen herausragenden Anspruch auf Naturtreue. Insbesondere eine Arbeit, in der Grass eine Gruppe in Ton modellierter Pilze mit einem Spiegel kombinierte, erinnert an die Montagen von fotografierten Zeichnungen und Gegenständen aus der Kooperation mit Maria Rama (Abb. 205). Der Vorgang der Neubearbeitung bekannter Sujets in einer neuen Technik sollte sich in den Neunzigerjahren im Vorfeld der Arbeit an den Fundsachen für Nichtleser (1997) wiederholen. Grass hatte damals zum ersten Mal seit dem Studium wieder Aquarelle gemalt und sich dabei vor allem seinem vertrauten Motivschatz gewidmet. 


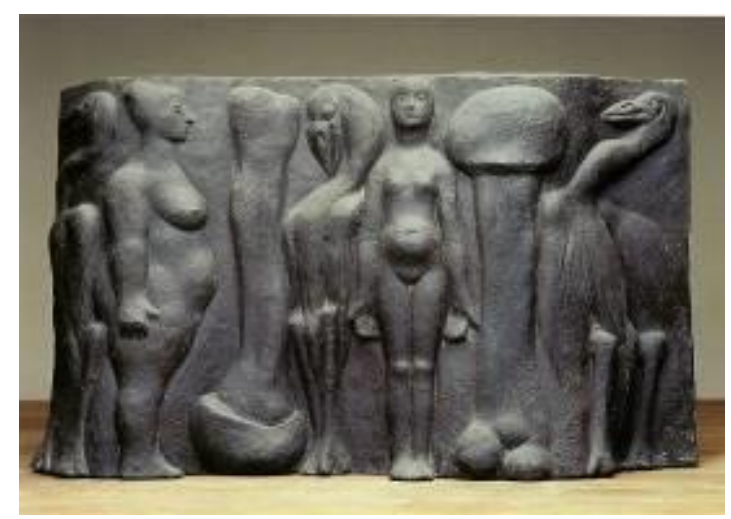

Abb. 201, Zwischen den Vögeln, 1981, Bronze

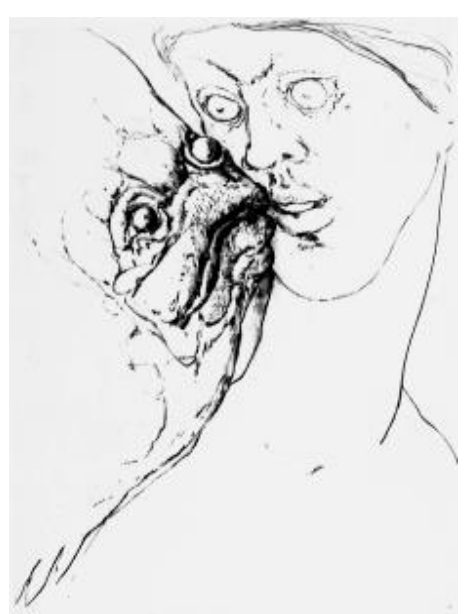

Abb. 202, Kuß II, 1975, Kaltnadelradierung auf Kupfer

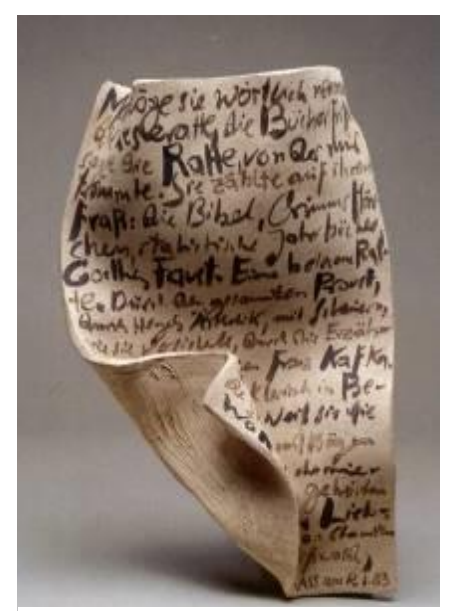

Abb. 204, Man möge sie wörtlich nehmen..., 1983, Terrakotta

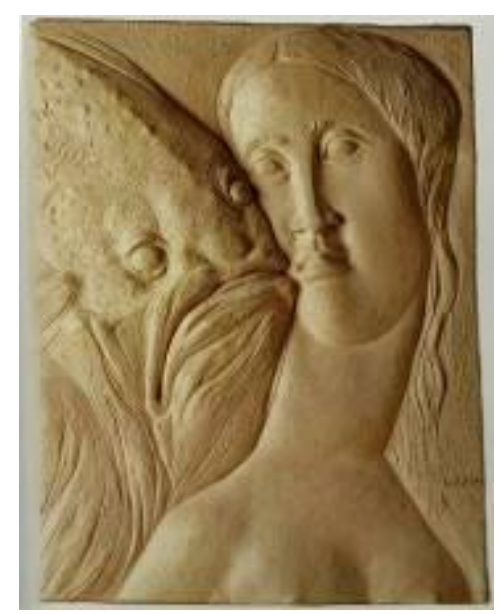

Abb. 203, Der Kuß, 1981, Terrakotta

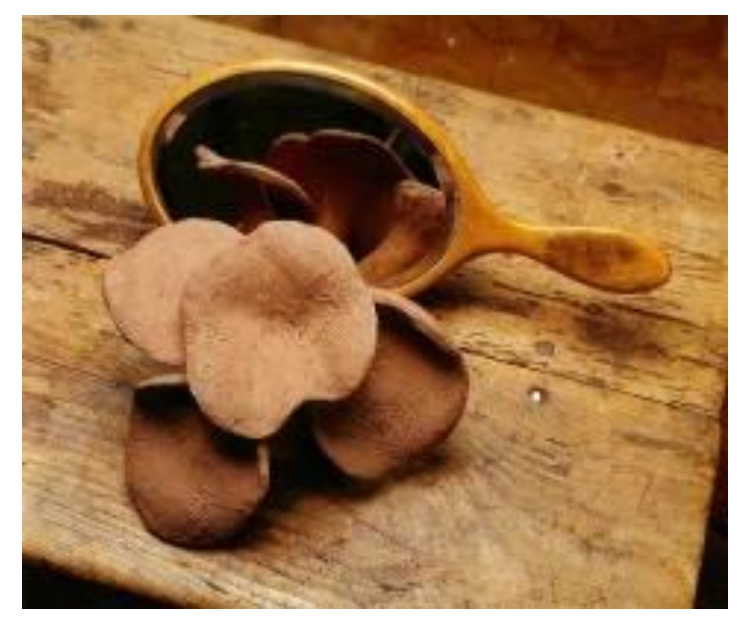

Abb. 205, Pilze, 1982, Terrakotta 
Echos wie diese zeigt auch eine Fotografie aus dem Buch Mariazuehren in zweierlei Weise. Im Jahr 1973 ist Grass darin neben einer Tuschezeichnung zu sehen, in der eine bereits 1963 in den Hundejahren sprachlich realisierte Komposition erkennbar ist: Aal und Euter (Abb. 206). ${ }^{636}$ Auch wenn dieses Foto keine so spannungsreiche und fein komponierte Inszenierung des Künstlers präsentiert wie das knapp zwanzig Jahre zuvor von Hans Rama aufgenommene Bild (vgl. S. 3, Abb. 1), ähneln sich die beiden Porträts. In beiden Fotos stehen Grass und seine Tierdarstellung in unmittelbarer Beziehung zueinander. Sie begegnen sich nahezu auf Augenhöhe und werden durch ein barock geschwungenes Element des Wohnraums - 1955 war es ein Spiegel - verbunden. Erneut wird der Bildraum gleichmäßig zwischen dem Künstler und seinem Werk aufgeteilt. 2011 in einem Gespräch befragt, was seinem ersten Gedichtband ohne die beigefügten Federzeichnungen gefehlt hätte, antwortete Grass nach kurzem Zögern: „meine andere Hälfte“. 637 Sollte die vorliegende Arbeit von ebendieser ein schärferes Bild geliefert haben, so wäre ihr Zweck erfüllt.

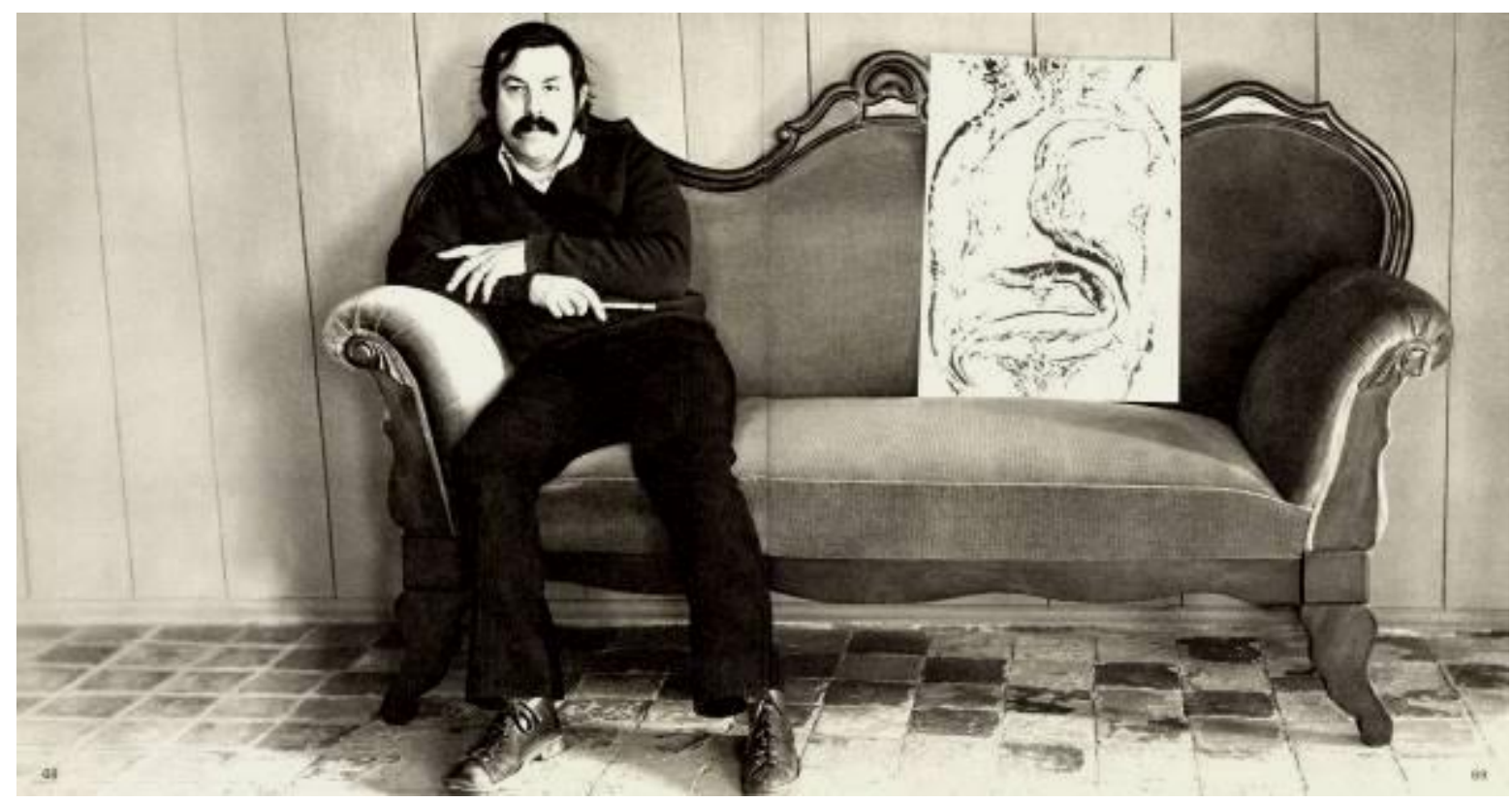

Abb. 206, Mariazuehren, München 1973, S. 68 f. (Aal und Euter, 1972, Tusche)

${ }^{636}$ Vgl. S. 282 der vorliegenden Untersuchung.

${ }^{637}$ Grass im Gespräch mit der Verfasserin am 5.12.2011: Krason (2011). 


\section{LITERATURVERZEICHNIS}

\section{Primärliteratur und Quellen}

\subsection{Werke von Günter Grass}

1.1.1. Zitierte Werkausgabe (zitiert mit röm. Zahl für den Band u. arab. Zahl für die Seite)

Werke. Göttinger Ausgabe, 12 Bände, Göttingen 2007.

Bd. 1 = Gedichte und Kurzprosa, hrsg. von Dieter Stolz.

Bd. 2 = Theaterspiele, hrsg. von Werner Frizen.

Bd. 3 = Die Blechtrommel.

Bd. $4=$ Katz und Maus, Hundejahre.

Bd. 5 = örtlich betäubt, Aus dem Tagebuch einer Schnecke.

Bd. $6=$ Der Butt, Das Treffen in Telgte.

Bd. 7 = Kopfgeburten, Die Rättin, Unkenrufe.

Bd. $8=$ Ein weites Feld .

Bd. $9=$ Mein Jahrhundert.

Bd. 10 = Im Krebsgang, Beim Häuten der Zwiebel.

Bd. 11 = Essays und Reden, 1955-1979.

Bd. 12 = Essays und Reden, 1980-2007.

\subsubsection{Veröffentlichungen außerhalb der Werkausgabe}

- (1956): Die Vorzüge der Windhühner. Gedichte und Zeichnungen, Berlin-Frohnau, Neuwied am Rhein.

- (1956a): Lilien aus Schlaf, in: Walter Höllerer (Hg.): Transit. Lyrikbuch der Jahrhundertmitte, hrsg. mit Randnotizen von Walter Höllerer, Frankfurt a. M.

- (1960): Gleisdreieck. Gedichte und Zeichnungen, Darmstadt, Berlin-Spandau, Neuwied am Rhein.

- (1963): Die Ballerina, Berlin-Friedenau.

- (1963a): Die Vorzüge der Windhühner. Gedichte und Zeichnungen, 2. Auflage, Berlin-Frohnau, Neuwied am Rhein.

- (1967): Ausgefragt. Gedichte und Zeichnungen, Berlin, Neuwied am Rhein.

- (1971): Aus dem Tagebuch einer Schnecke, Neuwied am Rhein, Darmstadt.

- (1973): Mariazuehren. Gedichte und Graphiken, mit Fotos von Maria Rama, München.

- (1983): Ach Butt, dein Märchen geht böse aus. Gedichte und Radierungen, Darmstadt.

- (1987): Mit Sophie in die Pilze gegangen. Lithographien und Gedichte, Göttingen.

- (1988): Zunge zeigen. Ein Tagebuch in Zeichnungen, Prosa und einem Gedicht, Darmstadt.

- (1990): Totes Holz. Ein Nachruf, Göttingen.

- (1991): Vier Jahrzehnte. Ein Werkstattbericht, Göttingen.

- (1993): Novemberland. 13 Sonette, Göttingen.

- (1997): Fundsachen für Nichtleser. Gedichte und Aquarelle, Göttingen.

- (1999): Auf einem anderen Blatt. Zeichnungen, Göttingen.

- (1999a): Mein Jahrhundert. Gedichte und Aquarelle, Göttingen. 
- (2001): Mit Wasserfarben. Aquarelle, Göttingen.

- (2001a): Fünf Jahrzehnte. Ein Werkstattbericht, Göttingen.

- (2002): Im Krebsgang. Eine Novelle, Göttingen.

- (2002a): Gebrannte Erde. Skulpturen, Göttingen.

- (2004): Letzte Tänze. Gedichte und Zeichnungen, Göttingen.

- (2004a): Lyrische Beute. Gedichte und Zeichnungen aus fünfzig Jahren, Göttingen.

- (2006): Beim Häuten der Zwiebel, Göttingen 2006.

- (2007): Die Vorzüge der Windhühner. Gedichte und Zeichnungen, Nachdruck der Erstauflage von 1956, Göttingen.

- (2008): Die Box. Dunkelkammergeschichten, Göttingen.

- (2010): Grimms Wörter. Eine Liebeserklärung, Göttingen.

- (2013): Hundejahre. Illustrierte Jubiläumsausgabe in drei Bänden, Göttingen.

- (2014): Sechs Jahrzehnte. Ein Werkstattbericht, Göttingen.

- (2015): Vonne Endlichkait. Prosa, Gedichte und Zeichnungen, Göttingen.

\subsubsection{Druckgrafische Mappenwerke und Künstlerbücher}

- Liebe geprüft. Sieben Radierungen und Gedichte, Bremen: Schünemann, 1974.

- Mit Sophie in die Pilze gegangen. Lithographien und Gedichte, Mailand: Upiglio, 1976.

- Als vom Butt nur die Gräte geblieben war. Mappe mit 7 Radierungen, hrsg. von Anselm Dreher, Berlin: Galerie Andre, 1977.

- Vatertag, 22 Lithographien, Hamburg: Edition Monika Beck, 1982.

\subsubsection{Werkverzeichnisse, Ausstellungskataloge und andere Sammelpublikationen von bildkünstlerischen Arbeiten, Arbeitsplänen und Aufzeichnungen}

Dreher, Anselm (Hg.) (1982, 1984): Günter Grass: Zeichnen und Schreiben, 2 Bde.: I: Zeichnungen und Texte 1954-1977, Textausw. u. Nachw. von Sigrid Mayer, Darmstadt; II: Radierungen und Texte 1972-1982, Textausw. u. Nachw. von Sigrid Mayer, Darmstadt.

Grass, Günter (1973): Mariazuehren. Gedichte und Graphiken, mit Fotos von Maria Rama, München. Grass, Günter (1999): Auf einem anderen Blatt. Zeichnungen, Göttingen.

Grass, Günter (2001): Mit Wasserfarben. Aquarelle, Göttingen.

Grass, Günter (2002a): Gebrannte Erde. Skulpturen, Lübeck.

Grass, Günter (2014): Sechs Jahrzehnte. Ein Werkstattbericht, hrsg. von Fritz G. Margull u. Hilke Ohsoling, Göttingen.

Kat. Ausst. Aachen (1997): Günter Grass. Ohne die Feder zu wechseln: Zeichnungen, Druckgraphiken, Aquarelle, Skulpturen, Ludwig-Forum für Internationale Kunst Aachen, 27.6.-7.9.1997, Göttingen. Kat. Ausst. Berlin (1992): Günter Grass: Ein Werkstattbericht. 1951-1992, hrsg. von der Staatlichen Kunsthalle Berlin, Staatliche Kunsthalle Berlin, 14.10.-18.11.1992, Göttingen.

Kat. Ausst. Kiel (1987): Günter Grass. Hundert Zeichnungen 1955 bis 1987, hrsg. von Jens Christian Jensen, Kunsthalle zu Kiel der CAU, 11.10.-22.11.1987, Kiel.

Margull, Fritze G. (Hg.) (1994): Günter Grass. In Kupfer, auf Stein. Das graphische Werk, erw. Neuaufl. der Erstausg. von 1986, Göttingen.

Ohsoling, Hilke (Hg., 2007, 2007a): Günter Grass: Catalogue Raisonné, Bd. 1: Radierungen / Bd. 2: Lithographien, Göttingen.

Trautwein, Wolfgang und Karin Kiwus (Hgg.) (2002): Fundsachen für Grass-Leser, Göttingen. 


\subsubsection{Gespräche}

Boie, Bernhild (1997): Die Disziplin wechseln, beim Gegenstand bleiben, in: Daniela Hermes (Hg.): Günter Grass. Der Autor als fragwürdiger Zeuge, München.

Fischer-Defoy, Christine (1992): Gespräch mit Günter Grass am 22.11.1989, in: Kat. Ausst. Berlin (1992), S. I, 2-7.

Fitschen, Jürgen (2011): unveröffentlichte Transkription eines Podiumsgesprächs mit Günter Grass auf Schloss Gottorf am 14.1.2011.

Krason, Viktoria (2011): unveröffentlichtes Gespräch mit Günter Grass am 5.12.2011.

Matthiesen Sigrun (2013): Dokumentarfilm: „Spätschicht" - Günter Grass bei der Arbeit an Radierungen zu Hundejahre.

Schuster, Peter-Klaus und Matthias Mende (2009): Gespräch mit Günter Grass über den künstlerischen Schaffensprozess im Spannungsfeld zwischen Motivation und Melancholie, gezeigt im AlbrechtDürer-Haus anlässlich der Ausstellung: Blicke auf Dürer - Ein Universalgenie im 21. Jahrhundert, 14.6.-2.8.2009, unveröffentlicht, Archiv des Albrecht-Dürer-Hauses.

Zimmermann, Harro und Günter Grass (1999): Vom Abenteuer der Aufklärung. Werkstattgespräche, Göttingen.

\subsection{Archivmaterial}

Universität der Künste Berlin, Universitätsarchiv:

- Studentenakte Günter Grass, 16 II 2515.

\section{Archiv des Albrecht-Dürer-Hauses, Nürnberg:}

- Peter-Klaus Schuster und Matthias Mende: Gespräch mit Günter Grass über den künstlerischen Schaffensprozess im Spannungsfeld zwischen Motivation und Melancholie, gezeigt im Albrecht-Dürer-Haus anlässlich der Ausstellung: Blicke auf Dürer - Ein Universalgenie im 21. Jahrhundert, 14.6.-2.8.2009.

\section{Günter Grass-Haus, Forum für Literatur und bildende Kunst:}

- siehe Abbildungsverzeichnis und Verzeichnis der Motivdarstellungen.

\section{Gdańska Galeria Güntera Grassa (Günter Grass Galerie Gdańsk):}

- siehe Verzeichnis der Motivdarstellungen.

\section{Günter und Ute Grass Stiftung:}

- handschriftliches Manuskript zum Prosatext „Das soll von mir sein?“ aus Vonne Endlichkait

(Grass (2015), S. 95), verfasst in Behlendorf am 11. Januar 2014.

- Konvolut der Düsseldorfer Studienarbeiten.

- weitere bildkünstlerische Arbeiten: siehe Abbildungsverzeichnis und Verzeichnis der Motivdarstellungen. 
Akademie der Künste Berlin, Günter-Grass-Archiv:

- Arbeitstagebücher: Nr. 172, Nr. 219, Nr. 965, Nr. 1753, Nr. 1755, Nr. 1757, Nr. 1758.

- Manuskripte, Notizen und Arbeitspläne: Nr. 49, Nr. 50, Nr. 169, Nr. 170, Nr. 178, Nr. 181-210, Nr. 219, Nr. 323, Nr. 343, Nr. 344, Nr. 533, Nr. 622, Nr. 948, Nr. 1039, Nr. 2081.

- Briefwechsel: Nr. 3365, Nr. 7040.

Akademie der Künste, Berlin, Sammlung Maria Rama: Nr. 42, Nr. 273.1, Nr. 538.

\section{Akademie der Künste, Berlin, Kunstsammlung:}

- siehe Abbildungsverzeichnis und Verzeichnis der Motivdarstellungen.

\subsection{Werke anderer Autoren und veröffentlichte Quellen}

Amery, Carl (1963): Die Kapitulation oder Deutscher Katholizismus heute, Reinbek bei Hamburg. Bachmann, Ingeborg (1965): Ein Ort für Zufälle, mit 13 Zeichnungen von Günter Grass, Berlin.

- (1995): Todesarten, Ein Ort für Zufälle, Requiem für Fanny Goldmann, Goldmann / RottwitzRoman und andere Texte, bearbeitet von Monika Albrecht und Dirk Göttsche, München, Zürich.

- (1999): Ein Ort für Zufälle, mit einem Nachwort von Klaus Wagenbach, Berlin.

Benjamin, Walter (1974): Gesammelte Schriften, unter Mitwirkung von Theodor W. Adorno und Gershom Sholem hrsg. von Rolf Tiedemann und Hermann Schweppenhäuser, Bd. 1.1., Frankfurt a. M. Böll, Heinrich (2007): Bekenntnis zur Trümmerliteratur (1952), in: Árpád Bernáth in Zusammenarbeit mit Annamária Gyurácz (Hgg.): Heinrich Böll, Werke, Kölner Ausgabe, Bd. 6, Köln 2007, S. 58-62.

Camus, Albert (2012): Der Mythos des Sisyphos, deutsch mit einem Nachwort von Vincent von Wroblewsky, Hamburg.

Diderot, Denis (1796/1797): La religieuse, Paris.

Die Nibelungen-Sage (1921): Die Nibelungen-Sage nach den Fresko-Gemälden von Julius Schnorr von Karolsfeld in der Königlichen Residenz zu München, photographiert im Auftrage seiner Majestät König Ludwig II. von Bayern, München.

Eckermann, Johann Peter (1981): Gespräche mit Goethe in den letzten Jahren seines Lebens, Frankfurt a. M.

Evers, Hans Gerhard (1951): Das Menschenbild in unserer Zeit, hrsg. im Auftrag der Stadt Darmstadt und des Komitees Darmstädter Gespräch 1950, Darmstadt.

Freud, Sigmund (1914): Die Traumdeutung, Leipzig und Wien.

Grass, Anna (1991a): Die dreizehnjährige Geschichte der Vogelscheuchen, in: Daniela Hermes und Volker Neuhaus (Hgg.): Die Danziger Trilogie von Günter Grass. Texte, Daten, Bilder, Frankfurt a. M. Greenberg, Clement (1997): Zu einem neueren Laokoon (1940), in: Karlheinz Lüdeking (Hg.): Die Essenz der Moderne. Ausgewählte Essays und Kritiken, Amsterdam, Dresden.

Hofer, Karl (1952): Aus Leben und Kunst, Berlin 1952.

Kafka, Franz (2008): Das Ehepaar und andere Schriften aus dem Nachlass. Originalfassung, Franz Kafka. Gesammelte Werke in zwölf Bänden, nach der Kritischen Ausgabe hrsg. von Hand-Gerd Koch. Bd. 8, Frankfurt am Main.

Kleist, Heinrich von (2001): Über das Marionettentheater (1810), in: Helmut Sembdner (Hg.): Heinrich von Kleist. Sämtliche Werke und Briefe, zweibändige Ausgabe in einem Band, München, S. 338-345. 
Kramer, Harry und Wolfgang Ramsbott (1990): Grenzwerte. Textsammlungen 1956-1961, in: Willhardt (1990), S. 74-81.

Mages, Sepp (1951): Zur Architekturplastik, in: Kamps (1951), S. 47.

- (1962): Granitmale, München.

Mataré, Ewald (1997): Tagebücher 1915 bis 1965, hrsg. von Sonja Mataré und Sabine Maja Schilling, Köln.

Pankok, Otto (1930): Stern und Blume, Düsseldorf.

- (1936): Die Passion: in 60 Bildern, Berlin.

- (1947): Zigeuner. Mit einer Einleitung von Rudolf Schröder, Düsseldorf.

- (1951): Unser Glaube an das Leben. In: Kamps (1951), S. 25-28.

- (1990): Stern und Blume. Holzschnitte - Texte - Dokumente, hg. von Hans Marquardt, achter Druck der Dürer-Presse, Leipzig.

Kamps, Heinrich (Hg.) (1951): Jahrbuch der Staatlichen Kunstakademie Düsseldorf, 1948-1950, Düsseldorf.

Klee, Paul (1971): Das bildnerische Denken, Schriften zur Form- und Gestaltungslehre, hrsg. und bearbeitet von Jörg Spiller, Basel, Stuttgart 1971.

Klibansky, Raymond, Erwin Panofsky und Fritz Saxl (1992): Saturn und Melancholie: Studien zur Geschichte der Naturphilosophie und Medizin, der Religion und der Kunst, Frankfurt a. M.

Panofsky, Erwin (1948): Albrecht Dürer, London.

Panofsky, Erwin und Fritz Saxl (1923): Dürers Melencolia I. Eine quellen- u. typengeschichtliche Untersuchung, Leipzig.

Peirce, Charles Sanders (1932): Elements of Logic, (= Collected Papers of Charles Sanders Peirce, Bd. 2) hrsg. von Charles Hartshorne u. Paul Wiess, Cambridge.

Sedlmayr, Hans (1998, 11. unveränderte Auflage [1. Auflage 1948]): Verlust der Mitte. Die bildende Kunst des 19. und 20. Jahrhunderts als Symptom und Symbol der Zeit, Salzburg, Wien.

Schlemmer, Oskar (1974): Mensch und Kunstfigur, in: Oskar Schlemmer, Laszlo Moholy-Nagy, Farkas Molnár (Hgg.): Die Bühne am Bauhaus, mit einem Nachwort von Walter Gropius, Mainz, Berlin, S. 7-21.

Schopenhauer, Artur (1996): Die Welt als Wille und Vorstellung, 2. Bd., textkritisch bearbeitet und hrsg. von Wolfgang Freiherr von Löhneysen, Frankfurt a. M., Leipzig.

Weininger, Otto (1920): Geschlecht und Charakter, Wien, Leipzig.

Runge, Philipp Otto (1976): Von dem Fischer un syner Frau. Ein Märchen nach Philipp Otto Runge, mit sieben Bildern von Marcus Behmer, einer Nacherzählung und einem Nachwort von Uwe Johnson, Frankfurt a. M.

Runge, Philipp Otto, Jacob und Wilhelm Grimm (2008): Von dem Machandelboom, Von dem Fischer un syner Frau: zwei Märchen, Jacob und Wilhelm Grimm, textkritisch hrsg. und kommentiert von Heinz Rölleke, Trier.

Stiftung Archiv der Akademie der Künste (Hg.) (1997): „,... und die Vergangenheit sitzt immer mit am Tisch". Dokumente zur Geschichte der Akademie der Künste (West), 1945/1954-1993, ausgewählt und kommentiert von Christine Fischer-Defoy, mit einem Vorwort von Walter Jens, Berlin. 


\section{Sekundärliteratur}

Abbott, Scott H. (1983): The raw and the cooked: Claude Lévi-Strauss and Günter Grass, in: Siegrid Mews (Hg.): The fisherman and his wife. Günter Grass's The Flounder in critical perspective, New York, S. 107-120.

Abelshauser, Werner (1985): Von der Mangelwirtschaft zum „Wirtschaftswunder" - Wiederaufbau an Rhein und Ruhr, in: Kat. Ausst. Bonn (1985), S. 43-71.

Ananieva, Anna (2008): Garten, in: Günter Butzer, Joachim Jacob (Hgg.): Metzler Lexikon literarischer Symbole, Stuttgart, S. 141-144.

Appleby, Michael C. u. a. (2004): Poultry behaviour and welfare, Wallingford.

Arker, Dieter (1989): „Nichts ist vorbei, alles kommt wieder". Untersuchungen zu Günter Grass' Blechtrommel, Heidelberg, zugl. Diss. Freie Univ. Berlin 1987.

Arnold, Hans Ludwig (1978): Graphiker Grass, in: Ders. (Hg.): Günter Grass. Text + Kritik, H. 1, S. 101-106.

- (Hg.) (1997): Blech getrommelt: Günter Grass in der Kritik, Göttingen 1997.

Artinger, Kai (Hg.) (2002): Wortbilder und Wechselspiele: das Günter Grass-Haus. Forum für Literatur und Bildende Kunst, Göttingen.

Bannasch, Bettina (2002): Künstlerische und Journalistische Prosa, in: Monika Albrecht u.

Dirk Göttsche (Hgg.): Bachmann-Handbuch: Leben - Werk - Wirkung, Stuttgart, S. 172-183.

Baudot, François (1997): Elsa Schiaparelli, Paris.

Barck, Karlheinz (Hg.) (1986): Surrealismus in Paris 1919-1939, Leipzig.

Barth, Anette (1997): Alexander Archipenkos plastisches CEuvre, 2 Bde., Frankfurt a. M., Berlin.

Bartsch, Kurt (1982): Ingeborg Bachmann, Stuttgart.

Berg, Nicolas (2010): Forschungen eines Hundes, in: Manfred Engel und Bernd Auerochs (Hg.):

Kafka Handbuch. Leben - Werk - Wirkung, Stuttgart/Weimar, S. 330-336.

Beloubek-Hammer, Anita (Hg.)(2015), Gerhard Altenbourg: Das gezeichnete Ich, Berlin.

Bergström, Ingvar (1983): Dutch still-life painting in the seventeenth century, New York.

Boehm, Gottfried (Hg.) (1994): Was ist ein Bild? München.

- (2001): Zwischen Auge und Hand: Bilder als Instrument der Erkenntnis, in: Institut für Theorie der Gestaltung und Kunst Zürich (Hg.): Mit dem Auge denken: Strategien der Sichtbarmachung in wissenschaftlichen und virtuellen Welten, Zürich, S. 43-54.

Brady, Philipp (1990): „Aus einer Kürbishütte gesehen": the poems, in: Philip Brady u. a. (Hgg.): Günter Grass's Der Butt. Sexual politics and the male myth of history, Oxford, S. 203-225.

Brakensiek, Stephan (2002): Ma(h)lzeit! Der gedeckte Tisch als Thema der flämischen Stilllebenmalerei, in: Kat. Ausst. Sinn und Sinnlichkeit. Das Flämische Stillleben 1550-1680, Kunsthistorisches Museum Wien und Kulturstiftung Ruhr Essen, 1.9.-8.12.2002, Lingen, S. 223-228.

Braun, Rebecca (2008): Constructing Authorship in the Work of Günter Grass, Oxford Univ. Press, Oxford.

Bredekamp, Horst (2005): Darwins Korallen. Die frühen Evolutionsdiagramme und die Tradition der Naturgeschichte, Berlin.

- (2005a): Die zeichnende Denkkraft: Überlegungen zur Bildkunst der Naturwissenschaften, in: Jörg Huber (Hg.): Einbildungen, Interventionen 14, Zürich, Wien, New York, S. 155-172.

- (2007): Galilei der Künstler. Der Mond, die Sonne, die Hand, Berlin.

- (2015): Galileis denkende Hand. Form und Forschung um 1600, Berlin.

Bude, Heinz (1987): Deutsche Karrieren. Lebenskonstruktionen sozialer Aufsteiger aus der FlakhelferGeneration, Frankfurt a. M. 
Buttlar, Adrian von, Kerstin Wittmann-Englert und Gabi Dolff-Bonekämper (Hgg.) (2013): Baukunst der Nachkriegsmoderne. Architekturführer Berlin 1949-1979. In der Reihe Forschungen zur Nachkriegsmoderne des Fachgebietes Kunstgeschichte am Institut für Kunstwissenschaft und Historische Urbanistik der Technischen Universität Berlin, Berlin.

Butzer, Günter (1998): Fehlende Trauer. Verfahren epischen Erinnerns in der deutschsprachigen Gegenwartsliteratur, München, zugl. Diss. Univ. München 1995.

Cepl-Kaufmann, Gertrude (1975): Günter Grass. Eine Analyse des Gesamtwerks unter dem Aspekt von Literatur und Politik, Kronenberg i. Ts., zugl. Diss. Univ. Düsseldorf 1974.

Chipp, Herschel B. (Hg.) (1995, 1995a): Picasso's paintings, watercolors, drawings and sculpture: a comprehensive illustrated catalogue (1885-1973), The Picasso Project, From Cubism to Neoclassicism (1917-1919), San Francisco / Neoclassicism 1, San Francisco.

Cremer-Bermbach, Susannah (1996): Herbert Zangs: Werkmonographie, Essen.

Crick, Joyce (1990): Future imperfect: time and the flounder, in: Philip Brady u. a. (Hgg.): Günter Grass's Der Butt. Sexual politics and the male myth of history, Oxford, S. 33-49.

Daemmrich, Horst S. u. Ingrid (1987): Themen und Motive in der Literatur: Ein Handbuch, Tübingen. Däufel, Christian (2013): Ingeborg Bachmanns Ein Ort für Zufälle: Ein interpretierender Kommentar, Berlin.

Damus, Martin (1991): Funktionen der bildenden Kunst im realen Sozialismus, Reinbek bei Hamburg.

- (1995): Kunst in der BRD 1945-1990. Funktionen der Kunst in einer demokratisch verfassten Gesellschaft, Reinbek bei Hamburg.

- (1997): Moderne Kunst in Westdeutschland 1945-1959. Versuche, Vergangenheit und Gegenwart rückwärtsgewandt zu bewältigen und die Moderne in Harmonie zu vollenden, in: Gerda Breuer (Hg.): Die Zähmung der Avantgarde: zur Rezeption der Moderne in den 50er Jahren, Basel, S. 25-42.

Dengler, Steffen (2010): Die Kunst der Freiheit? Die westdeutsche Kunst im Kalten Krieg und im wiedervereinigten Deutschland, München.

Detering, Heinrich (2016): Zeichensprache. Günter Grass, das Denkmal für die Göttinger Sieben und Grimms Wörter, in: Freipass. Forum für Literatur, Bildende Kunst und Politik 2, Schriften der Günter und Ute Grass Stiftung, S. 174-187.

Diller, Edward (1983): Raw and Cooked, Myth and Märchen, in: Siegrid Mews (Hg.): The fisherman and his wife. Günter Grass's The Flounder in critical perspective, New York,

S. 91-105.

Domscheit, Annette (1985): Ludwig Gabriel Schrieber (1907-1975). Maler, Bildhauer, Zeichner, mit Werkverzeichnis, Bonn, zugl. Diss. Univ. Bonn 1985

Durzak, Manfred (1971): Plädoyer für eine Rezeptionsästhetik. Anmerkungen zur deutschen und amerikanischen Literaturkritik am Beispiel von Günter Grass' örtlich betäubt, in: Akzente 18, S. 487-504.

Drügh, Heinz J. (2000): Anders-Rede. Zur Struktur und historischen Systematik des Allegorischen, Freiburg.

Eichner, Thomas (1994): Was heißt (hier) Intermedialität? In: Ders. und Ulf Bleckmann (Hgg.): Intermedialität / Vom Bild zum Text, Bielefeld, S. 11-28.

Elleström, Lars (2010): The Modalities of Media. A Model for Understanding Intermedial Relations, in: Ders. (Hg.): Media Borders, Multimodality and Intermediality, Basingstoke, S. 11-48.

Engel, Franz (Hg.) (2012): Das bildnerische Denken: Charles S. Peirce, Berlin.

Engels, Benedikt (2005): Das lyrische Umfeld der „Danziger Trilogie“ von Günter Grass, Würzburg, zugl. Diss. Univ. Bonn 2004. 
Essig, Rolf-Bernhard (2000): Der offene Brief. Geschichte und Funktion einer publizistischen Form von Isokrates bis Günter Grass, Würzburg, zugl. Diss. Univ. Bamberg 1999.

Fasse, Norbert (2018): „Mehr Gehalt, mehr Wahrhaftigkeit". Innerer Kompass, künstlerisches Arbeiten und widerständiges Handeln bei Otto Pankok. In: Freipass. Forum für Literatur, Bildende Kunst und Politik. Schriften der Günter und Ute Grass Stiftung 3, S. 72-122.

Filip, Jan und Machteld J. Mellink (1985): Frühe Stufen der Kunst, Propyläen Kunstgeschichte, Bd. 13, Berlin.

Fischer, André (1992): Inszenierte Naivität. Zur ästhetischen Simulation von Geschichte bei Günter Grass, Albert Drach und Walter Kempowski, München, zugl. Diss. Univ. Konstanz 1992.

Fischer-Defoy, Christine (2001): „Kunst, im Aufbau ein Stein“. Die Westberliner Kunst- und Musikhochschulen im Spannungsfeld der Nachkriegszeit, hrsg. von der Hochschule der Künste Berlin, Berlin.

- (2004): „Klee und das in seinem Gefolge Entstandene ist alles andere wie abstrakt“ -

Die Auseinandersetzung zwischen Karl Hofer und Willi Baumeister im Deutschen Künstlerbund, in: Kat. Ausst. Leipzig (2004), S. 182-191.

Frenzel, Elisabeth (2008): Motive der Weltliteratur: ein Lexikon dichtungsgeschichtlicher Längsschnitte, Stuttgart.

Frizen, Werner (1987): Drei Danziger. Arthur Schopenhauer - Max Halbe - Günter Grass, in: Schopenhauer Jahrbuch 68, S. 147-168.

- (2010): Günter Grass. Gedichte und Kurzprosa, Göttingen.

- (2015): Die Tragödie des Vatertags in Günter Grass' Butt, in: Freipass. Schriften der Ute und Günter Grass Stiftung 1, S. 178-197.

- (2018): Über die allmähliche Verfertigung des Romans beim Schreiben. Zur Entstehungsgeschichte des Butt. In: Freipass. Forum für Literatur, Bildende Kunst und Politik. Schriften der Günter und Ute Grass Stiftung 3, S. 292-328.

Geißler, Rolf (1976): Günter Grass. Ein Materialienbuch, Neuwied.

Gleinig, Kirsten und Urs Müller (1997): Das bildnerische Werk. Mariazuehren, Zeichnen und Schreiben I und II, In Kupfer, auf Stein, Vier Jahrzehnte, in: Heinz Ludwig Arnold (Hg.): Blech getrommelt. Günter Grass in der Kritik, Göttingen.

Glaser, Hermann (1991): Kleine Kulturgeschichte der Bundesrepublik Deutschland, 1945-1989, München.

Glozer, Laszlo (1997): Zwitscher Maschine - Mutmaßung über einen fehlenden Bindestrich, in: Kat. Ausst. München (1997), S. 128-132.

Gmelin, H. G (1996): Möller, Anton, in: J. Turner (Hg.), The Dictionary of Art, Bd. 21, London, New York 1996, S. 820.

Godfrey, Mark (2007): Abstraction and the Holocaust, New Haven, Conn. u.a.

Gorson, Peter (1990): Antiquiertheit und Modernität der Tiermetapher in der Gegenwartskunst, in: Gabriele Schultheiß Bock (Hg.): Animalia: Stellvertreter. Tierbilder in der zeitgenössischen Kunst, erschienen anlässlich der gleichnamigen Ausstellung im Haus am Waldsee, 22.9. -18.11.1990, Berlin, S. 125-143.

Grohn, Ursel (1980): Gustav Seitz. Das plastische Werk. Werkverzeichnis, bearbeitet von Ursel Grohn, mit einer Einführung von Alfred Hentzen, Hamburg.

Haberkamm, Klaus (1985): „Verspäteter Grimmelshausen aus der Kaschubei" - „Verspätete Utopie"? Simplicianisches in Grass' Butt, in: Simpliciana VI/VII, S. 123-138.

Harscheidt, Michael (1976): Wort - Zahl-Gott. Der, phantastische Realismus' in den Hundejahren, Bonn. 
Hartung, Hanne (1998): Über meinen Vater Karl Hartung, in: Kat. Ausst.: Karl Hartung. Werke und Dokumente. Ausstellung im Germanischen Nationalmuseum Nürnberg, 6.3.-1.6.1998, Nürnberg, S. 19-26.

Hartung, Harald (1984): Narr mit Silberblick. Der Lyriker Günter Grass, in: Franz Joseph Görtz (Hg.): Günter Grass: Auskunft für Leser, Darmstadt, Neuwied, S. 149-175.

Hauser, R. (1971): Askese, in: Joachim Ritter (Hg.): Historisches Wörterbuch der Philosophie, Bd. 1: A-C, Darmstadt, S. 538-540.

Held, Jutta (1981): Kunst und Kunstpolitik 1945-49. Kulturaufbau und Deutschland nach dem 2. Weltkrieg, Berlin (West).

Henkel, Hubert (1997): Die Zwitschermaschine des Deutschen Museums - ein Spielwerk mit Vogelstimmen, in: Kat. Ausst. Müchen 1997, S. 123-127

Hermand, Jost (1989): Kultur im Wiederaufbau. Die Bundesrepublik Deutschland 1945-1965, Frankfurt a. M., Berlin.

Henkel, Arthur und Albrecht Schöne (Hgg.) (1976): Emblemata: Handbuch zur Sinnbildkunst des XVI. und XVII. Jahrhunderts, Stuttgart.

Hille-Sandvoss, Angelika (1987): Überlegungen zur Bildlichkeit im Werk von Günter Grass, Stuttgart, zugl. Diss. Univ. Köln 1987.

Hoesterey, Ingeborg (1988): Verschlungene Schriftzeichen. Intertextualität von Literatur und Kunst in der Moderne/Postmoderne, Frankfurt a. M.

Hoffmann-Curtius, Kathrin (2014): Bilder zum Judenmord: Eine kommentierte Sichtung der Malerei und Zeichenkunst in Deutschland von 1945 bis zum Auschwitz-Prozess, Marburg.

Hofmann, Karl-Ludwig (Hg.) (1982): Otto Pankok: Zeichnungen, Grafik, Plastik, Berlin (West).

Hofmann, Werner (1997): Im Banne des Abgrunds. Der "Verlust der Mitte“ und der Exorzismus der Moderne: Über den Kunsthistoriker Hans Sedlmayr. In: Gerda Breuer (Hg.): Die Zähmung der Avantgarde. Zur Rezeption der Moderne in den 50er Jahren, Essen, S. 43-54.

Jappe, Georg (1990): Harry Kramer. Nicht das Vakuum füllen - die Leere realisieren. In: Willhardt (1990), S. 82-92.

Jensen, Jens Christian (1987): Günter Grass als Zeichner, in: Kat. Ausst. Kiel (1987). S. 13-22.

Joch, Peter (1997): Ohne die Feder zu wechseln. Deutungen zum bildnerischen Werk von Günter Grass, in: Kat. Ausst. Aachen (1997), S. 15-41.

- (2000): „Zaubern auf weissem Papier“ - Das graphische Werk von Günter Grass. Deutungen und Kommentare, Göttingen.

Johns, Catherine (2000): Sex or Symbol? Erotic Images of Greece and Rome, New York, Routeledge. Jürgs, Michael (2002): Bürger Grass. Biografie eines deutschen Dichters, München.

Junk, Viktor (1930): Handbuch des Tanzes, Stuttgart 1930.

Just, Georg (1972): Darstellung und Appell in der Blechtrommel von Günter Grass. Darstellungsästhetik vs. Wirkungsästhetik, Frankfurt a. M., 1972.

Jurgensen, Manfred (1974): Über Günter Grass. Untersuchungen zur sprachlichen Rollenfunktion, Bern.

- (1992): Die Sprachpuppen des Günter Grass, in: Gerd Labroisse und Dick van Stekelenburg

(Hgg.), Günter Grass, ein europäischer Autor? Amsterdamer Beiträge zur Germanistik, Bd. 35, S. $45-70$.

Kahmen, Volker (1981): Bruno Goller, Rohlandseck.

Kat. Ausst. Berlin (1977): Ludwig Gabriel Schrieber. 1907-1975. Aquarelle, Berliner Künstler der Gegenwart, Heft 22, aus Anlass der Ausstellung in den Räumen des Neuen Berliner Kunstvereins, 6.5.18.6.1977, Berlin. 
Kat. Ausst. Berlin (1979): Zinke, Berlin, 1959-1962, Anlauf, Fuchs, hrsg. vom Künstlerhaus Bethanien in Zsarb. mit d. Senator für kulturelle Angelegenheiten und dem Kunstamt Kreuzberg, Berlin.

Kat. Ausst. Berlin (1987): Eine Kulturmetropole wird geteilt. Literarisches Leben in Berlin (West), hrsg. vom Berliner Kulturrat anlässlich der Ausstellung des Realismusstudios der Neuen Gesellschaft für Bildende Kunst, Berlin.

Kat. Ausst. Berlin (1995): Schätze aus Berliner Museen: Erwerbungen aus Lottomitteln 1975-1995, anlässlich einer Ausstellung im Alten Museum am Lustgarten und im Kunstforum in der Grundkreditbank, 11.2.-5.6.1995, hrsg. von der Berliner Festspiele GmbH, Berlin.

Kat. Ausst. Berlin (2007): Ludwig Gabriel Schrieber. „Die Sonne, der Mond, die Frau“. Form und Sinnlichkeit - Zeichnungen und Skulpturen, hrsg. von Brigitta Schrieber und Dieter Brusberg, Ausstellung in der Galerie Brusberg, Berlin, 17.3.-28.4.2007, Berlin.

Kat. Ausst. Bonn (1985): Aus den Trümmern: Kunst und Kultur im Rheinland und Westfalen 19451952: Neubeginn und Kontinuität, Rhein. Landesmuseum Bonn, hrsg. von Klaus Honnef und Hans M. Schmidt, Köln.

Kat. Ausst. Cleveland (1999): Chong, Alan: Still-Life Paintings from the Netherlands, 1550-1720, Cleveland Museum of Art, 31.10.1999-1.9.2000, Amsterdam, Cleveland, Ohio.

Kat. Ausst. Dresden (2002): Mensch und Tier. Eine paradoxe Beziehung hg. von der Stiftung Deutsches Hygiene-Museum, Begleitbuch zur Ausstellung, Deutsches Hygiene-Museum, 22.11.200210.8.2003, Ostfildern-Ruit.

Kat. Ausst. Düsseldorf (1956): Deutscher Künstlerbund, 6. Ausstellung, Düsseldorf. Mit belgischen und holländischen Gästen, 2.5-5.6.1956, Berlin.

Kat. Ausst. Düsseldorf (1986): Bruno Goller: Werke aus sechs Jahrzehnten, anlässlich einer Ausstellung in der Kunstsammlung NRW, Düsseldorf, 5.10.-9.11.1986, Düsseldorf.

Kat. Ausst. Düsseldorf (1994): Oskar Schlemmer. Tanz, Theater, Bühne hg. von der Kunstsammlung Nordrhein-Westfalen, Düsseldorf, der Kunsthalle Wien, dem Sprengel Museum Hannover und dem Bühnenarchiv Oskar Schlemmer anlässlich der Ausstellungen vom 30.7.-16.10.1994 / 11.11.199429.1.1995 / 19.2.-21.5.1995, Düsseldorf.

Kat. Ausst. Frankfurt a. M. (1980): Zwischen Krieg und Frieden. Gegenständliche und realistische Tendenzen in der Kunst nach '45, hrsg. vom Frankfurter Kunstverein, Steinernes Kunsthaus, 24.10.7.12.1980, Berlin (West) 1980.

Kat. Ausst. Frankfurt a. M. (2011): Ingrid Pfeiffer (Hg.): Surreale Dinge: Skulpturen und Objekte von Dalí bis Man Ray, Schirn Kunsthalle Frankfurt, 22.2.-29.5.2011, Frankfurt a. M.

Kat. Ausst. Gdańsk (2013): Zangs at Grass's. Structural formations. Herbert Zangs and Günter Grass, hrsg. von der Gdańsk City Gallery, 28.9.2013-12.1.2014, Gdańsk.

Kat. Ausst. Leipzig (2004): Schmidt, Hans-Werner (Hg.): Willi Baumeister - Karl Hofer. Begegnung der Bilder. Anlässlich einer Ausstellung im Museum der bildenden Künste Leipzig, 19.12.2004-27.2.2005, Bielefeld.

Kat. Ausst. Los Angeles (2018): Glenn Phillips, Philipp Kaiser, Doris Chon und Pietro Rigolo (Hgg.): Harald Szeemann - Museum der Obsessionen. Anlässlich einer Ausstellung im Getty Research Institute, Los Angeles, 6. Februar-6. Mai 2018, in der Kunsthalle Bern, 9. Juni-2. September 2018 und in der Kunsthalle Düsseldorf, 10. Oktober 2018-20. Januar 2019, Zürich.

Kat. Ausst. München (1997): Margareta Benz-Zauner, Sabine Cichowski, Werner Heinzerling (Hgg.): Paul Klee: „Und ich flog". Paul Klee in Schleißheim! Anlässlich einer Ausstellung in der Flugwerft Schleißheim, 8.5.-20.9.1997, München.

Klapheck, Anna (1959): Lehrer an der Kunstakademie. Porträts der Professoren, in: Rheinische Post, 6.5.1959. 
Kinefuchi, Hiroki (2002): Zahnarzt, Ratte, Monitor. Zur Bildkommunikation bei Günter Grass, in: Doitsu-bungaku 108, S. 186-198.

Kniesche, Thomas W. (2002): „Distrust the Ornament”. Günter Grass and the Textual/Visual Imagination. In: Gegenwartsliteratur. Ein germanistisches Jahrbuch 1, S. 1-20.

Kölbel, Martin (Hg.) (2007): Ein Buch, ein Bekenntnis: Die Debatte um Günter Grass' Beim Häuten der Zwiebel, Göttingen.

- (Hg.) (2013): Willy Brandt und Günter Grass. Der Briefwechsel, Göttingen.

Krämer, Sybille, Werner Kogge, Gernot Grube (Hgg., 2007): Spur. Spurenlesen als Orientierungstechnik und Wissenskunst, Frankfurt a. M.

Krason, Viktoria (2009): Zum Verhältnis von bildender Kunst und Erzählung in der Blechtrommel, in: Jörg-Philipp Thomsa (Hg.): Ein Buch schreibt Geschichte. 50 Jahre Die Blechtrommel, Lübeck, S. 35-64.

- (2010): Danzig-Variationen im Werk von Günter Grass, in: Jörg-Philipp Thomsa u. Viktoria Krason (Hgg.), Von Danzig nach Lübeck. Günter Grass und Polen, Lübeck, S. 35-42.

- (2013): Bildende Kunst und Imagination in Günter Grass' Beim Häuten der Zwiebel, in: Miroslaw Ossowski (Hg.): Günter Grass. Werk und Rezeption, Studia Germanica Gdanensia 28, S. 81-92.

- (2013a): „Zauberei mit den Bräuten Christi” - Nonnen in Wort und Bild im Werk von Günter Grass, in: Anselm Weyer und Volker Neuhaus (Hgg.), Von Katz und Maus und mea culpa. Religiöse Motive im Werk von Günter Grass. Kölner Studien zur Literaturwissenschaft, hrsg. von Volker Neuhaus, Bd. 19, Frankfurt a. M., S. 85-114.

- (2016): Erste Bilder und Plastiken von Günter Grass - eine Fundsache aus Düsseldorf, in: Freipass. Forum für Literatur, Bildende Kunst und Politik 2, Schriften der Günter und Ute Grass Stiftung, S. 110-131.

Krause, Markus (1998): Karl Hartung 1908-1967. Metamorphosen von Mensch und Natur. Monographie und Werkverzeichnis, Katalogbuch anlässlich der Ausstellung im Germanischen Nationalmuseum Nürnberg, 4.3.-1.6.1998, München.

Krystof, Doris (1994): „Die Schlemmerkostüme nehmen die Verpackung der Kosmonauten vorweg”. Zur Rezeption von Schlemmers Bühnenwerk, in: Kat. Ausst. Düsseldorf (1994), S. 50-62.

Kunstakademie Düsseldorf (Hg.): Otto Pankok, Düsseldorf 1958 (o. Seitenzahlen).

Kurz, Paul Konrad (1969): Windhühner ausgefragt. Zur Lyrik von Günter Grass, in: Ders.: Über moderne Literatur II, Standorte und Deutungen, Frankfurt a. M., S. 237-264.

Laufhütte, Hartmut (1988): „Nein, fuhr kein Blitz aus der Wolke.“ Zu Günter Grass: „Die Ballade von der schwarzen Wolke.", in: Gunter E. Grimm (Hg.): Gedichte und Interpretationen. Deutsche Balladen, Stuttgart, S. 444-457.

Lemke, Michael (2011): Vor der Mauer. Berlin in der Ost-West-Konkurrenz 1948-1961, Zeithistorisches Studien hrsg. von dem Zentrum für Zeithistorische Forschung Potsdam, Band 48, Köln, Weimar, Wien.

Leonhard, Karin (2013): Bildfelder. Stillleben und Naturstücke des 17. Jahrhunderts, Berlin, zugl. Habil. Univ. Eichstätt-Ingolstadt 2012.

Lichtenstern, Christa (1993): Voraussetzungen und Entwicklungen naturästhetischer Perspektiven in der Skulptur und Plastik nach 1945, in: Marburger Jahrbuch für Kunstwissenschaft, 23. Band, Plastische Erkenntnis und Verantwortung. Studien zur Skulptur und Plastik nach 1945, Marburg, S. 19-42. Lurker, Manfred (1988): Wörterbuch der Symbolik, Stuttgart.

Männig, Maria (2017): Hans Sedlmayrs Kunstgeschichte. Eine kritische Studie, Köln, Weimar, Wien. 
Maiser, Myriam (2007): Der Streit um die Moderne im Deutschen Künstlerbund unter dem ersten Vorsitzenden Karl Hofer. Eine Analyse der Ausstellungen von 1951 bis 1955, zugl. Univ. Dissertation an der FU-Berlin.

Marchand, Wolf R. (2011): Die Wahlillustrierte dafür, in: Ders. (Hg.): Günter Grass auf Tour für Willy Brandt. Die legendäre Wahlkampfreise 1969, Berlin, S. 70-87.

Mason, Ann Lois (1974): The Skeptical Muse: A Study of Günter Grass' Conception of the Artist. Stanford German Studies hrsg. vom Institut für Germanistik der Universität Stanford, Kalifornien, Vol. 5, Bern, Frankfurt a. M.

Mayer, Sigrid (1982): Nachwort, in: Dreher (1982), S. 122-129.

- (1982): Graphische und lyrische Quellen zum Butt, in: Gertrud Mayer Pickar (Hg.), Adventures of a Flounder: Critical Essays on Günter Grass' Der Butt, München,

S. 16-23.

- (1995): Rückblick und Ausblick. Fünfzig Jahre im Spiegel des bildnerischen und literarischen Werkes von Günter Grass, in: Gerhard P. Knapp und Gerd Labroisse (Hgg.): 1945-1995. Fünfzig Jahre deutschsprachige Literatur in Aspekten, Amsterdam, Atlanta, S. 455-478.

Mayer(-Iswandy), Claudia (1988): Von „Unterbrechungen“ und „Engführungen“. Lyrik und Prosa in Butt und Rättin, in: H. L. Arnold (Hg.): Günter Grass. Text +Kritik. 1/1a, 6. Auflage: Neufassung, S. 84-92.

Mende, Mende (1979): Das alte Nürnberger Rathaus: Baugeschichte und Ausstattung des großen Saales und der Ratsstube, Nürnberg.

Mertens, Mathias (2005): Figurationen von Autorschaft in Öffentlichkeit und Werk von Günter Grass, Weimar.

Metken, Günter (1990): „Tanzspiel. Maschinenspiel. Elektrischer Tanz“, in: Willhardt, Michael (Hg.): Ein Frisör aus Lingen. Harry Kramer, Freren, S. 55-64.

Michalski, Katarzyna und Sergiusz (2010): Spider, London.

Michaud, Eric (1994): Das ,Triadische Ballett' zwischen Krieg und Technik, in: Kat. Ausst. Düsseldorf (1994), S. 46-49.

Minden, Michael (1990): Implications of the narrative technique in Der Butt, in: Philipp Brady u. a.

(Hgg.): Günter Grass's Der Butt: Sexual politics and the male myth of history, Oxford, S. 187-202.

- (2013): „Grass auseinandergeschrieben:“ Günter Grass' Hundejahre und Mimesis, in: The German Quarterly 86.1 (Winter 2013), S. 25-42.

Mitchell, J. W. T. (2008): Über den Vergleich hinaus: Bild, Text und Methode, in: Bildtheorie, hrsg. u. mit einem Nachwort von Gustav Frank, Frankfurt a. M., S. 136-171.

Moser, Sabine (2000): Günter Grass: Romane und Erzählungen, Berlin.

Müller, Hedwig und Patricia Stöckemann (1994): Zur Bestimmung des Ausdruckstanzes, in: Ausdruckstanz in Deutschland - Eine Inventur. Mary Wigman-Tage 1993, Dresden, 16.-19.9.1993. Zu tanzkünstlerischen und tanzpädagogischen Aspekten des Ausdruckstanzes, Jahrbuch Tanzforschung 5 (1993), Wilhelmshaven, S. 22-31.

Müller, Maria (1994a): Das Triadische Ballett, in: Kat. Ausst. Düsseldorf (1994), S. 156-161.

Münkel, Daniela (2001): Trommeln für die SPD. Die Sozialdemokratische Wählerinitiative, in: Kai Schlüter (Hg.): Günter Grass auf Tour für Willy Brandt. Die legendäre Wahlkampfreise 1969, Berlin, S. $190-223$.

Mundt, Hannelore (1989): „Doktor Faustus“ und die Folgen. Kunstkritik als Gesellschaftskritik im deutschen Roman seit 1947, Bonn.

Neubauer-Petzoldt, Ruth (2008): Schlüssel, in: Günter Butzer und Joachim Jacob (Hgg.): Metzler Lexikon literarischer Symbole, 2. Auflage, Stuttgart, S. 328-330. 
Neuhaus, Volker (1985): Das Chaos hoffnungsvoll leben... Zu Günter Grass' lyrischem Werk. In: Manfred Durzak (Hg.): Zu Günter Grass. Geschichte auf dem poetischen Prüfstand, Stuttgart, S. 20-45.

- (1988a): Das christliche Erbe bei Günter Grass. In: Text + Kritik. Günter Grass, S. 108-119.

- (1991): „Das biedermeierliche Babel" - Günter Grass und Düsseldorf, in: Ders. u. Daniela Hermes (Hgg.): Die „Danziger Trilogie" von Günter Grass. Texte, Daten, Bilder, Frankfurt a. M., S. 133-143.

- (1995): Nachwort zu Günter Grass: Mit Sophie in die Pilze gegangen, München, ohne Paginierung.

- (2009): Der „Roman meiner Epoche, verkleidet in die Geschichte eines hoch-prekären und sündigen Künstlerlebens.", in: Jörg-Philipp Thomsa (Hg.): Ein Buch schreibt Geschichte. 50 Jahre Die Blechtrommel, Lübeck, S. 65-78.

- (2010): Günter Grass, Stuttgart.

- (2010a): Günter Grass. Hundejahre. Kommentar und Materialien, Göttingen.

- (2012): Günter Grass. Eine Biographie, Göttingen.

Neumann, Bernd (1985): Konturen ästhetischer Opposition in den fünfziger Jahren. Zu Günter Grass' Die Blechtrommel (Erscheinungsjahr 1959), in: Manfred Durzak (Hg.): Zu Günter Grass. Geschichte auf dem poetischen Prüfstand, Stuttgart, S. 46-64.

Neumann, Helga (2016): „Der Schriftsteller als Zeitgenosse, wie ich meine, wird immer verquer zum Zeitgeist liegen." Zum Günter-Grass-Archiv in der Akademie der Künste, Berlin, in: Freipass. Forum für Literatur, Bildende Kunst und Politik 2, Schriften der Günter und Ute Grass Stiftung, S. 236-251.

Nowald, Inken (1978): Die Nibelungenfresken von Julius Schnorr von Carolsfeld im Königsbau der Münchner Residenz, 1827-1867. Schriften der Kunsthalle zu Kiel hg. von Jens Christian Jensen, Heft 3, Kiel.

Ohff, Heinz (1977): Einführung. In: Ludwig G. Schrieber. Aquarelle 1907-1975, Berliner Künstler der Gegenwart, Heft 22.

Overbeck, Cyrus und Oliver Müller (1995): Maler, Graphiker, Bildhauer. Eine Biographie, Düsseldorf. Øhrgaard, Per (1983): „He, Butt! Das ist deine andere Wahrheit.“ Die Romantik als Bezugspunkt in der deutschen Gegenwartsliteratur, in: Sven-Aage Jorgensen u. a. (Hgg.): Aspekte der Romantik. Vorträge des Kolloquiums am 25./26.4.1983, München, S. 128-145.

O’Neill, Patrick (1982): The Scheherazade Syndrome: Günter Grass' Meganovel Der Butt, in: Gertrud Bauer Pickar (Hg.): Adventures of a flounder. Critical essays on Günter Grass' Der Butt, München, S. 1-15.

Paaß, Michael (2009): Kulturelles Gedächtnis als epische Reflexion. Zum Werk von Günter Grass, Bielefeld.

Piontek, Heinz (1970): Männer, die Gedichte machen. Zur Lyrik heute, Hamburg.

Platen, Edgar (2001): Schreiben und Zeichnen gegen den zunehmenden Verlust. Zu Günter Grass' neuen, alle meine Möglichkeiten versammelnden Form, in: Ders. (Hg.): Perspektiven-suche. Zur Darstellung von Zeitgeschichte in der deutschsprachigen Gegenwartsliteratur, München, S. 142-160.

Postuwka, Gabriele (1999): Moderner Tanz und Tanzerziehung. Analyse historischer und gegenwärtiger Entwicklungstendenzen, Schorndorf.

Rajewsky, Irina O. (2002): Intermedialität, Tübingen.

- (2010): Border Talks: The Problematic Status of Media Borders in the Current Debate about Intermediality, in: Lars Elleström (Hg.): Media Borders, Multimodality and Intermediality, Basingstoke, S. 51-68.

Reddick, John (1975): The ,Danzig Trilogy' of Günter Grass, London. 
Renz, Christine (2000): Geschichte(n) erzählen im Zeichen von Schnecke und Zweifel. Überlegungen zu Günter Grass' Aus dem Tagebuch einer Schnecke, in: Cornelia Blasberg und Franz-Josef Deiters (Hgg.): Geschichtserfahrung im Spiegel der Literatur. Festschrift für Jürgen Schröder zum 65. Geburtstag, Tübingen, S. 365-398.

Reuter, Guido (2014): Die künstlerische Ausbildung in den Jahren des Wiederaufbaus, in: Die Geschichte der Kunstakademie Düsseldorf seit 1945, hrsg. von der Kunstakademie Düsseldorf, München, S. 132-155.

Römhild, Dorothee (2013): „Der Hund ist scharf und hält sicher nicht viel von Künstlern“. Zur kynozentrischen Poetologie der Hundejahre im Spannungsfeld der Ontologie und Ästhetik, in: Volker Neuhaus und Anselm Weyer (Hgg.): „Von Katz und Maus und mea culpa“. Religiöse Motive bei Günter Grass, Kölner Studien zur Literaturwissenschaft, Bd. 20, Frankfurt a. M., S. 35-48.

Rothenberg, Jürgen (1976): Günter Grass. Das Chaos in verbesserter Ausführung. Geschichte als Thema und Aufgabe des Prosawerks, Heidelberg.

Rühmkorf, Peter (1978): Das lyrische Weltbild der Nachkriegsdeutschen (1962), in: Jürgen Manthey (Hg.), Strömungslehre I, Hamburg, S. 11-43.

Rudolph, Ekkehart (Hg.) (1971): Protokoll zur Person. Autoren über sich und ihre Werke, München. Rudtke, Tanja (2008): Essen/Verzehren, in: Günter Butzer und Joachim Jacobs (Hgg.): Metzler Lexikon literarischer Symbole, Stuttgart.

Sammer, Marianne (2008): Hahn, in: Günter Butzer und Joachim Jacob (Hgg.): Metzler Lexikon literarischer Symbole, 2. Auflage, Stuttgart, S. $144 \mathrm{f}$.

- (2008): Henne, in: Günter Butzer und Joachim Jacob (Hgg.), Metzler Lexikon literarischer Symbole, 2. Auflage, Stuttgart, S. 152.

Schade, E. Richard (2007): Layers of Meaning, War, Art: Grass's Beim Häuten der Zwiebel, in: German Quarterly, S. 279-301.

Scheffer, Katrin (2007): Schwebende, webende Bilder. Strukturbildende Motive und Blickstrategien in Hugo von Hofmannsthals Prosaschriften, Marburg, zugl. Diss. Univ. Marburg 2007.

Schelsky, Helmut (1957): Die skeptische Generation: eine Soziologie der deutschen Jugend, Düsseldorf.

Scheper, Dirk (1988): Oskar Schlemmer - das triadische Ballett und die Bauhausbühne, Berlin. Schlinsog, Elke (2005): Berliner Zufälle: Ingeborg Bachmanns „Todesarten“-Projekt, Würzburg. Schlüter, Kai (2010): Günter Grass im Visier: die Stasi-Akte. Eine Dokumentation mit Kommentaren von Günter Grass und Zeitzeugen, Berlin.

- (2011): „In einem VW-Bus von Wahlkreis zu Wahlkreis“. Einleitung, in: Ders. (Hg.): Günter Grass auf Tour für Willy Brandt. Die legendäre Wahlkampfreise 1969, Berlin, S. 190-223.

Schöne, Albrecht (1964): Emblematik und Drama im Zeitalter des Barock, München.

Simons, Patricia (2011): The sex of men in premodern Europe: a cultural history, Cambridge.

Schilling, Klaus von (2002): Schuldmotoren. Artistisches Erzählen in Günter Grass', Danziger Trilogie', Bielefeld.

Schirrmacher, Beate (2012): Musik in der Prosa von Günter Grass. Intermediale Bezüge - Transmediale Perspektiven, Acta Universitatis Stockholmiensis, Stockholmer Germanistische Forschungen 76, Stockholm, zugl. Diss. Univ. Stockholm 2012.

- (2015): Günter Grass intermedial. Text zwischen Bild und Klang in Ein weites Feld. In: Freipass.

Schriften der Günter und Ute Grass Stiftung 1, S. 221-233.

Schneede, Uwe M. (2006): Die Kunst des Surrealismus: Malerei, Skulptur, Dichtung, Fotografie, Film, München. 
Schneider, Steffen (2008): Leda, in: Moog-Grünewald, Maria (Hg.), Mythenrezeption. Die antike Mythologie in Literatur, Musik und Kunst von den Anfängen bis zur Gegenwart, Der Neue Pauly, Supplement, Band 5, Stuttgart/Weimar, S. 408-412.

Schrott, Petra (1987): Das Scheitern des kulturellen Neubeginns, in: Kat. Ausst. Eine Kulturmetropole wird geteilt. Literarisches Leben in Berlin (West) hrsg. vom Berliner Kulturrat anläßlich der Ausstellung des Realismusstudios der Neuen Gesellschaft für Bildende Kunst, Berlin, S. 15-32.

Schwartze-Köhler, Hannelore (2009): Die Blechtrommel von Günter Grass. Bedeutung, Erzähltechnik und Zeitgeschichte, Berlin.

Schwerzmann, Katia (2012): Dimensionen des Graphismus: Die drei Pole der Linie, in: Christian Driesen et. al. (Hgg.): Über Kritzeln. Graphismen zwischen Bild, Schrift, Text und Zeichen, Zürich, S. 39-58.

Shafi, Monika (2011): Günter Grass's Beim Häuten der Zwiebel, in: Stuart Taberner (Hg.): The novel in Germany since 1990, Cambridge, S. 270-283.

Standfuss, Katja (2008): Gegenständlichkeit, Zur „neuen alle meine Möglichkeiten versammelnden Form“. Die Text-Bild-Bände von Günter Grass (=Göteborger Germanistische Forschungen 5), Göteborg, zugl. Univ. Diss. Göteborg 2008.

Stallbaum, Klaus (1989): Kunst und Künstlerexistenz im Frühwerk von Günter Grass, Köln, zugl. Diss. Univ. Köln 1988.

Stamm, Rainer (1994): Vogelscheuchen, in: Kat. Ausst. Düsseldorf (1994), S. 258 f.

Stolz, Dieter (1994): Vom privaten Motivkomplex zum poetischen Weltentwurf. Konstanten und Entwicklungen im literarischen Werk von Günter Grass (1956-1986), Würzburg, zugl. Diss. Techn. Univ. Berlin 1992.

- (2010): Günter Grass. Theaterspiele. Kommentar und Materialien, Göttingen.

Spies, Werner (2008): Der Surrealismus und seine Zeit, Berlin.

Sprenger, Jonathan (2013): Günter Grass und Maria Rama. Eine Begegnung in Leben und Werk, in: Berliner Hefte zur Geschichte des literarischen Lebens 10, S. 195-203.

Spycher, Peter (1976): Die bösen Köche von Günter Grass - ein absurdes Drama? In: Geißler (1976), S. 33-73.

Steuer, Jennifer: Versteinernde Blicke. Schamdiskurse in Günter Grass' Die Blechtrommel (1959), in: Joachim Küchenhoff/Joachim Pfeiffer/CarlPietzker (Hgg.): Scham. Freiburger literaturpsychologische Gespräche, Würzburg 2013, S. 169-188.

Tank, Kurt Lothar (1965): Günter Grass, Berlin.

- (1973): Deutsche Politik im literarischen Werk von Günter Grass, in: Manfred Jurgensen (Hg.): Kritik - Thesen - Analysen, Bern, München, S. 167-189.

Thomas, Karin (2002): Kunst in Deutschland seit 1945, Köln.

Thompson, Mary L. (1990): Günter Grass' Graphiken, in: Daniela Hermes und Volker Neuhaus (Hgg.): Günter Grass im Ausland. Texte, Daten, Bilder zur Rezeption, Frankfurt a. M., S. 115-126.

Tollowitz-Scharf, Viola (2011): Magischer Monumentalismus. Ein neues Verhältnis zur Wirklichkeit im Werk von Bruno Goller, Domenico Gnoli, Konrad Klapheck und Peter Klasen, Online-Resource: urn:nbn:de:gbv:700-201104208052, zugl. Diss. Univ. Osnabrück, Osnabrück.

Trier, Eduard (1956): Ewald Mataré, Köln.

Wagenbach, Klaus (1963): Günter Grass, in: Klaus Nonnenmann (Hg.): Schriftsteller der Gegenwart, 53 Porträts, Ölten, Freiburg, S. 118-126.

Wagner-Egelhaaf, Martina (2005): Autobiographie, 2., aktualisierte und erw. Aufl., Stuttgart.

Warren, René u. Austin Wellek (1985): Theorie der Literatur, Neuaufl., Frankfurt a. M.

Warncke, Carsten-Peter (2005): Symbol, Emblem, Allegorie: Die zweite Sprache der Bilder, Köln. 
Weber, Alexander (1995): Günter Grass' use of baroque literature, London.

Weidhase, Helmut (1990): Mimesis, in: Günther und Irmgard Schweikle (Hgg.), in: Metzler Literatur Lexikon. Begriffe und Definitionen, Stuttgart, S. 304.

Weigel, Sigrid (2015): Grammatologie der Bilder, Berlin.

Weisstein, Ulrich (1992): Literatur und bildende Kunst: ein Handbuch zur Theorie und Praxis eines komparatistischen Grenzgebietes, Berlin.

Werner, Florian (2015): Schnecken. Ein Portrait von Florian Werner, Naturkunden, Nr. 20, hrsg. von Judith Schalansky, Berlin.

Weyer, Anselm (2007): Günter Grass und die Musik, Frankfurt a. M. u.a., zugl. Diss. Univ. Köln 2005.

- (2009): „The Great Pretender" und die „falschen Fünfziger" auf Blech getrommelt. Die zeitliche Perspektive Oskar Matzeraths, in: Günter Häntzschel u. a. (Hgg.): Das Jahr 1959 in der deutschsprachigen Literatur, treibhaus. Jahrbuch für die Literatur der fünfziger Jahre, Bd. 5, München.

Willhardt, Michael (Hg.) (1990): Ein Frisör aus Lingen. Harry Kramer, Freren.

Wilpert, Gero von (2001): Sachwörterbuch der Literatur, Stuttgart.

Wieser, Theodor (1968): Günter Grass, Neuwied, Berlin.

Wolff, Vera (2011): Fortschritt, in: Uwe Fleckner, Martin Warnke und Hendrik Ziegler (Hgg.): Handbuch der politischen Ikonographie, Bd. 1, München, S. 346-352.

Wróblewska, Marta (2016): Die Danziger Günter-Grass-Galerie, in: Freipass. Forum für Literatur, Bildende Kunst und Politik 2, Schriften der Günter und Ute Grass Stiftung, S. 271-272.

Wyder, Margrit (1998): Goethes Naturmodell. Die Scala Naturae und ihre Transformationen, Köln, zugl. Diss. Univ. Zürich, 1996.

Zimmermann, Friederike (2007): „Mensch und Kunstfigur" - Oskar Schlemmers intermediale Programmatik, Freiburg im Breisgau.

Zissel-May, Brigitte (1974): Gegenständlichkeit und Weltbild. Eine Untersuchung zur Lyrik von Günter Grass, Tulane, zugl. Diss. Tulane University, 1974. 


\section{ABBILDUNGSVERZEICHNIS}

1. Hans Rama, Günter Grass in Berlin, 1955, Fotografie, Akademie der Künste, Berlin, Günter GrassArchiv / Sammlung Maria Rama, Nr. 42, (c) Akademie der Künste, Berlin.

2. Günter Grass, Die Vorzüge der Windhühner, Berlin-Frohnau, Neuwied am Rhein: Luchterhand 1956, 2. Auflage 1963, S. 38 f., Seitenformat: $20 \times 14$ cm, (C) Günter und Ute Grass Stiftung / Steidl Verlag.

3. Günter Grass, Mädchen, 1950, Bronze, Höhe: $98 \mathrm{~cm}$, Günter und Ute Grass Stiftung, Abb. aus: Günter Grass: Gebrannte Erde. Skulpturen, Göttingen: Steidl 2002, S. 20, Foto: Dirk Reinartz, (c) Günter und Ute Grass Stiftung / Steidl Verlag / Foto: Estate Dirk Reinartz.

4. Günter Grass, Mädchen mit Apfel, 1950, Bronze, Höhe: 47 cm, Günter und Ute Grass Stiftung, Abb. aus: ebd., S. 15, Foto: Dirk Reinartz, (C Günter und Ute Grass Stiftung / Steidl Verlag / Foto: Estate Dirk Reinartz.

5. Gustav Seitz, Gefesselte, 1949, Bronze, Höhe: 155 cm, WV 73, Gustav Seitz Museum. Zentrum für Kunst und Kulturpädagogik, Abb. aus: http://gustav-seitz-

museum.de/plastik/plastik htm/abb003.htm, letzter Zugriff am 2.2.2019, @ Gustav Seitz Stiftung, Hamburg.

6. Otto Pankok, Junge, 1930, Kohle, o. A., Abb. aus: Otto Pankok: Stern und Blume, Freihochschulbund Düsseldorf 1930, Abb. 130, (C) Otto Pankok Stiftung, Hünxe Drevenack.

7. Günter Grass, Skizzenbuch, Italien, 1951, Tusche, Papierformat: $23 \times 17,3 \mathrm{~cm}$, Günter und Ute Grass Stiftung, (C) Günter und Ute Grass Stiftung.

8. Günter Grass, Skizzenbuch, Italien, 1951, Tusche, Papierformat: 23 x 17,3 cm, Günter und Ute Grass Stiftung, (C) Günter und Ute Grass Stiftung.

9. Günter Grass, Mönchskopf, 1951, Gips, o. A., Verbleib unbekannt, Abb. aus: Günter Grass: Sechs Jahrzehnte. Ein Werkstattbericht, hrsg. von Fritz G. Margull u. Hilke Ohsoling, Göttingen: Steidl 2014, S. 16, (C) Günter und Ute Grass Stiftung / Steidl Verlag.

10. Pablo Picasso, Ruhender Bildhauer, II, Suite Vollard, Blatt 63, 1933, Radierung, 19,4 x 26,7 cm, Kunstmuseum Pablo Picasso Münster, Inv.-Nr. GMP-01-SV-B 325, C Succession Picasso/VG-BildKunst, Bonn 2019.

11. Günter Grass, Skizze, nach der Italienreise, 1951/1952, Kohle, o. A., Verbleib unbekannt, Abb. aus: Günter Grass: Sechs Jahrzehnte. Ein Werkstattbericht, hrsg. von Fritz G. Margull u. Hilke Ohsoling, Göttingen: Steidl 2014, S. 17, (c) Günter und Ute Grass Stiftung / Steidl Verlag.

12. Günter Grass, Torso, 1951, Gips, heute stark beschädigt, Günter und Ute Grass Stiftung, Abb. aus: ebd., S. 16, @ Günter und Ute Grass Stiftung / Steidl Verlag.

13. Alexander Archipenko, Grüne Konkave / Frau, ihr Haar kämmend, 1913, Terrakotta, Höhe: $48 \mathrm{~cm}$, Privatsammlung Frances Archipenko Gray, USA, Inv.-Nr.: $\mathrm{Cr} \mathrm{N}^{\circ}$, s.13-02A, (C) courtesy of The Archipenko Foundation / VG Bild-Kunst, Bonn 2019.

14. Pablo Picasso, Pferd und sein jonglierender Dompteur, 1920, Kreide, 21,5 x 27,3 cm, Musée Picasso, Paris, Inv. : MP952, Abbildung: @ bpk / RMN - Grand Palais / René-Gabriel Ojéda;

(C) Succession Picasso / VG-Bild-Kunst, Bonn 2019.

15. Günter Grass, Skizzenbuch, 1952, Frankreich, Feder/Tusche, 19,5 x 14,5 cm, Günter und Ute Grass Stiftung, (C) Günter und Ute Grass Stiftung.

16. Günter Grass, Skizzenbuch, Frankreich, 1952, Feder/Tusche, Papierformat: 19 x 14,5 cm, Günter und Ute Grass Stiftung, (C) Günter und Ute Grass Stiftung.

17. Günter Grass, Skizzenbuch, Frankreich, 1952, Feder/Tusche, Papierformat: 19 × 14,5 cm, Günter und Ute Grass Stiftung, (c) Günter und Ute Grass Stiftung. 
18. Günter Grass, Frau mit Kinderwagen, 1952, Bleistift, 17,3 x 12,1 cm, Günter Grass-Haus, Inv.-Nr. GGH-G 615/2005, Abb. aus: Günter Grass: Sechs Jahrzehnte. Ein Werkstattbericht, hrsg. von Fritz G. Margull u. Hilke Ohsoling, Göttingen: Steidl 2014, S. 29, (c) Günter und Ute Grass Stiftung / Steidl Verlag.

19. Günter Grass, o. T., um 1952, Feder/Tusche, 49,5 x 34 cm, Günter Grass-Haus, Inv.-Nr. GGH-G 16/2018, (C) Günter und Ute Grass Stiftung.

20. Otto Dix, Die Skatspieler, 1920, Öl und Collage auf Leinwand, $110 \times 87 \mathrm{~cm}$, Neue Nationalgalerie, Staatliche Museen zu Berlin, erworben durch die Freunde der Nationalgalerie und das Land Berlin, Inv.-Nr. FNG 74/95, (c) Neue Nationalgalerie, SMB / Jörg P. Anders / VG Bild-Kunst, Bonn 2019.

21. Günter Grass, Frau mit Hut, 1952, Aquarell, 47 x 32 cm, Sammlung Würth, Inv.-Nr. 8938, Abb. aus: Günter Grass: Mit Wasserfarben. Aquarelle, Göttingen: Steidl 2001, S. 14, @ Günter und Ute Grass Stiftung / Steidl Verlag.

22. Günter Grass, Pariser Vorortstraße, 1952, Aquarell, 36,2 x 22,5 cm, Günter und Ute Grass Stiftung, Abb. aus: ebd., S. 17, (C) Günter und Ute Grass Stiftung / Steidl Verlag.

23. Ewald Mataré, Huhn, 1928, Bronze, Höhe: $25 \mathrm{~cm}$, Verbleib unbekannt, Abb. aus: Hanns Theodor Flemming: Ewald Mataré, München: Prestel 1955, Tafel 5, Foto: Privatarchiv Ewald Mataré, (c) Museum Kurhaus Kleve / VG Bild-Kunst, Bonn 2019.

24. Günter Grass, Henne, 1956, Bronze, Höhe: $46 \mathrm{~cm}$, Günter und Ute Grass Stiftung, Abb. aus: Günter Grass: Gebrannte Erde. Skulpturen, Göttingen: Steidl 2002, S. 16, Foto: Dirk Reinartz, (c) Günter und Ute Grass Stiftung / Steidl Verlag / Foto: Estate Dirk Reinartz.

25. Bruno Goller, Kleiderschrank, 1947, Öl auf Leinwand, 85 x $65 \mathrm{~cm}$, Privatbesitz, Abb. aus: Bruno Goller: Werke aus sechs Jahrzehnten, anlässlich einer Ausstellung in der Kunstsammlung NRW, Düsseldorf, 5.10.-9.11.1986, Düsseldorf: Kunstsammlung Düsseldorf 1986, S. 31, @ Bruno GollerArchiv e. V.

26. Bruno Goller, Zwei Reifen, 1924, Öl auf Leinwand, 86 x 55 cm, Privatbesitz, Abb. aus: ebd., S. 22, (C) Bruno Goller-Archiv e. V.

27. Bruno Goller, Das Ohr, 1956, Öl auf Leinwand, $160 \times 105$ cm, Privatbesitz, Abb. aus: ebd., S. 45, (C) Bruno Goller-Archiv e. V.

28. Bruno Goller, Bild der Zahlen, 1954, Öl auf Leinwand, $150 \times 115 \mathrm{~cm}$, Nachlass des Künstlers, ebd., S. 42, (c) Bruno Goller-Archiv e. V.

29. Günter Grass, Arbeitstagebuch, 1952, S. 149 (letzte Seite), blaue Tinte, Akademie der Künste, Berlin, Günter-Grass-Archiv, Nr. 965, (c) Günter und Ute Grass Stiftung.

30. Karl Hartung, Durchlöcherte Form (Abstrakte Form), 1935, Bronze, Höhe: 42 cm, Privatbesitz, Abb. aus: Markus Krause: Karl Hartung 1908-1967. Metamorphosen von Mensch und Natur. Monographie und Werkverzeichnis, Katalogbuch anlässlich der Ausstellung im Germanischen Nationalmuseum Nürnberg, 4.3.-1.6.1998, München: Prestel 1998, S. 39, WV 149, Foto: Ewald Gnilka / FotoGnilka, Berlin, (C) VG Bild-Kunst, Bonn 2019.

31. Karl Hartung, Liegender, 1935/1938, Gips/Bronze, Höhe: 42 cm, Privatbesitz/Sprengel Museum, Hannover, Abb. aus: ebd. S. 99, WV 158, Foto: Ewald Gnilka / Foto-Gnilka, Berlin, (C VG-BildKunst, Bonn 2019.

32. Karl Hartung, Vegetative Form, um 1939, Makassar-Ebenholz, Höhe: $48,5 \mathrm{~cm}$, Privatbesitz, Abb. aus: ebd., S. 42, WV 250, Foto: Frank Bartsch, Berlin, (C VG Bild-Kunst, Bonn 2019.

33. Karl Hartung, Figurenwand I, 1953, Terrakotta, Breite: 38 cm, Privatbesitz, Abb. aus: ebd., S. 132, WV 504, Foto: Ewald Gnilka / Foto-Gnilka, Berlin, (C VG Bild-Kunst, Bonn 2019.

34. Karl Hartung, Neese II, 1957, Gips/Bronze, Höhe: 35 cm, Privatbesitz, Abb. aus: ebd., S. 141, WV 588, Foto: Ewald Gnilka / Foto-Gnilka, Berlin, (C VG Bild-Kunst, Bonn 2019. 
35. Ludwig Gabriel Schrieber, Europa II, 1948, Öl auf Leinwand, 75 x 92,5 cm, WV G 42, Galerie Remmert und Barth, Düsseldorf, (C) Simon P. Schrieber.

36. Ludwig Gabriel Schrieber, Stehende mit erhobenen Armen, 1950, Nussbaum, Höhe: $43 \mathrm{~cm}$, WV P18, Privatbesitz: Simon P. Schrieber, (C) Simon P. Schrieber.

37. Ludwig Gabriel Schrieber, Tänzerin, 1962/1963, Bronze, Höhe: 79 cm, WV P82, Privatbesitz: Simon P. Schrieber, @ Simon P. Schrieber.

38. Ludwig Gabriel Schrieber, Vor der Tür II, 1969, Relief, Stuck, bemalt, $210 \times 150 \mathrm{~cm}$, WV P104, Privatbesitz: Simon P. Schrieber, (C) Simon P. Schrieber.

39. Günter Grass, Hahn, 1954, Steinguss, Höhe: 27 cm, Günter und Ute Grass Stiftung, Abb. aus: Günter Grass: Gebrannte Erde. Skulpturen, Göttingen: Steidl 2002, S. 17, Foto: Dirk Reinartz, (C Günter und Ute Grass Stiftung / Steidl Verlag / Foto: Estate Dirk Reinartz.

40. Karl Hartung, Vogel, um 1937, Bronze, Breite: $40 \mathrm{~cm}$, Privatbesitz, Abb. aus: Markus Krause: Karl Hartung 1908-1967. Metamorphosen von Mensch und Natur. Monographie und Werkverzeichnis, Katalogbuch anlässlich der Ausstellung im Germanischen Nationalmuseum Nürnberg, 4.3.1.6.1998, München: Prestel 1998, S. 98, WV 195, (c) VG Bild-Kunst, Bonn 2019.

41. Günter Grass, Huhn, 1955, Terrakotta, Höhe: 44 cm, Privatbesitz, Abb. aus: Günter Grass: Gebrannte Erde. Skulpturen, Göttingen: Steidl 2002, S. 18, Foto: Dirk Reinartz, (C Günter und Ute Grass Stiftung / Steidl Verlag / Foto: Estate Dirk Reinartz.

42. Günter Grass, Vögel, 1955, Gipsrelief, 39 × 68,5 cm, Günter und Ute Grass Stiftung, Abb. aus: Günter Grass: Sechs Jahrzehnte. Ein Werkstattbericht, hrsg. von Fritz G. Margull u. Hilke Ohsoling, Göttingen: Steidl 2014, S. 41, (c) Günter und Ute Grass Stiftung / Steidl Verlag.

43. Günter Grass, Butt, 1955, Bronze, Breite: $54,5 \mathrm{~cm}$, Günter und Ute Grass Stiftung, Abb. aus: Günter Grass: Gebrannte Erde. Skulpturen, Göttingen: Steidl 2002, S. 17, Foto: Dirk Reinartz, (C Günter und Ute Grass Stiftung / Steidl Verlag / Foto: Estate Dirk Reinartz.

44. Günter Grass, Bergsee, 1954, Aquarell, 24,3 x 32,4 cm, Günter und Ute Grass Stiftung, (c Günter und Ute Grass Stiftung.

45. Ludwig Gabriel Schrieber, Kleiner Kirschbaum, 1953, Aquarell, 38,5 x 25 cm, Galerie Remmert und Barth, Foto: Jörg Schanze, Düsseldorf, (C Simon P. Schrieber.

46. Günter Grass, Butt, 1955, Fettkohle, $42,9 \times 61 \mathrm{~cm}$, Verbleib unbekannt, Abb. aus: Günter Grass: Sechs Jahrzehnte. Ein Werkstattbericht, hrsg. von Fritz G. Margull u. Hilke Ohsoling, Göttingen: Steidl 2014, S. 48, (C) Günter und Ute Grass Stiftung / Steidl Verlag.

47. Max Ernst, L'évadé (Der Ausbrecher) (Blatt 30 in: histoire naturelle), 1926, Lichtdruck, 50 × 32,3 cm, Staatsgalerie Stuttgart, Inv.-Nr. A 2014/7947,30, Foto: (c) Staatsgalerie Stuttgart, Graphische Sammlung; (C) VG Bild-Kunst, Bonn 2019.

48. Henry Moore, Leaf Figure No. 4, 1952, Bronze, Höhe: $49,5 \mathrm{~cm}$, Centro de Arte Reina Sofia, Madrid, Inv.-Nr. LH 326 cast 6, (c) Henry Moore Foundation.

49. Günter Grass, Skizze frei nach Dalí, 1954, Feder/Tusche, 17,8 x 22,7 cm, Günter Grass-Haus, Inv.Nr.: GGH-G 1098/2005, (c) Günter und Ute Grass Stiftung.

50. Salvador Dalí, Traum, verursacht durch den Flug einer Biene um einen Granatapfel, eine Sekunde vor dem Aufwachen, 1944, Öl auf Holz, 51 x $41 \mathrm{~cm}$, Museo Nacional Thyssen-Bornemisza, Madrid, Inv.-Nr. 510 (1974.46), (C Salvador Dalí, Fundació Gala-Salvador Dalí / VG Bild-Kunst, Bonn 2019; Provenienz: Museo Nacional Thyssen-Bornemisza, Madrid.

51. Günter Grass, Pepita, 1955, Bleistift, 60,8 x 41,8 cm, Günter Grass-Haus, Inv.-Nr. GGH-G 557/2005, (c) Günter und Ute Grass Stiftung.

52. Salvador Dalí, Hummertelefon / Hummer- oder aphrodisisches Telefon, 1936, Metall, Kunststoff, Glas, 23,3 x 17,4 cm, Museumsstiftung Post und Telekommunikation, Museum für Kommunikati- 
on Frankfurt am Main, Inv.-Nr. 4.0.34173, Foto: Roman März, (C Salvador Dalí, Fundació GalaSalvador Dalí / VG Bild-Kunst, Bonn 2019.

53. Elsa Schiaparelli in Zusammenarbeit mit Salvador Dali, Abendkleid / Woman's Dinner Dress, Februar 1937, bemalte Seide, synthetisches Pferdehaar, Paris, 132,1 cm Länge, 55,9 cm Taillenumfang, Philadelphia Museum of Modern Art, Geschenk von Mme Elsa Schiaparelli, Inv.-Nr. 1969232-52, Foto: (C) Philadephia Museums of Modern Art; @ Salvador Dalí, Fundació Gala-Salvador Dalí / VG Bild-Kunst, Bonn 2019.

54. Günter Grass, Skizze zum Gedicht „Unfall“, 1955, Feder/Tusche, 14,8 x 21 cm, Günter Grass-Haus, Inv.-Nr.: GGH-G 534/2005, (c) Günter und Ute Grass Stiftung.

55. Günter Grass, Skizze zum Gedicht „Vogelflug", 1955, Feder/Tusche, 43 x 30,5 cm, Günter GrassHaus, Inv.-Nr.: GGH-G 543/2005, (c) Günter und Ute Grass Stiftung.

56. Günter Grass, o. A., 1956, Bleistift, $21 \times 29,5 \mathrm{~cm}$, Günter und Ute Grass Stiftung, (C Günter und Ute Grass Stiftung.

57. Günter Grass, Die Vorzüge der Windhühner, Berlin-Frohnau, Neuwied am Rhein: Luchterhand 1956, Umschlag, Rückseite, 20,5 x 14,5 cm, @ Günter und Ute Grass Stiftung / Steidl Verlag.

58. Günter Grass, Die Vorzüge der Windhühner, Berlin-Frohnau, Neuwied am Rhein: Luchterhand 1956, S. 6, Seitenformat: 20,2 × 14,2 cm, (c) Günter und Ute Grass Stiftung / Steidl Verlag.

59. Günter Grass, Gleisdreieck, Darmstadt: Luchterhand 1960, S. 72 f., Seitenformat: 27 x 20,4 cm, (verwendetes Bildwerk: Diana, Fettkreide), (c) Günter und Ute Grass Stiftung / Steidl Verlag.

60. Nach Leochares, Artemis, Götting der Jagd, genannt „Diana von Versailles“, erste Hälfte des zweiten Jh. n. Chr. (Kopie, Original: 340-320 v. Chr.), Marmor, Höhe: 201 cm, Louvre, Paris, Foto: Eric Gaba, 2005, Abb. aus:

https://commons.wikimedia.org/wiki/File:Diane de Versailles Leochares 2.jpg, letzter Zugriff am 2.2.2019, (C) gemeinfrei.

61. Pablo Picasso, Zwei laufende Frauen am Strand, 1922, Öl auf Leinwand, $32 \times 41$ cm, Musée Picasso, Paris, Inv.-Nr. MP78, Abbildung: (c) bpk / RMN - Grand Palais / Jean-Gilles Berizzi; (c) Succession Picasso / VG-Bild-Kunst, Bonn 2019.

62. Günter Grass, Skizzenbuch, Italien, Sommer bis Frühherbst 1951, Feder/Tusche, Papierformat: $23 \times 17,3 \mathrm{~cm}$, Günter und Ute Grass Stiftung, (C) Günter und Ute Grass Stiftung.

63. Günter Grass, Huhn, 1952, Feder/Tusche, 16,5 x 19 cm, Günter Grass-Haus, Inv.-Nr.: GGH-G 564/2005, Abb. aus: Günter Grass: Sechs Jahrzehnte. Ein Werkstattbericht, hrsg. von Fritz G. Margull u. Hilke Ohsoling, Göttingen: Steidl 2014, S. 30, (C) Günter und Ute Grass Stiftung / Steidl Verlag.

64. Pablo Picasso, Coq/Hahn, 1918, Gouache auf Papier, 22,6 x 27,8 cm, Musée Picasso, Paris, Inv.-Nr. MP798, Abbildung: @ bpk-Bildagentur / RMN - Grand Palais / image RMN-GP;

(C) Succession Picasso / VG-Bild-Kunst, Bonn 2019.

65. Günter Grass, Huhn, 1954, Steinguss, Höhe: 27 cm, Günter und Ute Grass Stiftung, Abb. aus: Günter Grass: Sechs Jahrzehnte. Ein Werkstattbericht, hrsg. von Fritz G. Margull u. Hilke Ohsoling, Göttingen: Steidl 2014, S. 40, (C) Günter und Ute Grass Stiftung / Steidl Verlag.

66. Günter Grass, Huhn, 1954, Steinguss, o. A., Verbleib unbekannt, Abb. aus: ebd., @ Günter und Ute Grass Stiftung / Steidl Verlag.

67. Günter Grass, Hahn im Gebirge, 1954, Radierung, 9,5 x 26,5 cm (Platte), Günter Grass-Haus, Inv.Nr.: GGH-G 592/2005, Abb. aus: ebd., (C) Günter und Ute Grass Stiftung / Steidl Verlag.

68. Günter Grass, Vogel, 1954, Feder/Tusche, 22 x 7,3 cm, Günter Grass-Haus, Inv.-Nr.: GGH-G 1043/2005, (c) Günter und Ute Grass Stiftung. 
69. Günter Grass, Vogel, 1954, Fettkreide, 33 x 12,9 cm, Günter Grass-Haus, Inv.-Nr.: GGH-G 1044/2005, (C) Günter und Ute Grass Stiftung.

70. Günter Grass, Skizze für ein Ballettlibretto, 1955, Feder/Tusche, Verbleib unbekannt, Abb. aus: Günter Grass: Sechs Jahrzehnte. Ein Werkstattbericht, hrsg. von Fritz G. Margull u. Hilke Ohsoling, Göttingen: Steidl 2014, S. 74, (c) Günter und Ute Grass Stiftung / Steidl Verlag.

71. Peter Paul Rubens, Leda mit dem Schwan, 1598-1600, Öl auf Eichenholz, $122 \times 182 \mathrm{~cm}$, Staatliche Kunstsammlungen Dresden, Gemäldegalerie Alte Meister, Foto: H. P. Klut, @ Gemäldegalerie Alte Meister, Staatliche Kunstsammlungen Dresden, Foto: H. P. Klut.

72. Francesco Melzi nach Leonardo da Vinci, Leda und der Schwan, 1508-1515, Öl auf Holz, 130 x 77,5 $\mathrm{cm}$, Galleria degli Uffizi, Florenz, Abb. aus:

https://commons.wikimedia.org/wiki/File:Leda Melzi Uffizi.jpg, letzter Zugriff am 2.2.2019, (C) gemeinfrei.

73. Günter Grass, Frau mit Vogel / Leda, 1955, Feder/Sepia, 23,9 x 18 cm, Günter Grass-Haus, Inv.-Nr.: GGH-G 1087/2005 , Abb. aus: Günter Grass. Hundert Zeichnungen 1955 bis 1987, hrsg. von Jens Christian Jensen, Kunsthalle zu Kiel der CAU, 11.10.-22.11.1987, Kiel 1987, S. 31, (c) Günter und Ute Grass Stiftung / Steidl Verlag.

74. Günter Grass, Leda, 1956, Feder/Tusche, $95,4 \times 64,7 \mathrm{~cm}$, Verbleib unbekannt, Abb. aus: Anselm Dreher (Hg.), Günter Grass: Zeichnen und Schreiben, 2 Bde., 1. Bd.: Zeichnungen und Texte 19541977, Darmstadt: Luchterhand 1982, S. 25, Nr. 11, C Günter und Ute Grass Stiftung / Steidl Verlag.

75. Günter Grass, Mädchen- und Vogelkopf, 1955, Feder/Tusche, 34,9 x 22,5 cm, Günter Grass-Haus, Inv.-Nr.: GGH-G 563/2005, Abb. aus: Günter Grass: Lyrische Beute. Gedichte und Zeichnungen aus fünfzig Jahren, Göttingen: Steidl 2004, S. 14, (c) Günter und Ute Grass Stiftung / Steidl Verlag.

76. Günter Grass, Die Vorzüge der Windhühner, Berlin-Frohnau, Neuwied am Rhein: Luchterhand 1956, Umschlag, Seitenformat: $20 \times 14 \mathrm{~cm}$, (c) Günter und Ute Grass Stiftung / Steidl Verlag.

77. Günter Grass, $A B C, 1956$, Feder/Tusche, $16,5 \times 11,5 \mathrm{~cm}$, Günter und Ute Grass Stiftung, (C Günter und Ute Grass Stiftung.

78. Günter Grass, Huhn mit Schlüssel, 1955, Feder/Tusche, laviert, $48,5 \times 62,7 \mathrm{~cm}$, Privatbesitz, Abb. aus: Anselm Dreher (Hg.), Günter Grass: Zeichnen und Schreiben, 2 Bde., 1. Bd.: Zeichnungen und Texte 1954-1977, Darmstadt: Luchterhand 1982, S. 6, (C Günter und Ute Grass Stiftung / Steidl Verlag.

79. Günter Grass, Die Vorzüge der Windhühner, Berlin-Frohnau, Neuwied am Rhein: Luchterhand 1956, S. 54 f., Seitenformat: 20 x 14 cm (verwendetes Bildwerk: K der Käfer, Feder/Tusche), (c) Günter und Ute Grass Stiftung / Steidl Verlag.

80. Günter Grass, Lingua, 1955, Feder/Tusche, 42,8 x 30,5 cm, Günter Grass-Haus, Inv.-Nr.: GGH-G 535/2005, (c) Günter und Ute Grass Stiftung.

81. Günter Grass, Die Vorzüge der Windhühner, Berlin-Frohnau, Neuwied am Rhein: Luchterhand 1956, 2. Auflage: 1963, S. 38, Seitenformat: 20 x 14 cm (verwendetes Bildwerk: Fünf Vögel, Feder/Tusche), (c) Günter und Ute Grass Stiftung / Steidl Verlag.

82. Günter Grass, Vogel, 1955, Bronze, Höhe: $87 \mathrm{~cm}$, Verbleib unbekannt, Abb. aus: Günter Grass: Gebrannte Erde. Skulpturen, Göttingen: Steidl 2002, S. 22, Foto: Dirk Reinartz, (C Günter und Ute Grass Stiftung / Steidl Verlag / Foto: Estate Dirk Reinartz.

83. Günter Grass, Vogel, 1955, Bronze, Höhe: 87 cm, Detailansicht, Günter und Ute Grass Stiftung, Abb. aus: ebd., Foto: Dirk Reinartz, (C Günter und Ute Grass Stiftung / Steidl Verlag / Foto: Estate Dirk Reinartz. 
84. Constantin Brancusi, Vogel im Raum, um 1924, polierte Bronze, schwarzer Marmor, 127,8 cm x 45 $\mathrm{cm}$, Sockel: $16 \mathrm{~cm}$, Philadelphia Museum of Art, The Louise and Walter Arensberg Collection, Inv.Nr. 1950-134-14,15, (C) Artists Rights Society (ARS), New York / ADAGP, Paris; Succession Brancusi - All rights reserved / VG Bild-Kunst, Bonn 2019.

85. Günter Grass, Die Vorzüge der Windhühner, Berlin-Frohnau, Neuwied am Rhein: Luchterhand 1956, S. 26, Seitenformat: 20,2 x 14,2 cm, (C) Günter und Ute Grass Stiftung / Steidl Verlag.

86. Günter Grass, Umschlagentwurf für Die Blechtrommel (Ausschnitt), 1959, Plakafarben, 20,5 x 42 cm, Günter Grass-Haus, Inv.-Nr.: GGH-G 609/2005, Abb. aus: Günter Grass: Sechs Jahrzehnte. Ein Werkstattbericht, hrsg. von Fritz G. Margull u. Hilke Ohsoling, Göttingen: Steidl 2014, S. 84, () Günter und Ute Grass Stiftung / Steidl Verlag.

87. Günter Grass, Manuskript zum Gedicht „Theater“ („Zauberei mit den Bräuten Christi“), um 1957, Bleistift, 26,9 × $21 \mathrm{~cm}$, Akademie der Künste, Berlin, Günter-Grass-Archiv, Nr. 948, ( Günter und Ute Grass Stiftung.

88. Plakat für eine Ausstellung von Günter Grass in der Galerie „zinke“ mit einer Federzeichnung von Günter Grass, 1961, Verbleib unbekannt, Abb. aus: Günter Grass: Sechs Jahrzehnte. Ein Werkstattbericht, hrsg. von Fritz G. Margull u. Hilke Ohsoling, Göttingen: Steidl 2014, S. 93, (c) Günter und Ute Grass Stiftung / Steidl Verlag.

89. Günter Grass, Versammlung, 1961, Pinsel/Tusche, 62,8 x 48,6 cm, Günter Grass-Haus, Inv.-Nr.: GGH-G 744/2005, Abb. aus: ebd., S. 107, (c) Günter und Ute Grass Stiftung / Steidl Verlag.

90. Günter Grass, Ein Pulk Nonnen, 1961, Pinsel/Tusche, laviert, Verbleib unbekannt, o. A., Abb. aus: Günter Grass: Auf einem anderen Blatt. Zeichnungen, Göttingen: Steidl 1999, S. 34, (c) Günter und Ute Grass Stiftung / Steidl Verlag.

91. Günter Grass, Die Ballerina, Berlin: Friedenauer Presse 1963, 2. Auflage, 1965, Umschlag, Titelbild, $21 \times 14,8 \mathrm{~cm}$, (C) Günter und Ute Grass Stiftung /Friedenauer Presse.

92. Günter Grass, Schwester Agneta, 1957, Bleistift und Kohle, 65,3 x $50 \mathrm{~cm}$, Verbleib unbekannt, Abb. aus: Anselm Dreher (Hg.), Günter Grass: Zeichnen und Schreiben, 2 Bde., 1. Bd.: Zeichnungen und Texte 1954-1977, Darmstadt: Luchterhand 1982, S. 21, C Günter und Ute Grass Stiftung / Steidl Verlag.

93. Maria Wichłacz-Musielak, Vinzentinerin Jean Gabriel Batke mit Flügelhaube, 1961, Fotografie, Abb. aus:

https://de.wikipedia.org/wiki/Genossenschaft_der_T\%C3\%B6chter_der_christlichen_Liebe_vom_ hl._Vinzenz_von_Paul\#/media/File:S\%C5\%93ur_Jean_Gabriel_Batke.jpg, letzter Zugriff am: 21.9.2016.

94. Günter Grass, Vinzentinerin, 1957, Bleistift, 50 x 65,2 cm, Günter Grass-Haus, Inv.-Nr.: GGH-G 669/2005, (C) Günter und Ute Grass Stiftung.

95. Günter Grass, Manuskript und Zeichnung zum Gedicht „Mit Wind“, um 1957, Tusche, 26,9 × $21 \mathrm{~cm}$, Akademie der Künste, Berlin, Günter-Grass-Archiv, Nr. 533, @ Günter und Ute Grass Stiftung.

96. Günter Grass, Gleisdreieck, Darmstadt: Luchterhand 1960, S. 46 f. (verwendetes Bildwerk: Zwei Nonnen, Fettkreide), Seitenformat: $27 \times 20,4 \mathrm{~cm}$, (c) Günter und Ute Grass Stiftung / Steidl Verlag.

97. Günter Grass, Gleisdreieck, Darmstadt: Luchterhand 1960, S. 48, (verwendetes Bildwerk: Neun Nonnen, Fettkreide), Seitenformat: $27 \times 20,4 \mathrm{~cm}$, (C) Günter und Ute Grass Stiftung / Steidl Verlag.

98. Günter Grass, Gleisdreieck, Darmstadt: Luchterhand 1960, S. 53 f., (verwendetes Bildwerk: Nonnen versammelt, Fettkreide), Seitenformat: $27 \times 20,4 \mathrm{~cm}$, (c) Günter und Ute Grass Stiftung / Steidl Verlag. 
99. Günter Bruno Fuchs, Eine schwere Last, 1961, Pinsel/Tusche, $31 \times 42 \mathrm{~cm}$, Nachlass G. B. Fuchs, Berlin, Abb. aus: Zinke, Berlin, 1959-1962, Anlauf, Fuchs, hrsg. vom Künstlerhaus Bethanien in Zsarb. mit d. Senator für kulturelle Angelegenheiten und dem Kunstamt Kreuzberg, Berlin 1979, S. 78, (C) Nachlass Günter Bruno Fuchs.

100. Günter Anlauf, Meine Freunde Fuchs und Schnell, o. D., Bronze, o. A., Abb. aus: ebd., S. 90, (C) Hilde Zenker.

101. Günter Grass, Hüpfende/Springende Nonne, Pinsel/Tusche, laviert, 1960, 85,7 x $61 \mathrm{~cm}$, Günter Grass-Haus, Inv.-Nr.: GGH-G 1071/2005, Abb. aus: Anselm Dreher (Hg.), Günter Grass: Zeichnen und Schreiben, 2 Bde., 1. Bd.: Zeichnungen und Texte 1954-1977, Darmstadt: Luchterhand 1982, S. 61, Abb. 36, (c) Günter und Ute Grass Stiftung / Steidl Verlag.

102. Günter Grass, Knieende Nonnen, 1960, Pinsel/Tusche, laviert, o. A., Verbleib unbekannt, Abb. aus: Günter Grass: Auf einem anderen Blatt. Zeichnungen, Göttingen: Steidl 1999, S. 35, (C) Günter und Ute Grass Stiftung / Steidl Verlag.

103. Günter Grass, Betende/Knieende Nonne, 1961, Pinsel/Tusche, laviert, o. A., Verbleib unbekannt, Abb. aus: ebd., S. 38, (C) Günter und Ute Grass Stiftung / Steidl Verlag.

104. Günter Grass, Äbtissin kleidet zwei Novizinnen ein, 1961, Pinsel/Tusche, laviert, $88 \times 62,5 \mathrm{~cm}$, Verbleib unbekannt, Abb. aus: Anselm Dreher (Hg.), Günter Grass: Zeichnen und Schreiben, 2 Bde., 1. Bd.: Zeichnungen und Texte 1954-1977, Darmstadt: Luchterhand 1982, S. 62, Nr. 37, (c Günter und Ute Grass Stiftung / Steidl Verlag.

105. Günter Grass, Ruhende Nonnen, 1962, Pinsel/Tusche, laviert, 43,9 × $62 \mathrm{~cm}$, Günter Grass-Haus, Inv.-Nr.: GGH-G 713/2005, (c) Günter und Ute Grass Stiftung.

106. Günter Grass, Skizze zum Ballett Die Vogelscheuchen, 1957, Pinsel/Tusche, laviert, 42,2 × 56,3 cm, Günter Grass-Haus, Inv.-Nr.: GGH-G 651/2005, Abb. aus: Anselm Dreher (Hg.), Günter Grass: Zeichnen und Schreiben, 2 Bde., 1. Bd.: Zeichnungen und Texte 1954-1977, Darmstadt: Luchterhand 1982, S. 33, Abb. 16, (C) Günter und Ute Grass Stiftung / Steidl Verlag.

107. Günter Grass, Skizze zum Ballett Die Vogelscheuchen, 1957, Feder/Tusche, 32,6 x 28,5 cm, Günter Grass-Haus, Inv.-Nr.: GGH-G 528/2005, Abb. aus: Günter Grass: Sechs Jahrzehnte. Ein Werkstattbericht, hrsg. von Fritz G. Margull u. Hilke Ohsoling, Göttingen: Steidl Verlag 2014, S. 79, (C) Günter und Ute Grass Stiftung / Steidl Verlag.

108. Günter Grass, Mechanische Vogelscheuchen, 1960, Fettkreide, 43,1 x $61 \mathrm{~cm}$, Verbleib unbekannt, Abb. aus: Anselm Dreher (Hg.), Günter Grass: Zeichnen und Schreiben, 2 Bde., 1. Bd.: Zeichnungen und Texte 1954-1977, Darmstadt: Luchterhand 1982, S. 35, Abb. 18, (C Günter und Ute Grass Stiftung / Steidl Verlag.

109. Oskar Schlemmer, Das Triadischen Ballett, Figurinen als Teil der Revue Wieder Metropol, im Metropol-Theater, Berlin, 1926, Fotograf: E. Schneider, Bühnen Archiv Oskar Schlemmer, Photo Archiv C. Raman Schlemmer, (C2019 Bühnen Archiv Oskar Schlemmer, 28824 Oggebbio Italia, www.schlemmer.org.

110. Oskar Schlemmer, Das Triadische Ballett, Figurine mit Kugelhänden, Gelbe Reihe, 1922, Bühnen Archiv Oskar Schlemmer, erstmals veröffentlicht 1925 in Oskar Schlemmer: Die Bühne im Bauhaus, München 1925, Photo Archiv C. Raman Schlemmer, (C2019 Bühnen Archiv Oskar Schlemmer, 28824 Oggebbio Italia, www.schlemmer.org.

111. Oskar Schlemmer, Vogelscheuchen, Der Ritter, 1928, Bleistift, Aquarell, Gold- und Silberbronze auf weißlichem Maschinenbütten, auf Karton aufgezogen, 50,9/50,7 x 37,9/38,3 cm, Bühnen Archiv Oskar Schlemmer, erstmals veröffentlicht in Vogelscheuchen Programmfaltblatt Stadttheater Hagen i. W., Photo Archiv C. Raman Schlemmer, (C2019 Bühnen Archiv Oskar Schlemmer, 28824 Oggebbio Italia, www.schlemmer.org. 
112. Harry Kramer und Wolfgang Ramsbott, Still aus dem Film Die Schleuse, 1961, Abb. aus: Stefan Lüddemann: Harry Kramer. Kunst der Gegenwart aus Niedersachsen, Bd. 64, hrsg. durch die Niedersächsische Lotto Stiftung, Bonn: Artnetworkx 2007, S. 23, (C) VG Bild-Kunst, Bonn 2019.

113. Harry Kramer und Wolfgang Ramsbott, Still aus dem Film Die Schleuse, 1961, Abb. aus: ebd., S. 23, (c) VG Bild-Kunst, Bonn 2019.

114. Die Nibelungen-Sage, Sigfried und Kriemhild, nach dem Fresko-Gemälde von Julius Schnorr von Karolsfeld i. d. Königlichen Residenz zu München, photographiert im Auftrage seiner Majestät König Ludwig II. von Bayern von Jos. Albert, Königl. Bayer. \& Kaiserl. Russ. Hofphotograph, München 1921, Eigenthum und Verlag von Jos. Albert Briennerstrasse 45, Tafel 2, (C) gemeinfrei.

115. George Grosz und John Heartfield, Der wildgewordene Spießer Heartfield (elektro-mechanische Tatlin-Plastik), 1920, Rekonstruktion Michael Sellmann 1988, Installation (Schneiderpuppe, Revolver, Klingel, Messer und Gabel, „C", „27", Gebiss, schwarzer Adlerorden, EK II, Osram Glühbirne), $130 \times 45 \times 45 \mathrm{~cm}$, Berlinische Galerie, erworben aus Projektmitteln des Senators für Kulturelle Angelegenheiten, Berlin, 1988, Inv.-Nr. BG-0 7083/93, (C Estate of George Grosz, Princeton, N. J. / VG Bild-Kunst, Bonn 2019; (c) The Heartfield Community of Heirs / VG Bild-Kunst, Bonn 2019.

116. Paul Klee, Zwitscher-Maschine, 1922, Ölpause, Aquarell und Stift/Tinte auf Papier, auf Karton aufgezogen, Papier: 41,3 × 30,5 cm, Karton: 63,8 x 48,1 cm, Erwerb 564.1939, (c) 2019. Digital image, The Museum of Modern Art, New York/Scala, Florenz.

117. Günter Grass, Skizze zum Ballett Die Vogelscheuchen, 1957, Pinsel/Tusche, laviert, 42,2 ×56,3 cm, Günter Grass-Haus, Inv.-Nr.: GGH-G 528/2005, Abb. aus: Anselm Dreher (Hg.), Günter Grass:

Zeichnen und Schreiben, 2 Bde., 1. Bd.: Zeichnungen und Texte 1954-1977, Darmstadt: Luchterhand 1982, S. 33, Abb. 16, (c) Günter und Ute Grass Stiftung / Steidl Verlag.

118. Günter Grass, Hundejahre, Göttingen: Steidl 2013 (1963), dreibändige illustriert Jubiläumsausgabe, Seitenformat: $25 \times 17,5 \mathrm{~cm}$, Bd. 1, S. 49, (C) Günter und Ute Grass Stiftung / Steidl Verlag.

119. Ingeborg Bachmann, Ein Ort für Zufälle, mit 13 Zeichnungen von Günter Grass, Berlin: Wagenbach 1965, S. 6, Seitenformat: 21,2 x 12,5 cm, (C 1965, 1999 Verlag Klaus Wagenbach; Bildwerk:

(C) Günter und Ute Grass Stiftung / Steidl Verlag.

120. Ingeborg Bachmann, Ein Ort für Zufälle, mit 13 Zeichnungen von Günter Grass, Berlin: Wagenbach 1965, S. 31, Seitenformat: 21,2 x 12,5 cm, (C 1965, 1999 Verlag Klaus Wagenbach; Bildwerk:

(C) Günter und Ute Grass Stiftung / Steidl Verlag.

121. Ingeborg Bachmann, Ein Ort für Zufälle, mit 13 Zeichnungen von Günter Grass, Berlin: Wagenbach 1965, S. 60 f., Seitenformat: 21,2 x 12,5 cm, (C 1965, 1999 Verlag Klaus Wagenbach; Bildwerk:

(c) Günter und Ute Grass Stiftung / Steidl Verlag.

122. Ingeborg Bachmann, Ein Ort für Zufälle, mit 13 Zeichnungen von Günter Grass, Berlin: Wagenbach 1965, S. 17, Seitenformat: 21,2 x 12,5 cm, (C 1965, 1999 Verlag Klaus Wagenbach; Bildwerk:

(c) Günter und Ute Grass Stiftung / Steidl Verlag.

123. Günter Grass, Ausgefragt, Darmstadt: Luchterhand 1967, S. 84, Seitenformat: 20,5 x $14 \mathrm{~cm}$, (C) Günter und Ute Grass Stiftung / Steidl Verlag.

124. Günter Grass, Aus dem Tagebuch einer Schnecke, Darmstadt: Luchterhand 1972, Umschlag, $20,5 \times 27,5 \mathrm{~cm}$, (c) Günter und Ute Grass Stiftung / Steidl Verlag.

125. Günter Grass, Aus dem Tagebuch einer Schnecke, Darmstadt: Luchterhand 1972, Umschlag, Titelbild, 20,5 x $12 \mathrm{~cm}$, (C) Günter und Ute Grass Stiftung / Steidl Verlag.

126. Günter Grass, zu „Meine grüne Wiese“, 1955, Feder/Tusche, 48,6 x 63 cm, Akademie der Künste, Berlin, Kunstsammlung, Inv.-Nr. HZ 2007, Standort III-3, (C) Günter und Ute Grass Stiftung / VG Bild-Kunst, Bonn 2019. 
127. Thomas Hoepker, Günter Grass mit Hahn, 1969, Fotografie, Galerie Mucha,

(C) Thomas Hoepker/Magnumphotos.

128. Maria Rama, Günter Grass mit Schnecke, 1972, Fotografie, Akademie der Künste, Berlin, Grass-Archiv / Sammlung Maria Rama, Nr. 273.1, (c) Akademie der Künste, Berlin.

129. Günter Grass, Roman-Entwurf, 8.8.1969, Kugelschreiber/Bleistift, Akademie der Künste, Berlin, Günter-Grass-Archiv, Nr. 169, (C) Günter und Ute Grass Stiftung.

130. Günter Grass, „Schema: Im Schneckenhaus“, Berlin, 20. Nov. 1969, Feder/Tusche, Verbleib unbekannt, Abb. aus: Günter Grass: Sechs Jahrzehnte. Ein Werkstattbericht, hrsg. von Fritz G. Margull u. Hilke Ohsoling, Göttingen: Steidl 2014, S. 163, (c) Günter und Ute Grass Stiftung / Steidl Verlag.

131. Günter Grass, Arbeitsplan zu Beim Häuten der Zwiebel, 26. Juli 2003, Feder/Tusche, Günter und Ute Grass Stiftung, Abb. aus: ebd., S. 504, @ Günter und Ute Grass Stiftung / Steidl Verlag.

132. Günter Grass, Selbst mit Schnecken, 20.5.1972, Bleistift auf Zeichenkarton, $65 \times 100 \mathrm{~cm}$, Privatbesitz, Abb. aus: Anselm Dreher (Hg.), Günter Grass: Zeichnen und Schreiben, 2 Bde., 1. Bd.:

Zeichnungen und Texte 1954-1977, Darmstadt: Luchterhand 1982, S. 87, Nr. 54, (C Günter und Ute Grass Stiftung / Steidl Verlag.

133. Günter Grass, „Die Gleitspur“, 22.8.1971, Tinte, Akademie der Künste, Berlin, Günter-GrassArchiv, Nr. 2081, (C) Günter und Ute Grass Stiftung.

134. Günter Grass, Schneckenkomposition, 1972, Kohle, 50,8 x 72,8 cm, Günter Grass-Haus, Inv.-Nr. GGH-G 881/2005, Abb. aus : Günter Grass: Sechs Jahrzehnte. Ein Werkstattbericht, hrsg. von Fritz G. Margull u. Hilke Ohsoling, Göttingen: Steidl 2014, S. 148, (c) Günter und Ute Grass Stiftung / Steidl Verlag.

135. Salvador Dalí, Gebirgssee, 1938, Öl auf Leinwand, 73 x $91 \mathrm{~cm}$, Tate Gallery of Modern Art, London, Foto: (C) Tate, London 2019, (C) Salvador Dalí, Fundació Gala-Salvador Dalí / VG Bild-Kunst, Bonn 2019.

136. Ausschnitt aus Abb. 135.

137. Günter Grass, Besetzt / Schnecke hört mit, 1971, Feder/Tusche, 29,6 x 40,8 cm, Günter GrassHaus, Inv.-Nr.: GGH-G 886/2005, Abb. aus: Günter Grass: Lyrische Beute. Gedichte und Zeichnungen aus fünfzig Jahren, Göttingen: Steidl 2004, S. 147, @ Günter und Ute Grass Stiftung / Steidl Verlag.

138. Günter Grass, Pfeilschnelle Schnecke, 12.3.1971, Bleistift, Privatbesitz, 51 x $73 \mathrm{~cm}$, Abb. aus: Anselm Dreher (Hg.), Günter Grass: Zeichnen und Schreiben, 2 Bde.: I: Zeichnungen und Texte 1954-1977, Darmstadt: Luchterhand 1982, S. 88, Abb. 55, (C) Günter und Ute Grass Stiftung / Steidl Verlag.

139. Festina lente, 1613, Wandbild, Nürnberg, Altes Rathaus, zerstört 1944/1945, Aufnahme von Müller und Sohn 1943/1945, Foto: Müller \& Sohn, @ Zentralinstitut für Kunstgeschichte, Farbdiaarchiv.

140. Günter Grass, Mit Pilz und Schnecke, 1971, Kohle, Günter Grass-Haus, Inv.-Nr. GGH-G 883/2005, $51 \times 72,8 \mathrm{~cm}$, (c) Günter und Ute Grass Stiftung.

141. Günter Grass, zu Schnecke in der Tuchler Heide, 6.4.1972, Bleistift, 29,8 × 39, 2 cm, Günter GrassHaus, Inv.-Nr.: GGH-G 890/2005, Abb. aus: Günter Grass: Sechs Jahrzehnte. Ein Werkstattbericht, hrsg. von Fritz G. Margull u. Hilke Ohsoling, Göttingen: Steidl 2014, S. 154, (C) Günter und Ute Grass Stiftung / Steidl Verlag.

142. Günter Grass, Schnecke in Eilat, 13.11.1971, Bleistift, 29,7 x 39,2 cm, Günter Grass-Haus, Inv.-Nr. GGH-G 891/2005, Abb. aus: ebd., S. 150, (c) Günter und Ute Grass Stiftung / Steidl Verlag. 
143. Albrecht Dürer, Melencolia I, 1514, Kupferstich, 23,8 x 18,5 cm, Staatliche Museen zu Berlin, Kupferstichkabinett, Inv.-Nr.: 102-1893, Foto: Jörg P. Anders, (c) Kupferstichkabinett. Staatliche Museen zu Berlin.

144. Günter Grass, Schnecke am Wasserturm, 15.8.1971, Bleistift, 23,4 x 17,1 cm, Verbleib unbekannt, Abb. aus: Günter Grass. Hundert Zeichnungen 1955 bis 1987, hrsg. von Jens Christian Jensen, Kunsthalle zu Kiel der CAU, 11.10.-22.11.1987, Kiel 1987, S. 83, (c) Günter und Ute Grass Stiftung / Steidl Verlag.

145. Günter Grass, Mariazuehren, München: F. Bruckmann KG 1973, S. 18 f., Seitenformat: 23 x $22 \mathrm{~cm}$ (verwendetes Bildwerk: Pilze, Glas mit Schnecken und Klinge, 1972, Blei), (c) Günter und Ute Grass Stiftung / Verlag F. Bruckmann KG, München.

146. Günter Grass, Mariazuehren, München: F. Bruckmann KG 1973, S. 22 f., Seitenformat: 23 x $22 \mathrm{~cm}$ (verwendetes Bildwerk: Pilze, 1972, Feder/Tusche, Foto), (c) Günter und Ute Grass Stiftung / Verlag F. Bruckmann KG, München.

147. Günter Grass, Mariazuehren, München: F. Bruckmann KG 1973, S. 24 f., Seitenformat: 23 x 22 cm (verwendetes Bildwerk: Pimmelpilze, 1973, Radierung) (c) Günter und Ute Grass Stiftung / Verlag F. Bruckmann KG, München.

148. Bekrönter Phallus mit Flügeln und Glöckchen, 1375-1425, Blei-Zinn-Legierung, 2,9 × 2,8 cm, Family Van Beuningen Collection, Langbroek, Niederlande, Inv.-Nr. 1856, (c) Family Van Beuningen Collection, Langbroek, Niederlande.

149. Günter Grass, Ohr im Wind, 1974, Ätzradierung auf ausgesägtem Kupfer, 24 x $16 \mathrm{~cm}$ (Platte), 40,8 x 38,2 cm (Papier), aus dem Portfolio Liebe geprüft, 1974, Günter Grass-Haus, Inv.-Nr.: GGH-G 69/2005, Abb. aus: Hilke Ohsoling (Hg.), Günter Grass: Catalogue Raisonné, Bd. 1: Radierungen, Göttingen: Steidl 2007, S. 143, R 69, C Günter und Ute Grass Stiftung / Steidl Verlag.

150. Bruno Goller, Das Ohr, 1956, Öl auf Leinwand, $160 \times 105 \mathrm{~cm}$, Privatbesitz, Abb. aus: Bruno Goller: Werke aus sechs Jahrzehnten, anlässlich einer Ausstellung in der Kunstsammlung NRW, Düsseldorf, 5.10.-9.11.1986, Düsseldorf: Kunstsammlung Düsseldorf 1986, S. 45, (C) Bruno Goller-Archiv e. V.

151. Günter Grass, Liebe geprüft, 1974, Ätzradierung auf Kupfer, 16 × $30 \mathrm{~cm}$ (Platte), 38,2 × 40,8 cm (Papier), aus dem Portfolio Liebe geprüft, 1974, Günter Grass-Haus, Inv.-Nr.: GGH-G 66/2005, Abb. aus: Hilke Ohsoling (Hg.), Günter Grass: Catalogue Raisonné, Bd. 1: Radierungen, Göttingen: Steidl 2007, S. 137, R 66, (C) Günter und Ute Grass Stiftung / Steidl Verlag.

152. Günter Grass, Mit Brille neuerdings, 1974, Ätzradierung auf Kupfer, $16 \times 20 \mathrm{~cm}$ (Platte), 38,2 x 40,8 cm (Papier), aus dem Portfolio Liebe geprüft, 1974, Günter Grass-Haus, GGH-G 67/2005, Abb. aus: ebd., S. 139, R 67, (c) Günter und Ute Grass Stiftung / Steidl Verlag.

153. Günter Grass, Fruchtbarer Pilz, 1974, Ätzradierung auf ausgesägtem Kupfer, $20 \times 12 \mathrm{~cm}$ (Platte), 38,2 x 40,8 cm (Papier), aus dem Portfolio Liebe geprüft, 1974, Günter Grass-Haus, Inv.-Nr.: GGHG 68/2005, Abb. aus: ebd., S. 141, R 68, @ Günter und Ute Grass Stiftung / Steidl Verlag.

154. Relief mit Phallus und Inschrift: ",hic habitat felicitas", vor 79 n. Chr., Stein, gefunden in Pompeji, Italien, Archäologischen Nationalmuseum Neapel, Inv.-Nr. 27741, Abb. aus:

https://commons.wikimedia.org/wiki/File:Rilievo con fallo e iscrizione \%27hic habitat felicitas $\% 27$, da panificio dell\%27insula della casa di pansa, I sec dc, 27741.JPG, letzter Zugriff am 2.2.2019, Foto: Sailko, (C) gemeinfrei.

155. Günter Grass, Große Pilze, 1972, Ätzradierung auf Kupfer, 33 × $40 \mathrm{~cm}$ (Platte), 50 x $65 \mathrm{~cm}$ (Papier), Günter Grass-Haus, Inv.-Nr.: GGH-G 16/2005, Abb. aus: ebd., S. 37, R 16, @ Günter und Ute Grass Stiftung / Steidl Verlag. 
156. Günter Grass, Mit Sophie in die Pilze gegangen, Göttingen: Steidl 1987, S. 7, Seitenformat: 30,2 x $21,5 \mathrm{~cm}$, (C) Günter und Ute Grass Stiftung / Steidl Verlag.

157. Günter Grass, Mit Sophie in die Pilze gegangen, Göttingen: Steidl 1987, S. 8 f., Seitenformat: 30,2 x $21,5 \mathrm{~cm}$, (C) Günter und Ute Grass Stiftung / Steidl Verlag.

158. Günter Grass, Mit Sophie in die Pilze gegangen, Göttingen: Steidl 1987, S. 12 f., Seitenformat: 30,2 $x 21,5 \mathrm{~cm}$, (C) Günter und Ute Grass Stiftung / Steidl Verlag.

159. Günter Grass, Mit Sophie in die Pilze gegangen, Göttingen: Steidl 1987, S. 20 f., Seitenformat: 30,2 x 21,5 cm, (C) Günter und Ute Grass Stiftung / Steidl Verlag.

160. Günter Grass, Mit Sophie in die Pilze gegangen, Göttingen: 1987, S. 24 f., Seitenformat: 30,2 × 21,5 $\mathrm{cm}$, (C) Günter und Ute Grass Stiftung / Steidl Verlag.

161. Günter Grass, Mit Sophie in die Pilze gegangen, Göttingen: Steidl 1987, S. 28 f., Seitenformat: 30,2 x 21,5 cm, (C) Günter und Ute Grass Stiftung / Steidl Verlag.

162. Eugène Delacroix, Die Freiheit führt das Volk, 1830, Öl auf Leinwand, $260 \times 325$ cm, Louvre, Paris, Abb. aus: Erich Lessing Culture and Fine Arts Archives via artsy.net, via:

https://de.wikipedia.org/wiki/Die_Freiheit_f\%C3\%BChrt_das_Volk\#/media/File:Eug\%C3\%A8ne_D elacroix_-_Le_28_Juillet._La_Libert\%C3\%A9_guidant_le_peuple.jpg, letzter Zugriff am 21.9.2016, (C) gemeinfrei.

163. Günter Grass, Butt, Darmstadt: Luchterhand 1977, Buchumschlag 21 × 28,5 cm, (C) Günter und Ute Grass Stiftung / Steidl Verlag.

164. Günter Grass, Butt in Sand gebettet, 1977, Ätzradierung auf Kupfer, $26 \times 44,5 \mathrm{~cm}$ (Platte), $50 \times 65 \mathrm{~cm}$ (Papier), Blatt I/VII der Mappe Als vom Butt nur die Gräte geblieben war, Galerie André, Berlin 1977, Abb. aus: Abb. aus: Hilke Ohsoling (Hg.), Günter Grass: Catalogue Raisonné, Bd. 1: Radierungen, Göttingen: Steidl 2007, S. 213, R 104, (C) Günter und Ute Grass Stiftung / Steidl Verlag.

165. Günter Grass, Butt II, 1977, Ätzradierung auf Kupfer, $33 \times 40 \mathrm{~cm}$ (Platte), 50 x $65 \mathrm{~cm}$ (Papier), Blatt II/VII der Mappe Als vom Butt nur die Gräte geblieben war, Galerie André, Berlin 1977, Abb. aus: ebd., S. 215, R 105, (C) Günter und Ute Grass Stiftung / Steidl Verlag.

166. Günter Grass, Der Butt, 1977, Ätzradierung auf Kupfer, 30 x $40 \mathrm{~cm}$ (Platte), 50 × $65 \mathrm{~cm}$ (Papier), Blatt III/VII der Mappe Als vom Butt nur die Gräte geblieben war, Galerie André, Berlin 1977, Abb. aus: ebd., S. 217, R 106, (C) Günter und Ute Grass Stiftung / Steidl Verlag.

167. Günter Grass, Butt mit Messer, 1977, Ätzradierung auf Kupfer, $28 \times 40 \mathrm{~cm}$ (Platte), $50 \times 65 \mathrm{~cm}$ (Papier), Blatt IV/VII der Mappe Als vom Butt nur die Gräte geblieben war, Galerie André, Berlin 1977, Abb. aus: ebd., S. 219, R 107, (C) Günter und Ute Grass Stiftung / Steidl Verlag.

168. Günter Grass, Als vom Butt nur die Gräte geblieben war, 1977, Ätzradierung auf Kupfer, $30 \mathrm{x}$ $40 \mathrm{~cm}$ (Platte), $50 \times 65 \mathrm{~cm}$ (Papier), Blatt V/VII der Mappe Als vom Butt nur die Gräte geblieben war, Galerie André, Berlin 1977, Abb. aus: ebd., S. 221, R 108, @ Günter und Ute Grass Stiftung / Steidl Verlag.

169. Günter Grass, Kopf und Gräte, 1977, Ätzradierung auf Kupfer, 30 × $45 \mathrm{~cm}$ (Platte), $50 \times 65 \mathrm{~cm}$ (Papier), Blatt VI/VII der Mappe Als vom Butt nur die Gräte geblieben war, Galerie André, Berlin 1977, Abb. aus: ebd., S. 223, R 109, (C) Günter und Ute Grass Stiftung / Steidl Verlag.

170. Günter Grass, Als das Märchen zu Ende war, 1977, 38 × $38 \mathrm{~cm}$ (Platte), 50 × $65 \mathrm{~cm}$ (Papier), Blatt VII/VII der Mappe Als vom Butt nur die Gräte geblieben war, Galerie André, Berlin 1977, Ätzradierung auf Kupfer, Abb. aus: ebd., S. 225, R 110, (C) Günter und Ute Grass Stiftung / Steidl Verlag.

171. Günter Grass, Aale mit Euter, 1972, Ätzradierung auf Kupfer, $37 \times 26 \mathrm{~cm}$ (Platte), $50 \times 65 \mathrm{~cm}$ (Papier), Günter Grass-Haus, Inv.-Nr.: GGH-G 17/2005, ebd., S. 39, R 17, ( Günter und Ute Grass Stiftung / Steidl Verlag. 
172. Günter Grass, Puppe und Aal, 1973, Ätzradierung auf Kupfer, $25 \times 50 \mathrm{~cm}$ (Platte), $50 \times 65 \mathrm{~cm}$ (Papier), Günter Grass-Haus, Inv.-Nr.: GGH-G 41/2005, Abb. aus: ebd., S. 87, R 41, (c) Günter und Ute Grass Stiftung / Steidl Verlag.

173. Günter Grass, Kein Traum, 1973, Ätzradierung auf Kupfer, 18 x 40 cm, 50 x 65 cm, Günter GrassHaus, Inv.-Nr.: GGH-G 43/2005, Abb. aus: ebd., S. 91, R 43.

174. Günter Grass, Wewelsflether Blatt, 1972, Ätzradierung auf Kupfer, 26 × $37 \mathrm{~cm}$ (Platte), 53,7 x 69,5 cm (Papier), Günter Grass-Haus, Inv.-Nr.: GGH-G 13/2005, Abb. aus: ebd., S. 31, R 13, (C) Günter und Ute Grass Stiftung / Steidl Verlag.

175. Pieter Claesz, Hering mit einem Glas Bier und einem Brötchen, 1636, Öl auf Holz, 36 x 49 cm, Museum Boijmanns van Beuningen, Rotterdamm, Abb. aus Web Gallery of Art via: https://commons.wikimedia.org/wiki/File:Pieter Claesz 003.jpg, letzter Zugriff am 2.2.2019, (C) gemeinfrei.

176. Günter Grass, Butt I, 1973, Ätzradierung auf Kupfer, $23 \times 20 \mathrm{~cm}$ (Platte), 50 × $65 \mathrm{~cm}$ (Papier), Abb. aus: Hilke Ohsoling (Hg.), Günter Grass: Catalogue Raisonné, Bd. 1: Radierungen, Göttingen: Steidl 2007, S. 59, R 27, C Günter und Ute Grass Stiftung / Steidl Verlag.

177. Günter Grass, Ulbricht-Karikatur zum Komplex „,Vogelscheuchen“, 1961, Feder/Tusche, 21,6 x 13,9 cm, Günter Grass-Haus, Inv.-Nr.: GGH-G 747/2005, Abb. aus: Günter Grass: Sechs Jahrzehnte. Ein Werkstattbericht, hrsg. von Fritz G. Margull u. Hilke Ohsoling, Göttingen: Steidl 2014, S. 106, (C) Günter und Ute Grass Stiftung / Steidl Verlag.

178. Ingeborg Bachmann, Ein Ort für Zufälle, mit 13 Zeichnungen von Günter Grass, Berlin: Wagenbach 1965, S. 67, Seitenformat: 21,2 x 12,5 cm, C 1965, 1999 Verlag Klaus Wagenbach; Bildwerk: (C) Günter und Ute Grass Stiftung / Steidl Verlag.

179. Günter Grass, Schuh und Steinbeißer, 1972, Ätzradierung auf Kupfer, $33 \times 40 \mathrm{~cm}$ (Platte), $50 \times 65$ cm (Papier), Günter Grass-Haus, Inv.-Nr.: GGH-G 61/2005, Abb. aus: Hilke Ohsoling (Hg.), Günter Grass: Catalogue Raisonné, Bd. 1: Radierungen, Göttingen: Steidl 2007, S. 127, R 61, (C) Günter und Ute Grass Stiftung / Steidl Verlag.

180. Günter Grass, Fußlange Scholle, 1972, Ätzradierung auf Kupfer, 33 x $40 \mathrm{~cm}$ (Platte), 53,7 x 69,8 cm (Papier), Günter Grass-Haus, Inv.-Nr.: GGH-G 14/2005, Abb. aus: ebd., S. 33, R 14, @ Günter und Ute Grass Stiftung / Steidl Verlag.

181. Günter Grass, Kuß II, 1975, Kaltnadelradierung auf Kupfer, $45 \times 33 \mathrm{~cm}$ (Platte), 65 x $50 \mathrm{~cm}$ (Papier), Günter Grass-Haus, Inv.-Nr.: GGH-G 93/2005. Abb. aus: ebd., S. 191, R 93, (C Günter und Ute Grass Stiftung / Steidl Verlag.

182. Günter Grass, Paar, 1979, Ätzradierung auf Kupfer, $28 \times 18 \mathrm{~cm}$ (Platte), $50 \times 65 \mathrm{~cm}$ (Papier), Abb. aus: ebd., S. 291, R 143, (C Günter und Ute Grass Stiftung / Steidl Verlag.

183. Günter Grass, Mann im Butt, 1978, Ätzradierung auf Kupfer, $40 \times 52 \mathrm{~cm}$ (Platte), $50 \times 65 \mathrm{~cm}$ (Papier), Günter Grass-Haus, Inv.-Nr.: GGH-G 143/2005, Abb. aus: ebd., S. 271, R 133, (C) Günter und Ute Grass Stiftung / Steidl Verlag.

184. Günter Grass, Szenisches Madrigal, 1974, Ätzradierung auf Kupfer, 15 × 20 cm (Platte), 40,8 x 38,2 cm (Papier), aus dem Portfolio Liebe geprüft, Günter Grass-Haus, Inv.-Nr. GGH-G 71/2005, Abb. aus: ebd., S. 147, R 71, (C Günter und Ute Grass Stiftung / Steidl Verlag.

185. Günter Grass, Alle vier, 1982, Lithografie, 76 × $56 \mathrm{~cm}$ (Papier), Blatt II/XXII aus dem Zyklus Vatertag, 1982, Günter Grass-Haus, o. Inv.-Nr., Abb. aus: Abb. aus: Hilke Ohsoling (Hg.), Günter Grass: Catalogue Raisonné, Bd. 2: Lithografien, Göttingen: Steidl 2007, S. 47, L 15, (C Günter und Ute Grass Stiftung / Steidl Verlag. 
186. Günter Grass, Mit Pilzhüten, 1982, Lithografie, 56 x $76 \mathrm{~cm}$ (Papier), Blatt III/XXII aus dem Zyklus Vatertag, 1982, Günter Grass-Haus, o. Inv.-Nr., Abb. aus: ebd., S. 49, L 16, @ Günter und Ute Grass Stiftung / Steidl Verlag.

187. Günter Grass, Siggi und Fränki, 1981, Lithografie, 56 x $76 \mathrm{~cm}$ (Papier), Blatt XII/XXII, aus dem Zyklus Vatertag, 1982, Günter Grass-Haus, o. Inv.-Nr., Abb. ab: ebd., S. 67, L 25, @ Günter und Ute Grass Stiftung / Steidl Verlag.

188. Günter Grass, Sind doch die Frauen wie schon Goethe sagte, 1982, Lithografie, 56 x $76 \mathrm{~cm}$ (Papier), Blatt XIV/XXII aus dem Zyklus Vatertag, 1982, Günter Grass-Haus, o. Inv.-Nr., Abb. aus: ebd., S. 71, L 27, (C) Günter und Ute Grass Stiftung / Steidl Verlag.

189. Günter Grass, Streit, 1981, Lithografie, $56 \times 76 \mathrm{~cm}$ (Papier), Blatt XV/XXII aus dem Zyklus Vatertag, Günter Grass-Haus, o. Inv.-Nr., Abb. aus: ebd., S. 73, L 28, (C) Günter und Ute Grass Stiftung / Steidl Verlag.

190. Günter Grass, Die Krähen folgten, 1981, Lithografie, 56 x $76 \mathrm{~cm}$ (Papier), Blatt XVI/XXII, aus dem Zyklus Vatertag, 1982, Günter Grass-Haus, o. Inv.-Nr., Abb. aus: ebd., S. 75, L 29,

(C) Günter und Ute Grass Stiftung / Steidl Verlag.

191. Günter Grass, War das noch ein Mensch, 1981, Lithografie, 56 x $76 \mathrm{~cm}$ (Papier), Blatt XX/XXII, aus dem Zyklus Vatertag, 1982, Günter Grass-Haus, o. Inv.-Nr., Abb. aus: ebd., S. 83, L 33, (C) Günter und Ute Grass Stiftung / Steidl Verlag.

192. Günter Grass, Novemberland, Göttingen: Steidl 1993, Umschlag, Titelbild, $23 \times 14 \mathrm{~cm}$, (c) Günter und Ute Grass Stiftung / Steidl Verlag.

193. Günter Grass, Mein Jahrhundert, Göttingen: Steidl 1999, Umschlag, $31,5 \times 53 \mathrm{~cm}$, (C) Günter und Ute Grass Stiftung / Steidl Verlag.

194. Günter Grass, Grimms Wörter, Göttingen: Steidl 2010, Umschlag, Titelbild, 24 × 35 cm, (C) Günter und Ute Grass Stiftung / Steidl Verlag.

195. Günter Grass, Denkmal der Göttinger Sieben, Göttingen, 2011, Stahl, Höhe: 3 m, Foto: Stefan Flöper, Abb. aus: https://commons.wikimedia.org/wiki/File:G\%C3\%B6ttinger Sieben Grass.jpg, letzter Zugriff am 2.2.2019, (c) gemeinfrei.

196. Günter Grass, Die Rättin - Plan II, Wewelsfleth, 1983, Lithografie, 77 x $58 \mathrm{~cm}$ (Papier), Günter Grass-Haus, 328/2005, Abb. aus: Abb. aus: Hilke Ohsoling (Hg.), Günter Grass: Catalogue Raisonné, Bd. 2: Lithografien, Göttingen: Steidl 2007, S. 121, L 52, (c) Günter und Ute Grass Stiftung / Steidl Verlag.

197. Günter Grass, Treffen in Telgte, Darmstadt: Luchterhand 1979, Umschlag, $20 \times 28 \mathrm{~cm}$, (C) Günter und Ute Grass Stiftung / Steidl Verlag.

198. Günter Grass, Zunge zeigen, Darmstadt: Luchterhand 1988, Umschlag, 27,5 x $41 \mathrm{~cm}$, (C) Günter und Ute Grass Stiftung / Steidl Verlag.

199. Günter Grass, Totes Holz, Göttingen: Steidl 1990, Umschlag, 27,5 x 40 cm, (c) Günter und Ute Grass Stiftung / Steidl Verlag.

200. Günter Grass, Zunge zeigen, Darmstadt: Luchterhand 1989, S. 8 f., 27 x 37 cm, @ Günter und Ute Grass Stiftung / Steidl Verlag.

201. Günter Grass, Zwischen den Vögeln, 1981, Relief, Bronze, 45 x 56,5 cm, Abb. aus: Günter Grass: Gebrannte Erde. Skulpturen, Göttingen: Steidl 2002, S. 35, Foto: Dirk Reinartz, (c) Günter und Ute Grass Stiftung / Steidl Verlag / Foto: Estate Dirk Reinartz.

202. Günter Grass, $K u ß ~ I I, 1975$, Kaltnadelradierung auf Kupfer, $45 \times 33 \mathrm{~cm}$ (Platte), 65 x $50 \mathrm{~cm}$ (Papier), Günter Grass-Haus, Inv.-Nr.: GGH-G 93/2005, Abb. aus: Abb. aus: Hilke Ohsoling (Hg.), Günter Grass: Catalogue Raisonné, Bd. 1: Radierungen, Göttingen: Steidl 2007, S. 191, R 93, (C) Günter und Ute Grass Stiftung / Steidl Verlag. 
203. Günter Grass, Der Kuß, 1981, Terrakotta, 51,5 x 37,5 cm, Abb. aus: Günter Grass: Gebrannte Erde. Skulpturen, Göttingen: Steidl 2002, S. 15, Foto: Dirk Reinartz, @ Günter und Ute Grass Stiftung / Steidl Verlag / Foto: Estate Dirk Reinartz.

204. Günter Grass, Man möge sie wörtlich nehmen..., 1983, Terrakotta, 34 x 23 cm, Abb. aus: ebd., S. 110, Foto: Dirk Reinartz, (c) Günter und Ute Grass Stiftung / Steidl Verlag.

205. Günter Grass, Pilze, 1982, Terrakotta, Breite: 26,5 cm, Abb. aus: ebd., S. 63, Foto: Dirk Reinartz, (C) Günter und Ute Grass Stiftung / Steidl Verlag / Foto: Estate Dirk Reinartz.

206. Günter Grass, Mariazuehren, München: F. Bruckmann KG 1973, S. 68 f. (verwendetes Bildwerk: Aale und Euter, 1972, Pinsel/Tusche), (C Günter und Ute Grass Stiftung / Verlag F. Bruckmann KG, München.

Allen Rechteinhaberinnen und -inhabern sei für ihre Abdruckgenehmigungen und in vielen Fällen auch für die großzügige Bereitstellung von Bildvorlagen herzlich gedankt. Die Verfasserin hat sich redlich bemüht, die Zuständigen für alle Abbildungen zu ermitteln. Falls solche dennoch übersehen wurden, geschah dies nicht absichtsvoll. Betroffene Personen und Institutionen werden gebeten, sich gegebenenfalls an die Niedersächsische Staats- und Universitätsbibliothek Göttingen zu wenden. 


\section{MOTIVVERZEICHNIS}

\section{aller erhaltenen und/oder reproduzierten bildnerischen Darstellungen von Vögeln, Nonnen, Vogelscheuchen, Schnecken, Pilzen und Fischen aus den Jahren 1947 bis 1977}

Die folgende Auflistung speist sich aus den bisher veröffentlichten Werkverzeichnissen und Ausstellungskatalogen zum bildkünstlerischen Schaffen von Günter Grass sowie aus Recherchen in den Archiven der Berliner Akademie der Künste (AdK), des Lübecker Günter Grass-Hauses (GGH) und der Günter-Grass-Galerie in Gdańsk (GGM), in welchen Zeichnungen, Aquarelle, Druckgrafiken und Plastiken des Künstlers aus dem relevanten Zeitraum vorliegen. Viele Arbeiten des Bildhauers und Grafikers befinden sich in Privatbesitz. Verkäufe und Schenkungen wurden jedoch nicht systematisch dokumentiert und die Bestände der Günter und Ute Grass Stiftung und des Steidl Verlags waren während der Recherchephase für diese Untersuchung noch nicht vollständig inventarisiert. Da bis auf eine Ausnahme keine der Publikationen, die Abbildungen seiner Bildwerke enthalten, Auskunft über den Aufenthaltsort der originalen Arbeiten bietet, ${ }^{638}$ kann über den Verbleib eines in einem Buch abgedruckten Werkes nur dann zuverlässig informiert werden, wenn sich das Original in einem der obengenannten Archive befindet.

Die meisten Radierungen und Lithografien von Günter Grass aus dem behandelten Schaffenszeitraum liegen der Akademie der Künste, dem Günter Grass-Haus, dem Steidl Verlag und der Günter und Ute Grass Stiftung gleichermaßen mit je einem Exemplar vor. Sie sind mit Hilfe der Nummerierungen aus dem 2007 von Hilke Ohsoling herausgegebenen Catalogue Raisonné an allen Orten gleichermaßen gut recherchierbar, sodass im Fall dieser Druckgrafiken auf eine Aufzählung der einzelnen Sammlungsorte im Verzeichnis verzichtet wird. Die Abgüsse der Plastiken von Günter Grass befinden sich nahezu vollständig in mindestens einer Ausführung im Besitz der Günter und Ute Grass Stiftung (GUGS) - auch bei diesen Werken entfällt im Folgenden die Sammlungsbezeichnung.

Im angefügten Verzeichnis sind Grass' Arbeiten erstens nach Motiven und zweitens in chronologischer Ordnung angeführt. Drittens wurde innerhalb der einzelnen Jahre nach Gattungen unterschieden: Auf Zeichnungen und Aquarelle folgen Druckgrafiken und Plastiken. Die Titel sind aus den Publikationen oder Inventaren der Sammlungen übertragen worden. Häufig hat ein Bildwerk in verschiedenen Veröffentlichungen verschiedene Bezeichnungen erhalten, die im Verzeichnis entsprechend in allen Varianten angeführt sind. Eine Aussage darüber, welche Titel Grass selbst vergeben hat und welche von den Herausgebern der Publikationen bzw. den zuständigen Sammlungsmitarbeiterinnen und -mitarbeitern vergeben wurden, kann nachträglich nicht mehr gemacht werden. Eine große Mehrheit der Titel zählt die im Kunstwerk dargestellten Objekte auf. Sie dienen deshalb im Folgenden zugleich als Kurzbeschreibungen der Werke. Ergänzt werden sie anderenfalls um eine Deskription in Stichpunkten (diese sind im Gegensatz zu den Titeln ist nicht kursiv, sondern gerade gesetzt), um Leserinnen und Lesern einen ersten Eindruck von den geschaffenen Motivzusammenstellungen zu geben.

${ }^{638}$ Eine Ausnahme macht der Kat. Ausst. Berlin (1992). Auch innerhalb dieses Katalogs sind die Angaben jedoch nicht vollständig und müssten zudem auf ihre Aktualität hin überprüft werden. 


\section{VÖGEL}

\begin{tabular}{|c|c|c|c|c|}
\hline Datierung & Titel & Technik & Quelle der Abb. & Sammlung \\
\hline 1951 & Windhühner 1 / Erste Hühnerzeichnungen & Tusche & $\begin{array}{l}\text { Grass (1999), S. 10; Grass (2014), } \\
\text { S. } 30\end{array}$ & \\
\hline 1951 & Windhühner 2 / Erste Hühnerzeichnungen & Tusche & Grass (1999), S. 11 & \\
\hline 1951 & Windhühner 3 / Erste Hühnerzeichnungen & Tusche & Grass (1999), S. 12 & \\
\hline 1951 & Windhühner 4 / Erste Hühnerzeichnungen & Tusche & Grass (1999), S. 13 & \\
\hline $\begin{array}{l}1951 / \\
1952\end{array}$ & Hahn & Tusche & Grass (2014), S. 30 & \\
\hline $\begin{array}{l}1951 / \\
1952\end{array}$ & Huhn & Tusche & Grass (2014), S. 30 & \\
\hline 1952 & Hahn & Tusche & & GGH-G 597/2005 \\
\hline 1952 & Huhn & Tusche & Grass (2014), S. 30 & GGH-G 564/2005 \\
\hline 1952 & Skizzen aus Skizzenbuch von 1952, Hühner & Tusche & & GUGS, o. A. \\
\hline 1954 & Skizze für eine Hahnplastik & Bleistift & Grass (2002a), S. 153 & \\
\hline 1954 & Skizze für eine Hahnplastik & Bleistift & Grass (2002a), S. 153 & \\
\hline 1954 & Hahn & Aquarell & & GGH-G 1080/2005 \\
\hline 1954 & Hahn & Aquarell & Grass (2001), S. 20 & \\
\hline 1954 & Huhn & $\begin{array}{l}\text { Aquarell, } \\
\text { Tusche }\end{array}$ & Grass (2001), S. 20 & \\
\hline 1954 & Huhn im Visier & Tusche & & GGH-G 1097/2005 \\
\hline 1954 & $\begin{array}{l}\text { Skizze frei nach Dalí, surreale Landschaft mit Elefantenhahn, } \\
\text { Venushenne und Totenvogel }\end{array}$ & Tusche & Frizen (2010), S. 199 & GGH-G 1098/2005 \\
\hline 1954 & Vogel & Bleistift & & GGH-G 1043/2005 \\
\hline 1954 & Vogel & Fettkreide & & GGH-G 1044/2005 \\
\hline 1954 & Hahn & Radierung & Grass (2014), S. 44 & GGH-G 592/2005 \\
\hline 1954 & Huhn & Radierung & & GGH-G 593/2005 \\
\hline 1954 & Hahn & Steinguss & Grass (2014), S. 38 & \\
\hline 1954 & Hahn & Steinguss & Grass (2014), S. 38 & \\
\hline 1955 & Das Suppenhuhn (v.) / Hahn mit Kirchturm und Schlüssel (r.) & Tusche & & GGH-G 544/2005 \\
\hline
\end{tabular}




\begin{tabular}{|c|c|c|c|c|}
\hline 1955 & $\begin{array}{l}\text { Die Vorzüge der Windhühner, S. 26, Abbildung einer } \\
\text { Zeichnung zum Gedicht „Beobachtet beim Attentat“: } \\
\text { Vogelkopf }\end{array}$ & $\begin{array}{l}\text { Original: } \\
\text { Tusche }\end{array}$ & Grass (1956), S. 26 & \\
\hline 1955 & $\begin{array}{l}\text { Die Vorzüge der Windhühner, S. 38, Abbildung einer } \\
\text { Zeichnung zum Prosagedicht „Fünf Vögel“: fünf Vögel }\end{array}$ & $\begin{array}{l}\text { Original: } \\
\text { Tusche }\end{array}$ & Grass (1963a), S. 38 & \\
\hline 1955 & Drei Vögel & Tusche & $\begin{array}{l}\text { Kat. Ausst. Kiel (1987), S. 25, } \\
\text { Abb. } 2\end{array}$ & \\
\hline 1955 & Frau mit Spiegel und Vogel & Tusche & & GGH-G 583/2005 \\
\hline 1955 & Frau mit Vogel / Leda & $\begin{array}{l}\text { Sepia über } \\
\text { Bleistift }\end{array}$ & $\begin{array}{l}\text { Kat. Ausst. Kiel (1987), S. 31, } \\
\text { Abb. } 7 .\end{array}$ & GGH-G 1087/2005 \\
\hline 1955 & Fünf Vögel & Kohle & & $\begin{array}{l}\text { AdK, Inv.-Nr.: HZ } \\
2008, \text { Standort III - } \\
1\end{array}$ \\
\hline 1955 & Großes Huhn & Tusche laviert & $\begin{array}{l}\text { Grass (1973), S. 32; Dreher } \\
(1982), \text { S. } 17, \text { Abb. } 7\end{array}$ & \\
\hline 1955 & Hahn mit Steuergefieder in Spiralform & Tusche & Grass (2014), S. 50 & \\
\hline 1955 & Hahn & Sepia, laviert & Dreher (1982), S. 13, Abb. 4 & GGH-G 585/2005 \\
\hline 1955 & Hahn & Tusche, laviert & Dreher (1982), S. 14, Abb. 5 & \\
\hline 1955 & Hahn und Schlüssel & Tusche, laviert & Dreher (1982), S. 15, Abb. 6 & \\
\hline 1955 & Hähne & Kohle & & GGH-G 559/2005 \\
\hline 1955 & Hähne & Tusche & & GGH-G 560/2005 \\
\hline 1955 & Henne & Kohle & & $\begin{array}{l}\text { AdK, Inv.-Nr.: HZ } \\
\text { 2001, Standort III-3 }\end{array}$ \\
\hline 1955 & Huhn & Bleistift & & GGH-G 1099/2005 \\
\hline 1955 & Huhn im Gebirge & Bleistift & & GGH-G 659/2005 \\
\hline 1955 & Mädchen- und Vogelkopf & Tusche & Grass (2004a), S. 16 & GGH-G 563/2005 \\
\hline 1955 & Skizze für Ballettlibretto: Vogel und Tänzerin & Tusche & Grass (2014), S. 74 & \\
\hline 1955 & Skizze: Hahn mit Steuergefieder, das wie ein Ohr geformt ist & Tusche & Grass (2014), S. 42 & \\
\hline 1955 & Skizze: Vogel, mit Steuergefieder, das wie eine Öse geformt ist & Tusche & Grass (2014), S. 44 & \\
\hline 1955 & Skizze zu den Vorzügen der Windhühner: vier Windhühner & Tusche & Grass (2014), S. 54 & \\
\hline 1955 & $\begin{array}{l}\text { Skizze zu den Vorzügen der Windhühner: Windhühner mit } \\
\text { Bleistift }\end{array}$ & Tusche & Grass (2014), S. 55 & GGH-G 537/2005 \\
\hline
\end{tabular}




\begin{tabular}{|c|c|c|c|c|}
\hline 1955 & $\begin{array}{l}\text { Skizze zu den Vorzügen der Windhühner: zwei Vögel und ein } \\
\text { Stuhl }\end{array}$ & Tusche & Grass (2014), S. 52 & \\
\hline 1955 & Städtischer Hahn & Tusche & $\begin{array}{l}\text { Kat. Ausst. Kiel (1987), S. 27, } \\
\text { Abb. } 4\end{array}$ & \\
\hline 1955 & Tanzende Vögel & Tusche & & GGH-G 605/2005 \\
\hline 1955 & Windhühner mit Blei & Tusche & & GGH-G 537/2005 \\
\hline 1955 & $\begin{array}{l}\text { Zeichnung zu den Vorzügen der Windhühner, zum Gedicht } \\
\text { „Vogelflug“, Vögel und Betrachter }\end{array}$ & Tusche & & GGH-G 543/2005 \\
\hline um 1955 & Hahn als Uhrzeiger & Tusche & & $\begin{array}{l}\text { AdK, Inv.-Nr.: HZ } \\
\text { 2013, Standort } \\
\text { Berlin III-2 } \\
\end{array}$ \\
\hline 1955 & $\begin{array}{l}\text { Hahn, Hahn, dessen Steuergefieder in eine Stadtarchitektur } \\
\text { übergeht }\end{array}$ & Holzschnitt & Grass (2014), S. 45 & GGH-G 591/2005 \\
\hline 1955 & Huhn & Terrakotta & Grass (2002a), S. 18 & \\
\hline 1955 & Vögel & Gipsrelief & Grass (2014), S. 41 & \\
\hline 1955 & Vogel & Bronze & Grass (2002a), S. 22 f. & \\
\hline 1956 & Ballspielen zwischen Pelikanen & Bleistift & & GGH-G 584/2005 \\
\hline 1956 & $\begin{array}{l}\text { Die Vorzüge der Windhühner, Umschlag: Windhühner (v.) und } \\
\text { Hahn mit inwendiger Treppe, Schlüssel und Architektur (r.) }\end{array}$ & $\begin{array}{l}\text { Original: } \\
\text { Tusche }\end{array}$ & Grass (1956); Grass (2014), S. 57 & \\
\hline 1956 & Elf Vögel / Drei und acht Vögel & Kohle & $\begin{array}{l}\text { Dreher (1982), S. 27, Abb. 12; Kat. } \\
\text { Ausst. Kiel (1987), S. 34, Abb. 10; } \\
\text { Kat. Ausst. Berlin (1995), S. 241, } \\
\text { Abb. } 5\end{array}$ & $\begin{array}{l}\text { AdK, Standort: Inv.- } \\
\text { Nr. HZ 2000, } \\
\text { Überformate }\end{array}$ \\
\hline 1956 & Eule mit Puppe & Kohle & & GGM/0001/2009 \\
\hline 1956 & Frau mit Vogel & Bleistift & & GGH-G 1078/2005 \\
\hline 1956 & Frauen und Vogel & Tusche & & GGH-G 653/2005 \\
\hline 1956 & Hahn & Aquarell & & GGH-G 1077/2005 \\
\hline 1956 & Hahn mit inwendiger Treppe zu Die Vorzüge der Windhühner & Tusche & & GGH-G 598/2005 \\
\hline 1956 & Hahn und Pflanze & Bleistift & & GGH-G 660/2005 \\
\hline 1956 & Halbakt mit Vogel & Papier & & GGH-G 581/2005 \\
\hline
\end{tabular}




\begin{tabular}{|c|c|c|c|c|}
\hline 1956 & Leda, Frau mit Vogel & Tusche & $\begin{array}{l}\text { Dreher (1982), S. 25, Abb. 11; Kat. } \\
\text { Ausst. Kiel (1987), S. 39, Abb. } 15\end{array}$ & \\
\hline 1956 & Schmaler Vogel & Kohle & & $\begin{array}{l}\text { AdK, Inventar-Nr.: } \\
\text { HZ 2009, Standort } \\
\text { III-3 }\end{array}$ \\
\hline 1956 & Skizze: Frau mit Vogel & Bleistift & Grass (2014), S. 62 & \\
\hline 1956 & Skizze zu Die Vorzüge der Windhühner / Windhühner mit Blei & Tusche & Grass (1999), S. 20 & GGH-G 356/2005 \\
\hline 1956 & Streitende Vögel & Tusche & $\begin{array}{l}\text { Dreher (1982), S. 29, Abb. 13; Kat. } \\
\text { Ausst. Kiel (1987), S. 35, Abb. } 11\end{array}$ & \\
\hline 1956 & Vogelpaar / Zwei Vögel & Tusche & $\begin{array}{l}\text { Grass (1973), S. 13; Kat. Ausst. } \\
\text { Kiel (1987), S. 33, Abb. } 9\end{array}$ & GGH-G 1041/2005 \\
\hline 1956 & Zwei Vögel & Bleistift & & GGH-G 1042/2005 \\
\hline 1956 & Henne & Bronze & Grass (2002a), S. 16 & \\
\hline 1957 & Beinahe Vögel & Kohle & & GGH-G 673/2005 \\
\hline 1957 & Frauen und Vögel versammelt & Kohle & $\begin{array}{l}\text { Kat. Ausst. Kiel (1987), S. 46, } \\
\text { Abb. } 22\end{array}$ & \\
\hline 1957 & Fünf Vögel & Bleistift & & $\begin{array}{l}\text { AdK, Inventar-Nr.: } \\
\text { HZ 2005, Standort } \\
\text { III-1 }\end{array}$ \\
\hline 1957 & Magere Vögel, Vögel und Köche & Kohle & Grass (1999), S. 23 & \\
\hline 1957 & Nonne und fünf Vögel & Kohle, Kreide & Grass (1973), S. 11 & $\begin{array}{l}\text { AdK, Inv.-Nr.: HZ } \\
\text { 2733, Standort III-1 }\end{array}$ \\
\hline 1957 & Skizzen für das Ballett Die Gans und die fünf Köche & Tusche & Grass (2014), S. 76 & \\
\hline 1957 & Viele Vögel & Bleistift & & GGH-G 603/2005 \\
\hline 1957 & Viele Vögel und Frauen & Bleistift & & GGH-G 652/2005 \\
\hline 1957 & Vogelköpfe & Kohle & Grass (1999), S. 21 & \\
\hline 1957 & Zwei Mädchen mit Vogel & $\begin{array}{l}\text { Kohle, } \\
\text { gewischt }\end{array}$ & $\begin{array}{l}\text { Kat. Ausst. Kiel (1987), S. 42, } \\
\text { Abb. } 18\end{array}$ & $\begin{array}{l}\text { AdK, Inv.-Nr.: HZ } \\
\text { 1999, Standort III-3 }\end{array}$ \\
\hline 1957 & Zwei Vögel & Kohle & & GGH-G 1079/2005 \\
\hline um 1957 & $\begin{array}{l}\text { Manuskript zum Gedicht „Theater" aus dem Gedichtzyklus } \\
\text { „Zauberei mit den Bräuten Christi“ mit Zeichnung: Koch, Vogel } \\
\text { und Nonne, zwei Varianten }\end{array}$ & Tusche/Blei & Grass (2014), S. 88 (Tusche) & $\begin{array}{l}\text { Literaturarchiv der } \\
\text { AdK, Grass-Archiv, } \\
\text { Sig. } 948\end{array}$ \\
\hline
\end{tabular}




\begin{tabular}{|c|c|c|c|c|}
\hline 1957 & Eule und Puppe & Lithografie & Grass (2014), S. 78 & \\
\hline 1957 & elf Stelzvögel & Lithografie & Grass (2014), S. 78 & GGH-G 336/2005 \\
\hline 1957 & drei und acht Vögel & Lithografie & & GGH-G 337/2005 \\
\hline 1957 & fünf Vögel & Lithografie & & GGH-G 338/2005 \\
\hline 1957 & fünf Vögel & Lithografie & & GGH-G 339/2005 \\
\hline 1957 & zwei Hühner & Lithografie & & GGH-G 589/2005 \\
\hline $\begin{array}{l}1957 / \\
1958\end{array}$ & Skizze für das Ballett Die Vogelscheuchen: sechs Vögel & Tusche & Grass (2014), S. 80 & \\
\hline 1958 & Frauen und Vögel versammelt & Kohle & $\begin{array}{l}\text { Kat. Ausst. Kiel (1982), S. 46, } \\
\text { Abb. } 22\end{array}$ & \\
\hline 1958 & Hahn und Schlüssel & Kohle & Grass (1999), S. 25 & \\
\hline 1960 & $\begin{array}{l}\text { Gleisdreieck, S. 22, Abbildung einer Zeichnung zum Gedicht } \\
\text { „Die Ballade von der schwarzen Wolke“: weiße Henne }\end{array}$ & $\begin{array}{l}\text { Original: } \\
\text { Kohle/ } \\
\text { Fettkreide }\end{array}$ & Grass (1960), S. 22 & \\
\hline 1960 & $\begin{array}{l}\text { Gleisdreieck, S. 25, Abbildung einer Zeichnung zum Gedicht } \\
\text { „Die Ballade von der schwarzen Wolke“: schwarze Henne }\end{array}$ & $\begin{array}{l}\text { Original: } \\
\text { Kohle/ } \\
\text { Fettkreide }\end{array}$ & Grass (1960), S. 25 & \\
\hline 1960 & $\begin{array}{l}\text { Gleisdreieck, S. 77, Abbildung einer Zeichnung zum Gedicht „In } \\
\text { eigener Sache“: drei Gruppen schwarzer Vögel }\end{array}$ & $\begin{array}{l}\text { Original: } \\
\text { Kohle/ } \\
\text { Fettkreide }\end{array}$ & Grass (1960), S. 77 & \\
\hline 1960 & Hahn, Skizze & Kohle & & GGM/0003/2009 \\
\hline 1960 & Sechs Vögel & Tusche, laviert & $\begin{array}{l}\text { Kat. Ausst. Kiel (1987), S. 55, } \\
\text { Abb. } 30\end{array}$ & GGH-G 758/2005 \\
\hline 1960 & $\begin{array}{l}\text { Umschlagentwurf zum Gedichtband Im Ei, später Gleisdreieck: } \\
\text { brütende Henne }\end{array}$ & Tusche & Grass (2014), S. 86 & \\
\hline 1960 & Viele Vögel & Tusche & & GGH-G 745/2005 \\
\hline 1961 & Amseln & Tusche & Dreher (1982), S. 69, Abb. 41 & \\
\hline 1961 & $\begin{array}{l}\text { Skizzen zum Vogelscheuchen-Komplex in den Hundejahren: } \\
\text { Bismarck-Vogelscheuche mit Vogel / Bismarck als } \\
\text { Vogelscheuche }\end{array}$ & Tusche & Grass (2014), S. 106 & GGH-G 746/2005 \\
\hline 1961 & $\begin{array}{l}\text { Skizzen zum Vogelscheuchen-Komplex in den Hundejahren: } \\
\text { Ulbricht-Scheuche und Vogel }\end{array}$ & Tusche & Grass (2014), S. 106 & GGH-G 747/2005 \\
\hline
\end{tabular}




\begin{tabular}{|c|c|c|c|c|}
\hline 1961 & $\begin{array}{l}\text { Viele Vögel / Skizze zum Vogelscheuchen-Komplex in den } \\
\text { Hundejahren }\end{array}$ & Fettkreide & Grass (2014), S. 106 & GGH-G 797/2005 \\
\hline 1961 & Viele Vögel & Tusche & $\begin{array}{l}\text { Kat. Ausst. Kiel (1987), S. 63, } \\
\text { Abb. } 38\end{array}$ & \\
\hline 1961 & $\begin{array}{l}\text { Vögel treffen sich / Versammlung / Tuschezeichnung zum } \\
\text { Vogelscheuchen-Komplex in den Hundejahren }\end{array}$ & Tusche & $\begin{array}{l}\text { Dreher (1982), S. 67, Abb. 40; } \\
\text { Grass (2014), S. } 107\end{array}$ & GGH-G 744/2005 \\
\hline 1961 & $\begin{array}{l}\text { Vögel und Vogelscheuchen zu den Hundejahren: Frauen, Vögel } \\
\text { und Scheuchen }\end{array}$ & Tusche & Grass (2014), S. 110 & \\
\hline 1965 & Das Huhn soll geschlachtet werden, Huhn und Koch & Tusche & Dreher (1982), S. 79, Abb. 48 & \\
\hline 1965 & $\begin{array}{l}\text { Ein Ort für Zufälle, S. 41, Abbildung der Zeichnung Hahn mit } \\
\text { Bierflaschen }\end{array}$ & $\begin{array}{l}\text { Original: } \\
\text { Tusche }\end{array}$ & Bachmann (1965), S. 41 & GGH-G 727/2005 \\
\hline 1965 & $\begin{array}{l}\text { Ein Ort für Zufälle, S. 6, Abbildung der Zeichnung Kranich im } \\
\text { Stacheldraht, zugl. Zeichnung für den Umschlag von Ein Ort für } \\
\text { Zufälle }\end{array}$ & $\begin{array}{l}\text { Original: } \\
\text { Tusche }\end{array}$ & $\begin{array}{l}\text { Bachmann (1965), S. 6; Kat. } \\
\text { Ausst. Kiel (1987), S. 73, Abb. 46; } \\
\text { Grass (2014), S. } 127\end{array}$ & GGH-G 731/2005 \\
\hline 1965 & $\begin{array}{l}\text { Ein Ort für Zufälle, S. 49, Abbildung der Zeichnung } \\
\text { Nymphensittiche und Panzer }\end{array}$ & $\begin{array}{l}\text { Original: } \\
\text { Tusche }\end{array}$ & Bachmann (1965), S. 49 & \\
\hline 1965 & Fünf Vögel & $\begin{array}{l}\text { Tusche, } \\
\text { Bleistift }\end{array}$ & & GGH-G 726/2005 \\
\hline 1965 & Huhn und Koch & Tusche & Dreher (1982), S. 78, Abb. 47 & \\
\hline 1965 & $\begin{array}{l}\text { Plakatentwürfe für die Bundestagswahl 1965: Hahnköpfe mit } \\
\text { SPD-Schriftzug }\end{array}$ & $\begin{array}{l}\text { Tusche, } \\
\text { Plakafarbe }\end{array}$ & Grass (2014), S. 133 & \\
\hline 1965 & Sieben Vögel & Tusche & $\begin{array}{l}\text { Kat. Ausst. Kiel (1987), S. 75, } \\
\text { Abb. } 48\end{array}$ & \\
\hline 1972 & Hahn zwischen Schnecken & Kohle & Dreher (1982), S. 95, Abb. 60 & \\
\hline 1973 & $\begin{array}{l}\text { Mariazuehren, S. } 12 \text { f., Überblendung eines Fotos des } \\
\text { Elbstrands mit einem Foto der Zeichnung Vogelpaar / Zwei } \\
\text { Vögel, } 1956\end{array}$ & $\begin{array}{l}\text { Zeichnung: } \\
\text { Tusche }\end{array}$ & Grass (1973), S. 12 f. & \\
\hline 1973 & $\begin{array}{l}\text { Mariazuehren, S. } 30 \text { f., Überblendung eines Fotos von einem } \\
\text { von Harz umschlossenen Entenkopf mit einem Foto der } \\
\text { Zeichnung: Vogelkopf, } 1966\end{array}$ & $\begin{array}{l}\text { Zeichnung: } \\
\text { Tusche }\end{array}$ & Grass (1973), S. 30 f. & \\
\hline 1973 & $\begin{array}{l}\text { Mariazuehren, S. } 32 \text { f., Doppelseite zusammengestellt aus } \\
\text { einem Foto der Zeichnung Großes Huhn, } 1955 \text { und einem Foto } \\
\text { von Maria Rama, das Grass am Elbufer zeigt }\end{array}$ & $\begin{array}{l}\text { Zeichnung: } \\
\text { Tusche }\end{array}$ & Grass (1973), S. 32 f. & \\
\hline
\end{tabular}




\begin{tabular}{|c|c|c|c|c|}
\hline 1973 & $\begin{array}{l}\text { Mariazuehren, S. } 32 \text { f., Doppelseite aus verschiedenen } \\
\text { Fotografien und Werkabbildungen, darunter die Zeichnung } \\
\text { aus Ein Ort für Zufälle (1965), S. 49: Nymphensittiche und } \\
\text { Panzer }\end{array}$ & $\begin{array}{l}\text { Zeichnung: } \\
\text { Tusche }\end{array}$ & $\begin{array}{l}\text { Grass (1973), S. } 38 \text { f.; Bachmann } \\
(1965), \text { S. } 49\end{array}$ & \\
\hline 1975 & Gemischte Gesellschaft I, Vögel, Köche, Frauen & $\begin{array}{l}\text { Kaltnadel- } \\
\text { radierung }\end{array}$ & Ohsoling (2007), R 94 & \\
\hline 1977 & Gänsekopf I & $\begin{array}{l}\text { Kaltnadel- } \\
\text { radierung }\end{array}$ & Ohsoling (2007), R 117 & \\
\hline 1977 & Gänsekopf II & $\begin{array}{l}\text { Kaltnadel- } \\
\text { radierung }\end{array}$ & Ohsoling (2007), R 118 & \\
\hline 1977 & Gänsekopf III & $\begin{array}{l}\text { Kaltnadel- } \\
\text { radierung }\end{array}$ & Ohsoling (2007), R 119 & \\
\hline o. D. & $\begin{array}{l}\text { Amsel, Drossel, Fink und Star, Umschlagentwurf zu den } \\
\text { späteren Hundejahren }\end{array}$ & Tusche & & GGH-G 784/2005 \\
\hline o. D. & Eule & Tusche & Grass (2004a), S. 36 & \\
\hline o. D. & Geschichte, Vogel und Mensch auf Wendeltreppe & Tusche & Grass (2004a), S. 24 & \\
\hline o. D. & Hähne & Fettkreide & Grass (2004a), S. 6 & \\
\hline o. D. & Henne & Tusche & Grass (2004a), S. 50 & \\
\hline o. D. & $\begin{array}{l}\text { Schachspiel, Schachbrett, mit Frauenfiguren, Steinbock, Eule } \\
\text { und Hahnenkopf }\end{array}$ & Kohle & Grass (2004), S. 9 & \\
\hline o. D. & Vier Vogelköpfe & Tusche & Grass (2004a), S. 8 & \\
\hline o. D. & Vögel mit Stift, vier Windhühner mit Bleistift & Tusche & Grass (2004a), S. 5 & \\
\hline
\end{tabular}

\section{NONNEN}

\begin{tabular}{|l|l|l|l|}
\hline Datierung & Titel & Technik & Quelle der Abb. \\
\hline 1957 & Nonne und fünf Vögel & $\begin{array}{l}\text { Kohle und } \\
\text { Kreide }\end{array}$ & Grass (1973), S. 11 \\
\hline 1957 & Nonne zwischen Köchen & Bleistift & $\begin{array}{l}\text { Kat. Ausst. Kiel (1987), S. 44, } \\
\text { Abb. 20 }\end{array}$ \\
\hline
\end{tabular}




\begin{tabular}{|c|c|c|c|c|}
\hline 1957 & Schwester Agneta & $\begin{array}{l}\text { Bleistift und } \\
\text { Kohle }\end{array}$ & $\begin{array}{l}\text { Kat. Ausst. Kiel (1987), S. 43, } \\
\text { Abb. } 19\end{array}$ & \\
\hline 1957 & Schwester Agneta & Kohle & Dreher (1982), S. 23, Abb. 10 & \\
\hline 1957 & Vinzentinerin & Bleistift & & GGH-G 669/2005 \\
\hline 1957 & Vinzentinerin & Bleistift & Dreher (1982), S. 21, Abb. 9. & \\
\hline 1957 & Zwei Nonnen & Kohle & $\begin{array}{l}\text { Kat. Ausst. Kiel (1987), S. 45, Abb. } \\
21\end{array}$ & \\
\hline 1957 & Zwei Nonnen & Bleistift & & $\begin{array}{l}\text { AdK, Inv. Nr.: HZ } \\
\text { 2004, Standort III-2 }\end{array}$ \\
\hline um 1957 & $\begin{array}{l}\text { Manuskript zum Gedicht „Theater“ aus dem Gedichtzyklus } \\
\text { „Zauberei mit den Bräuten Christi“, mit Zeichnung: Koch, } \\
\text { Vogel und Nonne, zwei Varianten }\end{array}$ & Tusche/Blei & Grass (2014), S. 88. (Tusche) & $\begin{array}{l}\text { Literaturarchiv der } \\
\text { AdK, Grass-Archiv, } \\
\text { Sig. } 948\end{array}$ \\
\hline 1958 & Nonnen & Bleistift & & GGH-G 635/2005 \\
\hline 1958 & Zwei Nonnen & Tusche, laviert & & GGH-G 624/2005 \\
\hline 1960 & Äbtissin & Kohle & & GGM/0004/2009 \\
\hline 1960 & Äbtissin & Tusche & & GGH-G 705/2005 \\
\hline 1960 & Ausflug der Nonnen & Tusche & & GGH-G 712/2005 \\
\hline 1960 & Beim Morgengebet, fünf betende Nonnen & Tusche, laviert & $\begin{array}{l}\text { Kat. Ausst. Kiel (1987), S. 62, } \\
\text { Abb. } 37 .\end{array}$ & GGH-G 709/2005 \\
\hline 1960 & Betende Nonne & Tusche & Grass (2014), S. 92 & \\
\hline 1960 & Ein Pulk Nonnen & Tusche & Grass (1999), S. 34 & \\
\hline 1960 & Fünf Nonnen mit Regenschirmen & Fettkreide & & GGH-G 711/2005 \\
\hline 1960 & $\begin{array}{l}\text { Gleisdreieck, S. } 46 \text { f., Abbildung einer Zeichnung zum } \\
\text { Gedichtzyklus „Zauberei mit den Bräuten Christi“: Zwei } \\
\text { Nonnen }\end{array}$ & $\begin{array}{l}\text { Original: } \\
\text { Kohle/ } \\
\text { Fettkreide }\end{array}$ & Grass (1960), S. 46 f. & \\
\hline 1960 & $\begin{array}{l}\text { Gleisdreieck, S. 48, Abbildung einer Zeichnung zum } \\
\text { Gedichtzyklus „Zauberei mit den Bräuten Christi“: Neun } \\
\text { Nonnen }\end{array}$ & $\begin{array}{l}\text { Original: } \\
\text { Kohle/ } \\
\text { Fettkreide }\end{array}$ & Grass (1960), S. 48 & \\
\hline 1960 & $\begin{array}{l}\text { Gleisdreieck, S. } 52 \text { f., Abbildung einer Zeichnung zum } \\
\text { Gedichtzyklus „Zauberei mit den Bräuten Christi“: Nonnen } \\
\text { versammelt }\end{array}$ & $\begin{array}{l}\text { Original: } \\
\text { Kohle/ } \\
\text { Fettkreide }\end{array}$ & Grass (1960), S. 52 f. & \\
\hline
\end{tabular}




\begin{tabular}{|c|c|c|c|c|}
\hline 1960 & Hüpfende Nonne / Springende Nonne & Tusche, laviert & $\begin{array}{l}\text { Dreher (1982), S. 61, Abb. 36; Kat. } \\
\text { Ausst. Kiel (1987), S. 61, Abb. } 36\end{array}$ & GGH-G 1071/2005 \\
\hline 1960 & Kleine Nonne I & Tusche & Grass (1999), S. 36 & \\
\hline 1960 & Kniende Nonne & Tusche & Kat. Ausst. Aachen (1997), S. 45 & $\begin{array}{l}\text { Ludwig Forum für } \\
\text { internationale } \\
\text { Kunst, Aachen }\end{array}$ \\
\hline 1960 & Knieende Nonnen & Tusche & Grass (1999), S. 35 & \\
\hline 1960 & Laufende Nonnen & Tusche & & GGH-G 1073/2005 \\
\hline 1960 & Neun stehende Nonnen & Kohle & & $\begin{array}{l}\text { GGM/0003/2009 } \\
\text { (Vorderseite) }\end{array}$ \\
\hline 1960 & Nonne & Kohle & & GGH-G 708/2005 \\
\hline 1960 & Nonne / Betende Nonne & Bleistift & $\begin{array}{l}\text { Kat. Ausst. Kiel (1987), S. 60, } \\
\text { Abb. } 35 .\end{array}$ & $\begin{array}{l}\text { AdK, Inv.-Nr.: HZ } \\
\text { 1997, Standort III-1 }\end{array}$ \\
\hline 1960 & Nonnen & Tusche & Ausst. Kat. Aachen (1997), S. 44 & $\begin{array}{l}\text { Ludwig Forum für } \\
\text { internationale } \\
\text { Kunst, Aachen }\end{array}$ \\
\hline 1960 & Ritter und Nonnen & Tusche & Grass (2014), S. 109 & \\
\hline 1960 & Nonnen und Ritter (verso), Arbeitsplan Hundejahre (recto) & Tusche & & GGH-G 1074/2005 \\
\hline 1960 & Viele Nonnen & Tusche & & GGH-G 1072/2005 \\
\hline 1960 & $\begin{array}{l}\text { Zeichnung zum Gedichtzyklus „Zauberei mit den Bräuten } \\
\text { Christi“: sieben fliegende Nonnen }\end{array}$ & Fettkreide & Grass (2014), S. 92 & \\
\hline 1960 & $\begin{array}{l}\text { Zeichnung zum Gedichtzyklus „Zauberei mit den Bräuten } \\
\text { Christi“/ Zwei ruhende Nonnen }\end{array}$ & Fettkreide & Grass (2014), S. 93 & GGH-G 710/2005 \\
\hline 1960 & Zwei Nonnen, tanzende Nonnen & Tusche & & $\begin{array}{l}\text { AdK, Inv.-Nr.: HZ } \\
\text { 1998, Standort III-1 }\end{array}$ \\
\hline 1961 & Betende Nonne / Knieende Nonne & Tusche & $\begin{array}{l}\text { Grass (2014), S. 90; Grass (1999), } \\
\text { S. } 38\end{array}$ & GGH-G 1075/2005 \\
\hline 1961 & Dicke Nonne & Tusche & Grass (1973), S. 10 & \\
\hline 1961 & $\begin{array}{l}\text { Die Äbtissin kleidet zwei Novizinnen ein / Einkleidung der } \\
\text { Novizinnen }\end{array}$ & Tusche & $\begin{array}{l}\text { Dreher (1982), S. 62, Abb. 37; Kat. } \\
\text { Ausst. Kiel (1987), S. 69, Abb. 42; } \\
\text { Grass (2014), S. } 111\end{array}$ & $\begin{array}{l}\text { AdK, Inv.-Nr.: HZ } \\
\text { 1996, Standort III-1 }\end{array}$ \\
\hline 1961 & Die Novizin wird eingekleidet & Tusche & Dreher (1982), S. 65, Abb. 39 & GGH-G 1069/2005 \\
\hline
\end{tabular}




\begin{tabular}{|c|c|c|c|c|}
\hline 1961 & Einkleidung der Novizin & Tusche & Dreher (1982), S. 63, Nr. 38 & \\
\hline 1961 & Konvent, große Nonnengruppe & Tusche, laviert & Dreher (1982), S. 59, Nr. 35 & \\
\hline 1961 & Küchennonne & Tusche & & GGH-G 707/2005 \\
\hline 1961 & Nonne bei Gegenwind & Bleistift & Grass (2004a), S. 55 & \\
\hline 1961 & Plakat, Zinke, Vogelkopf mit Flügelhaube & $\begin{array}{l}\text { Zeichnung: } \\
\text { Tusche }\end{array}$ & Grass (2014), S. 93 & \\
\hline 1961 & Skizzen nach Nonnen & Tusche & Grass (2014), S. 93 & \\
\hline 1961 & Tanzende Nonne & Bleistift & & GGH-G 704/2005 \\
\hline 1962 & Ruhende Nonnen & Tusche, laviert & & GGH-G 713/2005 \\
\hline 1963 & Titelbild von Günter Grass: Die Ballerina, tanzende Nonne & Tusche & Grass (1963), Umschlag & \\
\hline 1972 & Nonne mit Aal & Ätzradierung & Ohsoling (2007), R 18 & \\
\hline 1973 & $\begin{array}{l}\text { Mariazuehren, S. } 10 \text { f., Doppelseite zusammengestellt aus } \\
\text { Abb. der Zeichnungen: Nonne mit Vögeln, } 1957 \text { und Dicke } \\
\text { Nonne, } 1961\end{array}$ & $\begin{array}{l}\text { Zeichnungen: } \\
\text { Kreide / Kohle } \\
\text { und Tusche }\end{array}$ & Grass (1973), S. 11 & $\begin{array}{l}\text { Kohlezeichnung: } \\
\text { AdK, Inv.-Nr.: HZ } \\
\text { 2733, Standort III- } \\
1 .\end{array}$ \\
\hline
\end{tabular}

\section{VOGELSCHEUCHEN}

\begin{tabular}{|c|c|c|c|c|}
\hline Datierung & Titel & Technik & Quelle der Abb. & Sammlung \\
\hline 1957 & Jagdszene, Scheuchen, Pferde und Blechbläser / Pferdeballett & Tusche, laviert & Grass (1999), S. 22 & GGH-G 650/2005 \\
\hline 1957 & Skizze für das Ballett Die Vogelscheuchen: sechs Stelzvögel & Tusche, laviert & Grass (2014), S. 80 & GGH-G 602/2005 \\
\hline 1957 & Skizze für das Ballett Die Vogelscheuchen: vier Scheuchen & Tusche & Grass (2014), S. 79 & GGH, o. Inv.-Nr. \\
\hline 1957 & Vogelscheuchen: zwei Scheuchen & Fettkreide & & GGH-G 528/2005 \\
\hline 1957 & Vogelscheuchen, vier Vogelscheuchen & Tusche, laviert & Dreher (1982), S. 33, Abb. 16 & GGH-G 527/2005 \\
\hline $\begin{array}{l}1957 / \\
1958\end{array}$ & $\begin{array}{l}\text { Skizze für das Ballett Die Vogelscheuchen: drei Scheuchen auf } \\
\text { Pferden }\end{array}$ & Tusche & Grass (2014), S. 79 & \\
\hline $\begin{array}{l}1957 / \\
1958\end{array}$ & $\begin{array}{l}\text { Skizze für das Ballett Die Vogelscheuchen: zwei Tänzer als } \\
\text { Vögel verkleidet }\end{array}$ & Kohle & Grass (2014), S. 79 & \\
\hline 1958 & Scheuchenballett: sechs Vogelscheuchen & Tusche & Dreher (1982), S. 33, Abb. 17 & GGH-G 674/2005 \\
\hline 1958 & $\begin{array}{l}\text { Skizze für das Ballett Die Vogelscheuchen: sieben } \\
\text { Vogelscheuchen }\end{array}$ & Tusche & Grass (2014), S. 81 & \\
\hline 1958 & Skizze, Vogelscheuchen & & & GGH-G 651/2005 \\
\hline
\end{tabular}




\begin{tabular}{|c|c|c|c|c|}
\hline 1960 & $\begin{array}{l}\text { Gleisdreieck, S. } 32 \text { f., Abbildung einer Zeichnung zum Gedicht } \\
\text { „Die Vogelscheuchen“: Männliche Scheuchen, vier } \\
\text { Vogelscheuchen in Vogelgestalt }\end{array}$ & $\begin{array}{l}\text { Original: } \\
\text { Kohle/ } \\
\text { Fettkreide }\end{array}$ & $\begin{array}{l}\text { Grass (1960), S. } 32 \text { f., Dreher } \\
\text { (1982), S. 35, Abb. } 19\end{array}$ & \\
\hline 1960 & $\begin{array}{l}\text { Gleisdreieck, S. } 36 \text { f., Abbildung einer Zeichnung zum Gedicht } \\
\text { „Die Vogelscheuchen“: vier Vogelscheuchen }\end{array}$ & $\begin{array}{l}\text { Original: } \\
\text { Kohle/ } \\
\text { Fettkreide }\end{array}$ & Grass (1960), S. 36 f. & \\
\hline 1960 & Mechanische Scheuchen & Kohle & Dreher (1982), S. 35, Abb. 18 & \\
\hline 1960 & Ritter und Nonnen & Tusche & Grass (2014), S. 109 & \\
\hline 1960 & Nonnen und Ritter (verso), Arbeitsplan Hundejahre (recto) & & & GGH-G 1074/2005 \\
\hline 1961 & $\begin{array}{l}\text { Skizze zum Vogelscheuchen-Komplex in den Hundejahren: } \\
\text { Bismarck-Scheuche mit Vogel / Bismarck als Vogelscheuche }\end{array}$ & Tusche & Grass (2014), S. 106 & GGH-G 746/2005 \\
\hline 1961 & $\begin{array}{l}\text { Skizze zum Vogelscheuchen-Komplex in den Hundejahren: } \\
\text { große Vogelgruppe }\end{array}$ & Bleistift & $\begin{array}{l}\text { Dreher (1982), S. 67, Abb. 40; } \\
\text { Grass (1999), S. 39; Grass (2014), } \\
\text { S. } 106\end{array}$ & \\
\hline 1961 & $\begin{array}{l}\text { Skizze zum Vogelscheuchen-Komplex in den Hundejahren: } \\
\text { Ulbricht-Scheuche und Vogel }\end{array}$ & Tusche & Grass (2014), S. 106 & GGH-G 747/2005 \\
\hline 1961 & $\begin{array}{l}\text { Skizze zum Vogelscheuchen-Komplex in den Hundejahren: } \\
\text { Windmühlennonnenscheuche }\end{array}$ & Tusche & Grass (2014), S. 106 & \\
\hline 1961 & $\begin{array}{l}\text { Vögel und Vogelscheuchen zu den Hundejahren: Frauen, Vögel } \\
\text { und Scheuchen }\end{array}$ & Tusche & Grass (2014), S. 110 & \\
\hline 1961 & $\begin{array}{l}\text { Skizze zum Vogelscheuchen-Komplex in den Hundejahren: } \\
\text { Vogelscheuchen mit Bischofs-Vogelscheuche }\end{array}$ & Tusche & Grass (2014), S. 110 & \\
\hline o. D. & Stabile und bewegte Scheuchen & Tusche & Grass (2014a), S. 76 f. & \\
\hline
\end{tabular}

\section{SCHNECKEN}

\begin{tabular}{|l|l|l|l|}
\hline Datierung & Titel & Technik & Quelle der Abb. \\
\hline 1955 & $\begin{array}{l}\text { Kriechende Schnecke zwischen kleinem Haus und großem } \\
\text { Wecker (zur Kurzprosa „Meine grüne Wiese“) }\end{array}$ & Tusche & Trautwein/Kiwus (2002) \\
\hline 1955 & Schnecke mit Torero & Tusche & $\begin{array}{l}\text { AdK, Inv.-Nr.: HZ } \\
\text { 2007, Standort III-3 }\end{array}$ \\
\hline
\end{tabular}




\begin{tabular}{|c|c|c|c|c|}
\hline 1956 & Drei Schnecken & Bleistift & & GGH-G 595/2005 \\
\hline 1969 & Schema: Im Schneckenhaus & Tusche & Grass (2014), S. 143 & \\
\hline 1970 & Entwurf zum Buchumschlag Aus dem Tagebuch einer Schnecke & Tusche & & GGH-G 877/2005 \\
\hline 1970 & Schnecken gegenläufig & Filzstift & & GGH-G 842/2005 \\
\hline 1970 & Schneckenlauf/Gespräch & Filzstift & Grass (2004a), S. 143 & GGH-G 841/2005 \\
\hline 1970 & Schnecken mit Häusern & Tusche & & GGH-G 688/2005 \\
\hline 1970 & Vorwärts & Filzstift & Grass (2004a), S. 144 & \\
\hline 1970 & Zu Aus dem Tagebuch einer Schnecke, Schnecke & Tusche & & GGH-G 685/2005 \\
\hline 1971 & Alge mit Schnecke & Kohle & $\begin{array}{l}\text { Kat. Ausst. Kiel (1987), S. 84, } \\
\text { Abb. } 57\end{array}$ & GGM/0006/2009 \\
\hline 1971 & Am Atlantikwall, Schnecke auf Bunkerdach & Bleistift & $\begin{array}{l}\text { Kat. Ausst. Kiel (1987), S. 81, } \\
\text { Abb. } 54\end{array}$ & \\
\hline 1971 & Am Atlantikwall, Schnecke auf Bunkerdach & Bleistift & & GGH-G 805/2005 \\
\hline 1971 & $\begin{array}{l}\text { Entwurf zum Buchumschlag Aus dem Tagebuch einer Schnecke } \\
\text { / Lisbeth }\end{array}$ & Bleistift & Grass (2014), S. 158 (oben) & GGH-H 888/2005 \\
\hline 1971 & $\begin{array}{l}\text { Entwurf zum Buchumschlag für Aus dem Tagebuch einer } \\
\text { Schnecke }\end{array}$ & Bleistift & Grass (2014), S. 158 (unten) & \\
\hline 1971 & Frau mit Schneckenhut & Bleistift & & GGM/0007/2009 \\
\hline 1971 & Die Revolutionäre folgen der Schnecke & Kohle & & GGH-G 884/2005 \\
\hline 1971 & Die Schnecke am Tischrand & Kohle & Dreher (1982), S. 85, Abb. 53 & \\
\hline 1971 & Die Schnecke fährt mit, Schnecke auf Autodach & Bleistift & $\begin{array}{l}\text { Kat. Ausst. Kiel (1987), S. 80, } \\
\text { Abb. } 53\end{array}$ & \\
\hline 1971 & Mit Pilz und Schnecke, weiblicher Torso mit Pilz und Schnecke & Kohle & & GGH-G 883/2005 \\
\hline 1971 & Salomons Säulen, Schnecke in Ruinenlandschaft & Bleistift & Grass (2014), S. 150 & \\
\hline 1971 & Schnecke am Wasserturm & Bleistift & $\begin{array}{l}\text { Kat. Ausst. Kiel (1987), S. 83, } \\
\text { Abb. } 56\end{array}$ & \\
\hline 1971 & Schnecke auf der Mole & Bleistift & $\begin{array}{l}\text { Kat. Ausst. Kiel (1987), S. 82, } \\
\text { Abb. } 55\end{array}$ & \\
\hline 1971 & Eilat, Schnecke in Eilat & Bleistift & Grass (2014), S. 150 & GGH-G 804/205 \\
\hline 1971 & Eilat, Schnecke in Eilat & Bleistift & & GGH-G 891/2005 \\
\hline 1971 & Schnecke bei Eilat & Bleistift & Dreher (1982), S. 92, Abb. 58 & \\
\hline 1971 & Schnecke hört mit / Besetzt, Schnecke auf Telefonhörer & Tusche & Grass (2004a), S. 147 & GGH-G 886/2005 \\
\hline
\end{tabular}




\begin{tabular}{|c|c|c|c|c|}
\hline 1971 & Schneckenwettlauf / Wettlauf & Tusche & $\begin{array}{l}\text { Grass (1999), S. 46, Grass (2004a), } \\
\text { S. } 141\end{array}$ & GGH-G 885/2005 \\
\hline 1971 & Schnecke und Schwein gegenläufig & Bleistift & $\begin{array}{l}\text { Kat. Ausst. Kiel (1987), S. 85, } \\
\text { Abb. } 58\end{array}$ & \\
\hline 1971 & Stillleben mit Schnecke, Pilze, Glühbirne und Nacktschnecke & Bleistift & Dreher (1982), S. 89, Abb. 56 & \\
\hline 1971 & Vulva, Pilz und Schnecke & Bleistift & & GGH-G 882/2005 \\
\hline 1972 & Akt mit Doppelschnecke und Rübe & Bleistift & $\begin{array}{l}\text { Kat. Ausst. Kiel (1987), S. 87, } \\
\text { Abb. } 60\end{array}$ & \\
\hline 1972 & Doppelschnecke & Rohrfeder & $\begin{array}{l}\text { Dreher (1982), S. 93, Abb. 59, } \\
\text { Grass (1973), S. } 47\end{array}$ & \\
\hline 1972 & $\begin{array}{l}\text { Entwurf zum Buchumschlag für Aus dem Tagebuch einer } \\
\text { Schnecke }\end{array}$ & Tusche & Grass (2014), S. 162 & \\
\hline 1972 & $\begin{array}{l}\text { Entwurf zum Buchumschlag für Aus dem Tagebuch einer } \\
\text { Schnecke }\end{array}$ & Blei/Kohle & & GGH-G 879/2005 \\
\hline 1972 & $\begin{array}{l}\text { Entwurf zum Buchumschlag für Aus dem Tagebuch einer } \\
\text { Schnecke }\end{array}$ & $\begin{array}{l}\text { Plakafarbe, } \\
\text { Tusche }\end{array}$ & & GGH-G 849/2005 \\
\hline 1972 & Hahn zwischen Schnecken & Kohle & Dreher (1982), S. 95, Abb. 60 & \\
\hline 1972 & Lisbeth im Flachland, Schnecken auf Torso mit Rettich & Tusche & Dreher (1982), S. 91, Abb. 57 & \\
\hline 1972 & Pfeilschnelle Schnecke & Bleistift & Dreher (1982), S. 88, Abb. 55 & \\
\hline 1972 & Puppe im Geäst, Puppe zwischen Ästen mit Schnecke & Kohle & $\begin{array}{l}\text { Grass (1973), S. 53; Dreher } \\
(1982), \text { S. 97, Abb. } 61\end{array}$ & \\
\hline 1972 & Schnecke am Tischrand / Schnecke und Maronenschale & Bleistift & $\begin{array}{l}\text { Dreher (1982), S. 85, Abb. 53; Kat. } \\
\text { Ausst. Kiel (1987), S. 86, Abb. } 59\end{array}$ & \\
\hline 1972 & $\begin{array}{l}\text { Schnecken / Schneckenkomposition/Skizze zu Aus dem } \\
\text { Tagebuch einer Schnecke: verschiedene } \\
\text { Schneckenkompositionen in Miniatur }\end{array}$ & Kohle & Grass (2014), S. 148 & GGH-G 881/2005 \\
\hline 1972 & Schneckenwettlauf, Schnecken und Pilze & Kohle & Grass (2014), S. 160 & \\
\hline 1972 & Selbst mit Schnecken / Selbstporträt mit Schnecken & Bleistift & $\begin{array}{l}\text { Dreher (1982), S. 87, Abb. 54; Kat. } \\
\text { Ausst. Kiel (1987), S. 88, Abb. } 61\end{array}$ & \\
\hline 1972 & Schnecke auf Füllfederhalter & Tusche & Grass (2014), S. 148 & GGH-G 855/2005 \\
\hline 1972 & Schnecke auf Rasierklinge / Über die Klinge & Tusche & $\begin{array}{l}\text { Grass (2014), S. 148, } \\
\text { Grass (2004a), S. } 146\end{array}$ & GGH-G 856/2005 \\
\hline
\end{tabular}




\begin{tabular}{|c|c|c|c|c|}
\hline 1972 & $\begin{array}{l}\text { Wewelsflether Stillleben: Schnecke auf Vulva, Rübe, Aal, } \\
\text { Kuheuter und Pilze }\end{array}$ & Bleistift & $\begin{array}{l}\text { Kat. Ausst. Kiel (1987), S. 93, } \\
\text { Abb. } 65\end{array}$ & \\
\hline 1972 & $\begin{array}{l}\text { Zeichnung zu Aus dem Tagebuch einer Schnecke: Schnecke an } \\
\text { der Weichsel }\end{array}$ & Bleistift & Grass (2014), S. 154 (oben) & \\
\hline 1972 & $\begin{array}{l}\text { Zeichnung zu Aus dem Tagebuch einer Schnecke: Schnecke in } \\
\text { Berglandschaft }\end{array}$ & Bleistift & Grass (2014), S. 152 & \\
\hline 1972 & $\begin{array}{l}\text { Zeichnung zu Aus dem Tagebuch einer Schnecke: Schnecke in } \\
\text { Delphi }\end{array}$ & Bleistift & Grass (2014), S. 152 & \\
\hline 1972 & $\begin{array}{l}\text { Zeichnung zu Aus dem Tagebuch einer Schnecke: Schnecke in } \\
\text { der Tuchler Heide }\end{array}$ & Bleistift & Grass (2014), S. 154 (unten) & \\
\hline 1972 & $\begin{array}{l}\text { Zeichnung zu Aus dem Tagebuch einer Schnecke: Schnecke in } \\
\text { der Tuchler Heide }\end{array}$ & Bleistift & & GGH-G 890/2005 \\
\hline 1972 & $\begin{array}{l}\text { Zeichnung zu Aus dem Tagebuch einer Schnecke, Schnecke in } \\
\text { Landschaft }\end{array}$ & Bleistift & Grass (2014), S. 156 (oben) & \\
\hline 1972 & Östlich der Oder, Schnecke in Landschaft & Bleistift & Grass (2014), S. 156 (unten) & GGH-G 889/2005 \\
\hline 1972 & Bei Lisbeth, Schnecke auf Vulva & Ätzradierung & Ohsoling (2007), R 10 & \\
\hline 1972 & In Polen unterwegs, Schnecke in Landschaft & Ätzradierung & Ohsoling (2007), R 9 & \\
\hline 1972 & Kleiner Schneckenwettlauf & Ätzradierung & Ohsoling (2007), R 11 & \\
\hline 1972 & Lisbeth, Umschlagmotiv zum Tagebuch & Ätzradierung & Ohsoling (2007), R 1 & \\
\hline 1972 & $\begin{array}{l}\text { Lisbeth mit Schnecke, weiblicher Unterkörper mit } \\
\text { langstieligem Pilz und Schnecke }\end{array}$ & Ätzradierung & Ohsoling (2007), R 2 & \\
\hline 1972 & Schnecke am Kreuz & Ätzradierung & Ohsoling (2007), R 8 & \\
\hline 1972 & Schnecke im Schwarzwald & Ätzradierung & Ohsoling (2007), R 5 & \\
\hline 1972 & Schnecke in Eilat & Ätzradierung & Ohsoling (2007) R 4 & \\
\hline 1972 & Schneckenwettlauf I & Ätzradierung & Ohsoling (2007), R 6 & \\
\hline 1972 & Schneckenwettlauf II & Ätzradierung & Ohsoling (2007), R 7 & \\
\hline 1972 & Selbstporträt I, Selbstbildnis mit Schnecken & Ätzradierung & Ohsoling (2007), R 12 & \\
\hline 1972 & Selbstporträt II, Selbstbildnis mit Schnecken & Ätzradierung & Ohsoling (2007), R 15 & \\
\hline 1972 & Wasserturmschnecke & Ätzradierung & Ohsoling (2007), R 3 & \\
\hline 1973 & $\begin{array}{l}\text { Mariazuehren, S. } 4 \text { f., Foto einer Backsteinwand überblendet } \\
\text { mit dem Foto der Zeichnung: Schneckenwettlauf, } 1972\end{array}$ & $\begin{array}{l}\text { Zeichnung: } \\
\text { Kohle }\end{array}$ & Grass (1973), S. 4 f. & \\
\hline
\end{tabular}




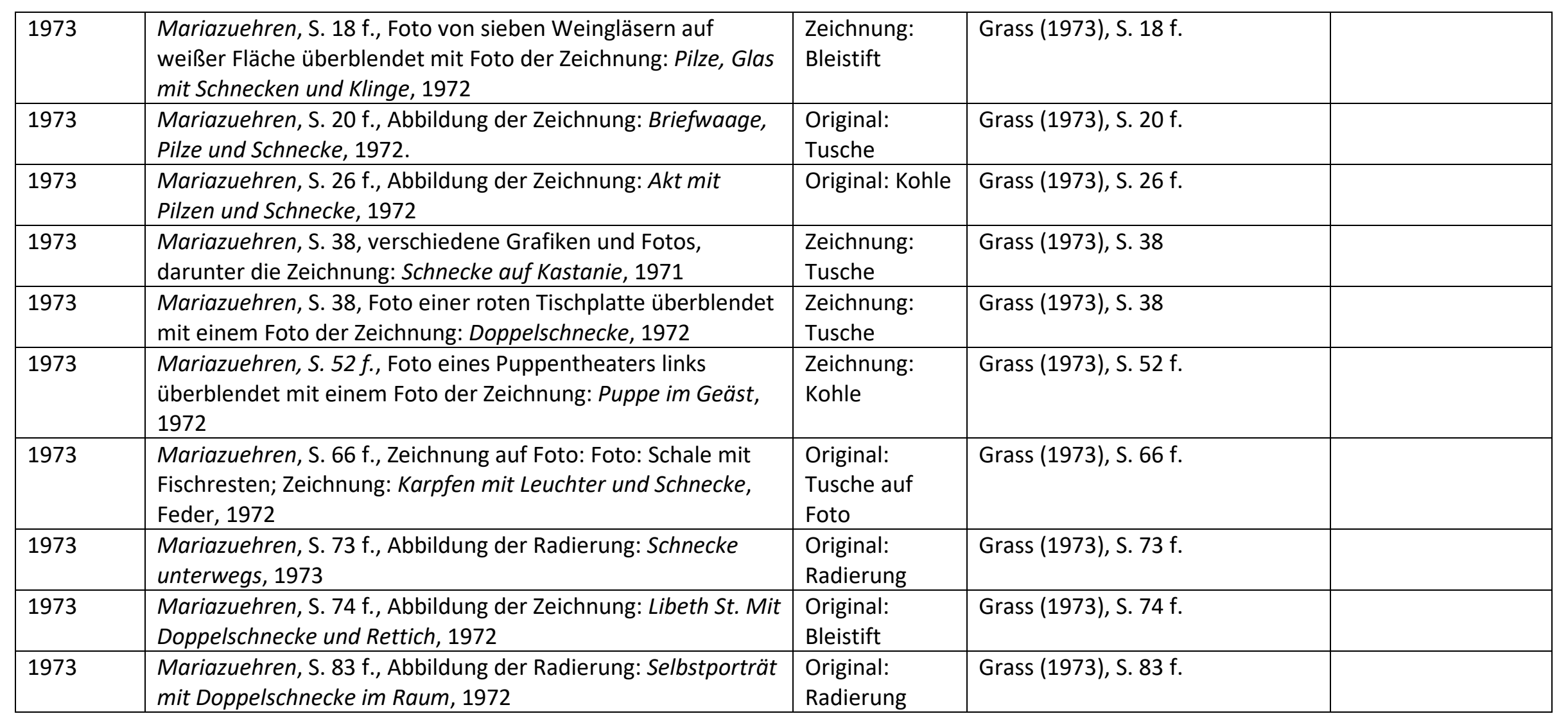

PILZE

\begin{tabular}{|l|l|l|l|l|}
\hline Datierung & Titel & Technik & Quelle der Abb. & Sammlung \\
\hline 1967 & $\begin{array}{l}\text { Ausgefragt, S. 84, Abbildung einer Zeichnung zum Gedicht } \\
\text { „Gemüsetest“: Pilz und Wurm, im Hintergrund: Explosion } \\
\text { einer Atombombe }\end{array}$ & $\begin{array}{l}\text { Original: } \\
\text { Bleistift }\end{array}$ & Grass (1967), S. 84 & \\
\hline 1971 & Mit Pilz und Schnecke, Torso mit Pilz und Schnecke & Kohle & GGH-G 883/2005 \\
\hline 1971 & Stillleben mit Schnecke, Pilze, Glühbirne und Schnecke & Bleistift & Dreher (1982), S. 89, Abb 56 & \\
\hline
\end{tabular}




\begin{tabular}{|c|c|c|c|c|}
\hline 1971 & Vulva, Pilz und Schnecke & Bleistift & & GGH-G 882/2005 \\
\hline 1972 & Schneckenwettlauf, Schnecken und Pilze & Kohle & Grass (2014), S. 160 & \\
\hline 1972 & $\begin{array}{l}\text { Wewelsflether Stillleben, Schnecke auf Vulva, Rübe, Aal, } \\
\text { Kuheuter und Pilze }\end{array}$ & Bleistift & $\begin{array}{l}\text { Kat. Ausst. Kiel (1987), S. 93, } \\
\text { Abb. } 65\end{array}$ & \\
\hline 1972 & Fruchtbare Pilze & Ätzradierung & Ohsoling (2007), R 23 & \\
\hline 1972 & Große Pilze, Pilze, Penis und Vulva & Ätzradierung & Ohsoling (2007), R 16 & \\
\hline 1972 & Pimmelpilz & Ätzradierung & Ohsoling (2007), R 22 & \\
\hline 1973 & Pilze für Vatertag, versteift & Bleistift & & GGH-H 831/2005 \\
\hline 1973 & Zeichnung aus der Serie Mein Schuh: Schuh, Brille und Pilze & Bleistift & Grass (2014), S. 200 & \\
\hline 1973 & Liegender Pilz & Ätzradierung & Ohsoling (2007), R 48 & \\
\hline 1973 & Pilze im Schoß & Ätzradierung & Ohsoling (2007), R 52 & \\
\hline 1973 & Viele Pilze & $\begin{array}{l}\text { Ätzradierung } \\
\text { mit Aquatinta }\end{array}$ & Ohsoling (2007), R 35 & \\
\hline 1973 & $\begin{array}{l}\text { Mariazuehren, S. } 18 \text { f., Foto von Gläsern auf weißer Fläche } \\
\text { überblendet mit der Zeichnung: Pilze, Glas mit Schnecken und } \\
\text { Klinge, } 1972\end{array}$ & $\begin{array}{l}\text { Zeichnung: } \\
\text { Bleistift }\end{array}$ & Grass (1973), S. 18 f. & \\
\hline 1973 & $\begin{array}{l}\text { Mariazuehren, S. } 20 \text { f., Abbildung der Zeichnung: Briefwaage, } \\
\text { Pilze und Schnecke, } 1972\end{array}$ & $\begin{array}{l}\text { Original: } \\
\text { Tusche }\end{array}$ & Grass (1973), S. 20 f. & \\
\hline 1973 & $\begin{array}{l}\text { Mariazuehren, S. } 22 \text { f., Schwarzweißfoto von zwei Pilzen, } \\
\text { darauf Zeichnung von Pilzen: im Buchverzeichnis angeführt } \\
\text { als: „Pilze, Feder und Foto, 1973“ }\end{array}$ & $\begin{array}{l}\text { Original: Foto } \\
\text { und Tusche }\end{array}$ & $\begin{array}{l}\text { Grass (1973), S. } 22 \text { f.; Grass } \\
(2014), \text { S. } 192\end{array}$ & \\
\hline 1973 & $\begin{array}{l}\text { Mariazuehren, S. } 24 \text { f., Abbildung der Radierung: Pimmelpilze, } \\
1973\end{array}$ & $\begin{array}{l}\text { Original: } \\
\text { Radierung }\end{array}$ & Grass (1973), S. 24 f. & \\
\hline 1973 & $\begin{array}{l}\text { Mariazuehren, S. } 26 \text { f., Abbildung der Zeichnung: Akt mit } \\
\text { Pilzen und Schnecke, } 1972\end{array}$ & Original: Kohle & Grass (1973), S. $26 \mathrm{f}$. & \\
\hline 1973 & $\begin{array}{l}\text { Mariazuehren, S. } 28 \text { f., Fotografie der Zeichnung Pilze, 1972, } \\
\text { auf Steinfliesenboden und darüber gestreuten Pilzen }\end{array}$ & Original: Kohle & Grass (1973), S. 28 f. & \\
\hline 1974 & Ein Wurf Pilze & Tusche & Dreher (1982), S. 108, Abb. 70 & \\
\hline 1974 & $\begin{array}{l}\text { Fruchtbarer Pilz, aus dem Portfolio Liebe geprüft, Pilz und } \\
\text { Phallus }\end{array}$ & Ätzradierung & Ohsoling (2007), R 68 & \\
\hline 1974 & „Immer war schon wer da...", Text, Pilze und Brille & Tusche & & GGH-G 845/2005 \\
\hline 1974 & „Kein Spaß“, Text und Pilze & Tusche & Grass (2014), S. 184 & \\
\hline
\end{tabular}




\begin{tabular}{|c|c|c|c|c|}
\hline 1974 & "Ich verlor meine Brille", Text, Pilze, Brille und Daumen & Tusche & Grass (2014), S. 178 & GGH-G 858/2005 \\
\hline 1974 & „Wir suchen“, Text, Pilze und Brille & Tusche & Grass (2004a), S. 154 & GGH-G 826/2005 \\
\hline 1974 & „Wir unterscheiden...", Text und Pilze & Tusche & & GGH-G 844/2005 \\
\hline 1974 & Zeichnung zu Der Butt, Pilze neben Nägeln & Bleistift & Grass (2014), S. 176 & \\
\hline 1974 & $\begin{array}{l}\text { Zeichnung zu Mit Sophie in die Pilze gegangen, Selbstporträt } \\
\text { mit Pilz und Sprechblase }\end{array}$ & Tusche & Grass (2014), S. 204 & \\
\hline 1974 & In die Pilze gegangen, Brille, Pilze und Selbstbildnis & $\begin{array}{l}\text { Kaltnadel- } \\
\text { radierung }\end{array}$ & Ohsoling (2007), R 85 & \\
\hline 1974 & $\begin{array}{l}\text { Mit Sophie in die Pilze gegangen, Frau mit Pilzhut und anderen } \\
\text { Pilzen }\end{array}$ & $\begin{array}{l}\text { Kaltnadel- } \\
\text { radierung }\end{array}$ & Ohsoling (2007), R 90 & \\
\hline 1974 & Pilz und Daumen & $\begin{array}{l}\text { Kaltnadel- } \\
\text { radierung }\end{array}$ & Ohsoling (2007), R 89 & \\
\hline 1974 & Pilze besehen, Brille, Pilze und Selbstbildnis & $\begin{array}{l}\text { Kaltnadel- } \\
\text { radierung }\end{array}$ & Ohsoling (2007), R 87 & \\
\hline 1974 & Sophie, Frau mit phallischem Pilz auf dem Kopf & $\begin{array}{l}\text { Kaltnadel- } \\
\text { radierung }\end{array}$ & Ohsoling (2007), R 88 & \\
\hline 1975 & Männlicher Pilz, phallischer Pilz und glatzköpfiger Mann & Tusche & Dreher (1982), 17, Abb. 69 & \\
\hline 1975 & Mannshohe Pilze, zwei große Pilze und ein Mann & Kohle & Grass (2014), S. 202 & \\
\hline 1975 & Phallische Pilze & Tusche & $\begin{array}{l}\text { Kat. Ausst. Kiel (1987), S. 101, } \\
\text { Abb. } 73\end{array}$ & \\
\hline 1975 & Demeter, Steinkreis um einen einzelnen Pilz & Lithografie & Ohsoling (2007a), L 2 & \\
\hline 1975 & Mit Hut, Portrait von Veronika Schröter mit Pilzhut & Lithografie & Ohsoling (2007a), L 1 & \\
\hline 1976 & Butt und Pilz & $\begin{array}{l}\text { Kaltnadel- } \\
\text { radierung }\end{array}$ & Ohsoling (2007), R 103 & \\
\hline 1976 & $\begin{array}{l}\text { Mit Sophie in die Pilze gegangen, Künstlerbuch mit } 48 \text { Seiten, } \\
\begin{aligned} 1976 & \\
- & \text { Pilz mit Schriftzug: „Mit Sophie in die Pilze gegangen“, S. } 5 \\
- & \text { Pilze neben gleichgroßer männlicher und weiblicher Figur, } \\
& \text { S. } 6 \mathrm{f} . \\
- & \text { Frau mit Pilzhut neben Mann der aus einem } \\
& \text { trichterförmigem Pilzhut gleitet, S. } 10 \mathrm{f} . \\
\text { - } & \text { vier trichterförmige Pilze, aus denen Schriftzüge, } \\
& \text { Streichhölzer und Zigarettenstummel hervortreten, S. } 18 \mathrm{f} .\end{aligned}\end{array}$ & Lithografie & $\begin{array}{l}\text { Ohsoling (2007a), L 4; Grass } \\
\text { (1987) mit abweichender } \\
\text { Seitenzählung. }\end{array}$ & \\
\hline
\end{tabular}




\begin{tabular}{|c|c|c|c|}
\hline & $\begin{array}{ll} & \text { neben vergrößertem Pilz hockender Mann, S. } 22 \\
-\quad & \text { trichterförmiger Pilz, der durch eine Nabelschnur mit einem } \\
& \text { nackten Säugling verbunden ist, S. } 23 \\
\text { - } & \text { Frau mit Pilz als Kopfbedeckung und Mann, dessen Gesicht } \\
& \text { halb von einem Pilz und einer darauf sitzenden Brille } \\
& \text { verdeckt ist, S. } 26 \mathrm{f.} \\
\text { - } & \text { Pilz mit zwei Nägeln, S. } 31 \\
\text { - } & \text { zwei Pilze mit einem Schuh, S. } 35 \\
\text { - } & \text { trichterförmiger Pilz mit daraus hervorgehendem } \\
& \text { Schriftzug, S. } 39 \\
\text { - } & \text { zwei einander mit trichterförmigen Hüten zugewendete } \\
& \text { Pilze, dazwischen Schrift, S. } 42 \mathrm{f} .\end{array}$ & & \\
\hline 1977 & Pilzköpfe, Pilze und Text & Tusche & GGH-G 827/2005 \\
\hline
\end{tabular}

FISCHE

\begin{tabular}{|c|c|c|c|c|}
\hline Datierung & Titel & Technik & Quelle der Abb. & Sammlung \\
\hline 1954 & Früher Butt & $\begin{array}{l}\text { Kaltnadel- } \\
\text { radierung }\end{array}$ & & GGH-G 532/2005 \\
\hline 1955 & Butt & Fettkohle & Dreher (1982), S. 10, Abb. 2 & \\
\hline 1955 & $\begin{array}{l}\text { Die Vorzüge der Windhühner, S. 15, Abbildung einer } \\
\text { Zeichnung zum Gedicht „Die Schule der Tenöre“: Fischgräte }\end{array}$ & $\begin{array}{l}\text { Original: } \\
\text { Tusche }\end{array}$ & Grass (1963a), S. 15 & \\
\hline 1955 & Früher Butt & Fettkohle & $\begin{array}{l}\text { Kat. Ausst. Kiel (1987), S. 24, } \\
\text { Abb. 1; Grass (2014), S. } 48\end{array}$ & $\begin{array}{l}\text { AdK, Inv.-Nr.: HZ } \\
\text { 2023, Standort III-2 }\end{array}$ \\
\hline 1955 & $\begin{array}{l}\text { Skizze für ein Ballett-Libretto: Fisch, Mann und Frau unter } \\
\text { Wasser }\end{array}$ & Tusche & Grass (2014), S. 74 & \\
\hline 1955 & Butt & Bronzeguss & Grass (2014), S. 48 & \\
\hline $1955 / 1956$ & $\begin{array}{l}\text { Skizze zu Die Vorzüge der Windhühner: Fischgräte und } \\
\text { Weinglas }\end{array}$ & Tusche & Grass (2014), S. 53 & \\
\hline 1957 & Fisch & Kohle & & GGH-G 577/2005 \\
\hline 1959 & Krankenschwester mit Aal & Tusche & $\begin{array}{l}\text { Dreher (1982), S. 45, Abb. 26; } \\
\text { Grass (2014), S. } 83\end{array}$ & \\
\hline 1972 & Aale & Bleistift & Grass (2014), S. 178 & \\
\hline
\end{tabular}




\begin{tabular}{|c|c|c|c|c|}
\hline 1972 & Aale und Euter & Tusche & $\begin{array}{l}\text { Kat. Ausst. Kiel (1987), S. 91, } \\
\text { Abb. } 63\end{array}$ & \\
\hline 1972 & Aale und Euter & Tusche & Grass (1999), S. 47 & \\
\hline 1972 & $\begin{array}{l}\text { Wewelsflether Stilleben, Nacktschnecke auf Vulva, Rübe, Aal, } \\
\text { Kuheuter und Pilze }\end{array}$ & Bleistift & $\begin{array}{l}\text { Kat. Ausst. Kiel (1987), S. 93, } \\
\text { Abb. } 65\end{array}$ & \\
\hline 1972 & Aale mit Euter & Ätzradierung & Ohsoling (2007), R 17 & \\
\hline 1972 & Aal mit Ingwer & Ätzradierung & Ohsoling (2007), R 19 & \\
\hline 1972 & Die bösen Köche, Köche, Fischkopf und Fischgräte & Ätzradierung & Ohsoling (2007), R 21 & \\
\hline 1972 & Fußlange Scholle, Feder, Fußabdruck, Muschel und Scholle & Ätzradierung & Ohsoling (2007), R 14 & \\
\hline 1972 & Nonne mit Aal & Ätzradierung & Ohsoling (2007), R 18 & \\
\hline 1972 & Rotbarsch & Ätzradierung & Ohsoling (2007), R 26 & \\
\hline 1972 & Schollenkopf & Ätzradierung & Ohsoling (2007), R 20 & \\
\hline 1972 & Wewelsflether Blatt, Weinglas, Schlüsselbund, Pilze und Fisch & Ätzradierung & Ohsoling (2007), R 13 & \\
\hline 1973 & Aal und Ingwer & Bleistift & Ohsoling (2007), R 19 & \\
\hline 1973 & Aale an der Stör, Aale und Kopfweiden & $\begin{array}{l}\text { Asphaltlack, } \\
\text { Tusche }\end{array}$ & $\begin{array}{l}\text { Grass (1999), S. 51; Grass (2014), } \\
\text { S. } 205\end{array}$ & \\
\hline 1973 & Auferstehung I, Aale im Wasser & $\begin{array}{l}\text { Asphaltlack, } \\
\text { Tusche }\end{array}$ & $\begin{array}{l}\text { Grass (1999), S. 50; Grass (2014), } \\
\text { S. } 205\end{array}$ & \\
\hline 1973 & Auferstehung II, Aale im Wasser & $\begin{array}{l}\text { Asphaltlack, } \\
\text { Tusche }\end{array}$ & $\begin{array}{l}\text { Grass (1999), S. 52; Grass (2014), } \\
\text { S. } 201\end{array}$ & \\
\hline 1973 & Butt & Bleistift & & GGH-G 798/2005 \\
\hline 1973 & $\begin{array}{l}\text { Bleistiftzeichnungen aus der Serie Mein Schuh, 1973, Schuh } \\
\text { und Rotbarschkopf }\end{array}$ & Bleistift & Grass (2014), S. 200 & \\
\hline 1973 & Der Rotbarsch & $\begin{array}{l}\text { Asphaltlack, } \\
\text { Tusche }\end{array}$ & Grass (1999), S. 53 & \\
\hline 1973 & Federzeichnung zu Radierung: Aale & Tusche & Grass (2014), S. 201 & \\
\hline 1973 & Federzeichnung zu Radierung: Aale im Wasser & Tusche & Grass (2014), S. 205 & \\
\hline 1973 & Federzeichnung zu Radierung: Aale und Kopfweiden & Tusche & Grass (2014), S. 205 & \\
\hline 1973 & $\begin{array}{l}\text { Federzeichnung zu Radierung: Fußabdruck und Scholle / } \\
\text { Fußlange Scholle }\end{array}$ & Tusche, Sepia & Grass (2014), S. 201 & GGH-G 799/2005 \\
\hline 1973 & Fußlange Scholle, Scholle neben Fußabdruck & Bleistift & & GGH-G 873/2005 \\
\hline 1973 & Hai über Land & Kohle & & GGH-G 874/2005 \\
\hline
\end{tabular}




\begin{tabular}{|c|c|c|c|c|}
\hline 1973 & Haifischkopf & Kohle & Grass (2014), S. 172 & GGH-G 875/2005 \\
\hline 1973 & Hai über Land, Haikopf & Tusche & Kat. Ausst. Kiel (1987), S. 95 & \\
\hline 1973 & Hai über Land, Haikopf, Glas und Schere & Bleistift & Kat. Ausst. Kiel (1987), S. 94 & \\
\hline 1973 & $\begin{array}{l}\text { Rohrfederzeichnung zum Gedicht „Kein Traum“; Aal, aus einer } \\
\text { Vulva gleitend, Füße }\end{array}$ & Tusche & Grass (2014), S. 180 & \\
\hline 1973 & Kein Traum, Aal, aus einer Vulva gleitend & Tusche, Sepia & & GGH-G 880/2005 \\
\hline 1973 & $\begin{array}{l}\text { Federzeichnung auf einem Foto von Maria Rama; auf dem } \\
\text { Foto: Fischkopf, in der Zeichnung: Schere, Auge, Weinglas, } \\
\text { Rübe, Zigaretten und Text }\end{array}$ & Tusche, Foto & Grass (2014), S. 192 & \\
\hline 1973 & $\begin{array}{l}\text { Federzeichnung auf einem Foto von Maria Rama; auf dem } \\
\text { Foto: Grass über einen Deich laufend, in der Zeichnung } \\
\text { rechtsoben: Fisch, Ziegenbockschädel und Text }\end{array}$ & Tusche, Foto & Grass (2014), S. 190 & \\
\hline 1973 & $\begin{array}{l}\text { Federzeichnung auf einem Foto von Maria Rama; auf dem } \\
\text { Foto: steiniges Flussufer, Zeichnung: Aalkopf }\end{array}$ & Tusche, Foto & Grass (2014), S. 193 & \\
\hline 1973 & $\begin{array}{l}\text { Federzeichnung auf einem Foto von Maria Rama; auf dem } \\
\text { Foto: Weide, in der Zeichnung: Aal }\end{array}$ & Tusche, Foto & Grass (2014), S. 193 & \\
\hline 1973 & $\begin{array}{l}\text { Mariazuehren, S. } 8 \text { f., Komposition aus handschriftl. } \\
\text { Textzeilen und drei Radierungen: Euter und Aal, 1973, } \\
\text { Störaale, 1973, Aalköpfe, } 1973\end{array}$ & $\begin{array}{l}\text { Original: } \\
\text { Radierung }\end{array}$ & Grass (1973), S. 8 f. & \\
\hline 1973 & $\begin{array}{l}\text { Mariazuehren, S. } 44 \text { f., Zeichnungen auf Fotos: Spaziergang } \\
\text { mit Fundsachen, 1973: zwei mit Tusche dick gerahmte Fotos: } \\
\text { 1. Grass mit seinen Söhnen an der Elbe (hineingezeichnet: } \\
\text { Auge, Aalkopf, Nagel) 2. Fischköpfe auf einem Teller } \\
\text { (hineingezeichnet: Aale, Rettich) }\end{array}$ & $\begin{array}{l}\text { Original: } \\
\text { Tusche auf } \\
\text { Fotos }\end{array}$ & Grass (1973), S. 44 f. & \\
\hline 1973 & $\begin{array}{l}\text { Mariazuehren, S. } 58 \text { f., Zeichnung auf Foto: Stillleben, 1973, } \\
\text { Foto: Fischkopf; Zeichnung: Schere, Auge, Weinglas, Rübe, } \\
\text { Zigaretten und Text }\end{array}$ & $\begin{array}{l}\text { Original: } \\
\text { Tusche auf } \\
\text { Foto }\end{array}$ & Grass (1973), S. 58 f. & \\
\hline 1973 & $\begin{array}{l}\text { Mariazuehren, S. } 66 \text { f., Zeichnung auf Foto, Foto: Schale mit } \\
\text { Fischresten; Zeichnung: Karpfen mit Leuchter und Schnecke, } \\
1972\end{array}$ & $\begin{array}{l}\text { Original: } \\
\text { Tusche auf } \\
\text { Foto }\end{array}$ & Grass (1973), S. 66 f. & \\
\hline 1973 & $\begin{array}{l}\text { Mariazuehren, S. } 68 \text { f., fotografisches Porträt von Grass, } \\
\text { neben ihm im Bild: Zeichnung: Aale und Euter, } 1972\end{array}$ & $\begin{array}{l}\text { Zeichnung: } \\
\text { Tusche }\end{array}$ & Grass (1973), S. 68 f. & \\
\hline
\end{tabular}




\begin{tabular}{|c|c|c|c|c|}
\hline 1973 & $\begin{array}{l}\text { Mariazuehren, S. } 70 \text { f., nebeneinander platzierte } \\
\text { Radierungen: Rotbarschköpfe, } 1971 \text { und Butt, } 1973\end{array}$ & $\begin{array}{l}\text { Original: } \\
\text { Radierung }\end{array}$ & Grasss (1973), S. 70 f. & \\
\hline 1973 & Aal und Euter & Ätzradierung & Ohsoling (2007), R 49 & \\
\hline 1973 & An der Stör I, Aale und Kopfweiden & Ätzradierung & Ohsoling (2007), R 24 & \\
\hline 1973 & An der Stör II, Aale und Kopfweiden & Ätzradierung & Ohsoling (2007), R 25 & \\
\hline 1973 & Butt I, Buttkopf & Ätzradierung & Ohsoling (2007), R 27 & \\
\hline 1973 & Der Puppe Wiederkehr, Puppe und Fischkopf & Ätzradierung & Ohsoling (2007), R 42 & \\
\hline 1973 & Rotbarsch & Ätzradierung & Ohsoling (2007), R 26 & \\
\hline 1973 & Drei Stangenfische II, drei Barschköpfe & Ätzradierung & Ohsoling (2007), R 46 & \\
\hline 1973 & Frau mit Fisch & Ätzradierung & Ohsoling (2007), R 57 & \\
\hline 1973 & Großer Aalfang & Ätzradierung & Ohsoling (2007), R 54 & \\
\hline 1973 & Große Auferstehung, Aale im Wasser & Ätzradierung & Ohsoling (2007), R 30 & \\
\hline 1973 & Hai über Land, Haikopf & Ätzradierung & Ohsoling (2007), R 44 & \\
\hline 1973 & Kein Traum, Aal, aus Vulva gleitend & Ätzradierung & Ohsoling (2007), R 43 & \\
\hline 1973 & Kleine Auferstehung, Aale im Wasser & Ätzradierung & Ohsoling (2007), R 29 & \\
\hline 1973 & Kleine Scholle & Ätzradierung & Ohsoling (2007), R 47 & \\
\hline 1973 & Kleiner Aalfang & Ätzradierung & Ohsoling (2007), R 45 & \\
\hline 1973 & Puppe und Aal & Ätzradierung & Ohsoling (2007), R 41 & \\
\hline 1973 & $\begin{array}{l}\text { Szenisches Madrigal, aus dem Portfolio Liebe geprüft, } \\
\text { Fischkopf neben menschlicher Augenpartie }\end{array}$ & Ätzradierung & Ohsoling (2007), R 71 & \\
\hline 1974 & $\begin{array}{l}\text { Bei Kochfisch Agnes erinnert, Manuskript über der Zeichnung } \\
\text { einer Fischgräte }\end{array}$ & Tusche & Grass (2014), S. 169 & \\
\hline 1974 & $\begin{array}{l}\text { Manuskript zu Der Butt mit eingefügter Darstellung eines } \\
\text { Butts }\end{array}$ & Tusche & Grass (2014), S. 175 & \\
\hline 1974 & Schwangere mit Aal & Bleistift & & GGH-G 851/2005 \\
\hline 1974 & $\begin{array}{l}\text { Streit der Fische, zwei Fischköpfe; aus den Mündern dringen } \\
\text { Zeigefinger, die ineinander verhakt sind }\end{array}$ & Tusche & $\begin{array}{l}\text { Kat. Ausst. Kiel (1987), S. 97, } \\
\text { Abb. } 69\end{array}$ & \\
\hline 1974 & Zeichnung zum Gedicht „Jettes Puppe“, Puppe und Fisch & Tusche & Grass (2014), S. 186 & \\
\hline 1974 & Aal und Euter II & $\begin{array}{l}\text { Kaltnadel- } \\
\text { radierung }\end{array}$ & Ohsoling (2007), R 86 & \\
\hline 1974 & Damals im Mai, Fischkopf und Zeigefinger & $\begin{array}{l}\text { Kaltnadel- } \\
\text { radierung }\end{array}$ & Ohsoling (2007), R 77 & \\
\hline
\end{tabular}




\begin{tabular}{|c|c|c|c|c|}
\hline 1974 & $K u ß I$, Kuss von Butt und Frau & $\begin{array}{l}\text { Kaltnadel- } \\
\text { radierung }\end{array}$ & Ohsoling (2007), R 83 & \\
\hline 1974 & $\begin{array}{l}\text { Rotbarsch, Steinbeißer und Gelber Leng, drei Fischköpfe auf } \\
\text { Stangen gespießt }\end{array}$ & $\begin{array}{l}\text { Kaltnadel- } \\
\text { radierung }\end{array}$ & Ohsoling (2007), R 73 & \\
\hline 1974 & Schuh und Steinbeißer & Ätzradierung & Ohsoling (2007), R 61 & \\
\hline 1974 & Stangenfische & Ätzradierung & Ohsoling (2007), R 72 & \\
\hline 1975 & $K u ß I I$, Kuss von Butt und Frau & $\begin{array}{l}\text { Kaltnadel- } \\
\text { radierung } \\
\end{array}$ & Ohsoling (2007), R 93 & \\
\hline 1975 & Fußabdruck und Fisch & Kohle & Grass (2014), S. 170 & \\
\hline 1975 & Aal und Butt gegenübergestellt & Tusche & Grass (2014), S. 166 & \\
\hline 1975 & Puppe mit Aal & Bleistift & Grass (1999), S. 61 & \\
\hline 1976 & Butt und Pilz & $\begin{array}{l}\text { Kaltnadel- } \\
\text { radierung }\end{array}$ & Ohsoling (2007), R 103 & \\
\hline 1976 & Der Aal, den ich Ilsebill schenkte, Selbstbildnis mit Aal & Ätzradierung & Ohsoling (2007), R 99 & \\
\hline 1976 & Eva (Porträt Eva Figes), Frauenporträt mit Fisch & $\begin{array}{l}\text { Kaltnadel- } \\
\text { radierung }\end{array}$ & Ohsoling (2007), R 97 & \\
\hline 1976 & Lenz unterwegs, Siegfried Lenz, Butt, Auge und Pilz & $\begin{array}{l}\text { Kaltnadel- } \\
\text { radierung }\end{array}$ & Ohsoling (2007), R 96 & \\
\hline 1976 & Renate will nicht, Frauenporträt mit Fisch & $\begin{array}{l}\text { Kaltnadel- } \\
\text { radierung }\end{array}$ & Ohsoling (2007), R 95 & \\
\hline 1977 & $\begin{array}{l}\text { Als ich mit Ute unseren Pißpott kaufte / Mann im Butt, } \\
\text { Selbstbildnis mit Butt }\end{array}$ & Tusche & Grass (1999), S. 65 & GGH-G 822/2005 \\
\hline 1977 & Puppe mit Aal & Bleistift & & GGH-G 840/2005 \\
\hline 1977 & $\begin{array}{l}\text { Butt in Sand gebettet, Blatt I/VII der Mappe Als vom Butt nur } \\
\text { die Gräte geblieben war }\end{array}$ & Ätzradierung & Ohsoling (2007), R 104 & \\
\hline 1977 & $\begin{array}{l}\text { Butt II, Blatt II/VII der Mappe Als vom Butt nur die Gräte } \\
\text { geblieben war }\end{array}$ & Ätzradierung & Ohsoling (2007), R 105 & \\
\hline 1977 & $\begin{array}{l}\text { Der Butt, 1977, Blatt III/VII der Mappe Als vom Butt nur die } \\
\text { Gräte geblieben war }\end{array}$ & Ätzradierung & Ohsoling (2007), R 106 & \\
\hline 1977 & $\begin{array}{l}\text { Butt mit Messer, Blatt IV/VII der Mappe Als vom Butt nur die } \\
\text { Gräte geblieben war }\end{array}$ & Ätzradierung & Ohsoling (2007), R 107 & \\
\hline
\end{tabular}




\begin{tabular}{|c|c|c|c|c|}
\hline 1977 & $\begin{array}{l}\text { Als vom Butt nur die Gräte geblieben war, Blatt V/VII der } \\
\text { Mappe Als vom Butt nur die Gräte geblieben war }\end{array}$ & Ätzradierung & Ohsoling (2007), R 108 & \\
\hline 1977 & $\begin{array}{l}\text { Kopf und Gräte, Blatt VI/VII der Mappe Als vom Butt nur die } \\
\text { Gräte geblieben war }\end{array}$ & Ätzradierung & Ohsoling (2007), R 109 & \\
\hline 1977 & $\begin{array}{l}\text { Als das Märchen zu Ende war, Blatt VII/VII der Mappe Als vom } \\
\text { Butt nur die Gräte geblieben war }\end{array}$ & Ätzradierung & Ohsoling (2007), R 110 & \\
\hline 1977 & Großer Butt & $\begin{array}{l}\text { Ätzradierung } \\
\text { mit Aquatinta }\end{array}$ & Ohsoling (2007), R 111 & \\
\hline 1977 & Fingerzeig I, Fischkopf mit Zeigefinger & Ätzradierung & Ohsoling (2007), R 112 & \\
\hline o. D. & Aale und Euter (v.) / Euter (r.) & Bleistift & & GGH-G 792/2005 \\
\hline o. D. & Butt & Bleistift & Grass (2004a), S. 151 & \\
\hline o. D. & Mann im Pilz & Kohle & Grass (2004a), S. 180 & \\
\hline o. D. & So groß, Mann mit zwei menschengroßen Pilzen & Tusche & Grass (2004a), S. 181 & \\
\hline o. D. & Vorm Kuss / Frau mit Flunder & Tusche & Grass (2004a), S. 168 f. & GGH-G 821/2005 \\
\hline o. D. & $\begin{array}{l}\text { Zweikampf, zwei Fischköpfe mit Zeigefingern im Maul, } \\
\text { ineinander verhakt }\end{array}$ & Kohle & Grass (2004a), S. 176 & \\
\hline
\end{tabular}




\section{DANK}

Die vorliegende Arbeit wurde durch das Zentrum für Kulturwissenschaftliche Forschung Lübeck und aus Mitteln des Leibniz-Preises von Heinrich Detering an der Georg-August-Universität Göttingen, Seminar für Deutsche Philologie, gefördert. Ohne diese Finanzierung hätte die Dissertation nicht entstehen können, und ich danke den genannten Institutionen und vor allem den darin wirkenden Menschen für ihre Unterstützung und ihr Vertrauen.

Für anregende Gespräche, wichtige Hinweise und hilfreiche Korrekturen gilt mein herzlicher Dank: Günter Grass †, Heinrich Detering, Horst Bredekamp, Dieter Stolz, Hilke Ohsoling, Jörg-Philipp Thomsa, Helga Neumann, Ulrich Härter + , Herta Härter, Eva Pankok + , Simon P. Schrieber, Maren Ermisch, Christoph Bongert, Anja Pawel, Friederike Krippner, Karolina Kühn, Jeanne Bindernagel, Philipp Bürger, Franz Engel, Cornelia Escher, Eva Eisenhofer, Kathrin Meyer, Valeska Neumann, Johannes Schütz und Marian Zabel. 


\section{EIDESSTATTLICHE ERKLÄRUNG}

Hiermit versichere ich an Eides statt, dass ich die eingereichte Dissertation mit dem Titel: Günter Grass und die bildende Kunst. Eine interdisziplinäre Untersuchung der Schaffensjahre 1947 bis 1977 selbständig und ohne unerlaubte Hilfe verfasst habe. Anderer als der von mir angegebenen Hilfsmittel und Schriften habe ich mich nicht bedient. Alle wörtlich oder sinngemäß den Schriften anderer Autorinnen oder Autoren entnommenen Stellen habe ich kenntlich gemacht. Die Abhandlung ist zuvor noch nicht veröffentlicht worden und noch nicht Gegenstand eines Promotionsverfahrens gewesen.

Dresden, den 16. April 2019,

Viktoria Krason 